
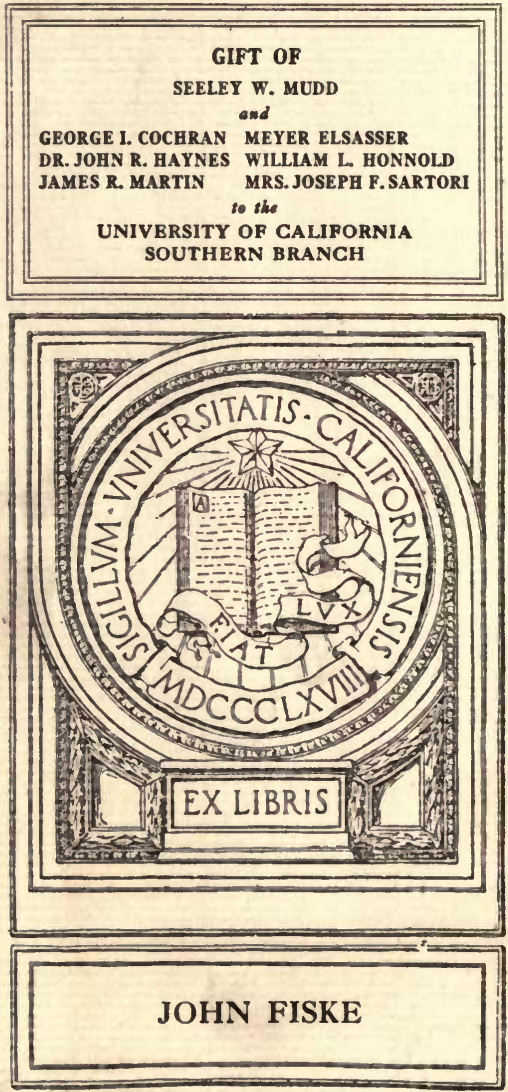
This book is DUE on the last date stamped below

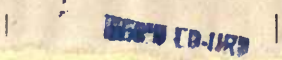




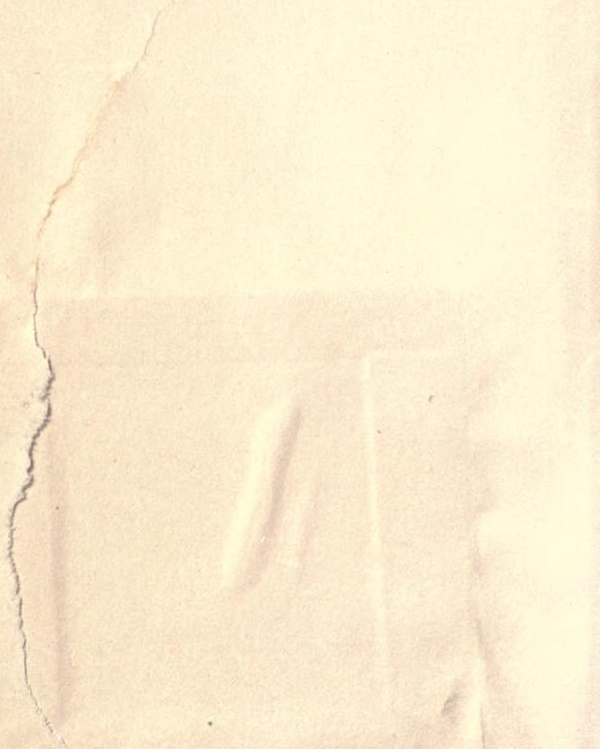




\title{
THE PRINCIPLES OF BIOLOGY
}

\author{
BY \\ HERBERT SPENCER
}

IN TWO VOLUMES

i. VOL. II

REVISED AND ENLARGED EDITION

1899

NEW YORK

D. APPLETON AND COMPANY

1900

80803 


$$
\begin{gathered}
4 \\
\hdashline \\
\vdots
\end{gathered}
$$

Copyright, 1867, 1899,

BY D. APPLETON AND COMPANY. 


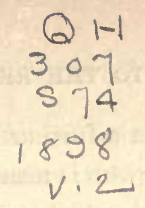

\section{PREFACE}

\section{TO THE REVISED AND ENLARGED EDITION OF VOL. II.}

To the statements made in the preface to the first volume of this revised edition, there must here be added a few having special reference to this second volume.

One of them is that the revision has not been carried out in quite the same way, but in a way somewhat less complete. When reviewing the first volume a friendly critic, Prof. Lloyd Morgan, said :-

"But though the intellectual weight has also been augmented, it is an open question whether it would not have been wiser to leave intact a treatise, \&c. . . . relegating corrections and additions to notes and appendices."

I think that Prof. Morgan is right. Though at the close of the preface to volume I, I wrote :- " in all sections not marked as new, the essential ideas set forth are the same as they were in the original edition of 1864," yet the reader who has not read this statement, or does not bear it in mind, will suppose that all or most of the enunciated conceptions are of recent date, whereas only a small part of them are. I have therefore decided to follow, in this second volume, a course somewhat like that suggested by Prof. Morgansomewhat like, I say, because in sundry cases the amendments could not be satisfactorily made by appended notes. 
But there has been a further reason for this change of method. An invalid who is nearly eighty cannot with prudence enter upon work which will take long to complete. Hence I have thought it better to make the needful alterations and additions in ways requiring relatively moderate time and labour.

The additions made to this volume are less numerous and less important than those made to the first volume. A new chapter ending Part V, on "The Integration of the Organic World," serves to round off the general theory of Evolution in its application to living things. Beyond a new section $(\S 289 a)$ and the various foot-notes, serving chiefly the purpose of elucidation, there are notes of some signifcance appended to Chapters I, III, IV, and V, in Part IV, Chapters V and VIII, in Part V, and Chapters IX, X, and $\mathrm{XII}$ in Part VI. Moreover there are three further appendices, $D^{2}, F$, and $G$, which have, I think, considerable significance as serving to make clearer some of the views expressed in the body of the work.

Turning from the additions to the revisions, I have to say that the aid needed for bringing up to date the contents of this volume, has been given me by the gentlemen who gave me like aid in revising the first volume: omitting Prof. Perkin, within whose province none of the contents of this volume fall. Plant-Morphology and Plant-Physiology have been overseen by Mr. A. G. Tansley. Criticisms upon parts dealing with Animal Morphology I owe to Mr. J. T. Cunningham and Prof. E. W. MacBride. And the statements included under Animal Physiology have been checked by Mr. W. B. Hardy. 
For reasons like those named in the preface to the first volume, I have not submitted the proofs of this revised second volume to these gentlemen: a fact which it is needful to name, since one or other of them might else be held responsible for some error which is not his but mine. It is the more requisite to say this because while, in respect of matters of fact, I have, save in one or two eases, accepted their corrections as not to be questioned, I have not always done this in respect of matters of inference, but in sundry places have adhered to my own interpretations.

Perhaps I may be excused for expressing some satisfaction that I have not been obliged to relinquish the views set forth in 1864-7. The hypothesis of physiological units-or, as I would now call them, constitutional units-has been adopted by several zoologists under modified forms. So far as I am aware, the alleged general law of organic symmetry has not called forth any manifestations of dissent. The suggested theory of vertebrate structure appears to have become current; and from the investigations of the late Prof. Cope, has received verification. The conclusions drawn in Part VI on "The Laws of Multiplication," have not, I believe, been controverted. And though only some works on botany have given currency to the doctrine set forth in Appendix C, "On Circulation and the Formation of Wood in Plants," yet I have met with no attempt to disprove it. The only views contested by certain of the gentlemen above named, are those concerning the origin of the two great phænogamic types of plants, and the origin of the annulose type of animals. I have not, however, perhaps because of natural bias-found myself compelled 
viii PREFACE TO THE REVISED EDITION.

to surrender these views. My reasons for adhering to them will be found in notes to the ends of Chapters III and IV in Part IV, and in Appendix $\mathrm{D}^{2}$.

On now finally leaving biological studies, it remains only to say that I am glad I have survived long enough to give this work its finished form.

BRIGHTON,

October, 1899. 


\section{PREFACE TO VOL. II.}

The proof sheets of this volume, like those of the last volume, have been looked through by Dr. Hooker and Prof. Huxley; and I have, as before, to thank them for their valuable criticisms, and for the trouble they have taken in checking the numerous statements of fact on which the arguments proceed. The consciousness that their many duties render time extremely precious to them, makes me feel how heavy is my obligation.

Part IV., with which this volume commences, contains numerous figures. Nearly one half of them are repetitions, mostly altered in scale and simplified in execution, of figures, or parts of figures, contained in the works of various Botanists and Zoologists. Among the authors whom I have laid under contribution, I may name Berkeley, Carpenter, Cuvier, Green, Harvey, Hooker, Huxley, MilneEdwards, Ralfs, Smith. The remaining figures, numbering 150 , are from original sketches and diagrams.

The successive instalments which compose this volume, were issued to the Subscribers at the following dates:-No. 13 (pp. 1-80) in January, 1865; No. 14 (pp. 81-160) in June, 1865; No. 15 (pp. 161-240) in December, 1865 ; No. 16 (pp. 241-320) in June, 1866 ; No. 17 (pp. 321-400) in November, 1866 ; and No. 18 (pp. 401-566) in March, 1867.

London, March 23rd, 1867. 



\section{CONTENTS OF VOL. II.}

\section{PART IV.-MORPHOLOGICAL DEVELOPMENT.}

CHAP.

PAGE

I.-THE PROBLEMS OF MORPHOLOGY • . . . . . . 3

II.-THE MORPHOLOGICAL COMPOSITION OF PLANTS . . $\quad 17$

III.-ThE MORPHOLOGICAL COMPOSITION OF PLANTS-Continued . 37

IV.-Te MORPHOLOGICAL COMPOSITION OF ANIMALS - • $\quad 85$

V.-The Morphological composition of animaLs-Continued 111

VI.-Morphological differentiation in plants • • • 128

VII.-The general Shapes of Plants . • • • . . 134

VIII.-THE SHAPES OF BRANCHES • . . • • • . 145

IX.-The shapes of LEAVES . • • • . . . . 152

X.-The Shapes of Flowers . . . . . . . 161

XI.-The shapes of vegetal cells . . . . . . 175

XII.-Changes of Shape otherwise caused - • . . 178

XIII.-Morphological differentiation in animals . . . 183

XIV.-The general Shapes of animals . . . . . 186

XV.-The shapes of vertebrate SKeletons . • . . 209

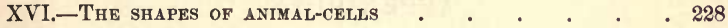

XVII.-SumMary OF MORPHOLOGICAL DeVElopment . . . . 231

PART V.-PHYSIOLOGICAL DEVELOPMENT.

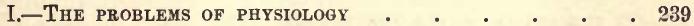

II.-Differentiations BETWEen the OUTER AND INNER tis-

SUES OF PLANTS .

III.-Differentiations among the outer tissues of plants . 251

IV.-Differentiations AMONg the inNer tissues of PLANTS . 272 
CHAP.

V.-Physiological integration in plants $\quad \ldots \quad \ldots \quad$. $\quad$. 292

VI.-DIFFERENTIATIONS BETWEEN THE OUTER AND INNER TISSUES

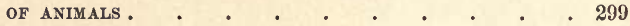

VII.-Differentiations AMONG the OUTER TISSUES OF ANIMALS. 309 VIII.-Differentiations AMONG the iNNER tissues OF ANIMALS . 323

IX.-Physiological integration in animals . . . . 373

X.-Summary of physiological deVelopment • • • . 384

$\mathrm{X}^{\mathrm{A}}$.-The integration of The ORganic world • • • . 396

\section{PART VI.-LAWS OF MULTIPLICATION.}

I.-THE FACTORS . . . . . . . . . . 411

II.-À PRIORI PRINCIPLE . . . . . . . . 417

III.-OBVERSE ’̀ PRIORI PRINCIPLE . . . . . . . 424

IV.-Difficulties of inductive verification . . . . 432

V.-ANTAgonism Between growth aNd asexual genesis . 439

VI.-ANTAgonism BETWEen Growth ANd SEXUAL genesis . • 448

VII.-The ANTAGONISM BETWEeN DEVELOPMENT AND GENESIS, ASEXUAL AND SEXUAL . . . . . . . 461

VIII.-ANTAGONISM BETWEEN EXPENDITURE AND GENESIS • • 467

IX.-Coincidence BetweEn high nUtRition AND genesis • • 475

X.-SPecialities of these Relations . . . . . . 486

XI.-INTERPRETATION AND QUALIFICATION • • • . . 497

XII.-Multiplication of the human RACE • • • • • 506

$\checkmark$ XIII.-HumaN population in the future . . . . . 522

\section{APPENDICES.}

A.-Substitution of Axial For foliar organs in plants - 541

B.-A criticism on Prof. OWen's theory of the vertebrate SKELETON • . . . . . . . . . . 548

C.-ON CiRculation and the Formation of WOOD in Plants . 567

D.-ON THE ORIGIN OF THE VERTEBRATE TYPE . • . . . 599

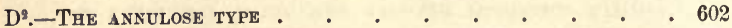

E.-The shapes aNd arRangements of Flowers . . • 608

F.-Physiological (or constitutional) units _ . . . 612

G.-The inheritance of FUnCtionally-CAUSED Modifications - 618 


\section{PART IV.}

\section{MORPH OLOGICAL DEVELOPMENT.}




\section{CHAPTER I.}

THE PROBLEMS OF MORPHOLOGY.

§175. The division of Morphology from Physiology, is one which may be tolerably-well preserved so long as we do not carry our inquiries beyond the empirical generalizations of their respective phenomena; but it is one which becomes in great measure nominal, when the phenomena are to be rationally interpreted. It would be possible, after analyzing our Solar System, to set down certain general truths respecting the sizes and distances of its primary and secondary members, omitting all mention of their motions; and it would be possible to set down certain other general truths respecting their motions, without specifying their dimensions or positions, further than as greater or less, nearer or more remote. But on seeking to account for these general truths, arrived at by induction, we find ourselves obliged to consider simultaneously the relative sizes and places of the masses, and the relative amounts and directions of their motions. Similarly with organisms. Though we may frame sundry comprehensive propositions respecting the arrangements of their organs, considered as so many inert parts; and though we may establish several wide conclusions respecting the separate and combined actions of their organs, without knowing anything definite respecting the forms and positions of these organs; yet we cannot reach such a rationale of the facts as 
the hypothesis of Evolution aims at, without contemplating structures and functions in their mutual relations. Everywhere structures in great measure determine functions; and everywhere functions are incessantly modifying structures. In Nature the two are inseparable co-operators; and Science can give no true interpretation of Nature without keeping their co-operation constantly in view. An account of organic evolution, in its more special aspects, must be essentially an account of the inter-actions of structures and functions, as perpetually altered by changes of conditions.

Hence, when treating apart Morphological Development and Physiological Development, all we can do is to direct our attention mainly to the one or to the other, as the case may be. In dealing with the facts of structure, we must consider the facts of function only in such general way as is needful to explain the facts of structure; and conversely when dealing with the facts of function.

$\S 176$. The problems of Morphology fall into two distinct classes, answering respectively to the two leading aspects of Evolution. In things which evolve there go on two processes -increase of mass and increase of structure. Increase of mass is primary, and in simple evolution takes place almost alone. Increase of structure is secondary, accompanying or following increase of mass with more or less regularity, wherever evolution rises above that form which small inorganic bodies, such as crystals, present to us. As the fundamental antagonism between Dissolution and Evolution consists in this, that while the one is an integration of motion and disintegration of matter, the other is an integration of matter and disintegration of motion; and as this integration of matter accompanying disintegration of motion, is a necessary. antecedent to the differentiation of the matter so integrated; it follows that questions concerning the mode in which the parts are united into a whole, must be dealt with before 
questions concerning the mode in which these parts become modified.*

This is not obviously a morphological question. But an illustration or two will make it manifest that fundamental differences may be produced between aggregates by differences in the degrees of composition of the increments: the ultimate units of the increments being the same. Thus an accumulation of things of a given kind may be made by adding one at a time. Or the things may be tied up into bundles of ten, and the tens placed together. Or the tens may be united into hundreds, and a pile of hundreds formed. Such unlikenesses in the structures of masses are habitually seen in our mercantile transactions. Articles which the consumer recognizes as single, the retailer keeps wrapped up in dozens, the wholesaler sends in gross, and the manufacturer supplies in packages of a hundred gross. That is, they severally increase their stocks by units of simple, of compound, and of doubly-compound kinds. Similarly result those differences of morphological composition which we have first to consider. An organism consists of units. These units may be aggregated into a mass by the addition of unit to unit. Or they may be united into groups, and the groups joined together. Or these groups of groups may be so combined as to form a doubly-compound aggregate. Hence there arises respecting each organic form the question-is its composition of the first, second, third, or fourth order?-does it exhibit units of a singly-compounded kind only, or are these consolidated into units of a doubly-compounded kind, or a triply-compounded kind? And if it displays double or triple composi-

* It seems needful here to say, that allusion is made in this paragraph to a proposition respecting the ultimate natures of Evolution and Dissolution, which is contained in an essay on The Classification of the Sciences, published in March, 1864. When the opportunity comes, I hope to make the definition there arrived at, the basis of a re-organization of the second part of First Principles : giving to that work a higher devclopment, and a greater cohesion, than it at present possesses. [The intention here indicated was duly carried out in 1867.] 
tion, the homologies of its different parts become problems. Under the disguises induced by the consolidation of primary, secondary, and tertiary units, it has to be ascertained which answer to which, in their degrees of composition.

Such questions are more intricate than they at first appear; since, besides the obscurities caused by progressive integration, and those due to accompanying modifications of form, further obscurities result from the variable growths of units of the different orders. Just as an army may be augmented by recruiting each company, without increasing the number of companies; or may be augmented by making up the full complement of companies in each regiment, while the number of regiments remains the same; or may be augmented by putting more regiments into each division, other things being unchanged; or may be augmented by adding to the number of its divisions without altering the components of each division; or may be augmented by two or three of these processes at once; so, in organisms, increase of mass may result from additions of units of the first order, or those of the second order, or those of still higher orders; or it may be due to simultaneous additions to units of several orders. And this last mode of integration being the general mode, puts difficulties in the way of analysis. Just as the structure of an army would be made less easy to understand if companies often outgrew regiments, or regiments became larger than brigades; so these questions of morphological composition are complicated by the indeterminate sizes of the units of each kind: relatively-simple units frequently becoming more bulky than relatively-compound units.

$\S 17 \%$. The morphological problems of the second class are those having for their subject-matter the changes of shape which accompany changes of aggregation. The most general questions respecting the structure of an organism, having been answered when it is ascertained of what units it is composed as a whole, and in its several parts; there come the more 
special questions concerning its form-form in the ordinary sense. After the contrasts caused by variations in the process of integration, we have to consider the contrasts caused by variations in the process of differentiation. To speak specifically-the shape of the organism as a whole, irrespective of its composition, has to be accounted for. Reasons have to be found for the unlikeness between its general outlines and the general outlines of allied organisms. And there have to be answered kindred inquiries respecting the proportions of its component parts:-Why, among such of these as are homologous with one another, have there arisen the differences that exist? And how have there been produced the contrasts between them and the homologous parts of organisms of the same type?

Very numerous are the heterogeneities of form presenting themselves for interpretation under these heads. The ultimate morphological units combined in any group, may be differentiated individually, or collectively, or both: each of them may undergo changes of shape; or some of them may be changed and others not; or the group may be rendered multiform by the greater growth of some of its units than of others. Similarly with the compound units arising by union of these simple units. Aggregates of the second order may be made relatively complex in form, by inequalities in the rates of multiplication of their component units in diverse directions; and among a number of such aggregates, numerous unlikenesses may be constituted by differences in their degrees of growth, and by differences in their modes of growth. Manifestly, at each higher stage of composition the possible sources of divergence are multiplied still further.

That facts of this order can be accounted for in detail is not to be expected-the data are wanting. All that we may hope to do is to ascertain their general laws. How this is to be attempted we will now consider.

$\S 178$. The task before us is to trace throughout these 
phenomena the process of evolution; and to show how, as displayed in them, it conforms to those first principles which evolution in general conforms to. Two sets of factors have to be taken into account. Let us look at them.

The factors of the first class are those which tend directly to change an organic aggregate, in common with every other aggregate, from that more simple form which is not in equilibrium with incident forces, to that more complex form which is in equilibrium with them. We have to mark how, in correspondence with the universal law that the uniform lapses into the multiform, and the less multiform into the more multiform, the parts of each organism are ever becoming further differentiated; and we have to trace the varying relations to incident forces by which further differentiations are entailed. We have to observe, too, how each primary modification of structure, induced by an altered distribution of forces, becomes a parent of secondary modifications-how, through the necessary multiplication of effects, change of form in one part brings about changes of form in other parts. And then we have also to note the metamorphoses constantly being induced by the process of segregation-by the gradual union of like parts exposed to like forces, and the gradual separation of like parts exposed to unlike forces. The factors of the second class which we have to keep in view throughout our interpretations, are the formative tendencies of organisms themselves - the proclivities inherited by them from antecedent organisms, and which past processes of evolution have bequeathed. We have seen it to be inferable from various orders of facts $(\S \S 65,84,97-97 g)$, that organisms are built up of certain highly-complex molecules, which we distinguished as physiological units [or constitutional units as they might otherwise be called] - each kind of organism being built up of units peculiar to itself. We recognized in these units, powers of arranging themselves into the forms of the organisms to which they belong; analogous to the powers which the molecules of inorganic substances have of aggregating into specific crystal- 
line forms. We have consequently to regard this proclivity of the physiological units, as producing, during the development of any organism, a combination of internal forces that expend themselves in working out a structure in equilibrium with the forces to which ancestral organisms were exposed; but not in equilibrium with the forces to which the existing organism is exposed, if the environment has been changed. Hence the problem in all cases is, to ascertain the resultant of internal organizing forces, tending to reproduce the ancestral form, and external modifying forces, tending to cause deviations from that form. Moreover, we have to take into account, not only the characters of immediately-preceding ancestors, but also those of their ancestors, and ancestors of all degrees of remoteness. Setting out with rudimentary types, we have to consider how, in each successive stage of evolution, the structures acquired during previous stages have been obscured by further integrations and further differentiations; or, conversely, how the lineaments of primitive organisms have all along continued to manifest themselves under the superposed modifications.

\$179. Two ways of carrying on the inquiry suggest themselves. We may go through the several great groups of organisms, with the view of reaching, by comparison of parts, certain general truths respecting the homologies, the forms, and the relations of their parts; and then, having dealt with the phenomena inductively, may retrace our steps with the view of deductively interpreting the general truths reached. Or, instead of thus separating the two investigations, we may carry them on hand in hand-first establishing each general truth empirically, and then proceeding to the rationale of it. This last method will, I think, conduce to both brevity and clearness. Let us now thus deal with the first class of morphological problems.

[Note.-In preparation for treating of morphological de- 
velopment, sundry other general considerations should have been included in the foregoing chapter when originally published. This seems the most appropriate place for now naming them. Some were implicitly contained in the first volume, but it will be well definitely to state these, as well as the others not yet implied.

Interpretation of the forms of organisms and the forms of their parts, must depend mainly on the conclusions previously drawn respecting their phylogeny; and the drawing of such conclusions must be guided by recognition of the various factors of Evolution, as well as by recognition of certain extremely general results of Evolution and certain concomitants of Evolution.

A primary one among these is that no existing species can exhibit more than approximately the ancestral structure of any other existing species. As all ancestors have disappeared, so, in a greater or less degree, the traits, specific, generic, or ordinal, which distinguished the earlier of them have disappeared. Setting out with the familiar symbol, a tree, let us regard its peripheral twigs as representing extant species; let us assume that the interior of the tree is filled up with some supporting substance, leaving only the ends of the living twigs projecting; and let us suppose the trunk, main branches, secondary branches, tertiary branches, \&c., have decayed away. Then if we take these decayed parts to stand for the divergent and re-divergent lines of evolution which are represented by fossils in the Earth's crust, it will be manifest, first, that no one of the living superficial twigs (or species) exhibits the ancestral organization whence any other of the living superficial twigs (or species) has been developed; it will be manifest, second, that the generic structure inherited by any existing species must be a structure out of which came sundry allied species - the fork, as it were, at which adjacent twigs diverged; and third, that the ancestor of an order must, in like manner, be sought at some point decper down in the symbolic tree-a place of divergence of 
the sub-branches representing allied genera. Similarly with the ancestral types of classes, still deeper down in the tree or further back in time. So that phylogeny becomes more and more speculative as its questions become more and more radical. And the difficulty is made greater by the deficiency of palæontological evidence.

One obvious corollary is that an ancestral type from which sundry allied types now existing diverged, was, speaking generally, simpler than these; since the divergent types became different by the superposing of modifications, adding to their complexities. There is a further reason for inferring that the least specialized member of any group is more like the remote ancestor than any of the others; for every adaptation stands in the way of subsequent re-adaptations: it presents a greater amount of structure to be undone. To get some idea of the ancestral type where no extant member of the group is manifestly simpler than the rest, the method must be to take all its extant members and, after letting their differences mutually cancel, observe what remains common to them all.

But there are difficulties standing in the way of phylogeny, and consequently of morphology, much greater than these. Returning to our symbolic tree, it is clear that it would be far from easy to say of any one twig which extinct subbranch, branch, and main branch it belonged to, even supposing that the growths of all parts had been uniformly outwards. Immensely more perplexing, then, must be the affiliation if various of the branches, sub-branches, \&c., have sent out backward-growing shoots which have come to the surface only after prolonged retrograde courses, and if other branches have sent shoots into regions occupied by alien branches-shoots bearing twigs which come to the surface along with those to which they are but remotely allied. The problems of origin and of structure which organisms present, are met by both of the difficulties thus symbolized.

One of them arises from the prevalence of retrograde 
metamorphoses. Throughout the animal world these are variously displayed by parasites, multitudinous in their kinds; for most of them belong to types much higher in organization. Changed habits and consequent changed structures have so transferred them that only by study of their embryonic stages can their kinships be made out. And these retrograde metamorphoses, conspicuous among parasites, have, in the course of evolution, affected some members of all groups; for in all groups the struggle for existence has compelled some to adopt careers less trying but less profitable.

Not only by forcing on many kinds of organisms simpler ways of living, and consequent degeneracy, has the universal competition caused obscuring transformations. It has done this also by tempting many other kinds of organisms to adopt ways of life not simpler than before but merely different. Pressure continually prompts every type to intrude on other types' spheres of activity; and so causes it to assume certain structural characters of the types whose spheres it invades, masking its previous characters. Modifications hence arising have, in the great mass of cases, been superposed one on another time after time. The aquatic animal becomes through several transitions a land-animal, and then the land-animal through other transitions becomes now an aërial animal like the bat and now an aquatic animal like the whale. Certain kinds of birds furnish extreme illustrations. There was the change from the fish to the water-breathing amphibian and then to the air-breathing amphibian; thence to the reptile living on the Earth's surface; thence to the flying reptile and the bird; then came the diving birds, joining with their aërial life a life passed partly in the water; and finally came a type like the penguin, in which the power of flight has been lost and the water has again become the almost exclusive medium, except for breathing. Of course the mouldings and re-mouldings of structure resulting from these successive unlike modes of life, in many cases put great difficultics in the way of ascer- 
taining which are the original corresponding parts. Some parts have become abnormally large; others have dwindled or disappeared; and the relative positions of parts have often been greatly changed. A bat's wing and a bird's wing are analogous organs, but their frameworks are but partially homologous. While in the bird the terminal parts of the fore-limb do little towards supporting the wing, in the bat the wing is mainly supported by enormously-developed terminal parts.

The effects of the struggle to survive, which here prompts a simpler life with resulting degeneracy and there a different life with resulting new developments, are far from being the only causes of morphological obscurations. Fulfilment of certain highly general requirements gives certain common traits to plants of widely divergent classes; and fulfilment of certain other highly general requirements gives certain common traits to animals of widely divergent classes. It was remarked in the first volume ( $\S 54 f)$ that the cardinal distinction between the characters of plants and animals arises from the fact that while the chief food of plants is universally present the food of animals is scattered. Here it has to be added that to utilize the universally distributed food the ordinary plant needs the aid of light, and has to acquire structures enabling it to get that aid; while the ordinary animal, to utilize the scattered food, must acquire the structures needful for locomotion. Let us contemplate separately the traits hence resulting in the vegetal world and the traits hence resulting in the animal world.

The familiar plantain meets the requirement by growing stiff leaves enabling it to press down the competing grasses around which would else shade it; but the great majority of ordinary plants meet the requirement by raising themselves into the air. Hence the need for a stem, and hence the fact that plants of widely unlike natures similarly form stems which, in achieving strength enough to support the foliage and resist the wind, acquire certain adaptive structures hav- 
ing a general similarity. Here from the edge of a pool is a reed, and here from the adjacent copse is a hemlock: the one having grown tall in escaping the shade of its companions and the other in escaping the shade of the surrounding brushwood. On being cut across each discloses a tube, and each exhibits septa dividing this tube into chambers. In either case by the tubular structure is gained the greatest strength with the least material; but there is no morphological kinship between the tubes nor between the septa. Still more marked is the simulation of homology by analogy in another plant which the adjacent ditch may furnish-the common Horsetail. In this, again, we see an elongated vertical-growing part, raising the foliage into the air; and, as before, this is tubular and divided by septa. A type utterly alien from the other two has, by survival of the fittest, been similarly moulded to meet mechanical needs.

Passing now to the obscurations in the animal world caused by alterations favouring locomotion, we note first that the locomotive power is at the outset very slight. Among many orders of Protozoa, as also among many low types of Metazoa, vibratile cilia are the most general agents of locomotion-necessarily feeble locomotion. Regarded in the mass, the Colenterata, when not stationary like the Hydra or higher types in the hydroid stage, usually possess only such small self-mobility as the slow rhythmical contractions of their umbrella-disks effect, or else such as is effected by bands of cilia or of vibratile plates, as in the Beroe. Even among these low tpes of Metazoa, however, in which ordinarily the radial structure is conspicuous, or but slightly obscured by an ovoid form as in the Ctenophora, we find, in the Cestus veneris, extreme obscuration caused by an elongation which facilitates movement through the water; alike by the actions of its vibratile plates and by its undulations, which simulate those of sundry higher animals.

And here we come upon the essential fact to be recognized. Elongation favours locomotion in various ways that are 
severally taken advantage of by different types of creatures. (1) To a given mass of moving matter the resistance of the medium decreases along with decrease in the area of its transverse section, and this implies increase of length: a given force will move the lengthened mass along with greater facility. (2) Reaching a certain point the elongated form enables an animal to progress by undulations, as in the water fish do, and even some cœlenterates and turbellarians do, and as on land snakes do: lateral resistances serving in either case as fulcra. (3) Lengthening of the body serves otherwise to aid locomotion in the creeping or burrowing worm, which, utilizing the statical resistance of its hinder part thrusts onwards its fore part, and then, holding fast its fore part by the aid of minute seto, draws the hinder part after it. But elongation, doubly advantageous at first, while the body is itself the chief instrument of locomotion, gradually loses its advantageousness as special instruments of locomotion are developed. (4) This we see in that locomotive action effected by limbs, which, many and small in the lower Arthropoda and becoming few and larger in the higher, at length give great activity to a shortened and consolidated body: a stage reached only through stages of decreasing elongation accompanying increase of limb-power. (5) In the Vertebrata locomotion by undulations comes, along certain lines of evolution, to be replaced by that limb-locomotion which accompanies the rise from water-life to land-life: the evolution of Amphibians exhibiting the transition. Further, we see among mammals that as limbs become efficient the elongated body ceases to be itself instrumental in locomotion, but that still some elongation remains a characteristic. (7) Finally, where limb-locomotion reaches its highest degree, as in birds, elongation disappears.

These classes of familiar facts I have recalled to show that, in the course of evolution, achievement by plants of the all-essential elevation into the air and by animals of the all-essential power of movement have developed this trait 
of elongation in various types; and that in each kingdom acquisition of the common trait has had a tendency now to obscure morphological equivalence, and now to give the appearance of kinship where there is none. A further purpose has been to prepare the way for a question hereafter to be discussed-whether, in the various types of either kingdom, the elongation is effected in the same ways or in different ways. We shall have to ask whether the vertically growing part is always, like that of Lessonia, a simple individual, or whether, as possibly in Phænogams, it is a united series of individuals; and similarly whether the elongated body is always single, like that of a molluse, or whether, as possibly in annulose animals, it is a series of united individuals.] 


\section{CHAPTER II.}

THE MORPHOLOGICAL COMPOSITION OF PLANTS.

$\S 180$. Evolution implies insensible modifications and gradual transitions, which render definition difficult-which make it impossible to separate absolutely the phases of organization from one another. And this indefiniteness of distinction, to be expected $\grave{a}$ priori, we are compelled to recognize $\grave{a}$ posteriori, the moment we begin to group morphological phenomena into general propositions. Thus, on inquiring what is the morphological unit, whether of plants or of animals, we find that the facts refuse to be included in any rigid formula. The doctrine that all organisms are built up of cells, or that cells are the elements out of which every tissue is developed, is but approximately true. There are living forms of which cellular structure cannot be asserted; and in living forms that are for the most part cellular, there are nevertheless certain portions which are not produced by the metamorphosis of cells. Supposing that clay were the only material available for building, the proposition that all houses are built of bricks, would bear about the same relation to the truth, as does the proposition that all organisms are composed of cells. This generalization respecting houses would be open to two criticisms:-first, that certain houses of a primitive kind are formed, not of bricks, but out of unmoulded clay; and second, that though other houses consist mainly of bricks, yet their chimney-pots, drain-pipes, and 
ridge-tiles, do not result from combination or metamorphosis of bricks, but are made directly out of the original clay. And of like natures are the criticisms which must be passed on the generalization, that cells are the morphological units of organisms. To continue the simile, the truth turns out to be, that the primitive clay or protoplasm out of which organisms are built, may be moulded either directly, or with various degrees of indirectness, into organic structures. The physiological units which we are obliged to assume as the components of this protoplasm, must, as we have seen, be the possessors of those proclivities which result in the structural arrangements of the organism. The assumption of such structural arrangements may go on, and in many cases does go on, by the shortest route; without the passage through what we call metamorphoses. But where such structural arrangements are reached by a circuitous route, the first stage is the formation of these small aggregates which, under the name of cells, are currently regarded as morphological units.

The rationale of these truths appears to be furnished by the hypothesis of evolution. We set out with molecules some degrees higher in complexity than those molecules of nitrogenous colloidal substance into which organic matter is resolvable; and we regard these very much more complex molecules as having the implied greater instability, greater sensitiveness to surrounding influences, and consequent greater mobility of form. Such being the primitive physiological units, organic evolution must begin with the formation of a minute aggregate of them-an aggregate showing vitality by a higher degree of that readiness to change its form of aggregation which colloidal matter in general displays; and by its ability to unite the nitrogenous molecules it meets with, into complex molecules like those of which it is composed. Obviously, the earliest forms must have been minute; since, in the absence of any but diffused organic matter, no form but a minute one could find nutriment. Obviously, too, 
it must have been structureless; since, as differentiations are producible only by the unlike actions of incident forces, there could have been no differentiations before such forces had had time to work. Hence, distinctions of parts like those required to constitute a cell were necessarily absent at first. And we need not therefore be surprised to find, as we do find, specks of protoplasm manifesting life, and yet showing no signs of organization.

A further stage of evolution is reached when the imperfectly integrated molecules forming one of these minute aggregates, become more coherent; at the same time as they pass into a state of heterogeneity, gradually increasing in its definiteness. That is to say, we may look for the assumption by them, of some distinctions of parts, such as we find in cells and in what are called unicellular organisms. They cannot retain their primordial uniformity; and while in a few cases they may depart from it but slightly, they will, in the great majority of cases, acquire a decided multiformity: there will result the comparatively integrated and comparatively differentiated Protophyta and Protozoa. The production of minute aggregates of physiological units being the first step, and the passage of such minute aggregates into more consolidated and more complex forms being the second step, it must naturally happen that all higher organic types, subsequently arising by further integrations and differentiations, will everywhere bear the impress of this earliest phase of evolution. From the law of heredity, considered as extending to the entire succession of living things during the Earth's past history, it follows that since the formation of these small, simple organisms must have preceded the formation of larger and more complex organisms, the larger and more complex organisms must inherit their essential characters. We may anticipate that the multiplication and combination of these minute aggregates or cells, will be conspicuous in the early developmental stages of plants and animals; and that throughout all subsequent stages, cell-production and cell-differentiation 
will be dominant characteristics. The physiological units peculiar to each higher species will, speaking generally, pass through this form of aggregation on their way towards the final arrangement they are to assume; because those primordial physiological units from which they are remotely descended, aggregated into this form. And yet, just as in other cases we found reasons for inferring $(§ 131)$ that the traits of ancestral organization may, under certain conditions, be partially or wholly obliterated, and the ultimate structure assumed without passing through them; so, here, it is to be inferred that the process of cell-formation may, in some cases, be passed over.

Thus the hypothesis of evolution prepares us for those two radical modifications of the celldoctrine which the facts oblige us to make. It leads us to expect that as structureless portions of protoplasm must have preceded cells in the process of general evolution; so, in the special evolution of each higher organism, there will be an habitual production of cells out of structureless blastema. And it leads us to expect that though, generally, the physiological units composing a structureless blastema, will display their inherited proclivities by cell-development and metamorphosis; there will nevertheless occur cases in which the tissue to be formed, is formed by direct transformation of the blastema.*

* Let me here refer those who are interested in this question, to Prof. Huxley's eriticism on the cell-doctrine, published in the Medico-Chirurgical Review in 1853.

A critic who thinks the above statements are "rather misleading" admits that the lowest types of organisms yield them support, saying that "there are certainly masses of protoplasm containing many nuclei, but no trace of cellular structure, in both animals and plants. Such non-ccllular masses may exist during development and later become separated up into cells, but there are certain low organisms in which such masses exist in the adult state. They are called by some botanists non.cellular, by others multi-nucleate cells. Clearly the difference lies in the criteria of a cell. There are also some Protozsa, and the Bncteria, in which no nucleus has certainly been denınstrated. But it is usual to consider the bodies of such organisms as cells nevertheless, and it is supposed that such cells represent 
Interpreting the facts in this manner, we may recognize that large amount of truth which the cell-doctrine contains, without committing ourselves to the errors involved by a sweeping assertion of it. We are enabled to understand how it happens that organic structures are usually cellular in their composition, at the same time that they are not universally so. We are shown that while we may properly continue to regard the cell as the morphological unit, we must constantly bear in mind that it is such only in a qualified sense.

$\S 181$. These aggregates of the lowest order, each formed of physiological units united into a group that is structurally single and cannot be divided without destruction of its individuality, may, as above implied, exist as independent organisms. The assumption to which we are committed by the hypothesis of evolution, that such so-called uni-cellular plants were at first the only kinds of plants, is in harmony with the fact that habitats not occupied by plants of higher orders, commonly contain these protophytes in great abundance and great variety. The various species of Pleurococcacex, of Desmidiacex, and Diatomacece, supply examples of morphological units living and propagating separately, under numerous modifications of form and structure. Figures 1, 2, and 3 , represent a few of the commonest types.

Mostly, simple plants are too small to be individually

a stage of development in which the nucleus has not yet been evolved, though the chemical substance 'nuclein' has been formed in some of them"

Perhaps it will be most correct to say that, exeluding the minute, nonnucleated organisms, all the higher organisms-Metazoa and Metaphyta-are composed throughout of cells, or of tissues originally cellular, or of materials which have in the course of development been derived from cells. It must, however, be borne in mind that, according to sundry leading biologists, cells in the strict sense are not the immediate products either of the primitive fissions or of subsequent fissions; but that the multiplying so-called cells are nucleated masses of protoplasm which remain connected by strands of protoplasm, and which acquire limiting membranes by a secondary process. So that, in the view of Mr. Adam Sedgwick and others, the substance of an organism is in fact a continuous mass of vacuolated protoplasm. 
visible without the microscope. But, in some cases, these vegetal aggregates of the first order grow to appreciable

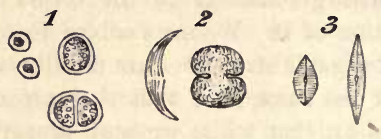

sizes. In the mycelium of some fungi, we have single cells developed into long branched filaments, or ramified tubules, that are of considerable lengths. An analogous structure characterizes certain tribes of Alga, of which Codium adhorens, Fig. 4, may serve as an example. In Botrydium, another alga, Fig. 5, we have a structure which is described as simulating a higher plant, with root, stem, bud, and fruit, all produced by the branching of a single cell. And among
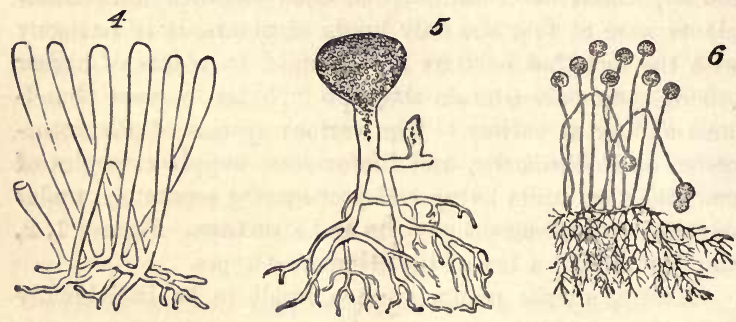

fungi the genus Mucor, Fig. 6, furnishes an example of allicd kind.* Here, though the size attained is much greater than that of many organisms which are morphologically compound, we are compelled to consider the morphological composition as simple; since the whole can no more be separated into minor wholes, than can the branched vascular

* In further illustration, Mr. Tansley names the fact that in the genus Caulerpa we have extrenely complicated forms often of considerable size produced in the same wav. The various snceics simulate very perfectly the members of different arouns amons the higher plants, such as Ilorse-tails, Mosses, Cactuses, Conifers and the like. 
system of an animal. In these cases we have considerable bulk attained, not by a number of aggregates of the first order being united into an aggregate of the second order, but by the continuous growth of an aggregate of the first order.

§182. The transition to higher forms begins in a very unobtrusive manner. Among these aggregates of the first order, an approach towards that union by which aggregates of the second order are produced, is indicated by mere juxtaposition. Protophytes multiply rapidly; and their rapid multiplication sometimes causes crowding. When, instead of floating free in the water, they form a thin film on a moist surface, or are imbedded in a common matrix of mucilage; the mechanical obstacles to dispersion result in a kind of feeble integration, vaguely shadowing forth a combined group. Somewhat more definite combination is shown us by such plants as Palmella botryoides. Here the members of a family of cells, arising by the spontaneous fission of a parentcell, remain united by slender threads of that jelly-like substance which envelops their surfaces. In some Diatomacece several individuals, instead of completely separating, hold together by their angles; and in other Diatomacea, as the Bacillaria, a variable number of units cohere so slightly, that they are continually moving in relation to one another.

This formation of aggregates of the second order, faintly indicated in feeble and variable unions like the above, may be traced through phases of increasing permanence and definiteness, as well as increasing extent. In the yeast-plant, Fig. 7, we have cells which may exist singly, or joined into groups of several; and which have their shapes scarcely at all modified by their connexion. Among the Desmidiacea, it happens in many cases that the two individuals produced by division of a parent-individual, part as soon as they are fully formed; but in other cases, instead of parting they compose a group of two. Allied kinds show us how, by subsequent fissions of the adherent individuals and their progeny, there 
result longer groups; and in some species, a continuous thread of them is thus produced. Figs. 8, 9, 11, exhibit these several stages. Fig. 10 represents a Scenedesmus in which

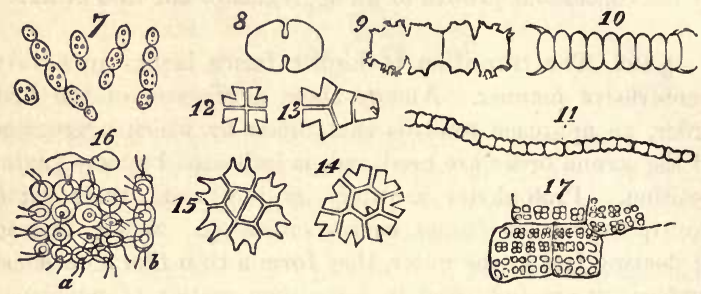

the individuation of the group is manifest. Instead of linear aggregation, many protophytes illustrate central aggregation; as shown in Figs. 12, 13, 14, 15. Other instances are furnished by such forms as the Gonium pectorale, Fig. 16 ( $a$ being the front view, and $b$ the edge view), and the Sarcina ventriculi, Fig. 17. Further, we have that spherical mode of aggregation of which the Volvox globator furnishes a familiar instance.

Thus far, however, the individuality of the secondary aggregate is feebly pronounced: not simply in the sense that it is small; but also in the sense that the individualities of the primary aggregates are very little subordinated. But on seeking further, we find transitions towards forms in which the compound individuality is more dominant, while the simple individualities are more obscured. Obseuration of one kind accompanies mere increase of size in the secondary aggregate. In proportion to the greater number of the morphological units held together in one mass, beeomes their relative insignifieance as individuals. We see this in the irregularly-spreading lichens that form patches on rocks; and in such creeping fungi as grow in films or laminæ on decaying wood and the bark of trees. In these cases, however, the integration of the component cells is of an almost 
mechanical kind. The aggregate of them is scarcely more individuated than a lump of inorganic matter: as witness the way in which the lichen extends its curved edges in this or that direction, as the surface favours; or the way in which the fungus grows round and imbeds the shoots and leaves that lie in its way, just as so much plastic clay might do. Though here, in the augmentation of mass, we see a progress towards the evolution of a higher type, we have as yet none of that definiteness required to constitute a compound unit, or true aggregate of the second order.

Another kind of obscuration of the morphological units, is brought about by their more complete coalescence into the form of some structure made by their union. This is well exemplified among the Confervoidece and Conjugata. In Fig. 18, there
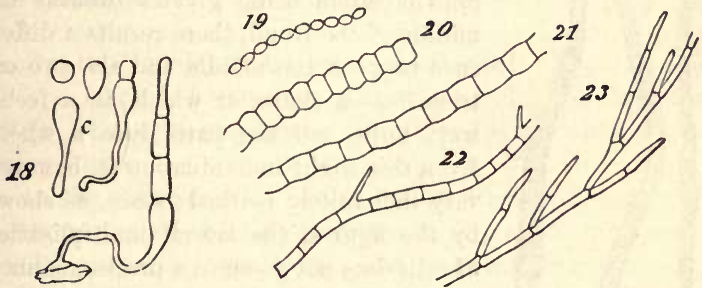

are represented the stages of a growing Mougeotia genuflexa, in which this merging of the simple individualities into the compound individuality, is shown in the history of a single plant; and in Figs. 19, 20, 21; 22, 23, are represented a series of species from this group, and that of Cladophora, ${ }^{*}$ in which we see a progressing integration. While, in the lower types, the primitive spheroidal forms of the cells are scarcely altered, in the higher types the cells are so fused together as to constitute cylinders divided by septa. Here, however,

* It may be objected that in Cladophora the separate compartments of the thallus sererally contain many nuclei, making it doubtful whether they descend from uni-nucleate cells. If, howerer, they do not they simply illustrate another form of integration. 
the indefiniteness is still great. There are no specific limits to the length of any thread thus produced, and there is none of that differentiation of parts required to give a decided individuality to the whole.

To constitute something like a true aggregate of the second order, capable of serving as a compound unit that may be combined with others like itself into still higher aggregates, there must exist both mass and definiteness.

§183. An approach towards plants which unite these characters, may be traced in such forms as Bangia ciliaris, Fig. 24. The multiplication of cells here takes place, not in

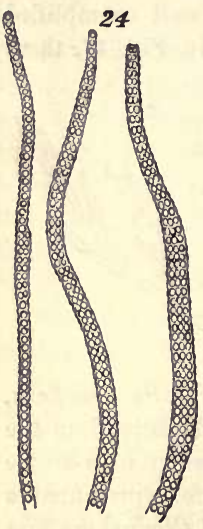

a longitudinal direction only, but also in a transverse direction; and the transverse multiplication being greater towards the middle of the frond, there results a difference between the middle and the two extremities-a character which, in a feeble way, unites all the parts into a whole. Even this slight individuation is, however, very indefinitely marked; since, as shown by the figures, the lateral multiplication of cells does not go on in a precise manner.

From some such type as this there appear to arise, through slight differences in the modes of growth, two closely-allied groups of plants, having individualities somewhat more pronounced. If, while the cells multiply longitudinally; their lateral multiplication goes on in one direction only, there results a flat surface, as in the genus Ulva (Sea-lettuce) or in the upper part of the thallus of Enteromorpha Linza, Fig. 25; or where the lateral multiplication is less uniform in its rate, in types like Fig. 26. But where the lateral multiplication occurs in two directions transverse to one another, a hollow frond may be produced-sometimes irregularly spheroidal, and sometimes 
irregularly tubular; as in Enteromorpha intestinalis, Fig. 27. And often, as in Enteromorpha compressa, Fig. 28, and other

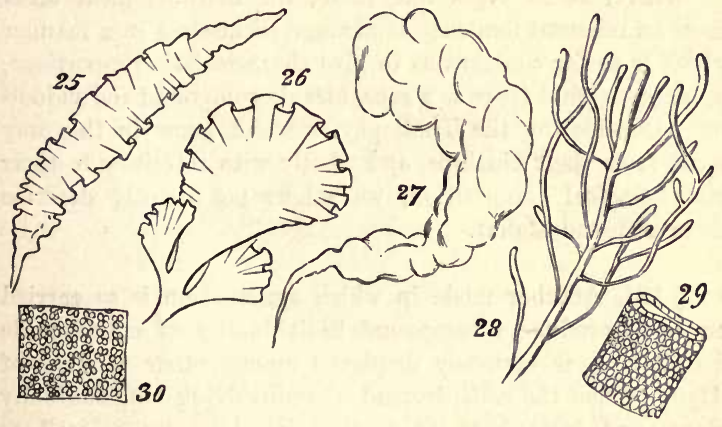

species, this tubular frond becomes branched. Figs. 29 and 30 are magnified portions of such fronds, showing the simple cellular aggregation which allies them with the preceding forms.

In the common Fuci of our coasts, other and somewhat higher stages of this integration are displayed. We have fronds preserving something like constant breadths and dividing dichotomously with approximate regularity. Though the subdivisions so produced are not to be regarded as separate fronds, but only as extensions of one frond, they foreshadow a higher degree of composition; and by the comparatively methodic way in which they are united, give to the aggregate a more definite, as well as a more complex, individuality.

Many of the higher lichens exhibit an analogous advance. While in the lowest lichens, the different parts of the thallus are held together only by being all attached to the supporting surface, in the higher lichens the thallus is so far integrated that it can support itself by attachment to such surface at one point only. And then, in still more developed kinds, we find the thallus assuming a 
dichotomously-branched form, and so gaining a more specific character as well as greater size.

Where, as in types like these, the morphological units show an inherent tendency to arrange themselves in a manner which is so far constant as to give characteristic proportions, we may say that there is a recognizable compound individuality. Considering the Thallophytes which grow in this way apart from their kinships, and wholly with reference to their morphological composition, we might not inaptly describe them as pseudo-foliar.

$\S 184$. Another mode in which aggregation is so carried on as to produce a compound individuality of considerable definiteness, is variously displayed among other families of Alga. When the cells, instead of multiplying longitudinally alone, and instead of all multiplying laterally as well as longitudinally, multiply laterally only at particular places, they produce branched structures.

Indications of this mode of aggregation occur among the Confervoidea, as shown in Figs. 22, 23. Though, in some of the more developed Algae which exhibit the ramified arrangement in a higher degree, the component cells are, like those of the lower Alga, united together end to end, in such way as but little to obscure their separate forms, as in Cladophora Hutchinsia, Fig. 31; they nevertheless evince greater subordination to the whole of which they are parts, by arranging themselves more methodically. Still further pronounced becomes the compound individuality when, while the component cells of the branches unite completely into jointed cylinders, the component cells of the stem form an axis distinguished by its relative thickness and complexity. Such types of structures are indicated by Figs. 32, 33-figures representing small portions of plants which are quite treelike in their entire outlines. On examining Figs. 34, 35, 36, which show the structures of the stems in these types, it will be seen, too, that the component cells in becoming more 
coherent, have undergone changes of form which obscure their individualities more than before. Not only are they
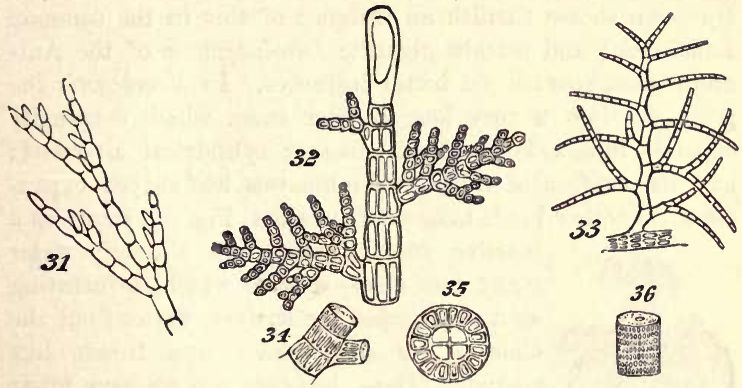

much elongated, but they are so compressed as to be prismatic rather than cylindrical. This structure, besides displaying integration of the morphological units carried on in two directions instead of one; and besides displaying this higher integration in the greater merging of the individualities of the morphological units in the general individuality; also displays it in the more pronounced subordination of the branches and branchlets to the main stem. This differentiation and consolidation of the stem, brings all the secondary growths into more marked dependence; and so renders the individuality of the aggregate more decided.

We might not inappropriately call this type of structure pseud-axial. It simulates that of the higher plants in certain superficial characters. We see in it a primary axis along which development may continue indefinitely, and from which there bud out, laterally, secondary axes of like naturc, bearing like tertiary axes; and this is a mode of growth with which Phænogams make us familiar.

$\S 185$. Some of the larger Alga supply examples of an integration still more advanced; not simply inasmuch as they unite much greater numbers of morphological units 
into eontinuous masses, but also inasmuch as they combine the pseudo-foliar structure with the pseud-axial structure. Our own shores furnish an instance of this in the common Laminaria; and eertain gigantic Laminariacece of the Antarctie seas, furmish yet better instanees. In Necrocystis the germ develops a very long slender stem, which eventually expands into a large bladder-like or eylindrical air-vessel; and the surface of this bears numerous leaf-shaped expansions. Another kind, Lessonia fuscescens, Fig. 37, shows us a

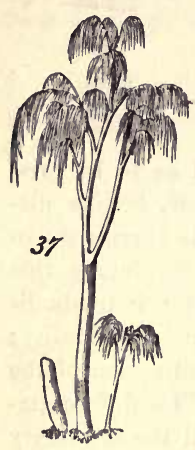
massive stem growing up through water many feet deep-a stem which, bifurcating as it approaches the surface, flattens out the ends of its subdivisions into fronds like ribands. These, however, are not true foliar appendages, since they are merely expanded continuations of the stem. In Egregia branches of the thallus not only take the form of leaves, but these are differentiated into several eategories in aecordance with a division of labour. In any of these Laminariacece the whole plant, great as may be its size, and made up though it seems to be of many groups of morphological units, united into a compound group by their marked subordination to a connecting mass, is nevertheless a single thallus, which is added to by intercalary growth at the "transition-place," at the junction of the stem-like and leaf-like portions. The aggregate is still an aggregate of the second order.

But among eertain of the highest Algox, we do find something more than this union of the pseud-axial with the pseudo-foliar strueture. In addition to pseud-axes of comparative complexity; and in addition to pseudo-folia that are like leaves, not only in their general shapes but in having mid-ribs and even veins; there are the beginnings of a higher stage of integration. Figs. 38, 39, and 40, show some of the steps. In Rhodymenia palmata, Fig. 38, the 
parent-frond is comparatively irregular in form, and without a mid-rib; and along with this very imperfect integration,

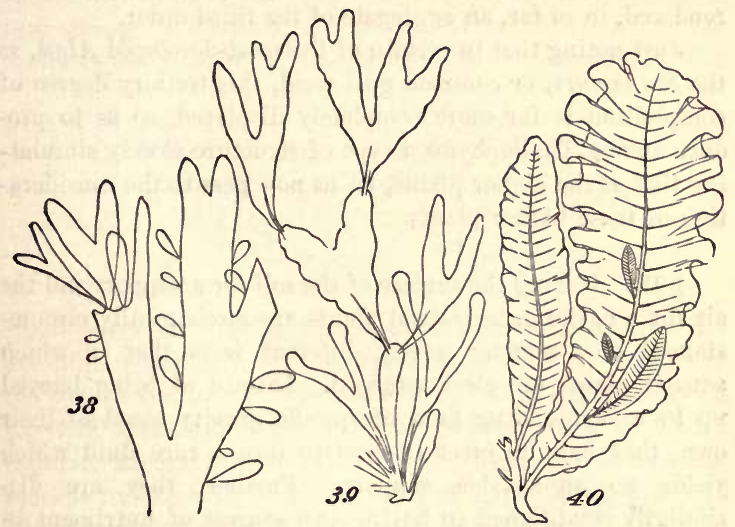

we see that the secondary fronds growing from the edges are distributed very much at random, and are by no means specific in their shapes. A considerable advance is displayed by Phyllophora rubens, Fig. 39. Here the frond, primary, secondary, or tertiary, betrays some approach towards regularity in both form and size; by which, as also by its partially-developed mid-rib, there is established a more marked individuality; and at the same time, the growth of the secondary fronds no longer occurs anywhere on the edge, in the same plane as the parent-frond, but from the surface at specific places. Delesseria sanguinea, Fig. 40, illustrates a much more definite arrangement of the same kind. The fronds of this plant, quite regularly shaped, have their parts decidedly subordinated to the whole; and from their midribs grow other fronds which are just like them. Each of :these fronds is an organized group of those morphological units which we distinguish as aggregates of the first order. And in this case, two or more such aggregates of the second 
order, well individuated by their forms and structures, are united together; and the plant composed of them is thus rendered, in so far, an aggregate of the third order.

Just noting that in certain of the most-developed Alga, as the Sargassum, or common gulf-weed, this tertiary degree of composition is far more completely displayed, so as to produce among Thallophytes a type of structure closely simulating that of the higher plants, let us now pass to the consideration of these higher plants.

$\S 186$. Having the surface of the soil for a support and the air for a medium, terrestrial plants are mechanically circumstanced in a manner widely different from that in which aquatic plants are circumstanced. Instead of being buoyed up by a surrounding fluid of specific gravity equal to their own, they have to erect themselves into a rare fluid which yields no appreciable support. Further, they are dissimilarly conditioned in having two sources of nutriment in place of one. Unlike the Alga, which derive all the materials for their tissues from the water bathing their entire surfaces, and use their roots only for attachment, most of the plants which cover the Earth's surface, absorb part of their food through their imbedded roots and part through their exposed leaves. These two marked unlikenesses in the relations to surrounding conditions, profoundly affect the respective modes of growth. We must duly bear them in mind while studying the further advance of composition.

The class of plants to which we now turn-that of the Archegoniata-is nearly related by its lower members to the classes above dealt with: so much so, that some of the inferior liverworts are quite licheniform, and are often mistaken for lichens. Passing over these, let us recommence our synthesis with such members of the class as repeat those indications of progress towards a higher composition, which we have just observed among the more-developed Alga. The Jungermanniacea furnish us with a series of types, clearly indicating the 
transition from an aggregate of the second order to an aggregate of the third order. Figs. 41, and 42, indicate the structure among the lowest of this group. Here there is but an incomplete development of the second order of aggregate. The

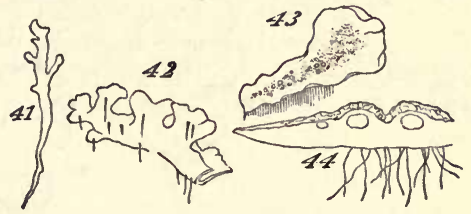

frond grows as irregularly as the thallus of a lichen: it is indefinite in size and outline, spreading hither or thither as the conditions favour. Moreover, it lacks the differentiations required to subordinate its parts to the whole: it is uniformly cellular, having neither mid-rib nor veins; and it puts out rootlets indifferently from all parts of its under-surface. In Fig. 43, Pellia epiphylla, we have an advance on this type. There is here, as shown in the transverse section, Fig. 44, a thickening of the frond along its central portion, producing something like an approach towards a mid-rib; and from this the rootlets are chiefly given off. The outline, too, is much less irregular; whence results greater distinctness of the individuality. A further step is displayed in Metzgeria furcata, Fig. 45. The frond of this plant, comparatively well integrated by the distribution of its substance around a decided mid-rib, and by its comparatively-definite outlines, produces secondary fronds. There is what is called proliferous growth; and occasionally, as shown in Fig. 46, representing an enlarged portion, the growth is doubly-proliferous. In these cases, however, the tertiary aggregate, so far as it is formed, is but very feebly integrated; and its integration is but temporary. For not only do these younger fronds that bud out from the mid-ribs of older fronds, develop rootlets of their own; but as soon as they are well grown and adequately rooted, they dissolve their connexions with the parent-fronds, 
and become quite independent.

From these transitional forms we pass, in the higher Jungermanniacece, to

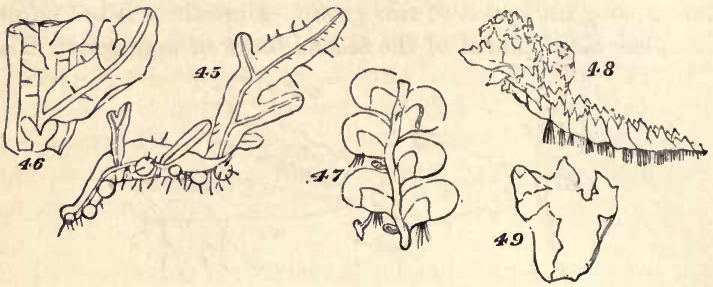

forms composed of many fronds that are permanently united by a continuous stem. A more-developed aggregate of the third order is thus produced. But though, along with increased definiteness in the secondary aggregates, there is here an integration of them so extensive and so regular, that they are visibly subordinated to the whole they form; yet the subordination is really very incomplete. In some instances, as in Radula complanata, Fig. 47 , the leaflets develop roots from their under surfaces, just as the primitive frond does; and in the majority of the group, as in J. capitata, Fig. 48, roots are given off all along the connecting stem, at the spots where the leaflets or frondlets join it: the result being that though the connected frondlets form a physical whole, they do not form, in any decided manner, a physiological whole; since successive portions of the united series, carry on their functions independently of the rest.

Finally, the most developed members of the group, whether lineally descended from the less developed or from an early type common to the two, present us with tertiary aggregates which are physiologically as well as physically integrated.* Not lying

* The great mass of early ancestral types-plant and animal-consisting of soft tissucs, have left no remains whatever, and we have no reason to suppose that those which left remains fell within the direct ancestral lines of any existing forms. Contrariwise, we have reason to suppose that they fell within lines of evolution out of which the lines ending in existing forms diverged. We must therefore infer that the difficulties of affiliation which arise if we 
prone like the kinds thus far described, but growing erect, the stem and attached leaflets become dependent upon a single root or group of roots; and being so prevented from carrying on their functions separately, are made members of a compound individual: there arises a definitely-established aggregate of the third degree of composition.

The facts as arranged in the above order are suggestive. Minute aggregates, or cells, the grouping of which we traced in $\S 182$, showed us analogous phases of indefinite union, which appeared to lead the way towards definite union. We see here among compound aggregates, as we saw there among simple aggregates, the establishment of a specific form, and a size that falls within moderate limits of variation. This passage from less definite extension to more definite extension, seems in the one case, as the other, to be accompanied by the result, that growth exceeding a certain rate, ends in the formation of a new aggregate, rather than an enlargement of the old. And on the higher stage, as on the lower, this process, irregularly carried out in the simpler types, produces in them unions that are but temporary; while in the more-developed types, it proceeds in a systematic way, and ends in the production of a permanent aggregate that is doubly compound.

contemplate divergent types now existing, would not arise if we had before us all the early intermediate types. The Mammalia differ in sundry respects from all other kinds of Vertebrata-Fishes, Reptiles, Birds; and if the absence of hair, mammæ, and two occipital condyles, in these other vertebrates were taken to imply a fundamental distinction, it might, in the absence of any known fossil links, be inferred that the Mammalia belonged to a separate phylum. But these differences are not held to negative the assumed relationship. Similarly among plants. We must not reject an hypothesis respecting a certain supposed type, because the existing types it must have been akin to present traits which it could not have had. We are justified in assuming, within limits, a hypothetical type, unlike existing types in traits of some importance. Hence results the answer to a criticism passed on the above argument, that it implies relations between the undeveloped and developed forms of the Jungermanniacea such as the facts do not show us. This objection is met on remembering that the types in which the supposed transition took place disappcared myriads of years ago. 
Must we then conclude that as cells, or morphological units, are integrated into a unit of a higher order, which we call a thallus or frond; so, by the integration of fronds, there is evolved a structure such as the above-delineated species possess? Whether this is the interpretation to be given of these plants, we shall best see when considering whether it is the interpretation to be given of plants which rank above them. Thus far we have dealt only with the Cryptogamia. We have now to deal with the Phanerogamia or Phænogamia. 


\section{CHAPTER III.}

THE MORPHOLOGICAL COMPOSITION OF PLANTS, CONTINUED.

$\S 18 \%$ THAT advanced composition arrived at in the Archegoniato, is carried still further in the Flowering Plants. In these most-elevated vegetal forms, aggregation of the third order is always distinctly displayed; and aggregates of the fourth, fifth, sixth, \&c., orders are very common.

Our inquiry into the morphology of these flowering plants, may be advantageously commenced by studying the development of simple leaves into compound leaves. It is easy to trace the transition, as well as the conditions under which it occurs; and tracing it will prepare us for understanding how, and when, metamorphoses still greater in degree take place.

$\S 188$. If we examine a branch of the common bramble, when in flower or afterwards, we shall not unfrequently find a simple or undivided leaf, at the insertion of one of the lateral flower-bearing axes, composing the terminal cluster of flowers. Sometimes this leaf is partially lobed; sometimes cleft into three small leaflets. Lower down on the shoot, if it be a lateral one, occur larger leaves, composed of three leaflets; and in some of these, two of the leaflets may be lobed more or less deeply. On the main stem the leaves, usually still larger, will be found to have five leaflets. Supposing the plant to be a well-grown one, it will furnish all 
gradations between the simple, very small leaf, and the large composite leaf, containing sometimes even seven leaflets. Figs. 50 to 64 , represent leading stages of the transition.

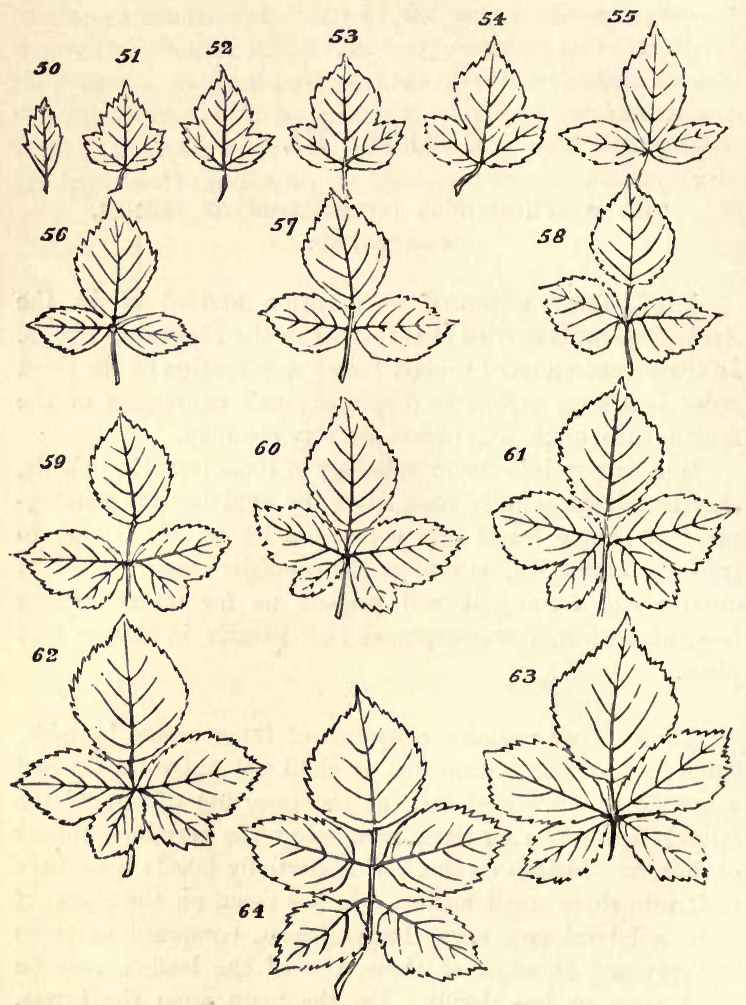

What determines this transition? Observation shows that the quintuple leaves occur where the materials for growth are supplied in greatest abundance; that the leaves become 
less and less compound, in proportion to their remoteness from the main currents of sap; and that where an entire absence of divisions or lobes is observed, it is on leaves within the flower-bunch: at the place, that is, where the forces which cause growth are nearly equilibrated by the forces which oppose growth; and where, as a consequence, gamogenesis is about to be set in $(\S 78)$. Additional evidence that the degree of nutrition determines the degree of composition of the leaf, is furnished by the relative sizes of the leaves. Not only, on the average, is the quintuple leaf much larger in its total area than the triple leaf; but the component leaflets of the one, are usually much larger than those of the other. The like contrasts are still more marked between triple leaves and simple leaves. This connection of decreasing size with decreasing composition, is conspicuous in the series of figures: the differences shown being not nearly so great as may be frequently observed. Confirmation may be drawn from the fact that when the leading shoot is broken or arrested in its growth, the shoots it gives off (provided they are given off after the injury), and into which its checked currents of sap are thrown, produce leaves of five leaflets where ordinarily leaves of three leaflets occur. Of course incidental circumstances, as variations in the amounts of sunshine, or of rain, or of matter supplied to the roots, are ever producing changes in the state of the plant as a whole; and by thus affecting the nutrition of its leaf-buds at the times of their formation, cause irregularities in the relations of size and composition above described. But taking these causes into account, it is abundantly manifest that a leaf-bud of the bramble will develop into a simple leaf or into a leaf compounded in different degrees, according to the quantity of assimilable matter brought to it at the time when the rudiments of its structure are being fixed. And on studying the habits of other plants-on observing how annuals that have compound leaves usually bear simple leaves at the outset, when the assimilating surface is but small; and how, when compound- 
leaved plants in full growth bear simple leaves in the midst of compound ones, the relative smallness of such simple leaves shows that the buds from which they arose were illsupplied with sap; it will cease to be doubted that a foliar organ may be metamorphosed into a group of foliar organs, if furnished, at the right time, with a quantity of matter greater than can be readily organized round a single centre of growth. An examination of the transitions through which a compound leaf passes into a doubly-compound leaf, as scen in the various intermediate forms of leaflets in Fig. 65, will further enforce this conclusion.

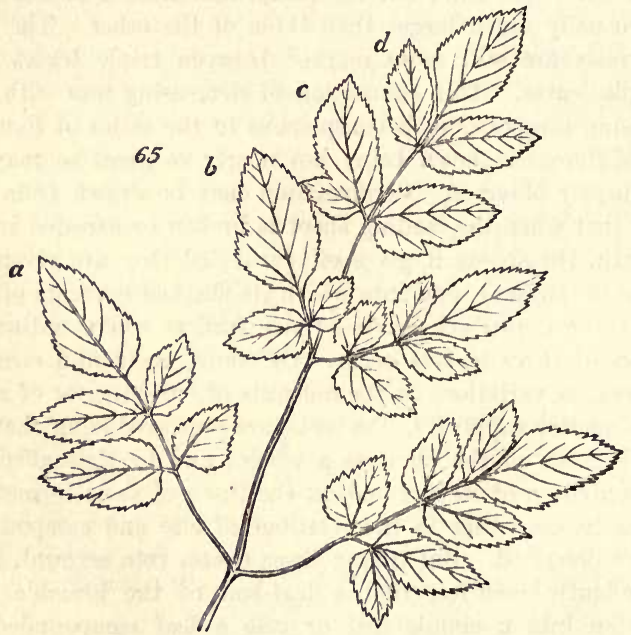

Here we may advantageously note, too, how in such cases the leaf-stalk undergoes concomitant changes of structure. In the bramble-leaves above described, it becomes compound simultaneously with the leaf-the veins become mid-ribs while the mid-ribs become petioles. Moreover, the secondary stalks, and still more the main stalks, bear thorns similar in their 
shapes, and approaching in their sizes, to those on the stem; besides simulating the stem in colour and texture. In the petioles of large compound leaves, like those of the common Heracleum, we see still more distinctly both internal and external approximations in character to axes. Nor are there wanting plants whose large, though simple, leaves, are held out far from the stems by foot-stalks that are, near the ends, sometimes so like axes that the transverse sections of the two are indistinguishable; as instance the Calla palustris.

One other fact respecting the modifications which leaves undergo, should be set down. Not only may leaf-stalks assume to a great degree the characters of stems, when they have to discharge the functions of stems, by supporting many leaves or very large leaves; but they may assume the characters of leaves, when they have to undertake the functions of leaves. The Australian Acacias furnish a remarkable illustration of this. Acacias elsewhere found bear pinnate leaves; but the majority of those found in Australia bear what appear to be simple leaves. It turns out, however, that these are merely leaf-stalks flattened out into foliar shapes: the laminæ of the leaves being undeveloped. And the proof is that in young plants, showing their kinships by their embryonic characters, these leaf-like petioles bear true leaflets at their ends. A metamorphosis of like kind occurs in Oxalis bupleurifolia, Fig. 66. The fact most deserving of notice, however, is that these leafstalks, in usurping the general aspects and functions of leaf-blades, have, to some extent, also usurped their

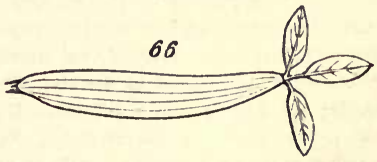
structures: though their venation is not like that of the leafblades they replace, yet they have veins, and in some cases mid-ribs.

Reduced to their most general expression, the truths above shadowed forth are these:-That group of morphological units, or cells, which we see integrated into the compound 
unit called a leaf, has, in each higher plant, a typical form, due to the special arrangement of these cells around a midrib and veins. If the multiplication of morphological units, at the time when the leaf-bud is taking on its main outlines, exceeds a certain limit, these units begin to arrange themselves round secondary centres, or lines of growth, in such ways as to repeat, in part or wholly, the typical form: the larger veins become transformed into imperfect mid-ribs of partially independent leaves; or into complete mid-ribs of quite separate leaves. And as there goes on this transition from a single aggregate of cells to a group of such aggregates, there simultaneously arises, by similarly insensible steps, a distinct structure which supports the several aggregates thus produced, and unites them into a compound aggregate. These phenomena should be carefully studied; since they give us a key to more involved phenomena.*

$\S 189$. Thus far we have dealt with leaves ordinarily so called: briefly indicating the homologies between the parts of the simple and the compound. Let us now turn to the homologies among foliar organs in general. These have been

* There is much force in the criticism passed on the above paragraph, and by implication on some preceding paragraphs, that though in plants which tend to produce compound leaves the production is largely dependent on the supply of nutriment, yet the unqualified statement of this relation as a general one, is negatived by the existence of plants which bear only simple leaves, however much high nutrition causes growth. But mostly valid though this objection is, it is probably not universally valid. I am led to say this by what occasionally occurs in flowers. The flowering stem of the Hyacinth is single; but I have seen a cultivated Hyacinth in which one of the flowers had developed into a lateral spike. Still more striking evidence was once supplied to me by Agrimony. All samples of this plant previously seen had single flowering spikes, but some years ago I met with one, extremely luxuriant, in which sone flowers of the primitive spike were replaced by lateral spikes; and I am not sure that some of these, again, did not bear lateral spikes. Now if in plants which, in probably millions of cases, have thelr flowering stems single, excessive nutrition changes certain of their flowers into new spikes, it is a reasonable supposition that in like manner plants which are thought invariably to hear only single learea, will, under kindred condi. tions, bear compound leaves. 
made familiar to readers of natural history by popularized outlines of The Metamorphosis of Plants-a title, by the way, which is far too extensive; since the phenomena treated of under it, form but a small portion of those it properly includes.

Passing over certain vague anticipations which have been quoted from ancient writers, and noting only that some clearer recognitions were reached by Joachim Jung, a Hamburg professor, in the middle of the 17th century; we come to the Theoria Generationis, which Wolff published in 1759, and in which he gives definite forms to the conceptions that have since become current. Specifying the views of Wolff, Dr. Masters writes:- “After speaking of the homologous nature of the leaves, the sepals and petals, an homology consequent on their similarity of structure and identity of origin, he goes on to state that the "pericarp is manifestly composed of several leaves, as in the calyx, with this difference only, that the leaves which are merely placed in close contact in the calyx, are here united together' ; a view which he corroborates by referring to the manner in which many capsules open and separate 'into their leaves.' The seeds, too, he looks upon as consisting of leaves in close combination. His reasons for considering the petals and stamens as homologous with leaves, are based upon the same facts as those which led Linnæus, and, many years afterwards, Goethe, to the same conclusion. 'In a word,' says Wolff, 'we see nothing in the whole plant, whose parts at first sight differ so remarkably from each other, but leaves and stem, to which latter the root is referrible." " It appears that Wolff, too, enunciated the now-accepted interpretation of compound fruits : basing it on the same evidence as that since assigned. In the essay of Goethe, published thirty years after, these relations among the parts of flowering plants were traced out in greater detail, but not in so radical a way; for Goethe did not, as did Wolff, verify his hypothesis by dissecting buds in their early stages of development. Goethe appears to have 
arrived at his conclusions independently. But that they were original with him, and that he gave a more variouslyillustrated exposition of them than had been given by Wolff, does not entitle him to anything beyond a secondary place, among those who have established this important generalization.

Were it not that these pages may be read by some to whom Biology, in all its divisions, is a new subject of study, it would be needless to name the evidence on which this nowfamiliar generalization rests. For the information of such it will suffice to say, that the fundamental kinship existing among all the foliar organs of a flowering plant, is shown by the transitional forms which may be traced between them, and by the occasional assumption of one another's forms. "Floral leaves, or bracts, are frequently only to be distinguished from ordinary leaves by their position at the base of the flower; at other times the bracts gradually assume more and more of the appearance of the sepals." The sepals, or divisions of the calyx, are not unlike undereloped leaves: sometimes assuming quite the structure of leaves. In other cases, they acquire partially or wholly the colours of the petals-as, indeed, the bracts and uppermost stem-leaves occasionally do. Similarly, the petals show their alliances to the foliar organs lower down on the axis, and to those higher up on the axis. On the one hand, they may develop into ordinary leaves that are green and veined; and, on the other hand, as so commonly seen in double flowers, they may bear anthers on their edges. All varieties of gradation into neighbouring foliar organs may be witnessed in stamens. Flattened and tinted in various degrees, they pass insensibly into petals, and through them prove their homology with leaves; into which, indeed, they are transformed in flowers that become wholly foliaceous. The style, too, is occasionally changed into petals or into green leaflets; and even the ovules are now and then seen to take on leaf-like forms. Thus we have clear evidence that in Plrnogams, all the 
appendages of the axis are homologues: they are all modified leaves.

Wolff established, and Goethe further illustrated, another general law of structure in flowering plants. Each leaf commonly contains in its axil a bud, similar in structure to the terminal bud. This axillary bud may remain undeveloped; or it may develop into a lateral shoot like the main shoot; or it may develop into a flower. If a shoot bearing lateral flowers be examined, it will be found that the internode, or space which separates each leaf with its axillary flower from the leaf and axillary flower above it, becomes gradually less towards the upper end of the shoot. In some plants, as in the fox-glove, the internodes constitute a regularly-diminishing series. In other plants, the series they form suddenly begins to diminish so rapidly, as to bring the flowers into a short spike: instance the common orchis. And again, by still more sudden dwarfing of the internodes, the flowers are brought into a cluster; as they are in the cowslip. On contemplating a clover flower, in which this clustering has been carried so far as to produce a compact head; and on considering what must happen if, by a further arrest of axial development, the foot-stalks of the florets disappear; it will be seen that there must result a crowd of flowers, seated close together on the end of the axis. And if, at the same time, the internodes of the upper stemleaves also remain undeveloped, these stem-leaves will be grouped into a common involucre: we shall have a composite flower, such as the thistle. Hence, to modifications in the developments of foliar organs, have to be added modifications in the developments of axial organs. Comparisons disclose the gradations through which axes, like their appendages, pass into all varieties of size, proportion, and structure. And we learn that the occurrence of these two kinds of metamorphosis, in all conceivable degrees and combinations, furnishes us with a proximate interpretation of morphological composition in Phænogams. 
I say a proximate interpretation, because there remain to be solved certain deeper problems; one of which at once presents itself to be dealt with under the present head. Leaves, petals, stamens, \&c., being shown to be homologous foliar organs; and the part to which they are attached, proving to be an indefinitely-extended axis of growth, or axial organ; we are met by the questions,-What is a foliar organ? and What is an axial organ? The morphological composition of a Phænogam is undetermined, so long as we cannot say to what lower structures leaves and shoots are homologous; and how this integration of them originates. To these questions let us now address ourselves.

$\S 190-1$. Already, in $\S 78$, reference has been made to the occasional development of foliar organs into axial organs: the special case there described being that of a fox-glove, in which some of the sepals were replaced by flower-buds. The observation of these and some analogous monstrosities, raising the suspicion that the distinction between foliar organs and axial organs is not absolute, led me to examine into the matter; and the result has been the deepening of this suspicion into a eonviction. Part of the evidence is given in Appendix A.

Some time after having reached this conviction, I found on looking into the literature of the subject, that analogous irregularities had suggested to other observers, beliefs similarly at variance with the current morphological creed. Difficulties in satisfactorily defining these two elements, have served to shake this creed in some minds. To others, the strange leaf-like developments which axes undergo in certain plants, have afforded reasons for doubting the constancy of this distinction which vegetal morphologists usually draw. And those not otherwise rendered sceptical, have been made to hesitate by such cases as that of the Nepaul-barley, in which the glume, a foliar organ, becomes developed into an axis and bears flowers. In his essay-" Vegetable Morph- 
ology: its History and Present Condition," * whence I have already quoted, Dr. Masters indicates sundry of the grounds for thinking that there is no impassable demarcation between leaf and stem. Among other difficulties which meet us if we assume that the distinction is absolute, one is implied by this question:- "What shall we say to cases such as those afforded by the leaves of Guarea and Trichilia, where the leaves after a time assume the condition of branches and develop young leaflets from their free extremities, a process less perfectly seen in some of the pinnate-leaved kinds of Berberis or Mahonia, to be found in almost every shrubbery?"

A class of facts on which it will be desirable for us here to dwell a moment, before proceeding to deal with the matter deductively, is presented by the Cactacea. In this remarkable group of plants, deviating in such varied ways from the ordinary phænogamic type, we find many highly instructive modifications of form and structure. By contemplating the changes here displayed within the limits of a single order, we shall greatly widen our conception of the possibilities of metamorphosis in the regetal kingdom, taken as a whole. Two different, but similarly-significant, truths are illustrated. First, we are shown how, of these two components of a flowering plant, commonly regarded as primordially distinguished, one may assume, throughout numerous species, the functions, and to a great degree the appearance, of the other. Second, we are shown how, in the same individual, there may occur a re-metamorphosis: the usurped function and appearance being maintained in one part of the plant, while in another part there is a return to the ordinary appearance and function. We will consider these two truths separately. Some of the Euphorbiacea, which simulate Cactuses, show us the stages through which such abnormal structures are arrived at. In Euphorbia splendens, the lateral axes are considerably swollen at their distal ends, so as often to be club-shaped: still, however, being covered with bark

* See British and Foreign Medico-Chirurgical Reviewo for January, 1862. 
of the ordinary colour, and still bearing leaves. But in kindred plants, as Euphorbia neriifolia, this swelling of the lateral axes is carried to a far greater extent; and, at the same time, a green colour and a fleshy consistence have been acquired: the typical relations nevertheless being still shown by the few leaves that grow out of these soft and swollen axes. In the Cactacea, which are thus resembled by plants not otherwise allied to them, we have indications of a parallel transformation. Some kinds, not commonly brought to England, bear leaves; but in the species most familiar to us, the leaves are undeveloped and the axes assume their functions. Passing over the many varieties of form and combination which these green succulent growths display, we have to note that in some genera, as in Phyllocactus, they become flattened out into foliaceous shapes, having mid-ribs and something approaching to veins. So that here, and in the genus Epiphyllum, which has this character still more marked, the plant appears to be composed of fleshy leaves growing one upon another. And then, in Rhipsalis, the same parts are so leaf-like, that an uncritical observer would regard them as leaves. These which are axial organs in their homologies, have become foliar organs in their analogies. When, instead of comparing these strangely-modified axes in different genera of Cactuses, we compare them in the same individual, we meet with transformations no less striking. Where a tree-like form is produced by the growth of these foliaceous shoots, one on another; and where, as a consequence, the first-formed of them become the main stem that acts as support to secondary and tertiary stems; they lose their green, succulent character, acquire bark, and become woody. In resuming the functions of axes they resume the structures of axes, from which they had deviated. In Fig. 71 are shown some of the leaf-like axes of Rhipsalis rhombea in their young state; while Fig. 72 represents the oldest portion of the same plant, in which the foliaceous characters are quite obliterated, and there has resulted 
an ordinary stem-structure.

One further fact is to be noted. At the same time that their leaf-like appearances are lost, the axes also lose their separate individualities. As they become stemlike, they also become integrated; and they do this so effectually that their original points of junction, at

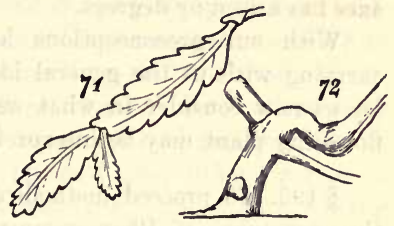
first so strongly marked, are effaced, and a consolidated trunk is produced.

Joined with the facts previously specified, these facts help us to conceive how, in the evolution of flowering plants in general, the morphological components that were once distinct, may become extremely disguised. We may rationally expect that during so long a course of modification, much greater changes of form, and much more decided fusions of parts, have taken place. Seeing how, in an individual plant, the single leaves pass into compound leaves, by the development of their veins into mid-ribs while their petioles begin to simulate axes; and seeing that leaves ordinarily exhibiting definitely-limited developments, occasionally produce other leaves from their edges; we are led to suspect the possibility of still greater changes in foliar organs. When, further, we find that within the limits of one natural order, petioles usurp the functions and appearances of leaves, at the same time that in other orders, as in Ruscus, lateral axes so simulate leaves that their axial nature would by most not be suspected, did they not bear flowers on their mid-ribs or edges; and when, among Cactuses, we perceive that such metamorphoses and re-metamorphoses take place with great facility; our suspicion that the morphological elements of Phænogams admit of profound transformations, is deepened. And then, on discovering how frequent are the monstrosities which do not seem satisfactorily explicable without admitting the development of foliar organs into axial organs; we become 
ready to entertain the hypothesis that during the evolution of the phænogamic type, the distinction between leaves and axes has arisen by degrees.

With our preconceptions loosened by such facts, and carrying with us the general idea which such facts suggest, let us now consider in what way the typical structure of a flowering plant may be interpreted.

$\S 192$. To proceed methodically, we must seek a clue to the structures of Phanerogams, in the structures of those inferior plants that approach to them-Archegoniatre. The various divisions of this class present, along with sundry characters which ally them with Thallophytes, other characters by which the phænogamic structure is shadowed forth. While some of the inferior Hepatica or Liverworts, severally consist of little more than a thallus-like frond, among the higher members of this group, and still more among the Mosses and Ferns, we find a distinctly marked stem.* Some Archegoniates (or rather Rhizoids) have foliar expansions that are indefinite in their forms; and some have quite definitely-shaped leaves. Roots are possessed by all the more developed genera of the class; but there are other genera, as Sphagnum, which have no roots. Here the fronds are formed of only a single layer of cells; and there a double layer gives them a higher character-a differ-

* Schleiden, who chooses to regard as an axis that which Mr. Berkeley, with more obvious truth, calls a mid-rib, says:- " The flat stem of the Liverworts presents many varieties, consisting frequently of one simple laycr of thin-walled cells, or it exhibits in its axis the elements of the ordinary stem." This passage exemplifies the wholly gratuitous hypotheses which men will sometimes espouse, to escape hypotheses they dislike. Schleiden, with the positiveness characteristic of him, asserts the primordial distinction between axial organs and foliar organs. In the higher Archegoniates he sees an undeniable stem. In the lower Archegoniates, clearly allied to them by their fructification, there is no structure having the remotest resemblance to a stem. But to save his hypothesis, Schleiden calls that "a flat stem," which is obviously a structure in which stem and leaf are not differentiated. He is the more to be blamed for this unphilosophical assumption, since he is merciless in his strictures on the unphilosophical assumptions of other botanists. 
ence exhibited between closely allied genera of one group, the Mosses. Equally varied are the developments of the foliarorgans in their detailed structures: now being without midribs or veins; now having mid-ribs but no veins; now having both mid-ribs and veins. Nor must we omit the similarly-significant circumstance, that whereas in the lower Archegoniates the reproductive elements are immersed here and there in the thallus-like frond, they are, in the higher orders, seated in well-specialized and quite distinct fructifying organs, having analogies with the flowers of Phænogams. Thus, many facts imply that if the Phænogamic type is to be analyzed at all, we must look among the Archegoniates for its morphological components, and the manner of their integration.

Already we have seen among the lower Cryptogamia, how, as they became integrated and definitely limited, aggregates acquire the habit of budding out other aggregates, on reaching certain stages of growth. Cells produce other cells endogenously or exogenously; and fronds give origin to other fronds from their edges or surfaces. We have seen, too, that the new aggregates so produced, whether of the first order or the second order, may either separate or remain connected. Fissiparously-multiplying cells in some cases part company, while in other cases they unite into threads or laminæ or masses; and fronds originating proliferously from other fronds, sometimes when mature disconnect themselves from their parents, and sometimes continue attached to them. Whether they do or do not part, is clearly determined by their nutrition. If the conditions are such that they can severally thrive better by separating after a certain development is reached, it will become their habit then to separate; since natural selection will favour the propagation of those which separate most nearly at that time. If, conversely, it profits the species for the cells or fronds to continue longer attached, which it can only do if their growths and subsequent powers of multiplication are thereby increased, it must happen, through the continual survival of the fittest, that 
longer attachment will become an established characteristic; and, by persistence in this process, permanent attachment will result when permanent attachment is advantageous. That disunion is really a consequence of relative innutrition, and union a consequence of relative nutrition, is clear $\grave{a}$ posteriori. On the one hand, the separation of the new individuals, whether in germs or as developed aggregates, is a dissolving away of the connecting substance; and this implies that the connecting substance has ceased to perform its function as a channel of nutriment. On the other hand, where, as we see among Phænogams, there is about to take place a separation of new individuals in the shape of germs, at the point where the nutrition is the lowest, a sudden increase of nutrition will cause the impending separation to be arrested; and the fructifying elements, reverting towards the ordinary form, thereupon develop in connexion with the parent. Turning to the Archegoniates, we find among them many indications of this transition from discontinuous development to continuous development. Thus the Liverworts give origin to new plants by cells which they throw off from their surfaces; as, indeed, we have seen that much higher plants do. "According to Bischoff," says Schleiden, "both the cells of the stem (Jungermannia [now Lophocolea] bidentata) and those of the leaves (J. exsecta) separate themselves as propagative cells from the plant, and isolated cells shoot out and develop while still connected with the parent plant into small cellular bodies (Metzgeria furcata), which separate from the plant, and grow into new plants, as in Mnium androgynum among the Mosses." Now in the way above explained, these propagative cells and proliferous buds, may continue developing in connexion with the parent to various degrees before separating; or the buds which are about to become fructifying organs may similarly, under increased nutrition, develop into young fronds. As Sir W. Hooker says of the male fructification in Metzgeria furcata,- " "It has the appearance of being a young shoot or innovation (for in colour 
and texture I can perceive no difference) rolled up into a spherical figure." On finding in this same plant, that sometimes the proliferously-produced frond buds out from itself another frond before separating from the parent, as shown in Fig. 46, it becomes clear that this long-continued connexion may readily pass into permanent connexion. And when we see how, even among Phænogams, buds may either detach themselves as bulbils, or remain attached and become shoots; we can scarcely doubt that among inferior plants, less definite in their modes of organization, such transitions must continually occur.

Let us suppose, then, that Fig. 73 is the frond of some primitive Archegoniate, similar in general characters to Pellia epiphylla, Fig. 43 ; bearing, like it, the fructifying buds on its upper surface, and having a slightly-marked mid-rib and rootlets. And suppose that, as shown, a secondary frond is proliferously produced from the mid-rib, and continues attached to it. Evidently the ordinary discontinuous development, can thus become a continuous development, only on condition that there is an adequate supply, to the secondary frond, of such materials as are furnished by the rootlets: the remaining materials being obtainable by itself from the air. Hence, that portion of the mid-rib lying between the secondary
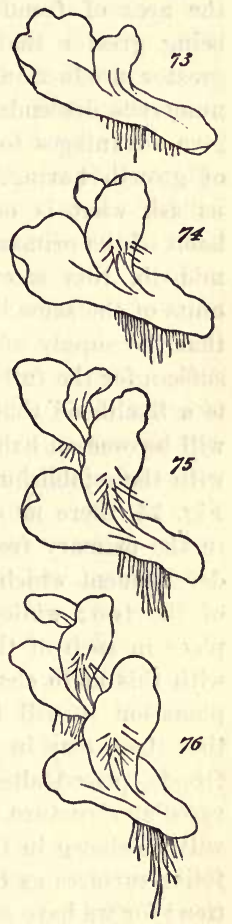
frond and the chief rootlets, having its function increased, will increase in bulk. An additional consequence will be a greater concentration of the rootlets-there will be extra growth of those which are most serviceably placed. Observe, 
next, that the structure so arising is likely to be maintained. Such a variation implying, as it does, circumstances especially favourable to the growth of the plant, will give to the plant extra chances of leaving descendants; since the area of frond supported by a given area of the soil, being greater than in other individuals, there may be a greater production of spores. And then, among the more numerous descendants thus secured by it, the variation will give advantages to those in which it recurs. Such a mode of growth having, in this manner, become established, let us ask what is next likely to result. If it becomes the habit of the primary frond to bear a secondary frond from its mid-rib, this secondary frond, composed of physiological units of the same kind, will inherit the habit; and supposing that the supply of mineral matters obtained by the rootlets suffices for the full development of the secondary frond, there is a likelihood that the growth from it of a tertiary frond, will become an habitual characteristic of the variety. Along with the establishment of such a tertiary frond, as shown in Fig. 74, there must arise a further development of mid-rib in the primary frond, as well as in the secondary frond-a development which must bring with it a greater integration of the two; while, simultaneously, extra growth will take place in such of the rootlets as are most directly connected with this main channel of circulation. Without further explanation it will be seen, on inspecting Figs. 75 and 76, that there may in this manner result an integrated series of fronds, placed alternately on opposite sides of a connecting vascular structure. That this connecting vascular structure will, as shown in the figures, become more distinct from the foliar surfaces as these multiply, is no unwarranted assumption; for we have seen in compound-leaved plants, how, under analogous conditions, mid-ribs become developed into separate supporting parts, which acquire some of the characters of axes while assuming their functions. And now mark how clearly the structure thus built up by integration 
of proliferously-growing fronds, corresponds with the structure of the more developed Jungermanniacex. Each of the fronds successively produced, repeating the characters of its parent, will bear roots; and will bear them in homologous places, as shown. Further, the united mid-ribs having but very little rigidity, will be unable to maintain an erect position. Hence there will result the recumbent, continuouslyrooted stem, which these types exhibit: an embryo phænogam having the weakness of an embryo.*

A natural concomitant of the mode of growth here described, is that the stem, while it increases longitudinally, increases scarcely at all transversely: hence the old name Acrogens. Clearly the transverse development of a stem is the correlative, partly of its function as a channel of circulation, and partly of its function as a mechanical support. That an axis may lift its attached leaves into the air, implies thickness and solidity proportionate to the mass of such leaves; and an increase of its sap-vessels, also proportionate to the mass of such leaves, is necessitated when the roots are all at one end and the leaves at the other. But in the generality of Acrogens, these conditions, under which arises the necessity for transverse growth of the axis, are absent wholly or in great part. The stem habitually creeps below the surface, or lies prone upon the surface; and where it grows in a vertical or inclined direction, does this by attaching itself to a vertical or inclined object. Moreover, throwing out rootlets, as it mostly does, at intervals throughout its length, it is not called upon in any considerable degree, to transfer nutritive materials from one of its ends to the other.

- To this interpretation it is objected that "the more developed Jungermanniaces" do not appear to have arisen from the lower forms of Jungermanniacese-that is to say, from such lower forms as are now existing. It may, however, be contended that this fact does not exclude the interpretation given; since the higher forms may well bave been evolved, not from any of the lower forms we now know, but from lower forms which have become extinct. This, indeed, is the implication of the evolutionary process as pointed out in the note to Chap. I. If then we assume some early type of intcrmediate structure, the explanation may not improbably hold. 
Hence this peculiarity which gives their name to the Acrogens, now called Archegoniates, is a natural accompaniment of the low degree of specialization reached in them. And that it is an incidental and not a necessary peculiarity, is demonstrated by two converse facts. On the one hand, in those higher Acrogens which, like the tree-ferns, lift large masses of foliage into the air, there is just as decided a transverse expansion of the axis as in dicotyledonous trees. On the other hand, in those Dicotyledons which, like the common Dodder, gain support and nutriment from the surfaces over which they creep, there is no more lateral expansion of the axis than is habitual among Acrogens or Archegoniates. Concluding, as we are thus fully justified in doing, that the lateral expansion accompanying longitudinal extension, which is a general characteristic of Phanerogams as distinguished from Archegoniates, is nothing more than a concomitant of their usually-vertical growth; * let us now go on to consider how vertical growth originates, and what are the structural changes it involves.

$\S 193$. Plants depend for their prosperity mainly on air and light: they dwindle where they are smothered, and thrive where they can expand their leaves into free space and sunshine. Those kinds which assume prone positions, consequently labour under disadvantages in being habitually interfered with by one another-they are mutually shaded and

* I am indebted to Dr. Hooker for pointing out further facts supporting this view. In his Flora Antaretica, he describes the genus Lessonia (sce Fig. 37), and especially $L$. ovata, as having a mode of growth simulating that of the dieotyledonous trees, not only in general form but in internal structure. The tall vertical stem thickens as it grows, by the periodical addition of layers to its periphery. That even Thallophytes should thus, under certain conditions, present a transversely-increasing axis, shows that there is nothing absolutely characteristic of Phanerogams in their habit of stem-thickening. Mr. Tansley gives me further verification by the state. ment that "it is also now certain that members of the Equisetinece and Lycopodinea, as well as some Ferns which flourished in Carboniferous times, had secondary thickening in their stems quite comparable to that of modern Dicotyledonous trees." 
mutually injured. Such of them, however, as happen, by variations in mode of growth, to rise higher than others, are more likely to flourish and leave offspring than others. That is to say, natural selection will favour the more uprightgrowing forms. Individuals with structures which lift them above the rest, are the fittest for the conditions; and by the continual survival of the fittest, such structures must become established. There are two essentially-different ways in which the integrated series of fronds above described, may be modified so as to acquire the stiffness needful for maintaining perpendicularity. We will consider them separately.

A thin layer of substance gains greatly in power of resisting a transverse strain, if it is bent round so as to form a tube: witness the difference between the pliability of a sheet of paper when outspread, and the rigidity of the same sheet of paper when rolled up. Engineers constantly recognize this truth, in devising appliances by which the greatest strength shall be obtained at the smallest cost of material; and among organisms, we see that natural selection habitually establishes structures conforming to the same principle, wherever lightness and stiffness are to be combined. The cylindrical bones of mammals and birds, and the hollow shafts of feathers, are examples. The lower plants, too, furnish cases where the strength needful for maintaining an upright position, is acquired by this rolling up of a flat thallus or frond. In Fig. 77 we have an Alga which approaches towards a tubular distribution of substance; and which has a consequent rigidity. Sundry common forms of lichen, having the

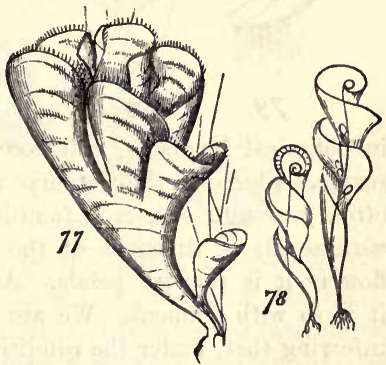
thallus folded into a branched tube, still more decidedly display the connexion between this structural arrangement 
and this mechanical advantage. And from the particular class of plants we are here dealing with-the Archegoniatesa type is shown in Fig. 78, Riella helicophylla, similarly characterized by a thin frond that is made stiff enough to stand, by an incurving which, though it does not produce a hollow cylinder, produces a kindred form. If, then, as we have seen, natural selection or survival of the fittest will favour such among these recumbent Archegoniates as are enabled, by variations in their structures, to maintain raised postures; it will favour the formation of fronds that curve round upon themselves, and curve round upon the fronds growing out of them. What, now, will be the result should such a modification take place in the group of proliferous fronds represented in Fig. 76? Clearly, the result will be a structure like that shown in Fig. 79. And if this inrolling becomes more complete, a form like Jungermannia cordifolia,

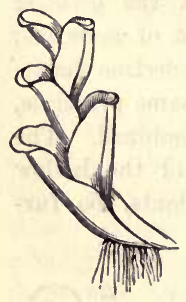

79

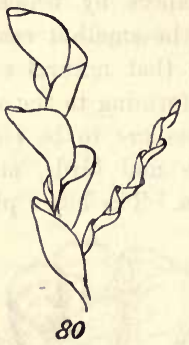
represented in Fig. 80, will be produced.

When the successive fronds are thus folded round so completely that their opposite edges meet, these opposite edges will be apt to unite: not that they will grow together after being formed, but that they will develop in connexion; or, in botanical language, will become "adnate." That foliar surfaces which, in their embryonic state, are in close contact, often join into one, is a familiar fact. It is habitually so with sepals or divisions of the calyx. In all campanulate flowers it is so with petals. And in some tribes of plants it is so with stamens. We are therefore well warranted in inferring that, under the conditions above described, the successive fronds or leaflets will, by union of their remote edges, first at their points of origin and afterwards higher up, 
form sheaths inserted one within another, and including the axis.

This incurving of the successive fronds, ending in the formation of sheaths, may be accompanied by different sets of modifications. Supposing Fig. 81 to be a transverse section of such type ( $a$ being the mid-rib, and $b$ the expansion of an older frond; while $c$ is a younger frond proliferously developed within it), there may begin two divergent kinds of changes, leading to two contrasted structures. If, while frond continues to grow out of frond, the series of united mid-ribs continues to be the channel of circulation between the uppermost fronds and the roots-if, as a consequence, the compound mid-rib, or rudimentary axis, continues to increase in size laterally; there will arise the series of transitional forms represented by the transverse sections $82,83,84,85$; ending in the production of a solid axis,
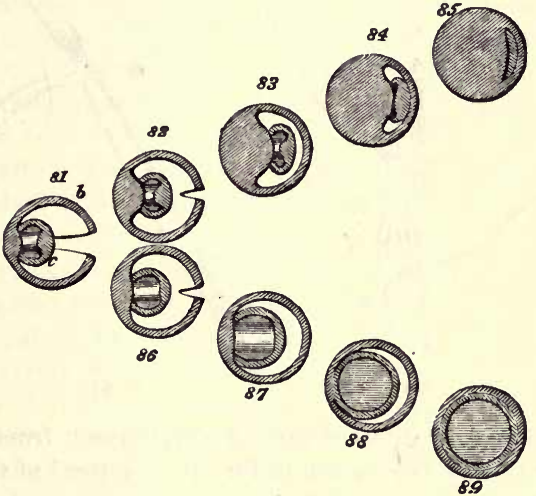

everywhere wrapped round by the foliar surface of the frond, as an outer layer or sheath. But if, on the other hand, circumstances favour a form of plant which maintains its uprightness at the smallest cost of substance-if the vascular bundles of each succeeding mid-rib, instead of remaining concentrated, become distributed all round the tube 
formed by the infolded frond; then the structure eventually reached, through the transitional forms $86,87,88,89$, will be a hollow cylinder.* And now observe how the two structures thus produced, correspond with two kinds of Monocotyledons. Fig. 90 represents a species of Dendrobium, in which we see clearly how each leaf is but a continuation of the external layer of a solid axis-a sheath such as would result from the infolded edges of a frond becoming adnate; and on examining how the sheath of each leaf includes the one above it, and how the successive sheaths include the axis, it will be manifest that the relations of parts are just such as exist in the united series of fronds shown in Fig. 79-the successive nodes answering to the successive points of origin of the fronds. Conversely, the stem of a grass, Fig. 91, dis-

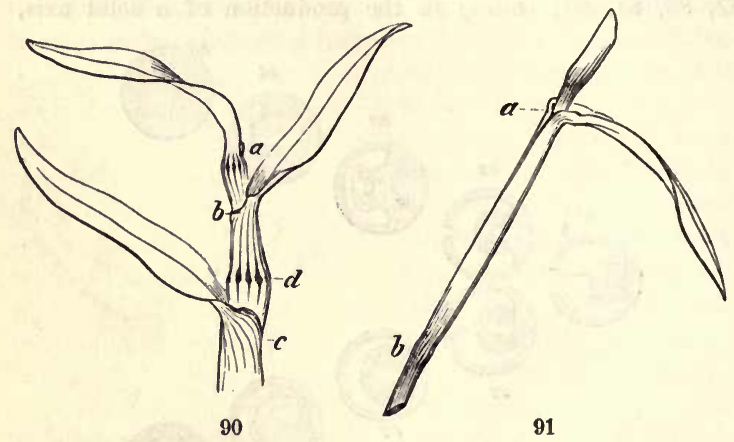

plays just such relations of parts, as would result from the development of the type shown in Fig. 79, if instead of the midribs thickening into a solid axis, the matter composing them became evenly distributed round the foliar surfaces, at the same time that the incurved edges of the foliar surfaces united. The arrangements of the tubular axis and its appendages, thus resulting, are still more instructive than those

* See note at the end of the chapter. 
of the solid axis. For while, even more clearly than in the Dendrobium, we see at the point $b$, a continuity of structure between the substance of the axis below the node, and the substance of the sheath above the node: we see that this sheath, instead of having its edges united as in Dendrobium, has them simply overlapping, so as to form an incomplete hollow cylinder which may be taken off and unrolled; and we see that were the overlapping edges of this sheath united all the way from the node $a$ to the node $b$, it would constitute a tubular axis, like that which precedes it or like that which it includes. And then, giving an unexpected conclusiveness to the argument, it turns out that in one family of grasses, the overlapping edges of the sheaths do unite: thus furnishing us with a demonstration that tubular structures are produced by the incurving and joining of foliar surfaces; and that so, hollow axes may be interpreted as above, without making any assumption unwarranted by fact. One further correspondence between the type thus ideally constructed, and the monocotyledonous type, must be noted. If, as already pointed out, the transverse growth of an axis arises when the axis comes to be a channel of circulation between all the roots at one of its extremities and all the leaves at the other; and if this lateral bulging must increase as fast as the quantity of foliage to be brought in communication with the roots increases-especially if such foliage has at the same time to be raised high above the earth's surface; what must happen to a plant constructed in the manner just described? The elder fronds or foliar organs, ensheathing the younger ones, as well as the incipient axis serving as a bond of union, are at first of such circumference only as suffices to inclose these undeveloped parts. What, then, will take place when the inclosed parts growwhen the axis thickens while it elongates? Evidently the earliest-formed sheaths, not being large enough for the swelling axis, must burst; and evidently each of the laterformed sheaths must, in its turn, do the like. There must 
result a gradual exfoliation of the successive sheaths, like that indicated as beginning in the above figure of Dendrobium; which, at $a$, shows the bud of the undeveloped parts just visible above the enwrapping sheaths, while at $b$, and $c$, it shows the older sheaths in process of being split open. That is to say, there must result the mode of growth which helped to give the name Endogens to this class.

The other way in which an integrated series of fronds may acquire the rigidity needful for maintaining an erect position, has next to be considered. If the successive fronds do not acquire such habit of curling as may be taken advantage of by natural selection, so as to produce the requisite stiffness; then, the only way in which the requisite stiffness appears producible, is by the thickening and hardening of the fused series of mid-ribs. The incipient axis will not, in this case, be inclosed by the rolled-up fronds; but will continue exposed. Survival of the fittest will favour the genesis of a type, in which those portions of the successive mid-ribs that enter into the continuous bond, become more bulky than the disengaged portions of the mid-ribs: the individuals which thrive and have the best chances of leaving offspring, being, by the hypothesis, individuals having axes stiff enough to raise their foliage above that of their fellows. At the same time, under the same influences, there will tend to result an elongation of those portions of the mid-ribs, which become parts of the incipient axis; seeing that it will profit the plant to have its leaves so far removed from one another, as to prevent mutual interferences. Hence, from the recumbent type there will evolve, by indirect equilibration ( $\$ 167$ ), such modifications as are shown in Figs. 92, 93, 94; the first of which is a slight advance on the ideal type represented in Fig. 76, arising in the way described; and the others of which are actual plants-Haplomitrium Hookeri, and Plagiochila decipiens. Thus the higher Archegoniates show us how, along with an assumption of the upright attitude, there does go on, as we see there must go on, a separa- 
tion of the leaf-producing parts from the root-producing parts; a greater development of that connecting portion of the successive fronds, by which they are kept in communica-
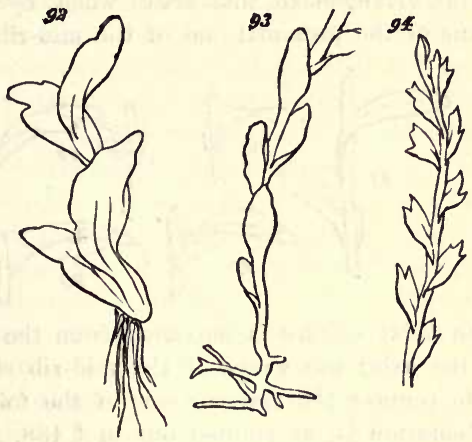

tion with the roots, and raised above the ground; and a consequent increased differentiation of such connecting portion from the parts attached to it. And this lateral bulging of the axis, directly or indirectly consequent on its functions as a support and a channel, being here unrestrained by the early-formed fronds folded round it, goes on without the bursting of these. Hence arises a leading character of what is called exogenous growth-a growth which is, however, still habitually accompanied by exfoliation, in flasks, of the outermost layers, continually being cracked and split by the accumulation of layers within them. And now if we examine plants of the exogenous type, we find among them many displaying the stages of this metamorphosis. In Fig. 95, is shown a form in which the continuity of the axis with the mid-rib of the leaf, is manifest-a continuity that is conspicuous in the common thistle. Here the foliar expansion, running some distance down the axis, makes the included portion of the axis a part of its mid-rib; just as in the ideal types above drawn. By the greater growth of the internodes, 
which are very variable, not only in different plants but in the same plant, there results a modification like that delineated in Fig. 96. And then, in such forms as Fig. 97, there is shown the arrangement that arises when, by more rapid development of the proximal end of the mid-rib, the distal

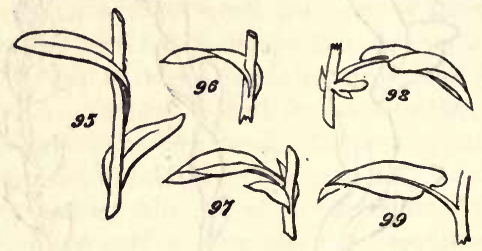

part of the foliar surface is separated from the part which embraces the axis: the wings of the mid-rib still serving, however, to connect the two portions of the foliar surface. Such a separation is, as pointed out in $\S 188$, an habitual occurrence; and in some compound leaves, an actual tearing of the inter-venous tissue is caused by extra growth of the mid-rib. Modifications like this, and the further one in Fig. 98 , we may expect to be established by survival of the fittest, among those plants which produce considerable masses of leaves; since the development of mid-ribs into footstalks, by throwing the leaves further away from the axes, will diminish the shading of the leaves, one by another. And then, among plants of bushy growth, in which the assimilating surfaces become still more liable to intercept one another's light, natural selection will continue to give an advantage to those which carry their assimilating surfaces at the ends of the petioles, and do not develop assimilating surfaces close to the axis, where they are most shaded. Whence will result a disappearance of the stipules and the foliar fringes of the midribs; ending in the production of the ordinary stalked leaf, Fig. 99, which is characteristic of trees. Meanwhile, the axis thickens in proportion to the number of leaves it has to carry, and to put in communication with the roots; and so 
there comes to be a more marked contrast between it and the petioles, severally carrying a leaf each.*

$\S 194$. When, in the course of the process above sketched out, there has arisen such community of nutrition among the fronds thus integrated into a series, that the younger ones are aided by materials which the older ones have elaborated; the younger fronds will begin to show, at earlier and earlier periods of development, the structures about to originate from them. Abundant nutrition will abbreviate the intervals between the successive prolifications; so that eventually, while each frond is yet imperfectly formed, the rudiment of the next will begin to show itself. All embryology justifies this inference. The analogies it furnishes lead us to expect that when this serial arrangement becomes organic, the growing part of the series will show the general relations of the forthcoming parts, while they are very small and unspecialized. What will in such case be the appearances they assume? We shall have no difficulty in perceiving what it will be, if we take a form like that shown in Fig. 92, and dwarf its several parts at the same time that we generalize them. Figs. 100, 101, 102, and 103, will show the result;
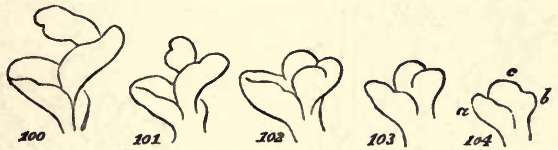

and in Fig. 104, which is the bud of a dicotyledon, we see how clear is the morphological correspondence: $a$ being the rudiment of a foliar organ beginning to take shape; $b$ being the almost formless rudiment of the next foliar organ; and

* Since this paragraph was put in type [this refers to the first edition], I have observed that in some varieties of Cineraria, as probably in other plants, a single individual furnishes all these forms of leaves-all gradations between unstipulated leaves on long petioles, and leaves that embrace the axis. It may be added that the distribution of these various forms is quite in harmony with the rationale above given. 
$c$ being the quite-undifferentiated part whence the rudiments of subsequent foliar organs are to arise.

And now we are prepared for entering on a still-remaining question respecting the structure of Phænogams-what is the origin of axillary buds? As the synthesis at present stands, it does not account for these; but on looking a little more closely into the matter, we shall find that the axillary buds are interpretable in the same manner as the terminal buds. So to interpret them, however, we must return to that process of proliferous growth with which we set out, for the purpose of observing some facts not before named. Delesseria hypoglossum, Fig. 105, represents a seaweed of the same genus as one outlined in Fig. 40 ; but of a species in which proliferous growth is carried much further. Here, not only does the primary frond bud out many secondary fronds from its mid-rib; but most of the secondary fronds similarly bud out several tertiary fronds; and even by some of the tertiary
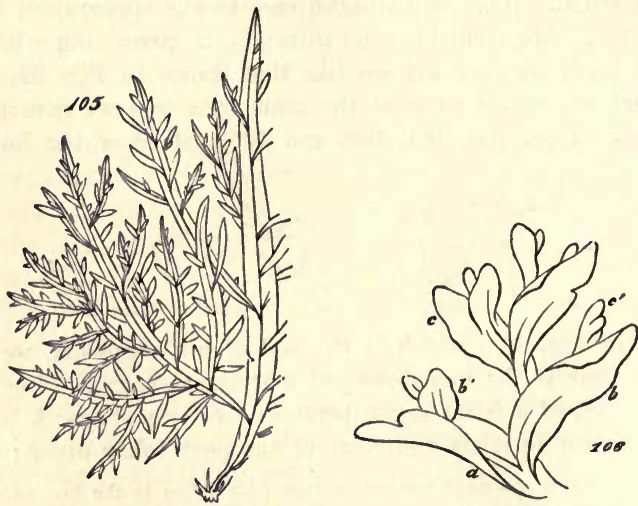

fronds, this prolification is repeated. Besides being shown that the budding out of several fronds from one frond, may become habitual; we are also shown that it may become a 
habit inherited by the fronds so produced, and also by the fronds they produce: the manifestation of the tendency being probably limited only by failure of nutrition. That under fit conditions an analogous mode of growth will occur in fronds of the acrogenic type, like those we set out with, is shown by the case of Metzgeria furcata, Figs. 45, 46, in which such compound prolification is partially displayed. Let us suppose, then, that the frond $a$, Fig. 106, produces not only a single secondary frond $b$, but also another such secondary frond $b^{\prime}$. Let us suppose, further, that the frond $b$ is in like manner doubly proliferous: producing both $c$ and $c^{\prime}$. Lastly, let us suppose that in the second frond $b^{\prime}$ which $a$ produces, as well as in the second frond $c^{\prime}$ which $b$ produces, the doubly-proliferous habit is manifested. If, now, this habit grows organic-if it becomes, as it naturally will become, the characteristic of a plant of luxuriant growth, the unfolding parts of which can be fed by the unfolded parts; it will happen with each lateral series, as with the main series, that its successive components will begin to show themselves at earlier and earlier stages of development. And in the same way that, by dwarfing and generalizing the original series, we arrive at a structure like that of the terminal bud; by dwarfing and generalizing a lateral series, as shown in Figs. 10\%-110, we arrive at a structure answering in nature and position to the axillary bud.

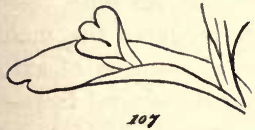

107

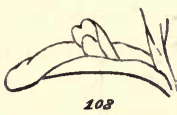

108

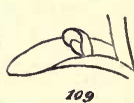

109

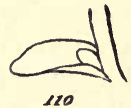

110

Facts confirming these interpretations are afforded by the structure and distribution of buds. The phænogamic axis in its primordial form, being an integrated series of folia; and the development of that part by which these folia are held together at considerable distances from one another, taking place afterwards; it is inferable from the general 
principles of embryology, that in its rudimentary stages, the phænogamic shoot will have its foliar parts more clearly marked out than its axial parts. This we see in every bud. Every bud consists of the rudiments of leaves packed together without any appreciable internodal spaces; and the internodal spaces begin to increase with rapidity, only when the foliar organs have been considerably developed. Moreover, where nutrition falls short, and arrest of development takes place-that is, where a flower is formed-the internodes remain undeveloped: the unfolding ceases before the later-acquired characters of the phænogamic shoot are assumed. Lastly, as the hypothesis leads us to expect, axillary buds make their appearances later than the foliar organs which they accompany; and where, as at the ends of shoots, these foliar organs show failure of chlorophyll, the axillary buds are not produced at all. That these are inferable traits of structure, will be manifest on inspecting Figs. 106-110; and on observing, first, that the doublyproliferous tendency of which the axillary bud is a result, implies abundant nutrition; and on observing, next, that the original place of secondary prolification, is such that the foliar surface on which it occurs, must grow to some extent before the bud appears.

On thus looking at the matter-on contemplating afresh the ideal type shown in Fig. 106, and noting how, by the conditions of the case, the secondary prolifications must cease before that primary prolification which produces the main axis; we are enabled to reconcile all the phenomena of axillary gemmation. We see harmony among the several factsfirst, that the axillary bud becomes a lateral, leaf-bearing axis if there is abundant material for growth; second, that its development is arrested, or it becomes a flower-bearing axis, if the supply of sap is but moderate; third, that it is absent when the nutrition is failing. We are no longer committed to the gratuitous assumption that, in the phænogamic type, there must exist an axillary bud to each foliar 
organ; but we are led to conclude, à priori, that which we find, a posteriori, that axillary buds are as normally absent in flowers as they are normally present lower down the axis. And then, to complete the argument, we are prepared for the corollary that axillary prolification may naturally arise even at the ends of axes, should the failing nutrition which causes the dwarfing of the foliar organs to form a flower, be suddenly changed into such high nutrition as to transform the components of the flower into appendages that are green, if not otherwise leaf-like-a condition under which only, this phenomenon is proved to occur.

$\S 195$. One more question presents itself, when we contrast the early stages of development in the two classes of Phænogams; and a further answer, supplied by the hypothesis, gives to the hypothesis a further probability. It is characteristic of a monocotyledon, to have a single seed-leaf or cotyledon; and it is characteristic of a dicotyledon, to have at least two cotyledons, if not more than two. That is to say, the monocotyledonous mode of germination everywhere coexists with the endogenous mode of growth; and along with the exogenous mode of growth, there always goes either a dicotyledonous or polycotyledonous germination. Why is this? Such correlations cannot be accidentalcannot be meaningless. A true theory of the phænogamic types in their origin and divergence, should account for the connexion of these traits. Let us see whether the foregoing theory does this.

The higher plants, like the higher animals, bequeath to their offspring more or less of nutriment and structure. Superior organisms of either kingdom do not, as do all inferior organisms, cast off their progeny in the shape of minute portions of protoplasm, unorganized and without stocks of material for them to organize; but they either deposit along with the germs they cast off, certain quantities of albuminoid substance to be appropriated by them while they 
develop themselves, or else they continue to supply such substance while the germs partially develop themselves before their detachment. Among plants this constitutes one distinction between seeds and spores. Every seed contains a store of food to serve the young plant during the first stages of its independent life; and usually, too, before the seed is detached, the young plant is so far advanced in structure, that it bears to the attached stock of nutriment much the same relation that the young fish bears to the appended yelkbag at the time of leaving the egg. Sometimes, indeed, the development of chlorophyll gives the seed-leaves a bright green, while the seed is still contained in the parentpod. This early organization of the phænogam must be supposed rudely to indicate the type out of which the phænogamic type arose. On the foregoing hypothesis, the seed-leaves therefore represent the primordial fronds; which, indeed, they simulate in their simple, cellular, unveined structures. And the question here to be asked isdo the different relations of the parts in young monocotyledons and dicotyledons correspond with the different relations of the primordial fronds, implied by the endogenous and the exogenous modes of growth? We shall find that they do.

Starting, as before, with the proliferous form shown in Fig. 111, it is clear that if the strength required for maintaining the vertical attitude, is obtained by the rolling up of the fronds, the primary frond will more and more conceal the secondary frond within it. At the same time, the secondary frond must continue to be dependent on the first for its nutrition; and, being produced within the first, must be prevented by defective supply of light and air, from ever becoming synchronous in its development with the first. Hence, this infolding which leads to the endogenous mode of growth, implies that there must always continue such pre-eminence of the first-formed frond or its representative, as to make the germination monocotyledonous. Figs. 111 to 115 , show the transitional forms that would result from the infolding of 
the fronds. In Fig. 116 (a vertical section of the form represented in Fig. 115) are exhibited the relations of the successive fronds to each other. The modified relations that would result, if the nutrition of the embryo admitted of anticipatory development of the successive fronds, are shown in Fig. $11 \%$. And how readily the structure may pass into that of the monocotyledonous germ, will be seen on inspecting Fig. 118;
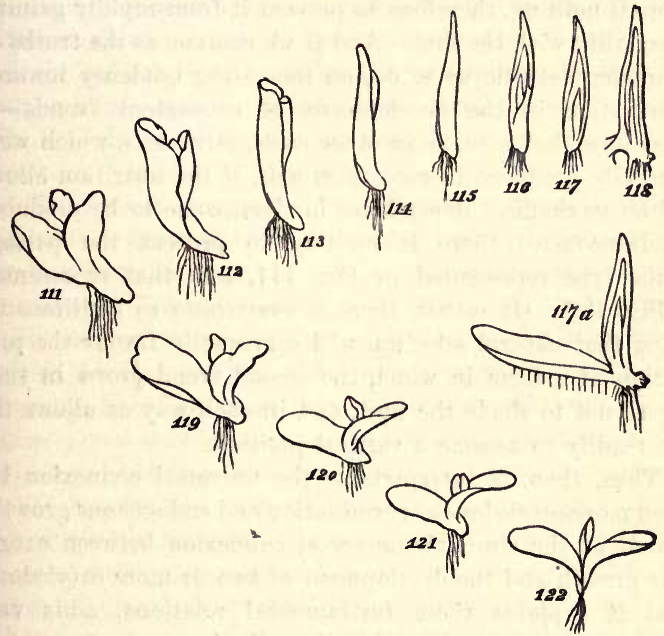

which is a vertical section of an actual monocotyledon at an early stage-the incomplete lines at the left of its root, indicating its connexion with the seed.*

Contrariwise,

* Since these figures were put on the block, it has occurred to me that the relations would be still clearer, were the primary frond represented as not taking part in these processes of modification, which have been described as giving rise to the ercet form; as, indeed, the rooting of its under surface will prevent it from doing in any considerable degree. In such case, each of the Figs. 111 to 117, should have a horizontal rooted frond at its base, homologous with the pro-embryo among Acrogens. This primary frond would then more manifestly stand in the same relation to the rest, as the 
where the strength required for maintaining an upright attitude is not obtained by the rolling up of the fronds, but by the strengthening of the continuous mid-rib, the second frond, so far from being less favourably circumstanced than the first, becomes in some respects even more favourably circumstanced: being above the other, it gets a greater share of light, and it is less restricted by surrounding obstacles. There is nothing, therefore, to prevent it from rapidly gaining an equality with the first. And if we assume, as the truths of embryology entitle us to do, an increasing tendency towards anticipation in the development of subsequent fronds-if we assume that here, as in other cases, structures which were originally produced in succession will, if the nutrition allows and no mechanical dependence hinders, come to be produced simultaneously; there is nothing to prevent the passage of the type represented in Fig. 111, into that represented in Fig. 122. Or rather, there is everything to facilitate it; seeing that natural selection will continually favour the production of a form in which the second frond grows in such way as not to shade the first, and in such way as allows the axis readily to assume a vertical position.

Thus, then, is interpretable the universal connexion between monocotyledonous germination and endogenous growth; as well as the similarly-universal connexion between exogenous growth and the development of two or more cotyledons. That it explains these fundamental relations, adds very greatly to the probability of the hypothesis.

$\S 196$. While we are in this manner enabled to discern the kinship that exists between the higher vegetal types themselves, as well as between them and the lower types; we cotyledon does to the plumule-both by position, and as a supplier of nutriment. Fig. 117a, which I am enabled to add, shows that this would complete the interpretation. Of the dicotyledonous series, it is needful to add no further explanation than that the difference in habit of growth, will permit the second frond to root itself as wcll as the first; and so to become an additional source of nutriment, similarly circumstanced to the first and equal with it. 
are at the same time supplied with a rationale of those truths which vegetal morphologists have established. Those homologies which Wolff indicated in their chief outlines and Goethe followed out in detail, have a new meaning given to them when we regard the phænogamic axis as having been evolved in the way described. Forming the modified conception which we are here led to do, respecting the units of which a flowering plant is composed, we are no longer left without an answer to the question-What is an axis? And we are helped to understand the naturalness of those correspondences which the successive members of each shoot display. Let us glance at the facts from our present standpoint.

The unit of composition of a Phænogam, is such portion of a shoot as answers to one of the primordial fronds. This portion is neither one of the foliar appendages nor one of the internodes; but it consists of a foliar appendage together with the preceding internode, including the axillary bud where this is developed. The parts intercepted by the dotted lines in Fig. 123, eonstitute such a segment; and the truc homology is between this and any other foliar organ with the portion of the axis below it. And now observe how, when we take this for the unit of composition, the metamorphoses which the phænogamic axis displays, are inferable from known laws of development. Embryology teaches us that arrest of development shows itself first in the absence of those parts that have arisen latest in the course of evolution; that if defect of nutrition causes an earlier arrest, parts that are of more ancient origin abort; and that the part alone produced when the supply of materials fails near the outset, is the primordial part. We must infer, therefore, that in each segment of a Phænogam, the foliar organ, which answers to the primordial frond, will be the most constant element; and that the internode and the axillary bud, will be saccessively less constant. This we find. Along with a smaller size of foliar surface implying lower nutrition, it is usual to see a 
much-diminished internode and a less-pronounced axillary bud, as in Fig. 124. On approaching the flower, the axillary bud disappears; and the segment is reduced to a small foliar surface, with an internode which is in most

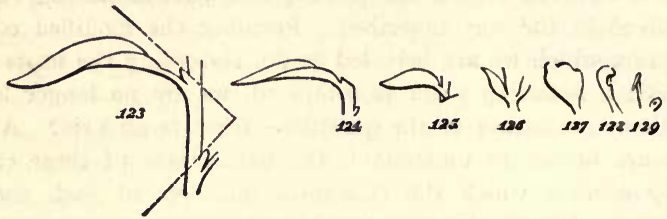

cases very short if not absent, as in 125 and 126 . In the flower itself, axillary buds and internodes are both wanting: there remains only a foliar surface (127), which, though often larger than the immediately preceding foliar surface, shows failing nutrition by absence of chlorophyll. And then, in the quite terminal organs of fructification (129), we have the foliar part itself reduced to a mere rudiment. Though these progressive degenerations are by no means regular, being in many cases varied by adaptations to particular requirements, yet it cannot, I think, be questioned, that the general relations are as described, and that they are such as the hypothesis leads us to expect.

Nor are we without a kindred explanation of certain remaining traits of foliar organs in their least-developed forms. Petals, stamens, pistils, \&c., besides reminding us of the primordial fronds by their diminished sizes, and by the want of those several supplementary parts which the preceding segments possess, also remind us of them by their histological characters: they consist of simple cellular tissue, scarcely at all differentiated. The fructifying cells, too, which here make their appearance, are borne in ways like those in which the lower Acrogens bear them-at the edge of the frond, or at the end of a peduncle, or immersed in the general substance; as in Figs. 128 and 129. Nay, it might even be said that 
the colours assumed by these terminal folia, call to mind the plants out of which we conclude that Phænogams have been evolved; for it is said of the fronds of the Jungermanniacea, that, "though under certain circumstances of a pure green, they are inclined to be shaded with red, purple, chocolate, or other tints."

As thus understood, then, the homologies among the parts of the phænogamic axis are interpretable, not as due to a needless adhesion to some typical form or fulfilment of a predetermined plan; but as the inevitable consequences of the mode in which the phænogamic axis originates.

$\S 19 \%$. And now it remains only to observe, in confirmation of the foregoing synthesis, that it at once explains for us various irregularities. When we see leaves sometimes producing leaflets from their edges or extremities, we recognize in the anomaly a resumption of an original mode of growth: fronds frequently do this. When we learn that a flowering plant, as the Drosera intermedia, has been known to develop a young plant from the surface of one of its leaves, we are at once reminded of the proliferous growths and fructifying organs in the Liverworts. The occasional production of bulbils by Phænogams, ceases to be so surprising when we find it to be habitual among the inferior Acrogens, and when we see that it is but a repetition, on a higher stage, of that selfdetachment which is common among proliferously-produced fronds. Nor are we any longer without a solution of that transformation of foliar organs into axial organs, which not uncommonly takes place. How this last irregularity of development is to be accounted for, we will here pause a moment to consider. Let us first glance at our data.

The form of every organism, we have seen, must depend on the structures of its physiological [or constitutional] units. Any group of such units will tend to arrange itself into the complete organism, if uncontrolled and placed in fit conditions. Hence the development of fertilized germs; and 
hence the development of those self-detached cells which characterize some plants. Conversely, physiological units which form a small group involved in a larger group, and are subject to all the forces of the larger group, will become subordinate in their structural arrangements to the larger group -will be co-ordinated into a part of the major whole, instead of co-ordinating themselves into a minor whole. This antithesis will be clearly understood on remembering how, on the one hand, a small detached part of a hydra soon moulds itself into the shape of an entire hydra; and how, on the other hand, the cellular mass that buds out in place of a lobster's lost claw, gradually assumes the form of a claw -has its parts so moulded as to complete the structure of the organism: a result which we cannot but ascribe to the forces which the rest of the organism exerts upon it. Consequently, among plants, we may expect that whether any portion of protoplasm moulds itself into the typical form around an axis of its own, or is moulded into a part subordinate to another axis, will depend on the relative mass of its physiological units-the accumulation of them that has taken place before the assumption of any structural arrangement. A few illustrations will make clear the validity of this inference. In the compound leaf, Fig. 65, the several lateral growths $a, b, c, d$, are manifestly homologous; and on comparing a number of such leaves together, it will be seen that one of these lateral growths may assume any degree of complexity, according to the degree of its nutrition. Every fern-leaf exemplifies the same general truth still better. Whether each sub-frond remains an undeveloped wing of the main frond, or whether it organizes itself into a group of frondlets borne by a secondary rib, or whether, going further, as it often does, it gives rise to tertiary ribs bearing frondlets, is determined by the supply of materials for growth; since such higher developments are most marked at points where the nutrition is greatest; namely, next the stem. But the clearest evidence is afforded among the Alga, 
which, not drawing nutriment from roots, have their parts much less mutually dependent; and are therefore capable of showing more clearly, how any part may remain an appendage or may become the parent of appendages, according to circumstances. In the annexed Fig. 130, representing a branch of Ptilota plumosa, we see how a wing grows into a wing-bearing branch if its nutrition passes a certain point. This form, so strikingly like that of the feathery crystallizations 130 of many inorganic substances, implies that, as in such crystallizations, the simplicity or complexity of structure at any place depends on the quantity of matter that has to be arranged at that place in a given time.*

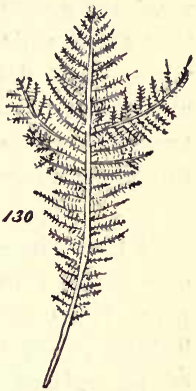

Hence, then, we are not without an interpretation of those over-developments which the phænogamic axis occasionally undergoes. Fig. 104, represents the phænogamic bud in its rudimentary state. The lateral process $b$, which ordinarily becomes a foliar appendage, differs very little from the terminal process $c$, which is to become an axis-differs mainly in having, at this period when its form is being determined, a smaller bulk. If while thus undifferentiated, its nutrition remains inferior to that of the terminal process, it becomes moulded into a part that is subordinate to the general axis. But if, as sometimes happens, there is supplied to it such an abundance of the materials needful for growth, that it becomes as large as the terminal process; then we

* How the element of time modifies the result, is shown by the familiar fact that erystals rapidly formed are small, and become relatively large when left to form more slowly. If the quantity of molecules contained in a solution is relatively great, so that the mutual polarities of the molecules crowded together in every place throughout the solution are intense, there arises a crystalline aggregation around loeal axes; whereas, in proportion as the local action of molecules on one another is rendercd less inteuse by their wider dispersion, they become relatively more subordinate to the forces exerted on them by the larger agfregates of molccules that are at greater distances, and thus are left to arrange themselves round fewer axes into larger crystals. 
may naturally expect it to begin moulding itself round an axis of its own: a foliar organ will be replaced by an axial organ. And this result will be especially liable to occur, when the growth of the axis has been previously undergoing that arrest which leads to the formation of a flower; that is when, from defect of materials, the terminal process has almost ceased to increase, and when some concurrence of favourable causes brings a sudden access of sap which reaches the lateral processes before it reaches the terminal process.*

$\S 198$. The general conclusion to which these various lines of evidence converge, is, then, that the shoot of a flowering plant is an aggregate of the third degree of composition. Taking as aggregates of the first order, those small portions of protoplasm which ordinarily assume the forms under which they are known as cells; and considering as aggregates of the second order, those assemblages of such cells which, in the lower cryptogams, compose the various kinds of thallus; then that structure, common to the higher cryptogams and to phænogams, in which we find a series of such groups of cells bound up into a continuous whole, must be regarded as an aggregate of the third order. The inference drawn from analysis, and verified by a synthesis which corresponds in a remarkable manner with the facts, is that those compound parts which, in Monocotyledons and Dicotyledons are called axes, have really arisen by integration of such simple parts as in lower plants are called fronds. Here, on a higher

* It is objected that these transformations should be much commoner than they are, were they caused solely by the variations of nutrition described. The reply is that they are comparatively rare in uneultivated plants, where such variations are not frequent. The occurrence of them is chicfly among cultivated plants which, being artificially manured, are specially liable to immense accessions of nutriment, caused now by sudden supplles of fertilizing matters, and now by sudden arrival of the roots at such matters already deposited in the soil. It is to these great changes of nutrition, especially apt to take place in gardens, that these monstrosities are ascribed; and it seems to me that they are as frequent as may be expected. 
level, appears to have taken place a repetition of the process already observed on lower levels. The formation of those small groups of physiological units which compose the lowest protophytes, is itself a process of integration; and the consolidation of such groups into definitely-circumscribed and coherent cells or morphological units, is a completing of the process. In those coalescences by which many such cells are joined into threads, and dises, and solid or flattenedout masses, we see these morphological units aggregating into units of a compound kind: the different phases of the transition being exemplified by groups of various sizes, various degrees of cohesion, and various degrees of definiteness. And now we find evidences of a like process on a larger scale: the compound groups are again compounded. Moreover, as before, there are not wanting types of organization by which the stages of this higher integration are shadowed forth. From fronds that occasionally produce other fronds from their surfaces, we pass to those that habitually produce them; from those that do so in an indefinite manner, to those that do so in a definite manner; and from those that do so singly, to those that do so doubly and triply through successive generations of fronds. Even within the limits of a sub-class, we find gradations between fronds irregularly proliferous, and groups of such fronds united into a regular series.

Nor does the process end here. The flowering plant is rarely uniaxial-it is nearly always multiaxial. From its primary shoot there grow out secondary shoots of like kind. Though occasionally among. Phænogams, and frequently among the higher Cryptogams, the germs of new axes detach themselves under the form of bulbils, and develop separately instead of in connexion with the parent axis; yet in most Phænogams the germ of each new axis maintains its connexion with the parent axis: whence results a group of axes - an aggregate of the fourth order. Every tree, by the pro- 
duction of branch out of branch, shows us this integration repeated over and over again; forming an aggregate having a degree of composition too complex to be any longer defined.

[NotE.-A criticism passed on the general argument set forth in the foregoing sections, runs as follows:- "I have already pointed out that the process of evolution by which you believe the Liverworts with a distinct axis and appendages to have been produced from the thalloid forms is not founded on sound evidence either in comparative morphology or development. But even if we admit that such an integration of a proliferously-produced colony might have given rise to the leafy Jungermanniacea, there are even more weighty objections to the supposition that the same process produced the shoot structures of the flowering plants. In the first place the flowering plant-body is not homologous with the liverwort plant-body, since they represent different generations. The liverwort plant-body or gametophyte, i.e., the generation bearing sexual organs, is homologous with the prothallus of ferns and other Pteridophytes, and in the Flowering Plants with reduced structures contained within the spores (embryo-sac and pollen-grain) but still giving rise to sexual cells. The liverwort spore-capsule and its accessory parts (in fact everything produced from the fertilized egg) is homologous with the sporogonium of the mosses, and, as most botanists think, with the leafy plant-body of Pteridophytes and Phanerogams. This generation is called the sporophyte and from the spores which it produces are developed the gametophytes of the next generation. These generalizations were first established by Hofmeister, and all subsequent work has tended to establish them more firmly. The only doubtful question is (and the doubt is mainly, I think, peculiar to myself, certainly not being shared by the majority of botanists) whether the sporophyte of Mosses and Liverforts is really homologous with that of Pteridophytes and 
Phanerogams, whether it may not rather be regarded as a parallel development along another line of descent from the Green Algæ.

" Hence we must look for the origin of the shoot-structure of flowering plants in the sporophytes of the Pteridophytes, from which group there is no reason to doubt that the phanerogams have arisen in descent. The various groups of Pteridophytes vary much in the organization of these shootsystems, as a mental glance at the types exhibited by the Ferns, Horse-tails, Club-mosses, Ophioglossacea, and the isolated Isoetes will convince you at once. It may be that some of these groups are independent in descent, i.e., that the Pteridophyta are polyphyletic, and the current hypothesis with regard to the phanerogams is that they have arisen by two, if not three, separate lines of descent from different groups of Pteridophytes (this is indicated in the classificatory diagram on p. 377 of vol. I). I should not, however, care to pin my faith to these or to any such lines of ancestry. Still I think we must look for the ancestors of the Flowering Plants among the Pteridophytes, and the latter always have a good distinction between axis and appendages. The problem of the evolution of these differentiated sporophytic shoots is undoubtedly the great outstanding problem of morphology. Various attempts have been made to solve it, of which probably the most important is the theory of Profs. Bown and Campbell, who derive the Pteridophytes from some Liverwort like Anthoceros, but the sporophyte of course from the sporophytic portion of the plant (not much more than a spore-capsule), the prothallus of the Fern representing the vegetative thallus of Anthoceros. I am not wholly convinced by these undoubtedly ingenious hypotheses, in support of which an immense amount of facts have been collected; but my position would, I know, simply ' put us to ignorance again' on this question.

"I have discussed this at some length in order to bring out clearly the immense difficulty of constructing a well- 
grounded theory of the origin of the differentiated shootsystem of the higher plant. I confess I don't think it can be done at all with the materials at present at our disposal. Of course it is just possible to suppose that some ancestral sporophyte had the structure of a proliferous thalloid liverwort gametophyte, and that from it was evolved the phanerogamic shoot in the ways you suggest. This gives us absolutely no clue, however, to any Pteridophytic shoot, which ought to be intermediate (more or less) between the hypothetical ancestor and the Phanerogam, and is furthermore, as far as I can see, not supported by an atom of evidence of any kind. It is true that your theory fits in well with the phenomena exhibited by phanerogamic shoots themselves, but this fact you will see must lose much of its significance if the hypothesis lacks foundation.

"With regard to your method of explaining the fundamental characters of 'Exogens' and 'Endogens,' this of course is part of the same hypothesis; but I may point out that since Von Mohl and Sanio, between 1855 and 1865, showed (1) that the growth at the stem apex of a monocotyledon was not endogenous, and (2) that the "thickening ring' near the apex of a dicotyledon was not to be confused, as had been done up till then, with the ring of secondary meristem or true cambium, which arose lower down, and only in woody or practically woody stem, the terms 'Exogen' and 'Endogen' have necessarily fallen into disuse, since they imply a false conception of what happens. Both monocotyledons and dicotyledons have a 'thickening ring,' which gives rise to the primary vascular cylinder of the stem. When the stem is of considerable thickness, as in Palms, \&c., it grows by the active cell-division of its outer layers, so that both classes are 'exogenous' in this sense; while the addition of a centrifugal zone of secondary wood is confined to certain Dicotyledons (Trees, shrubs, \&c.).

"The distinction between the embryos, moreover, is not absolute. The single cotyledon is usually terminal in mono- 
cotyledons, but not always (Dioscoracea have lateral cotyledons), but the plumule may push through it (Grasses) or make its exit sideways (Palms), or be formed at the side (Alisma); and Dicotyledons very similarly.

"The occurrence of completely sheathing leaves in grasses is perhaps correlated with the absence of cambium, but grasses are an aberrant type among monocotyledons, and secondary thickening is only found in very few genera of this class, so that the correlation is, so to speak, negative and indirect. . . . It is clear that the greater part of the discussion will have to be re-written."

For the reasons assigned in the preface I cannot undertake to re-write the discussion, as suggested. It must stand for what it is worth. All I can do is here to include along with it the foregoing criticisms.

I may, however, indicate the line of defence I should take were I to go again into the matter. The objections are based on the structure of existing Liverworts and Phænogams. But I have already referred to the probability-or, indeed, the certainty-that in conformity with the general principle set forth in the note to Chapter I, we must conclude that the early types of Liverworts out of which the Phænogams are supposed to have evolved, as well as the early types of Phænogams in which the stages of evolution were presented, no longer exist. We must infer that forms simpler than any now known, and more intermediate in their traits, were the forms concerned; and if so, it may be held that the incongruities with the hypothesis which are presented by existing forms, do not negative it. The scepticism my critic himself expresses respecting the current interpretation is a partial justification of this view. Moreover, his admission that the theory set forth "fits in well with the phenomena exhibited by phanerogamic shoots," must, I think, be regarded as weighty evidence. On the Evolution-hypothesis we are obliged to suppose that the Monocotyledons and Dicotyledons respectively arose by integration of fronds; and if to the 
question after what manner the integration took place, there is an hypothesis which renders it comprehensible, and agrees both with the structures of the two kinds of shoots and the structures of the two kinds of seeds, as well as with various of the other phenomena the two types present, it has strong claims for acceptance.

Reconsideration suggests the following remarks.

1. Alternation of generations is a means of furthering multiplication. To be effective each member of either generation must be a self-supporting centre of growth or diffusion or both. Hence if, as in the Liverworts, one of the so-called alternating generations is not independent, but a permanent growth on the other-a parasite-it is a misuse of words to call the arrangement Alternation of generations. (Since this was written I have found that Sir Edward Fry takes the same view. He approvingly quotes Professor Bower, who says that "the alternation of generations is not an accurate statement of facts or a useful analogy.")

2. The alternating of sexual and non-sexual processes is not fundamentally distinctive; for, as shown by sundry Archegoniates, it is an inconstant trait, and as shown by Klebs' experiments on Vaucheria, the conditions may be varied so as to determine its occurrence or non-occurrence. Nay, the same individual may reproduce in either way.

3. Still more significant is the fact that in some of the marine Thallophytes, there is a process like that which in a moss or a fern is considered an alternation of generations, whereas in others, as the Brown Wrack (Fucus), each generation is sexual. Thus the presence or absence of this mode of genesis cannot be a cardinal distinction.

4. With these facts before us, it is not only a reasonable supposition but a highly probable supposition, that there have existed plants of the Liverwort type in which the so-called alternation of generations did not take place. If so, nearly all the foregoing objections to my hypothesis fall to the ground.] 


\section{CHAPTER IV.}

THE MORPHOLOGICAL COMPOSITION OF ANIMALS.

$\S 199$. Wнат was said in $\S 180$, respecting the ultimate structure of organisms, holds more manifestly of animals than of plants. That throughout the regetal kingdom the cell is the morphological unit, is a proposition admitting of a better defence, than the proposition that the cell is the morphological unit throughout the animal kingdom. The qualifications with which, as we saw, the cell-doctrine must be taken, are qualifications thrust upon us more especially by the facts which zoologists have brought to light. It is among the Protozoa that there occur numerous cases of vital activity displayed by specks of protoplasm; and from the minute anatomy of all creatures above these, are drawn the numerous proofs that non-cellular tissues may arise by direct metamorphosis of mixed colloidal substances.*

* Since this naragraph was published in 1865 , much has been learned con. cerning cell-structure, as is shown in Chapter VI ${ }^{A}$ of Part I. While some assert that there exist portions of living protoplasm without nuclei, others assert that a nueleus is in every case present, and that where it does not exist in a definite aggregated form it exists in a dispersed form. As remarked in the chapter named, "the evidence is somewbat strained to justify this dogma." Words are taken in their non-natural senses, if one which connotes an individualized body is applied to the widely-diffused components of such a body; and this perverting of proper meanings leads to obscuration of what may perhaps be an essential truth. As argued in the chapter named $(\$ \S 74 e, 74 f)$, nuclcar matter is, as shown by its chemical character, an extremely unstable substance, the molecular changes of which, perpetually going on, initiate 
Our survey of morphological composition throughout the animal kingdom, must therefore begin with those undifferentiated aggregates of physiological units [or constitutional units], out of which are formed what we call, with considerable license, morphological units.

$\S 200$. In that division of the Protozoa distinguished as Rhizopoda, are presented, under various modifications, these minute portions of living organic matter, so little differentiated, if not positively undifferentiated, that animal individuality can scarcely be claimed for them. Figs. 131, 132, and 133, represent certain nearly-allied types of these-Amceba,
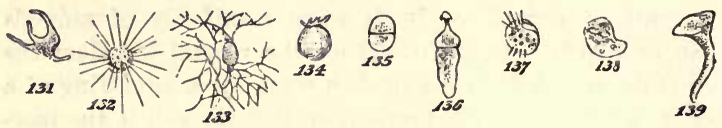

Actinophrys, and Lieberkühnia. The viscid jelly or sarcode, comparable in its physical properties to white of egg, out of which one of these creatures is mainly formed, shows us in various ways, the feebleness with which the component physiological units are integrated-shows us this by its very slight cohesion, by the extreme indefiniteness and mutability of its form, and by the absence of a limiting membrane. It is no longer held even by unqualified adherents of the cell-doctrine that the Amøba has an investment. Its outer surface, compared to the film which forms on the surface of paste, does not prevent the taking of solid particles into the mass of the body, and does not, in such kindred forms as Fig. 133, prevent the pseudopodia from coalescing when they meet. Hence it cannot properly have the name of a cell-wall. A considerable portion of the body, however, in Diffugia, shoeks, producing changes all around. In the earlier stages of cell-evolution this unstable substance is dispersed throughout the cytoplasm; whereas in the more advanced stages it is gathered together in one mass. If so, instead of saying there is a dispersed nucleus we should say there are the materials of a nuelcus not yet.integrated. 
Fig. 134, has a denser coating formed of agglutinated foreign particles; so that the protrusion of the pseudopodia is limited to one part of it. And in the solitary Foraminifera, like Gromia, the sarcode is covered over most of its surface by a delicate calcareous shell, pierced with minute holes, through which the slender pseudopodia are thrust. The Gregarina exhibits an advance in integration, and a consequent greater definiteness. Figs. 135 and 136, exemplifying this type, show the complete membrane in which the substance of the creature is contained. Here there has arisen what may be properly called a cell: under its solitary form this animal is truly unicellular. Its embryology has considerable significance. After passing through a certain quiescent, "encysted" state, its interior breaks up into small portions, which, after their exit, assume forms like that of the Amoba; and from this young condition in which they are undifferentiated, they pass into that adult condition in which they have limiting membranes. If this development of the individual Gregarina typifies the mode of evolution of the species, it yields further support to the belief, that fragments of sarcode existed earlier than any of the structures which are called cells. Among aggregates of the first order, there are some much more highly developed. These are the Infusoria, constituting the most numerous of the Protozoa, in species as in individuals. Figs. 137, 138, and 139 , are examples. In them we find, along with greater definiteness, a considerable heterogeneity. The sarcode of which the body consists, has an indurated outer layer, bearing cilia and sometimes spines; there is an opening serving as mouth, a permanent œsophagus, and a cavity or cavities, temporarily formed in the interior of the sarcode, to serve as one or more stomachs; and there is a comparatively specific arrangement of these and various minor parts.

Thus in the animal kingdom, as in the regetal kingdom, there exists a class of minute forms having this peculiarity, that no one of them is separable into a number of visible 
components homologous with one another-no one of them can be resolved into minor individualities. Its proximate units are those physiological units of which we conclude every organism consists. The aggregate is an aggregate of the first order.

$\S 201$. Among plants are found types indicating a transition from aggregates of the first order to aggregates of the second order; and among animals we find analogous types. But the stages of progressing integration are not here so distinct. The reason probably is, that the simplest animals, having individualities much less marked than those of the simplest plants, do not afford us the same facilities for observation. In proportion as the limits of the minor individualities are indefinite, the formation of major individualities out of them, naturally leaves less conspicuous traces.

Be this as it may, however, in such types of Protozoa as the compound Radiolaria, we find that though there is reason to regard the aggregate as an aggregate of the second order, yet its divisibility into minor individualities like those just described, is less manifest. Fig. 140 representing Spharozoum

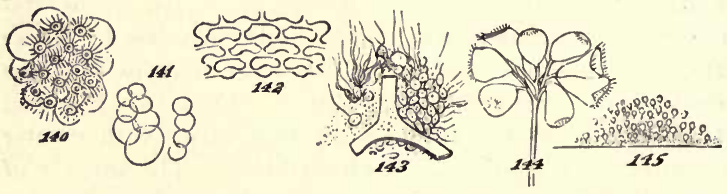

punctatum, one of the group, illustrates this. The sceptically-minded may perhaps doubt whether we can regard the "cellæform bodies" contained in it, as the morphological units of the animal. The jelly-like mass in which they are imbedded, is but indefinitely divisible into portions having each a cell or nucleus for its centre.* Among the

* This statement seems at variance with the figure; but the figure is very inaccurate. Its inaccuracy curiously illustrates the vitiation of evidence. When I saw the drawing on the block, I pointed out to the draughtsman, 
Foraminifera, we find only indefinite evidence of the coalescence of aggregates of the first order, into aggregates of the second order. There are solitary Foraminifers, allied to the creature represented in Fig. 134. Certain ideal types of combination among them, are shown in Fig. 141. And setting out from these, we may ascend in various directions to kinds compounded to an immense variety of degrees in an immense variety of ways. In all of them, however, the separability of the major individuality into minor individualities, is very incomplete. The portion of sarcode contained in one of these calcareous chambers, gives origin to an external bud; and this presently becomes covered, like its parent, with calcareous matter: the position in which each successive chamber is so produced, determining the form of the compound shell. But the portions of sarcode thus budded out one from another, do not become distinctly individualized. Fig. 142, representing the living net-work which remains when the shell of an Orbitolite has been dissolved, shows the continuity that exists among the occupants of its aggregated chambers.*

In the compound Infusoria, the component units remain quite distinct. Being, as aggregates of the first order, much more definitely organized, their union into aggregates of the second order does

that he had made the surrounding curves much more obvinusly related to the contained bodies, than they were in the original (in Dr. Carpenter's Foraminificra); and having looked on while he in great measure remedied this defect, thought no further care was needed. Now, however, on seeing the figure in the printer's proof, I find that the engraver, swayed by the same supposition as the draughtsman that such a relation was meant to be shown, has made his lines represent it still more decidedly than those of the draught:man before they were corrected. Thus, vague linear representations, like vague verbal ones, are apt to grow more definite when repeated. Iypothesis warps perceptions as it warps thoughts.

* Though the subdivision into chambers of the shell does not corrcspond to the subdivision into cell-units it may still be held that since in the solitary types the subdivision of the nueleus is followed by formation of new individuals which separate, and since in the compound types the subdivision of the nucleus is followed by growth and formation of new chambers, the com. jound type must be reçarded as an aggregate of the second order. 
not destroy their original individualities. Among the Vorticellce, of which two kinds are delineated in Figs. 144 and 145 , there are various illustrations of this: the members of the community being sometimes appended to a single stem; sometimes attached by long separate stems to a common base; and sometimes massed together.

Thus far, these aggregates of the second order exhibit but indefinite individualities. The integration is physical; but not physiological. Though, in the Polycytharia, there is a shape that has some symmetry; and though, in the Foraminifera, the formation of successive chambers proceeds in such methodic ways as to produce quite-regular and tolerably-specific shells; yet no more in these than in the Sponges or the compound Vorticella, do we find such co-ordination as gives the whole a life predominating over the lives of its parts. We have not yet reached an aggregate of the second order, so individuated as to be capable of serving as a unit in still higher combinations. But in the class Coelenterata, this advance is displayed. The common Hydra, habitually taken as the type of the lowest division of this class, has specialized parts performing mutually-subservient functions, and thus exhibiting a total life distinct from the lives of the units. Fig. 146 represents one of these creatures in its contracted state and in its expanded state; while Fig. 147 is a diagram
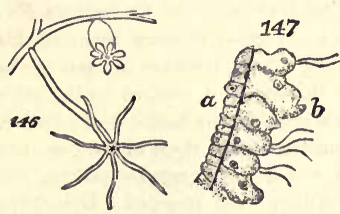
showing the wall of this creature's sac-like body as seen in section under the microscope: $a$ and $b$ being the outer and inner cellular layers; while between them is the "mesoglœa" or "structureless lamella," the supporting or skeletal layer. But this lowly-organized tissue of the Hydra, illustrates a phase of integration in which the lives of the minor aggregates are only partially-subordinated to the life of the major aggregate formed by them. For a Hydra's substance is separable 
into Amœba-like portions, capable of moving about independently. If we bear in mind how analogous are the extreme extensibility and contractility of a Hydra's body and tentacles, to the properties displayed by the sarcode among Rhizopods; we may infer that probably the movements and other actions of a Hydra, are due to the halfindependent co-operation of the Amœba-like individuals composing it.

$\S 202$. A truth which we before saw among plants, we here see repeated among animals - the truth that as soon as the integration of aggregates of the first order into aggregates of the second order, produces compound wholes so specific in their shapes and sizes, and so mutually dependent in their parts, as to have distinct individualities; there simultaneously arises the tendency in them to produce, by gemmation, other such aggregates of the second order. The approach towards definite limitation in an organism, is, by implication, an approach towards a state in which growth passing a certain point, results, not in the increase of the old individual, but in the formation of a new individual. Thus it happens that the common polype buds out other polypes, some of which very shortly do the like, as shown in Fig. 148: a process paralleled by the fronds of sundry Alga, and by those of the lower Jungermanniacear. And just as, among these last plants, the proliferously-produced fronds, after growing to certain sizes and developing root-
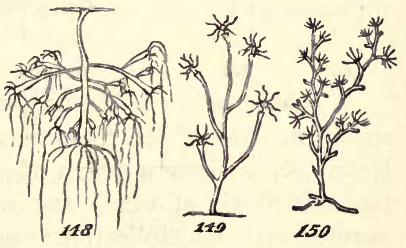

lets, detach themselves from their parent fronds; so among these animals, separation of the young ones from the bodies of their parents ensues when they have acquired tolerably complete organizations.

There is reason to think that the parallel holds still fur- 
ther. Within the limits of the Jungermanniacea, we found that while some genera exhibit this discontinuous development, other genera exhibit a development that is similar to it in all essential respects, save that it is continuous. And here within the limits of the Hydrozoa, we find, along with this genus in which the gemmiparous individuals are presently cast off, other genera in which they are not cast off, but form a permanent aggregate of the third order. Figs. 149 and 150, exemplify these compound Hydrozoa-one of them showing this mode of growth so carried out as to produce a single axis; and the other showing how, by repetitions of the process, lateral axes are produced. Integrations

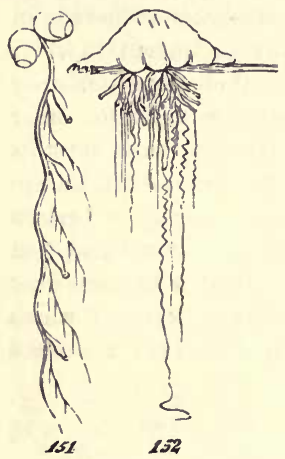

characterizing certain higher genera of the Hydrozoa which swim or float instead of being fixed, are indicated by Figs. 151 and 152: the first of them representing the type of a group in which the polypes growing from an axis, or cœnosare, are drawn through the water by the rhythmical contractions of the organs from which they hang; and the second of them representing a Physalia the component polypes of which are united into a cluster, attached to an air-vessel.

A parallel series of illustrations might be drawn from that second division of the Colenterata, known as the Actinozoa. Here, too, we have a group of species-the Sea-anemonesthe individuals of which are solitary. Here, too, we have agamogenetic multiplication: occasionally by gemmation, but more frequently by that modified process called spontaneous fission. And here, too, we have compound forms resulting from the arrest of this spontaneous fission before it is complete. To give examples is needless; sinee they would but show, in more varied ways, the truth already made suffi- 
ciently clear, that the compound Coclenterata are aggregates of the third order, produced by integration of aggregates of the second order such as we have in the Hydra. As before, it is manifest that on the hypothesis of evolution, these nigher integrations will insensibly arise, if the separation of the gemmiparous polypes is longer and longer postponed; and that an increasing postponement will result by survival of the fittest, if it profits the group of individuals to remain united instead of dispersing.*

$\S 203$. The like relations exist, and imply that the like processes have been gone through, among those more highlyorganized animals called Polyzoa and Tunicata. We have solitary individuals, and we have variously-integrated groups of individuals: the chief difference between the evidence here furnished, and that furnished in the last case, being the absence of a type obviously linking the solitary state with the aggregated state.

This integration of aggregates of the second order, is carried on among the Polyzoa in divers ways, and with different degrees of completeness. The little patches of minute cells, shown as magnified in Fig. 153, so common on the fronds of sea-weeds and the surfaces of rocks at low-water mark, display little beyond mechanical combination. The adjacent indi-

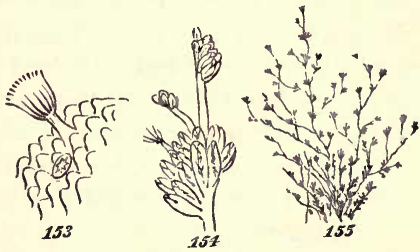

*A critic says the question is "what are the forces internal or external which produce union or separation." A proximate reply is-degrec of nutrition. As in a plant new individuals or rudiments of them are cast off where nutrition is failing, so in a compound animal. The connecting part dwindles if it ceases to carry nutriment. 
viduals, though severally originated by gemmation from the same germ, have but little physiological dependence. In kindred kinds, however, as shown in Figs. 154 and 155, one of which is a magnified portion of the other, the integration is somewhat greater: the co-operation of the united individuals being shown in the production of those tubular branches which form their common support, and establish among them a more decided community of nutrition.

Among the Áscidians this general law of morphological composition is once more displayed. Each of these creatures subsists on the nutritive particles contained in the water which it draws in through one orifice and sends out through another; and it may thus subsist either alone, or in connexion with others that are in some cases loosely aggregated and in other cases closely aggregated. Fig. 156, Phallusia
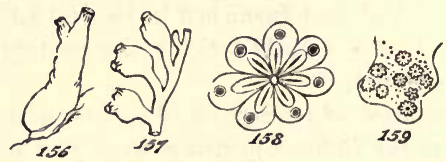

mentula, is one of the solitary forms. A type in which the individuals are united by a stolon that gives origin to them by successive buds, is shown in Perophora, Fig. 15\%. Among the Botryllida, of which one kind is drawn on a small scale in Fig. 159, and a portion of the same on a larger scale in Fig. 158, there is a combination of the individuals into annular clusters, which are themselves imbedded in a common gelatinous matrix. And in this group there are integrations even a stage higher, in which several such clusters of clusters grow from a single base. Here the compounding and recompounding appears to be carried further than anywhere else in the animal kingdom.

Thus far, however, among these aggregates of the third order, we see what we before saw among the simpler aggregates of the second order-we see that the component individualities are but to a very small extent subordinated to 
the individuality made up of them. In nearly all the forms indicated, the mutual dependence of the united animals is so slight, that they are more fitly comparable to societies, of which the members co-operate in securing certain common benefits. There is scarcely any specialization of functions among them. Only in the last type described do we see a number of individuals so completely combined as to simulate a single individual. And even here, though there appears to be an intimate community of nutrition, there is no physiological integration beyond that implied in several mouths and stomachs having a common vent.*

$\S 204$. We come now to an extremely interesting question. Does there exist in other sub-kingdoms composition of the third degree, analogous to that which we have found so prevalent among the Colenterata and the Polyzoa and Tunicata? The question is not whether elsewhere there are tertiary aggregates produced by the branching or clustering of secondary aggregates, in ways like those above traced; but whether elsewhere there are aggregates which, though otherwise unlike in the arrangement of their parts, nevertheless consist of parts so similar to one another that we may suspect them to be united secondary aggregates. The various compound types above described, in which the united animals maintain their individualities so distinctly that the individuality of the aggregate remains vague, are constructed in such ways that the united animals carry on their several activities with scarcely any mutual hindrance. The members of a branched Hydrozoon, such as is shown in Fig. 149 or Fig. 150, are so placed that they can all spread their tentacles and catch their prey as well as though separately attached to stones or weeds. Packed side by side on a flat surface or

* It has been pointed out that I have here understated the evidence of physiological integration. An instance of it among Hydrozoa is shown in Fig. 151, but by a strange oversight I have forgotten to name the various cases furnished by the Siphonophora in which the individual polypes of a compound aggregate are greatly specialized in adaptation to different functions. 
forming a tree-like assemblage, the associated individuals among the Polyzoa are not unequally conditioned: or if one has some advantage over another in a particular case, the mode of growth and the relations to surrounding objects are so irregular as to prevent this advantage re-appearing with constancy in successive generations. Similarly with the Ascidians growing from a stolon or those forming an annular cluster: each of them is as well placed as every other for drawing in the currents of sea-water from which it selects its food. In these cases the mode of aggregation does not expose the united individuals to multiform circumstances; and therefore is not calculated to produce among them any structural multiformity. For the same reason no marked physiological division of labour arises among them; and consequently no combination close enough to disguise their several individualities. But under converse conditions we may expect converse results. If there is a mode of integration which necessarily subjects the united individuals to unlike sets of incident forces, and does this with complete uniformity from generation to generation, it is to be inferred that the united individuals will become unlike. They will severally assume such different functions as their different positions enable them respectively to carry on with the greatest advantage to the assemblage. This heterogeneity of function arising among them, will be followed by heterogeneity of structure; as also by that closer combination which the better enables them to utilize one another's functions. And hence, while the originally-like individuals are rendered unlike, they will have their homologies further obscured by their progressing fusion into an aggregate individual of a higher order.

These converse conditions are in nearly all cases fulfilled where the successive individuals arising by continuous development are so budded-off as to form a linear series. I say in nearly all cases, because there are some types in which the associated individuals, though joined in single file, are 
not thereby rendered very unlike in their relations to the environment; and therefore do not become differentiated and integrated to any considerable extent. I refer to such Ascidians as the Salpida. These creatures float passively in the sea, attached together in strings. Being placed side by side and having mouths and vents that open laterally, each of them is as well circumstanced as its neighbours for absorbing and emitting the surrounding water; nor have the individuals at the two extremities any marked advantages over the rest in these respects. Hence in this type, and in the allied type Pyrosoma, which has its component individuals built into a hollow cylinder, linear aggregation may exist without the minor individualities becoming obscured and the major individuality marked: the conditions under which a differentiation and integration of the component individuals may be expected, are not fulfilled. But where the chain of individuals produced by gemmation, is either habitually fixed to some solid body by one of its extremities or moves actively through the water or over submerged stones and weeds, the several members of the chain become differently conditioned in the way above described; and may therefore be expected to become unlike while they become united. A clear idea of the contrast between these two linear arrangements and their two diverse results, will be obtained by considering what happens to a row of soldiers, when changed from the ordinary position of a single rank to the position of Indian file. So long as the men stand shoulder to shoulder, they are severally able to use their weapons in like ways with like efficiency; and could, if called on, similarly perform various manual processes directly or indirectly conducive to their welfare. But when, on the word of command "right face," they so place themselves that each has one of his neighbours before him and another behind him, nearly all of them become incapacitated for fighting and for many other actions. They can walk or run one after another, so as to produce movement of the file in 
the direction of its length; but if the file has to oppose an enemy or remove an obstacle lying in the line of its march, the front man is the only one able to use his weapons or hands to much purpose. And manifestly such an arrangement could become advantageous only if the front man possessed powers peculiarly adapted to his position, while those behind him facilitated his actions by carrying supplies, \&c. This simile, grotesque as it seems, serves to convey better perhaps than any other could do, a clear idea of the relations that must arise in a chain of individuals arising by gemmation, and continuing permanently united end to end. Such a chain can arise only on condition that combination is more advantageous than separation; and for it to be more advantageous, the anterior members of the series must become adapted to functions facilitated by their positions, while the posterior members become adapted to functions which their positions permit. Hence, direct or indirect equilibration or both, must tend continually to establish types in which the connected individuals are more and more unlike one another, at the same time that their several individualities are more and more disguised by the integration consequent on their mutual dependence.

Such being the anticipations warranted by the general laws of evolution, we have now to inquire whether there are any animals which fulfil them. Very little search suffices; for structures of the kind to be expected are abundant. In that great division of the animal kingdom at one time called $A n$ nulosa, but now grouped into Annelida and Arthropoda, we find a variety of types having the looked-for characters. Let us contemplate some of them.

$\S 205$. An adult Chætopod is composed of segments which repeat one another in their details as well as in their general shapes. Dissecting one of the lower orders, such as is shown in Fig. 160, proves that the successive segments, besides having like locomotive appendages, like branchiæ, and 
sometimes even like pairs of eyes, also have like internal organs. Each has its enlargement of the alimentary canal; each its contractile dilatation of the great blood-vessel; each its portion of the double nervous cord, with ganglia when

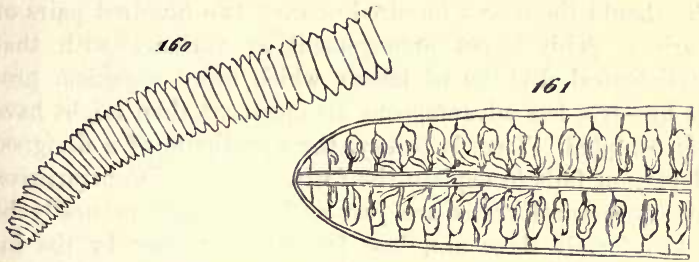

these exist; each its branches from the nervous and vascular trunks answering to those of its neighbours; each its similarly answering set of muscles; each its pair of openings through the body-wall; and so on throughout, even to the organs of reproduction. That is to say, every segment is in great measure a physiological whole-every segment contains most of the organs essential to individual life and multiplication: such essential organs as it does not contain, being those which its position as one in the midst of a chain, prevents it from having or needing.

If we ask what is the meaning of these homologies, no adequate answer is supplied by any current hypothesis. That this "vegetative repetition" is carried out to fulfil a predetermined plan, was shown to be quite an untenable notion $(\S \S 133,134)$. On the one hand, we found nothing satisfactory in the conception of a Creator who prescribed to himself a certain unit of composition for all creatures of a particular class, and then displayed his ingenuity in building up a great variety of forms without departing from the " archetypal idea." On the other hand, examination made it manifest that even were such a conception worthy of being entertained, it would have to be relinquished; since in each class there are numerous deviations from the supposed " archetypal idea." Still less can these traits of structure be accounted 
for teleologically. That certain organs of nutrition and respiration and locomotion are repeated in each segment of a dorsibranchiate annelid, may be regarded as functionally advantageous for a creature following its mode of life. But why should there be a hundred or even two hundred pairs of ovaries? This is an arrangement at variance with that physiological division of labour which every organism profits by -is a less advantageous arrangement than might have been adopted. That is to say, the hypothesis of a designed adaptation fails to explain the facts.

Contrariwise, these structural traits are just such as might naturally be looked for, if these annulose forms have arisen by the integration of simpler forms. Among the various compound animals already glanced at, it is very general for the united individuals to repeat one another in all their parts-reproductive organs included. Hence if, instead of a clustered or branched integration, such as the Colenterata, Polyzoa and Tunicata exhibit, there occurs a longitudinal integration; we may expect that the united individuals will habitually indicate their original independence by severally bearing germproducing or sperm-producing organs.

The reasons for believing one of these creatures to be an aggregate of the third order, are greatly strengthened when we turn from the adult structure to the mode of development. Among the Dorsibranchiata and Tubicola, the embryo leaves the egg in the shape of a ciliated gemmule, not much more differentiated than that of a polype. As shown in Fig. 162, it is a nearly globular mass; and its interior consists of untransformed cells. The first appreciable change is an elongation and a simultaneous commencement of segmentation. The segments multiply by a modified gemmation, which takes place from the hinder end of the penultimate segment. And considerable progress in marking out these divisions is made before the internal organization begins. Figs. 163, 164, 165, represent some of these early stages. In annelids of other orders, the embryo assumes the segmented 
form while still in the egg. But it does this in just the same manner as before. Indeed, the essential identity of the two modes of development is shown by the fact that the segmentation within the egg is only partially carried out: in
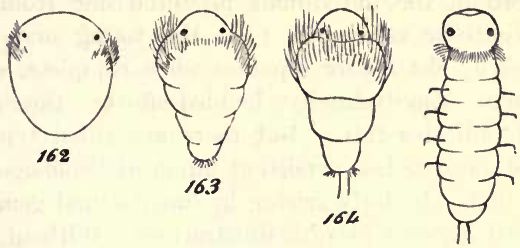

165

all these types the segments continue to increase in number for some time after hatching.

Now this process is as like that by which compound animals in general are formed, as the different conditions of the case permit. When new individuals are budded-out laterally, their unfolding is not hindered-there is nothing to disguise either the process or the product. But gemmæ produced one from another in the same straight line, and remaining connected, restrict one another's developments; and that the resulting segments are so many gemmiparously-produced individuals, is necessarily less obvious.

$\S 206$. Evidence remains which adds very greatly to the weight of that already assigned. Thus far we have studied only the individual segmented animal; considering what may be inferred from its mode of evolution and final organization. We have now to study segmented animals in general. Comparison of different groups of them and of kinds within each group, will disclose various phases of progressive integration of the nature to be anticipated.

Among the simpler Platyhelminthes, as in some kinds of Planaria, transverse fission occurs. A portion of a Planaria separated by spontaneous constriction, becomes an inde- 
pendent individual. Sir J. G. Dalyell found that in some cases numerous fragments artificially separated, grew into perfect animals.* In these creatures which thus remind us of the lowest Hydrozoa in their powers of agamogenetic multiplication, the individuals produced one from another do not continue connected. As the young ones laterally budded-off by the Hydra separate when complete, so do the young ones longitudinally budded-off by the Planaria. Fig. 166 indicates this. But there are allied types which show us a more or less persistent union of homologous parts, or individuals, similarly arising by longitudinal gemmation. $\dagger$ The cestoid Entozoa furnish illustrations. Without dwelling on the fact that each segment of a Trnia, like each separate Planaria, is an independent hermaphrodite; and without specifying the sundry common structural traits which add probability to the suspicion that there is some kinship between the individuals of the one order and the segments of the other; it will suffice to point out that the two types are so far allied as to demand their union under the same subclass title. And recognizing this kinship, we see significance in the fact that in the one case the longitudinally-produced gemmæ separate as complete individuals, and in the other continue united as segments in smaller or larger numbers and for shorter or longer periods. In Tania echinococcus,

* Recently Mr T. H. Morgan has made elaborate experiments which show that Planaria Maculata may be cut into many pieces from various parts and of various shapes-even a slice out of the side-and each, if not too small, will produce a perfect animal.

+ Since this was written in 1865 there has come to light evidence more completely to the point than any at that time known. In the subdivision of Platyhelminthes known as Turbellaria, there are some, the Microstomida which, by a process of segmentation form "chains of 4 , then 8 , then 16 , and sometimes even 32 individuals." "Each forms a mouth [lateral] and for some time the chain persists, but the individuals ultimately become sexually matured and then separate." (Shipley, Zoology of the Invertebrata, p. 92.) Here it should be remarked that the lateral mouths enable the members of a string to feed separately, and that nutrition not being interfered with they doubtless gain some advantage by temporary maintenance of their unionprobably in creeping. 
represented in Fig. 167, we have a species in which the number of segments thus united does not exceed four. In Echinobothrium typus there are eight or ten; and in cestoids generally they are numerous.*

A considerable hiatus occurs between this phase of integration and the next higher phase which we meet with; but it is not greater than the hiatus between the types of the Platyhelminthes and the Chatopoda, which present the two phases. Though it is
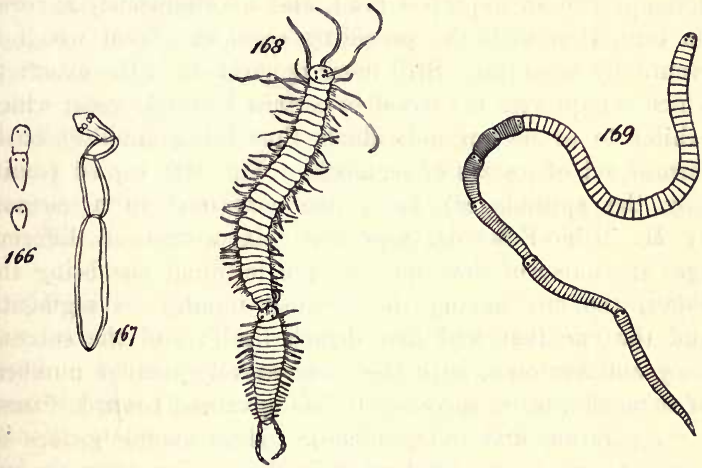

doubtful whether separation of single segments occurs among the Annelida, $\uparrow$ yet very often we find strings of segments,

* I find that the reasons for regarding the segment of a Tonia as answering to an individual of the second order of aggregation, are much stronger than I supposed when writing the above. Van Beneden says:-"Le Proglottis (segment) ayant acquis tout son développement, se détache ordinairement de la colonie et continue encore à croître dans l'intestin du même animal; il change même souvent de forme et semble doué d'une nouvelle vie; ses angles s'effacent, tout le corps s'arrondit, et il nage comme une Planaire au milieu des muscosités intestinales."

† Though this was doubtful in 1865 it is no longer doubtful. In an individual Ctenodrilus monostylus, which multiplies by dividing and subdividing itself, "parts arise which are destitute of both head and anus and at times consist of only a single segment." In another species, C. pardalis, there is separation into many segments; and each segment before separating forms a budding zone out of which other segments are afterwards produced, completing the animal (Korschelt and Heider, Embryology, i, 301-2). 
arising by repeated longitudinal budding, which after reaching certain lengths undergo spontaneous fission: in some cases doing this so as to form two or more similar strings of segments constituting independent individuals; and in other cases doing it so that the segments spontaneously separated are but a small part of the string. Thus a Syllis, Fig. 168, after reaching a certain length, begins to transform itself into two individuals: one of the posterior segments develops into an imperfect head, and simultaneously narrows its connexion with the preceding segments, from which it eventually separates. Still more remarkable is the extent to which this process is carried in certain kindred types; which exhibit to us several individuals thus being simultaneously formed out of groups of segments. Fig. 169, copied (omitting the appendages) from one contained in a memoir by M. Milne-Edwards, represents six worms of different ages in course of development: the terminal one being the eldest, the one having the greatest number of segments, and the one that will first detach itself; and the successively anterior ones, with their successively smaller numbers of segments, being successively less advanced towards fitness for separation and independence. Here among groups of segments we see repeated what in the previous cases occurs with single segments. And then in other annelids we find that the string of segments arising by gemmation from a single germ becomes a permanently united whole: the tendency to any more complete fission than that which marks out the segments, being lost; or, in other words, the integration having become relatively complete.

Leaving out of sight the question of alliance among the types above grouped together, that which it here concerns us to notice is, that longitudinal gemmation does go on; that it is displayed in that primitive form in which the gemmæ separate as soon as produced; that we have types in which such gemmæ hang together in groups of four, or in groups of eight and ten, from which however the gemmæ successively separate as individuals; 
that among higher types we have long strings of similarlyformed gemmæ which do not become individually independent, but separate into organized groups; and that from these we advance to forms in which all the gemmæ remain parts of a single individual.

One other significant fact must be added. There are cases in which annelids multiply by lateral gemmation.* That the longitudinallyproduced gemmæ which compose an annelid, should thus have, one of them or several of them, the power of laterally budding-off gemmæ, from which other annelids arise, gives further support to the hypothesis that, primordially, the segments were independent individuals. And it suggests this belief the more strongly because, in certain types of Colenterata, we see that longitudinal and lateral gemmation $d o$ occur together, where the longitudinally-united gemmæ are demonstrably independent individuals.

$\S 20 \%$. Though it seems next to impossible that we shall ever be able to find a type such as that which is here supposed to be the unit of composition of the annulose type, since we must assume such a type to have been long since extinct, yet the foregoing evidence goes far towards showing that an annulose animal is an aggregate of the third order. This repetition of segments, sometimes numbering several hundreds, like one another in all their organs even down to those of reproduction, while it is otherwise unaccountable, is fully accounted for if these segments are homologous with the separate individuals of some lower type. The gemmation by which these segments are produced, is as similar as the conditions allow, to the gemmation by which compound

* In place of those originally here instanced about which there are disputes, I may give an undoubted one described by McIntosh, the Syllis ramosa, a species of chætopod living in hexactinellid sponges from the Arafura Sea, which branches laterally repeatedly so as to extend in all directions through the canals of the sponge. In most cases the buds terminate in oval segments with two long cirri each. But male and female buds were found, provided each with a head, and containing ovaries and testes. Sometimes these sexual buds had become separate from the branched stock. 
animals in general are produced. As among plants, and as among demonstrably-compound animals, we see that the only thing required for the formation of a permanent chain of gemmiparously-produced individuals, is that by remaining associated such individuals will have advantages greater than are to be gained by separation. Further, comparisons of the annuloid and lower annulose forms, disclose a number of those transitional phases of integration which the hypothesis leads us to expect. And, lastly, the differences among these united individuals or successive segments, are not greater than the differences in their positions and functions explain-not greater than such differences are known to produce among other united individuals: witness sundry compound Hydrozoa.

Indirect evidence of much weight has still to be given. Thus far we have considered only the less-developed Annulosa. The more integrated and more differentiated types of the class remain. If in them we find a carrying further of the processes by which the lower types are here supposed to have been evolved, we shall have additional reason for believing them to have been so evolved. If we find that in these superior orders, the individualities of the united segments are much less pronounced than in the inferior, we shall have grounds for suspecting that in the inferior the individualities of the segments are less pronounced than in those lost forms which initiated the annulose sub-kingdom.

[NotE.-Partly from the wish to incorporate further evidence, and partly from the wish to present the evidence, old and new, in a more effective order, I decide here to recast the foregoing exposition.

Significant traits of development are exhibited in common by two groups otherwise unallied-certain of the Platyhelminthes and certain of the lower Annulosa. Of the Platyhelminthes the ordinary type is an unsegmented creature: a 
Planarian or a Trematode exemplifying it. Among the free forms, as in some Planarians, there occurs transverse fission, and prompt separation of the segments; while among some other free forms, as the Microstomida, the two segments first produced, themselves become segmented while still adherent, and this process is repeated until a string is formed. Another group of the Platyhelminthes, the Cestoid Entozoa, exhibit analogous processes. There are unsegmented forms, as the Caryophyllaeus, and there are forms in which the segments, now few now many, adhere together in chains; the terminal members of which, however, eventually separate, and having before separation approached the trematode structure, become independent individuals which grow, creep about, and continue the race. In both of these types the condition under which the gemmiparously-produced members remain connected, is that they shall be able to feed individually: in the one case by lateral mouths, in the other case by absorption through the integument. It is further observable that in both cases separation of the component individuals occurs at sexual maturity, when advantage in nutrition has ceased to be the dominant need and dispersion of the species has taken its place in degree of importance.

Among Annelids, higher though they are in type, we find parallelisms. Usually in its first stage an annelid is unsegmented, but as fast as it elongates lines of segmentation indent its surface. This segmentation proceeds in various ways, and the segments exhibit various degrees of dependence. In some low types, spontaneous fission goes on to the extent of producing single segments, each of which has such vitality that it buds out anterior and posterior parts at its two ends. Thus alike in the simple form which exists before segmentation and in the form exhibited by a detached segment, we have a unit analogous to each of the units which are joined together in certain free Turbellaria and in the Cestoids: the difference being that in the Annelids the sexually-mature units do not individually disunite. But though there does 
not take place separation of single completed segments, there takes place separation of groups of segments, which are either sexually mature at the time they drop off or presently become so. And the groups of segments which have become sexually mature before they drop off, have simultaneously acquired swimming organs and developed eyes, enabling them to spread and diffuse the species. Sundry biologists recognize a parallelism between that detachment of developed segments which goes on in the cestoid Entozoa, and that which goes on in the Scyphomedusa. The successively detached members of the strobila are sexually-matured or maturing individuals which, as medusæ, are fitted for swimming about, multiplying, and reaching other habitats; while each detached proglottis of the cestoid is, by the nature of its medium, limited to creeping about. Clearly this fissiparous process in such Annelids as the Syllida, which has similarly been compared to the strobilization of the Scyphomedusa, differs simply in the respect that single segments are not adapted for locomotion, and it therefore profits the species to separate in groups. All these facts and analogies point to the conclusion that the remote ancestor of the Annelids was an unsegmented creature homologous with each of the segments of an existing Annelid.

This conclusion is supported by other kinds of evidence here to be added. The larvæ of Annelids are very various; but amid their differences there is a recognizable type. "The Trochophore is the typical larval form of the Annelid stem ": a trochophore being a curious spheroidal ciliated structure suggestive of cœlenterate affinities. And this unsegmented larva, representing the remote ancestor from which the many Annelid types diverged, is similar to the larvæ of the Rotifera and the Mollusca: a trochophore is common to all these great classes. Moreover since, among the Rhizota (a sub-class of the Rotifera), there is a species, Trochosphara, solitary and free-swimming, resembling in form and structure a trochophore, though it is not a larva but an adult, we get further 
evidence that there was a primitive creature of this general character, of which the trochophores of Mollusca, Rotifera, and Annelida are divergent modifications, and which was unsegmented: the implication being that the segmentation or the Annelida was superinduced. That this segmentation resulted from gemmation is implied by what are called polytrochal larvæ. These "sometimes appear as a stage succeeding other larval types. Thus those of Arenicola marina arise from larvæ which at first were monotrochal, later became telotrochal, and finally, by the appearance of new ciliated rings between those already present, assumed the stage of polytrochal larvæ. . . . This condition warrants the assumption that the segmented forms are to be looked upon as the younger, the unsegmented, on the other hand, as the phylogenetically older." (Korschelt and Heider, i, 278.) And that the above-described rings of cilia mark off segments is shown by the case of Ophryotrocha puerilis, which " remains, as it were, in a larval condition, since the segments retain their ciliation throughout life." (Ib., 27\%.) Yet one more significant fact must be named. In early stages of development each segment of an archiannelidan has cœlomic spaces separate from those of neighbouring segments, but in the adult the septa "generally break down either partially or completely, so that the perivisceral cavity becomes a continuous space from end to end of the animal." (Sedgwick, Text Book, 449.) While this fact is congruous with the hypothesis here maintained, it is incongruous with the hypothesis that the annelid was originally an elongated creature which afterwards became segmented; since in that case the implication would be that the cœlomic septa, not arising from recapitulation of an ancestral structure, but originated by the process of segmentation, were first superfluously formed and then destroyed.

Various lines of evidence thus converge to the conclusion that an annulose animal is an aggregate of the third order.

In June, 1865, when No. 14 of my serial containing the 
foregoing chapter was issued, I supposed myself to be alone in holding this belief respecting the annulose type, and long continued to suppose so. Over thirty years later, however, in M. Edmond Perrier's work, La Philosophie Zoologique avant Darwin, I found mention of a lecture delivered by M. LacazeDuthiers at the École Normale Supérieure in Paris, and reported in the Revue des Cours Scientifiques for January 28, 1865 , in which he enunciated a like belief. Judging, however, by the account of this lecture which M. Perrier gives (he was present), it appears that M. Lacaze-Duthiers simply contended that this view of the annulose structure as arising by union of once-independent units, is suggested by certain a priori considerations. There is no indication that he assigned any of the classes of facts above given, which go to show that it has thus arisen.

For further facts and arguments concerning the genesis of the annulose type, see Appendix D 2.] 


\section{CHAPTER V.}

THE MORPHOLOGICAL COMPOSITION OF ANIMALS, CONTINUED.

$\S 208$. Insects, Arachnids, Crustaceans, and Myriapods, are all members of that higher division of the Annulosa* called Articulata or now more generally Arthropoda. Though in these creatures the formation of segments may be interpreted as a disguised gemmation; and though, in some of them, the number of segments increases by this modified budding after leaving the egg, as it does among the Annelids; yet the process is not nearly so dominant: the segments are usually much less numerous than we find them in the types last considered. In most eases, too, the segments are in a greater degree differentiated one from another, at the same time that they are severally more differentiated within themselves. Nor is there any instance of spontaneous fission taking place in the series of segments composing an articulate animal. On the contrary, the integration, always great enough permanently to unite the segments, is frequently carried so far as to hide very completely the individualities of some or many of them; and occasionally, as among the Acari, the consolidation, or the arrest of segmentation, is so

* The name Annulosa, once used to embrace the Annelida and Arthropoda, has of late ceased to be used. It seems to me better than Appendiculata, both as being more obviously descriptive and as being more exclusive. 
decided as to leave scarcely a trace of the articulate structure: the type being in these cases indicated chiefly by the presence of those characteristically-formed limbs, which give the alternative name Arthropoda to all the higher Annulosa. Omitting the parasitic orders, which, as in other cases, are aberrant members of their sub-kingdom, comparisons between the different orders prove that the higher are strongly distinguished from the lower, by the much greater degree in which the individuality of the tertiary aggregate dominates over the individualities of those secondary aggregates called segments or "somites," of which it is composed. The successive Figs. 170 - 176, representing (without their limbs) a

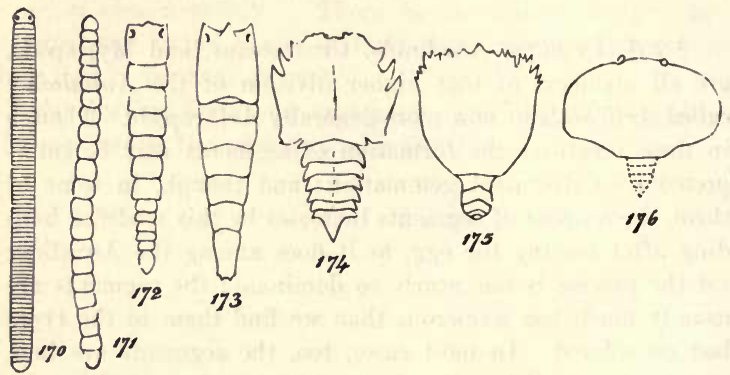

Julus, a Scolopendra, an isopodous Crustacean, and four kinds of decapodous Crustaceans, ending with a Crab, will convey at a glance an idea of the way in which that greater size and heterogeneity reached by the higher types, is accompanied by an integration which, in the extreme cases, nearly obliterates all traces of composite structure. In the Crab the posterior segments, usually folded underneath the shell, alone preserve their primitive distinctness. So completely confluent are the rest, that it seems absurd to say that a Crab's carapace is composed of as many segments as there are pairs of limbs, foot-jaws, and antennæ attached to it; and were it not that during early stages of the Crab's develop- 
ment the segmentation is faintly marked, the assertion might be considered illegitimate.

That all articulate animals are thus composed from end to end of homologous segments, is, however, an accepted doctrine among naturalists. It is a doctrine that rests on careful observation of three classes of facts-the correspondences of parts in the successive "somites" of an adult articulate animal; the still more marked correspondences of such parts as they exist in the embryonic or larval articulate animal; and the maintenance of such correspondences in some types, which are absent in types otherwise near akin to them. The nature of the conclusion which these evidences unite in supporting, will best be shown by the annexed copies from the lecture-diagrams of Prof. Huxley; exhibiting the typical structures of a Myriapod, an Insect, a Spider, and a Crustacean, with their relations to a common plan, as interpreted by him.

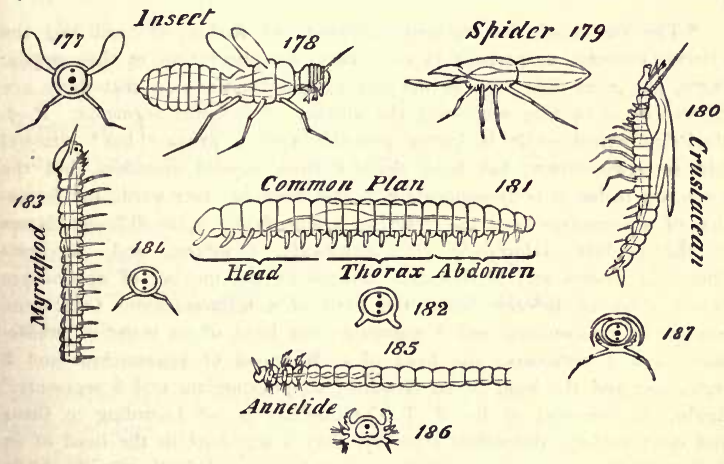

Treating of these homologies, Prof. Huxley says " that a striking uniformity of composition is to be found in the heads of, at any rate, the more highly organized members of these four classes; and that, typically, the head of a Crustacean, an Arachnid, a Myriapod, or an Insect, is composed of six 
somites (or segments corresponding with those of the body) and their appendages, the latter being modified so as to serve the purpose of sensory and manducatory organs." *

Thus even in the higher Arthropoda, the much greater consolidation and much greater heterogeneity do not obliterate all evidence of the fact, that the organism is an aggregate of the third order. Comparisons show that it is divisible into a number of proximate units, each of which is akin in certain fundamental traits to its neighbours, and each of which is an aggregate of the second order, in so far as it is an organized combination of those aggregates of the first order which we call morphological units or cells. And that these segments or somites, which make up an annulose animal, were originally aggregates of the second order having independent individualities, is an hypothesis which gathers further support from the contrast between the higher and the lower Arthropods, as well as from the contrast between the Arthropods

* The fusion of the segments forming the Arthropod head and the extreme changes, or perhaps in some eases disappearances, of their appendages, put great difficulties in the way of identification; so that there are differences of opinion respecting the number of included segments. Prof. MacBride writes:- "It is highly probable that a primary head (præoral lobe or præstomium) has been derived from annelid ancestors, but the secondary fusion of body-segments with this head, in other words the formation of a secondary head, has gone on independently in the different classes of the phylum Arthropoda, viz., Arachnida, Crustacea, and Tracheata (including Insects and Myriapods). Judged by the number of appendages (which gives an inferior limit) the head of a malacostracous Crustacean consists of præstomium and 8 segments; the head of an insect of præstomium and 4 segments; the head of a Myriapod of prestomium and 3 segments; and the head of an Arachnid of præstomium and 3 segments." Again, the comment of Mr. J. T. Cunningham is :- "According to Claus and most modern authorities there are only 5 segments in the head of an Arthropod, the eyes not counting as appendages; and further it should be noted that the second pair of antennæ are wanting in Insects."

of course difference of opinion respecting the number of somites in the head involves difference of opinion respecting the number constituting the entire body, which, in the higher Arthropods, is said by some to be 19 and by others 20 . But those who thus differ in detail, agree in regarding all the segments of head and body as homologous, and this is the essential point with which we are here concerned. 
in general and the Annelids. For if that masking of the individualities of the segments which we find distinguishes the higher forms from the lower, has been going on from the beginning, as we may fairly assume; it is to be inferred that the individualities of the segments in the lower forms, were originally more marked than they now are. Reversing those processes of change by which the most developed Annulosa have arisen from the least developed; and applying in thought this reversed process to the least developed, as they were described in the last Chapter; we are brought to the conception of attached segments that are all completely alike, and have their individualities in no appreciable degree subordinated to that of the chain they compose. From which there is but one step to the conception of gemmiparouslyproduced individuals which severally part one from another as soon as they are formed.

$\S 209$. We must now return to a junction whence we diverged some time ago. As before explained under the head of Classification, organisms do not admit of uni-serial arrangement, either in general or in detail; but everywhere form groups within groups. Hence, having traced the phases of morphological composition up to the highest forms in any sub-kingdom, we find ourselves at the extremity of a great branch, from which there is no access to another great branch, except by going back to some place of bifurcation low down in the tree.

There exist such similarities of shape and structure between the larval forms of low Molluses and those of Annelids and Rotifers, as to show that there was an early type common to them all; and its probable characters, suggested by comparison, seem to imply that it had arisen from some cœlenterate type, intermediate between the Cnidaria and the Ctenophora. But there is this noteworthy difference between the molluscan larva and the allied larvæ, that it gives origin to only one animal and not to a group of animals, united or 
disunited. No true Mollusc multiplies by gemmation, either continuous or discontinuous; but the product of every fertilized germ is a single individual.

It is a significant fact that here, where for the first time we have homogenesis holding throughout an entire sub-kingdom, we have also throughout an entire sub-kingdom no case in which the organism is divisible into two, three, or more, like parts. There is neither any such clustering or branching as a cœlenterate or molluscoid animal usually displays; nor is there any trace of that segmentation which characterizes the Annulosa. Among these animals in which no single egg produces several individuals, no individual is separable into several homologous divisions. This connexion will be seen to have a probable meaning, on remembering that it is the converse of the connexion which obtains among the Annulosa, considered as a group.

A Molluse, then, is an aggregate of the second order. Not only in the adult animal is there no sign of a multiplicity of like parts that have become obscured by integration; but there is no sign of such multiplicity in the embryo. And this unity is just as conspicuous in the lowest Lamellibranch as in the highest Cephalopod.

It may be well to note, however, more especially because it illustrates a danger of misinterpretation presently to be guarded against, that there are certain Molluses which simulate the segmented structure. Externally a Chiton, Fig. 188,

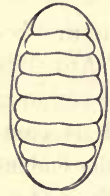

188
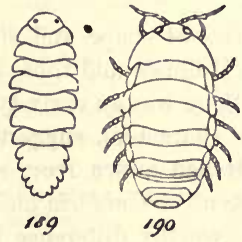

does from the preceding one. appears to be made up of divisions substantially like those of the creature Fig. 189 ; and one who judged only by externals, would say that the creature Fig. 190 differs as much from the creature Fig. 189, as this But the truth is, that while 190 and 189 are closely-allied types, 189 differs from 188 
much more widely than a man does from a fish. And the radical distinction between them is this:-Whereas in the Crustacean the segmentation is carried transversely through the whole mass of the body, so as to render the body more or less clearly divisible into a series of parts which are similarly composed; in the Molluse the segmentation is limited to the shell carried on its upper surface, and leaves its body as completely undivided as is that of a common slug.* Were the body cut through at each of the divisions, the section of it attached to each portion of the shell would be unlike all the other sections. Here the segmentation has a purely functional derivation-is adaptive instead of genetic. The similarly-formed and similarly-placed parts, are not homologous in the same sense as are the appendages of a phænogamic axis or the limbs of an insect.

$\S 210$. In studying the remaining and highest sub-kingdom of animals, it is important to recognize this radical difference in meaning between that likeness of parts which is produced by likeness of modifying forces, and that likeness of parts which is due to primordial identity of origin. On our recognition of this difference depends the view we take of certain doctrines that have long been dominant, and have still a wide currency.

Among the Vertebrata, as among the Mollusca, homogenesis is universal. The two sub-kingdoms are like one another and unlike the remaining sub-kingdoms in this, that in all the types they severally include, a single fertilized ovum produces only a single individual. It is true that as the eggs of certain gasteropods occasionally exhibit spontaneous fission

* Prof. MacBride corrects this statement by saying that "The ctenidia or gills (which in Mollusca generally are represented only by a single pair) are here represented by a large number of pairs; they do not, however, correspond in either number or position to the shell plates." It may, I think, be contended that if these had any morphological significance, they would not differ in arrangement from the shell plates, and would not be limited to this special type of Molluse. 
of the vitelline mass, which may or may not result in the formation of two individuals; so among vertebrate animals we now and then meet with double monsters, which appear to imply such a spontaneous fission imperfectly carried out. But these anomalies serve to render conspicuous the fact, that in both these sub-kingdoms the normal process is the integration of the whole germ-mass into a single organism, which at no phase of its development displays any tendency to separate into two or more parts.

Equally as throughout the Mollusca, there holds throughout the Vertebrata the correlative fact, that not even in its lowest any more than in its highest types, is the body divisible into homologous segments. The vertebrate animal, under its simplest as under its most complex form, is like the molluscous animal in this, that you cannot cut it into transverse slices, each of which contains a digestive organ, a respiratory organ, a reproductive organ, \&c. The organs of the leastdeveloped fish as well as those of the most-developed mammal, form but a single physiological whole; and they show not the remotest trace of having ever been divisible into two or more physiological wholes. That segmentation which the vertebrate animal usually exhibits throughout part of its organization, is the same in origin and meaning as the segmentation of a Chiton's shell; and no more implies in the vertebrate animal a composite structure, than do the successive pairs of branchiæ of the Doto, or the transverse rows of branchiæ in the Eolis, imply composite structure in the molluscous animal. To some this will seem a very questionable proposition; and had we no evidence beyond that which adult vertebrate animals of developed types supply, it would be a proposition not easy to substantiate. But abundant support for it is to be found in the structure of the vertebrate embryo, and in the comparative morphology of the Vertebrata in general.

Embryologists teach us that the primordial relations of parts are most clearly displayed in the early stages of evo- 
lution; and that they generally become partially or completely disguised in its later stages. Hence, were the vertebrate animal on the same level as the annulose animal in degree of composition-did it similarly consist of segments which are homologous in the sense that they are the proximate units of composition; we ought to find this fundamental fact most strongly marked at the outset. As in the annelid-embryo the first conspicuous change is the elongation and division into segments, by constrictions that encircle the whole body; and as in the arthropod embryo the blastoderm becomes marked out transversely into pieces which extend themselves round the yelk before the internal organization has made any appreciable progress; so in the embryo of every vertebrate animal, had it an analogous com. position, the first decided change should be a segmentation implicating the entire mass. But it is not so. Sundry important differentiations occur before any divisions begin to show themselves. There is the defining of that elongated, elevated area with its longitudinal groove, which becomes the seat of subsequent changes; there is the formation of the notochord lying beneath this groove; there is the growth upwards of the boundaries of the groove into the dorsal laminæ, which rapidly develop and fold over in the region of the head. Rathke, as quoted and indorsed by Prof. Huxley, describes the subsequent changes as follows:- "The gelatinous investing mass, which, at first, seems only to constitute a band to the right and to the left of the notochord forms around it, in the further course of development, a sheath, which ends in a point posteriorly. Anteriorly, it sends out two processes which underlie the lateral parts of the skull, but very soon coalesce for a longer or shorter distance. Posteriorly, the sheath projects but little beyond the notochord; but, anteriorly, for a considerable distance, as far as the infundibulum. It sends upwards two plates, which embrace the future central parts of the nervous system laterally, probably throughout their entire length." That is to say, in the 
Vertebrata the first step is the marking out on the blastoderm of an integrated structure, within which segments subsequently appear. When these do appear, they are for some time limited to the middle region of the spinal axis; and no more then than ever after, do they implicate the general mass of the body in their transverse divisions. On the contrary, before vertebral segmentation has made much progress, the rudiments of the vascular system are laid down in a manner showing no trace of any primordial correspondence of its parts with the divisions of the axis.

Equally at variance with the belief that the vertebrate animal is essentially a series of homologous parts, is the heterogeneity which exists among these parts on their first appearance. Though in the head of an adult articulate animal there is little sign of divisibility into segments like those of the body; yet such segments, with their appropriate ganglia and appendages, are easily identifiable in the articulate embryo. But in the Vertebrata this antithesis is reversed. At the time when segmentation has become decided in the dorsal region of the spine, there is no trace of segments in the parts which are to form the skull-nothing whatever to suggest that the skull is being formed out of divisions homologous with vertebræ.* And minute observation no more discloses any such homology than does general appearance. "Remak," says Prof. Huxley, "has more fully proved than any other observer, the segmentation into 'urwirbel,' or proto-vertebræ, which is characteristic of the vertebral column, stops at the occipital margin of the skull-the base of which, before ossification, presents no trace of that segmentation which occurs throughout the vertebral column."

Consider next the evidence supplied by comparative morphology. In preceding sections ( $\$ 206,208$,) it has been

* Though it is alleged that at a later stage the posterior part of the skull is formed by fusion of divisions which are assumed to represent vertebræ, yet it is admitted that the anterior part of the skull never shows any signs of such division. Moreover in both parts the bones show no trace of primitive segmentation. 
shown that among annulose animals, the divisibility into homologous parts is most clearly demonstrable in the lowest types. Though in decapodous Crustaceans, in Insects, in Arachnids, there is difficulty in identifying some or many of the component somites; and though, when identified, they display only partial correspondences; yet on descending to Annelids, the composition of the entire body out of such somites becomes conspicuous, and the homology between each somite and its neighbours is shown by the repetition of one another's structural details, as well as by their common gemmiparous origin: indeed, in some cases we have the homology directly demonstrated by seeing a somite of the body transformed into a head. If, then, a vertebrate animal had a segmental composition of kindred nature, we ought to find it most elearly marked in the lowest Vertebrata and most disguised in the highest Vertebrata. But here, as before, the fact is just the reverse. Among the Vertebrata of developed type, such segmentation as really exists remains conspicuous-is but little obscured even in parts of the spinal column formed out of integrated vertebræ. Whereas in the undeveloped vertebrate type, segmentation is scarcely at all traceable.* The Amphioxus, Fig. 191, is not only without

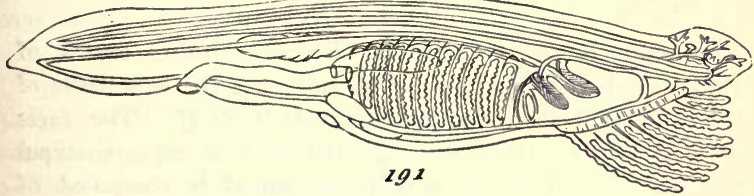

ossified vertebræ; not only is it without cartilaginous representatives of them; but it is even without anything like distinct membranous divisions. The spinal column exists as a continuous notochord: the only signs of incipient segmentation being given by its membranous sheath, in the upper part of which "quadrate masses of somewhat denser

* See note at the end of the chapter. 
tissue seem faintly to represent neural spines." Moreover, throughout sundry groups of fishes and amphibians, the segmentation remains very imperfect: only certain peripheral appendages of the vertebræ becoming defined and solidified, while in place of the bodies of the vertebræ there still continues the undivided notochord. Thus, instead of being morphologically composed of vertebral segments, the vertebrate animal in its primitive form is entirely without vertebral segments; and vertebral segments begin to appear only as we advance towards developed forms. Once more, evidence equally adverse to the current hypothesis meets us on observing that the differences between the parts supposed to be homologous, are as great at first as at last. Did the vertebrate animal primordially consist of homologous segments from snout to tail; then the segments said to compose the skull ought, in the lowest Vertebrata, to show themselves much more like the remaining segments than they do in the highest Vertebrata. But they do not. Fishes have crania made up of bones that are no more clearly arrangeable into segments like vertebræ, than are the cranial bones of the highest mammal. Nay, indeed, the case is much stronger. The simplest fish possessing a skeleton, has a cranium composed of cartilage that is not segmented at all!

Besides being inconsistent with the leading truths of Embryology and Comparative Morphology, the hypothesis of Goethe and Oken is inconsistent with itself. The facts brought forward to show that there exists an archetypal vertebra, and that the vertebrate animal is composed of archetypal vertebræ arranged in a series, and severally modified to fit their positions-these facts, I say, so far from proving as much, suffice, when impartially considered, to disprove it. No assigned, nor any conceivable, attribute of the supposed archetypal vertebra is uniformly maintained. The parts composing it are constant neither in their number, nor in their relative positions, nor in their modes of ossification, 
nor in the separateness of their several individualities when present. There is no fixity of any one element, or connexion, or mode of development, which justifies even a suspicion that vertebræ are modelled after an ideal pattern. To substantiate these assertions here would require too much space, and an amount of technical detail wearisome to the general reader. The warrant for them will be found in a criticism on the osteological works of Prof. Owen, originally published in the British and Foreign Medico-Chirurgical Review for Oct. 1858. This criticism I add in the Appendices, for the convenience of those who may wish to study the question more fully. (See Appendix B.)

Everything, then, goes to show that the segmental composition which characterises the apparatus of external relation in most Vertebrata, is not primordial or genetic, but functionally determined or adaptive. Our inference must be that the vertebrate animal is an aggregate of the second order, in which a relatively superficial segmentation has been produced by mechanical intercourse with the environment. We shall hereafter see that this conception leads us to a consistent interpretation of the facts-shows us why there has arisen such unity in variety as exists in every vertebral column, and why this unity in variety is displayed under countless modifications in different skeletons.*

$\S 211$. On glancing back at the facts wrought together in these two chapters, we see it to be probable that there has gone on among animals a process like that which we saw reason to think has gone on among plants. Minute aggregates of those physiological units which compose living protoplasm,

* A qualifying fact should be named. When the production of vertebral segments has become constitutionally established, so that there is an innate tendency to form them, there arises a liability to form supernumerary ones; and this, from time to time recurring, may lengthen the series, as in the body of a snake or the neck of a swan. This qualification, however, affects equally the hypothesis of an ideal type and the hypothesis of mechanical genesis. 
exist as Protozoa: some of them incoherent, indefinite, and almost homogeneous, and others of them more coherent, definite, and heterogeneous. By union of these nucleated particles of sarcode, are produced various indefinite aggregates of the second order-Sponges, Polycytharia, Foraminifers, \&c.; in which the compound individuality is scarcely enough marked to subordinate the primitive individualities. But in other types, as in Hydra, the lives of the morphological units are in a considerable degree, though not wholly, merged in the life of the integrated body they form. As the primary aggregate, when it passes a certain size, undergoes fission or gemmation; so does the secondary aggregate. And as on the lower stage so on the higher, we see cases in which the gemmiparously-produced individuals part as soon as formed, and other cases in which they continue united, though in great measure independent. This massing of secondary aggregates into tertiary aggregates, is variously carried on among the Hydrozoa, the Actinozoa, the Polyzoa, and the Tunicata. In most of the types so produced, the component individualities are very little subordinated to the individuality of the composite mass - there is only physical unity and not physiological unity; but in certain of the oceanic Hydrozoa, the individuals are so far differentiated and combined as very much to mask them. Forms showing us clearly the transition to well-developed individuals of the third order, are not to be found. Nevertheless, in the great sub-kingdom Annulosa, there are traits of structure, development, and mode of multiplication, which go far to show that its members are such individuals of the third order; and in the relations to external conditions involved by the mode of union, we find an adequate cause for that obscuration of the secondary individualities which we must suppose has taken place. The two other great sub-divisions, Mollusca and Vertebrata, between the lower members of which there are suggestive points of community, present us only with aggregates of the second order, that have in many cases become very large and 
very complex. We find in them no trace of the union of gemmiparously-produced individuals. Neither the molluscous nor the vertebrate animal shows the faintest trace of a segmentation affecting the totality of its structure; and we see good grounds for concluding that such segmentation as exceptionally occurs in the one and usually occurs in the other, is superinduced.

[Note:-A critic calls in question the statement on p. 121 respecting the Amphioxus. At the outset, however, he admits that in the Amphioxus "the central nervous system and the notochord are not segmented." In the Annelid, however, the central nervous system is segmented, and there is segmentation of the part which, as a supporting structure, is analogous to the notochord in respect of function-the outer part which represents the exo-skeleton in contrast to the endo-skeleton. He goes on to say that "the gut is not involved [in the segmentation] and exhibits in Amphioxus just as it does in worms differentiations entirely independent of the segmentation of the mesoblast." Part of this statement is, I think, not congruous with all the facts. In Protodrilus, one of the lowest of the Archiannelida, " the intestine is moniliform, there being a constriction between each segment" and the next. (Shipley.) Complete segmentation of the intestine is obviously impossible, since, were the canal divided into portions by septa, no food could pass. But the fact that the gut has these successive expansions and constrictions, corresponding to the successive segments, and giving to each segment a partially-separate stomach, shows that segmentation has gone as far as consists with the carrying on of the lives of the segments. No such partial segmentation exists in the Amphioxus. Thus, then, three fundamental structures-the directive structure, the supporting structure, and the alimentary structure-are respectively simple in the lowest vertebrate and segmented, or 
partially segmented, in the lowest Annelid. Again, while it is said that the gill-clefts exhibit segmentation, it is admitted that this has no relevance to any constitutional segmentation: "they are segmented on a plan of their own" irrespective of other organs. Another allegation is that the ovaries of Amphioxus are segmented. Their segmentation, however, like that of the gills, is isolated, and may be considered as illustrating those repetitions of like parts seen in supernumerary vertebræ in various creatures-a repetition which becomes habitual if the resulting structure is advantageous to the species. On the statement that while the Amphioxus has no rudiments of a renal system the Elasmobranch embryo has such rudiments, which are as distinctly segmented as the nephridia of a worm, two comments may be made. The first is that if in these Vertebrates the nephridia bear a relation to the general structure like that which they do in Annelids, then one would expect to find the segmental arrangement shown in the lowest type, as in Annelids, rather than in a type considerably advanced in development. Should it be replied that in the Amphioxus an excretory system had not yet arisen, though one is required for the higher organization of an Elasmobranch, then the answer may be that since the segmental arrangement in the Elasmobranch corresponds with that of the myotomes, it has no reference to any primordial segmentation, since the myotomes have been functionally generated. The second comment is that whereas the nephridia of the Annelid have independent external openings, the nephridia in the Elasmobranch have not. These discharge their secretions into certain general tubes of exit common to them all; showing that each of them, instead of being a member of a partially independent structure, is united with others in subordination to a general structure. That is to say, the segmentations are far from being parallel in their essential natures. The assertion accompanying these criticisms, that there is "no difference in principle between the segmentation of Amphioxus 
and Annelid" is difficult to reconcile with the visible contrast between the two. Whatever local segmentations there are in an Amphioxus appear to me quite unlike " in principle" to those which an Annelid exhibits. Could its portion of gut be duly supplied with nutriment, the segment of a low Annelid could carry on its vital functions independently. In the parts of the Amphioxus we see nothing approaching to this. Cut it into transverse sections and no one of them contains anything like the assemblage of structures required for living. The Amphioxus is a physiological whole, and in that respect differs radically from the Annelid, each segment of which is in chief measure a physiological whole. No occurrence of local segmentation in the $\mathrm{Am}$ phioxus can obliterate this fundamental contrast.

An accompanying contrast tells the same story. On ascending from the lowest to the highest annulose types we see a progressing integration, morphological and physiological; so that whereas in a low annelid the successive parts are in large measure independent in their structures and in their lives, in a high arthropod, as a crab, most of the parts have lost their individualities and have become merged in a consolidated organism with a single life. Quite otherwise is it in the vertebrate series. Its lowest member is at the very outset a complete morphological and physiological whole, and the formation of those serial parts which some think analogous to the serial parts of an Annelid, begins at a later stage and becomes gradually pronounced. That is to say, the course of transformation is reversed.] 


\section{CHAPTER VI.}

\section{MORPIIOLOGICAL DIFFERENTIATION IN PLANTS.}

$\S 212$. WHILE, in the course of their evolution, plants and animals have displayed progressive integrations, there have at the same time gone on progressive differentiations of the resulting aggregates, both as wholes and in their parts. These differentiations and the interpretations of them, form the second class of morphological problems.

We commence as before with plants. We have to consider, first, the several kinds of modification in shape they have undergone; and, second, the relations between these kinds of modification and their factors. Let us glance at the leading questions that have to be answered.

$\S 213$. Irrespective of their degrees of composition, plants may, and do, become changed in their general forms. Are their changes capable of being formulated? The inquiry which meets us at the outset is-does a plant's shape admit of being expressed in any universal terms?-terms that remain the same for all genera, orders, and classes.

After plants considered as wholes, have to be considered their proximate components, which vary with their degrees of composition, and in the highest plants are what we call branches. Is there any law traccable among the contrasted shapes of different branches in the same plant? Do the relative developments of parts in the same branch conform to any law? And are these laws, if they exist, allied with one 
another and with that to which the shape of the whole plant conforms?

Descending to the components of these components, which in developed plants we distinguish as leaves, there meet us kindred questions respecting their relative sizes, their relative shapes, and their shapes as compared with those of foliar organs in general. Of their morphological differentiations, also, it has to be asked whether they exemplify any truth that is exemplified by the entire plant and by its larger parts.

Then, a step lower, we come down to those morphological units of which leaves and fronds consist; and concerning these arise parallel inquiries touching their divergences from one another and from cells in general.

The problems thus put together in several groups cannot of course be rigorously separated. Evolution presupposes transitions which make all such classings more or less conventional; and adherence to them must be subordinate to the needs of the occasion.

$\S 214$. In studying the causes of the morphological differentiations thus divided out and prospectively generalized, we shall have to bear in mind several orders of forces which it will be well briefly to specify.

Growth tends inevitably to initiate changes in the shape of any aggregate, by altering both the amounts of the incident forces and the forces which the parts exert on one another. With the mechanical actions this is obvious. Matter that is sensibly plastic cannot be increased in mass without undergoing a change in its proportions, consequent on the diminished ratio of its cohesive foree to the force of gravitation. With the physiological actions it is equally obvious. Increase of size, other things equal, alters the relations of the parts to the material and dynamical factors of nutrition; and by so affecting differently the nutrition of different parts, initiates further changes of proportions. 
In plants of the third order it is thus with the proximate components: they are subject to mutual influences that are unlike one another and are continually changing. The earlier-formed units become mechanical supporters of the later-formed units, and so experience modifying forces from which the later-formed units are exempt. Further, these elder units simultaneously begin to serve as channels through which materials are carried to and from the younger unitsanother cause of differentiation that goes on increasing in intensity. Once more, there arise ever-strengthening contrasts between the amounts of light which fall upon the youngest or outermost units and the eldest or innermost units; whence result structural contrasts of yet another kind. Evidently, then, along with the progressive integration of cells into fronds, of fronds into axes, and of axes into plants still more composite, there come into play sundry causes of differentiation which act on the whole and on each of its parts, whatever their grade. The forces to be overcome, the forces to be utilized, and the matters to be appropriated, do not remain the same in their proportions and modes of action for any two members of the aggregate: be they members of the first, second, third, or any other order.

$\S 215$. Nor are these the only kinds and causes of heterogeneity which we have to consider. Beyond the more general changes produced in the relative sizes and shapes of plants and their parts by progressive aggregation, there are the more particular changes determined by the more particular conditions.

Plants as wholes assume unlike attitudes towards their environments; they have many ways of articulating their parts with one another; they have many ways of adjusting their parts towards surrounding agencies. These are causes of special differentiations additional to those general differentiations that result from increase of mass and increase of composition. In each part considered individually, there arises 
a characteristic shape consequent on that relative position towards external and internal forces, which the mode of growth entails. Every member of the aggregate presents itself in a more or less peculiar way towards the light, towards the air, and towards its point of support; and according to the relative homogeneity or heterogeneity in the incidence of the agencies thus brought to bear on it, will be the relative homogeneity or heterogeneity of its shape.

$\S 216$. Before passing from this à priori view of the morphological differentiations which necessarily accompany morphological integrations, to an à posteriori view of them, it seems needful to specify the meanings of certain descriptive terms we shall have to employ.

Taking for our broadest division among forms, the regular and the irregular, we may divide the latter into those which are wholly irregular and those which, being but partially irregular, suggest some regular form to which they approach. By slightly straining the difference between them, two current words may be conveniently used to describe these subdivisions. The entirely irregular forms we may class as asymmetrical-literally as forms without any equalities of dimensions. The forms which approximate towards regularity without reaching it, we may distinguish as unsymmetrical: a word which, though it asserts inequality of dimensions, has been associated by use rather with such slight inequality as constitutes an observable departure from equality.

Of the regular forms there are several classes, differing in the number of directions in which equality of dimensions is repeated. Hence results the need for names by which symmetry of several kinds may be expressed.

The most regular of figures is the sphere: its dimensions are the same from centre to surface in all directions; and if cut by any plane through the centre, the separated parts are equal and similar. This is a kind of symmetry which stands alone, and will be hereafter spoken of as spherical symmetry. 
When a sphere passes into a spheroid, either prolate or oblate, there remains but one set of planes that will divide it into halves, which are in all respects alike; namely, the planes in which its axis lies, or which have its axis for their line of intersection. Prolate and oblate spheroids may severally pass into various forms without losing this property. The prolate spheroid may become egg-shaped or pyriform, and it will still continue capable of being divided into two equal and similar parts by any plane cutting it down its axis; nor will the making of constrictions deprive it of this property. Similarly with the oblate spheroid. The transition from a slight oblateness, like that of an orange, to an oblateness reducing it nearly to a flat disc, does not alter its divisibility into like halves by every plane passing through its axis. And clearly the moulding of any such flattened oblate spheroid into the shape of a plate, leaves it as before, symmetrically divisible by all planes at right angles to its surface and passing through its centre. This species of symmetry is called radial symmetry. It is familiarly exemplified in such flowers as the daisy, the tulip, and the dahlia.

From spherical symmetry, in which we have an infinite number of axes through each of which may pass an infinite number of planes severally dividing the aggregate into equal and similar parts; and from radial symmetry, in which we have a single axis through which may pass an infinite number of planes severally dividing the aggregate into equal and similar parts; we now turn to bilateral symmetry, in which the divisibility into equal and similar parts becomes much restricted. Noting, for the sake of completeness, that there is a sextuple bilateralness in the cube and its derivative forms which admit of division into equal and similar parts by planes passing through the three diagonal axes and by planes passing through the three axes that join the centres of the surfaces, let us limit our attention to the three kinds of bilateralness which here concern us.

The first of these is triple 
bilateral symmetry. This is the symmetry of a figure having three axes at right angles to one another, through each of which there passes a single plane that divides the aggregate into corresponding halves. A common brick will serve as an example; and of objects not quite so simple, the most familiar is that modern kind of spectacle-case which is open at both ends. This may be divided into corresponding halves along its longitudinal axis by cutting it through in the direction of its thickness, or by cutting it through in the direction of its breadth; or it may be divided into corresponding halves by cutting it across the middle.

Of objects which illustrate double bilateral symmetry, may be named one of those boats built for moving with equal facility in either direction, and therefore made alike at stem and stern. $\mathrm{Ob}$ viously such a boat is separable into equal and similar parts by a vertical plane passing through stem and stern; and it is also separable into equal and similar parts by a vertical plane cutting it amidships.

To exemplify single bilateral symmetry it needs but to turn to the ordinary boat of which the two ends are unlike. Here there remains but the one plane passing vertically through stem and stern, on the opposite sides of which the parts are symmetrically disposed.

These several kinds of symmetry as placed in the foregoing order, imply increasing heterogeneity. The greatest uniformity in shape is shown by the divisibility into like parts in an infinite number of infinite series of ways; and the greatest degree of multiformity consistent with any regularity, is shown by the divisibility into like parts in only a single way. Hence, in tracing up organic evolution as displayed in morphological differentiations, we may expect to pass from the one extreme of spherical symmetry, to the other extreme of single bilateral symmetry. This expectation we shall find to be completely fulfilled. 


\section{CHAPTER VII.}

THE GENERAL SHAPES OF PLANTS.

§ 21\%. Among protophytes those exemplified by Pleurococcus vulgaris are by general consent considered the simplest. As shown in Fig. 1, they are globular cells presenting no obvious differentiation save that between inner and outer parts. Their uniformity of figure coexists with a mode of life involving the uniform exposure of all their sides to incident forces. For though each individual may have its external parts differently related to environing agencies, yet the new individuals produced by spontaneous fission, whether they part company or whether they form clusters and are made polyhedral by mutual pressure, have no means of maintaining parallel relations of position among their parts. On the contrary, the indefiniteness of the attitudes into which successive generations fall, must prevent the rise of any unlikeness between one portion of the surface and another. Spherical symmetry continues because, on the average of cases, incident forces are equal in all directions.

Other orders of Protophyta have much more special forms, along with much more special attitudes: their homologous parts maintaining, from generation to generation, unlike relations to incident forces. The Desmidiacere and Diatomacea, of which Figs. 2 and 3 show examples, severally include genera characterized by triple bilateral symmetry. A Navicula is divisible into corresponding halves by a trans- 
verse plane and by two longitudinal planes-one cutting its valves at right angles and the other passing between its valves. The like is true of those numerous transversely-constricted forms of Desmidiacea, exemplified by the second of the individuals
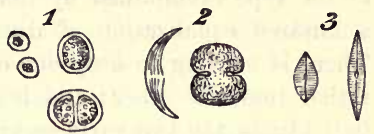
represented in Fig. 2. If now we ask how a Navicula is related to its environment, we see that its mode of life exposes it to three different sets of forces: each set being resolvable into two equal and opposite sets. A Navicula moves in the direction of its length, with either end foremost. Hence, on the average, its ends are subject to like actions from the agencies to which its motions subject it. Further, either end while moving exposes its right and left sides to amounts of influence which in the long run must be equal. If, then, the two ends are not only like one another, but have corresponding right and left sides, the symmetrical distribution of parts answers to the symmetrical distribution of forces. Passing to the two edges and the two flat surfaces, we similarly find a clue to their likenesses and differences in their respective relations to the things around them. These locomotive protophytes move through the entangled masses of fragments and fibres produced by decaying organisms and confervoid growths. The interstices in such matted accumulations are nearly all of them much longer in one dimension than in the rest-form crevices rather than regular meshes. Hence, a small organism will have much greater facility of insinuating itself through this débris, in which it finds nutriment, if its transverse section is flattened instead of square or circular. And while we see how, by survival of the fittest, a flattened form is likely to be acquired by diatoms having this habit; we also see that likeness will be maintained between the two flat surfaces and between the two edges. For, on the average, the relations of the two flat surfaces to the sides of the openings through which the 
diatom passes, will be alike; and so, too, on the average, will be the relations of the two edges.

In desmids of the type exemplified by the second individual in Fig. 2, a kindred equalization of dimensions is otherwise insured. There is nothing to keep one of the two surfaces uppermost rather than the other; and hence, in the long succession of individuals, the two surfaces are sure to be similarly exposed to light and agencies in general. When to this is added the fact that spontaneous fission occurs transversely in a constant way, it becomes manifest that the two ends, while they are maintained in conditions like one another, are maintained in conditions unlike those of the two edges. Here then, as before, triple bilateral symmetry in form, coexists with a triple bilateral symmetry in the average distribution of actions.

Still confining our attention to aggregates of the first order, let us next note what results when the two ends are permanently subject to different conditions. The fixed unicellular plants, of which examples are given in Figs. 4, 5 , and 6 , severally illustrate the contrast in shape arising
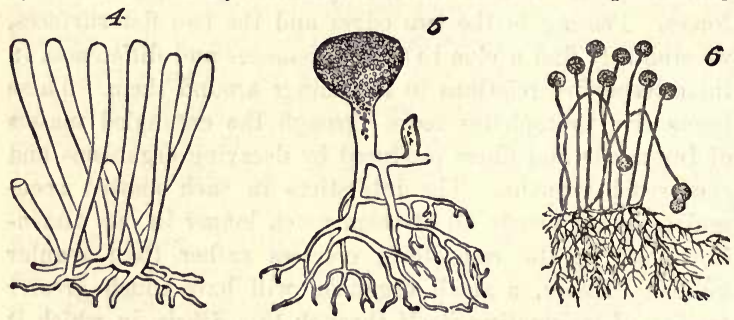

between the part that is applied to the supporting surface and the part that extends into the surrounding medium. These two parts which are the most unlike in their relations to incident forces, are the most unlike in the forms. Observe, next, that the part which lifts itself into the water or air, is more or less decidedly radial. Each outward growing tubule of Codium adharens, Fig. 4, has its parts disposed with some regularity around its axis; the upper stem and spore-vessel 
of Botrydium, Fig. 5, display a lateral growth that is approximately equal in every direction; and the stems of the Mucor, Fig. 6, shoot up with an approach to evenness on all sides. Plants of this low type are naturally very variable in their modes of growth: each individual being greatly modified in form by its special circumstances. But they nevertheless show us a general likeness between parts exposed to like forces, as well as a general unlikeness between parts exposed to unlike forces.

Respecting the forms of these aggregates of the first order, it has only to be added that they are asymmetrical where there is total irregularity in the incidence of forces. We have an example in the indefinitely contorted and branched shape of a fungus-cell, growing as a mycelium among the particles of soil or through the interstices of organic tissue.

$\S 218$. Re-illustrations of the general truths which the forms of these vegetal aggregates of the first order display, are furnished by vegetal aggregates of the second order. The equalities and inequalities of growth in different directions, prove to be similarly related to the equalities and inequalities of environing actions in different directions.

Of spherical symmetry an instance occurs in Eudorina elegans. The ciliated cells are here so united as to produce a small, mulberry-shaped, hollow ball which, being similarly conditioned on all sides, shows no unlikenesses of structure. An allied form, however, Volvox globator, presents a highly instructive, though very trifling, modification. It is not absolutely homogeneous in its structure and is not absolutely homogeneous in its motions. The waving cilia of its component cells have fallen into such slight heterogeneities of action as to cause rotation in a constant direction; and along with a fixed axis of rotation there has arisen a fixed axis of progression. A concomitant fact is that the cells of the colony exhibit an appreciable differentiation in relation to the fixed axis. There is an incipient divergence from 
spherical uniformity along with this slight divergence from uniformity of conditions.

Vegetal aggregates of the second order are usually fixed: locomotion is exceptional. Fixity implies that the surface of attachment is differently circumstanced from the free surface. Hence we may expect to find, as we do find, that among these rooted aggregates of the second order, as among those of the first order, the primary contrast of shape is between the adherent part and the loose part. Sea-weeds variously exemplify this. In some the fronds are very irregular and in some tolerably regular; in some the form is pseudo-foliar and in some pseud-axial; but differing though they do in these respects, they agree in having the end which is attached to a solid body unlike the other end. The same truth is seen in such secondary aggregates as the common Agarics, or rather in their immensely-developed organs of fructification. A puff-ball, Fig. 192, presents no other obvious unlikeness of parts than that between its under and upper surfaces. So too with the stalked kinds that frequent our woods and pastures. In the types which Figs. 193, 194, 195, delineate, the unlikenesses between the rooted ends and the expanded ends, as well as between the under and upper surfaces of the expanded ends, are obviously related to this fundamental contrast of conditions. Nor is this relation less clearly displayed in the sessile fungi which grow out from the sides of trees, as shown at $a, b$, Fig. 196.

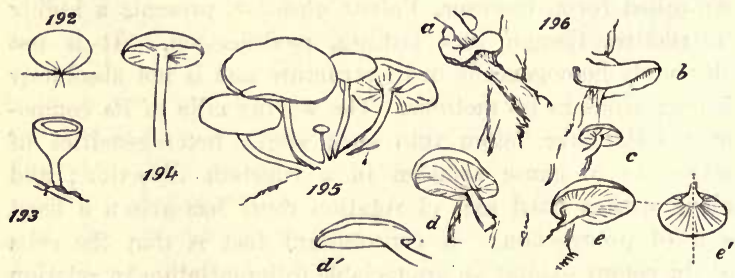

That which is common to this and the preceding types, is the contrast between the attached end and the free end. 
From what these forms have in common, let us turn to that which they have not in common, and observe the causes of the want of community. A puff-ball shows us in the simplest way, the likeness of parts accompanying likeness of conditions, along with the unlikeness of parts accompanying unlikeness of conditions. For while, if we cut vertically through its centre, we find a difference between top and bottom, if we cut horizontally through its centre, we find no differences among its several sides. Being, on the average of cases, similarly related to the environment all round, it remains the same all round. The radial symmetry of the mushroom and other vertically-growing fungi, illustrates this connexion of cause and effect still better. But now mark what happens in the group of Agaricus noli-tangere, shown in Fig. 195. Radially symmetrical as is the type, and radially symmetrical as are those centrally-placed individuals which are equally crowded all round, we see that the peripheral individuals, dissimilarly circumstanced on their outer sides and on their sides next the group, have partially changed their radial symmetry into bilateral symmetry. It is no longer possible to make two corresponding halves by any vertical plane cutting down through the pileus and the stem; but there is only one vertical plane that will thus produce corresponding halves - the plane on the opposite sides of which the relations to the environment are alike. And then mark that the divergence from all-sided symmetry towards two-sided symmetry, here caused in the individual by special circumstances, is characteristic of the race where the habits of the race constantly involve two-sidedness of conditions. Besides being exemplified by such comparatively undifferentiated types as certain Polypori, Fig. 196, $a, b$, this truth is exemplified by members of the genus just named. In Agaricus horizontalis, Fig. 196, $c$, we have a departure from radial symmetry that is conspicuous only in the form of the stem. A more decided bilateralness exists in $A$. subpalmatus, shown in elevation at $d$ and in section at $d^{\prime}$. And 
Lentinus flabelliformis, of which $e$ and $e^{\prime}$ are different views, exhibits complete bilateralness-a bilateralness in which there is the greatest likeness of the parts that are most similarly conditioned, and the greatest unlikeness of the parts that are most dissimilarly conditioned.

Among plants of the second order of composition, it will suffice to note one further class of facts which are the converse of the foregoing and have the same implications. These are the facts showing that along with habitual irregularity in the relations to external forces, there is habitual irregularity in the mode of growth. Besides finding such facts among Thallophytes, as in the tubers of underground fungi and in the creeping films of sessile lichens, which severally show us variations of proportions obviously caused by variations in the amounts of the influences on their different sides, we also, among Archegoniates of inferior types, find irregularities of form along with irregularities in environing actions. The fronds of the Marchantiacea or such Jungermanniacea as are shown in Figs. 41, 42, 43, illustrate the way in which each lowly-organized aggregate of the second order,not individuated by the mutual dependence of its parts, has its form determined by the balance of facilities and resistances which each side of the frond meets with as it spreads.

$\S 219$. Among plants displaying integration of the third degree, and among plants still further compounded, these same truths are equally manifest. In the forms of such plants we see primary contrasts and secondary contrasts which, no less clearly than the foregoing, are related to contrasts of conditions.

That flowering plants from the daisy up to the oak, have in common the fundamental unlikeness between the upward growing part and the downward growing part; and that this most marked unlikeness corresponds with the most marked unlikeness between the two parts of their environment, soil and air; are facts too conspicuous to be named 
were they not important items in the argument. More instructive perhaps, because less familiar, is the fact that we miss this extreme contrast in flowering plants which have not their higher and lower portions exposed to conditions thus extremely contrasted. A parasite like the Dodder, growing in entangled masses upon other plants, from which it sucks the juices, is not thus divisible into two strongly-distinguished halves.

Leaving out of consideration the difference between the supporting part and the supported part in phænogams, and looking at the supported part only, we observe between its form and the habitual incidence of forces, a relation like that which we observed in the simpler plants. Phænogams that are practically if not literally uniaxial, and those which develop their lateral axes only in the shape of axillary flowers, when uninterfered with commonly send up vertical stems round which the leaves and flowers are disposed with a more or less decided radial symmetry. Gardens and fields supply us with such instances as the Tulip and the Orchis; and, on a larger scale, the Palms and the Aloes are fertile in examples. The exceptions, too, are instructive. Besides the individual divergences arising from special interferences, there are to be traced general divergences where the habits of the plants expose them to general interferences in anything approaching to constant ways. Plants which, like the Foxglove, have spikes of flowers that are borne on flexible footstalks, have their flowers habitually bent round to one face of the stem: an unlikeness of distribution probably caused by unlikeness in the relation to the Sun's rays. The wild Hyacinth, too, with stem so flexible that its upper part droops, shows us how a consequent difference in the action of gravity on the flowers, causes them to deviate from their typicallyradial arrangement towards a bilateral arrangement.

Much more conspicuous are these general and special relations of form to general and special actions in the environment, among phænogams that are multiaxial. That when 
standing alone, and in places where the winds do not injure them nor adjacent things shade them, shrubs and trees develop with tolerable evenness on all sides, is an obvious truth. Equally obvious is the truth that, when growing together in a wood, and mutually interfered with on all sides, trees still show obscurely radial distributions of parts; though, under such conditions, they have tall taper stems with branches directed upwards-a difference of shape clearly due to the different incidence of forces. And almost equally obvious is the truth, that a tree of this same kind growing at the edge of the wood, has its outer branches well developed and its inner branches comparatively ill-developed. Fig. 19\%, which
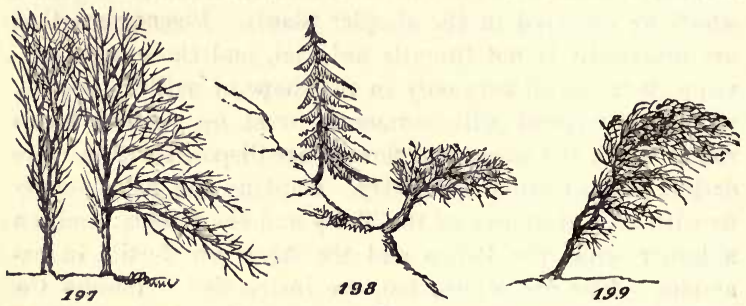

inaccurately represents this difference, will serve to make it manifest that while one of the peripheral trees can be cut into something like two similar halves by a vertical plane directed towards the centre of the wood-a plane on each side of which the conditions are alike-it cannot be cut into similar halves by any other plane. A like divergence from an indefinitely-radial symmetry towards an indefinitely-bilateral symmetry, occurs in trees that have their conditions made bilateral by growing on inclined surfaces. Two of the common forms observable in such cases are given in Fig. 198. Here there is divisibility into parts that are tolerably similar, by a vertical plane running directly down the hill; but not by any other plane. Then, further, there is the bilateralness, similar in general meaning though differently caused, often seen in trees exposed to strong prevailing winds. Almost 
every sea-coast has abundant examples of stunted trees which, like the one shown in Fig. 199, have been made to deviate from their ordinary equal growth on all sides of a vertical axis, to a growth that is equal only on the opposite sides of a vertical plane directed towards the wind's eye.

From among vegetal aggregates of the third order, we have now only to add examples of the entirely asymmetrical form which accompanies an entirely irregular distribution of incident forces. Creeping plants furnish such examples. They show, both when climbing up vertical or inclined surfaces and when trailing on the ground, that their branches grow hither and thither as the balance of forces aids or opposes; and the general outline is without symmetry of any kind, because the environing influences have no kind of regularity in their arrangement.

$\S 220$. Along with some unfamiliar facts, I have here set down facts which are so familiar as to seem scarcely worth noting. It is because these facts have become meaningless to perceptions deadened by infinite repetitions of them, that it is needful here to point out their meanings. Not alone for its intrinsic importance has the unlikeness between the attached ends and the free ends been traced among plants of all degrees of integration. Nor is it simply because of the significance they have in themselves, that instances have been given of those varieties of symmetry and asymmetry which the free ends of plants equally display: be they plants of the first, second, third, or any higher order. Neither has the only other purpose been that of showing how, in the radial symmetry of some vegetal aggregates and the single bilateral symmetry of others, there are traceable the same ultimate principles as in the spherical symmetry and triple bilateral symmetry of certain minute plants first described. But the main object has been to present, under their simplest aspects, those general laws of morphological differentiation which are fulfilled by the component parts of each plant. 
If organic form is determined by the distribution of forces, and the approach in every case towards an equilibrium of inner actions with outer actions; then this relation between forms and forces must hold alike in the organism as a whole in its proximate units, and in its units of lower orders. Formulas which express the shapes of entire plants in terms of surrounding conditions, must be formulas which also express the shapes of their several parts in terms of surrounding conditions. If, therefore, we find that a plant as a whole is radially symmetrical or bilaterally symmetrical or asymmetrical, according as the incident forces affect it equally on all sides of an axis, or affect it equally only on the opposite sides of one plane, or affect it equally in no two directions; then, we may expect that, in like manner, each member of a plant will display radial symmetry where environing influences are alike along many radii, bilateral symmetry where there is bilateralness of environing influences, and unsymmetry or asymmetry where there is partial or entire departure from a balance of surrounding actions.

To show that this expectation is borne out by the facts, will be the object of the following four chapters. Let us begin with the largest parts into which plants are divisible; and proceed to the successively smaller parts. 


\section{CHAPTER VIII.}

THE SHAPES OF BRANCHES.

\$221. AGgREGates of the first order supply a few examples of forms ramified in an approximately-regular manner, under conditions which subject their parts to approximately-regular distributions of forces. Some unicellular Algce, becoming elaborately branched, assume very much the aspects of small trees; and show us in their branches analogous relations of forms to forces. Bryopsis plumosa may be instanced. Fig. 200 represents the end of one of its lateral ramifications, above and beneath which come others of like characters. Here it will be seen that the attached and free ends differ; that

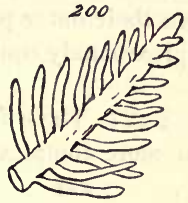
the two sides are much alike; and that they are unlike the upper and under surfaces, which resemble one another. The more highly developed members of the same group of Alga, the Siphonea, show a marked radial symmetry coexisting with very elaborate branching, e.g., Neomeris, Cymopolia, and others.

§222. Fig. 201 shows us how, in an aggregate of the second order, each proximate component is modified by its relations to the rest; just as we before saw a whole fungus of the same type modified

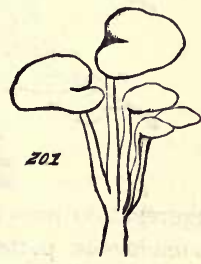

145 
by its relations to environing objects. If a branch of the fungus here figured, be compared with one of the fungi clustered together in Fig. 195, or, still better, with one of the laterally-growing fungi shown in Fig. 196, there will be perceived a kindred transition from radial to bilateral symmetry, occurring under kindred conditions. The portion of the pileus next to the side of attachment is undeveloped in this branched form as in the simpler form; and in the one case as in the other, the stem is modified towards the side of attachment. A division into similar halves, which, as shown in Fig. $196 e$, might be made of the whole fungus by a vertical plane passing through the centre of the pileus and the axis of the supporting body, might here be made of the branch, by a vertical plane passing through the centre of its pileus and the axis of the main stem. Among aggregates of this order, the Alga furnish cases of kindred nature. In the branches of Lessonia, Fig. 37, may be observed a substantiallysimilar relationship. As their inner parts are less developed than their outer parts, while their two sides are developed in approximately equal degrees, they are rendered bilateral.

$\S 223$. These few cases introduce us to the more familiar but more complex cases which plants of the third degree of
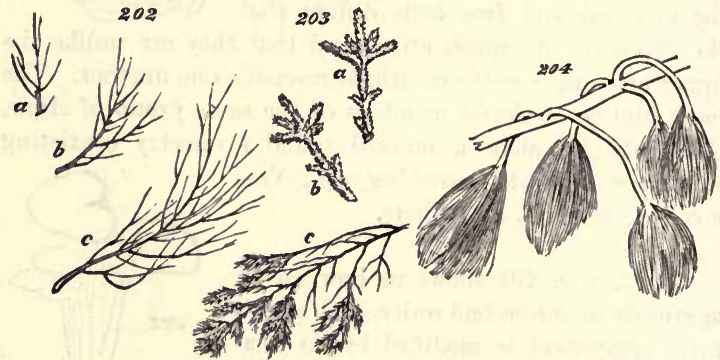

aggregation present. At $a, b, c$, Fig. 202, are sketched three homologous parts of the same tree: $a$ being the leading 
shoot; $b$ a lateral branch near the top, and $c$ a lateral branch lower down. There is here a double exemplification. While the branch $a$, as a whole, has its branchlets arranged with tolerable regularity all round, in eorrespondence with its equal exposure on all sides, each branchlet shows by its curve as much bilateral symmetry as its simple form permits. The branch $b$, dissimilarly circumstanced on the side next the main stem and on the side away from it, has an approximate bilateralness as a whole, while the bilateralness of its branchlets varies with their respective positions. And in the branch $c$, having its parts still more differently conditioned, these traits of structure are still more marked. Extremely strong contrasts of this kind occur in trees having very regular modes of growth. The uppermost branches of a Spruce-fir have radially-arranged branchlets: each of them, if growing vigorously, repeats the type of the leading shoot, as shown in Fig. 203, $a, b$. But if we examine branches lower and lower down the tree, we find the vertically-growing branchlets bear a less and less ratio to the horizontallygrowing ones; until, towards the bottom, the radial arrangement has wholly merged into the bilateral. Shaded and confined by the branches above them, these eldest branches develop their offshoots in those directions where there is most space and light: becoming finally quite flattened and fan-shaped, as shown at Fig. 203, c. And on remembering that each of these eldest branches, when first it diverged from the main stem, was radial, we see not only that between the upper and lower branches does this contrast in structure hold, but also that each branch is transformed from the radial to the bilateral by the progressive change in its environment.

Other forces besides those which aid or hinder growth, conspire to produce this two-sided character in lateral branches. The annexed Fig. 204, sketched from an example of the Pinus Coulterii at Kew, shows very clearly how, by mere gravitation, the once radially-arranged branchlets may be so bent as to produce in the branch as a whole a 
decided bilateralness. A full-grown Araucaria, too, exhibits in its lower branches modifications similarly caused; and in each of such branches there may be remarked the further fact, that its upward-bending termination has a partiallymodified radialness, at the same time that its drooping lateral branchlets give to the part nearer the trunk a completely bilateral character.

Now in these few instances, typical of countless instances which might be given, we see, as we saw in the case of the fungi, that the same thing is true of the parts in their relations to the whole and to one another, which is true of the whole in its relations to the environment at large. Entire trees become bilateral instead of radial, when exposed to forces that are equal only on opposite sides of one plane; and in their branches, parallel changes of form occur under parallel changes of conditions.

$\S 224$. There remains to be said something respecting the distribution of leaves. How a branch carries its leaves constitutes one of its characters as a branch, and is to be considered apart from the characters of the leaves themselves. The principles hitherto illustrated we shall here find illustrated still further.

The leading shoot and all the upper twigs of a fir-tree, have their pin-shaped leaves evenly distributed all round, or placed radially; * but as we descend we find them beginning to assume a bilateral distribution; and on the lower, horizontally-growing branches, their distribution is quite bilateral. $\dagger$ Between the Irish and English kinds of Yew, there is a contrast of like significance. The branches of the one, shooting up as they do almost vertically, are clothed with leaves

* Here and throughout, the word radial is applied equally to the spiral and the whorled structures. These, as being alike on all sides, are similarly distinguished from arrangements that are alike on two sides only.

+ It should be added that this ehange of distribution is not due to change in the relative positions of the insertions of the leaves but to their twistings. 
all round; while those of the other, which spread laterally, bear their leaves on the two sides. In trees with betterdeveloped leaves, the same principle is more or less manifest in proportion as the leaves are more or less enabled by their structures to maintain fixed positions. Where the foot-stalks are long and slender, and where, consequently, each leaf, according to its weight, the flexibility and twist of its footstalk, and the direction of the branch it grows from, falls into some indefinite attitude, the relations are obscured. But where the foot-stalks are stiff, as in the Laurel, it will be found, as before, that from the topmost and upward-growing branches the leaves diverge on all sides; while the undermost branches, growing out from the shade of those above, have their leaves so turned as to bring them into rows horizontally spread out on the two sides of each branch.

A kindred truth, having like implications, comes into view when we observe the relative sizes of leaves on the same branch, where their sizes differ. Fig. 205 represents a branch of a Horse-chestnut, taken from the lowermost fringe of the tree, where the light has been to a great extent intercepted from all but the most protruded parts. Beyond the fact that the leaves become by appropriate growths of their foot-stalks bilaterally distributed on this droop-

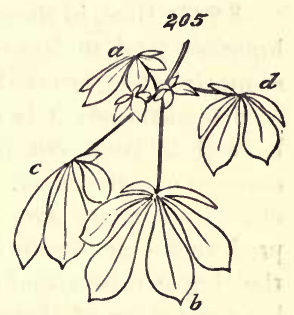
ing branch, instead of being distributed symmetrically all round, as on one of the ascending shoots, we have here to note the fact that there is unequal development on the upper and lower sides. Each of the compound leaves acquires a foot-stalk and leaflets that are large in proportion to the supply of light; and hence, as we descend towards the bottom of the tree, the clusters of leaves display increasing contrasts. How marked these contrasts become will be seen on comparing $a$ and $b$, which form one pair of leaves that 
are normally equal, or $c$ and $d$, which form another pair normally equal.

Let us not omit to note, while we have this case before us, the proof it affords that these differences of development are in a considerable degree determined by the different conditions of the parts after they have been unfolded. Though those inequalities of dimensions whence the differentiations of form result, may be in many cases largely due to the inequalities in the circumstances of the parts while in the bud (which are, however, representative of inequalities in ancestral circumstances); yet these are clearly not the sole causes of the unlikenesses which eventually arise. This bilateralness resulting from the unequal sizes of the leaves, must be considered as due to the differential actions that come into play after the leaves have assumed their typical structures.

$\S 225$. How, in the arrangement of their twigs and leaves, branches tend to lapse from forms that are approximately symmetrical to forms that are quite asymmetrical, need not be demonstrated: it is sufficiently conspicuous. But it may be well to point out how the tendency to do this further enforces our argument. The comparatively regular buddingout of secondary axes and tertiary axes, does not usually produce an aggregate which maintains its regularity, for the simple reason that many of the axes abort. Terminal buds are some of them destroyed by birds; others are burrowed into by insects; others are nipped by frost; others are broken off or injured during gales of wind. The environment of each branch and its branchlets is thus ever being varied on all sides: here, space being left vacant by the death of some shoot that would ordinarily have occupicd it; and there, space being trenched on by the lateral growth of some adjacent branch that has had its main axis broken. Hence the asymmetry, or heterogeneity of form, assumed by the branch, is caused by the asymmetrical distribution 
of incident forces-a result and a cause which go on ever complicating.

$\S 226$. One conspicuous trait in the shapes of branches has still to be named. Their proximal or attached ends differ from their distal or free ends, in the same way that the lower ends of trees differ from their upper ends. This fact, like the fact to which it is here paralleled, has had its significance obscured by its extreme familiarity. But it shows in a striking way how the most differently-conditioned parts become the most strongly contrasted in their structures. A phænogamic axis is made up of homologous segments, marked off from one another by the nodes; and a compound branch consists of groups of such segments. The earliest-formed segments, alike of the tree and of each branch, serve as mechanical supports and channels for sap to the successive generations of segments that grow out of them; and become more and more shaded by their progeny as these increase. Hence the progressively-increasing contrasts which, while mainly due to the unlikenesses of bulk accompanying differences of age, are in part due to the unlikenesses of structure which differences of relation to the environment have caused.

§22\%. Thus, then, it is with the proximate parts of plants as it is with plants as wholes. The radial symmetry, the bilateral symmetry, and the asymmetry, which branches display in different trees, in different parts of the same tree, and at different stages of their own growths, prove to be all consequent on the ways in which they stand towards the entire plexus of surrounding actions. The principle that the growths are unequal in proportion as the relations of parts to the environment are unequal, serves to explain all the leading traits of structure. 


\section{CHAPTER IX.}

THE SHAPES OF LEAVES.

$\S 228$. NeXT in the descending order of composition come compound leaves. The relative sizes and distributions of their leaflets, as affecting their forms as wholes, have to be considered in their relations to conditions. Figs. 206, 207, represent leaves of the common Oxalis and of the Marsilea, in which radial symmetry is as completely displayed as the small number of leaflets permits. This equal development of the leaflets on all sides, occurs where the foot-stalks, growing up vertically from creeping or underground stems, are so long that the leaves either do not interfere with one another or do it in an inconstant way: the leaflets are not differently conditioned on different sides, as they are where the foot-stalks grow out in the ordinary manner. How unlikeness of position influences the leaflets is clearly shown in a Clover-leaf, Fig. 208, which deviates from the Oxalis-leaf but slightly towards bilateralness, as it deviates from it but slightly in the attitude of its petiole; which is a little inclined away from the others borne by the same procumbent axis. A familiar example of an almost radial symmetry along with almost equal relations to surrounding conditions, occurs in the root-leaves of the Lupin, Fig. $209 \mathrm{~b}$. Here though we have lateral divergence from a vertical axis, yet the long foot-stalks preserve nearly erect positions, and carry their leaves to such distances from the axis, that the development of the leaflets on the side next it is not much 
hindered. Still the interference of the leaves with one another is, on the average, somewhat greater on the proximal side than on the distal side; and hence the interior leaflets are rather less than the exterior leaflets. In further proof of which influence, let it be added that, as shown in the figure, at $a$, the leaves growing out of the flowering-stem deviate towards the two-sided form more decidedly. Two-sidedness is much greater where there is a greater relative proximity of the inner leaflets to the axis, or where the foot-stalk approaches towards a horizontal position. The Horse-chestnut, Fig. 205, already instanced as showing how the arrangements and sizes of leaflets are determined by the incidence of forces, serves also to show how the incidence of forces deter-
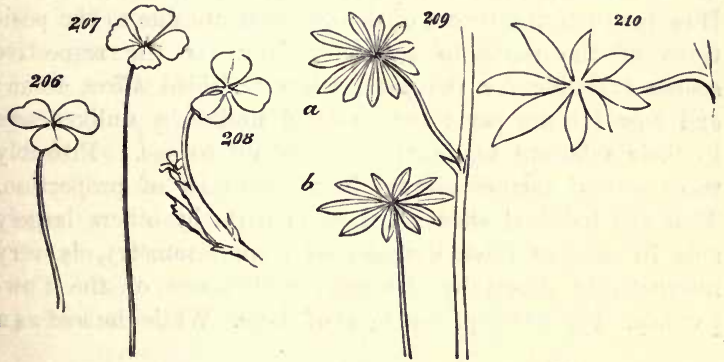

mines the relative sizes and arrangements of leaflets. Fig. 210 , which shows a leaf of the Bombax, further illustrates this relation of structure to conditions.

Compound leaves that are completely bilateral, present us with modifications of form exemplifying the same general truth in another way. In them the proximal and distal parts have none of that resemblance which we see in those intermediate forms just described. The portion next the axis and the portion furthest from the axis are entirely different; and the only likeness is between the wings or leaflets on opposite sides of the main foot-stalk or mid-rib. On turning back to Fig. 65, it will be seen that the compound leaf there 
drawn to exemplify another truth, serves also to exemplify this truth: the homologous parts $a, b, c, d$, while they are unlike one another, are, in their main proportions, severally like the parts with which they are paired. And here let us not overlook a characteristic which is less conspicuous but not less significant. Each of the lateral wings has winglets that are larger on the one side than on the other; and in each case the two sides are dissimilarly conditioned. Even in the several components of each wing may be traced a like divergence from symmetry, along with a like inequality in the relations to the rest: the proximal half of each leaflet is habitually larger than the distal half. In the leaves of the Bramble, previously figured, kindred facts are presented. How far such differences of development are due to the positions of the parts in the bud; how far the respective spaces available for the parts when unfolded affect them; and how far the parts are rendered unlike by unlikenesses in their relations to light; it is difficult to say. Probably these several factors operate in all varieties of proportion. That the habitual shading of some parts by others largely aids in causing these divergences from symmetry, is very instructively shown by the compound leaves of the Cowparsnip. Fig. 211 represents one of these. While the leaf as a
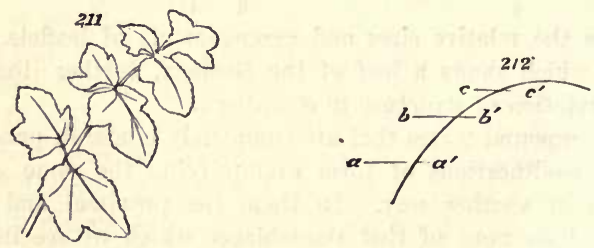

whole is bilaterally symmetrical, each of the wings has an unsymmetrical bilateralness: the side next the axis being larger than the remoter side. How does this happen? Fig. 212, which is a diagrammatic section down the mid-rib of the leaf, showing its inclined attitude and the positions of the 
wings $a, b$, $c$, will make the cause clear. As the wings overlap, like the bars of a Venetian blind, each intercepts some light from the one below it; and the one below it thus suffers more on its distal side than on its proximal side. Hence the smaller development of the distal side. That this is the cause is further shown by the proportion that is maintained between the degree of obscuration and the degree of non-development; for this unlikeness is greater between the two sides $a$ and $a^{\prime}$, than between $b$ and $b^{\prime}$ or $c$ and $c^{\prime}$, at the same time that the interference is greater in the lower wings than in the upper. Of course in this case and in the kindred cases hereafter similarly interpreted, it is not meant that this differentiation is consequent solely, or even chiefly, on the differential actions experienced by the individual plant. Though there is good reason to believe that the rate of growth in each part of each leaf is affected by the incidence of light, yet contrasts so marked and so systematic as these are not explicable without taking into account the inheritance of modifications either functionally caused or caused by spontaneous variation. Clearly, the tendency will be towards the preservation of a plant which distributes its chlorophyll in the most advantageous way; and hence there will always be a gravitation towards a form in which shaded parts of leaves are undeveloped.

$\S 229$. From compound leaves to simple ones, we find transitions in leaves of which the divisions are partial instead of total; and in these we see, with equal clearness, the relations between forms and positions that have been traced thus far. Fig. 213 is the leaf of a Winter-aconite in which, round a vertical petiole, there is a radial distribution of halfseparated leaflets. The Cecropia-leaf, Fig. 214, shows us a two-sided development of the parts beginning to modify, but not obliterating, the all-sided arrangement; and this mixed symmetry occurs under conditions that are intermediate. A more marked degree of the same relation is pre- 
sented in the leaf of the Lady's Mantle, Fig. 215. And then in the Sycamore and the Vine, we have a cleft type of
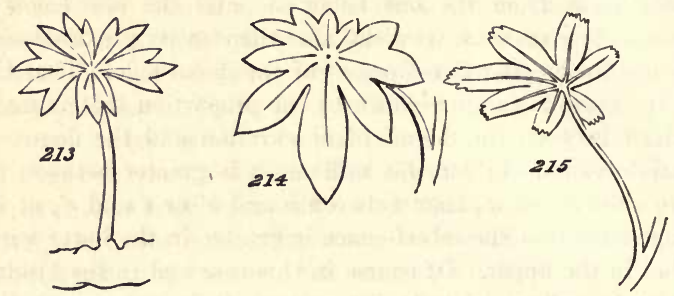

leaf in which a decided bilateralness of form co-exists with a decided bilateralness of conditions.

The quite simple leaves to which we now descend, exhibit, very distinctly, a parallel series of facts. Where they grow up on long and completely-independent foot-stalks, without definite subordination to some central vertical axis, the leaves. of water-plants are symmetrically peltate. Of this the sacred Indian-bean, Fig. 216, furnishes an example. Here there is only a trace of bilateralness in the venation of the leaf, corresponding to the very small difference of the conditions on the proximal and distal sides. In the Victoria regia, Fig. 217, the foot-stalks, though radiating almost horizontally from a centre, are so long as to keep the leaves quite remote from one another; and in it each leaf is almost symmetrically peltate, with a bilateralness indicated only by a seam over the line of the foot-stalk. The leaves of the Nymphaa, Fig. 218, more closely clustered, and having less
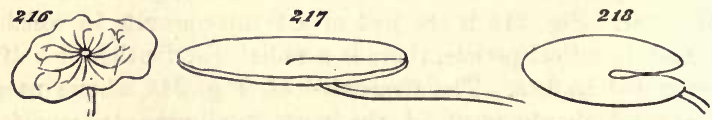

room transversely than longitudinally, exhibit a marked advance to the two-sided form; not only in the excess of the length over the breadth, but in the existence of a cleft, 
where in the Victoria regia there is merely a seam. Among land-plants similar forms are found under analogous conditions. The common Hydrocotyle, Fig. 219, which sends
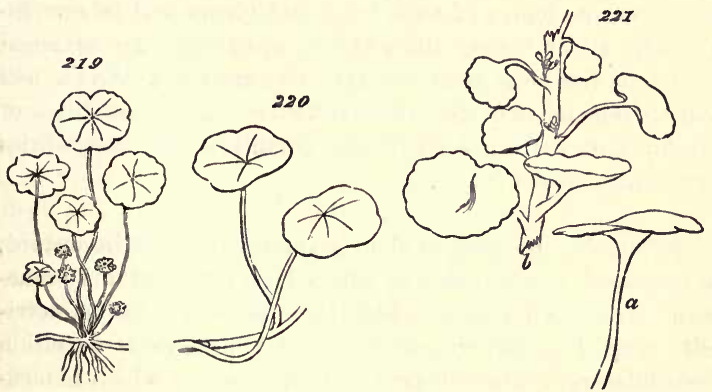

up direct from its roots a few almost upright leaf-stalks, has these surmounted by peltate leaves; which leaves, however, diverge slightly from radial symmetry in correspondence with the slight contrast of circumstances which their grouping involves. Another case is supplied by the Nasturtium, Fig. 220 , which combines the characters-a creeping stem, long leaf-stalks growing up at right angles to it, and unsymmetrically peltate leaves, of which the least dimension is, on the average, towards the stem. But perhaps the most striking illustration is that furnished by the Cotyledon umbilicus, Fig. 221, in which different kinds of symmetry occur in the leaves of the same plant, along with differences in their relations to conditions. The root-leaves, $a$, growing up on vertical petioles before the flower-stalk makes its appearance, are symmetrically peltate; while the leaves which subsequently grow out of the flower-stalk, $b$, are at the bottom transitionally bilateral, and higher up completely bilateral.

That the bilateral form of leaf is the ordinary form, corresponds with the fact that, ordinarily, the circumstances of the leaf are different in the direction of the plant's axis from what they are in the opposite direction, while 
transversely the circumstances are alike. It is needless to give diagrams to illustrate this extremely familiar truth. Whether they are broad or long, oval or heart-shaped, pointed or obtuse, the leaves of most trees and plants will be remembered by all as having the ends by which they are attached unlike the free ends, while the two sides are alike. And it will also be remembered that these equalities and inequalities of development correspond with the equalities and inequalities in the incidence of forees.

$\S 230$. A confirmation that is interesting and important, is furnished by the cases in which leaves present unsymmetrical forms in positions where their parts are unsymmetrically related to the environment. A considerable deviation from bilateral symmetry may be seen in a leaf which habitually so carries itself, that the half on the one side of the mid-rib is more shaded than the other half. The drooping branches of the Lime, delineated in Fig. 222, show us leaves so arranged
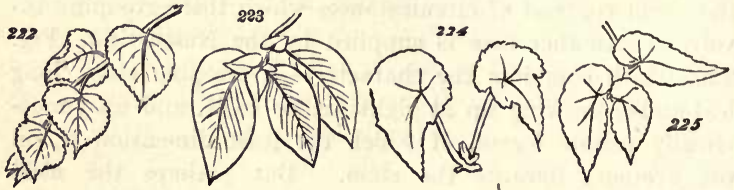

and so modified. On examining their attitudes and their relations one to another, it will be found that each leaf is so inclined that the half of it next the shoot grows over the shoot and gets plenty of light; while the other half so hangs down that it comes a good deal into the shade of the preceding leaf. The result is that having leaves which fall into these positions, the species profits by a large development of the exposed halves; and by survival of the fittest, acting along with the direct effect of extra exposure, this modification beeomes established. How unquestionable is the connexion between the relative positions of the halves and their relative developments, will be admitted on observing a 
converse case. Fig. 223 represents a shoot of Strobilanthes glomeratus. Here the leaves are so set on the stem that the inner half of each leaf is shaded by the subsequently-formed leaf, while its outer half is not thus shaded; and here we find the inner half less developed than the outer half. But the most conclusive evidence of this relation between unsymmetrical form and unsymmetrical distribution of surrounding forces, is supplied by the genus Begonia; for in it we have a manifest proportion between the degree of the alleged effect and the degree of the alleged cause. These plants produce their leaves in pairs, in such ways that the connate leaves interfere with one another, much or little according as the foot-stalks are short or long; and the result is a correlative divergence from symmetry. In Begonia nelumbiifolia, which has petioles so long that the connate leaves are not kept close together, there is but little deviation from a bilaterally-peltate form; whereas, accompanying the comparatively marked and constant proximity in $B$. pruinata, Fig. 224, we see a more decidedly unsymmetrical shape; and in $B$. mahringii, Fig. 225, the modification thus caused is pushed so far as to destroy the peltate structure.*

$\S 231$. Again, then, we are taught the same truth. Here, as before, we see that homologous units of any order become

* We may note that some of these leaves, as those of the Lime, furnish indications of the ratio which exists between the effects of individual circumstances and those of typical tendencies. On the one hand, the leaves borne by these drooping branches of the Lime are with hardly an exception unsrmmetrical more or less decidedly, even in positions where the causes of unsymmetry are not in action: a fact showing us the repetition of the type irrespective of the conditions. On the other hand, the degree of deviation from symmetry is extremely rariable, even on the same shoot: a fact proving that the eircumstances of the individual leaf are influential in modifying its form. But the most striking evidence of this direct modification is afforded by the suekers of the Lime. Growing, as these do, in approximately upright attitudes, the leaves they bear do not stand to one another in the way above described, and the causes of unsymmetry are not in action; and here, though there is a general leaning to the unsymmetrical form, a large proportion of the leares become quite symmetrical. 
differentiated in proportion as their relations to incident forces become different. And here, as before, we see that in each unit, considered by itself, the differences of dimension are greatest in those directions in which the parts are most differently conditioned; while there are no differences between the dimensions of the parts that are not differently conditioned.*

* It was by an observation on the forms of leaves, that I was first led to the views set forth in the preceding and succeeding chapters on the morphological differentiation of plants and animals. In the year 1851, during a country ramble in which the structures of plants had been a topic of conversation with a friend-Mr. G. H. Lewes-I happened to pick up the leaf of a buttercup, and, drawing it by its foot-stalk through my fingers so as to thrust together its deeply-cleft divisions, observed that its palmate and almost radial form was changed into a bilateral one; and that were the divisions to grow together in this new position, an ordinary bilateral leaf would result. Joining this observation with the familiar fact that leaves, in common with the larger members of plants, habitually turn themselves to the light, it occurred to me that a natural change in the circumstances of the leaf might readily cause such a modification of form as that which $I$ had produced artificially. If, as they often do with plants, soil and climate were greatly to change the habit of the buttereup, making it branched and shrub-like; and if these palmate leaves were thus much overshadowed by one another; would not the inner segments of the leaves grow towards the periphery of the plant where the light was grcatest, and so change the palmate form into a more decidedly bilateral form? Immediately I began to look round for evidence of the relation between the forms of leaves and the general characters of the plants they belong to; and soon found some signs of connexion. Certain anomalies, or seeming anomalies, however, prevented me from then pursuing the inquiry much further. But consideration cleared up these difficultics; and the idea afterwards widened into the general doetrine here elaborated. Occupation with other things prevented me from giving expression to this general doctrine until Jan. 1859; when I published an outline of it in the Medico-Chirurgical Revievo. 


\section{CHAPTER X.}

THE SHAPES OF FLOWERS.

§ 232. Following an order like that of preceding chapters, let us first note a few typical facts respecting the forms of clusters of flowers, apart from the forms of the flowers themselves. Two kindred kinds of Leguminosa serve to show how the members of clusters are distributed in an all-sided manner or in a two-sided manner, according as the circumstances are alike on all sides or alike on only two sides. In Hippocrepis, represented in Fig. 226, the flowers growing at the end of a vertical stem, are arranged round it in radial symmetry. Contrariwise in Melilotus, Fig. 227 , where the axillary stem bearing the flowers is so placed in relation to the main stem, that its outer and inner faces are differently conditioned, the flowers are all on the outer face: the cluster is bilaterally symmetrical, since it may be cut into approximately equal and similar

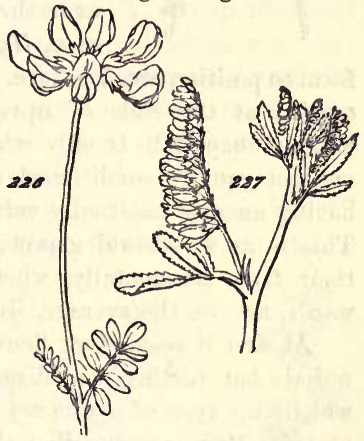
groups by a vertical plane passing through the main axis.

Plants of this same tribe furnish clusters of intermediate characters having intermediate conditions. Among these, as among the clusters which other types present, may be 
found some in which conformity to the general law is not obvious. The discussion of these apparent anomalies would carry us too much out of our course. A clue to the explanation of them will, I believe, be found in the explanation presently to be given of certain kindred anomalies in the forms of individual flowers.

$\S 233$. The radially-symmetrical form is common to all individual flowers that have vertical axes. In plants which are practically if not literally uniaxial, and bear their flowers at the ends of upright stalks, so that the faces open horizontally, the petals are disposed in an all-sided way. Crocuses, Tulips, and Poppies are familiar examples of this structure occurring under these conditions. A Ranunculus
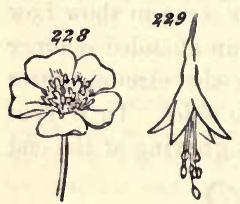
flower, Fig. 228, will serve as a typical one. Similarly, flowers which have peduncles flexible enough to let them hang directly downwards, and are not laterally incommoded, are also radial; as in the Fuchsia, Fig. 229, as in Cyclamen, Hyacinth, \&c. These relations of form to position are, I believe, uniform. Though some flowers carried at the ends of upright or downright stems have oblique shapes, it is only when they have inclined axes or are not equally conditioned all round. No solitary flower having an axis habitually vertical, presents a bilateral form. This is as we should expect; since flowers which open out their faces horizontally, whether facing upwards or downwards, are, on the average, similarly affected on all sides.

At first it seems that flowers thus placed should alone be radial; but further consideration discloses conditions under which this type of symmetry may exist in flowers otherwise placed. Remembering that the radial form is the primitive form-that, morphologically speaking, it results from the contraction into a whorl, of parts that are originally arranged in the same spiral succession as the leaves; we must expcet 
it to continue wherever there are no forces tending to change it. What now must be the forces tending to change it? They must be forces which do not simply affect differently the different parts of an individual flower. They must be forces which affect in like contrasted ways the homologous parts of other individual flowers, both on the same plant and on surrounding plants of the same species. A permanent modification can be expected only in cases where, by inheritance, the effects of the modifying causes accumulate. That they may accumulate the flowers must keep themselves so related to the environment, that the homologous parts may, generation after generation, be subjected to like differentiating forces. Hence, among a plant's flowers which maintain no uniformity in the relations of their parts to surrounding influences, the radial form will continue. Let us glance at the several causes which entail this variability.

When flowers are borne on many branches, which have all inclinations from the vertical to the horizontal-as are the flowers of the Apple, the Plum, the Hawthorn-they are placed in countless different attitudes. Consequently, any spontaneous variation in shape which might be advantageous were the attitude constant, is not likely to be advantageous; and any functionally-produced modification in one flower, is likely to be neutralized in offspring by some opposite functionally-produced modification in another flower. It is quite comprehensible, therefore, that irregularly-branched plants should thus preserve their laterally-borne flowers from undergoing permanent deviations from their primitive radial symmetry. Fig. 230, representing a blossoming twig of the Blackthorn, illustrates this. Again, upright

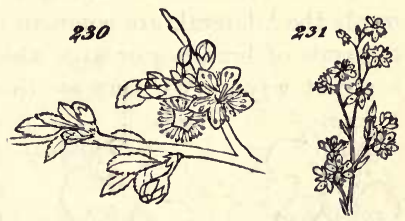
panicles, such as those of the Saxifrage exemplified in Fig. 231, and irregular terminal groups of flowers other- 
wise named, furnish conditions under which there is similarly an absence of determinate relations between the parts of the flowers and the incident forces; and hence an absence of bilateralness.

This inconstancy of relative position is produced in various other ways-by extreme flexibility of the stems, as in the Blue-bell; by the tendency of the peduncles to curl to a greater or less extent in diverse directions, as in Pyrola; by special twistings of the peduncles, differing in degree in different individuals, as in Convolvulus; by unusual laxity of the petals, as in Lythrum. Elsewhere the like general result arises from a progressive change of attitude, as in Myosotis, the stem of which as it unfolds causes each flower to undergo a transition from an upward position of the mouth to a lateral position; or as in most Cruciferce, where the like effect follows from an altered direction of the peduncle.

There are, however, certain scemingly-anomalous cases where radial symmetry is maintained by laterally-placed flowers, which keep their parts in relative positions that are tolerably constant. The explanation of these exceptions is not manifest. It is only when we take into account certain inıcident actions liable to be left unremembered, that we find a probable solution. It will be most convenient to postpone the consideration of these cases until we have reached the general rule to which they are exceptions.

§ 234. Transitions varying in degree from the radial towards the bilateral, are common in flowers that are borne at the ends of branches or axes which are inclined in tolerably constant ways, We may see this in sundry garden flowers
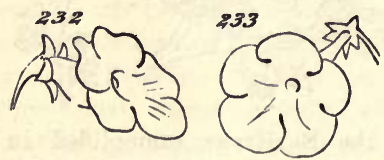

such as Petunia, or such as Isoloma and Achimenes, shown in Figs. 232 and 233. If these plants be examined, it will be perceived that the mode of growth makes the flower unfold in a partially one- 
sided position; that its parts of attachment have rigidity sufficient to prevent this attitude from being very much interfered with; and that though the individual flowers vary somewhat in their attitudes, they do not vary to the extent of neutralizing the differentiating conditions-there remains an average divergence from a horizontal unfolding of the flower, to account for its divergence from radial symmetry.

We pass insensibly from forms like these, to forms having bilateral symmetry strongly pronounced. Some such forms occur among flowers that grow at the ends of upright stems; as in Pinguicula, and in the Violet tribe. But this happens only where, in successive generations, the flower unfolds its parts sideways in constant relative positions. And in the immense majority of flowers having well-marked two-sided forms, the habitual exposure of the different parts to different sets of forces, is effectually secured by the mode of placing. As illustrations, I may name the genera-Orchis, Utricularia, Salvia, Salix, Delphinium, Mentha, Teucrium, Ajuga, Ballota, Galeopsis, Lamium, Stachys, Nepeta, Marrubium, Calamintha, Melittis, Prunella, Scutellaria, Bartsia, Euphrasia, Rhinanthus, Melampyrum, Pedicularis, Linaria, Digitalis, Orobanche, Fumaria, \& $c$.; to which may be added all the Grasses and all the Papilionacea. In most of these cases the flowers, being sessile on the sides of upright stems, are kept in quite fixed attitudes; and in the other cases the peduncles are very short, or else stiff enough to secure general uniformity in the positions. A few of the more marked types are shown in Figs. 234 to 241.

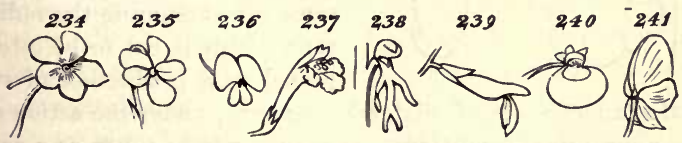

Very instructive evidences here meet us. Sometimes within the limits of one genus we find radial flowers, bilateral flowers, and flowers of intermediate characters. The genus 
Begonia may be instanced. In B. rigida the flowers, various in their attitudes, are in their more conspicuous characters radial: though there is a certain bilateralness in the calyx, the five petals are symmetrically disposed all round. $B$. Wageneriana furnishes two forms of flowers. On the same individual plant may be found radial flowers like Fig. 242, and others, like Fig. 243, which are merging into the bilateral. More decided is the bilateralness in B. albo-coccinea, Fig. 244; and still more in B. nitida, Fig. 245. While in B. heraclei-
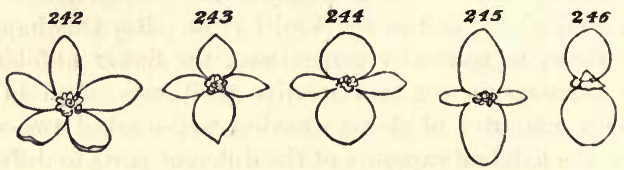

folia, Fig. 246, the change reaches its extreme by the disappearance of the lateral petals. On examining the modes of growth in these several species, they will be seen to explain these changes in the manner alleged.

Even more conclusive are the nearly-allied transformations occurring in artificially-produced varieties of the same species. Gloxinia may be named in illustration. In Fig. 247 is represented one of the ordinary forms, which shows us bilateralness of shape along with a mode of growth that renders the conditions alike on the two sides while different above and below.

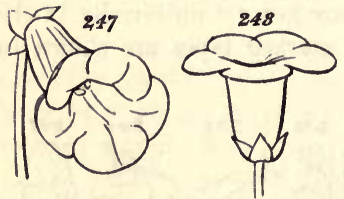

But in G. erecta, Fig. 248, we have the flower assuming an upright attitude, and at the same time assuming the radial type. This is not to be interpreted as a production of radial symmetry out of bilateral symmetry, under the action of the appropriate conditions. It is rather to be taken as a case of what is termed "peloria"-a reversion to the primitive radial type, from which the bilateral modification had been derived. The significant inference to be drawn from it is, 
that this primitive radial type had an upright attitude; and that the derivation of a bilateral type from it, occurred along with the assumption of an inclined attitude.

We come now to a group of cases above referred to, in which radial symmetry continues to co-exist with that constant lateral attitude ordinarily accompanied by the twosided form. Two examples will suffice: one a very large flower, the Hollyhock, and the other a very small flower, the Agrimony. Why does the radial form here remain unchanged? and how does its continuance consist with the alleged general law?

Until quite recently I have been unable to find any probable answers to these questions. When the difficulty first presented itself, I could think of no other possible cause for the anomaly, than that the parts of the Hollyhock-flower, unfolding spirally as they do, might have different degrees of spiral twist in different flowers, and might thus not be unfolded in sufficiently-constant positions. But this seemed a questionable interpretation; and one which did not obviously apply to the case of the Agrimony. It was only on inquiring what are the special causes of modifications in the forms of flowers, that a more feasible explanation suggested itself; and this would probably never have suggested itself, had not Mr. Darwin's investigations into the fertilization of Orchids led me to take into account an unnoticed agency.

The actions which affect the forms of leaves, affect much less decidedly the forms of flowers; and the forms of flowers are influenced by actions which do not influence the forms of leaves. Partly through the direct action of incident forces and partly through the indirect action of natural selection, leaves get their parts distributed in ways that most facilitate their assimilative functions, under the circumstances in which they are placed; and their several types of symmetry are thus explicable. But in flowers, the petals and fructifying organs of which do not contain chlorophyll, the tendency to grow most where the supply of light is greatest, is less decided, if 
not absent; and a shape otherwise determined is hence less liable to alter in consequence of altered relations to sun and air. Gravity, too, must be comparatively ineffective in causing modifications: the smaller sizes of the parts, as well as their modes of attachment, giving them greater relative rigidity. Not, indeed, that these incident forces of the inor-

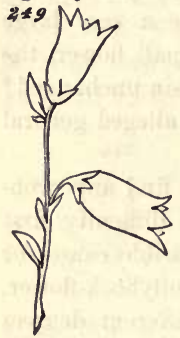
ganic world are here quite inoperative. Fig. 249, representing a species of Campanula, shows that the developments of individual flowers are somewhat modified by the relations of their parts to general conditions. But the fact to be observed is, that the extreme transformations which flowers undergo are not likely to be thus caused: some further cause must be sought. And if we bear in mind the functions of flowers, we shall find in their adaptations to these functions, under conditions that are extremely varied, an adequate cause for the different types of symmetry, as well as for the exceptions to them. Flowers are parts in which fertilization is effected; and the active agents of this fertilization are insects-bees, moths, butterflies, \&c. Mr. Darwin has shown in many cases, that the forms and positions of the essential organs of fructification, are such as to facilitate the actions of insects in transferring pollen from the anthers of one flower to the pistil of another-an arrangement produced by natural selection. And here we shall find reason for concluding, that the forms and positions of those subsidiary parts which give their shapes to flowers, similarly arise by the survival of individuals which have the subsidiary parts so adjusted as to aid this fertilizing process-the deviations from radial symmetry being among such adjustments. The reasoning is as follows. So long as the axis of a flower is vertical and the conditions are similar all round, a bee or butterfly alighting on it, will be as likely to come from one side as from another; and hence, hindrance rather than facilitation would 
result if the several sides of the flower did not afford it equally free access. In like manner, flowers which are distributed over a plant in such ways that their dises open out on planes of all directions and inclinations, will have no tendency to lose their radial symmetry; since, on the average, no part of the periphery is differently related to insectagency from any other part. But flowers so fixed as to open out sideways in tolerably-constant attitudes, have their petals differently related to insect-agency. A bee or butterfly coming to a laterally-growing flower, does not settle on it in one way as readily as in another; but almost of necessity settles with the axis of its body inclined upwards towards the stem of the plant. Hence the side-petals of a flower so fixed, habitually stand to the alighting insect in relations different from those in which the upper and lower petals stand; and the upper and lower petals differ from one another in their relations to it. If, then, there so arises an habitual attitude of the insect towards the petals, there is likely to be some arrangement of the petals that will be most convenient to the insect-will most facilitate its entrance into the flower. Thus we see in many cases, that a long undermost petal or lip, by enabling the insect to settle in such way as to bring its head opposite to the opening of the tube, aids its fertilizing agency. But whatever be the special modifications of the corolla which facilitate the actions of the particular insects concerned, all of them will conduce to bilateral symmetry; since they will be alike for the two sides but unlike for the top and bottom.

And now we are prepared for understanding the exceptions. Flowers growing sideways can become thus adapted by survival of the fittest, only if they are of such sizes and structures that insect-agency can affect them in the way described. But in the plants named above, this condition is not fulfilled. A Hollyhock-flower is so open, as well as so large, that its petals are not in any appreciable degree differently related to the insects which visit it. On the other hand, the flower of the 
Agrimony is so small, that unless visited by insects of a corresponding size which settle as bees and butterflies settle, its parts will not be affected in the alleged manner. That all anomalies of this kind can at once be satisfactorily explained, is scarcely to be expected: the circumstances of each case have to be studied. But it seems not improbable that they are due to causes of the kind indicated.*

$\S 235$. We have already glanced at clusters of flowers for the purpose of considering their shapes as clusters. We must now return to them to observe the modifications undergone by their component flowers. Among these occur illustrations of great significance.

An example of transition from the radial to the bilateral form in clustered flowers of the same species, is furnished by the cultivated Geraniums, called by florists Pelargoniums. Some of these, bearing somewhat small terminal clusters of flowers, which are closely packed together with their faces almost upwards, have radially-symmetrical flowers. But among other varieties having terminal clusters of which the members are mutually thrust on one side by crowding, the flowers depart very considerably from the radial shape

* It is objected to the above interpretation that "many flowers of sizes intermediate between the Hollyhock and the Agrimony are radially symmetrical and yet grow sideways. I may mention various Liliacex, e.g. CHo. rophytum, Eucomis, Muscari, Anthericum. Sagittaria, also, has many of its flowers in this position. Further, if the higher insects alight on flowers in a definite way. as they do, the parts of the flower must bear different relations to the visiting insect, however large, so that flowers unvisited ought all to be zygomorphic." My reply is that in the sense which here concerns us, the different petals of the Hollyhock-flower do not bear different relations to the visiting insect; since, practically, the upper and lateral petals bear no physieal relations at all: in so far as the visiting bee is concerned they are non-existent. The argument implics that change in the form of a flower from the radial to the bilateral is likely to take place only when the contact-relations of the petals to the visiting insect, are such as to make some forms facilitate its action more than others; and the large petals of the Hollyhock cannot facilitate its action at all. In respect of the Liliacces instanced, it is needful to inquire whether the structures are such that this alleged cause of bilateral symmetry can come into play. 
towards the bilateral shape. A like result occurs under like conditions in Rhododendrons and Azaleas. The Verbena, too, furnishes an illustration of radial flowers rendered slightly two-sided by the slight two-sidedness of their relations to other flowers in the cluster. And among the Crucifera a kindred case occurs in the cultivated Candytuft.

Evidence of a somewhat different kind is offered us by clustered flowers in which the peripheral members of the clusters differ from the central members; and this evidence is especially significant where we find allied species that do not exhibit the deviation, at the same time that they do not fulfil the conditions under which it may be expected. Thus, in Scabiosa succisa, Fig. 250, which bears its numerous small flowers in a hemispherical knob, the component flowers, similarly circumstanced, are all equal and all radial; but in Scabiosa arvensis, Fig. 251, in which the numerous small flowers form a flattened disk only the confined central ones are radial: round the edge the flowers are much larger and conspicuously bilateral.

But the most remarkable
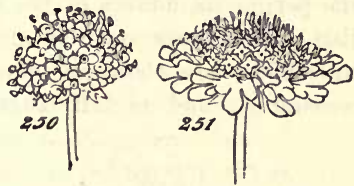
and most conclusive proofs of these relations between forms and positions, are those given by the clustered flowers called Umbelliferce. In some cases, as where the component flowers have all plenty of room, or where the surface of the umbel is more or less globular, the modifications are not conspicuous; but where, as inViburnum, Charophyllum, Anthriscus, Torilis, Caucalis, Daucus, Tordylium, \&c., we have flowers clustered in such ways as to be differently conditioned, we find a number of modifications that are marked and varied in proportion as the differences of conditions are marked and varied. In Charophyllum, where the flowers of each umbellule are closely placed so as to form a flat surface, but where the umbellules are wide apart and form a dispersed umbel, the umbellules do not differ from one another; though among the 
flowers of each umbellule there are decided differences: the central flowers being small and radial, while the peripheral ones are large and bilateral. But in other genera, where not only the flowers of each umbellule but also the umbellules themselves, are closely clustered into a flat surface, the umbellules themselves become contrasted; and many remarkable secondary modifications arise. In an umbel of Heracleum, for instance, there are to be noted the facts;--first, that the external umbellules are larger than the internal ones; second, that in each umbellule the central flowers are less developed than the peripheral ones; third, that this greater development of the peripheral flowers is most marked in the outer umbellules; fourth, that it is most marked on the outer sides of the outer umbellules; fifth, that while the interior flowers of each umbellule are radial, the exterior ones are bilateral; sixth, that this bilateralness is most marked in the peripheral flowers of the peripheral umbellules; seventh, that the flowers on the outer sides of these peripheral umbellules are those in which the bilateralness reaches a maximum; and eighth, that where the outer umbellules

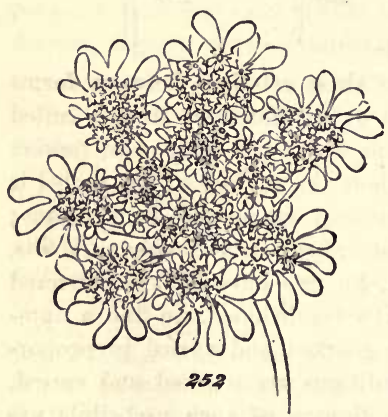
touch one another, the flowers, being unsymmetrically placed, are unsymmetrically bilateral.* The like modifications are displayed, though not in so clearly-traceable a way, in an umbel of Tordylium, Fig. 252. Considering how obviously these various forms are related to the various conditions, we should be scarcely able, even in the

* I had intended here to insert a figure exhibiting these differencea; but as the Cow-parsnip does not flower till July, and as I can find no drawing of the umbel which adequately represents its details, I am obliged to take another instance. 
absence of all other facts, to resist the conclusion that the differences in the conditions are the causes of the differences in the forms.

Composite flowers furnish evidence so nearly allied to that which clustered flowers furnish, that we may fitly glance at them under the same head. Such a common type of this order as the Sun-flower, exemplifies the extremely marked difference which arises in many of these plants between the closely-packed internal florets, each similarly circumstanced on all sides, and the external florets, not similarly circumstanced on all sides. In Fig. 253, representing the inner and outer florets of a Daisy, the contrast is

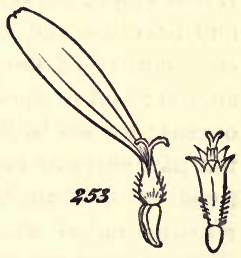
marked between the small radial corolla of the one and the larger bilateral corolla of the other. In many cases, however, this contrast is less marked: the inner florets also having their outward-growing prolongations-a difference possibly related to some difference in the habits of the insects that fertilize them. Nevertheless, these composite flowers which have inner florets with strap-shaped corollas outwardly directed, equally conform to the general principle; both in the radial arrangement of the assemblage of florets, and in the bilateral shape of each floret; which has its parts alike on the two sides of a line passing from the centre of the assemblage to the circumference.

Certain other members of this order fulfil the law somewhat differently. In Centaurea, for instance, the inner florets are small and vertical in direction, while the outer florets are large and lateral in direction. And here may be remarked, in passing, a clear indication of the effect which great flexibility of the petals has in preventing a flower from losing its original radiate form; for while in $C$. cyanus, the large outward-growing florets, having short, stiff divisions of the corolla, are decidedly bilateral, in $C$. scabiosa, where the divisions of the 
corolla are long and flexible, the radial form is scarcely at all modified. On bearing in mind the probable relations of the forms to insect-agency, the meaning of this difference will not be difficult to understand.*

$\S 236$. In extremely-varied ways there are thus re-illustrated among flowers, the general laws of form which leaves and branches and entire plants disclose to us. Composed as each cluster of flowers is of individuals that are originally similar; and composed as each flower is of homologous foliar organs; we see both that the like flowers become unlike and the like parts of each flower become unlike, where the positions involve unlike incidence of forces. The symmetry remains radial where the conditions are equal all round; shows deviation towards two-sidedness where there is slight two-sidedness of conditions; becomes decidedly bilateral where the conditions are decidedly bilateral; and passes into an unsymmetrical form where the relations to the environment are unsymmetrical.

* It has been pointed out to me that "the extreme development of the corolla so often found in the outer flowerg or on the outer side of the outer flowers in elosely packed inflorescences, associated as it often is with disappearance of stamens or carpels or both, is usually put down to specialization of these outer flowers for attractive purposes. Since the whole inflorescence is increased in conspicuousness by such a modification, it is supposed that natural selection favoured those plants which sacrificed a portion of their seed-bearing capacity for the supposed greater advantage of sccuring more insect visits." But granting this interpretation, it may still be held that increase of attractiveness due to increase of area must be achieved by florets at the periphery, and that their ability to achieve it depends on their having an outer, unoccupied, space which the inner florets have not; so that, though in a more indirect way, their different development is determined by different exposure to conditions. 


\section{CHAPTER XI.}

THE SHAPES OF VEGETAL CELLS.

$\S 23 \%$. WE come now to aggregates of the lowest order. Already something has been said $(\S 217)$ concerning the forms of those morphological units which exist as independent plants. But it is here requisite briefly to note the modifications undergone by them where they become components of larger plants.

Of the numerous cell-forms which are found in the tissues of the higher plants, it will suffice to give, in Fig. 254, representing a section of a leaf, a single example. In this it will be seen that the cells forming the upper and lower sur- $e$ faces, $a$ and $b$, have differences of shape related $d$ to differences in the inci- $b$ dence of forces: they are more or less flattened in

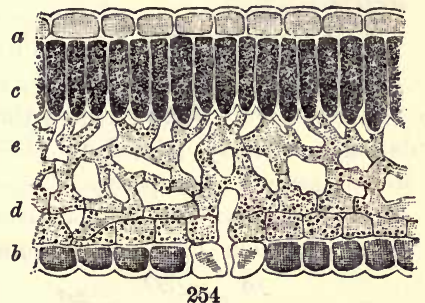

254 relation to the environment. The underneath cells at $c$, form a class which, similarly exposed to light at their outer ends, and, as we may assume, largely developed in adjustment to their active assimilative functions, are, by mutual pressure, made to grow more in the direction of their lengths than in the direction of their breadths. Then on the other side we see that the cells $d$, next above the outer layer, while approximately similar, become more and more dissimilar as they diverge from the surface, ard are quite 
irregular in the interior $e$, where there is no definiteness in the conditions to which they are exposed. Thus the divergences of these cells from primordial sphericity are such as correspond with unlikenesses in their circumstances. And throughout the more complex modifications which the cells of other tissues exhibit, the like correspondences hold.

Among plants of a lower order of aggregation, we have already seen how cells become metamorphosed as they become integrated into masses having definite organizations. The higher Alga, exemplified in Figs. 32, 34, 35, show this very

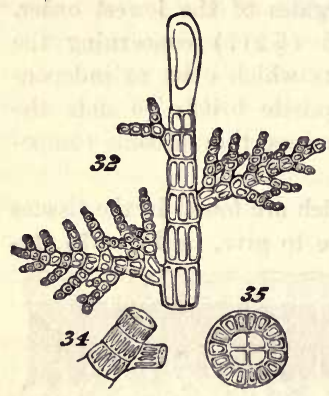
clearly. Here the departure from the simple cell-form to the form of an elongated prism, is manifestly subordinated to the contrasts in the relations of the parts. And it is interesting to observe how, in one of the branches of Fig. 32, we pass from the small, almost-spherical cells which terminate the branchlets, to the large, much-modified cells which join the main stem, through gradations obviously related in their changed forms to the altered actions their positions expose them to.

More simply, but quite as conclusively, do the inferior Alga, of which Figs. 19-23 are examples, show us how

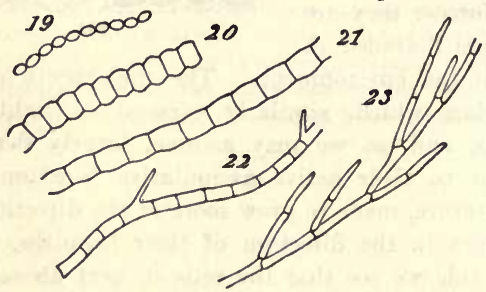

cells pass from their original spherical symmetry into radial symmetry, as they pass from a state in which they are simi- 
larly-conditioned on all sides, to a state in which two of their opposite sides or ends are conditioned in ways that are like one another, but unlike the ways in which all other sides are conditioned.

Still more instructive are the morphological differentiations of those protophytes in which the first steps towards a higher degree of integration are shown. In Fig. 10, representing one of the transitional forms of Desmidiacere, it is to be noted that besides the difference between the transverse and longitudinal dimensions, which the component units display in common, the two end-units differ from the rest: they have

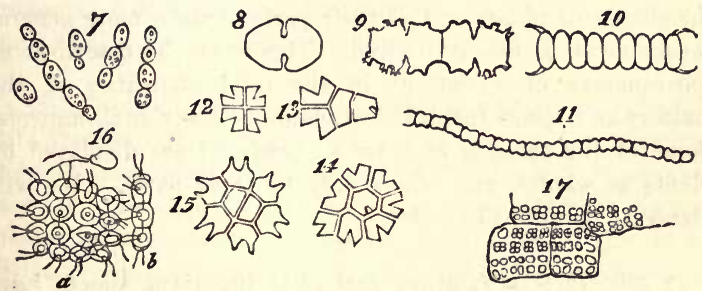

appendages which the rest have not. Once more, where the integration is carried on in such ways as to produce not strings but clusters, there arise contrasts and correspondences just such as might be looked for. All the four members of the group shown in Fig. 12, are similarly conditioned; and each of them has a bilateral shape answering to its bilateral relations. In Fig. 14 we have a number of similarly-bilateral individuals on the circumference, including a central individual differing from the rest by having the bilateral character nearly obliterated. And then, in Fig. 15, we have two central components of the group, deviating more decidedly from those that surround them.*

* One of my critics writes:- "This chapter might of course be enormously extended. not only as in the preceding ones by citation of quite similar cases, but by the introduction of fresh groups of cases." 


\section{CHAPTER XII.}

CHANGES OF SHAPE OTHERWISE CAUSED.

$\S 238$. Besides the more special causes of modification in the shapes of plants and of their parts, certain more general causes must be briefly noticed. These may be described as consequences of variations in the total quantities of the matters and forces furnished to plants by their environments. Some of the changes of form so produced are displayed by plants as wholes, and others only by their parts. We will glance at them in this order.

$\S 239$. It is a familiar fact that luxuriant shoots have relatively-long internodes; and, conversely, that a shoot dwarfed from lack of sap, has its nodes closely clustered: a concomitant result being that the lateral axes, where these are developed, become in the one case far apart and in the other case near together. Fig. 255 represents a branch to

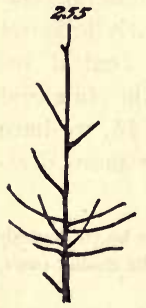
the parts of which the longer and shorter internodes so resulting give differential characters. A whole tree being in many cases simultaneously thus affected by states of the earth or the air, all parts of it may have such variations impressed on them; and, indeed, such variations, following more or less regularly the changes of the seasons, give to many trees manifest 
traits of structure. In Fig. 256, a shoot of Phyllocactus crenatus, we have an interesting example of a variation essentially of the same nature, little as it appears to be so. For each of the lateral indentations is here the seat of an axillary bud; and these we see are separated by internodes which, becoming broader as they become longer, and narrower as they become shorter, produce changes of form that correspond with changes in the luxuriance of growth.

To complete the statement it must be added that these variations of nutrition often determine the development or non-development of lateral axes; and by so doing cause still more marked structural differences. The Fox-glove may be named as a plant which illustrates this truth.*

$\S 240$. From the morphological differentiations caused by unlikenesses of nutrition felt by the whole plant, we pass now to those which are thus caused in some of its parts and not in others. Among such are the contrasts between flowering axes, and the axes that bear leaves only. It has already been shown in $\S 78$, that the belief expressed by Wolff in a direct connexion between fructification and innutrition, is justified inductively by many facts of many kinds. Deductively too, in $\S 79$, we saw reason to conclude that such a relation would be established by survival of the fittest; seeing that it would profit a species for its members to begin sending off migrating germs from the ends of those axes which innutrition prevented from further agamogenetic multiplication. Once more, when considering the nature of the phænogamic axis, we found support for this belief in the fact

* Natural selection may have operated in establishing a constitutional tendency to other sudden abridgments. Mr. Tansley alleges that this is a part-cause of the varying distribution of leaves. He says:-“ "I have myself made some observations on the length of internodes in the Beech, and am satisfied that it follows quite other laws, connected with the suitable disposition of the leaves on the branch. Although I have not had the opportunity of following up this line of work so as in any way to generalize the results, I suspect that 'indirect equilibration' is a widespread cause of such variation." 
that the components of a flower exhibit a reversion to that type from which the phænogamic type has probably arisena reversion which the laws of embryology would lead us to look for where innutrition had arrested development.

Hence, then, we may properly count those deviations of structure which constitute inflorescence, as among the morphological differentiations produced by local innutrition. I do not mean that the detailed modifications which the essential and subservient organs of fructification display, are thus accounted for: we have seen reason to think them otherwise caused. But I mean that the morphological characters which distinguish gamogenetic axes in general from agamogenetic axes, such as non-development of the internodes and dwarfing of the foliar organs, are primarily results of failure in the supply of some material required for further growth.*

$\S 241$. Another trait which has to be noticed under this head, is the spiral, or rather the helical, arrangement of parts. The successive nodes of a phænogam habitually bear their appendages in ways implying more or less twist in the substance of the axis; and in climbing plants the twist is such

* It is but just to the memory of Wolff, here to point out that he was immensely in advanec of Goethe in his rationale of these metamorphoses. Whatever greater elaboration Gocthe gave to the theory considered as an induction, seems to me more than counter-balanced by the irrationality of his deductive interpretation; which unites mediæval physiology with Platonic philosophy. A dominant idea with him is that leaves exist for the purpose of carrying off crude juices - that " as long as there are crude juices to be carried of, the plant must be provided with organs competent to effect the task"; that while "the less pure fluids are got rid of, purer ones are introduced" and that "if nourishment is withheld, that operation of nature (flowering) is facilitated and hastencd; the organs of the nodes (leaves) become more refined in texture, the action of the purified juices becomes stronger, and the transformation of parts laving now become possible, takes place without delay." This being the proximate explanation, the ultimate explanation is, that Nature wishes to form flowers-that when a plant flowers it "attains the end prescribed to it by nature"; and that so "Nature-at length attains her object." Instead of vitiating his induction by a teleology that is as unwarranted in its assigned object as in its assigned means, Wolff ascribes the phenomena to a cause which, whether sufficient or not, is strictly scientific in 
as to produce a corkscrew shape. This structure is ascribable to differences of interstitial nutrition. Take a shoot which is growing vertically. It is clear that if the molecules are added with perfect equality on all sides, there will be no tendency towards any kind of lateral deviation; and the successively-produced parts will be perpendicularly over one another. But any inequality in the rate of growth on the different sides of the shoot, will destroy this straightness in the lines of growth. If the greatest and least rates of molecular increase happen to be on opposite sides, the shoot must assume a curve of single curvature; but in every other case of unequal molecular increase, a curve of double curvature must result. Now it is a corollary from the instability of the homogeneous, that the rates of growth on all sides of a shoot can never be exactly alike; and it is also to be inferred from the same general law, that the greatest and least rates of growth will not occur on exactly opposite sides of the shoot, at the same time that equal rates of growth are preserved by the two other sides. Hence, there must almost inevitably arise more or less of twist ; and the appendages of the internodes will so be prevented from occurring perpendicularly one over another.

A deviation of this kind, necessarily initiated by physical causes in conformity with the general laws of evolution, is likely to be made regular and decided by natural selection. For under ordinary circumstances, a plant profits by having its axis so twisted as to bring the appended leaves into positions which prevent them from shading one another. And, manifestly, modifications in the forms, sizes, and insertions of the leaves, may, under the same agency, lead to adapted modifications of the twist. We must therefore ascribe this common characteristic of phænogams, primarily to local differences of nutrition, and secondarily to survival of the fittest.

its character. Variation of nutrition is unquestionably a "true cause" of variation in plant-structure. We have here no imaginary action of a fictitious agency; but an ascertained action of a known agency. 
It is proper to add that there are some Monocotyledons, as Ravenala madagascariensis, in which this character does not occur. What conditions of existence they are that here hold this natural tendency in check, it is not easy to see.*

* The Natural History Review for July, 1865, contained an article on the doctrine of morphological composition set forth in the foregoing Chaps. I. to III. In this article, which unites exposition and criticism in a way that is unhappily not common with reviewers, it is suggested that the spiral structure may be caused by natural selection. When this article appeared, the foregoing five pages were standing over in type, as surplus from No. 14, issued in June, 1865. 


\section{CHAPTER XIII.}

\section{MORPHOLOGICAL DIFFERENTIATION IN ANIMALS.}

§ 242. THE general considerations which preluded our inquiry into the shapes of plants and their parts, equally serve, so far as they go, to prelude an inquiry into the shapes of animals and their parts. Among animals, as among plants, the formation of aggregates greater in bulk or higher in degree of composition, or both; is accompanied by changes of form in the aggregates as wholes as well as by changes of form in their parts; and the processes of morphological differentiation conform to the same general laws in the one kingdom as in the other.

It is needless to recapitulate the several kinds of modification to be explained, and the several factors that cooperate in working them. In so far as these are common to plants and animals, the preceding chapters have sufficiently familiarized them. Nor is it needful to specify afresh the several types of symmetry and their descriptive names; for what is true of them in the one case is true of them in the other. There is, however, one new and allimportant factor which we shall have now to take into account; and about this a few preliminary remarks are requisite.

$\S 243$. This new factor is motion-motion of the organism in relation to surrounding objects, or of the parts of the 
organism in relation to one another, or both. Though there are plants, especially of the simpler kinds, which move, and though a few of the simpler animals do not move; yet movements are so exceptional and unobtrusive in the one kingdom, while they are so general and conspicuous in the other, that the broad distinction commonly made is well warranted. What, among plants, is an inappreciable cause of morphological differentiation, becomes, among animals, the chief cause of morphological differentiation.

Rooted animals or animals otherwise fixed, of course present traits of structure nearest akin to those we have lately been studying. The motions of parts in relation to one another and to the environment, being governed by the mode of aggregation and mode of fixing, we are presented with morphological differentiations similar in their general characters to those of plants, and showing us parallel kinds of symmetry under parallel conditions. But animals which move from place to place are subject to an additional class of actions and reactions. These actions and reactions affect them in various ways according to their various modes of movement. Let us glance at the several leading relations between shape and motion which we may expect to find.

If an organism advances through a homogeneous medium with one end always foremost, that end, being exposed to forces unlike those to which the other end is exposed, may be expected to become unlike it; and supposing this to be the only constant contrast of conditions, we may expect an equal distribution of the parts round the axis of movementa radial symmetry. If, in addition to this habitual attitude of the ends, one surface of the body is always uppermost and another always lowermost, there arise between the top and bottom dissimilarities of conditions, while the two sides remain similarly conditioned. Hence it is inferable that such an organism will be divisible into similar halves by a vertical plane passing through its axis of motion-will have a bilateral symmetry. We may presume that this 
symmetry will deviate but little from double bilateralness where the upper and under parts are not exposed to stronglycontrasted influences; while we may rationally look for single bilateral symmetry of a decided kind, in creatures having dorsal and ventral parts conversant with very unlike regions of the environment: as in all cases where the movement is over a solid surface. If the movement, though over a solid surface, is not constant in direction, but takes place as often on one side as on another, radial symmetry may be again looked for; and if the motions are still more variously directed-if they are not limited to approximately-plane surfaces, but extend to surfaces that are distributed all around with a regular irregularity-an approach of the radial towards the spherical symmetry is to be anticipated.

Where the habits are such that the intercourse between the organism and its environment, does not involve an average equality of actions and reactions on any two or more sides, there may be expected either total irregularity or some divergence from regularity.

The like general relations between forms and incident forces are inferable in the component parts of animals, as well as in the animals as wholes. It is needless, however, to occupy space by descriptions of these. Let us now pass to the facts, and see how they confirm, à posteriori, the conclusions here reached à priori. 


\section{CHAPTER XIV.}

\section{THE GENERAL SHAPES OF ANIMALS.}

§244. Certain of the Protozoa are quite indefinite in their shapes, and quite inconstant in those indefinite shapes which they have-the relations of their parts are indeterminate both in space and time. In one of the simpler Rhizopods, at least during the active stage of its existence, no permanent distinction of inside and outside is established; and hence there can arise no established correspondence between the shape of the outside and the distribution of environing actions. But when the relation of inner and outer becomes fixed, either over part of the mass or over the whole of it, we have kinds of symmetry that correspond with the habitual incidence of forces. An Amøba in becoming encysted, passes from an indefinite, ever-changing form into a spherical form; and the order of symmetry which it thus assumes, is in harmony with the average equality of the actions on all its sides. In Diffugia, Fig. 134, and still better in Arcella, we have an indefinitely-radial symmetry occurring where the conditions are different above and below but alike all around. Among the Gregarinida the spherical symmetry and symmetry passing from that into the radial, are such as appear to be congruous with the simple circumstances of these creatures in the intestines of insects. But the relations of these lowest types to their environments are comparatively so indeterminate, and our knowledge of their actions so 
scanty, that little beyond negative evidence can be expected from the study of them.
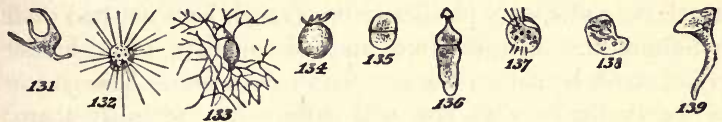

The like may be said of the Infusoria. These are more or less irregular. In some cases, where the line of movement through the water is tolerably definite and constant, we have a form that is approximately radial-externally at least. But usually, as shown in Figs. 137, 138, 139, there is either an unsymmetrical or an asymmetrical shape. And when one of these creatures is watched under the microscope, the congruity of this shape with the incidence of forces is manifest. For the movements are conspicuously varied and indeterminate-movements which do not expose any two or more sides of the mass to approximately equal sets of actions.*

$\S 245$. Among aggregates of the second order, as among aggregates of the first order, we find that of those possessing any definite shapes the lowest are spherical or spheroidal. Such are some of the Radiolaria, as Collozoum inerme. These bodies which float passively in the sea, and present in turn all their sides to the same influences, have their parts disposed with approximate regularity round a centre-approximate, because in the absence of locomotion a slight irregularity of growth, almost certain to take place, may cause a fixed attitude and a resulting deviation from spherical symmetry. The best cases in illustration of the truth here named, are furnished by rotating and locomotive organisms respecting which there is a dispute whether they are animal or vegetal-the Volvocinece. These, already instanced under

* A verifying comment on this paragraph runs as follows:- "In the Hypotricha Infusoria, which creep over solid surfaces, there is a differentiation between ventral and dorsal surface and nn approach to bilateral symmetry. The ventral surface is provided with movable cilia, the dorsal with immobile setæ." 
the one head in $\S 218$, may here be instanced afresh under the other. Further, among these secondary aggregates in which the units, only physically integrated, have not had their individualities merged into an individuality of a higher order, must be named the compound Infusoria. The cluster of Vorticella in Fig. 144, will sufficiently exemplify them; and the striking resemblance borne by its individuals to those of a radially-arranged cluster of flowers, will show how, under analogous conditions, the general principles of morphological differentiation are similarly illustrated in the two kingdoms.

$\S 246$. Radial symmetry is usual in low aggregates of the second order which have their parts sufficiently differentiated and integrated to give individualities to them as wholes. The Colenterata offer numerous examples of this. Solitary polypes-hydroid or helianthoid-mostly stationary, and when they move, moving with any side foremost, do not by locomotion subject their bodies to habitual contrasts of conditions. Seated with their mouths upwards or downwards, or else at all degrees of inclination, the individuals of a species taken together, are subject to no mechanical actions affecting some parts of their dises more than other parts. And this indeterminateness of attitude similarly prevents their relations to prey from being such as subject some of their prehensile organs to forces unlike those to which the rest are subject. The fixed end is differently conditioned from the free end, and the two are therefore different; but around the axis running from the fixed to the free end the conditions are alike in all directions, and the form therefore is radial. Again, among many of the simple freeswimming Hydrozoa, the same general truth is exemplified under other circumstances. In a common Medusa, advancing through the water by the rhythmical contractions of its disc, the mechanical reactions are the same on all sides; and as, from accidental causes, every part of the edge of the disc 
comes uppermost in its turn, no part is permanently affected in a different way from the rest. Hence the radial form continues.

In others of this same group, however, there occur forms which show us an incipient bilateralness; and help us to see how a more decided bilateralness may arise. Sundry of the Medusida are proliferous, giving origin to gemmæ from the body of the central polypite or from certain points on the edge of the disc; and this budding, unless it occurs equally on all sides, which it does not and is unlikely to do, must tend to destroy the balance of the disc, and to make its attitude less changeable. In other cases the growth of a large process [a much-developed tentacle] from the edge of the disc on one side, as in Steenstrupia, Fig. 25\%, constitutes a similar modification, and a cause of further modification. The animal is no longer divisible into any two quite similar halves, except those formed by a plane passing through the process; and unless the process is of the same specific gravity as the disc, it must tend towards either the lowest or the highest point, and must so serve to increase the bilateralness, by keeping the two sides of the disc similarly conditioned while the top and bottom are differently conditioned. Fig. 258 represents the underside of another Medusa, in which a more decided bilateralness is produced by the presence of two such processes. Among the simple free-swimming Actinozoa, occur like deviations from radial symmetry, along with like motions through the water in bilateral attitudes. Of this a Cydippe is a familiar example. Though radial in some of its characters, as in the distribution of its meridi-

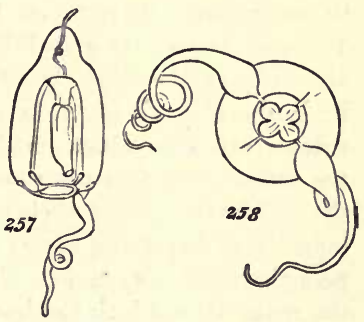
onal bands of locomotive paddles with their accompanying canals, this creature has a two-sided distribution of tentacles 
and various other parts, corresponding with its two-sided attitude in moving through the water. And in other genera of this group, as in Cestum, Eurhamphoca, and Callianira, that almost equal distribution of parts which characterizes the Beroe is quite lost.

Here seems a fit place to meet the objection which some may feel to this and other such illustrations, that they amount very much to physical truisms. If the parts of a Medusa are disposed in radial symmetry round the axis of motion through the water, there will of course be no means of maintaining one part of its edge uppermost more than another; and the equality of conditions may be ascribed to the radiateness, as much as the radiateness to the equality of conditions. Conversely, when the parts are not radially arranged around the axis of motion, they must gravitate towards some one attitude, implying a balance on the two sides of a vertical plane -a bilateralness; and the two-sided conditions so necessitated, may be as much ascribed to the bilateralness as the bilateralness to the two-sided conditions.

Doubtless the form and the conditions are, in the way alleged, necessary correlates; and in so far as it asserts this, the objection harmonizes with the argument. To the difficulty which it at the same time raises by the implied questionWhy make the form the result of the conditions, rather than the conditions the result of the form? the reply is this:The radial type, both as being the least differentiated type and as being the most obviously related to lower types, must be taken as antecedent to the bilateral type. The individual variations which incidental circumstances produce in the radial type, will not cause divergence of a species from the radial type, unless such variations give advantages to the individuals displaying them; which there is no reason to suppose they will always do. Those occasional deviations from the radial type, which the law of the instability of the homogeneous warrants us in cxpecting to take place, will, however, in some cases be beneficial; and will then be likely to estab- 
lish themselves. Such deviations must tend to destroy the original indefiniteness and variability of attitude-must cause gravitation towards an habitual attitude. And gravitation towards an habitual attitude having once commenced, will continually increase, where increase of it is not negatived by adverse agencies: each further degree of bilateralness rendering more decided the actions that conduce to bilateralness. If this reply be thought insufficient, it may be enforced by the further one, that as, among plants, the incident forces are the antecedents and the forms the consequents (changes of forces being in many cases visibly followed by changes of forms) we are warranted in concluding that the like order of cause and effect holds among animals.*

$\S 247$. Keeping to the same type but passing to a higher degree of composition, we meet more complex and varied illustrations of the same general laws. In the compound

* Criticisms on the above passage have shown the need for naming sundry complications. These complications chiefly, if not wholly, arise from changes in modes of life-changes from the locomotive to the stationary, and from the stationary to the locomotive. Referring to my statement that (ignoring the spherical) the radial type is the lowest and must be taken as antecedent to the bilateral type, it is alleged that all existing "radial animals above Protozoa are probably derived from freeswimming, bilaterally-symmetrical animals." If this is intended to include the planulæ of the hydroid polyps, then it seems rather a straining of the evidence. These locomotive embryos, described as severally having the structure of a gastrula with a closed mouth, can be said to show bilateralness only because the first two tentacles make their appearance on opposite sides of the mouth-a bilateralness which lasts only till two other tentacles make their appearance in a plane at right angles, so giving the radial structure. I think the criticism applies only to cases furnished by Echinoderms. The larvæ of these creatures have bilaterally-symmetrical structures, which they retain as long as they swim about and which such of them as fix themselves lose by becoming similarly related to conditions all round: the radial structure being retained by those types which, becoming subsequently detached, move about miscellaneously. But, as happens in some of the Sea-urchins and still more among the Holothurians, the structure is again made bilaterally-symmetrical by a locomotive life pursued with one end foremost. Should it be contended that the conditions and the forms are reciprocally influential-that either may initiate the other, it still remains unquestionable that ordinarily the conditions are the antecedents, as is 80 abundantly shown by plants. 
Colenterata, presenting clusters of individuals which are severally homologous with the solitary individuals last dealt with, we have to note both the shapes of the individuals thus united, and the shapes of the aggregates made up of them.

Such of the fixed Hydrozoa and Actinozoa as form branched societies, continue radial; both because their varied attitudes do not expose them to appreciable differences in their relations to those surrounding actions which chiefly concern them (the actions of prey), and because such differences, even if they were appreciable, would be so averaged in their effects on the dissimilarly-placed members of each group as to be

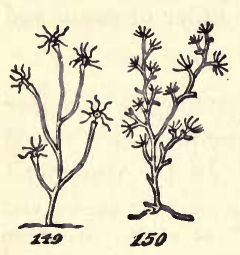
neutralized in the race. Among the treelike coral-polypedoms, as well as in such ramified assemblages of simpler polypes as are shown in Figs. 149, 150, we have, indeed, cases in many respects parallel to the cases of scattered flowers $(\S 233)$, which though placed laterally remain radial, because no differentiating agency can act uniformly on all of them. Meanwhile, in the groups which these united individuals compose, we see the shapes of plants further simulated under a further parallelism of conditions. The attached ends differ from the free ends as they do in plants; and the regular or irregular branches obviously stand to environing actions in relations analogous to those in which the branches of plants stand.

The members of those compound Colenterata which move through the water by their own actions, in attitudes that are approximately constant, show us a more or less distinct twosidedness. Diphyes, Fig. 259, furnishes an example. Each of the largely-developed and modified polypites forming its swimming sacs is bilateral, in correspondence with the bilateralness of its conditions; and in each of the appended polypites the insertion of the solitary tentacle produces a kindred divergence from the primitive radial type.

The aggregate, too, which here very much subordinates its mem- 
bers, exhibits the same conformity of structure to circumstances. It admits of symmetrical bisection by a plane passing through its two contractile sacs, or nectocalyces, but not

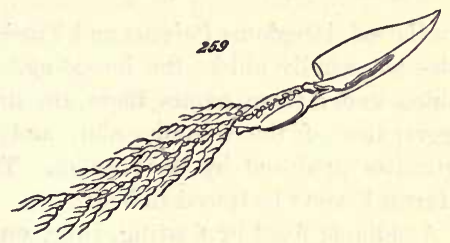

by any other plane; and the plane which thus symmetrically bisects it, is the vertical plane on the two sides of which its parts are similarly conditioned as it propels itself through the water.

Another group of the oceanic Hydrozoa, the Physophorida, furnishes interesting evidence-not so much in respect of the forms of the united individuals, which we may pass over, as in respect of the forms of the aggregates. Some of these are without swimming organs, and have their parts suspended from air-vessels which habitually float on the surface of the water. Hence the distribution of their parts is asymmetrical. The Physalia, Fig. 152, is an example. Here the relations of the integrated group of individuals to the environment are indefinite; and there is thus no agency tending to change that comparatively irregular mode of growth which is probably derived from a primordial type of the branched Hydrozoa.

So various are the modes of union among the compound Colenterata, that it is out of the question to deal with them all. Even did space permit, it would be impracticable for any one but a professed naturalist, to trace through-

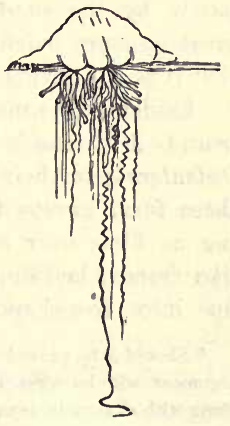


out this group the relations between shapes and conditions of existence. The above must be taken simply as a few of the most significant and easily-interpretable cases.

$\S 248$. In the sub-kingdoms Polyzoa and Tunicata we meet with examples not wholly unlike the foregoing. Among the types assembled under these names there are simple individuals or aggregates of the second order, and societies or tertiary aggregates produced by their union. The relations of forms to forces have to be traced in both.

Solitary Ascidians, fixed or floating, carry on an inactive and indefinite converse with the actions in the environment. Without power to move about vivaciously, and unable to catch any prey but that contained in the currents of water they absorb and expel, these creatures are not exposed to sets of forces which are equal on two or more sides; and their shapes consequently remain vague. Though internally their parts have a partially-symmetrical arrangement, due to their derivation, yet they are substantially unsymmetrical in that part of the body which is concerned with the environment. Fig. 156 is an example.* Among the composite Ascidians, floating and fixed, the shape of the aggregate, partly determined by the habitual mode of gemmation and partly by the surrounding conditions in each case, is in great measure indefinite. We can say no more about it than that it is not obviously at variance with the laws alleged.

Evidence of a more positive kind occurs among those compound Molluscoida which are most like the compound Colenterata in their modes of union-the Polyzoa. Many of these form groups that are more or less irregular-spreading as films over solid surfaces, combining into sea-weedlike fronds, budding out from creeping stolons, or growing up into tree-shaped societies; and besides aggregating

* Should it be proved that the Ascidian is a degraded vertebrate, then the argument will be strengthened; since loss of bilateral symmetry has gone along with change to asymmetrical conditions. 
irregularly they are irregularly placed on surfaces inclined in all directions. Merely noting that this asymmetrical distribution of the united individuals is explained by the absence of definiteness in the relations of the aggregate to incident forces, it concerns us chiefly to observe that the united individuals severally exemplify the same truth as do similarly-united individuals among the Colenterata. Averaging the members of each society, the ciliated tentacles they protrude are similarly related to prey on all sides; and therefore remain the same on all sides. This distribution of tentacles is not, however, without exception. Among the fresh-water Polyzoa there are some genera, as Plumatella and Crystatella, in which the arrangement of these parts is very decidedly bilateral. Some species of them show us such relations of the individuals to one another and to their surface of attachment, as give a clue to the modification; but in other species the meaning of this deviation from the radial type is not obvious.

$\S 249$. In the Platyhelminthes good examples of the connexions between forms and forces occur. The Planaria exemplifies the single bilateral symmetry which, even in very inferior forms, accompanies the habit of moving in one direction over a solid surface. Humbly organized as are these creatures and their allies the Nemertido, we see in them, just as clearly as in the highest animals, that where the movements subject the body to different forces at its two ends, different forces on its under and upper surfaces, and like forces along its two sides, there arises a corresponding form, unlike at its extremities, unlike above and below, but having its two sides alike.

The Echinodermata furnish us with instructive illustrations-instructive because among types that are nearly allied, we meet with wide deviations of form answering to marked contrasts in the relations to the environment. The facts fall into four groups.

The Crinoidea, once so abundant 
and now so rare, present a radial symmetry answering to an incidence of forces that are equal on all sides. In the general attitudes of their parts towards surrounding actions, they are like uniaxial plants or like polypes; and show, as those do, marked differences between the attached ends and the free ends, along with even distributions of parts all round their axes.

In the Ophiuridea, and in the Starfishes, we have radial symmetry co-existing with very different habits; but habits which nevertheless account for the maintenance of the form. Holding on to rocks and weeds by its simple or branched arms, or by the suckers borne on the under surface of its rays, one of these creatures moves about not always with one side foremost, but with any side foremost. Consequently, averaging its movements, its arms or rays are equally affected, and therefore remain the same on all sides.

On watching the ways of the common Sea-urchin, we are similarly furnished with an explanation of its spherical, or rather its spheroidal, figure. Here the habit is not to move over any one approximatelyflat surface; but the habit is to hold on by several surfaces on different sides at the same time. Frequenting crevices and the interstices among stones and weeds, the Sea-urchin protrudes the suckers arranged in meridional bands over its shell, laying hold of objects now on this side and now on that, now above and now below: the result being that it does not move in all directions over one plane but in all directions through space. Hence the approach in general form towards spherical symmetry-an approach which is, however, restrained by the relations of the parts to the mouth and vent: the conditions not being exactly the same at the two poles as at other parts of the surface. Still more significant is that deviation from this shape which occurs among such of the Echinidea as have habitats of a different kind, and consequently, different habits. The genera Echinocyamus, Spatangus, Brissus, and Amphidotus, diverge markedly towards a bilateral structure. These creatures are found not on rocky 
shores but on flat sea-bottoms, and some of them only on bottoms of sand or mud. Here, there is none of that distribution of surfaces on all sides which makes the spheroidal form congruous with the conditions. Having to move about over an approximately-horizontal plane, any deviation of structure arising accidentally which leads to one side being kept always foremost, will be an advantage: greater fitness to function becoming possible in proportion as function becomes fixed. Survival of the fittest will therefore tend to establish, under such conditions, a form that keeps the same part in advance- a form in which, consequently, the original radial symmetry diverges more and more towards bilateral symmetry.

$\S 250$. Very definite and comparatively uniform, are the relations between shapes and circumstances among the Annulosa: including under that title the Annelida and the Arthropoda. The agreements and the disagreements are equally instructive.

At one time or other of its life, if not throughout its life, every annulose animal is locomotive; and its temporary or permanent locomotion, being carried on with one end habitually foremost and one surface habitually uppermost, it fulfils those conditions under which bilateral symmetry arises. Accordingly, bilateral symmetry is traceable throughout the whole of this sub-kingdom. Traceable, we must say, because, though it is extremely conspicuous in the immense majority of annulose types, it is to a considerable extent obscured where obscuration is to be expected. The embryos of the Tubicolax, after swimming about a while, settle down and build themselves tubes, from which they protrude their heads; and in them, or in some of them, the bilateral symmetry is disguised by the development of head-appendages in an all-sided manner. The tentacles of Terebella are distributed much in the same way as those of a polype. The breathing organs in Sabella unispira, Fig. 260, do not corre- 
spond on opposite sides of a median plane. Even here, however, the body retains its primitive bilateralness; and it is further to be remarked that this loss of bilateralness in the external appendages, does not occur where the relations to external conditions continue bilateral: witness the Serpula, Fig. 261, which has its respiratory tufts arranged in a two-
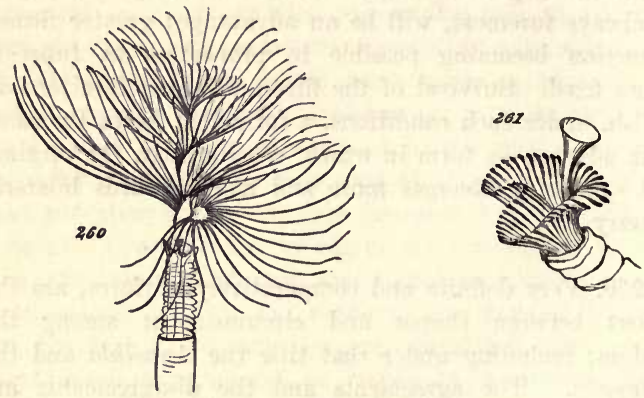

sided way, under the two-sided conditions involved by the habitual position of its tube.

The community of symmetry among the higher Annulosa, has an unobserved significance. That Flies, Beetles, Lobsters, Centipedes, Spiders, Mites, have in common the characters, that the end which moves in advance differs from the hinder end, that the upper surface differs from the under surface, and that the two sides are alike, is a truth received as a matter of course. After all that has been said above, however, it will be seen to have a meaning not to be overlooked; since it supplies a million-fold illustration of the laws which have been set forth. It is needless to give diagrams. Every reader can call to mind the unity indicated.

While, however, annulose animals repeat so uniformly these traits of structure, there are certain other traits in which they are variously contrasted; and their contrasts have to be here noted, as serving further to build up the general argument. In them we see the stages through which 
bilateral symmetry becomes gradually more marked, as the conditions it responds to become more decided. common Earth-worm may be instanced as a member of this sub-kingdom that is among the least-conspicuously bilateral. Though internally its parts have a two-sided arrangement; and though the positions of its orifices give it an external two-sidedness, at the same time that they establish a difference between the two ends; yet its two-sidedness is not strongly-marked. The form deviates but little from what we have distinguished as triple bilateral symmetry: if the creature is cut across the middle, the head and tail ends are very much alike; if cut in two along its axis by a horizontal plane, the under and upper halves are very much alike, externally if not internally; and if cut in two along its axis by a vertical plane, the two sides are quite alike. Figs. 263 and 264 will make this clear. Such creatures as the Julus and the Centipede, may be taken as showing a transition to double bilateral symmetry. Besides being divisible into exactly similar halves by a vertical plane passing through its axis, one of these animals may be bisected transversely into parts that differ only slightly; but if cut in
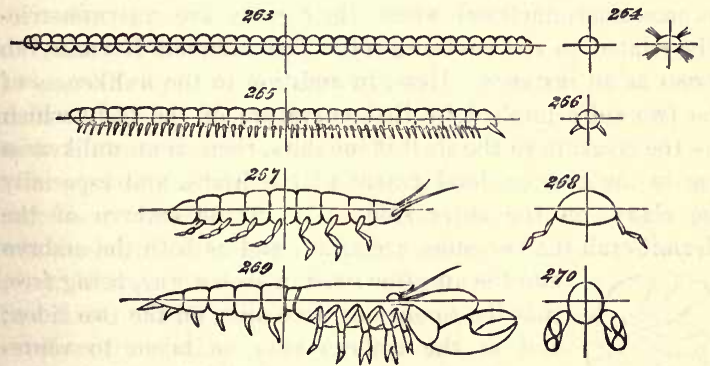

two by a horizontal plane passing through its axis, the under and upper halves are decidedly unlike. Figs. 265, 266, exhibit these traits. Among the isopodous crustaceans, the departure from these low types of symmetry is more 
marked. As shown in Figs. 267 and 268, the contrast between the upper and under parts is greater, and the head and tail ends differ more obviously.

In all the higher Arthropoda, the unlikeness between the front half and the hind half has become conspicuous. There is in them single bilateral symmetry of so pronounced a kind, that no other resemblance is suggested than that between the two sides. By Figs. 269 and 270, representing a decapodous crustacean divided longitudinally and transversely, this truth is made manifest. On calling to mind the habits of the creatures here drawn and described, it will be seen that they explain these forms. The incidence of forces is the same all around the Earth-worm as it burrows through the compact ground. The Centipede, creeping amid loose soil or débris or beneath stones, insinuates itself between solid surfaces-the interstices being mostly greater in one dimension than in others. And all the higher Annulosa, moving about as they do over exposed objects, have their dorsal and ventral parts as dissimilarly acted upon as are their two ends.

One other fact only respecting annulose animals needs to be noticed under this head - the fact, namely, that they become unsymmetrical where their parts are unsymmetrically related to the environment. The common Hermit-crab serves as an instance. Here, in addition to the unlikeness of the two sides implied by that curvature of the body which fits the creature to the shell it inhabits, there is an unlikeness due to the greater development of the limbs, and especially the claws, on the outer side. As in the embryo of the Hermit-crab the two sides are alike; and as both the embryo

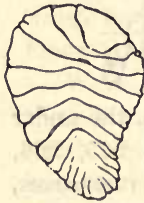

271 and the ancestor lived in such a way, bcing free, that the conditions were alike on the two sides; and as the embryo may be taken to represent the type from which the Hermit-crab has been derived; we have in this case evidence that a symmetrically-bilateral form has been moulded into an unsymmetrically-bilateral 
form, by the action of unsymmetrically-bilateral conditions. A further illustration is supplied by Bopyrus, Fig. 271: a parasite which lives in the branchial chamber of prawns, and whose habits similarly account for its distorted shape.

$\S 251$. Among the Mollusca we find more varied relations between shapes and circumstances. Some of these relations are highly instructive.

Mollusks of one order, the Pteropoda, swim in the sea much in the same way that butterflies fly in the air, and have shapes not altogether unlike those of butterflies. Fig. 272 represents one of these creatures. That its bilaterally-symmetrical shape harmonizes with its bilaterally-symmetrical conditions is sufficiently obvious.

Among the Lamellibranchiata, we have

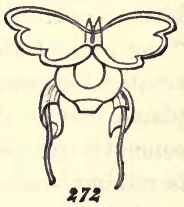
diverse forms accompanying diverse modes of life. Such of them as frequently move about, like the fresh-water Mussel, have their two valves and the contained parts alike on the opposite sides of a vertical plane: they are bilaterally symmetrical in conformity with their mode of movement. The marine Mussel, too, though habitually fixed, and though not usually so fixed that its two valves are similarly conditioned, still retains that bilateral symmetry which is characteristic of the order; and it does this because in the species considered as a whole, the two valves are not dissimilarly conditioned. If the positions of the various individuals are averaged, it will be seen that the differentiating actions neutralize one another. In certain other fixed Lamellibranchs, however, there is a considerable deviation from bilateral symmetry; and it is a deviation of the kind to be anticipated under the circumstances. Where one valve is always downwards, or next to the surface of attachment, while the other valve is always upwards, or next to the environing water, we may expect to find the two 
valves become unlike. This we do find: witness the Oyster. In the Oyster, too, we see a further irregularity. There is a great indefiniteness of outline, both in the shell and in the animal-an indefiniteness made manifest by comparing different individuals. We have but to remember that growing clustered together, as Oysters do, they must interfere with one another in various ways and degrees, to see how the indeterminateness of form and the variety of form are accounted for.

Among the Gasteropods modifications of a more definite kind occur. "In all Mollusks," says Professor Huxley, "the axis of the body is at first straight, and its parts are arranged symmetrically with regard to a longitudinal vertical plane, just as in a vertebrate or an articulate embryo." In some Gasteropods, as the Chiton, this bilateral symmetry is retained-the relations of the body to surrounding actions not being such as to disturb it. But in those more numerous types which have spiral shells, there is a marked deviation from bilateral symmetry, as might be expected. "This asymmetrical over-development never affects the head or foot of the mollusk": only those parts which, by inclosure in a shell, are protected from environing actions, lose their bilateralness; while the external parts, subjected by the movements of the creatures to bilateral conditions, remain bilateral. Here, however, a difficulty meets us. Why is it that the naked Gasteropods, such as our common slugs, deviate from bilateral symmetry, though their modes of movement are those along with which complete bilateral symmetry usually occurs? The reply is that their deviations from bilateral symmetry are probably inherited, and that they are maintained in such parts of their organization as are not exposed to bilaterally-symmetrical conditions. There is reason to believe that the naked Gasteropods are descended from Gasteropods which had shells: the evidence being that the naked Gasteropods have shells during the early stages of their development, and that some of them 
retain rudimentary shells throughout life. Now the shelled Gasteropods deviate from bilateral symmetry in the disposition of both the alimentary system and the reproductive system. The naked Gasteropods, in losing their shells, have lost that immense one-sided development of the alimentary system which fitted them to their shells, and have acquired that bilateral symmetry of external figure which fits them for their habits of locomotion; but the reproductive system remains one-sided, because, in respect to it, the relations to external conditions remain one-sided.

The Cephalopods show us bilaterally-symmetrical external forms along with habits of movement through the water in two-sided attitudes. At the same time, in the radial distribution of the arms, enabling one of these creatures to take an all-sided grasp of its prey, we see how readily upon one kind of symmetry there may be partially developed another kind of symmetry, where the relations to conditions favour it.

§252. The Vertebrata illustrate afresh the truths which we have already traced among the Annulosa. Flying through the air, swimming through the water, and running over the earth as vertebrate animals do, in common with annulose animals, they are, in common with annulose animals, different at their anterior and posterior ends, different at their dorsal and ventral surfaces, but alike along their two sides. This single bilateral symmetry remains constant under the extremest modifications of form. Among fish we see it alike in the horizontally-flattened Skate, in the vertically-flattened Bream, in the almost spherical Diodon, and in the greatlyelongated Syngnathus. Among reptiles the Turtle, the Snake, and the Crocodile all display it. And under the countless modifications of structure displayed by birds and mammals, it remains conspicuous.

A less obvious fact which it concerns us to note among the Vertebrata, parallel to one which we noted among the $A n$ nulosa, is that whereas the lower vertebrate forms deviate 
but little from triple bilateral symmetry, the deviation becomes great as we ascend. Figs. 273 and 274 show how, besides being divisible into similar halves by a vertical plane passing through its axis, a Fish is divisible into halves that are not very dissimilar by a horizontal plane passing through its axis, and also into other not very dissimilar halves by a plane cutting it transversely. If, as shown in Figs. 275 and 276, analogous sections be made of a superior Reptile, the divided parts differ more decidedly. When a Mammal and a
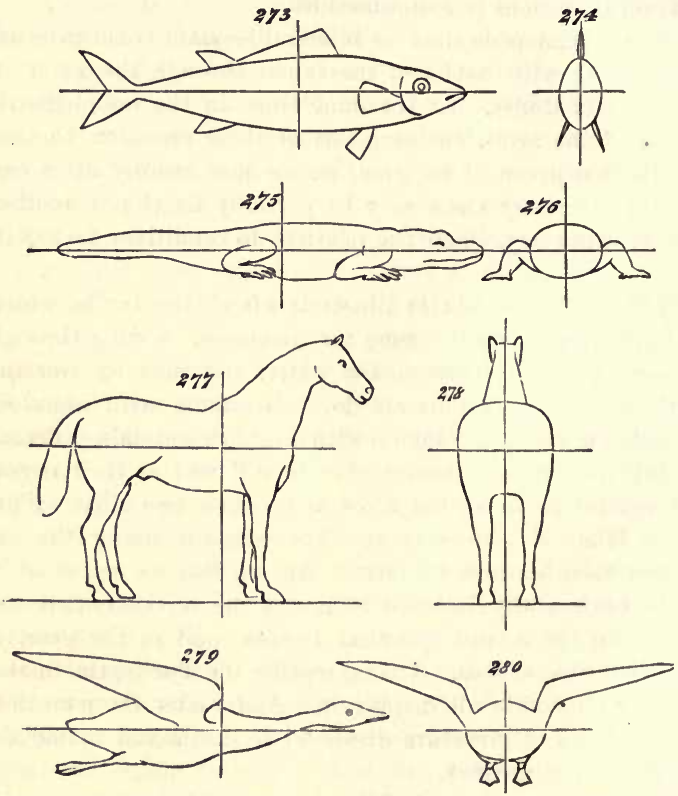

Bird are treated in the same way, as shown in Figs. 27\%, 278, and Figs. 279, 280, the parts marked off by the dividing planes are unlike in far greater degrees. On considering 
the mechanical converse between organisms of these several types and their environments - on remembering that the fish habitually moves through a homogeneous medium of nearly the same specific gravity as itself, that the terrestrial reptile either crawls on the surface or raises itself very incompletely above it, that the more active mammal, having its supporting parts more fully developed, thereby has the under half of its body made more different from the upper half, and that the bird is subject by its mode of life to yet another set of actions and reactions; we shall see that these facts are quite congruous with the general doctrine, and furnish further support to it.

One other significant piece of evidence must be named. Among the Annulosa we found unsymmetrical bilateralness in creatures having habits exposing them to unlike conditions on their two sides; and among the Vertebrata we find parallel cases. They are presented by the Pleuronectida - the order of distorted flat fishes to which the Sole and the Flounder belong. On the hypothesis of evolution, we must conclude that fishes of this order have arisen from an ordinary bilaterally-symmetrical type of fish, which, feeding at the bottom of the sea, gained some advantage by placing itself with one of its sides downwards, instead of maintaining the vertical attitude. Besides the general reason there are special reasons for concluding this. In the first place, the young Sole or Flounder is bilaterally symmetrical-has its eyes on opposite sides of its head and swims in the usual way. In the second place, the metamorphosis which produces the unsymmetrical structure sometimes does not take place-there are abnormal Flounders that swim vertically, like other fishes. In the third place, the transition from the symmetrical structure to the unsymmetrical structure may be traced. Almost incredible though it seems, one of the eyes is transferred from the under-side of the head to the upper-side: the transfer being effected by a distorted development of the cranial bones-atrophy of some and hypertrophy of others, 
along with a general twist. This metamorphosis furnishes several remarkable illustrations of the way in which forms become moulded into harmony with incident forces. For besides the divergence from bilateral symmetry involved by presence of both eyes upon the upper side, there is a further divergence from bilateral symmetry involved by differentiation of the two sides in respect to the contours of their surfaces and the sizes of their fins. And then, what is still more significant, there is a near approach to likeness between the halves that were originally unlike, but are, under the new cireumstances, exposed to like conditions. The body is divisible into similarly-shaped parts by a plane eutting it along the side from head to tail: "the dorsal and ventral instead of the lateral halves become symmetrical in outline and are equipoised."

$\S 253$. Thus, little as there seems in common between the shapes of plants and the shapes of animals, we yet find, on analysis, that the same general truths are displayed by both. The one ultimate prineiple that in any organism equal amounts of growth take place in those directions in which the incident forces are equal, serves as a key to the phenomena of morphological differentiation. By it we are furnished with interpretations of those likenesses and unlikenesses of parts, which are exhibited in the several kinds of symmetry; and when we take into aceount inherited effects, wrought under ancestral conditions contrasted in various ways with present conditions, we are enabled to comprehend, in a general way, the actions by which animals have been moulded into the shapes they possess.

To fill up the outline of the argument, so as to make it correspond throughout with the argument respecting vegetal forms, it would be proper here to devote a chapter to the differentiations of those homologous segments out of which animals of certain types are composed. Though, among most animals of the third degree of composition, such as the 
rooted Hydrozoa, the Polyzoa, and the Ascidioida, the united individuals are not reduced to the condition of segments of a composite individual, and do not display any marked differentiations; yet there are some animals in which such subordinations, and consequent heterogeneities, occur. The oceanic Hydrozoa form one group of them ; and we have seen reason to conclude that the Annulosa form another group: It is not worth while, however, to, occupy space in detailing these unlikenesses of homologous segments, and seeking specific explanations of them. Among the oceanic Hydrozoa they are extremely varied; and the habits and derivations of these creatures are so little known, that there are no adequate data for interpreting the forms of the parts in terms of their relations to the environment. Conversely, among the Annulosa those differentiations of the homologous segments which accompany their progressing integration, have so much in common, and have general causes which are so obvious, that it is needless to deal with them at any length. They are all explicable as due to the exposure of different parts of the chain of segments to different sets of actions and reactions: the most general contrast being that between the anterior segments and the posterior segments, answering to the most general contrast of conditions to which annulose animals subject their segments; and the more special contrasts answering to the contrasts of conditions entailed by their more special habits.

Were an exhaustive treatment of the subject practicable, there should here, also, come a chapter devoted to the internal structures of animals-meaning, more especially, the shapes and arrangements of the viscera. The relations between forms and forces among these inclosed parts are, however, mostly too obscure to allow of interpretation. Protected as the viscera are in great measure from the incidence of external forces, we are not likely to find much correspondence between their distribution and the distribution of external forces. In this case the influences, partly 
mechanical, partly physiological, which the organs exercise on one another, become the chief causes of their changes of figure and arrangement; and these influences are complex and indefinite. One general fact may, indeed, be noted-the fact, namely, that the divergence towards asymmetry which generally characterizes the viscera, is marked among those of them which are most removed from mechanical converse with the environment, but not so marked among those of them which are less removed from such converse. Thus while, throughout the Vertebrata, the alimentary system, with the exception of its two extremities, is asymmetrically arranged, the respiratory system, which occupies one end of the body, generally deviates but little from bilateral symmetry, and the reproductive system, partly occupying the other end of the body, is in the main bilaterally symmetrical: such deviation from bilateral symmetry as occurs, being found in its most interiorly-placed parts, the ovaries. Just indicating these facts as having a certain significance, it will be best to leave this part of the subject as too involved for detailed treatment.

Internal structures of one class, however, not included among the viscera, admit of general interpretation-structures which, though internal, are brought into tolerablydirect relations with environing forces, and are therefore subordinate in their forms to the distribution of those forces. These internal structures it will be desirable to deal with at some length; both because they furnish important illustrations enforcing the general argument, and because an interpretation of them which we have seen reason to reject, cannot be rejected without raising the demand for some other interpretation. 


\section{CHAPTER XV.}

THE SHAPES OF VERTEBRATE SKELETONS.

$\S 254$. WHEN an elongated mass of any substance is transversely strained, different parts of the mass are exposed to forces of opposite kinds. If, for example, a bar of metal or wood is supported at its two ends, as shown in Fig. 281, and has to bear a weight on its centre, its lower

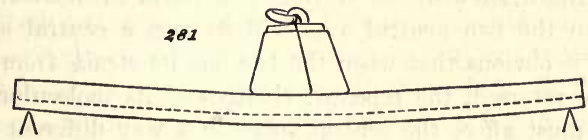

part is thrown into a state of tension, while its upper part is thrown into a state of compression. As will be manifest to any one who observes what happens on breaking a stick across his knee, the greatest degree of tension falls on the fibres forming the convex surface, while the fibres forming the concave surface are subject to the greatest degree of compression. Between these extremes the fibres at different depths are subject to different forces. Progressing upwards from the under surface of the bar shown in Fig. 281, the tension of the fibres becomes less; and progressing downwards from the upper surface, the compression of the fibres becomes less; until, at a certain distance between the two surfaces, there is a place at which the fibres are neither extended nor compressed. This, shown by the dotted line in 
the figure, is called in mechanical language the "neutral axis." It varies in position with the nature of the substance strained: being, in common pine-wood, at a distance of about five-eighths of the depth from the upper surface, or threeeighths from the under surface. Clearly, if such a piece of wood, instead of being subject to a downward force, is secured at its ends and subject to an upward force, the distribution of the compressions and tensions will be reversed, and the neutral axis will be nearest to the upper surface. Fig. 282 represents these opposite attitudes of the bar and the changed

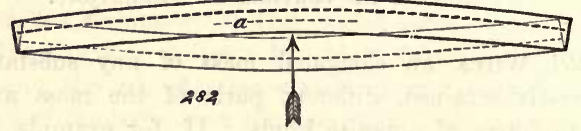

position of its neutral axis: the arrow indicating the direction of the force producing the upward bend, and the faint dotted line $a$, showing the previous position of the neutral axis. Between the two neutral axes will be seen a central space; and it is obvious that when the bar has its strain from time to time reversed, the repeated changes of its molecular condition must affect the central space in a way different from that in which they affect the two outer spaces. Fig. 283 is a diagram conveying some idea of these contrasts in molecular condition. If $\mathrm{A} \mathrm{B} \mathrm{C} \mathrm{D} \mathrm{be} \mathrm{the} \mathrm{middle} \mathrm{part} \mathrm{of} \mathrm{a} \mathrm{bar} \mathrm{thus}$ treated, while $\mathrm{G} \mathrm{H}$ and $\mathrm{K} \mathrm{L}$ are the alternating neutral axes; then the forces to which the bar is in each case subject, may be readily shown. Supposing the deflecting force to be acting in the direction of the arrow $\mathrm{E}$, then the tensions to which the fibres between $\mathrm{G}$ and $\mathrm{F}$ are exposed, will be represented by a series of lines increasing in length as the distance from $\mathrm{G}$ increases; so that the triangle G F M, will express the amount and distribution of all the molecular tensions. But the molecular compressions throughout the space from $G$ to $\mathrm{E}$, must balance the molecular tensions; and hence, if the triangle $\mathrm{G} \mathrm{E} \mathrm{N}$ be made equal to the tri- 
angle G F M, the parallel lines of which it is composed (here dotted for the sake of distinction) will express the amount and distribution of the compressions between $\mathrm{E}$ and $\mathrm{G}$.

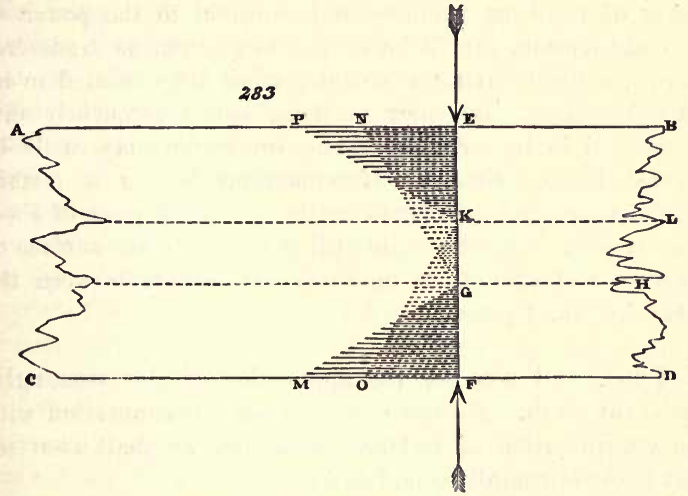

Similarly, when the deflecting force is in the direction of the arrow $\mathrm{F}$, the compressions and tensions will be quantitatively symbolized by the triangles $\mathrm{K} \mathrm{F} O$, and $\mathrm{K} \mathrm{E} \mathrm{P.} \mathrm{And}$ thus the several spaces occupied by full lines and by dotted lines and by the two together, will represent the different actions to which different parts of the transverse section are subject by alternating transverse strains. Here, then, it is made manifest to the eye that the central space between $\mathbf{G}$ and $K$, is differently conditioned from the spaces above and below it; and that the difference of condition is sharply marked off. The fibres forming the outer surface C D, are subject to violent tensions and violent compressions. Progressing inwards the tensions and compressions decreasethe tensions the more rapidly. As we approach the point G, the tensions to which the fibres are alternately subject, bear smaller and smaller ratios to the compressions, and disappear at the point G. Thence to the centre occur compressions only, of alternating intensities, becoming at the centre small 
and equal; and from the centre we advance, through a reverse series of changes, to the other side.

Thus it is demonstrable that any substance in which the power of resisting compression is unequal to the power of resisting tension, cannot be subject to alternating transverse strains, without having a central portion differentiated in its conditions from the outer portions, and consequently differentiated in its structure. This conclusion may easily be verified by experiment. If something- having a certain toughness but not difficult to break, as a thick piece of sheet lead, be bent from side to side till it is broken, the surface of fracture will exhibit an unlikeness of texture between the inner and outer parts.

$\S 255$. And now for the application of this seeminglyirrelevant truth. Though it has no obvious connection with the interpretation of vertebral structure, we shall soon see that it fundamentally concerns us.

The simplest type of vertebrate animal, the fish, has a mode of locomotion which involves alternating transverse strains. It is not, indeed, subjected to alternating transverse strains by some outer agency, as in the case we have been investigating: it subjects itself to them. But though the strains are here internally produced instead of externally produced, the case is not therefore removed into a wholly

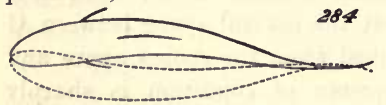

different category. For supposing Fig. 284 to represent the outline of a fish when bent on one side (the dotted lines representing its outline when the bend is reversed), it is clear that part of the substance forming the convex half must be in a state of tension. This state of tension implies the existence in the other half of some counter-balancing compression. And between the two there must be a neutral axis. The way in which this conclusion is reconcilable with the fact that there is tension somewhere in the concave side of a fish, since the curve is 
caused by muscular contractions on the concave side, will be made clear by the rude illustration which a bow supplies. A bow may be bent by a thrust against its middle (the two ends being held back), or it may be bent by contracting a string that unites its ends; but the distributions of mechanical forces within the wood of the bow, though not quite alike in the two cases, will be very similar. Now while the muscular action on the concave side of a fish differs from that represented by the tightened string of a bow, the difference is not such as to destroy the applicability of the illustration: the parallel holds so far as this, that within that portion of the fish's body which is passively bent by the contracting muscles, there must be, as in a strung bow, a part in compression, a part in tension, and an intermediate part which is neutral.

After thus seeing that even in the developed fish with its complex locomotive apparatus, this law of the transverse strain holds in a qualified way, we shall understand how much more it must hold in any form that may be supposed to initiate the vertebrate type-a form devoid of that segmentation by which the vertebrate type is more or less characterized. We shall see that assuming a rudimentary animal, still simpler than the Amphioxus, to have a feeble power of moving itself through the water by the undulations of its body, or some part of its body, there will necessarily come into play certain reactions which must affect the median portion of the undulating mass in a way unlike that in which they affect its lateral portions. And if there exists in this median portion a tissue which keeps its place with any constancy, we may expect that the differential conditions produced in it by the transverse strain, will initiate a differentiation. It is true that the distribution of the viscera in the Amphioxus, Fig. 191, and in the type from which we may suppose it to have arisen, is such as to interfere with this process. It is also true that the actions and reactions described would not of themselves give to the median portion 
a cylindrical shape, like that of the cartilaginous rod running along the back of the Amphioxus. But what we have here to note in the first place is, that these habitual alternate

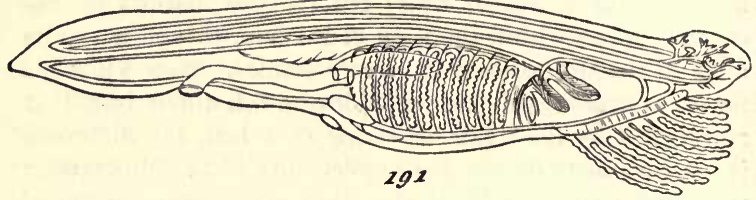

flexions have a tendency to mark off from the outer parts an unlike inner part, which may be seized hold of, maintained, and further modified, by natural selection, should any advantage thereby result. And we have to note in the second place, that an advantage is likely to result. The contractions cannot be effective in producing undulations, unless the general shape of the body is maintained. External muscular fibres unopposed by an internal resistant mass, would cause collapse of the body. To meet the requirements there must be a means of maintaining longitudinal rigidity without preventing bends from side to side; and such a means is presented by a structure initiated as described. In brief, whether we have or have not the actual cause, we have here at any rate "a true cause." Though there arc difficulties in tracing out the process in a definite way, it may at least be said that the mechanical genesis of this rudimentary vertebrate axis is quite conceivable. And even the difficulties may, I think, be more fully met than at first sight seems possible.

What is to be said of the other leading trait which the simplest vertebrate animal has in common with all higher vertebrate animals-the segmentation of its lateral muscular masses? Is this, too, explicable on the mechanical hypothesis? Have we, in the alternating transverse strains, a cause for the fact that while the rudimentary vertebrate axis 
is without any divisions, there are definite divisions of the substance forming the animal's sides? I think we have. A glance at the distribution of forces under the transverse strain, as represented in the foregoing diagrams, will show how much more severe is the strain on the outer parts than on the inner parts; and how, consequently, any modifications of structure eventually necessitated, will arise peripherally before they arise centrally. The perception of this may be enforced by a simple experiment. Take a stick of sealingwax and warm it slowly and moderately before the fire, so as to give it a little flexibility. Then bend it gently until it is curved into a semi-circle. On the convex surface small cracks will be seen, and on the concave surface wrinkles; while between the two the substance remains undistorted. If the bend be reversed and re-reversed, time after time, these cracks and wrinkles will become fissures which gradually deepen. But now, if changes of this class, entailed by alternating transverse strains, commence superficially, as they manifestly must; there arise the further questions-What will be the special modifications produced under these special conditions? and through what stages will these modifications progress? Every one has literally at hand an example of the way in which a flexible external layer that is now extended and now compressed, by the bending of the mass it covers, becomes creased; and a glance at the palms and the fingers will show that the creases are near one another where the skin is thin, and far apart where the skin is thick. Between this familiar case and the case of the rhinoceroshide, in which there are but a few large folds, various gradations may be traced. Now the like must happen with the increasing layers of contractile fibres forming the sides of the muscular tunic in such a type as that supposed. The bendings will produce in them small wrinkles while they are thin, but more decided and comparatively distant fissures as they become thick. Fig. 289, which is a horizontal longitudinal section, shows how these thickening layers will 
adjust themselves on the convex and the concave surfaces, supposing the fibres of which they are composed to be ob-

289
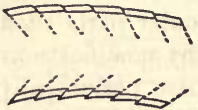
lique, as their function requires; and it is not difficult to see that when once definite divisions have been established, they will advance inwards as the layers develop; and will so produce a series of muscular bundles. Here then we have something like the myocommata [or myotomes as now called] which are traceable in the Amphioxus, and are conspicuous in all superior fishes.

$\S 256$. These are highly speculative conceptions. I have ventured to present them with the view of implying that the hypothesis of the mechanical genesis of vertebrate structure is not wholly at fault when applied to the most rudimentary vertebrate animal. Lest it should be alleged that the question is begged if we set out with a type which, like the Amphioxus, already displays segmentation throughout its muscular system, it seemed needful to indicate conceivable modes in which there may have been mechanically produced those leading traits that distinguish the Amphioxus. All I intend to suggest is that mechanical actions have been at work, and that probably they have operated in the manner alleged: so preparing the way for natural selection.

But now let us return to the region of established fact, and consider whether such actions and reactions as we actually witness, are adequate causes of those observed differentiations and integrations which distinguish the more-developed vertebrate animals. Let us see whether the theory of mechanical genesis affords us a deductive interpretation of the inductive generalizations.

Before proceeding, we must note a process of functional adaptation which here co-operates with natural selection. I refer to the usual formation of denser tissues at those parts of an organism which are exposed to the greatest 
strains-either compressions or tensions. Instances of hardening under compression are made familiar to us by the skin. We have the general contrast between the soft skin covering the body at large, and the indurated skin covering the inner surfaces of the hands and the soles of the feet. We have the fact that even within these areas the parts on which the pressure is habitually greatest have the skin always thickest; and that in each person special points exposed to special pressures become specially dense-often as dense as horn. Further, we have the converse fact that the skin of little-used hands becomes abnormally thin-even losing, in places, that ribbed structure which distinguishes skin subject to rough usage. Of increased density directly following increased tension, the skeletons, whether of men or animals, furnish abundant evidence. Anatomists easily discriminate between the bones of a strong man and those of a weak man, by the greater development of those ridges and crests to which the muscles are attached; and naturalists, on comparing the remains of domesticated animals with those of wild animals of the same species, find kindred differences. The first of these facts shows unmistakably the immediate effect of function on structure, and by obvious alliance with it the second may be held to do the same: both implying that the deposit of dense substance capable of great resistance, constantly takes place at points where the tension is excessive.

Taking into account, then, this adaptive process, continually aided by the survival of individuals in which it has taken place most rapidly, we may expect, on tracing up the evolution of the vertebrate axis, to find that as the muscular power becomes greater there arise larger and harder masses of tissue, serving the muscles as points d'appui; and that these arise first in those places where the strains are greatest. Now this is just what we do find. The myocommata are so placed that their actions are likely to affect first that upper coat of the notochord, where there are found 
"quadrate masses of somewhat denser tissue," which " seem faintly to represent neural spines," even in the Amphioxus. It is by the development of the neural spines, and after them of the. hæmal spines, that the segments of the vertebral column are first marked out; and under the increasing strains of more-developed myocommata, it is just these peripheral appendages of the vertebral segments that must be most subject to the forces which cause the formation of denser tissue. It follows from the mechanical hypothesis that as the muscular segmentation must begin externally and progress inwards, so, too, must the vertebral segmentation. Besides thus finding reason for the fact that in fishes with wholly cartilaginous skeletons, the vertebral segments are indicated by these processes, while yet the notochord is unsegmented; we find a like reason for the fact that the transition from the less-dense cartilaginous skeleton to the more-dense osseous skeleton, pursues a parallel course. In the existing Lepidosiren, which by uniting certain piscine and amphibian characters betrays its close alliance with primitive types, the axial part of the vertebral column is unossified, while there is ossification of the peripheral parts. Similarly with numerous genera of fishes classed as palæozoic. The fossil remains of them show that while the neural and hæmal spines consisted of bone, the central parts of the vertebræ were not bony. It may in some cases be noted, too, both in extant and in fossil forms, that while the ossification is complete at the outer extremities of the spines it is incomplete at their inner extremities-thus similarly implying centripetal development.

$\S 25 \%$. After these explanations the process of eventual segmentation in the spinal axis itself, will be readily understood. The original cartilaginous rod has to maintain longitudinal rigidity while permitting lateral flexion. As fast as it becomes definitely marked out, it will begin to concentrate within itself a great part of those pressures and tensions 
caused by transverse strains. As already said, it must be acted upon much in the same manner as a bow, though it is bent by forces acting in a more indirect way; and like a bow, it must, at each bend, have the substance of its convex side extended and the substance of its concave side compressed. So long as the vertebrate animal is small or inert, such a cartilaginous rod may have sufficient strength to withstand the muscular strains; but, other things equal, the evolution of an animal that is large, or active, or both, implies muscular strains which must tend to cause modification in such a cartilaginous rod. The results of greater bulk and of greater vivacity may be best dealt with separately.

As the animal increases in size, the rod will grow both longer and thicker. On looking back at the diagrams of forces caused by transverse strains, it will be seen that as the rod grows thicker, its outer parts must be exposed to more severe tensions and pressures if the degree of bend is the same. It is doubtless true that when the fish, advancing by lateral undulations, becomes longer, the curvature assumed by the body at each movement becomes less; and that from this cause the outer parts of the notochord are, other things equal, less strained - the two changes thus partially neutralizing one another. But other things are not equal. For while, supposing the shape of the body to remain constant, the force exerted in moving the body increases as the cubes of its dimensions, the sectional area of the notochord, on which fall the reactions of this exerted force, increases only as the squares of the dimensions: whence results a greater stress upon its substance. This, however, will not be very decided where there is no considerable activity. It is clear that augmenting bulk, taken alone, involves but a moderate residuary increase of strain on each portion of the notochord; and this is probably the reason why it is possible for a large sluggish fish like the Sturgeon, to retain the notochordal structure. But now, passing to the effects of greater activity, a like dynamical inquiry at once shows us how rapid- 
ly the violence of the actions and reactions rises as the movements become more vivacious. In the first place, the resistance of a medium such as water increases as the square of the velocity of the body moving through it; so that to maintain double the speed, a fish has to expend four times the energy. But the fish has to do more than this-it has to initiate this speed, or to impress on its mass the force implied by this speed. Now the vis viva of a moving body varies as the square of the velocity; whence it follows that the energy required to generate that vis viva is measured by the square of the velocity it produces. Consequently, did the fish put itself in motion instantaneously, the expenditure of energy in generating its own vis viva and simultaneously overcoming the resistance of the water, would vary as the fourth power of the velocity. But the fish cannot put itself in motion instantaneously-it must do it by increments; and thus it results that the amounts of the forces expended to give itself different velocities must be represented by some series of numbers falling between the squares and the fourth powers of those velocities. Were the increments slowly accumulated, the ratios of increasing effort would but little exceed the ratios of the squares; but whoever observes the sudden, convulsive action with which an alarmed fish darts out of a shallow into deep water, will see that the velocity is rapidly generated, and that therefore the ratios of increasing effort probably exceed the ratios of the squares very considerably. At any rate it will be clear that the efforts made by fishes in rushing upon prey or escaping enemies (and it is these extreme efforts which here concern us) must, as fishes become more active, rapidly exalt the strains to be borne by their motor organs; and that of these strains, those which fall upon the notochord must be exalted in proportion to the rest. Thus the development of locomotive power, which survival of the fittest must tend in most cases to favour, involves such increase of stress on the primitive cartilaginous rod as will tend, other things equal, to cause its modification. 
What must its modification be? Considering the complication of the influences at work, conspiring, as above indicated, in various ways and degrees, we cannot expect to do more than form an idea of its average character. The nature of the changes which the notochord is likely to undergo, where greater bulk is accompanied by higher activity, is rudely indicated by Figs. 291, 292, and 293. The successively
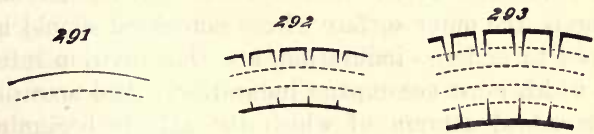

thicker lines represent the successively greater strains to which the outer layers of tissue are exposed; and the widening inter-spaces represent the greater extensions which they have to bear when they become convex, or else the greater gaps that must be formed in them. Had these outer layers to undergo extension only, as on the convex side, continued natural selection might result in the formation of a tissue elastic enough to admit of the requisite stretching. But at each alternate bend these outer layers, becoming concave, are subject to increased compression-a compression which they cannot withstand if they have become simply more extensible. To withstand this greater compression they must become harder as well as more extensible. How are these two requirements to be reconciled? If, as facts warrant us in supposing, a formation of denser substance occurs at those parts of the notochord where the strain is greatest; it is clear that this formation cannot so go on as to produce a continuous mass: the perpetual flexions must prevent this. If matter that will not yield at each bend, is deposited while the bendings are continually taking place, the bendings will maintain certain places of discontinuity in the depositplaces at which the whole of the stretching consequent on each bend will be concentrated. And thus the tendency will be to form segments of hard tissue capable of great resistance 
to compression, with intervals filled by elastic tissue capable of great resistance to extension-a vertebral column.

And now observe how the progress of ossification is just such as conforms to this view. That centripetal development of segments which holds of the vertebrate animal as a whole, as, if caused by transverse strains, it ought to do, and which holds of the vertebral column as a whole, as it ought to do, holds also of the central axis. On the mechanical hypothesis, the outer surface of the notochord should be the first part to undergo induration, and that division into segments which must accompany induration. And accordingly, in a vertebral column of which the axis is beginning to ossify, the centrums consist of bony rings inclosing a stillcontinuous rod of cartilage.

$\S 258$. Sundry other general facts disclosed by the comparative morphology of the Vertebrata, supply further confirmation. Let us take first the structure of the skull.

On considering the arrangement of the muscular flakes, or myocommata, in any ordinary fish which comes to table-an arrangement already sketched out in the Amphioxus-it is not difficult to see that that portion of the body out of which the head of the vertebrate animal becomes developed, is a portion which cannot subject itself to bendings in the same degree as the rest of the body. The muscles leveloped there must be comparatively short, and much interfered with by the pre-existing orifices. Hence the cephalic part will not partake in any considerable degree of the lateral undulations; and there will not tend to arise in it any such distinct segmentation as arises elsewhere. We have here, then, an explanation of the fact, that from the beginning the development of the head follows a course unlike that of the spinal column; and of the fact that the segmentation, so far as it can be traced in the head, is most readily to be traced in the occipital region and becomes lost in the region of the face. For if, as we have seen, the segmentation consequent on 
mechanical actions and reactions must progress from without inwards, affecting last of all the axis; and if, as we have seen, the region of the head is so circumstanced that the causes of segmentation act but feebly even on its periphery; then that terminal portion of the primitive notochord which is included in the head, having to undergo no lateral bendings, may ossify without division into segments.

Of other incidental evidences supplied by comparative morphology, let me next refer to the supernumerary bones, which the theory of Goethe and Oken as elaborated by Prof. Owen, has to get rid of by gratuitous suppositions. In many fishes, for example, there are what have been called interneural spines and inter-hæmal spines. These cannot by any ingenuity be affiliated upon the archetypal vertebra, and they are therefore arbitrarily rejected as bones belonging to the exo-skeleton; though in shape and texture they are similar to the spines between which they are placed. On the hypothesis of evolution, however, these additional bones are accounted for as arising under actions like those that gave origin to the bones adjacent to them. And similarly with such bones as those called sesamoid; together with others too numerous to name.

\$259. Of course the foregoing synthesis is to be taken simply as an adumbration of the process by which the vertebrate structure may have arisen through the continued actions of known agencies. The motive for attempting it has been two-fold. Having, as before said, given reasons for concluding that the segments of a vertebrate animal are not homologous in the same sense as are those of an annulose animal, it seemed needful to do something towards showing how they are otherwise to be accounted for; and having here, for our general subject, the likenesses and differences among the parts of organisms, as determined by incident forces, it seemed out of the question to pass by the problem presented by the rertebrate skeleton. 
Leaving out all that is hypothetical, the general argument may be briefly presented thus:-The evolution from the simplest known vertebrate animal of a powerful and active vertebrate animal, implies the development of a stronger internal fulcrum. The internal fulcrum cannot be made stronger without becoming more dense. And it cannot become more dense while retaining its lateral flexibility, without becoming divided into segments. Further, in conformity with the general principles thus far traced, these segments must be alike in proportion as the forces to which they are exposed are alike, and unlike in proportion as these forces are unlike; and so there necessarily results that unity in variety by which the vertebral column is from the beginning characterized. Once more, we see that the explanation extends to those innumerable and more marked divergences from homogeneity, which vertebræ undergo in the various higher animals. Thus, the production of vertebræ, the production of likenesses among vertebræ, the production of unlikenesses among vertebræ, and the production of unlikenesses among vertebral columns, are interpretable as parts of one general process, and as harmonizing with one general prineiple.

Whether sufficient or insufficient, the explanation here given assigns eauses of known kinds producing effects such as they are known to produce. It does not, as a solution of one mystery, offer another mystery of which no solution is to be asked. It does not allege a Platonic ióa, or fictitious entity, which explains the vertebrate skeleton by absorbing into itself all the inexplicability. On the contrary, it assumes nothing beyond agencies by which structures in general are moulded-agencies by which these particular structures are, indeed, notoriously modifiable. An ascertained cause of certain traits in vertebræ and other bones, it extends to all other traits of vertebræ; and at the same time assimilates the morphological phenomena they present to much wider classes of morphological phenomena. 
[NoTE.-The theory set forth in the foregoing chapter, is an elaboration of one suggested at the close of a criticism of Prof. Owen's Archetype and Homologies of the Vertebrate Skeleton, already referred to in $\S 210$ as having been published in the Medico-Chirurgical Review for October, 1858. It is now reproduced in Appendix B. Since the issue of this elaborated exposition, in No. 15 of my serial in December, 1865 , verifications of it have from time to time been published. In his work The Primary Factors of Organic Evolution, Prof. Cope of Philadelphia writes:-

"Mr. Herbert Spencer has endeavoured to account for the origin of the segmentation of muscles into myotomes, and the division of the sheath of the notochord into vertebræ, by supposing it to be due to the lateral swimming movements of the fishes, which first exhibit these structures. With this view various later authors have agreed, and I have offered some additional evidence of the soundness of this position with respect to the vertebral axis of Batrachia, and the origin of limb articulations. It is true that the origin of segmentation in the vertebral column of the true fishes and the Batrachia turns out to have been less simple in its process than was suggested by $\mathrm{Mr}$. Spencer, but his general principle holds good, now that paleontology has cleared up the subject" (pp. 367-8).

An allusion in the foregoing extract is made by Prof. Cope to certain observations set forth in his work entitled The Origin of the Fittest. On pp. 305-6 of it will be found the following sentences:-

"Now, all the Permian land-animals, reptiles and batrachians, retain this notochord with the elements of osseous vertebræ, in a greater or less degree of completeness. There are some in South Africa, I believe, in which the ossification has come clear through the notochord; but they are few. There is something to be said as to the condition of the column from a mechanical standpoint, and it is this: that the chorda exists, with its osseous elements disposed 
about it; and in the Permian batrachians, equally related to salamanders and frogs, these osseous elements are arranged in the sheath or skin of the chorda; and they are in the form of regular concave segments, very much like such segments as you can take from the skin of an orange-but parts of a cylinder, and having greater or less dimensions according to the group or species. Now, the point of divergence of these segments is on the side of the column. The contacts are placed on the side of the column where the segments separate-the upper segments rising and the lower segments coming downward. To the upper segments are attached the arches and their articulations, and the lower segments are like the segments of a cylinder. If you take a flexible cylinder, and cover it with a more or less inflexible skin or sheath, and bend that cylinder sidewise, you of course will find that the wrinkles or fractures of that part of the surface will take place along the line of the shortest curve, which is on the side; and, as a matter of fact, you have breaks of very much the character of the segments of the Permian Batrachia. . . . In the cylinder bending both ways, of course the shortest line of curve is right at the centre of the side of that cylinder, and the longest curve is of course at the summit and base, and the shortest curve will be the point of fracture. And that is exactly what I presume has happened in the case of the construction of the segments of the sheath of the vertebral column, by the lateral motion of the animal in swimming, and which has been the actual cause of the disposition of the osseous material in its form. . . That is the state of the vertebral column of many of the Vertebrata of the Permian period."

In his essay on "The Mechanical Causes of the Development of the Hard Parts of the Mammalia," published in the American Journal of Morphology (Vol. III), Prof. Cope has carried the interpretation further, by showing that in kindred ways the genesis of articulations and limb-bones may be ex- 
plained. On p. 163 he enunciates the general principle of his interpretation as follows:-

"It cannot have been otherwise than that, since the motions of animals continued during the evolution of their hard parts, these hard parts grew in exact adaptation to these movements. Thus at the points of greatest flexure joints would be formed, and between these joints the deposit would be continuous."

Evidently if osseous structures are produced by deposits of calcareous matters in pre-existing cartilaginous structures, or other structures of flexible materials, the deposits must be so carried on that while dense resistant masses are produced these must admit of such free movements as the creature's life necessitates, and must so form adapted joints.

Let it be understood, however, that the hypothesis set forth in the foregoing chapter and extended by Prof. Cope, which serves to interpret a large part of the phenomena of osseous structures in the Vertebrata, does not serve to interpret them all. While the formation of hard parts has been in large measure initiated and regulated by tensions and pressures, there are hard parts the formation of which cannot be thus explained. The bones of the skull are the most obvious instances. These are apparently referable to no other cause than the survival of the fittest-the survival of individual animals in which greater density of the braincovering yielded better protection against external injuries. Without enumerating other instances which might be given, it will suffice to recognize the truth that natural selection of favourable variations and the inheritance of functionallyproduced changes have all along co-operated: each of them in some cases acting alone, but in other cases both acting together.] 


\section{CHAPTER XVI.}

\section{THE SHAPES OF ANIMAL-CELLS.}

$\S 260$. AMONG animals as among plants, the laws of morphological differentiation must be conformed to by the morphological units, as well as by the larger parts and by the wholes formed of them. It remains here to point out that the conformity is traceable where the conditions are simple.

In the shapes assumed by those rapidly-multiplying cells out of which each animal is developed, there is a conspicuous

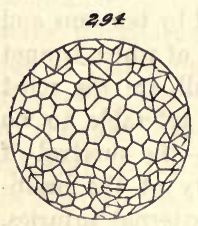
subordination to the surrounding actions. Fig. 294 represents the cellular embryonic mass that arises by repeated spontaneous fissions. In it we see how the cells, originally spherical, are changed by pressure against one another and against the limiting membrane; and how their likenesses and unlikenesses are determined by the likenesses and unlikenesses of the forces to which they are exposed. This fact may be thought scarcely worth pointing out. But it is worth pointing out, because what is here so obvious a consequence of mechanical actions, is in other cases a consequence of actions composite in their kinds and involved in their distribution. Just as the equalities and inequalities of dimensions among aggregated cells, are here caused by the equalities and inequalities among their mutual pressures in different directions; so, though less manifestly, the equalities 
and inequalities of dimensions among other aggregated cells, are caused by the equalities and inequalities of the osmotic, chemical, thermal, and other forces besides the mechanical, to which their different positions subject them.

$\S 261$. This we shall readily see on observing the ordinary structures of limiting membranes, internal and external. In Fig. 295, is shown a much-magnified section of a papilla from the gum. The cells of which it is composed originate in its deeper part; and are at first approximately spherical. Those of them

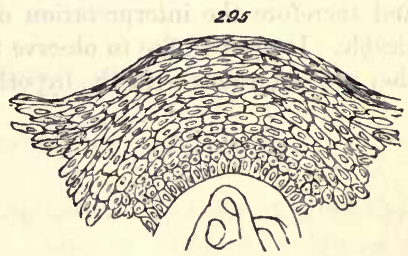
which, as they develop, are thrust outwards by the new cells that continually take their places, have their shapes gradually changed. As they grow and successively advance to replace the superficial cells, when these exfoliate, they become exposed to forces which are more and more different in the direction of the surface from what they are in lateral directions; and their dimensions gradually assume corresponding differences.

Another species of limiting membrane, called cylinderepithelium, is represented in Fig. 296. Though its mode of development is such as to render the shapes of its cells quite unlike those of pavement-

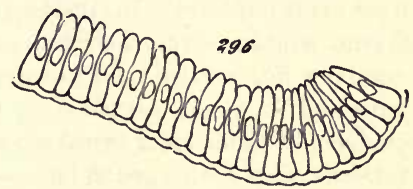
epithelium, as the above-described kind is sometimes called, its cells equally exemplify the same general truth. For the chief contrast which each of them presents, is the contrast between its dimension at right angles to the surface of the membrane, and its dimension parallel to that surface.

It is needless for our present purpose to examine further 
the evidence furnished by Histology; nor, indeed, would further examination of this evidence be likely to yield definite results. In the cases given above we have marked differences among the incident forces; and therefore have a chance of finding, as we do find, relations between these and differences of form. But the cells composing masses of tissue are severally subject to forces which are indeterminate; and therefore the interpretation of their shapes is impracticable. It must suffice to observe that so far as the facts go they are congruous with the hypothesis. 


\section{CHAPTER XVII.}

SUMMARY OF MORPHOLOGICAL DEVELOPMENT.

§262. That any formula should be capable of expressing a common character in the shapes of things so unlike as a tree and a cow, a flower and a centipede, is a remarkable fact; and is a fact which affords strong prima facie evidence of truth. For in proportion to the diversity and multiplicity of the cases to which any statement applies, is the probability that it sets forth the essential relations. Those connexions which remain constant under all varieties of manifestation, are most likely to be the causal connexions.

Still higher will appear the likelihood of an alleged law of organic form possessing so great a comprehensiveness, when we remember that on the hypothesis of Evolution, there must exist between all organisms and their environments, certain congruities expressible in terms of their actions and reactions. The forces being, on this hypothesis, the causes of the forms, it is inferable, $a$ priori, that the forms must admit of generalization in terms of the forces; and hence, such a generalization arrived at $\grave{a}$ posteriori, gains the further probability due to fulfilment of anticipation.

Nearer yet to certainty seems the conclusion thus reached, on finding that it does but assert in their special manifestations, the laws of Evolution in general-the laws of that universal re-distribution of matter and motion which hold 
throughout the totality of things, as well as in each of its parts.

It will be useful to glance back over the various minor inferences arrived at, and contemplate them in their ensemble from these higher points of view.

$\S 263$. That process of integration which every plant displays during its life, we found reason to think has gone on during the life of the vegetal kingdom as a whole. Protoplasm into cells, cells into folia, folia into axes, axes into branched combinations-such, in brief, are the stages passed through by every shrub; and such appear to have been the stages through which plants of successively-higher kinds have been evolved from lower kinds. Even among certain groups of plants now existing, we find aggregates of the first. order passing through various gradations into aggregates of the second order-here forming small, incoherent, indefinite assemblages, and there forming large, definite, coherent fronds. Similar transitions are traceable through which these integrated aggregates of the second order pass into aggregates of the third order: in one species the unions of parent-fronds with the fronds that bud out from them, being temporary, and in another species such unions being longer continued; until, in species still higher, by a gemmation which is habitual and regular, there is produced a definitelyintegrated aggregate of the third order-an axis bearing fronds or leaves. And even between this type and a type further compounded, a link occurs in the plants which cast off, in the shape of bulbils, some of the young axes they produce. As among plants, so among animals. A like spontaneous fission of cells ends here in separation, there in partial aggregation, while elsewhere, by closer combination of the multiplying units, there arises a coherent and tolerably definite individual of the second order. By the budding of individuals of the second order, there are in some cases produced other separate individuals like them; in some 
cases temporary aggregates of such like individuals; and in other cases permanent aggregates of them: certain of which become so definitely integrated that the individualities of their component members are almost lost in a tertiary individuality.

Along with this progressive integration there has gone on a progressive differentiation. Vegetal units of whatever order, originally homogeneous, have become heterogeneous while they have become united. Spherical cells aggregating into threads, into laminæ, into masses, and into special tissues, lose their sphericity; and instead of remaining all alike assume innumerable unlikenesses-from uniformity pass into multiformity. Fronds combining to form axes, severally acquire definite differences between their attached ends and their free ends; while they also diverge from one another in their shapes at different parts of the axes they compose. And axes, uniting into aggregates of a still higher order, become contrasted in their sizes, curvatures, and the arrangements of their appendages. Similarly among animals. Those components of them which, with a certain license, we class as morphological units, while losing their minor individualities in the major individualities formed of them, grow definitely unlike as they grow definitely combined. And where the aggregates so produced become, by coalescence, segments of aggregates of a still higher order, they, too, diverge from one another in their shapes.

The morphological differentiation which thus goes hand in hand with morphological integration, is clearly what the perpetually-complicating conditions would lead us to anticipate. Every addition of a new unit to an aggregate of such nnits, must affect the circumstances of the other units in all varieties of ways and degrees, according to their relative positions-must alter the distribution of mechanical strains throughout the mass, must modify the process of nutrition, must affect the relations of neighbouring parts to surrounding diffused actions; that is, must initiate a changed inci- 
dence of forces tending ever to produce changed structural arrangements.

$\S 264$. This broad statement of the correspondence between the general facts of Morphological Development and the principles of Evolution at large, may be reduced to statements of a much more specific kind. The phenomena of symmetry and unsymmetry and asymmetry, which we have traced out among organic forms, are demonstrably in harmony with those laws of the re-distribution of matter and motion to which Evolution conforms. Besides the myriadfold illustrations of the instability of the homogeneous, afforded by these aggregates of units of each order, which, at first alike, lapse gradually into unlikeness; and besides the myriad-fold illustrations of the multiplication of effects, which these ever-complicating differentiations exhibit to us; we have also myriad-fold illustrations of the definite equalities and inequalities of structures, produced by definite equalities and inequalities of forces.

The proposition arrived at when dealing with the causes of Evolution, " that in the actions and reactions of force and matter, an unlikeness in either of the factors necessitates an unlikeness in the effects; and that in the absence of unlikeness in either of the factors the effects must be alike" (First Principles, $\S 169$ ), is a proposition which implies all these particular likenesses and unlikenesses of parts which we have been tracing. For have we not everywhere seen that the strongest contrasts are between the parts that are most contrasted in their conditions; while the most similar parts are those most-similarly conditioned? In every plant the leading difference is between the attached end and the free end; in every branch it is the same; in every leaf it is the same. And in every plant the leading likenesses are those between the two sides of the branch, the two sides of the leaf, and the two sides of the flower, where these parts are two-sided in their conditions; or between all sides of the 
branch, all sides of the leaf, and all sides of the flower, where these parts are similarly conditioned on all sides. So, too, is it with animals which move about. The most marked contrasts they present are those between the part in advance and the part behind, and between the upper part and the under part; while there is complete correspondence between the two sides. Externally the likenesses and differences among limbs, and internally the likenesses and differences among vertebræ, are expressible in terms of this same law.

And here, indeed, we may see clearly that these truths are corollaries from that ultimate truth to which all phenomena of Evolution are referable. It is an inevitable deduction from the persistence of force, that organic forms which have been progressively evolved, must present just those fundamental traits of form which we find them present. It cannot but be that during the intercourse between an organism and its environment, equal forces acting under equal conditions must produce equal effects; for to say otherwise is, by implication, to say that some force can produce more or less than its equivalent effect, which is to deny the persistence of force. Hence those parts of an organism which are, by its habits of life, exposed to like amounts and like combinations of actions and reactions, must develop alike; while unlikenesses of development must as unavoidably follow unlikenesses among these agencies. And this being so, all the specialities of symmetry and unsymmetry and asymmetry which we have traced, are necessary consequences. 


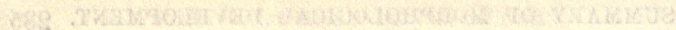

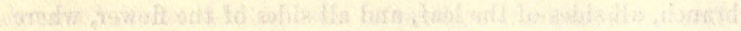

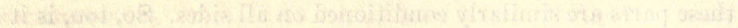

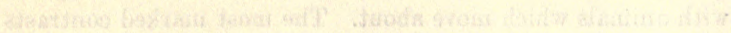

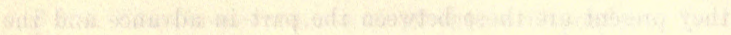

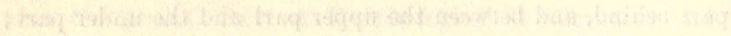

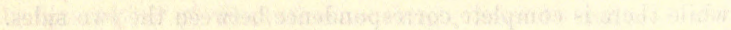

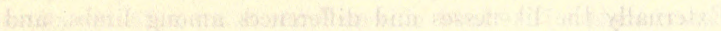

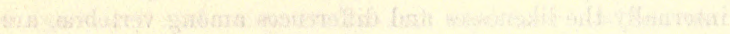

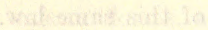

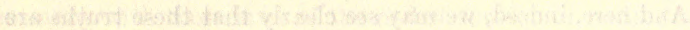

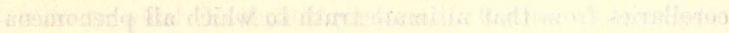

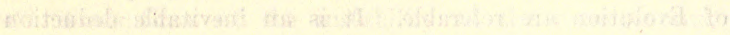

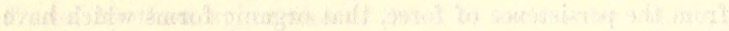

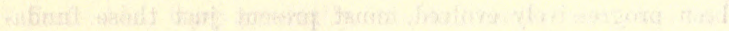

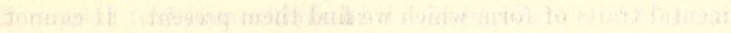

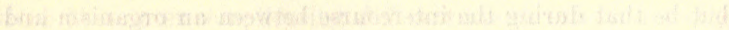

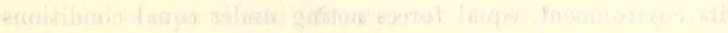

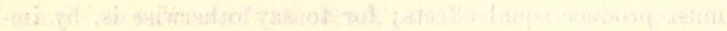

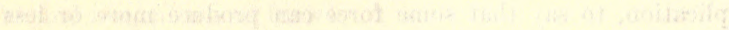

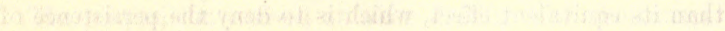

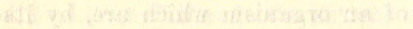

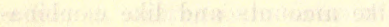

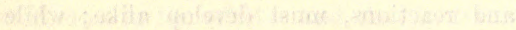

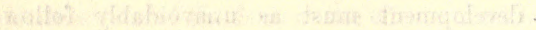

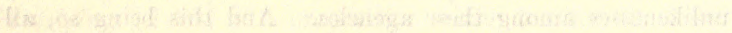

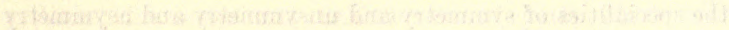

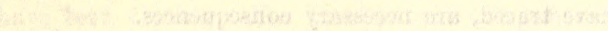




\section{PART V.}

PHYSIOLOGICAL DEVELOPMENT. 


$$
\begin{aligned}
& 49919
\end{aligned}
$$

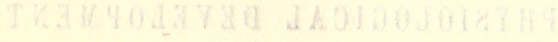




\section{CHAPTER I.}

\section{THE PROBLEMS OF PHYSIOLOGY.}

$\S 265$. The questions to be treated under the above title are widely different from those which it ordinarily expresses. We have no alternative, however, but to use Physiology in a sense co-extensive with that in which we have used Morphology. We must here consider the facts of function in a manner parallel to that in which we have, in the foregoing Part, considered the facts of structure. As, hitherto, we have concerned ourselves with those most general phenomena of organic form which, holding irrespective of class and order and sub-kingdom, illustrate the processes of integration and differentiation characterizing Evolution at large; so, now, we have to concern ourselves with the evidences of those differentiations and integrations of organic functions which have simultaneously arisen, and which similarly transcend the limits of zoological and botanical divisions. How heterogeneities of action have progressed along with heterogeneities of structure-that is the inquiry before us; and obviously, in pursuing it, all the specialities with which Physiology usually deals can serve us only as materials.

Before entering on the study of Morphological Development, it was pointed out that while facts of structure may be empirically generalized apart from facts of function, they cannot be rationally interpreted apart; and throughout the 
foregoing pages this truth has been made abundantly manifest. Here we are obliged to recognize the inter-dependence still more distinctly; for the phenomena of function cannot even be conceived without direct and perpetual consciousness of the phenomena of structure. Though the subject-matter of Physiology is as broadly distinguished from the subjectmatter of Morphology as motion is from matter; yet, just as the laws of motion cannot be known apart from some matter moved, so there can be no knowledge of function without a knowledge of some structure as performing function.

Much more than this is obvious. The study of functions, considered from our present point of view as arising by Evolution, must be carried on mainly by the study of the correlative structures. Doubtless, by experimenting on the organisms which are growing and moving around us, we may ascertain the connexions existing among certain of their actions, while we have little or no knowledge of the special parts concerned in those actions. In a living animal that can be conveniently kept under observation, we may learn the way in which conspicuous functions vary together-how the rate of a man's pulse increases with the amount of muscular exertion he is undergoing; or how a horse's rapidity of breathing is in part dependent on his speed. But though observations of this order are indispensablethough by accumulation and comparison of such observations we learn which parts perform which functions-though such observations, prosecuted so as to disclose the actions of all parts under all circumstances, constitute, when properly generalized and co-ordinated, what is commonly understood as Physiology; yet such observations help us but a little way towards learning how functions came to be established and specialized. We have next to no power of tracing up the genesis of a function considered purely as a function-no opportunity of observing the progressively-increasing quantities of a given action that have arisen in any order of organisms. In nearly all cases we are able only to show 
the greater growth of the part which we have found performs the action, and to infer that greater action of the part has accompanied greater growth of it. The tracing out of Physiological Development, then, becomes substantially a tracing out of the development of the organs by which the functions are known to be discharged-the differentiation and integration of the functions being presumed to have progressed hand in hand with the differentiation and integration of the organs. Between the inquiry pursued in Part IV, and the inquiry to be pursued in this Part, the contrast is that, in the first place, facts of structure are now to be used to interpret facts of function, instead of conversely; and, in the second place, the facts of structure to be so used are not those of conspicuous shape so much as those of minute texture and chemical composition.

$\S 266$. The problems of Physiology, in the wide sense above described, are, like the problems of Morphology, to be considered as problems to which answers must be given in terms of incident forces. On the hypothesis of Evolution these specializations of tissues and accompanying concentrations of functions, must, like the specializations of shape in an organism and its component divisions, be due to the actions and reactions which its intercourse with the environment involves; and the task before us is to explain how they are wrought-how they are to be comprehended as results of such actions and reactions.

Or, to define these problems still more specifically:-Those extremely unstable substances composing the protoplasm of which organisms are mainly built, have to be traced through the various modifications in their properties and powers, that are entailed on them by changes of relation to agencies of all kinds. Those organic colloids which pass from liquid to solid and from soluble to insoluble on the slightest molecular disturbance-those albumenoid matters which, as we see in clotted blood or the coagulable lymph poured 
out on abraded surfaces and causing adhesion between inflamed membranes, assume new forms with the greatest readiness-are to have their metamorphoses studied in connexion with the influences at work. Those compounds which, as we see in the quickly-acquired brownness of a bitten apple or in the dark stains produced by the milky juice of a Dandelion, immediately begin to alter when the surrounding actions alter, are to be everywhere considered as undergoing modifications by modified conditions. Organic bodies, consisting of substances that, as I here purposely remind the reader, are prone beyond all others to change when the incident forces are changed, we must contemplate as in all their parts differently changed in response to the different changes of the incident forces. And then we have to regard the concomitant differentiations of their reactions as being concomitant differentiations of their functions.

Here, as before, we must take into account two classes of factors. We have to bear in mind the inherited results of actions to which antecedent organisms were exposed, and to join with these the results of present actions. Each organism is to be considered as presenting a moving equilibrium of functions, and a correlative arrangement of structures, produced by the aggregate of actions and reactions that have taken place between all ancestral organisms and their environments. The tendency in each organism to repeat this adjusted arrangement of functions and structures, must be regarded as from time to time interfered with by actions to which its inherited equilibrium is not adjusted-actions to which, therefore, its equilibrium has to be re-adjusted. And in studying physiological development we have in all cases to contemplate the progressing compromise between the old and the new, ending in a restored balance or adaptation.

Manifestly our data are so scanty that nothing more than very general and approximate interpretations of this kind are possible. If the hypothesis of Evolution furnishes us with a rude conception of the way in which the 
more conspicuous and important differentiations of functions have arisen, it is as much as can be expected.

$\S 26 \%$. It will be best, for brevity and clearness, to deal with these physiological problems as we dealt with the morphological ones-to carry on the inductive statement and the deductive interpretation hand-in-hand: so disposing of each general truth before passing to the next. Treating separately vegetal organisms and animal organisms, we will in each kingdom consider:-first, the physiological differentiations and accompanying changes of structure which arise between outer tissues and inner tissues; next, those which arise between different parts of the outer tissues; and, finally, those which arise between different parts of the inner tissues. What little has to be said concerning physiological integration must come last. For though, in tracing up Morphological Evolution, we have to study those processes of integration by which organic aggregates are formed, before studying the differentiations that arise among their parts; we must, contrariwise, in tracing up Physiological Evolution, study the genesis of the different functions before we study the interdependence that eventually arises among them and constitutes physiological unity. 


\section{CHAPTER II.}

\section{DIFFERENTIATIONS BETWEEN THE OUTER AND INNER TISSUES OF PLANTS.}

$\S 268$. THE simplest plant presents a contrast between its peripheral substance and its central substance. In each protophyte, be it a spherical cell or a branched tube, or such a more-specialized form as a Desmid, a marked unlikeness exists between the limiting layer and that which it limits. These vegetal aggregates of the first order may differ widely from one another in the natures of their outer coats and in the natures of their contents. As in the Palmella-form of one of the lower Alga, there may exist a clothing of jelly; or, as in Diatom, the walls may take the form of silicious valves variously sculptured. The contained matter may be partly or wholly here green, there red, and in other cases brown. But amid all these diversities there is this one uniformity-a strong distinction between the parts in contact with the environment and the parts not in contact with the environment.

When we remember that this trait is one which these simple living bodies have in common with bodies that are not living - when we remember that each inorganic mass eventually has its outer part more or less differentiated from its inner part, here by oxidation, there by drying, and elsewhere by the actions of light, of moisture, of frost; we can scarcely resist the conclusion that, in the one case as in the other, the contrast is due to the unlike actions to which the 
parts are subject. Given an originally-homogeneous portion of protoplasm, and it follows from the general laws of Evolution (First Principles, $\S \S 149-155$ ), first, that it must lose its homogeneity, and, second, that the leading dissimilarities must arise between the parts most-dissimilarly conditionedthat is, between the outside and the inside. The exterior must bear amounts and kinds of force unlike the amounts and kinds which the interior bears; and from the persistence of force it follows inevitably that unlike effects must be wrought on them-they must be differentiated.

What is the limit towards which the differentiation tends? We have seen that the re-distribution of matter and motion whence, under certain conditions, evolution results, can never cease until equilibrium is reached - proximately a moving equilibrium, and finally a complete equilibrium (First Principles, $\S \S 170-175)$. Hence, the differentiation must go on until it establishes such differences in the parts as shall balance the differences in the forces acting on them. When dealing with equilibration in general, we saw that this process is what is called adaptation (First Principles, $\$ 173$ ) ; and, in this work, we saw that by it the totality of functions of an organism is brought into correspondence with the totality of actions affecting it ( $\$ \S 159-163)$. Manifestly in this case, as in all others, either death or adjustment must eventually result. A force falling on one of these minute aggregates of protoplasm, must expend itself in working its equivalent of change. If this force is such that in expending itself it disturbs beyond rectification the balance of the organic processes, then the aggregate is disintegrated or decomposed. But if it does not overthrow that moving equilibrium constituting the life of the aggregate, then the aggregate continues in that modified form produced by the expenditure of the force. Thus, by direct equilibration, continually furthered by indirect equilibration, there must arise this distinction between the outer part adapted to meet outer forces, and the inner part adapted to meet inner forces. And 
their respective actions, as thus meeting outer and inner forces, must be what we call their respective functions.

$\S 269$. Aggregates of the second order exhibit parallel traits, admitting of parallel interpretations. Integrated masses of cells or units homologous with protophytes, habitually show us contrasts between the characters of the superficial tissues and the central tissues. Such among these aggregates of the second order as have their component units arranged into threads or laminæ, single or double, cannot, of course, furnish contrasts of this kind; for all their units are as much external as internal. We must turn to the more or less massive forms.

Of these, among Fungi, the common Puff-ball is a good example-good because it presents this fundamental differentiation but little complicated by others. In it we have a cortical layer of interwoven hyphæ obviously unlike the mass of spores which it incloses. So far as the unlikeness between external and internal parts is concerned, we see here a relation analogous to that existing in the simple cell; and we see in it a similar meaning: there is a physiological differentiation corresponding to the difference in the incidence of forces.

Under various forms the Algce show just the same relation. Where, as in Codium Bursa, we have the ramified tubular branches of the thallus aggregated into a hollow globular mass, the outer and inner surfaces are contrasted both in colour and structure, though the tubules composing the two surfaces are continuous with one another. In Rivularia, again, we see the like, both in the radial arrangement of the imbedded threads and in the difference of colour between the exterior of the imbedding jelly and its interior. The more-developed Algae of all kinds repeat the antithesis. In branched stems, when they consist of more than single rows of cells, the outer cells become unlike the inner, as shown in Fig. 35. Such types as Chrysymenia rosea show us this 
unlikeness very conspicuously. And it holds even with ribbon-shaped fronds. Wherever one of these is composed of three, four, or more layers, as in Laminaria and Punctaria, the cells of the external layers are strongly distinguished from those of the internal layers, both by their comparative smallness and by their deep colour.

$\$ 270$. The higher plants variously display the like fundamental distinction between outer and inner tissues. Each leaf, thin as it is, exemplifies this differentiation of the parts immediately in contact with the environment from the parts not in immediate contact with the environment. Its epidermal cells, forming a protecting envelope, diverge physically and chemically from the mesophyll cells, which carry on the more active functions. And the contrast may be observed to establish itself in the course of development. At first the component cells of the leaf are all alike; and this unlikeness between the cells of the outer and inner layers, arises simultaneously with the rise of differences in their conditions-differences that have acted on all ancestral leaves as they act on the individual leaf.

An unlikeness more marked in kind but similar in meaning, exists between the bark of every branch and the tissues it clothes. The phænogamic axis, especially when it undergoes what is known as secondary thickening, is commonly characterized by an outer zone of cells (the cork layer) differing from the inner layers in character and function, as it differs from them in position. Subject as this outer layer is to the unmitigated actions of forces around-to abrasions, to extremes of heat and cold, to evaporation and soaking with water-its units have to be brought into equilibrium with these more violent actions, and have acquired molecular constitutions more stable than those of the interior cells. That is to say, the forces which differentiate the cortical part from the rest are the forces which it has to resist, and from which it passively protects the parts within. - How 
clearly this heterogeneity of structure and function is consequent upon' intercourse with the environment, every tree and shrub shows. The young shoots, alike of annuals and perennials, are quite green and soft at their extremities. Among plants of short lives, there is usually but a slight development of bark or none at all: such traces of it as the surface of the axis acquires being seen only at its lowermost or oldest portion. In long-lived plants, however, this formation of a tough opaque coating takes place more rapidly; and shows us distinctly the connexion between the degree of differentiation and the length of exposure. For, in a growing twig, we see that the bark, invisible at the bud, thickens by insensible gradations as we go downwards to the junction of the twig with the branch; and we come to still thicker parts of it as we descend along the branch towards the main stem. Moreover, on examining main stems we find that while in some trees the bark, cracked by expansion of the wood, drops off in flakes, leaving exposed patches of the inner tissue which presently become green and finally develop new bark; in other trees the exfoliated flakes continue adherent, and in the course of years form a rugged fissured coat: so producing a still more marked contrast between outside and inside. Of course the establishment of this heterogeneity is furthered by natural selection, which, where a protective covering is needed, gives an advantage to those individuals in which it has become strongest. But that this divergence of structure commences as a direct adaptation, is clearly shown by other facts than the foregoing. There is the fact that many of the plants which in our gardens develop bark with considerable rapidity, do not develop it with the same rapidity in a greenhouse. And there is the fact that plants which, in some climates, have their stems covered only by thin semi-transparent layers, acquire thick opaque layers when taken to other climates.

Just noting, for the sake of completeness, that in the roots of the higher plants there arises a contrast between 
outer and inner parts, parallel to the one we have traced in their branches, let me draw attention to another differentiation of the same ultimate nature, which the higher plants exhibit to us-a differentiation which, familiar though it is, gains a new meaning by association with those named above, and makes their meaning still more manifest. Each great plant shows it. When, by the budding of axes out of axes, there is produced one of those highly-compounded Phænogams which we call a tree, the central part of the aggregate becomes functionally and structurally unlike the peripheral part. On looking into a large tree, or even a small one which has thick foliage, like the Laurel, we see that the internal branches are almost or quite bare of leaves, while the leaf-clad branches form an external stratum; and all our experience unites in proving that this contrast arises by degrees, as fast as the growth of the tree entails a contrast between the conditions to which inner and outer branches are exposed. Now when, in these most-composite aggregates, we see a differentiation between peripheral and central parts demonstrably caused by a difference in the relations of these parts to environing forces, we get support for the conclusion otherwise reached, that there is a parallel cause for the parallel differentiations exhibited by all aggregates of lower orders -branches, leaves, cells.

\$2\%1. Before leaving this most general physiological differentiation, it may be well to say something respecting certain secondary unlikenesses which usually arise between interior and exterior. For the contrast is not, as might be supposed from the foregoing descriptions, a simple contrast: it is a compound contrast. The outer structure itself is usually divisible into concentric structures. This is equally true of a protophyte and of a phænogamic axis. Between the centre of an independent vegetal cell and its surface, there are at least two layers; and the bark coating the substance of a shoot, besides being itself compound, includes 
another tissue lying between it and the wood. What is the physical interpretation of these facts?

When a mass of something we distinguish as inert matter is exposed to external agencies capable of working changes in it-when it is chemically acted upon, or when, being dry, it is allowed to soak, or when, being wet, it is allowed to drythe changes set up progress in an equable way from the surface towards the centre. At any time during the process (supposing no other action supervenes) the modification wrought, first completed at the outside, either gradually diminishes as we approach the centre, or ceases suddenly at a certain distance from the centre. But now suppose that the mass, instead of being inert, is the seat of active changes -suppose that it is a portion of complex colloidal substance, permeable by light and by fluids capable of affecting its unstable molecules-suppose that its interior is a source of forces continually liberated and diffusing themselves outwards. Is it not likely that while at the centre the action of the internally-liberated forces will dominate, and while at the surface the action of the environing forces will dominate, there will be between the two a certain place at which their actions balance? May we not expect that this will be the place where the most unstable matter exists-the place outside of which the matter becomes relatively stable in the face of external forces, and inside of which the matter becomes relatively stable in the face of internal forces? And must we not conclude that though part of the adjustment is due to indirect equilibration, the initiation of it is due to direct equilibration?

But we are here chiefly concerned with the more general interpretation, which is independent of any such speculation as the foregoing. These contrasted tissues and the contrasted functions they severally perform are, beyond question, subordinated to the relations of outside and inside. And the evidence makes it tolerably clear that the unlike actions or forces involved by the relations of outside and inside, determine these contrasts-partly directly and partly indirectly. 


\section{CHAPTER III.}

DIFFERENTIATIONS AMONG THE OUTER TISSUES OF PLANTS.

$\S 272$. THE motionless protococcoid forms of lower Alga, which do not permanently expose any parts of their surfaces to actions unlike those which other parts are exposed to, have no parts of their surfaces unlike the rest in function and composition. This is what the hypothesis prepares us for. If physiological differentiations are determined by differences in the incidence of forces, then there will be no such differentiations where there are no such differences. Contrariwise, it is to be expected that the most conspicuous unlikeness of function and minute structure will arise between the mostdissimilarly circumstanced parts of the surface. We find that they do. The upper end and the lower end, or, more strictly speaking, the free end and the attached end, habitually present the strongest physiological contrasts.

Even aggregates of the first order illustrate this truth. Such so-called unicellular plants as those delineated in Figs. 4, 5, and 6 , show us, on comparing the contents of their fixed ends and their loose ends, that different processes are going on in them, and that different functions are being performed by their limiting membranes. Caulerpa prolifera, which "consists of a little creeping stem with roots below and leaves above," originating "in the growth of a body which may be regarded as an individual cell," supplies a still-better example. 
gates of the second order a like connexion is displayed in more various modes but with equal consistency. As before, the Puff-ball served to exemplify the primary physiological differentiation of outer parts from inner parts; so, here, it supplies a simple illustration of the way in which the differentiated outer part is re-differentiated, in correspondence with the chief contrast in its relations to the environment. The only marked unlikeness which the cortical layer of the Puff-ball presents, is that between the portion next the ground and the opposite portion. The better-developed Fungi exhibit a more decided heterogeneity of parallel kind. Such incrusting Alga as Ralfsia verrucosa furnish a kindred contrast; and in the higher Algae it is uniformly repeated.

Phænogams display this physiological differentiation very conspicuously. That earth and air are unlike portions of the environment, subjecting roots and leaves to unlike physical forces, which entail on them unlike reactions, and that the unlike functions and structures of their respective surfaces are fitted to these unlike physical forces, are familiar facts which it would be needless here to name, were it not that they must be counted as coming within a wider group of facts.

Is this unlikeness between the outer tissues of the attached ends and those of the free ends in plants, determined by their converse with the unlike parts of the environment? That they result from an equilibration partly arising in the individual and partly arising by the survival of individuals in which it has been carried furthest, is inferable à priori; and this à priori argument may be adequately enforced by arguments of the inductive order. A few typical ones must here suffice.

The gemmules of the Marchantia are little disc-shaped masses of cells composed of two or more layers. Their sides being alike, there is nothing to determine which side falls lowermost when one of them is detached. Whichever side falls lowermost, however, presently begins to send out rootlets, while 
the uppermost side begins to assume those characters which distinguish the face of the frond. When this differentiation has commenced, the tendency to its complete establishment becomes more and more decided; as is proved by the fact that if the positions of the surfaces be altered, the gemmule bends itself so as to re-adjust them: the change towards equilibrium with environing forces having been once set up, there is acquired, as it were, an increasing momentum which resists any counter-change. But the evidence shows that at the outset, the relations to earth and air alone determine the differentiation of the under surface from the upper.

The experiences of the gardener, multiplying his plants by cuttings and layers, constitute another class of evidences not to be omitted: they are commonplace but instructive examples of physiological differentiation. While circumstanced as it usually is, the meristematic tissue of each branch in a Phænogam continues to perform its ordinary function-regularly producing on its outer side the cortical substances, and on its inner side the vascular and woody tissues. But change the conditions to those which the underground part of the plant is exposed to, and there begins another differentiation resulting in underground structures. Contact with water often suffices alone to produce this result, as in the branches of some trees when they droop into a pool, or as occasionally with a cutting placed in a bottle of water; and when the light is excluded by imbedding the end of the cutting, or the middle of the stillattached branch, in the earth, this production of tissues adapted to the function of absorbing moisture and mineral constituents proceeds still more readily. With such cases may be grouped those in which this development of underground organs by an above-ground tissue, is not exceptional but habitual. Creeping plants furnish good illustrations. From the shoots of the Ground-Ivy, rootlets are put out into the soil in a manner differing but little from that in which they are put out by an imbedded layer; save 
that the process follows naturally-induced conditions instead of following artificially-induced conditions. But in the common Ivy which, instead of running along the surface of the earth, runs up inclined or vertical surfaces, we see the process interestingly modified without being essentially changed. The rootlets, here differentiated by their conditions into organs of attachment much more than organs of absorption, still develop on that side of the shoot next the supporting surface, and do not develop where the shoot, growing away from the tree or wall, is surrounded equally on all sides by light and air: thus showing, undeniably, that the production of the rootlets is determined by the differential incidence of forces. Though survival of the fittest doubtless furthered this transition yet it clearly did not initiate it.

That greenness which may be observed in these Ivy-branch rootlets while they are quite young, soft, and unshaded, introduces us to facts which are the converse of the foregoing facts; and proves that the parts ordinarily imbedded in the soil and adapted to its actions, acquire, often in very marked degrees, the superficial structures of the aërial parts, when they are exposed to light and air. This may be witnessed in Maize, which, when Juxuriant, sends out from its nodes near the ground, clusters of roots that are thick, succulent, and of the same colour as the leaves. Examples more familiar to us in England occur in every field of turnips. On noting how green is the uncovered part of a turnip-root, and how manifestly the area over which the grecnness extends varies with the area exposed to light, as well as with the degree of the exposure, it will be seen that beyond question, root-tissue assumes to a considerable extent the appearances and function of leaf-tissue, when subject to the same agencies. Let us not forget, too, that where exposed roots do not approach in superficial character towards leaves, they approach in superficial character towards stems: becoming clothed with a thick, fissured bark, like that of the trunk and 
branches.

But the most conclusive evidence is furnished by the actual substitutions of surface-structures and functions, that occur in aërial organs which have taken to growing permanently under ground, and in under-ground organs which have taken to growing permanently in the air. On the one hand, there is the rhizome exemplified by Ginger-a stem which, instead of shooting up vertically, runs horizontally below the surface of the soil, and assumes the character of a root, alike in colour, texture, and production of rootlets; and there is that kind of swollen under-ground axis, bearing axillary buds, which the Potato exemplifies-a structure which, though homologically an axis, simulates a tuberous root in surface-character, and when exposed to the air, manifests no greater readiness to develop chlorophyll than a tuberous root does. On the other hand, there are the aërial roots of certain Orchids which, habitually green at their tips, continue green throughout their whole lengths when kept moist; which have become leaf-like not only by this development of chlorophyll, but also by the acquirement of stomata; and which do not bury themselves in the soil when they have the opportunity.* Thus we have aërial organs so completely changed to fit under-ground actions, that they will not resume aërial functions; and under-ground organs so completely changed to fit aërial actions, that they will not resume under-ground functions.

That the physiological differentiation between the part of a plant's surface which is exposed to light and air and the part which is exposed to darkness and moisture and solid

* A critical comment made on this sentence runs as follows:- "The aërial roots of most epiphytic orchids contain chlorophyll in their cortex throughout their length, but the cortex being covered by a 'velamen' of aircontaining cells which break up and reflect incident light, the green colour is not visible through this opaque coat. When moistened the cells of the velamen take up water and the green colour immediately shows through. Such roots do not however possess stomata. The roots of certain species of Angrocum, bowever, contain the whole of the assimilating tissue of the plant." 
matter, is primarily due to the unlike actions of these unlike parts of the environment, is, then, clearly implied by observed facts-more clearly, indeed, than was to be expected. Considering how strong must be the inherited tendency of a plant to assume those special characters, physiological as well as morphological, which have resulted from an enormous accumulation of antecedent actions, it may be even thought surprising that this tendency can be counteracted to so great an extent by changed conditions. Such a degree of modifiability becomes comprehensible only when we remember how little a plant's functions are integrated, and how much, therefore, the functions going on in each part may be altered without having to overcome the momentum of the functions throughout the whole plant. But this modifiability being as great as it is, we can have no difficulty in understanding how, by the cumulative aid of natural selection, this primary differentiation of the surface in plants has become what we see it.

$\S 273$. We will leave now these contrasts between the free surfaces of plants and their attached or imbedded surfaces, and turn our attention to the secondary contrasts existing between different parts of their free surfaces. Were a full statement of the evidence practicable, it would be proper here to dwell on that which is furnished by the inferior classes. It might be pointed out in detail that where, as among the Alga, the free surfaces are not dissimilarly conditioned, there is no systematic differentiation of them-that the frond of an Ulva, the ribbon-shaped divisions of a Laminaria, and the dichotomous expansions of the Fuci which clothe the rocks between tide-marks, are alike on both sides; because, swayed about in all directions as they are by the waves and tides, their sides are equally affected. Conversely, from the Fungi might be drawn abundant proof that even among Thallophytes, unlikenesses arise between different parts of the free surfaces when their circumstances are unlike. 
In such laterally-growing kinds as are shown in Fig. 196b, the honey-combed under surface and the smooth leathery upper surface, have their contrasts related to contrasted conditions; and in the adjacently-figured Agarics, and other stalked genera, the pileus exhibits a parallel difference, explicable in a parallel way. But passing over Cryptogams it must suffice if we examine more at length these traits as they are displayed by Phænogams. Let us first note the dissimilarities between the outer tissues of stems and leaves.

That these dissimilarities arose by degrees, as fast as the units of which the phænogamic axis is composed became integrated, is a conclusion in harmony with the truth that in every shoot of every plant, they are at first slight and become gradually marked. Already, in briefly tracing the contrasts between the outer and inner tissues of plants, some facts have been named showing, by implication, how the cessation of the leaf-function in axes is due to that change of conditions entailed by the discharge of other functions. Here we have to consider more closely facts of this class, together with others immediately to the point. On pulling off from a stem of grass the successive sheaths of its leaves, the more-inclosed parts of which are of a fainter green than the outer parts, it will be found that the tubular axis eventually reached is of a still fainter green; but when the axis eventually shoots up into a flowering stem, its exposed part acquires as bright a green as the leaves. In other Monocotyledons, the leaf-sheaths of which are successively burst and exfoliated by the swelling axis, it may be observed that where the dead sheaths do not much obstruct the light and air, the surface of the axis underneath is full of chlorophyll. Dendrobium is an example. But when the dead sheaths accumulate into an opaque envelope, the chlorophyll is absent, and also, we may infer, the function which its presence habitually implies. Carrying with us this evidence, we shall recognize a like relation in Dicotyledons. While its outer layer remains tolerably transparent, an exogenous stem or 
branch continues to show, by the formation of chlorophyll, that it shares in the duties of the leaves; but in proportion as a bark which the light cannot penetrate is produced by the adherent flakes of dead skin, or by the actual deposit of a protective substance, the differentiation of duties becomes more decided.

Cactuses and Euphorbias supply us with converse facts having the same implication. The succulent axes so strangely combined in these plants, maintain for a long time the translucency of their outer layers and their greenness; and they so efficiently perform the offices of leaves that leaves are not produced. In some cases, axes that are not succulent participate largely in the leaf-function, or entirely usurp it-still, however, by fulfilling the same essential conditions. Occasionally, as in Statice brassicafolia, stems become fringed; and the fringes they bear assume, along with the thinness of leaves, their darker green and general aspect. In the genus Ruscus, the flattened axis simulates so closely the leaf-structure, that were it not for the flower borne on its midrib, or edge, its axial nature would hardly be suspected. And let us not omit to note that where axes usurp the characters of leaves, in their attitudes as well as in their shapes and thicknesses, there are contrasts between their under and upper surfaces, answering to the contrasts between the relations of these surfaces to the light. Of this Ruscus androgynus furnishes a striking example. In it the difference which the unaided eye perceives is much less conspicuous than that disclosed by the microscope; for I find that while the face of the pseudo-leaf has no stomata, the back is abundantly supplied with them. One more illustration must be added. Equally for the morphological and physiological truths which it enforces, the Mühlenbeckia platyclada is one of the most instructive of plants. In it the simulation of forms and usurpation of functions, are carried out in a much more marvellous way than among the Cactacex. Imagine a growth resembling in outline a very long willowleaf, but without a midrib, and having its two surfaces alike. 
Imagine that across this thin, green, semi-transparent structure, there are from ten to thirty divisions, which prove to be the successive nodes of an axis. Imagine that along the edges of this leaf-shaped aggregate of internodes, there arise axillary buds, some of which unfold into flowers, and others of which shoot up vertically into growths like the one which bears them. Imagine a whole plant thus seemingly composed of jointed willow-leaves growing from one another's edges, and some conception will be formed of the Mühlenbeckia. The two facts which have meaning for us here are-first, that the performance of leaf-functions by these axes goes along with the assumption of a leaf-like translucency; and, second, that these flattened axes, retaining their upright attitudes, and therefore keeping their two faces similarly conditioned, have these two faces alike in colour and texture.

That physiological differentiation of the surface which arises in Phænogams between axial organs and foliar organs, is thus traceable with tolerable clearness to those differences between their conditions which integration has entailedpartly in the way above described and partly in other ways still to be named. By its relative position, as being shaded by the leaves, the axis is less-favourably circumstanced for performing those assimilative actions effected by the aid of light. Further, that relatively-small ratio of surface to mass in the axis, which is necessitated by its functions as a support and a channel for circulation, prevents it from taking in, with the same facility as the leaves, those surrounding gases from which matter is to be assimilated. Both these special causes, however, in common with that previously assigned, fall within the general cause. And in the fact that where the differential conditions do not exist, the physiological differentiation does not arise, or is obliterated, we have clear proof that it is determined by unlikenesses in the relations of the parts to the environment.

§274. From this most general contrast between aërial 
surface-tissues - those of axes and those of folia-we pass now to the more special contrasts of like kind existing in folia themselves. Leaves present us with superficial differentiations of structure and function; and we have to consider the relations between these and the environing forces.

Over the whole surface of every phænogamic leaf, as over the fronds of the Pteridophyta, there extends a simple or compound epidermal layer, formed of cells that are closely united at their edges and devoid (in the Flowering Plants) of that granular colouring matter (chlorophyll) contained in the layers of cells they inclose: the result being that the membrane formed of them is comparatively transparent. On the submerged leaves of aquatic Phænogams, this outer layer is thin, delicate, and permeable by water; but on leaves exposed to the air, and especially on their upper surfaces, is comparatively strong, dense, often smooth and impermeable by water: being thus fitted to prevent the rapid escape of the contained juices by evaporation. Similarly, while the leaves of terrestrial plants which live in temperate climates, usually have comparatively thin coats thus composed, in climates that are both hot and dry, leaves are commonly clothed with a very thick cuticle. Nor is this all. The outside of an aërial leaf differs from that of a submerged leaf by containing a deposit of waxy substance. Whether this be exuded by the exposed surfaces of the cells, as some contend, or whether it is deposited within the cells, as thought by others, matters not in so far as the general result is concerned. In either case a waterproof coating is formed at the outermost sides of these outermost cells; and in many cases produces that polish by which the upper surface of the leaf is more or less distinguished from the under surface.

This external pellicle presents us with another contrast of allied meaning. On the upper surfaces of leaves subject to the direct action of the sun's rays, there are either few or none of those minute openings, or stomata, through which gases can enter or escape; but on the under surfaces these stomata 
are abundant: a distribution which, while permitting free absorption of the needful carbonic acid, puts a check on the exit of watery vapour. Two general exceptions to this arrangement may be noted. Leaves that float on the water have all their stomata on their upper sides, and leaves that are submerged have no stomata-modifications obviously appropriate to the conditions. What is to be said respecting the genesis of these differentiations? For the last there seems no direct cause: its cause must be indirect. The unlike actions to which the upper and under surfaces of leaves are subject, have no apparent tendency to produce unlikeness in the number of their breathing holes. Here the natural selection of spontaneous variations furnishes the only feasible explanation. For the first, however, there is a possible cause in the immediate actions of incident forces, which survival of the fittest continually furthers.

The fluid exhaling through the walls of the cells next the air, will be likely to leave behind suspended substances on their outer surfaces. On remembering the pellicle which is apt to form on thick solutions or emulsions as they dry, and how this pellicle as it grows retards the further drying, it will be perceived that the deposit of waxy matter next to the outer surfaces of the cuticular cells in leaves, is not improbably initiated by the evaporation which it eventually checks. Should it be so, there results a very simple case of equilibration. Where the loss of water is too great, this waxy pellicle left behind by the escaping water will protect most those individuals of the species in which it is thickest or densest; and by inheritance and continual survival of the fittest, there will be established in the species that thickness of the layer which brings the evaporation to a balance with the supply of water.

Another superficial differentiation, still more familiar, has to be noted. Every child soon learns to distinguish by its colour the upper side of a leaf from its under side, if the leaf is one that has grown in such way as to establish the relations of upper and under. The upper surfaces of leaves are 
habitually of a deeper green than the under. Microscopic examination shows that this deeper green results from the closer clustering of those parenchyma-cells full of chlorophyll that are in some way concerned with the assimilative actions; while beneath them are more numerous intercellular passages communicating with those openings or stomata through which is absorbed the needful air. Now when it is remembered that the formation of chlorophyll is clearly traceable to the action of light-when it is remembered that leaves are pale where they are much shaded and colourless when developed in the dark, as in the heart of a Cabbage-when it is remembered that succulent axes and petioles, like those of Sea-kale and Celery, remain white while the light is kept from them and become green when exposed; it cannot be questioned that this greater production of chlorophyll next to the upper surface of a leaf, is directly consequent on the greater amount of light received. Here, as in so many other cases, we must regard the differentiation as in part due to direct equilibration and in part to indirect equilibration. Familiar facts compel us to conclude that from the beginning, each individual foliar organ has undergone a certain immediate adaptation of its surfaces to the incidence of light; that when there arose a mode of growth which exposed the leaves of successive generations in similar ways, this immediatelyproduced adaptation, ever tending to be transmitted, was furthered by the survival of individuals inheriting it in the greatest degree; and that so there was gradually established that difference between the two surfaces which each leaf displays before it unfolds to the light, but which becomes more marked when it has unfolded.*

* The current doctrine that chlorophyll is the special substance concerned in regetal assimilation, either as an agent or as an incidental product, must be taken with considerable qualification. Besides the fact that among the Alga there are many red and brown kinds which thrive; and besides the fact that among the lower Archegoniates there are species which are purple or chocolate-coloured; there is the fact that Phænogams are not all green. We have the Copper-Beech, we have the black-purple Colens Verschaffellii, and we have the red variety of Cabbaire, which seems to flourish as well as the 
From the ordinary cases let us now pass to the exceptional cases. We will look first at those in which the two faces of the leaves differ but little, or not at all-their circumstances being similar or equal. Leaves that grow in approximatelyupright attitudes, and attitudes which do not maintain the relative positions of the two surfaces with constancy, may be expected to display an unusual likeness between the two surfaces; and among them we see it. The Grasses may be named as a group exemplifying this relation; and if, instead of comparing them as a group with other groups, we compare those dwarf kinds of them which spread out their leaves horizontally, with the large aspiring kinds, such as Arundo, we trace a like antithesis: in the one the contrast of upper and under is very obvious, while in the other it is scarcely to be detected. Leaves of various other Monocotyledons that grow in a similar way, similarly show us a near approach to uniformity of the two surfaces; as instance the genus Clivia and the thinner-leaved kinds of Yucca. Where the contrast of upper and under is greatly diminished by the assumption of a rounded or cylindrical form, instead of a flattened form, the same thing happens. The genus Kleinia furnishes illustrations. It may be remarked, too, that even within the limits of this genus there are instructive variations; for while in Kleinia ficoides the leaves, shaped like pea-pods, are broadest in a vertical direction, and have their lateral surfaces alike in conditions and structure, in other species the leaves, broader horizontally than vertically, exhibit unlikeness between the upper and under sides. Equally to the point is the evidence furnished by vertically-growing leaves that are cylindrical, as those of Sanseviera cylindrica, or as those of the Rush-tribe: the similarly-placed surface has all around a similar character.

Of kindred meaning,

other varieties. Chlorophyll, then, must be regarded simply as the most general of the colouring matters found in those parts of plants in which assimilation is being effected by the ageney of light. Though it is always present alonm with the red and hrown pigments, yet there is much evidence to show that these are the actual assimilative pigments. 
and still more conclusive, are the cases in which the under side of the leaf, being more exposed to light than the upper side, usurps the character and function of the upper side. If a common Flag be pulled to pieces, it will be seen that what answers to the face in other leaves, forms merely the inside of the sheath including the younger leaves, and is obliterated higher up. The two surfaces of the blade answer to the two under halves of a leaf that has been, as it were, folded together lengthways, with the two halves of its upper surface in contact. And here, in default of an upper surface, the under surface acquires its character and discharges its function. A like substitution occurs in Aristea corymbosa; and there are some of the Orchids, as Lockhartia, which display it in a very obvious way.

When joined with the foregoing evidence, the evidence which another kind of substitution supplies is of great weight. I refer to that which occurs in the Australian Acacias, already instanced as throwing light on morphological changes. In these plants the leaves properly so called are undeveloped, and the footstalks, flattened out into foliaceous shapes, acquire veins and midribs, and so far simulate leaves as ordinarily to be taken for them: a fact in itself of much physiological significance. But that which it concerns us especially to note, is the absence of distinction between the two faces of these phyllodes, as they are named, and the cause of its absence. These transformed petioles do not flatten themselves out horizontally, so as to acquire under and upper sides, as most true leaves do; but they flatten themselves out vertically: the result being that their two sides are similarly circumstanced with respect to light and other agencies; and there is consequently nothing to cause their differentiation. And then we find an analogous case where differential conditions arise, and where some differentiation results. In Oxalis bupleurifolia, Fig. 66, there is a similar flattening out of the petiole into a pseudo-leaf; but in it the flattening takes place in the same plane as the leaf, 
so as to produce an under and an upper surface; and here the two surfaces of the pseudo-leaf are slightly unlike-in contour if in nothing else.

$\S 275$. We now come to such physiological differentiations among the outer tissues of plants, as are displayed in the contrasts between foliar organs on the same axis, or on different axes - contrasts between the seed-leaves and the leaves subsequently formed, between submerged and aërial leaves in certain aquatic plants, between leaves and bracts, and between bracts and sepals. To deal even briefly with these implies information which even a professed botanist would have to increase by special inquiries, before attempting interpretations. Here it must suffice to say something respecting those marked unlikenesses existing between the tissues of the more characteristic parts of flowers, and the tissues of the homologous foliar organs.

It was pointed out in $\S 196$, that the terminal folia of a phænogamic axis have sundry characters in common with such fronds as those out of which we concluded that the phænogamic axis has arisen by integration-common characters of a kind to be expected. In their simple cellular composition, comparative want of chlorophyll, and deficiency of vascular structures, the undeveloped ends of leaf-shoots and the dcveloped ends of flower-shoots, approach to the fronds of the simpler Archegoniates. We also noted between them another resemblance. It is said of the Jungermanniacex, that " though under certain circumstances of a pure green, they are inclined to be shaded with red, purple, chocolate, or other tints;" and answering to this we have the facts that such colours commonly occur in the terminal folia of a phænogamic axis, when arrest of its development leads to the formation of a flower, and that very frequently they are visible at the ends of leaf-axes. In the unfolding parts of shoots, more or less of red, or copper-colour, or chocolatecolour, may generally be scen: often, indeed, it charac- 
terizes the leaves for some time after they are unfolded. Occasionally the traces of it are permanent; and, as in the scarlet terminal leaves of Poinsettia pulcherrima, we see that it may become, and continue, extremely conspicuous. The question, then, now to be asked is-has this colouring by which the immature part of the phænogamic axis is characterized, anything to do with the colouring of flowers? Has this difference between undeveloped folia and folia that are further developed, been increased by natural selection where an advantage accrued from it, until it has ended in the strong contrast we now see? I think we may not irrationally infer that this has happened.

Facts, very numerous and varied, united to warrant us in concluding that gamogenesis commences where the forces which conduce to growth are nearly equilibrated by the forces which resist growth ( $\S 78)$; and the induction that in plants, fertilized germs are produced at places where there is an approach towards this balance, we found to be in harmony with the deduction that an advantage to the species must be gained by sending off migrating progeny from points where nutrition is failing. Other things equal, failure of nutrition may be expected in parts which have the most remote or most indirect access to the materials furnished by the rootsmaterials which have to be carried great distances by a very imperfect apparatus. The ends of lateral axes are therefore the probable points of fructification, in aggregates of the third order that have taken to growing vertically. But if these points at which nutrition is failing, are also the points at which the colours inherited from lower types are likely to recur in more marked degrees than elsewhere; then we may infer that the organs of fructification will not unfrequently co-exist with such colours at the ends of such axes. How may the resulting contrast between the older fronds and the fronds next the germ-producing organs be increased? If uninterfered with it would be likely to diminish. These traits inherited from remote ancestry might be expected 
slowly to fade away. How, then, is the intensification of them to be explained?

If a contrast of the kind described favours the propagation of a race in which it exists, it will be maintained and increased; and if we take into account an agency of which Mr. Darwin has shown the great importance-the agency of insects-we shall have little difficulty in understanding how such a contrast may facilitate propagation. We cannot, of course, here assume the agency of insects so specialized in their habits as Bees and Butterflies; for their specialized habits imply the pre-existence of the contrast to be explained. But there is an insect-agency of a more general kind which may be fairly counted upon as coming into action. Various small Flies and Beetles wander over the surfaces of plants in search of food. It is a legitimate assumption that they will frequent most those parts in which they find most food, or food most to their liking - especially if at the same time they gain the advantage of concealment. Now the ends of axes, formed of young, soft, and closely-packed folia, are the parts which more than any others offer these several advantages. They afford shelter from enemies; they frequently contain exuded juices; and when they do not, their tissues are so tender as to be easily pierced in search of the sap. If, then, from the first, as at present, these ends of axes have been favourite haunts of small insects; and if, where the closely-clustered folia contained the generative organs, the insects frequenting them occasionally carried adherent fructifying cells from one plant to another, and so aided fertilization; it would follow that anything which made such terminal clusters more attractive to such insects, or more conspicuous to them, or both, would further the multiplication of the race, and would so be continually increased by the extra multiplication of individuals in which it was greatest. Here we find the clue. This contrast of colour between the folia next to the fructifying parts and all other folia, must constantly have facilitated insect-agency; sup- 
posing the insects to have had the power of distinguishing between colours. That Bees and Butterflies have this power is manifest. They may be watched flying from flower to flower, disregarding all other parts of the plants. And if the less-specialized insects possessed some degree of such discrimination, then the initial contrasts of colour above described would be maintained and increased. Let such a connexion be once established, and it must tend to become more decided. Insects most able to discern the parts of plants which afford what they seek, will be those most likely to survive and leave offspring. Plants presenting most of the desired food, and showing most clearly where it lies, will have their fertilization and multiplication furthered in the greatest degree. And so the mutual adaptation will become ever closer; while it is rendered at the same time more varied by the special requirements of the insects and of the plants in each locality, under each change of conditions. of course, the genesis of the sweet secretions and the odours of flowers, has a parallel interpretation. The simultaneous production of honey, or some kindred substance, is implied above; since, unless a bait co-existed with the colour, the colour would not attract insects, and would not be maintained and intensified by natural selection. Gums, and resins, and balsams, are familiar products of plants : apparently, in many cases, excreted as useless matters from various parts of their surfaces. These substances, admitting of wide variations in quality, as they do, afford opportunities for the action of natural selection wherever any of them, attractive to insects, happen to be produced near the organs of fructification. And this action of natural selection once set up, may lead to the establishment of a local excretion, to the production of an excretion more and more attractive, and to the disposal of the organ containing it in such a way as most to facilitate the carrying away of pollen. Similarly and simultaneously with odours. Odours, like colours, draw insects to flowers. After 
observing how Bees come swarming into a house where honey is largely exposed, or how Wasps find their way into a shop containing much ripe fruit, it cannot be questioned that insects are to a considerable extent guided by scent. Being thus sensitive to the aromatic substances which flowers exhale, they may, when the flowers are in large masses, be attracted by them from distances at which the flowers themselves are invisible. And manifestly, the flowers which so attract them from the greatest distances, increasing thereby their chances of efficient fertilization, will be most likely to perpetuate themselves. That is to say, survival of the fittest must tend to produce perfumes that are both more powerful and more attractive.

These physiological differentiations, then, which mark off the foliar organs constituting flowers from other foliar organs, are the consequences of indirect equilibration. They are not due to the immediate actions of unlike incident forces on the parts of the individual plant; but they are due to the actions of such unlike incident forces on the aggregate of individuals, generation after generation.*

$\S 276$. The unity of interpretation which we here find for phenomena of such various orders, could hardly be found

* This seems as fit a place as any for noting the fact, that the greater part of what we call beauty in the organic world, is in some way dependent on the sexual relation. It is not only so with the colours and odours of flowers. It is so, too, with the brilliant plumage of birds; and it is probable that the colours of the more conspicuous insects are in part similarly deternined. The remarkable circumstance is, that these characteristics, which have originated by furthering the production of the best offspring, while they are naturally those which render the organisms possessing them attractive to one another, directly or indirectly, shonld also be those which are so generally attractive to us-those without which the fields and woods would lose half their charm. It is inieresting, too, to observe how the conception of human beauty is in a considerable degree thus originated. And the trite observation that the element of beauty which grows out of the sexual relation is so predominant in rsthetic products-in music, in the drama, in fiction, in poetry - gains a new meaning when we see how deep down in organic nature this connexion extends. 
were the phenomena otherwise caused. That the stronger and the feebler contrasts among the different parts of the outer tissues in plants, should so constantly occur along with stronger and feebler contrasts among the incident forces, is in itself weighty evidence that unlike outer actions have çaused unlike inner actions, and correspondingly-unlike structures; either by changing the functional equilibrium in the individual, or by changing it in the race, or by both.

Even in the absence of more direct proof, there would be great significance in the marked differences that habitually exist between the exposed and imbedded parts of plants, between the stems and the leaves, and between the upper and under surfaces of the leaves. The significance of these differences is increased when we discover that they vary in degree as the differences in the conditions vary in degree. Still greater becomes the force of the evidence on finding that these strongly-contrasted parts may, when placed in one another's conditions, and kept in them from generation to generation, permanently assume one another's functions, and, in a great degree, one another's structures. Even more conclusive yet is the argument rendered, by the discovery that, where these substitutions of function and structure take place, the superinduced modifications differ in different circumstances; just as the original modifications do. The fact that a flattened stem simulating a vertically-growing leaf has its two surfaces alike, while when it simulates a horizontallygrowing leaf its upper and under surfaces differ, is a fact which, standing alone, might prove little, but proves much when joined with all the other evidence. And its profound meaning becomes the more obvious on discovering that the same thing happens with petioles when they usurp leaffunctions.

Finally, when we remember how rapidly analogous modifications of function and structure arise in the superficial tissues of individual plants, the general inference can scarcely be resisted. When we meet with so striking a case as that 
of the Begonia-leaf, a fragment of which stuck in the ground produces roots from its under surface and leaves from its upper surface-when we see that though, in this case, the typical structure of the plant presently begins to control the organizing process, yet the initial differentiations are set up by the differential actions of the environment; the presumption becomes extremely strong that the heterogeneities of surface which we have considered, result, as alleged, directly or indirectly from heterogeneities in the incident forces. 


\section{CHAPTER IV.}

\section{DIFFERENTIATIONS AMONG THE INNER TISSUES OF PLANTS.*}

$\S 27 \%$. IN passing from plants formed of threads or thin laminæ, to plants having some massiveness, we find that after the external and internal parts have become distinguished from one another, there arise distinctions among the internal parts themselves, as well as among the external parts themselves: the primarily-differentiated parts are both redifferentiated.

From types of very low organisation illustrations of this may be drawn. In the thinner kinds of Laminaria there exists but the single contrast between the outer layer of cells and an inner layer; but in larger species of the same genus, as L. digitata, there are three unlike layers on each side of a central layer differing from them-augmentation of bulk is accompanied by multiplication of concentric internal structures, having their unlikenesses obviously related to unlikenesses in their conditions. In Furcellaria and various Algae of similarly swollen forms, the like relation may be traced.

Just indicating the generality of this contrast, but not

* Students of vegetal physiology, familiar with the controversies respecting sundry points dealt with in this chapter, will probably be surprised to find taken for granted in it, propositions which they have habitually regarded as open to doubt. Hence it seems needful to say that the conclusions here set forth, have resulted from investigations undertaken for the purpose of forming opinions on several unsettled questions which I had to treat, but which I could find in books no adequate data for treating. The details of these investigations, and the entire argument of which this chapter is partly an abstract, will be found in Appendix C. 
attempting to seek in these lower types for any more specific interpretation of it, let us pass to the higher types. The argument will be amply enforced by the evidence obtained from them. We will look first at the conditions which they have to fulfil; and then at the ways in which the functions and structures adapting them to these conditions arise.

$\S 278$. A terrestrial plant that grows vertically needs no marked modification of its internal tissues, so long as the height it reaches is very small. As we before saw, the spiral or cylindrical rolling up of a simple cellular frond, or the more bulky growth of a simple cellular axis, may give the requisite strength; and the requisite circulation may be carried on through the unchanged cellular tissue. But in proportion as the height to be attained and the mass to be supported increase, the supporting part must acquire greater bulk or greater density, or both; and some modification that shall facilitate the transfer of nutritive liquids must take place. Hence, in the inner tissues of plants we may expect to find that structural changes answering to these requirements become marked, as the growth of the aërial part becomes great. Facts correspond with these expectations.

Among the liumbler Cormophytes, which creep over or raise themselves but little above, the surfaces they flourish upon, there is scarcely any internal differentiation: the vascular and woody structures, if not in all cases absolutely unrepresented, are rarely and very feebly indicated. But among the higher types - the Ferns and Lycopodiums which raise their fronds to considerable heights, there are vascular bundles and hard tissues like wood; and by the Tree-Ferns massive axes are developed. That the relation which thus shows itself among Cryptogams is habitual among Phænogams, scarcely needs saying.

Phænogams, however, are not universally thus characterized in a decided way. Besides the comparative want of woody tissue in flowering plants of humble growth, and 64 
besides the paucity of vessels in ordinary water-plants, there are cases of much more marked divergence from this typical internal structure. These exceptional cases occur under exceptional conditions, and are highly instructive. They are of two kinds.

One group of them is furnished by certain plants which are parasitic on the exposed roots of trees-parasitic not partially, as the Mistletoe, but to the extent of subsisting wholly on the sap they absorb. Funguslike in colour and texture, and having scales for leaves, these Balanophorce and Rafflesiacece are recognizable as Phænogams by scarcely any other traits than their fructifications. Along with their aborted leaves and absence of chlorophyll, there is a great degradation of those internal tissues by which Phænogams are commonly distinguished. Though Dr. [now Sir J.] Hooker has shown that they are not, as some botanists thought, devoid of spiral vessels; yet, as shown by the mistake previously made in classifying them, their appliances for circulation are rudimentary. And this trait goes along with a greatly-simplified distribution of nutriment. In the absence of leaves there can be but little down-current of sap, such as leaves usually supply to roots: there cannot be much beyond an upward current of the absorbed juices. The other cases occur where circulation is arrested or checked in a different way; namely, in plants that are wholly submerged. These are the Podostemacea. Clothing as they do the submerged rocks, their roots play the part of rhizomes, being attached to the substratum by hairs and other processes, and having the leaf-bearing and flower-bearing shoots on their surfaces. The latter spread out more or less horizontally and are also fixed to the substratum in the same manner as the roots. Observe then the connexion of facts. One of these Podostemacea needs no internal stiffening substance, for it exists in a medium of its own specific gravity; and being in a position to absorb water over its entire surface, it has no need for a circulation of crude sap-nor, indeed, in the absence of evaporation from any part of its surface, could 
any active circulation take place. Here, accordingly, the tracheal and mechanical elements are undeveloped. 'Though spiral vessels are not entirely absent, yet they are so rare as to do no more than verify the inference of phænogamic relationship drawn from the flowers.

The method of agreement, the method of difference, and the method of concomitant variations, thus unite in proving a direct relation between the demand for support and circulation, and the existence of these vascular woody bundles which the higher plants habitually possess. The question which we have to consider is - Under what influences are these structures, answering to these requirements, developed? How are these internal differentiations caused? The inquiry may be conveniently divided. Though the supporting tissues and the tissues concerned in the circulation of liquids are closely connected, and indeed entangled, with one another, we may fitly deal with them apart. Let us take first the supporting tissue.

$\S 279$. Many common-place facts indicate that the mechanical strains to which upright growing plants are exposed, themselves cause increase of the dense deposits by which such plants are enabled to resist such strains. There is the fact that the massiveness of a tree-trunk varies according to the stres's habitually put upon it. If the contrast between the slender stem of a tree growing in a wood and the bulky stem of a kindred tree growing in the fields, be ascribed to difference of nutrition rather than difference of exposure to winds; there is still the fact that a tree trained against a wall has a less bulky stem than a tree of the same kind growing unsupported; and that between the long weak branches of the one and the stiff ones of the other there are decided contrasts. If it be objected that a tree so trained and branches so borne have relatively less foliage, and that therefore these unlikenesses also are due to unlikenesses of general nutrition, which may in part be true; there are still such cases as those of 
garden plants, which when held up by tying them to sticks have weaker stems than when they are unpropped, and sink down if their props are taken away. Again, there is the evidence supplied by roots. Though the contrast between the feeble roots of a sheltered tree and the strong roots of an exposed tree, may, like the contrast of their stems, be mainly due to difference of nutrition, and therefore supplies but doubtful evidence, we get tolerably clear evidence where trees growing on inclined rocky surfaces, send into crevices that afford little moisture or nutriment, roots which nevertheless become thick where they are so directed as to bear great strains. Suspicion thus raised is strengthened into conviction by special evidences occurring in the places where they are to be expected. The Cactuses, with their succulent growths that pass into woody growths slowly and irregularly, give us the opportunity of tracing the conditions under which the wood is formed. Good examples occur in the genus Cereus, and especially in forms like C. crenulatus. Here, from a massive vertically-growing rod of fleshy tissue, two inches or more in diameter, there grow at intervals lateral rods similarly bulky, which, quickly curving themselves, take vertical directions. One of these heavy branches puts great strains on its own substance and that of the stem at their point of junction; and here both of them become brown and hard, while they continue green and succulent all around. Such differentiations may be traced internally before they are visible on the surface. If a joint of an Opuntia be sliced through longitudinally, the greater resistance to the knife alt around the narrow neck, indicates there a larger deposit of lignin than elsewhere; and a section of the tissue placed under the microscope, exhibits at the narrowest part a concentration of the woody and vascular bundles. Clear evidence of another kind has been noted by Mr. Darwin, in the organs of attachment of climbing plants. Speaking of Solanum jasminoides he says:- "When the flexible petiole of a half- or a quarter-grown leaf has clasped any object, in three 
or four days it increases much in thickness, and after several weeks becomes wonderfully hard and rigid; so that I could hardly remove one from its support. On comparing a thin transverse slice of this petiole with one from the next or older leaf beneath, which had not clasped anything, its diameter was found to be fully doubled, and its structure greatly changed. . . . This clasped petiole had actually become thicker than the stem close beneath; and this was chiefly due to the greater thickness of the ring of wood, which presented, both in transverse and longitudinal sections, a closely similar structure in the petiole and axis. The assumption by a petiole of this structure is a singular morphological fact; but it is a still more singular physiological fact that so great a change should have been induced by the mere act of clasping a support."

If there is a direct relation between mechanical stress and the formation of wood, it ought to explain for us the internal distribution of the wood. Let us see whether it does this.

When seeking in mechanical actions and reactions the cause of that indurated structure which forms the vertebrate axis ( $\$ 254-7)$, it was pointed out that in a transversely-strained mass, the greatest pressures and tensions are thrown on the molecules of the concave and convex surfaces. Hence, supposing the transversely-strained mass to be a cylinder, bent backwards and forwards not in one plane but now in this plane and now in that, its peripheral layers will be those on which the greatest stress falls. An ordinary dicotyledonous axis is such a cylinder so strained. The maintenance of its attitude either as a lateral shoot or a vertical shoot, implies subjection to the bendings caused by its own weight and by the ever-varying wind. These bendings imply tensions and pressures falling most severely first on one side of its outer layers and then on another. And if the dense substance able to resist these tensions and pressures is deposited most where they are greatest, we ought to find it taking the shape of a cylindrical casing. This is just what 
we do find. On cutting across a shoot in course of formation, we see its central space either unoceupied or occupied only by soft tissue. That the layer of hard tissue surrounding this is not the outermost layer, is true: there lies beyond it the cambium layer, from which it is formed, the plloëm, and the cortex. But outside of the soft phloëm there is frequently another layer of dense tissue now known as the pericyclic fibres, having frequently a tenacity greater even than that of the wood-a layer which, while it protects the cambium and offers additional resistance to the transverse strain, admits of being fissured as fast as the cylinder of wood thickens. That is to say, the deposit of resisting substance is as completely peripheral as the exogenous mode of growth permits. So, too, in general arrangement is it with the ordinary monocotyledonous stem. Different as is here the internal structure, there yet holds the same general distribution of tissues, answering to the same mechanical conditions. The vascular woody bundles, more abundant towards the outside of the stem than near the centre, produce a harder casing surrounding a softer core.

In the supporting structures of leaves we find significant deviations from this arrangement. While axes are on the average exposed to equal strains on all sides, most leaves, spreading out their surfaces horizontally, have their petioles subject to strains that are not alike in all directions; and in them the hard tissue is differently arranged. Its transverse section is not ring-shaped but crescent-shaped: the two horns being directed towards the upper surface of the petiole. That this arrangement is one which answers to the mechanical conditions, is not easy to demonstrate: we must satisfy ourselves by noting that here, where the distribution of forces is different, the distribution of resisting tissue is different. And then, showing conelusively the connexion between these differences, we have the fact that in petioles growing vertically and supporting peltate leaves-petioles which are therefore 
subject to equal transverse strains on all sides-the vascular bundles are arranged cylindrically, as in axes.

Such, then, are some of the reasons for concluding that the development of the supporting tissue in plants, is caused by the incident forces which this tissue has to resist. The individuals in which this direct balancing of inner and outer actions progresses most favourably, are those which, other things equal, are most likely to prosper; and, by habitual survival of the fittest, there is established a systematic and constant distribution of a deposit adapted to the circumstances of each type.

$\S 280$. The function of circulation may now be dealt with. We have to consider here by what structures this is discharged; and what connexion exists between the demand for them and the genesis of them.

The contrast between the rates at which a dye passes through simple cellular tissue and cellular tissue of which the units have been elongated, indicates one of the structural changes required to facilitate circulation. If placed with its cut surface in a coloured liquid, the parenchyma of a potato or the medullary mass of a cabbage-stalk, will absorb the liquid with extreme slowness; but if the stalk of a fungus be similarly placed, the liquid runs up it, and especially up its loose central substance, very quickly. On comparing the tissues which thus behave so differently, we find that whereas in the one case the component cells, packed close together, have deviated from their primitive sphericity only as much as mutual pressure necessitates, in the other case they are drawn out into long tubules with narrow spaces among them-the greatest dimensions of the tubules and the spaces being in the direction which the dye takes so rapidly. That which we should infer, then, from the laws of capillary action, is experimentally shown: liquid moving through tissues follows the lines in which the elements of the tissues are most 
elongated. It does this for two reasons. That narrowing of the cells and intercellular spaces which accompanies their elongation, facilitates capillarity; and at the same time fewer of the septa formed by the joined ends of the cells have to be passed through in a given distance.

Hence the general fact that the establishment of a rudimentary vascular system, is the formation of bundles of cells lengthened in the direction which the liquid is to take. This we see very obviously among the lower Cormophytes. In one of the lichen-like Iiverworts, the veins which, branching through its frond, serve as communications with its scattered rootlets, are formed of cells longer than those composing the general tissue of the frond: the lengths of these cells corresponding in their directions with the lengths of the veins. So, too, is it with the midribs of such fronds as assume more definite shapes; and so, too, is it with the creeping stems which unite many such fronds. That is to say, the current which sets towards the growing part from the part which supplies certain materials for growth, sets through a portion of the tissues composed of units that are longer in the line of the current than at right angles to that line.

The like is true of Phænogams. Omitting all other characteristics of those parts of them through which chiefly the currents of sap flow, we find the uniform fact to be that they consist of cells and intercellular spaces distinguished from others by their lengths. It is thus with veins, and midribs, and petioles; and if we wish proof that it is thus with stems, we have but to observe the course taken by a coloured solution into which a stem is inserted.

What is the original cause of this differentiation? Is it possible that this modification of cell-structure which favours the transfer of liquid towards each place of demand, is itself caused by the current which the demand sets up? Does the stream make its own channel? There are various reasons for thinking that it does. In the first place, the simplest and earliest channels, such as we see in the Liverworts, do not 
develop in any systematic way, but branch out irregularly, following everywhere the irregular lobes of the fronds as these spread; and on examining under a magnifier the places at which the veins are lost in the cellular tissue, it will be seen that the cells are there slightly longer than those around: suggesting that the lengthening of them which produces an extension of the veins, takes place as fast as the growth of the tissue beyond causes a current to pass through them. In the second place, a disappearance of the granular contents of these cells accompanies their union into a vein-a result which the transmission of a current may not improbably bring about. But be the special causes of this differentiation what they may, the evidence favours very much the conclusion that the general cause is the setting up of a current towards a place where the sap is being consumed.

In the histological development of the higher plants we find confirmation.

The more finished distributing canals in Phænogams are formed of cells previously lengthened. At parts of which the typical structure is fixed, and the development direct, this fact is not easy to trace; the cells rapidly take their elongated structures in anticipation of their pre-determined functions. But in places where new vessels are required in adaptation to a modifying growth, we may clearly trace this succession. The swelling root of a turnip, continually having its vascular system further developed, and the component vessels lengthened as well as multiplied, gives us an opportunity of watching the process. In it we see that the reticulated cells which unite to form ducts, arise in the midst of bundles of cells that have previously become elongated, and that they arise by transformation of such elongated cells; and we also see that these bundles of elongated cells have an arrangement suggestive of their formation by passing currents.

Are there grounds for thinking that these further transformations by which strings of elongated cells pass into vessels lined with spiral, annular, reticulated, or other 
frameworks, are also in any way determined by the currents of sap carried? There are some such grounds.

As just indicated, the only places where we may look for evidence with any rational hope of finding it, are places where some local requirement for vessels has arisen in consequence of some local development which the type does not involve. In these cases we find such evidence. Good illustrations occur in those genera of the Cactacea, which simulate leaves, like Epiphyllum and Phyllocactus. A branch of one of these is outlined in Fig. 256. As before explained this is a flattened axis; and the notches along its edges are the seats of the axillary buds. Most of these axillary buds are arrested; but occasionally one of them grows. Now if, taking an Epiphyllum-shoot which bears a lateral shoot, we compare the parts of it that are near the aborted axillary buds with the part that is near the developed axillary bud, we find a conspicuous difference. In the neighbourhood of an aborted axillary bud there is no external sign of any internal differentiation; and on holding up the branch against the light, the uniform translucency shows that there is no greater amount of dense tissue near it than in other parts of the succulent mass. But where an axillary bud has developed, a prominent rounded ridge joins the midrib of the lateral branch with the midrib of the parent branch. In the midst of this rounded ridge an opaque core may be seen. And on cutting through it, this opaque core proves to be full of vascular bundles imbedded in woody deposits. Clearly, these clusters of vessels imply transformations of the tissues, caused by the passage of increased currents of sap. The vessels were not there when the axillary bud was formed; they would not have developed had the axillary bud proved abortive; but they arise as fast as growth of the axillary bud draws the sap along the lines in which they lie. Verification is obtained by examining the internal structures. If longitudinal sections be made through a growing bud of Opuntia or 
Cereus, it will be found that the vessels in course of formation converge towards the point of growth, as they would do if the sap-currents determined their formation; that they are most developed near their place of convergence, which they would be if so produced; and that their terminations in the tissue of the parent shoot are partially-formed lines of irregular elongated cells, like those out of which the vessels of a leaf or bud are developed.

Concluding, then, that sap-vessels arise along the lines of least resistance, through which currents are drawn or forced, the question to be asked is-What physical process produces them? Their component cells, united end to end more or less irregularly in ways deternined by their original positions, form a channel much more permeable, both longitudinally and laterally, than the tissue around. How is this greater permeability caused?

The idea, first propounded I believe by Wolff, that the adjoined ends of the cells are perforated or destroyed by the passing current, is one for which much is to be said. Whether these septa are dissolved by the liquids they transmit, or whether they are burst by those sudden gushes which, as we shall hereafter see, must frequently take place along these canals, need not be discussed: it is sufficient for us that the septa do, in many cases, disappear, leaving internal ridges showing their positions; and, in other cases, become extremely porous. Though it is manifest that this is not the process of vascular development in tissues that unfold after pre-determined types, since, in these, the dehiscences or perforations of septa occur before such direct actions can have come into play; yet it is still possible that the disappearances of septa which now arise by repetition of the type were established in the type by such direct actions.

Be this as it may, however, a simultaneous change undergone by these longitudinallyunited cells must be otherwise caused. Frame-works are formed in them-frame-works which, closely fitting their inner surfaces, may consist either of successive rings, or con- 
tinuous spiral threads, or networks, or structures between spirals and networks, or networks with openings so far diminished that the cells containing them are distinguished as fenestrated. Their differences omitted, however, these structures have the common character that, while supporting the coats of the vessels, they also give special facilities for the passage of liquids, both through the sides of the transformed cells and through their united ends, where these are not destroyed.

To attempt any physical interpretation of this change is scarcely safe: the conditions are so complex. There are reasons for suspecting, however, that it arises from a vacuolation of the substance deposited on the cell-wall. If rapidly deposited, as it is likely to be along lines where sap is freely supplied, this may, in passing from the state of a soluble colloid to that of an insoluble colloid, so contract as to leave uncovered spaces on the cell-membrane; and this change, originally consequent on a physico-chemical action, may be so maintained and utilized by natural selection, as to result in structures of definite kinds, regularly formed in growing parts in anticipation of functions to be afterwards discharged. But, without alleging any special cause for this metamorphosis, we may reasonably conclude that it is in some way consequent upon the carrying of sap. If we examine tissues such as that in the interior of a growing turnip that has not yet become stringy, we may, in the first place, find bundles of elongated cells not having yet developed in them those fenestrated or reticulated structures by which the ducts are eventually characterized. Along the centres of adjacent bundles we may find incomplete lines of such cells-some that are partially or wholly transformed, with some between them that are not transformed. In other bundles, completed chains of such transformed cells are visible. And then, in still older bundles, there are several complete chains running side by side. All which facts imply a metamorphosis of the 
elongated cells, indirectly caused by the continued action of the currents carried.

$\S 281$. Here, however, presents itself a further problem. Taking it as manifest that there is a typical distribution of supporting tissue adapted to meet the mechanical strains a plant is exposed to by its typical mode of growth, and also that there goes on special adaptation of the supporting tissue to the special strains the individual plant has to bear; and taking it as tolerably evident that the sap-channels are originally determined by the passage of currents along lines of least resistance; there still remains the ultimate questionThrough what physical actions are established these general and special adjustments of supporting tissue to the strains borne, and these distributions of nutritive liquid required to make possible such adjustments? Clearly, if the external actions produce internal reactions; and if this play of actions and reactions results in a balancing of the strains by the resistances; we may rationally suspect that the incident forces are directly conducive to the structural changes by which they are met. Let us consider how they must work.

When any part of a plant is bent by the wind, the tissues on its convex surface are subject to longitudinal tension, and these extended outer layers compress the layers beneath them. Such of the vessels or canals in these subjacent layers as contain sap, must have some of this sap expelled. Part of it will be squeezed through the more or less porous walls of the canals into the surrounding tissue, thus supplying it with assimilable materials; while part of it, and probably the larger part, will be thrust along the canals longitudinally upwards and downwards. When the branch or twig or leaf-stalk recoils, these vessels, relieved from pressure, expand to their original diameters. As they expand, the sap rushes back into them from above and below. In whichever of these directions least has been expelled by the compression, 
from that direction most must return during the dilation; seeing that the force which more efficiently resisted the thrusting back of the sap is the same force which urges it into the expanded vessels again, when they are relieved from pressure. At the next bend of the part a further portion of sap will be squeezed out, and a further portion thrust fo"wards along the vessels. This rude pumping process thus serves for propelling the sap to heights which it could not reach by capillary action, at the same time that it incidentally serves to feed the parts in which it takes place. It strengthens them, too, just in proportion to the stress to be borne; since the more severe and the more repeated the strains, the greater must be the exudation of sap from the vessels or ducts into the surrounding tissue, and the greater the thickening of this tissue by secondary deposits.

By this same action the movement of the sap is determined either upwards or downwards, according to the conditions. While the leaves are active and evaporation is going on from them, these oscillations of the branches and petioles urge forward the sap into them; because so long as the vessels of the leaves are being emptied, the sap in the compressed vessels of the oscillating parts will meet with less resistance in the direction of the leaves than in the opposite direction. But when evaporation ceases at night, this will no longer be the case. The sap drawn to the oscillating parts, to supply the place of the exuded sap, must come from the directions of least resistance. A slight breeze will bring it back from the leaves into the gently-swaying twigs, a stronger breeze into the bending branches, a gale into the strained stem and roots-roots in which longitudinal tension produces, in another way, the same effects that transverse tension does in the branches.

Two possible misinterpretations must be guarded against. It is not to be supposed that this force-pump action causes movement of the sap towards one point rather than another: it is simply an aid to its movement. From the stock of sap 
distributed through the plant, more or less is everywhere being abstracted-here by evaporation, here by the unfolding of the parts into their typical shapes, here by both. The result is a tension on the contained liquid columns, which is greatest now in this direction and now in that. This tension it is which must be regarded as the force that determines the current upwards or downwards; and all which the mechanical actions do is to facilitate the transfer to the places of greatest demand. Hence it happens that in a plant prevented from oscillating, but having a typical tendency to assume a certain height and bulk, the demands set up by its unfolding parts will still cause currents; and there will still be alternate ascents and descents, according as the varying conditions change the direction of greatest demand - the only difference being that, in the absence of oscillations, the growth will be less vigorous. Similarly, it must not be supposed that mechanical actions are here alleged to be the sole causes of wood-formation in the individual plant. The tendency of the individual plant to form wood at places where wood has been habitually formed by ancestral plants, is manifestly a cause, and, indeed, the chief cause. In this, as in all other cases, inherited structures repeat themselves irrespective of the circumstances of the individual: absence of the appropriate conditions resulting simply in imperfect repetition of the structures. Hence the fact that in trained trees and hothouse shrubs, dense substance is still largely deposited; though not so largely as where the normal mechanical strains have acted. Hence, too, the fact, that in such plants as the Elephant's-foot or the Welwitschia mirabilis, which for untold generations can have undergone no oscillations, there is an extensive formation of wood (though not to any considerable height above the ground), in repetition of an ancestral type: natural selection having here maintained the habit as securing some other advantage than that of support.

Still, it must be borne in mind that though intermittent 
mechanical strains cannot be assigned as the direct causes of these internal differentiations in plants that are artificially sheltered or supported, they are assignable as the indirect causes; since the inherited structures, repeated apart from such strains, are themselves interpretable as accumulated results of such strains acting on successive generations of ancestral plants. This will become clear on combining the several threads of the argument and bringing it to a close, which we may now do.

$\S 282$. To put the co-operative actions in their actual order, would require us to consider them as working on individuals small modifications that become conspicuous and definite only by inheritance and gradual increase; but it will aid our comprehension without leading us into error, if we suppose the whole process resumed in a single continuouslyexisting plant.

As the plant erects the integrated series of fronds whose united parts form its rudimentary axis, the increasing area of frond-surface exposed to the sun's rays entails an increasing draught upon the liquids contained in the rudimentary axis. The currents of sap so produced, once established along certain lines of cells that offer least resistance, render them by their continuous passage more and more permeable. This establishment of channels is aided by the wind. Each bend produced by it while yet the tissue is undifferentiated, squeezes towards the place of growth and evaporation the liquids that are passing by osmose from cell to cell; and when the lines of movement become defined, each bend helps, by forcing the liquid along these lines, to remove obstructions and make continuous canals. As fast as this transfer of sap is facilitated, so fast is the plant enabled further to raise itself, and add to its assimilating surfaces; and so fast do the transverse strains, becoming greater, give more efficient aid. The canals thus formed can be neither in the centre of the rudimentary axis nor at its surface: for at neither of these 
places can the transverse strains produce any considerable compressions. They must arise along a tract between the outside of the axis and its core-a tract along which there occur the severest squeezes between the stretched outer layers and the internal mass. Just that distribution which we find, is the distribution which these mechanical actions tend to establish.

As the plant gains in height, and as the mass of its foliage accumulates, the strains thrown upon its axis, and especially the lower part of its axis, rapidly increase. Supposing the forms to remain similar, the strains must increase in the ratio of the cubes of the dimensions; or even in a somewhat higher ratio. One consequence must be that the compressions to which the vessels at the lower part of the incipient stem are subject, become greater as fast as the height to which the sap has to be raised becomes greater; and another consequence must be that the local exudation of sap produced by the pressure is proportionately augmented. Hence the materials for interstitial nutrition being there supplied more abundantly, we may expect thickening of the surrounding tissues to show itself there first: in other words, wood will be formed round the vessels of the lower part of the incipient stem. The resulting greater ability of this lower part of the stem to bear strains, renders possible an increase of height; and while after an increase of height the lowest part becomes still further strained, and still further thickens, the part above it, exposed to like actions, undergoes a like thickening. This induration, while it spreads upwards, also spreads outwards. As fast as the rude cylinder of dense matter formed in this way, begins to inclose the original vessels, it begins to play the part of a resistant mass, which more and more prevents the contained vessels from being squeezed; while between it and the outer layers the greatest compression occurs at each bend. Thus at the same time that the original vessels become useless, the peripheral cells of the developing wood become those which have their liquid 
contents squeezed out longitudinally and laterally with increasing force; and, consequently, amid them are formed new sap-channels, from which there is the most active local exudation, producing the greatest deposit of dense matter.

Thus fusing together, as it were, the individualities of successive generations of plants, and recognizing as allimportant that facilitation of the process which natural selection has all along given, we are enabled to interpret the chief internal differentiations of plants as consequent on an equilibration between inner and outer forces. Here, indeed, we see illustrated in a way more than usually easy to follow, the eventual balancing of outer actions by inner reactions. The relation between the demand for liquid and the formation of channels that supply liquid, as well as that between the incidence of strains and the deposit of substance which resists strains, are among the clearest special examples of the general truth that the moving equilibrium of an organism, if not overthrown by an incident force, must eventually be adjusted to it.

The processes here traced out are, of course, not to be taken as the only differentiating processes to which the inner tissues of plants have been subject. Besides the chief changes we have considered, various less conspicuous changes have taken place. These must be passed over as arising in ways too involved to admit of specific interpretations; even supposing them to have been produced by causes of the kind assigned. But the probability, or rather indeed the certainty, is that some of them have not been so produced. Here, as in nearly all other cases, indirect equilibration has worked in aid of direct equilibration; and in many cases indirect equilibration has been the sole agency. Besides ascribing to natural selection the rise of various internal modifications of other classes than those above treated, we must ascribe some even of these to natural selection. It is so with the dense deposits which form thorns and the shells of nuts: these cannot have resulted from any inner reactions imme- 
diately called forth by outer actions; but must have resulted mediately through the effects of such outer actions on the species. Let it be understood, therefore, that the differentiations to which the foregoing interpretation applies, are only those most conspicuous ones which are directly related to the most conspicuous incident forces. They must be taken as instances on the strength of which we may conclude that other internal differentiations have had a natural genesis, though in ways that we cannot trace. 


\section{CHAPTER V.}

\section{PHYSIOLOGICAL INTEGRATION IN PLANTS.}

$\S 283$. A GooD deal has been implied on this topic in the preceding chapters. Here, however, we must for a brief space turn our attention immediately to it.

Plants do not display integration in such distinct and multiplied ways as do animals. But its advance may be traced both directly and indirectly-directly in the increasing co-ordination of actions, and indirectly in the effect of this upon the powers and habits.

Let us group the facts under these heads: ascending in both cases from the lower to the higher types.

$\S 284$. The inferior Alga, along with little unlikeness of parts, show us little mutual dependence of parts. Having surfaces similarly circumstanced everywhere, much physiological division of labour cannot arise; and therefore there cannot be much physiological unity. Among the superior Alga, however, the differentiation between the attached part and the free part is accompanied by some integration. There is evidently a certain transfer of materials, which is doubtless facilitated by the elongated forms of the cells in the stem, and probably leads to the formation of dense tissue at the places of greatest strain, in a way akin to that recently explained in other cases. And where there is this co-ordination of actions, the parts are so far mutually dependent that 
each dies if detached from the other. That though the organization is so low neither part can reproduce the other and survive by so doing, is probably due to the circumstance that neither part contains any considerable stock of untransformed protoplasm, out of which new tissues may be produced.

Fungi and Lichens present no very significant advances of integration. We will therefore pass at once to the Archegoniates. In those of them which, either as single fronds or strings of fronds, spread over surfaces, and which, rooting themselves as they spread, do not need that each part should receive aid from remote parts, there is no developed vascular system serving to facilitate transfer of nutriment: the parts being little differentiated there is but little integration. But along with assumption of the upright attitude and the accompanying specializations, producing vessels for distributing sap and hard tissue for giving mechanical support, there arises a decided physiological division of labour; rendering the aërial part dependent on the imbedded part and the imbedded part dependent on the aërial part. Here, indeed, as elsewhere, these concomitant changes are but two aspects of the same change. Always the gain of power to discharge a special function involves a loss of power to perform other functions; and always, therefore, increased mutual dependence constituting physiological integration, must keep pace with that increased fitting of particular parts to particular duties which constitutes physiological differentiation.

Making a great advance among the Archegoniates, this physiological integration reaches its climax among Phænogams. In them we see interdependence throughout masses that are immense. Along with specialized appliances for support and transfer, we find an exchange of aid at great distances. We see roots giving the vast aërial growth a hold tenacious enough to withstand violent winds, and supplying water enough even during periods of drought; we see a stem and branches of corresponding strength for up- 
holding the assimilating organs under ordinary and extraordinary strains; and in these assimilating organs we see elaborate appliances for yielding to the stem and roots the materials enabling them to fulfil their offices. As a consequence of which greater integration accompanying the greater differentiation, there is ability to maintain life over an immense period under marked vicissitudes.

Even more conspicuously exemplified in Phænogams, is that physiological integration which holds together the functions not of the individual only but of the species as a whole. The organs of reproduction, both in their relations to other parts of the individual bearing them and in their relations to corresponding parts of other individuals, show us a kind of integration conducing to the better preservation of the race; as those already specified conduce to the better preservation of the individual. In the first place, this greater co-ordination of functions just described, itself enables Phænogams to bequeath to the germs they cast off, stores of nutriment, protective envelopes, and more or less of organization: so giving them greater chances of rooting themselves. In the second place, certain differentiations among the parts of fructification, the meaning of which Mr. Darwin has so admirably explained, give to the individuals of the species a kind of integration that makes possible a mutual aid in the production of vigorous offspring. And it is interesting to observe how, in that dimorphism by which in some cases this mutual aid is made more efficient, the greater degree of integration is dependent on the greater degree of differentiation-not simply differentiation of the fructifying organs from other parts of the plant bearing them, but differentiation of these fructifying organs from the homologous organs of neighbouring individuals of the same race. Another form of this co-ordination of functions which conduces to the maintenance of the species, may be here named-partly for its intrinsic interest. I refer to the strange processes of multiplication occurring in the genus Bryophyllum. It is well known that 
the succulent leaves of $B$. calycinum, borne on foot-stalks so brittle that they are easily snapped by the wind, send forth from their edges when they fall to the ground, buds which root themselves and grow into independent plants. The correlation here obviously furthering the preservation of the race, is more definitely established in another species of the genus-B. proliferum. This plant, shooting up to a considerable height, and having a stem containing but little woody fibre, habitually breaks near the bottom while still in flower; and is thus generally prevented from ripening its seeds. The multiplication is, however, secured in another way. Before the stem is broken young plants have budded out from the pedicels of the flowers, and have grown to considerable lengths; and on the fall of the parent they forthwith commence their separate lives. Here natural selection has established a remarkable kind of co-ordination between a special habit of growth and decay, and a special habit of proliferation.

$\S 285$. The advance of physiological integration among plants as we ascend to the higher types, is implied by their greater constancy of structure, as well as by the stricter limitations of their habitats and modes of life. "Complexity of structure is generally accompanied with a greater tendency to permanence in form," says Dr. [now Sir J.] Hooker; or, conversely, "the least complex are also the most variable." This is the second aspect under which we have to contemplate the facts.

The differences between the simpler Alga and Fungi are so feebly marked that botanists have had great difficulty in framing definitions of these classes. This structural indefiniteness is accompanied by functional indefiniteness. Algar, which are mostly aquatic, include many small forms that frequent the damp places preferred by Fungi. Among Fungi, there are kinds which lead submerged lives like the Algae. Besides this indistinctness of the classes, there is great variability in the shapes and modes of life of their species-a vari- 
ability so great that what were at first taken to be different species, or different genera, or even different orders, have proved to be merely varieties of one species. So inconstant in structure are the Alga that Schleiden quotes with approval the opinion of Kutzing, that " there are no species but merely forms of Alga:" an opinion which though now rejected sufficiently implies extreme indefiniteness. In all which facts we see that these lowest types of plants, little differentiated, are also but little integrated.

Archegoniates present a like relation between the small specialization of functions which constitutes physiological differentiation, and the small combination of functions which constitutes physiological integration. “Mosses," says Mr. Berkeley, "are no less variable than other cryptogams, and are therefore frequently very difficult to distinguish. Not only will the same species exhibit great diversity in the size, mode of branching, form and nervation of the leaves, but the characters of even the peristome itself are not constant." And concerning the classification of the remaining group, Filicales, he says:- "Not only is there great difficulty in arranging ferns satisfactorily, but it is even more difficult to determine the limits of species."

After this vagueness of separation as well as inconstancy of structure and habit among the lower plants, the stability of structure and habit and divisibility of groups among the higher plants, appear relatively marked. Though Phænogams are much more variable than most botanists have until lately allowed, yet the definitions of species and genera may be made with far greater precision, and the forms are far less capable of change, than among Cryptogams. And this comparative fixity of type, implying, as it does, a closer combination of the component functions, we see to be the accompaniment of the greater differentiation of those functions and of the structures performing them. That these characters are correlatives is further shown by the fact that the higher plants are more restricted in their habitats than 
the lower plants, both in space and time. "The much narrower delimitation in area of animals than plants," says Sir J. Hooker, "and greater restriction of Faunas than Floras, should lead us to anticipate that plant-types are, geologically speaking, more ancient and permanent than the higher animal types are, and so I believe them to be, and I would extend the doctrine even to plants of highly complex structure." "Those classes and orders which are the least complex in organization are the most widely distributed."

$\S 286$. Thus that which the general doctrine of evolution leads us to anticipate, we find implied by the facts. The physiological division of labour among parts, can go on only in proportion to the mutual dependence of parts; and the mutual dependence of parts can progress only as fast as there arise structures by which the parts are efficiently combined, and the mutual utilization of their actions made easy.

To say definitely by what process is brought about this co-ordination of functions which accompanies their specialization, is hardly practicable. Direct and indirect equilibration doubtless co-operate in establishing it. We may see, for example, that every increase of fitness for function produced in the aërial part of a plant by light, as well as every increase of fitness for function produced in its imbedded part by the direct action of the moist earth, must conduce to an increased current of the liquid evaporated from the one and supplied by the other-must serve, therefore, to aid the formation of sap-channels in the ways already described; that is-must serve to develop the structures through which mutual aid of the parts is given: the additional differentiation tends immediately to bring about the additional integration. Contrariwise, it is obvious that an inter-dependence such as we see between the secretion of honey and the fertilization of germs, or between the deposit of albumen in the cotyledons of an embryo-plant and its subsequent striking root, is a kind of integration in the actions of the individual or of the 
species, which no differentiation has a direct tendency to initiate. Hence we must regard the total results as due to a plexus of influences acting simultaneously on the individual and on the species: some chiefly affecting the one and some chiefly affecting the other.

[Note.-In Nature for June 11, 1896, Dr. Maxwell Masters, in an essay on " Plant Breeding," names an instructive fact concerning the production of varieties by" selection of slightly divergent forms. He says :-

" To the untrained eye, the primordial differences noted are often very slight; even the botanist, unless his attention be specially directed to the matter, fails to see minute differences which are perceptible enough to the raiser or his workmen. Nor must it be thought that these variations, difficult as they are to recognise in the beginning, are unimportant. On the contrary, they are interesting, physiologically, as the potential origin of new species, and very often they are commercially valuable also. These apparently trifling morphological differences are often associated with physiological variations which render some varieties, say of wheat, much better enabled to resist mildew and disease generally than others. Some, again, prove to be better adapted for certain soils or for some climates than others; some are less liable to injury from predatory birds than others, and so on."

Thus we are shown that, to a much greater degree than might be supposed, minute changes of forms and functions in one part of a plant are correlated with changes of forms and functions throughout it. The inter-dependence-that is to say, the physiological integration-is very close at the same time that it is very complex.

Here while naming these facts in illustration of physiological integration in plants I name them because they illustrate an important truth bearing upon the general question of heredity which I have dealt with in Appendix G, and to which I now especially draw attention.] 


\section{CHAPTER VI.}

\section{DIFFERENTIATIONS BETWEEN THE OUTER AND INNER}

TISSUES OF ANIMALS.

$\S 287$. WHAT was said respecting the primary physiological differentiation in plants, applies with little beyond change of terms to animals. Among Protozoa, as among Protophyta, the first definite contrast of parts is that between outside and inside. The speck of jelly or sarcode which appears to constitute the simplest animal, proves, on closer examination, to be a mass of substance containing a nucleus-a periplast in the midst of which there is a minute endoplast, consisting of a spherical membrane and its contents.

This parallel, only just traceable among these Rhizopods, which are perpetually changing the distribution of their outer substance, becomes at once marked in those higher Protozoa which have fixed shapes, and maintain constant relations between their surfaces and their environments. Indeed the Rhizopods themselves, on passing into a state of quiescence in which the relations of outer and inner parts are fixed, become encysted: there is formed a hardened outer coat different from the matter which it contains. And what is here a temporary character answering to a temporary definiteness of conditions, is in the Infusoria a constant character, answering to definite conditions that are constant. Each of these minute creatures, though not coated by a distinct membrane, has an outer layer of excreted substance forming a delicate cuticle.

$\S 288$. The early establishment of this primary contrast of 
tissues answering to this primary contrast of conditions, is no less conspicuous in aggregates of the second order. The feebly-integrated units of a Sponge, with individualities so little merged in that of the whole they form that most of them still retain their separate activities, nevertheless show us, in the unlikeness that arises between the outermost layer and the contained mass, the effect of converse with unlike conditions. This outermost layer is composed of units somewhat flattened and united into a continuous membrane-a kind of rudimentary skin.

Secondary aggregates in which the lives of the units are more subordinate to the life of the whole, carry this distinction further. The leading physiological trait of every coelenterate animal is the divisibility of its substance into endoderm and ectoderm-the part next the food and the part next the environment. Fig. 147 ( $\$ 201)$, representing a portion of the body-wall of a Hydra seen in section, gives some idea of this fundamental differentiation. The creature consists of a simple sac, the cavity of which is in communication with the surrounding water; and hence the unlikeness between the outer and inner layers has not become great. The essential contrast is that between the differentiated parts of what was originally the same part-a uniform membrane composed of juxtaposed cells.

For here, indeed, we are shown unmistakably how the primary contrast of structures follows upon the primary contrast of conditions. The ordinary form from which low types of the Metazoa set out, is a hollow sphere formed of cells packed side by side-a blastula, as it is called: all these cells being similarly exposed to the environment. The blastula presently changes into what is called a gastrula-a form resulting from the introversion of one of the sides of the blastula. If there be taken a small ball of vulcanized india-rubber, say an inch or more in diameter, and having a hole in it through which the air may escape, and if one side of it be thrust inwards so as to produce a cup, and if the 
wide opening of the eup be supposed to contract, thus becoming a narrow opening, there will result something like the gastrula form. Manifestly that part of the original layer which has become internal is differently conditioned from the rest which remains external: the one continuing to hold converse with the forces of the environment, while the other begins to hold converse with the nutritive matters taken into the sac-formed chamber-the archenteron or primitive stomach. Interesting evidence of the primitive externality of the digestive cavity is yielded by the fact that whereas the blastula consisted of ciliated cells, and whereas the ciliation persists throughout life on the outer layer, or parts of it, in sundry low types-even in some Chætopods-it persists also on the alimentary tract of sundry low types: not only in the Hydra but commonly in Nemertines, in some Platyhelminthes, and even in some leeches.

Besides being enabled thus to understand how an aggregate of $A m \propto b a$-form units, originally consisting of a single layer, may pass into an aggregate consisting of a double layer; we may also understand under what influences the transition takes place. If the habit which some of the primary aggregates have, of wrapping themselves round masses of nutriment, is followed by a secondary aggregate, there will naturally arise just that re-differentiation which the Hydra shows us.

$\S 289$. This account of the primary differentiation carries us only half-way towards a true conception of the distinction between outer and inner tissues. Though, using words in their current senses, this introverted part of the primitive layer has become internal in contrast with the remainder, which continues external, yet this introverted part has not become internal in the strict physiological sense. For it remains subject to the actions of those environing matters which are taken in as food: such environing matters, when they happen to be moving prey, acting upon it much as they 
might act upon the exterior. So that this introverted part has a quasi-externality. It has not the same absolute internality as have those parts which never come in contact with products of the outer world. Here we must briefly recognize the distinction between these parts and the parts thus far considered.

Reverting to our symbol, the india-rubber ball, it will be seen that the introversion may be so complete that the cavity is obliterated, with the result that the internal surfaces of the outer and inner layers come in contact. This is the state reached in the simplest cœlenterate animal, the Hydra: there being in it nothing more than a thin structureless lamella between the ectoderm and endoderm, as shown in Fig. 147. This lamella represents all that there is of strictly internal tissues. But the introversion, instead of bringing the inner surfaces of the ball into contact, may be so far incomplete as to leave a space, and in various creatures and embryos of others, symbolized by this arrangement, this space becomes occupied by a tissue formed from one or other or both of the two primary tissues-the mesoblast or mesoderm. This intermediate layer, sometimes, as in the Medusa, growing into a mass of jelly serving as a fulcrum for the creature's contractions, or, as in the Sponge, giving a passive basis to the active tissues, becomes in higher animals the layer out of which the structures that support the body and move it about, as well as those that distribute prepared nutriment, are developed. From it arise the bones, the muscles, and the vascular system-the masses of differentiated tissue which are truly internal and occupy what is called the body-cavity or peri-visceral space.

In the higher types of animals this space comes to be partially occupied by a structure that may be described as a cavity within a cavity-the cœlom. Most zoologists regard this as arising by a re-introversion of the archenteron or primary alimentary sac. It is easily to be perceived that after the introversion which produces this digestive cavity, the 
wall of the cavity may be again introverted in such way as to intrude into the peri-visceral space. The cœlom thus formed is subsequently shut off. Becoming included among the more truly internal structures, and in part giving origin to certain lining membranes, it has for its chief function the formation of organs for the excretion and emission of nitrogenous waste and of the generative products: some portions of it retaining, as a consequence, indirect connexions with the environment and characters usually accompanying such connexions.

Here we are not concerned with further details: the aim being simply to indicate the way in which out of the original layer, wholly external, there arise, by primary and secondary introversions, and the formation of intermediate membranes and spaces, the chief contrasts between outer and inner tissues, and how there simultaneously go on the differentiations accompanying different conditions.

$\S 289 a$. Another all-important differentiation between outer tissues and inner tissues has now to be set forth-that by which the nervous system becomes established and distinguished. Strangely enough, like the one above described, it is sequent upon an introversion: the nervous system is primarily a skin-structure and develops by the infolding of this skin-structure.

In creatures possessing the earliest rudiments of nerves these exist in certain superficial cells. Each has a small tubular orifice from which projects a minute hair, and each has on its under side processes running into the tissue below, and serving, as it seems, to conduct impressions from the projecting hair when it is disturbed by contacts with foreign bodies. A plexus of fibres bringing the inner processes of such cells into communication arises, and forms something like a nervous layer capable of propagating impulses in all directions. At a subsequent stage some of the superficial cells, ceasing to be themselves the recipients of external stimuli, sink inwards and become ganglion-cells con- 
nected with the nervous plexus-agents, as we must suppose, for the reception, multiplication, and diffusion of the impulses received from the outer cells.

As thus far developed, the nervous structure is one fitted only for a vague stimulation of dispersed contractile fibres, causing movements of an undirected kind. A concentration of these superficial nervous structures is a probable preliminary to the next change-an all-important change. For a part of the surface begins to sink inwards, forming, in the Vertebrata, a groove; and from the lining cells of this groove, which presently closes over, the central parts of the nervous system arise: definite nerves having meantime, as we may suppose, been developed out of the indefinite nervous plexus.

Neglecting what there is in this of a speculative nature, it is sufficient for the present purpose to recognize the undoubted fact that the nervous system is developed from the ectoderm, and that, originally external, it is made internal by a process of sinking in or by a process of definite introversion.

$\S 290$. Whether direct equilibration or indirect equilibration has had the greater share in producing these fundamental contrasts between the inner and outer tissues of animals, must be left undecided. The two causes have all along cooperated-modification of the individual accumulated by inheritance predominating in some cases, and in other cases modification of the race by survival of the incidentally fittest. On the other hand, the action of the medium on the organism cannot fail to change its surface more than its centre, and so differentiate the two; while, on the other hand, the surfaces of organisms inhabiting the same medium display extreme unlikenesses which cannot be due to the immediate actions of their medium. Let us dwell a moment on the antithesis.

We have abundant evidence that animal protoplasm is rapidly modified by light, heat, air, water, and the salts contained in water-coagulated, turned from soluble into insoluble, partially changed into isomeric compounds, or other- 
wise chemically altered. Immediate metamorphoses of this kind are often obviously produced in ova by changes of their media. At the outset, therefore, before yet there existed any such differentiation as that which now usually arises by inheritance, these environing agencies must have tended to originate a protective envelope. For a modification produced by them on the superficial part of the protoplasm, must either have been a decomposition or else the formation of a compound which remained stable under their subsequent action. There would be generated an outer layer of substance that was so molecularly immobile as to be incapable of further metamorphoses, while it would shield the contained protoplasm from that too-great action of external forces which, by rapidly changing the unstatle equilibrium of its molecules into a relatively stable equilibrium, would arrest development. Evidently organic evolution, whether individual or general, must always and everywhere have been subordinate to these physical necessities. Though natural selection, beginning with minute portions of protoplasm, must all along have tended to establish a molecular composition apt to undergo this differentiation of surface from centre to the most favourable extent, yet it must all along have done so while controlled by this process of direct equilibration.

Contrariwise, the many and great unlikenesses among the dermal structures of creatures inhabiting the same element, cannot be ascribed to any such cause. The contrasts between naked and shelled Gastropods, between marine Worms and Crustaceans, between soft-skinned Fishes and Fishes in armour like the Pterichthys, must have been produced entirely by natural selection. Environing forces are, as before, the ultimate causes; but the forces are now not so much those exercised by the medium as those exercised by the other inhabitants of the medium; and they do not act by modifying the surface of the individual, but by killing off individuals whose surfaces are least fitted to the requirements: thus slowly affecting the species. Still the dermal skeleton bristling 
with spines, which protects the Diodon or the Cyclichthys from enemies it could not escape, comes within the general formula of an outer tissue differentiated from inner tissues by the outer actions to which the creature is exposed: the differentiation having gone on until there is equilibrium between the destructive forces to be met and the protective forces which meet them.

If we venture to apportion the respective shares which mediate and immediate actions have had in differentiating outer from inner tissues, we shall probably not be far wrong in ascribing that part of the result which is alike in all animals, mainly to the direct actions of their media, while we ascribe the multitudinous unlikenesses of the results in various animals, partly to the indirect actions of the media, and partly to the indirect actions of other animals by which the media are inhabited. That is to say, while assigning the specialities of the differentiations to the specialities of converse with the agencies in the environment, most of them organic, we may assign to the constant and universal converse with its inorganic agencies, the universal characteristic of tegumentary structures-their growth outwards from a layer lying below the surface which continually produces new substance to replace the substance worn away or cast off.

Here let me add a piece of evidence which strengthens the general argument, at the same time that it justifies this apportionment. When ulceration has gone deep enough to destroy the tegumentary structures, these are never reproduced. The puckered surface formed where an ulcer heals, or where a serious burn has destroyed the skin, consists of modified connective tissue, which, as the healing goes on, spreads inwards from the edges of the ulcer: some of it, perhaps, growing from the portions of connective tissue that dip down between the muscular bundles. This connective tissue is normally covered by the epidermis and thus sheltered from environing actions. What has happened to it? It has now become the outermost layer. And how does it comport 
itself under its new conditions? It produces a superficial substance which plays the part of the epidermis and grows outwardly. For since the surface, subject to friction and exfoliation, has to be continually renewed, there must be a continual reproduction of an outermost layer from a layer beneath. That is to say, the contact of this deep-seated tissue with outer agencies, produces in it some approach towards that character which we find universally characterizes outertissue. But while we see under this exposure to the conditions common to all integument, a tendency to assume the structure common to all integument, we see no tendency to assume any of the specialities of tegumentary structure: no rudiments of glands or hair sacs make their appearance.

Analogous conclusions may be drawn respecting the processes of differentiation by which from the outer layer nervous tissue and finally a nervous system are evolved. Here, also, both direct and indirect equilibration appear to have operated. Two reasons may be assigned for the belief that the transformation of certain superficial cells into sensitive cells was initiated by exposure to external stimuli. The first is that, extremely unstable as protoplasm is, disturbances received by the outer side of a specially-exposed cell could scarcely fail to cause changes passing through it towards the interior mass of the body, and that perpetual repetition of such changes would tend to generate channels of easy transmission through the protoplasm. The second reason is that, if we do not assume this process of initiation but assume that survival of the fittest was the sole agency, then no reason can be assigned why the nervous system should not have been at the outset formed internally instead of being initiated externally and then transferred to the interior: the roundabout process would be inexplicable. At the same time the production of a central nervous system by introversion of superficial sensitive cells cannot be ascribed to the differentiating effects of external stimuli, but must be ascribed to natural selection. No perpetual repetition of 
outer disturbances would cause the sinking inwards, and covering up, of the specially-sensitive area and the plexus below it. But it is manifest that since these nervous structures, at once all-important and easily injured, would be safer if removed from the surface, survival of the fittest, continually preserving those in which they were more deeply seated, would tend to produce an arrangement in which all parts but the actual receivers of external stimuli became internal.

Hence, contemplating generally these two fundamental differentiations of inner from outer tissues, we may conclude that though their first stages resulted from direct equilibration, their subsequent and higher stages resulted from indirect equilibration. 


\title{
CHAPTER VII.
}

\author{
DIFFERENTIATIONS AMONG THE OUTER TISSUES OF \\ ANIMALS.
}

$\S 291$. THE outer tissues of animals, originally homogeneous over their whole surfaces, pass into a heterogeneity which fits their respective parts to their respective conditions. So numerous and varied are the implied differentiations, that it is impracticable here to deal with them all even in outline. To trace them up through classes of animals of increasing degrees of aggregation, would carry us into undue detail.

Did space permit, it would be possible to point out among the Protozoa, various cases analogous to that of the Arcella; which may be described as like a microscopic Limpet, having a sarcode body of which the upper surface has become horny, while the lower surface with its protruding pseudopodia, retains the primitive jelly-like character. That differentiations of this kind have been gradually established among these minute creatures through the unlike relations of their parts to the environment, is an inference supported by a form which, while the rest of the body has a scarcely distinguishable coating, "agrees with Arcella and Diffugia in having the pseudopodia protrusible from one extremity only of the body."

Many parallel specializations of surface among aggregates of the second order might be instanced from the Colenterata. In the $H y d r a$, the ectoderm presents over its whole area no conspicuous unlikenesses; but there usually exist in the hydroid polypes of superior types, decided contrasts between 
the higher and lower parts. While the higher parts retain their original characters, the lower parts excrete hard outer layers yielding support and protection. Various stages of the differentiation might be followed. "In Hydractinia," says Prof. Green, this horny layer "becomes elevated at intervals to form numerous rough processes or spines, while over the general surface of the ectoderm its presence is almost imperceptible." In other types, as in Cordylophora, it spreads part way up the animal's sides, ending indefinitely. In Bimeria it " extends itself so as to enclose the entire body of each polypite, leaving bare only the mouth and tips of the tentacles." While in Campanularia it has become a partiallydetached outer cell, into which the creature can retract its exposed parts.

But it is as needless as it would be wearisome to trace through the several sub-kingdoms the rise of these multiform contrasts, with the view of seeking interpretations of them. It will suffice if we take a few groups of the illustrations furnished by the higher animals.

$\S 292$. We may begin with those modifications of surface which subserve respiration. Though we ordinarily think of respiration as the quite special function of a quite special organ, yet originally it is not so. Little-developed animals part with their carbonic acid and absorb oxygen, through the general surface of the body. Bven in the lower types of the higher classes, the general surface of the body aids largely in aërating the blood; and the parts which discharge the greater part of this function are substantially nothing more than slightly altered and extended portions of the skin.

Such differentiations, marked in various degrees, are to be seen among Mollusca. In the Pteropoda the only modification which appears to facilitate respiration, is the minute vascularity of one part of the skin. Higher types possess special skin-developments. The Doris has appendages developed into elaborately-branched forms-small trees of blood-vessels 
covered by slightly-changed dermal tissues. And these arborescent branchiæ are gathered together into a single cluster. Thus there is evidence that large external respiratory organs have arisen by degrees from simple skin: as, indeed, they do arise during the development of each individual having them. Just as gradually as in the embryo a simple bud on the integument, with its contained vascular loop, passes by secondary buddings into a tree-like growth penetrated everywhere by dividing and sub-dividing bloodvessels; so gradually has there probably proceeded the differentiation which has turned part of the outer surface into an organ for excreting carbonic acid and absorbing oxygen.

Certain inferior vertebrate animals present us with a like metamorphosis of tissues. These are the Amphibia. The branchiæ here developed from the skin, are covered with cellular epidermis, not much thinner than that covering the rest of the body. Like it they have their surfaces speckled with pigment-cells; and are not even conspicuous by their extra vascularity-where they are temporary at least. They facilitate the exchange of gases in scarcely any other way than by affording a larger area of contact with the water, and interposing a rather thinner layer of tissue between the water and the blood-vessels. Those very simple branchiæ of the larval Amphibia that have them but for a short time, graduate into the more complex ones of those that have them for a long time or permanently ; showing, as before, the small stages by which this heterogeneity of surface accompanying heterogeneity of function may arise.

In whąt way are such differentiations established? Mainly, no doubt, by natural selection; but also to some degree, I think, by the inheritance of direct adaptations. That a portion of the integument at which aëration is favoured by local conditions, should thereby be led to grow into a larger surface of aëration, appears improbable. Survival of those individuals which happen to have this portion of the integu- 
ment somewhat more developed, seems here the only likely cause.

$\S 293$. Among the conspicuous modifications by which the originally-uniform outer layer is rendered multiform, are the protective structures. Let us look first at the few cases in which the formation of these is ascribable mainly to direct equilibration.

Already reference has been more than once made to those thickenings that occur where the skin is exposed to unusual pressure and friction. Are these adaptations inheritable? and may they, by accumulation through many generations, produce permanent dermal structures fitted to permanent or frequently-recurring stress? Take, for instance, the callosities on the knuckles of the Gorilla, which are adapted to its habit of partially supporting itself on its closed hands when moving along the ground. Shall we suppose that these defensive thickenings are produced afresh in each individual by the direct actions; or that they are inherited modifications caused by such direct actions; or that they are wholly due to the natural selection of spontaneous variations? The last supposition does not seem a probable one. Such thickenings, if spontaneous, would be no more likely to occur on the knuckles than on any other of the hundred equal areas forming the skin-surface at large; and the chances against their simultaneous occurrence on all eight knuckles would be incalculable. Moreover, the implication would be that those slight extra thicknesses of skin on the knuckles, with which we must suppose the selection to have commenced, were so advantageous as to cause survivals of the individuals having them, in presence of other superiorities possessed by other individuals. Then that survivals so caused, if they ever occurred at all, should have occurred with the frequency requisite to establish and increase the variation, is hardly supposable. And if we reject, as also unlikely, the reproduction of these callosities de novo in each individual (for 
this would imply that after a thousand generations each young gorilla began with knuckles having skin no thicker than elsewhere), there remains only the inference that they have arisen by the transmission and accumulation of functional adaptations.

Another case which seems interpretable only in an analogous way, is that of the spurs that are developed on the wings of certain birds-on those of the Chaja screamer for example. These are weapons of offence and defence. It is a familiar fact that some birds strike with their wings, often giving severe blows; and in the birds named, the blows are made more formidable by the horny, dagger-shaped growths standing out from those points on the wings which deliver them. Are these spurs directly or indirectly adaptive? To conclude that natural selection of spontaneous variations has caused them, is to conclude that, without any local stimulus, thickenings of the skin occurred symmetrically on the two wings at the places required; that such thickenings, so localized, happened to arise in birds given to using their wings in fight; and that on their first appearance the thickenings were decided enough to give appreciable advantages to the individuals distinguished by them-advantages in bearing the reactions of the blows if not in inflicting the blows. But to conclude this is, I think, to conclude against probability. Contrariwise, if we assume that the thickening of the epidermis produced by habitual rough usage is inheritable, the development of these structures presents no difficulty. The points of impact would become indurated in wings used for striking with unusual frequency. The callosities of surface thus generated, rendering the parts less sensitive, would enable the bird in which they arose to give, without injury to itself, more violent blows and a greater number of them: so, in some cases, helping it to conquer and multiply. Among its descendants, inheriting the modification and the accompanying habit, the thickening would be further increased in the same way: survival of the fittest tending ever to accelerate the process. 
Presently the horny nodes so formed, hitherto defensive only in their effects, would, by their prominence, become offensive -would make the blows given more hurtful. And now natural selection, aiding more actively, would mould the nodes into spurs: the individuals in which the nodes were most pointed would be apt to survive and propagate; and the pointedness generation after generation thus increased, would end in the well-adapted shape we see.

But if in these cases the differentiations which fit particular parts of the outer tissues to bear rough usage are caused mainly by the direct balancing of external actions by internal reactions, then we may suspect that the like is true of other modifications that occur where special strains and abrasions have to be met. Possibly it is true of sundry parts that are formed of hardened epidermis, such as the nails, claws, hoofs, and hollow horns of Mammals ; "all of which," says Prof. Huxley, " are constructed on essentially the same plan, being diverticula of the whole integument, the outer layer of whose ecderon has undergone horny metamorphosis." Leaving open, however, the question what tegumentary structures are due to direct equilibration, furthered and controlled by indirect equilibration, it is tolerably clear that direct equilibration has been one of the factors.

$\S 294$. Dermal structures of another class are developed mainly, if not wholly, by the actions of external causes on species rather than on individuals. These are the various kinds of clothing-hairs, feathers, quills, scales, scutes. Though it is no longer thought as at one time that all these various tegumentary structures are homologous with one another, yet it is unquestionable that sundry of the more conspicuous ones are. Those which are extremely unlike may be seen linked together by a long series of graduated forms. A retrograde metamorphosis from feathers to appendages that are almost scale-like, is well seen in the coat of the Penguin. There is manifest a transition from the 
bird-like covering to the fish-like covering-a transition so gradual that no place can be found where an appreciable break occurs; and if the scale-like appendages are not truly scales yet they exemplify an extreme metamorphosis. Less striking, perhaps, but scarcely less significant, are the modifications through which we pass from feathers to hairs, on the surfaces of the Ostrich and the Cassowary. The skin of the Porcupine shows us hairs and quills united by a series of intermediate structures, differing from one another inappreciably. Even more remarkable are certain other alliances of dermal structures. "It may be taken as certain, I think," says Prof. Huxley, “that the scales, plates, and spines of all fishes are homologous organs; nor as less so that the tegumentary spines of the Plagiostomes are homologous with their teeth, and thence with the teeth of all vertebrata."

Further details concerning these tegumentary structures are not needful for present purposes, and are indeed but indirectly relevant to the subject of physiological development. Here they are of interest to us only by involving the general question-What physical influences have brought them into existence? Still with a view to definite presentation of the problem, it will be well to contemplate the mode of development common to the most familiar of them.

Suppose a small pit to be formed on the previously flat skin; and suppose that the growth and casting off of horny cells which goes on over the skin in general, continues to go on at the usual rate over the depressed surface of this pit. Clearly the quantity of horny matter produced within this hollow, will be greater than that produced on a level portion of the skin subtending an equal area of the animal's outside. Suppose such a pit to be deepened until it becomes a small sac. If the exfoliation goes on as before, the result will be that the horny matter, expelled, as it must be, through the mouth of the sac, which now bears a small proportion to the internal surface of the sac, will be 
large in quantity compared with that exfoliated from a portion of the skin equal in area to the mouth of the sac: there will be a conspicuous thrusting forth of horny matter. Suppose once more that the sac, instead of remaining simple, has its bottom pushed up into its interior, like the bottom of a wine-bottle- the introversion being carried so far that the introverted part reaches nearly to the external opening, and leaves scarcely any space between the introverted part and the walls of the sac. It is easy to see that the exfoliation continuing from the surface of the introverted part, as well as from the inside of the sac generally, the horny matter cast off will form a double layer; and will come out of the sac in the shape of a tube having within its lower end the introverted part, as the core on which it is moulded, and from the apex of which is cast off the substance filling, less densely, its interior. The structure resulting will be what we know as a hair. Manifestly by progressive enlargement of the sac, and further complication of that introverted part on which the excreted substance is moulded, the protruding growth may be rendered larger and more involved, as we see it in quills and feathers. So that insensible steps, thus indicated in principle, carry us from the exfoliation of epidermis by a flat surface, to the exfoliation of it by a hollow simple sac, an introverted sac, and a sac further complicated; each of which produces its modified kind of tegumentary appendage.

But now, after contemplating this typical illustration, we return to the general question. What are the agencies which have been operative in developing these skinstructures? Indirect equilibration must have worked almost alone in producing them. No direct incidence of forces can have developed the enamelled armour of the Lepidosteus or the tesselated plates of the Glyptodon and its modern allies. Survival of the fittest must here and in multitudinous other cases be regarded as the sole cause.

§295. Among many other differentiations of the outer 
tissues, the most worthy to be noticed in the space that remains, are those by which organs of sense are formed. We will begin with the simplest and most closely allied to the foregoing.

Every hair that is not too long or flexible to convey to its rooted end a strain put upon its free end, is a rudimentary tactual organ; as may be readily proved by touching one of those growing on the back of the hand. If, then, a creature has certain hairs so placed that they are habitually touched by the objects with which it deals, or amid which it moves, an advantage is likely to accrue if these hairs are modified in a way that enables them the better to transmit the impressions derived. Such modified hairs we have in the vibrissa, or, as they are commonly called, the "whiskers" possessed by Cats and feline animals generally, as well as by Seals and many Rodents. These hairs are long enough to reach objects at considerable distances; they are so stiff that forces applied to their free ends, cause movements of their imbedded ends; and the sacs containing their imbedded ends being well covered with nerve-fibres, these developed hairs serve as instruments of exploration. By constant use of them the animal learns to judge of the relative positions of objects past which, or towards which, it is moving. When stealthily approaching prey or stealthily escaping enemies, such aids to perception are obviously important: indeed their importance has been proved by the diminished power of self-guidance in the dark, that results from cutting them off. These, then, are dermal appendages originally serving the purpose of clothing, but afterwards differentiated into sense-organs.

That eyes are essentially dermal structures seems scarcely conceivable. Yet an examination of their rudimentary types, and of their genesis in creatures that have them well developed, shows us that they really arise by successive modifications of the double layer composing the integument. They make their first appearance among the simpler animals as specks of pigment, covered by portions of epidermis slightly 
convex and a little more transparent than that around it. Here their fundamental community of structure with the skin is easy to trace; and the formation of them by differentiation of it presents no difficulty. Not so far in advance of these as much to obscure the relationship, are the eyes which the Crustaceans possess. 'In every fishmonger's shop we may see that the eyes of a Lobster are carried on pedicles; and when the Lobster casts its shell, the outer coat of each eye, being continuous with the epidermis of its pedicle, is thrown off along with the rest of the exoskeleton. Beneath the transparent epidermic layer, there exists a group of eyes of the kind which we see in an insect; and these, according to a high authority, are inclosed in the dermal system. Describing the arrangement of the parts, M. Milne Edwards writes:- " But the most remarkable circumstance is, that the large cavity within which the whole of these parallel columns, every one of which is itself a perfect eye, are contained, is closed posteriorly by a membrane, which appears to be neither more nor less than the middle tegumentary membrane, pierced for the passage of the optic nerve; so that the ocular chamber at large results from the separation at a point of the two external layers of the general envelope."

Thus too is it, in the main, even with the highly-developed eyes of the Vertebrata. "The three pairs of sensory organs appertaining to the higher senses," says Prof. Huxley- " the nasal sacs, the eyes, and the ears-arise as simple cœcal involutions of the external integument of the head of the embryo. That such is the case, so far as the olfactory sacs are concerned, is obvious, and it is not difficult to observe that the lens and the anterior chamber of the eye are produced in a perfectly similar manner. It is not so easy to see that the labyrinth of the ear arises in this way, as the sac resulting from the involution of the integument is small, and remains open but a very short time. But I have so frequently verified Huschke's and Remak's statement that it does so arise, that 
I entertain no doubt whatever of the fact. The outer ends of the olfactory sacs remain open, but those of the ocular auditory sacs rapidly close up, and shut off their contents from all direct communication with the exterior." That is to say, the eye considered as an optical apparatus is produced by metamorphoses of the skin: the only parts of it not thus produced, being the membranes lying between the sclerotic and the vitreous humour, including those retinal structures formed in them. All is tegumentary save that which has to appreciate the impressions which the modified integument concentrates upon it.

Thus, as Prof. Huxley has somewhere pointed out, there is a substantial parallelism between all the sensory organs in their modes of development; as there is, too, between their modes of action. A vibrissa may be taken as their common type. Increased impressibility by an external stimulus, requires an increased peripheral expansion of the nervous system on which the stimulus may fall; and this is secured by an introversion of the integument, forming a sac on the walls of which a nerve may ramify. That the more extended sensory area thus constituted may be acted upon, there requires some apparatus conveying to it from without the appropriate stimulus; and in the case of the vibrissa, this apparatus is the epidermic growth which, under the form of a hair, protrudes from the sac. And that the greatest sensitiveness may be obtained, the external action must be exaggerated or multiplied by the apparatus which conveys it to the recipient nerve; as, in the case of the vibrissa, it is by the development of a hair into an elastic lever, that transforms the slight force acting through considerable space on its exposed end, into a greater force acting through a smaller space at its rooted end. Similarly with the organs of the higher senses. In a rudimentary eye, the slightly modified sense cell has but a rudimentary nerve to take cognizance of the impression; and to concentrate the impression upon it, there is nothing beyond a thickening of the epidermis into a 
lens-shape. But the developed eye shows us a termination of the nerve greatly expanded and divided to receive the external stimulus. It shows us an introverted portion of the integument containing the apparatus by which the external stimulus is conveyed to the recipient nerve. The structure developed in this sac not only conveys the stimulus, but also, like its homologue, concentrates it; and in the one case as in the other, the structure which does this is an epidermic growth from the bottom of the sac. Even with the ear it is the same. Again we have an introverted portion of the integument, on the walls of which the nerve is distributed in the primitive ear. The otolithes contained in the sac thus formed, are bodies which are set in motion by the vibrations of the surrounding water, and convey these vibrations in an exaggerated form to the nerves. And though it is not alleged that these otolithes are developed from the epidermic lining of the chamber, yet as, if not so developed, they are concretions from the contents of an epidermic sac, they must still be regarded as epidermic products.

Whether these differentiations are due wholly to indirect equilibration, or whether direct equilibration has had a share in working them, are questions that must be left open. Possibly a short hair so placed on a mammal's face as to be very often touched, may, by conveying excitations to the nerves and vessels at its root, cause extra growth of the bulb and its appendages, and so the development of a vibrissa may be furthered. Possibly, too, the light itself, to which the tissues of some inferior animals are everywhere sensitive, may aid in setting up certain of the modifications by which the nervous parts of visual organs are formed: producing, as it must, the most powerful effects at those points on the surface which the movements of the animal expose to the greatest and most frequent contrasts of light and shade; and propagating from those points currents of molecular change through the organism. But it seems clear that the complexities 
of the sensory organs are not thus explicable. They must have arisen by the natural selection of favourable variations.

\$296. A group of facts, serving to elucidate those put together in the several foregoing sections, has to be added. I have reserved this group to the last, partly because it is transitional-links the differentiations of the literally outer tissues with those of the truly inner tissues. Though physically internal, the mucous coat of the alimentary canal has a quasi-externality from a physiological point of view. As was pointed out in the last chapter, the skin and the assimilating surface have this in common, that they come in direct contact with matters not belonging to the organism; and we saw that along with this community of relation to alien substances, there is a certain community of structure and development. The like holds with the linings of all internal cavities and canals that have external openings.

The transition from the literally outer tissues to those tissues which are intermediate between them and the truly inner tissues, is visible at all the orifices of the body; where skin and mucous membrane are continuous, and the one passes insensibly into the other. This visible continuity is associated not simply with a great degree of morphological continuity, but also with a great degree of physiological continuity. That is to say, these literally outer and quasi-outer layers are capable of rapidly assuming one another's structures and functions when subject to one another's conditions. Mucous surfaces, normally kept covered, become skin-like if exposed to the air; but resume more or less fully their normal characters when restored to their normal positions. These are truths familiar to pathologists. They continually meet with proofs that permanent eversion of the mucous membrane, even where it is by prolapse of a part deeply seated within the body, is followed by an adaptation eventually almost complete: originally moist, tender to the touch, and irritated by the air, the surface gradually becomes covered 
with a thick, dry cuticle; and is then scarcely more sensitive than ordinary integument.

Whether this equilibration between new outer forces and reactive inner forces, which is thus directly produced in individuals, is similarly produced in races, must remain as a question not to be answered in a positive way. On the one hand, we have the fact that among the higher animals there are cases of quasi-outer tissues which are in one species habitually ensheathed, while in another species they are not ensheathed; and that these two tissues, though unquestionably homologous, differ as much as skin and mucous membrane differ. On the other hand, there are certain analogous changes of surface, as on the abdomen of the Hermit-Crab, which give warrant to the supposition that survival of the fittest is the chief agent in establishing such differentiations; since the abdomen of a Hermit-Crab, bathed by water within the shell it occupies, is not exposed to physical conditions that directly tend to differentiate its surface from the surface of the thorax. But though in cases like this last, we must assign the result to the natural selection of variations arising incidentally; we may, I think, legitimately assign the result to the immediate action of changed conditions where, as in cases like the first, we see these producing in the individual, effects of the kinds observed in the race.

However this may be, the force of the general argument remains the same. In these exchanges of structure and function between the outer and quasi-outer tissues, we get undeniable proof that they are easily differentiable. And seeing this, we are enabled the more clearly to see how there have, in course of time, arisen those extreme and multitudinous differentiations of the outer tissues which have been glanced at. 


\section{CHAPTER VIII.}

\section{DIFFERENTIATIONS AMONG THE INNER TISSUES OF}

ANIMALS.

$\S 29 \%$. THE change from the outside of the lips to their inside, introduces us to a new series of interesting and instructive facts, joining on to those with which the last chapter closed. They concern the differentiations of those coats of the alimentary canal which, as we have seen, are physiologically outer, though physically inner.

These coats are greatly modified at different parts; and their modifications vary greatly in different animals. In the lower types, where they compose a simple tube running from end to end of the body, they are almost uniform in their histological characters; but on ascending from these types, we find them presenting an increasing variety of minute structures between their two ends. The argument will be adequately enforced if we limit ourselves to the leading modifications they display in some of the higher animals.

The successive parts of the alimentary canal are so placed with respect to its contents, that the physical and chemical changes undergone by its contents while passing from one end to the other, inevitably tend to transform its originally homogeneous surface into a heterogeneous surface. Clearly, the effect produced on the food at any part of the canal by trituration, by adding a secretion, or by absorbing its nutritive matters, implies the delivery of the food into the next part of the canal in a state more or less unlike its previous 
states-implies that the surface with which it now comes in contact is differently affected by it from the preceding surfaces-implies, that is, a differentiating action. To use concrete language;--food that is broken down in the mouth acts on the œsophagus and stomach in a way unlike that which it would have done had it been swallowed whole; the masticated food, to which certain solvents or ferments are added, becomes to the intestine a different substance from that which it must have otherwise been; and the altered food, resolved by these additions into its proximate principles, cannot have those proximate principles absorbed in the next part of the intestine, without the remoter parts being affected as they would not have been in the absence of absorption. It is true that in developed alimentary canals, such as the reasoning here tacitly assumes, these marked successive differentiations of the food are themselves the results of pre-established differentiations in the successive parts of the canal. But it is also true that actions and reactions like those here so definitely marked, must go on indefinitely in an undeveloped alimentary canal. If the food is changed at all in the course of its transit, which it must be if the creature is to live by it, then it cannot but act dissimilarly on the successive tracts of the alimentary canal, and cannot but be dissimilarly reacted on by them. Inevitably, therefore, the uniformity of the surface must lapse into greater or less multiformity: the differentiation of each part tending ever to initiate differentiations of other parts.

Not, indeed, that the implied process of direct equilibration can be regarded as the sole process. Indirect equilibration aids; and, doubtless, there are some of the modifications which only indirect equilibration can accomplish. But we have here one unquestionable cause-a cause that is known to work in individuals, changes of the kind alleged. Where, for instance, cancerous disease of the œsophagus so narrows the passage into the stomach as to prevent easy descent of the food, the esophagus above the obstruction becomes 
enlarged into a kind of pouch; and the inner surface of this pouch begins to secrete juices that produce in the food a kind of rude digestion. Again, stricture of the intestine, when it arises gradually, is followed by hypertrophy of the muscular coat of the intestine above the constricted part : the ordinary peristaltic movements being insufficient to force the food forwards, and the lodged food serving as a constant stimulus to contraction, the muscular fibres, habitually more exercised, become more bulky. The deduction from general principles being thus inductively enforced, we cannot, I think, resist the conclusion that the direct actions and reactions between the food and the alimentary canal have been largely instrumental in establishing the contrasts among its parts. And we shall hold this view with the more confidence on observing how satisfactorily, in pursuance of it, we are enabled to explain one of the most striking of these differentiations, which we will take as a type of the class.

The gizzard of a bird is an expanded portion of the alimentary canal, specially fitted to give the food that trituration which the toothless mouth of a bird cannot give. Besides having a greatly-developed muscular coat, this grindingchamber is lined with a thick, hard cuticle, capable of bearing the friction of the pebbles swallowed to serve as grindstones. This differentiation of the mucous coat into a ridged and tubercled layer of horny matter-a differentiation which, in the analogous organs of certain Mollusca, is carried to the extent of producing from this membrane cartilaginous plates, and even teeth-varies in birds of different kinds, according to their food. It is moderate in birds that feed on flesh and fish, and extreme in granivorous birds and others that live on hard substances. How does this immense modification of the alimentary canal originate? In the stomach of a mammal, the macerating and solvent actions are united with that triturating action which finishes what the teeth have mainly done; but in the bird, unable to masticate, these internal functions are specialized, and while the crop is the 
macerating chamber, the gizzard becomes a chamber adapted to triturate more effectually. This adaptation requires simply an exaggeration of certain structures and actions which characterize stomachs in general, and, in a less degree, alimentary canals throughout their whole lengths. The massive muscles of the gizzard are simply extreme developments of the muscular tunic, which is already considerably developed over the stomach, and incloses also the œesophagus and the intestine. The indurated lining of the gizzard, thickened into horny buttons at the places of severest pressure, is nothing more than a greatly strengthened and modified epithelium. And the grinding action of the gizzard is but a specialized form of that rhythmical contraction by which an ordinary stomach kneads the contained food, and which in the rosophagus effects the act of swallowing, while in the intestine it becomes the peristaltic motion. Allied as the gizzard thus clearly is in structure and action to the stomach and alimentary canal in general; and capable of being gradually differentiated from a stomach where a growing habit of swallowing food unmasticated entails more trituration to be performed before the food passes the pylorus; the question is-Does this change of structure arise by direct adaptation? There is warrant for the belief that it does. Besides such collateral evidence as that mucous membrane becomes horny on the toothless gums of old people, when subject to continual rough usage, and that the muscular coat of the intestine thickens where unusual activity is demanded of it, we have the direct evidence of experiment. Hunter habituated a sea-gull to feed on grain, and found that the lining of its gizzard became hardened, while the gizzardmuscles doubled in thickness. A like change in the diet of a kite was followed by like results. Clearly, if differentiations so produced in the individuals of a race under changed habits, are in any degree inheritable, a structure like a gizzard will originate through the direct actions and reactions between the food and the alimentary canal. 
Another case-a very interesting one, somewhat allied to this-is presented by the ruminating animals. Here several dilatations of the alimentary canal precede the true stomach; and in them large quantities of unmasticated food are stored, to be afterwards returned to the mouth and masticated at leisure. What conditions have made this specialization advantageous? and by what process has it been established? To both these questions the facts indicate answers which are not unsatisfactory.

Creatures that obtain their food very irregularly-now having more than they can consume, and now being for long periods without any-must, in the first place, be apt, when very hungry, to eat to the extreme limits of their capacities; and must, in the second place, profit by peculiarities which enable them to compensate themselves for long fasts, past and future. A perch which, when its stomach is full of young frogs, goes on filling its œsophagus also; or a trout which, rising to the fisherman's fly, proves when taken off the hook to be full of worms and insect-larvæ up to the very mouth, gains by its ability to take in such unusual supplies of food when it meets with themobviously thrives better than it would do could it never eat more than a stomachful. That this ability to feed greatly in excess of immediate requirement, is one that varies in individuals of the same race, we see in the marked contrast between our own powers in this respect, and the powers of uncivilized men; whose fasting and gorging are to us so astonishing. Carrying with us these considerations, we shall not be surprised at finding dilatations of the œesophagus in vultures and eagles, which get their prey at long intervals in large masses; and we may naturally look for them, too, in birds like pigeons, which, coming in flocks upon occasional supplies of grain, individually profit by devouring the greatest quantity in a given time. Now where the trituration of the food is, as in these cases, carried on in a lower part of the alimentary canal, nothing further is required than the storing-chamber; but for a mammal, having its grinding 
apparatus in its mouth, to gain by the habit of hurriedly swallowing unmasticated food, it must also have the habit of regurgitating the food for subsequent mastication. This correlation of habits with their answering structures, may, as we shall see, arise in a very simple way.

The starting point of the explanation is a familiar fact-the fact that indigestion, often resulting from excess of food, is apt to cause that reversed peristaltic action known as vomiting. From this we pass to the fact, also within the experience of most persons, that during slight indigestion the stomach sometimes quietly regurgitates a small part of its contents as far as the back of the mouth-giving an unpleasant acquaintance with the taste of the gastric juices. Exceptional facts of the same class help the argument a step further. “ There are certain individuals who are capable of returning, at will, a greater or smaller portion of the contents of the digesting stomach into the cavity of the mouth. . . . In some of these cases, the expulsion of the food has required a violent effort. In the majority it has been easily evoked or suppressed. While in others, it has been almost uncontrollable; or its non-occurrence at the habitual time has been followed by a painful feeling of fulness, or by the act of vomiting." Here we have a certain physiological action, occasionally happening in most persons and in some developed into a habit more or less pronounced: indigestion being the habitual antecedent.

Suppose, then, that gregarious animals, living on innutritive food such as grass, are subject to a like physiological action, and are capable of like variations in the degree of it. What will naturally happen? They wander in herds, now over places where food is scarce and now coming to places where it is abundant. Some masticate their food completely before swallowing it, while some masticate it incompletely. If an oasis, presently bared by their grazing, has not supplied to the whole herd a full meal, then the individuals which masticate completely will have had less than those which masticate incompletely_will not 
have had enough. Those which masticate incompletely and distend their stomachs with food difficult to digest, will be liable to these regurgitations; but if they re-masticate what is thus returned to the mouth (and we know that animals often eat again what they have vomited), then the extra quantity of food taken, eventually made digestible, will yield them more nourishment than is obtained by those which masticate completely at first. The habit initiated in this natural way, and aiding survival when food is scarce, will be apt to cause modifications of the alimentary canal. We know that dilatations of canals readily arise under habitual distensions. We know that canals habitually distended become gradually more tolerant of the contained masses that at first irritated them. And we know that there commonly take place adaptive modifications of their surfaces. Hence if a habit of this kind and the structural changes resulting from it, are in any degree inheritable, it is clear that, increasing in successive generations, both immediately by the cumulative effect of repetitions and mediately by survival of the individuals in which they are most decided, they may go on until they end in the peculiarities which Ruminants display.

$\S 298$. There are structures belonging to the same group which cannot, however, be accounted for in this way. They are the organs that secrete special products facilitating digestion-the liver, pancreas, and various smaller glands. All these appendages of the alimentary canal, large and independent as some of them seem, really arise by differentiations from its coats. The primordial liver consists of nothing more than bile-cells scattered along a tract of the intestinal surface. Accumulation of these bile-cells is accompanied by increased growth of the surface which bears them-a growth which at first takes the form of a cul-de-sac, having an outside that projects from the intestine into the peri-visceral cavity. As the mass of bile-cells becomes greater, there arise se- 
condary lateral cavities opening into the primary one, and through it into the intestine; until, eventually, these cavities with their coatings of bile-cells, become ramifying ducts distributed through the solid mass we know as a liver. How is this differentiation caused?

Before attempting any answer to this question, it is requisite to inquire the nature of bile. Is that which the liver throws into the intestines a waste product of the organic actions? or is it a secretion aiding digestion? or is it a mixture of these? Modern investigations imply that it is most likely the last. The liver is found to have a compound function. Bernard has proved to the satisfaction of physiologists, that there goes on in it a formation of glycogen - a substance which is transformed into sugar before it leaves the liver and is afterwards carried away by the blood to eventually disappear in the active organs, chiefly the muscles. It is also shown, experimentally, that there are generated in the liver certain biliary acids; and by the aid either of these or of some other compounds, it is clear that bile renders certain materials more absorbable. Its effect on fat is demonstrable out of the body; and the greatly diminished absorption of fat from the food when the discharge of bile into the intestine is prevented, is probably one of the causes of that pining away which results. But while recognizing the fact that the bile consists in part of a solvent, or solvents, aiding digestion, there is abundant evidence that one element of it is an effete product; and probably this is the primary element. The yellow-green substance called biliverdine in herbivora and bilirubin in man and carnivora, which gives its colour to bile, is a product the greater part of which is normally cast out from the system continually, as is shown by the contrast between the normal and abnormal colours of fæcal matters, and as is still more strikingly shown by the effects on the system when there is a stoppage of the excretion, and an attack of jaundice. Hence we are warranted in classing biliverdine as a waste product, and we 
may fairly infer that the excretion of it is the original function of the liver.

One further preliminary is requisite. We must for a moment return to those physico-chemical data set down in the first chapter of this work $(\S \S 7-8)$. We there saw that the complex and large-atomed colloids which mainly compose living organic matter, have extremely little molecular mobility; and, consequently, extremely little power of diffusing themselves. Whereas we saw not only that those absorbed matters, gaseous and liquid, which further the decomposition of living organic matter, have very high diffusibilities, but also that the products of the decomposition are much more diffusible than the components of living organic matter. And we saw that, as a consequence of this, the tissues give ready entrance to the substances which decompose them, and ready exit to the substances into which they are decomposed. Hence it follows that, under its initial form, uncomplicated by nervous and other agencies, the escape of effete matters from the organism, is a physical action parallel to that which goes on among mixed colloids and crystalloids that are dead or even inorganic. Excretion is a specialized form of this spontaneous action; and we have to inquire how the specialization arises.

Two causes conspire to establish it. The first is that these products of decomposition are diffusible in widely different degrees. While the carbonic acid and water permeate the tissues with ease in all directions, and escape more or less from the exposed surfaces, urea, and other waste substances incapable of being vaporized, cannot escape thus readily. The second is that the different parts of the body, being subject to different physical conditions, are from the outset sure severally to favour the exit of these various products of decomposition in various degrees. How these causes must have co-operated in localizing the excretions, we shall see on remembering how they now co-operate in localizing the separation of morbid materials. The characteristic substances of 
gout and rheumatism have their habitual places of deposit. Tuberculous matter, though it may be present in various organs, gravitates towards some much more than towards others. Certain products of disease are habitually got rid of by the skin, instead of collecting internally. Mostly, these have special parts of the skin which they affect rather than the rest; and there are those which, by breaking out symmetrically on the two sides of the body, show how definitely the places of their excretion are determined by certain favouring conditions, which corresponding parts may be presumed to furnish in equal degrees. Further, it is to be observed of these morbid substances circulating in the blood, that having once commenced segregating at particular places, they tend to continue segregating at those places. Assuming, then, as we may fairly do, that this localization of excretion, which we see continually commencing afresh with morbid matters, has always gone on with the matters produced by the waste of the tissues, let us take a further step, and ask how localizations become fixed. Other things equal, that which from its physical conditions is a place of least resistance to the exit of an effete product, will tend to become established as the place of excretion; since the rapid exit of an effete product will profit the organism. Other things equal, a place at which the excreted matter produces least detrimental effect will become the established place. If at any point the excreted matter produces a beneficial effect, then, other things equal, survival of the fittest will determine it to this point. And if facility of escape anywhere goes along with utilization of the escaping substance, then, other things equal, the excretion will be there localized still more decisively by survival of the fittest.

Such being the conditions of the problem, let us ask what will happen with the lining membrane of the alimentary canal. This, physiologically considered, is an external surface; and matters thrown off from it make their way out of the body. It is also a surface along which is moving the food 
to be digested. Now, among the various waste products continually escaping from the living tissues, some of the more complex ones, not very stable in composition, are likely, if added to the food, to set up changes in it. Such changes may either aid or hinder the preparation of the food for absorption. If an effete matter, making its exit through the wall of the intestine, hinders the digestive process, the enfeeblement and disappearance of individuals in which this happens, will prevent the intestine from becoming the established place for its exit. While if it aids the digestive process, the intestine will, for converse reasons, become more and more the place to which its exit is limited. Equally manifest is it that if there is one part of this alimentary canal at which, more than at any other part, the favourable effect results, this will become the place of excretion.

Thus, then, reverting to the case in question, we may understand how a product to be cast out, such as biliverdine, if it either directly or indirectly serves a useful purpose, when poured into a particular part of the intestine, may lead to the formation of a patch of excreting cells on its wall; and once this place of excretion having been established, the development of a liver is simply a question of time and natural selection.

§ 299. A differentiation of another order occurring in the alimentary canal, is that by which a part of it is developed into a lateral chamber or chambers, through which carbonic acid exhales and oxygen is absorbed. Comparative anatomy and embryology unite in showing that a lung is formed, just as a liver or other appendage of the alimentary canal is formed, by the growth of a hollow bud into the peri-visceral cavity, or space between the alimentary canal and the wall of the body. The interior of this bud is simply a cul-de-sac of the alimentary canal, with the mucous lining of which its own mucous lining is continuous. And the development of this cul-de-sac into an air-chamber, simple or compound, is 
merely a great extension of area in the internal surface of the cul-de-sac, along with that specialization which fits it for excreting and absorbing substances different from those which other parts of the mucous surface excrete and absorb.

These lateral air-chambers, universal among the higher Vertebrata and very general among the lower, and everywhere attached to the alimentary canal between the mouth and the stomach, have not in all cases the respiratory function. In most fishes that have them they are what we know as swim-bladders. In some fishes the cavities of these swim-bladders are completely shut off from the alimentary canal: nevertheless showing, by the communications which they have with it during the embryonic stages, that they are originally diverticula from it. In other fishes there is a permanent ductus pneumaticus, uniting the cavity of the swim-bladder with that of the gullet: the function, however, being still not respiratory in an appreciable degree, if at all. But in certain still extant representatives of the sauroid fishes, as the Lepidosteus, the air-bladder is "divided into two sacs that possess a cellular structure," and "the trachea which proceeds from it opens high-up in the throat, and is surrounded with a glottis." In the Amphibia the corresponding organs are chambers over the surfaces of which there are saccular depressions, indicating a transition towards the air-cells characterizing lungs; and accompanying this advance we see, as in the common Triton, the habit of coming up to the surface and taking down a fresh supply of air in place of that discharged.

How are the internal air-chambers, respiratory or nonrespiratory, developed? Upwards from the amphibian stage, in which they are partially refilled at long intervals, there is no difficulty in understanding how, by infinitesimal steps, they pass into complex and ever-moving lungs. But how is the differentiation that produces them initiated? How comes a portion of the internal surface to be specialized for converse with a medium to which it is not naturally 
exposed? The problem appears a difficult one; but there is a not unsatisfactory solution of it.

When many gold-fish are kept in a small aquarium, as with thoughtless cruelty they frequently are, they swim close to the surface, so as to breathe that water which is from instant to instant absorbing fresh oxygen. In doing this they often put their mouths partly above the surface, so that in closing them they take in bubbles of air; and sometimes they may be seen to continue doing this-the relief due to the slight extra aëration of blood so secured, being the stimulus to continue. Air thus taken in may be detained. If a fish that has taken in a bubble turns its head downwards, the bubble will ascend to the back of its mouth, and there lodge; and coming within reach of the contractions of the œsophagus, it may be swallowed. If, then, among fish thus naturally led upon occasion to take in air-bubbles, there are any having slight differences in the alimentary canal that facilitate lodgment of the air, or slight nervous differences such as in human beings cause an accidental action to become " a trick," it must happen that if an advantage accrues from the habitual detention of air-bubbles, those individuals most apt to detain them will, other things equal, be more likely than the rest to survive; and by the survival of descendants inheriting their peculiarities in the greatest degrees, and increasing them, an established structure and an established habit may arise. And that they do in some way arise we have proof. The common Loach swallows air, which it afterwards discharges loaded with carbonic acid.

From air thus swallowed the advantages that may be derived are of two kinds. In the first place, the fish is made specifically lighter, and the muscular effort needed to keep it from sinking is diminished-or, indeed, if the bubble is of the right size, is altogether saved. The contrast between the movements of a Goby, which, after swimming up towards the surface, falls rapidly to the bottom on ceasing its exertions, and the movements of a Trout, which remains suspended just 
balancing itself by slight undulations of its fins, shows how great an economy results from an internal float, to fishes which seek their food in mid-water or at the surface. Hence the habit of swallowing air having been initiated in the way described, we see why natural selection will, in certain fishes, aid modifications of the alimentary canal favouring its lodgment-modifications constituting air-sacs.

In the second place, while from air thus lodged in air-sacs thus developed, the advantage will be that of flotation only if the air is infrequently changed or never changed, the advantage will be that of supplementary respiration if the air-sacs are from time to time partially emptied and refilled. The requirements of the animal will determine which of the two functions predominates. Let us glance at the different sets of conditions under which these divergent modifications may be expected to arise.

The respiratory development is not likely to take place in fishes that inhabit seas or rivers in which the supply of aërated water never fails: there is no obvious reason why the established branchial respiration should be replaced by a pulmonic respiration. Indeed, if a fish's branchial respiration is adequate to its needs, a loss would result from the effort of coming to the surface for air; especially during those first stages of pulmonic development when the extra aëration achieved was but small. Hence in fishes so circumstanced, the air-chambers arising in the way described would naturally become specialized mainly or wholly into floats. Their contained air being infrequently changed, no advantage would arise from the development of vascular plexuses over their surfaces; nothing would be gained by keeping open the communication between them and the alimentary canal; and there might thus eventually result closed chambers the gaseous contents of which, instead of being obtained from without, were secreted from their walls, as gases often are from mucous membranes.

Contrariwise, aquatic vertebrates in which the swallowing of air-bubbles, becoming 
habitual, had led to the formation of sacs that lodged the bubbles; and which continued to inhabit waters not always supplying them with sufficient oxygen, might be expected to have the sacs further developed, and the practice of changing the contained air made regular, if either of two advantages resulted-either the advantage of being able to live in old habitats that had become untenable without this modification, or the advantage of being able to occupy new habitats. Now it is just where these advantages are gained that we see the pulmonic respiration coming in aid of the branchial respiration, and in various degrees replacing it. Shallow waters are liable to three changes which conspire to make this supplementary respiration beneficial. The summer's sun heats them, and raising the temperatures of the animals they contain, accelerates the circulation in these animals, exalts their functional activities, increases the production of carbonic acid, and thus makes aëration of the blood more needful than usual. Meanwhile the heated water, instead of yielding to the highly carbonized blood brought to the branchiæ the usual quantity of oxygen, yields less than usual; for as the heat of the water increases, the quantity of air it contains diminishes. And this greater demand for oxygen joined with smaller supply, pushed to an extreme where the water is nearly all evaporated, is at last still more intensely felt in consequence of the excess of carbonic acid discharged by the numerous creatures congregated in the muddy puddles that remain. Here, then, it is, that the habit of taking in air-bubbles is likely to become established, and the organs for utilizing them developed; and here it is, accordingly, that we find all stages of the transition to aërial respiration. The Loach before-mentioned, which swallows air, frequents small waters liable to be considerably warmed. The Amphipnous Cuchia, an anomalous eel-shaped fish, which has vascular air-sacs opening out at the back of the mouth, "is generally found lurking in holes and crevices, on the muddy banks of marshes or slow-moving rivers"; and 
though its air-sacs are not morphological equivalents of those above described, yet they equally well illustrate the relation between such organs and the environing condition. Still more significant is the fact that the Lepidosiren, or " mudfish" as it is called from its habits, though it is a true fish nevertheless has lungs. But it is among the Amphibia that we see most conspicuously this relation between the development of air-breathing organs, and the peculiarities of the habitats. Pools, more or less dissipated annually, and so rendered uninhabitable by most fishes, are very generally peopled by these transitional types. Just as we see, too, that in various climates and in various kinds of shallow waters, the supplementary aërial respiration is needful in different degrees; so do we find among the Amphibia many stages in the substitution of the one respiration for the other. The facts, then, are such as give to the hypothesis a vraisemblance greater than could have been expected.

The relative effects of direct and indirect equilibration in establishing this further heterogeneity, must, as in many other cases, remain undecided. The habit of taking in bubbles is scarcely interpretable as a result of spontaneous variation: we must regard it as arising accidentally during the effort to obtain the most aërated water; as being persevered in because of the relief obtained; and as growing by repetition into a tendency bequeathed to offspring, and by them, or some of them, increased and transmitted. The formation of the first slight modifications of the alimentary canal favouring the lodgment of bubbles, is not to be thus explained. Some favourable variation in the shape of the passage must here have been the initial step. But the gradual increase of this structural modification by the survival of individuals in which it is carried furthest, will, I think, be all along aided by immediate adaptation. The part of the alimentary canal previously kept from the air, but now habitually in contact with the air, must be in some degree modified by the action of the air; and the directly-produced modification, increasing 
in the individual and in successive individuals, cannot cease until there is a complete balance between the actions of the changed agency and the changed tissue.

$\S 300$. We come now to differentiations among the truly inner tissues-the tissues which have direct converse neither with the environment nor with the foreign substances taken into the organism from the environment. These, speaking broadly, are the tissues which lie between the double layer forming the integument with its appendages, and the double layer forming the alimentary canal with its diverticula. We will take first the differentiation which produces the vascular system.

Certain forces producing and aiding distribution of liquids in animals, come into play before any vascular system exists; and continue to further circulation after the development of a vascular system. The first of these is osmotic exchange, acting locally and having an indirect general action; the second is local variation of pressure, which movement of the body throws on the tissues and their contained liquids. A few words are needed in elucidation of each.

If in any creature, however simple, different changes are going on in parts that are differently conditioned-if, as in a Hydra, one surface is exposed to the surrounding medium while the other surface is exposed to dissolved food; then between the unlike liquids which the dissimilarly-placed parts contain, osmotic currents must arise; and a movement of liquid through the intermediate tissue must go on as long as an unlikeness between the liquids is kept up. This primary cause of re-distribution remains one of the causes of re-distribution in every more-developed organism: the passage of matters into and out of the capillaries is everywhere thus set up. And obviously in producing these local currents, osmose must also indirectly produce general currents, or aid them if otherwise produced. In the absence of a pumping organ, this force is probably an important aid to that 
movement of the nutritive liquids which the functions set up. How the second cause-the changes of internal pressure which an animal's movements produce-furthers circulation, will be sufficiently manifest. That parts which are bent or strained necessarily have their contained vessels squeezed, has been shown ( $\$ 281)$; and whether the bend or strain is caused, as in a plant, by an external force, or, as usually in an animal, by an internal force, there must be a thrusting of liquids towards places of least resistance-commonly places of greatest consumption. This which in animals without hearts is a main agent of circulation, continues to further it very considerably even among the highest animals. In these the effect becomes as it were systematized. The valves in the veins necessitate perpetual propulsions towards the heart.

Even in such simple types as the Hydrozoa, cavities in the tissues faintly indicate a structure which facilitates the transfer of nutritive matters. . These cavities become reservoirs filled with the plasma that slowly oozes through the substance of the body; and every movement of the animal, accompanied as it must be by changed pressures and tensions on these reservoirs, tends here to fill them and there to squeeze out their contents in that or the other direction-possibly aiding to produce, by union of several cavities, those lacunæ or irregular canals which the body in some cases presents.

Irregular canals of this kind, not lined with any membranes but being simply cavities running through the flesh, mainly constitute the vascular system in Polyzoa and Brachiopoda and some Mollusca. Though the central parts of a vascular system are rudely developed, yet its peripheral parts consist of sinuses permeating the tissues. The higher orders of Mollusca have a more developed system of vessels or arteries, which run into the substance of the body and end in lacunæ or simple fissures. This ending in lacunæ takes place at various distances from the vascular centre. In some genera the arterial structure is carried to the periphery of the blood-system, while in others it stops short midway. 
Throughout most orders of the Mollusca the back current of blood continues to be carried by channels of the original kind: there are no true veins, but the blood having been delivered into the tissues, finds its way back to the perivisceral cavity through inosculating sinuses. Among the Cephalopods, however, the afferent blood-canals, as well as the efferent ones, acquire distinct walls.

On putting together these facts, we may conceive pretty clearly the stages of vascular development. From the original reservoir of nutritive liquid between the alimentary canal and the wall of the body, a portion partially shut off becomes a contractile vessel; and by its actions there is produced a more rapid transfer of the nutritive liquid than was originally produced by the motions of the animal. Clearly, the extension of this contractile tube and the development from it of branches running hither and thither into the tissues, must, by defining the channels of blood throughout a part of its course, render its distribution more regular and active. As fast as this centrifugal growth advances, so fast are the efferent currents of blood, prevented from escaping laterally, obliged to move from the centre towards the circumference; and so fast also does the less-developed set of channels become, of necessity, occupied by afferent currents. When, by a parallel increase of definiteness, the lacunæ and irregular sinuses through which the afferent currents pass, become transformed into veins, the accompanying disappearance of all stagnant or slow-moving collections of blood, implies a further improvement in the circulation.

By what agency is effected this differentiation of a definite vascular system? No sufficient reply is obvious. The genesis of the primordial heart is not comprehensible as a result of direct equilibration, and we cannot readily see our way to it as a result of indirect equilibration; for it is diffcult to imagine what favourable variation natural selection could have seized hold of to produce such a structure. A contractile tube that aided the distribution of nutritive 
liquid, having been once established, survival of the fittest would suffice for its gradual extension and its successive modifications. But what were the early stages of the contractile tube, while it was yet not sufficiently formed to help circulation, and while it must nevertheless have had some advantage without which no selective process could go on? The question seems insoluble.

To another part of the question, however, an answer may be ventured. If we ask the origin of these ramifying channels which, first appearing as simple lacunæ, eventually become vessels having definite walls, a reply admitting of considerable justification, is, that the currents of nutritive liquid forced and drawn hither and thither through the tissues, themselves initiate these channels. We know that streams running over and through solid and quasi-solid inorganic matter, tend to excavate definite courses. We saw reason for concluding that the development of sap-channels in plants conforms to this general principle. May we not then suspect that the nutritive liquid contained in the tissue of a simple animal, made to ooze now in this direction and now in that by the changes of pressure which the animal's movements cause, comes to have certain lines along which it is thrust backwards and forwards more than along other lines; and must by repeated passings make these more and more permeable until they become lacunæ? Such actions will inevitably go on; and such actions appear competent to produce some, at least, of the observed effects. The leading facts which indicate that this is a part cause of vascular development are these.

Growths normally recurring in certain places at certain intervals, are accompanied by local formations of blood-vessels. The periodic maturation of ova among the Mammalia supplies an instance. Through the stroma of an ovarium are distributed innumerable minute vesicles, which, in their early stages, are microscopic. Of these, severally contained in their minute ovi-sacs, any one may develop: the determining 
cause being probably some slight excess of nutrition. When the development is becoming rapid, the capillaries of the neighbouring stroma increase and form a plexus on the walls of the ovi-sac. Now since there is no typical distribution of the developing ova; and since the increase of an ovum to a certain size precedes the increase of vascularity round it; we can scarcely help concluding that the setting up of currents towards the point of growth determines the formation of the blood-ressels. It may be that having once commenced, this local vascular structure completes itself in a typical manner; but it seems clear that this greater development of blood-vessels around the growing ovum is initiated by the draught towards it.

Abnormal growths show still better this relation of cause and effect. The false membranes sometimes found in the bronchial tubes in inflammatory diseases, may perhaps fairly be held abnormal in but a partial sense: it may be said that their vascular systems are formed after the type of the membranes to which they are akin. But this can scarcely be said of the morbid growths classed as malignant. The blood-vessels in an encephaloid cancer, are led to enlarge and ramify, often to an immense extent, by the unfolding of the morbid mass to which they carry blood. Alien as is the structure as a whole to the type of the organism; and alien in great measure as is its tissue to the tissue on which it is seated; it nevertheless happens that the growth of the alien tissue and accompanying abstraction of materials from the blood-vessels, determine a corresponding growth of these blood-vessels. Unless, then, we say that there is a providentially-created type of vascular structure for each kind of morbid growth (and even this would not much help us, since the vascular structure has no constancy within the limits of each kind), we are compelled to admit that in some way or other the currents of blood are here directly instrumental in forming their own channels.

One more piece of evidence, before cited as exemplifying adaptation ( $\$ 67)$, may be called to mind. 
When any main channel for blood, leading to or from a certain part of the body, has been rendered impervious, others among the channels leading to or from this same part, enlarge to the extent requisite for fulfilling the extra function that falls upon them: the enlargement being caused, as we must infer, by the increase of the currents carried.

Here, then, are facts warranting inductively the deduction above drawn. It is true that we are left in the dark respecting the complexities of the process. How the channels for blood come to have limiting membranes, and many of them muscular coats, the hypothesis does not help us to say. But the evidence assigned goes far to warrant the belief that vascular development is initiated by direct equilibration; though indirect equilibration may have had the larger share in establishing the structures which distinguish finished vascular systems.

$\S 301$. Of the inner tissues which remain let us next take bone. In what manner is differentiated this dense substance scrving in most cases for internal support?

When considering the vertebrate skeleton under its morphological aspect $(\S 256)$, it was pointed out that the formation of dense tissues, internal as well as external, is, in some cases at least, brought about by the mechanical forces to be resisted. Through what process it is brought about we could not then stay to inquire: this question being not morphological but physiological. Answers to some kindred questions have since been attempted. Certain actions to which the internal dense tissues of plants may be ascribed, have been indicated; and more recently, analogous actions have been assigned as causes of some external dense tissues of animals. We have now to ask whether actions of the same nature have produced these internal dense tissues of animals.

The problem is an involved one. Bones have more than one stage. They are membranous or cartilaginous before they become osseous; and their successive component substances 
so far differ that the effects of mechanical actions upon them differ. And having to deal with transitional states in which bone is formed of mixed tissues, having unlike physical properties and unlike minute structures, the effects of strains become too complicated to follow with precision. Anything in the way of interpretation must therefore be regarded as tentative. If analysis and comparison show that the phenomena are not inconsistent with the hypothesis of mechanical genesis, it is as much as can be expected. Let us first observe more nearly the mechanical conditions to which bones are subject.

The endo-skeleton of a mammal with the muscles and ligaments holding it together, may be rudely compared to a structure built up of struts and ties; of which, speaking generally, the struts bear the pressures and the ties bear the tensions. The framework of an ordinary iron roof will give an idea of the functions of these two elements, and of the mechanieal characters required by them. Such a framework consists partly of pieces which have each to bear a thrust in the direction of its length, and partly of pieces which have each to bear a pull in the direction of its length; and these struts and ties are differently formed to adapt them to these different strains. Further, it should be remarked that though the rigidity of the framework depends on the ties which are flexible, as much as on the struts which are stiff, yet the ties help to give the rigidity simply by so holding the struts in position that they cannot escape from the thrusts which fall on them. Now the like relation holds with a difference among the bones and muscles: the difference being that here the ties admit of being lengthened or shortened and the struts of being moved about upon their joints. The mechanical relations are not altered by this, however. The actions are of essentially the same kind in an animal that is standing, or keeping itself in a strained attitude, as in one that is changing its attitude-the same in so far that we have in each a set of flexible parts that are pulling and a set of 
rigid parts that are resisting. It needs but to remember the sudden collapse and fall which take place when the muscles are paralyzed, or to remember the inability of a bare skeleton to support itself, to see that the struts without the ties cannot suffice. And we have but to think of the formless mass into which a man would sink when deprived of his bones, to see that the ties without the struts cannot suffice. To trace the way in which a particular bone has its particular thrust thrown upon it, may not always be practicable. Though it is easy to perceive how a flexor or extensor of the arm causes by its tension a reactive pressure along the line of the humerus, and is enabled to produce its effect only by the rigidity of the humerus; yet it is not so easy to perceive how such bones as those of a horse's pelvis are similarly acted upon. Still, as the weight of the hind quarters has to be transferred from the back to the feet, and must be so transferred through the bones, it is manifest that though these bones form a very crooked line, the weight must produce a pressure along the axis of each: the muscles and ligaments concerned serving here, as in other cases, so to hold the bones that they bear the pressure instead of being displaced by it. Not forgetting that many processes of the bones have to bear tensions, we may then say that generally, though by no means universally, bones are internal dense masses that have to bear pressures-pressures which in the cylindrical bones become longitudinal thrusts. Leaving out exceptional cases, let us consider bones as masses thus circumstanced.

When giving reasons for the belief that the vertebrate skeleton is mechanically originated, one of the facts put in evidence was, that in the vertebrate series the transition from the cartilaginous to the osseous spine begins peripherally $(\S 257)$ : each vertebra being at first a ring of bone surrounding a mass of cartilage. And it was pointed out that this peripheral ossification is ossification at the region of greatest pressures. Now it is not vertebræ only that follow this course of development. In a cylindrical bone, though 
it is differently circumstanced, the places of commencing ossification are still the places on which the severest stress falls. Let us consider how such a bone that has to bear a longitudinal pressure is mechanically affected.

If the end of a walking-cane be thrust with force against the ground, the cane bends; and partially resuming its straightness when relieved, again bends, usually towards the same side, when the thrust is renewed. A bend so caused acts on the fibres of the cane in nearly the same way as does a bend caused by supporting the cane horizontally at its two ends and suspending a weight from its middle. In either case the fibres on the convex side are extended and the fibres on the concave side compressed. Kindred actions occur in a rod that is so thick as not to yield visibly under the force applied. In the absence of complete homogeneity of its substance, complete symmetry in its form, and an application of a force exactly along its axis, there must be some lateral deflection; and therefore some distribution of tensions and pressures of the kind indicated. And then, as the fact which here specially concerns us, we have to note that the strongest tensions and pressures are borne by the outer layers of fibres. Now the shaft of a long bone, subject to mechanical actions of this kind, similarly has its outer layer most strained. In this layer, therefore, on the mechanical hypothesis, ossification should commence, and here it does commence-commences, too, midway between the ends, where the bends produce on the superficial parts their most intense effects. But we have not in this place simply to observe that ossification commences at the places of greatest stress, but to ask what causes it to do this. Can we trace the physical actions which set up this deposit of dense tissue? It is, I think, possible to indicate a "true cause" that is at work; though whether it is a sufficient cause may be questioned. We concluded that in certain other cases, the formation of dense tissue indirectly results from the alternate squeezing and relaxation of the vessels running through the part; and the inquiry now to be made is, whether, in developing bone, 
the same actions go on in such ways as to produce the observed effects. At the outset we are met by what seems a fatal difficulty-cartilage is a non-vascular tissue: this substance of which unossified bones consist is not permeated by minute canals carrying nutritive liquid, and cannot, therefore, be a seat of actions such as those assigned. This apparent difficulty, however, furnishes a confirmation. For cartilage that is wholly without permeating canals does not ossify: ossification takes place only at those parts of it into which the canals penetrate. Hence, we get additional reason for suspecting that bone-formation is due to the alleged cause; since it occurs where mechanical strains can produce the actions described, but does not occur where mechanical strains cannot produce them. Let us consider more closely what the several factors are. It will suffice for the argument if we commence with the external vascular layer as already existing, and consider what will take place in it. Cartilage is elastic-is somewhat extensible, and spreads out laterally under pressure, but resumes its form when relieved. How, then, will the minute channels traversing it in all directions be affected at the places where it is strained by a bend? Those on the convex side will be laterally squeezed, in the same way that we saw the sap-vessels on the convex side of a bent branch are squeezed; and as exudation of the sap into the adjacent prosenchyma will be caused in the one case, so, in the other, there will be caused exudation of serum into the adjacent cartilage: extra nutrition and increase of strength resulting in both cases. The parallel ceases here, however. In the shoot of a plant, bent in various directions by the wind, the side which was lately compressed is now extended; and hence that squeezing of the sap-vessels which results from extension, suffices to feed and harden the tissue on all sides of the shoot. But it is not so with a bone. Having yielded on one side under longitudinal pressure, and resumed as nearly as may be its previous shape when the pressure is 
taken off, the bone yields again towards the same side when again longitudinally pressed. Hence the substance of its concave side, never rendered convex by a bend in the opposite direction, would not receive any extra nutrition did no other action come into play. But if we consider how intermittent pressures must act on cartilage, we shall see that there will result extra nutrition of the concave side also. Squeeze between two pieces of glass a thin bit of caoutchouc which has a hole through it. While the caoutchouc spreads out away from the centre, it also spreads inwards, so as partially to close the hole. Everywhere its molecules move away in directions of least resistance; and for those near the hole, the direction of least resistance is towards the hole. Let this hole stand for the transverse section of one of the minute canals or channels passing through cartilage, and it will be manifest that on the side of the unossified bone made concave in the way described, the compressed cartilage will squeeze the canals traversing it; and, in the absence of perfcet homogeneity in the eartilage, the squeeze will cause extra exudation from the canals into the cartilage. Thus every additional strain will give to the cartilage it falls upon, an additional supply of the materials for growth. So that presently the side which, by yielding more than any other, proves itself to be the weakest, will cease to be the weakest. What further will happen? Some other side will yield a little-the bends will take place in some other plane; and the portions of cartilage on which repeated tensions and pressures now fall will be strengthened. Thus the rate of nutrition, greatest at the place where the bending is greatest, and changing as the incidence of forces changes, will bring about at every point a balance between the resistances and the strains. Thus, too, there will be determined that peripheral induration which we see in bones so circumstanced. As in a shoot we saw that the woody deposit takes place towards the outside of the cylinder, where, according to the hypothesis, it ought to take place; so, here, we see that the 
excess of exudation and hardening, occurring where the strains are most intense, will form a cylinder having a dense outside and a porous or hollow inside.

These processes will be essentially the same in bones subject to more complex mechanical actions, such as sundry of the flat bones and others that serve as internal fulcra. Be the strains transverse or longitudinal, be they torsion strains or mixed strains, the outer parts of the bone will be more affected by them than its inner parts. They will therefore tend everywhere to produce resisting masses having outer parts more dense than their inner parts. And by causing most growth where they are most intense, they will call out reactive forces adequate to balance them.

There are doubtless obstacles in the way of this interpretation. It may be said that the forces acting on the outer layers in the manner described, would compress the canals too little to produce the alleged effects; and if evenly distributed along the whole lengths of the layers, they would probably do so. But it needs only to bend a flexible mass and observe the tendency to form creases on the concave surface, to feel assured that along the surface of an ossifying bone, the yielding of the tissue when bent will not be uniform. In the absence of complete homogeneity, the interstitial yielding will take place at some points more than others, and at one point above all others. When, at the weakest point-the centre of commencing ossification-an extra amount of deposit has been caused, it will cease to be the weakest; and adjacent points, now the weakest, will become the places of yielding and induration. It may be further objected that the hypothesis is incompatible with the persistence of cartilage for so long a time between the epiphysis of bones and the bony masses which they terminate. But there is the reply that the places occupied by this cartilage being places at which the bone lengthens, the non-ossification is in part apparent only-it is rather that new cartilage is formed as fast as the pre-existing cartilage ossifies; and there is the further reply 
that the slowness of the ultimate ossification of this part, is due to its non-vascularity, and to mechanical conditions which are unfavourable to its acquirement of vascularity. Once more, there is the demurrer that in the epiphyses ossification does not begin at the surface but within the mass of the cartilage. Explanation of this implies ability to follow out the mechanical actions in a resilient substance which, like india-rubber, admits of being distorted in all ways by pressure and recovering its form, and it seems impossible to say how the more superficial and more deep-seated canals traversing it will be respectively affected.

Of course it is not meant that this osseous development by direct equilibration takes place in the individual. Though it is a corollary from the argument that in each individual the process must be furthered and modified by the particular actions to which the particular bones are exposed; yet the leading traits of structure assumed by the bones are assumed in conformity with the inherited type. This, however, is no difficulty. The type itself is to be regarded as the accumulated result of such modifications, transmitted and increased from generation to generation. The actions above described as taking place in the bone of an individual, must be understood as producing their total effect little by little in the corresponding bones of a long series of individuals. Even if but a small modification can be so wrought in the individual, yet if such modification, or a part of it, is inheritable, we may readily understand how, in the course of geologic epochs, the observed structures may arise in the assigned way.

Here may fitly be added a strong confirmation. If we find cases where individual bones, subject in exceptional degrees to the actions described, present in exceptional amounts the modifications attributed to them, we are greatly helped in understanding how there may be produced in the race that aggregate of modifications which the hypothesis implies. Such cases occur in ricketty children. I am indebted to Mr. Busk for pointing out these abnormal formations of dense tissue, that are not apparently explicable as results of 
mechanical actions and re-actions. It was only on tracing out the processes here at work, that there suggested itself the specific interpretation of the normal process, as above set forth.

When, from constitutional defect, bones do not ossify with due rapidity, and are meanwhile subject to the ordinary strains, they become distorted. Remembering how a mass which has been made to yield in any direction by a force it cannot withstand, is some little time before it recovers completely its previous form, and usually, indeed, undergoes what is called a "permanent set;" it is inferable that when a bone is repeatedly bent at the same time that the liquid contained in its canals is poor in the materials for forming dense tissue, there will not take place a proportionate strengthening of the parts most strained; and these parts will give way. This happens in rickets. But this having happened, there goes on what, in teleological language, we call a remedial process. Supposing the bone to be one commonly affected-a femur; and supposing a permanent bend to have been caused in it by the weight of the body; the subsequent result is an unusual deposition of cartilaginous and osseous matter on the concave side of the bone. If the bone is represented by a strung bow, then the deposit occurs at the part represented by the space between the bow and the string. And thus occurring where its resistance is most effective, it increases until the approximately-straight piece of bone formed within the arc, has become strong enough to bear the pressure without appreciably yielding. Now this direct adaptation, seeming so like a special provision, and furnishing so remarkable an instance of what, in medical but unscientific language, is called the vis medicatrix naturce, is simply a result of the above-described mechanical actions and re-actions, going on under the exceptional conditions. Each time such a bent bone is subject to a force which again bends it, the severest compression falls on the substance of its concave side. Each time, then, the canals running through this part of its substance are violently squeezed- 
far more squeezed than they or any other of the canals would have been, had the bone remained straight. Hence, on every repetition of the strain, these canals near the concave surface have their contents forced out in more than normal abundance. The materials for the formation of tissue are supplied in quantity greater than can be assimilated by the tissue already formed; and from the excess of exuded plasma, new tissue arises.* A layer of organizable material accumulates between the concave surface and the periosteum; in this, according to the ordinary course of tissuegrowth, new vessels appear; and the added layer presently assumes the histological character of the layer from which it has grown. What next happens? This added layer, further from the neutral axis than that which has thrown it out, is now the most severely compressed, and its ressels are the most severely squeezed. The place of greatest exudation and most rapid deposit of matter, is therefore transferred to this new layer; and at the same time that active nutrition increases its density, the excess of organizable material forms another layer external to it: the successive layers so added, encroaching on the space between the concave surface of the bone and the chord of its are.

What limits the encroachment on this space?-what stops the process of filling it up? The answer to this question will be manifest when observing that there comes into play a cause which gradually diminishes the forces falling on each new layer. For the transverse sectional area is step by step increased; and an increase of the area over which the weight borne is distributed, implies a relatively smaller pressure upon each part of it. Further, as the transverse dimensions of the bone increase, the materials composing its convex and concave layers, becoming further from the neutral axis, become better

* To this implied inference it is objected that "excess of nutritive material does not necessarily lead to correspondingly increased growth." My reply is that a concomitant factor is activity of the tissue, and that in its absence growth is not to be expected. 
placed for resisting the strains to be borne. So that both by the increased quantity of dense matter and by its mechanically more-advantageous position, the bendings of the bone are progressively decreased. But as they are decreased, each new layer formed on the concave surface has its substance and its vessels less compressed; and the resulting growth and induration are rendered less rapid. Evidently, then, the additions, slowly diminishing, will eventually cease; and this will happen when the bone no longer bends. That is to say, the thickening of the bone will reach its limit when there is equilibrium between the incident forces and the forces which resist them. Here, indeed, we may trace with great clearness the process of direct equilibration-may see how an unusual force, falling on the moving equilibrium of an organism and not overthrowing it, goes on working modifications until the re-action balances the action.

That, however, which now chiefly concerns us, is to note how this marked adaptation supports the general argument. Unquestionably bone is in this case formed under the influence of mechanical stress, and formed just where it most effectually meets the stress. This result, not otherwise explained, is explained by the hypothesis above set forth. And when we see that this special deposit of bone is accounted for by actions like those to which bone-formation in general is ascribed, the probability that these are the actions at work becomes very great.*

* In recent years (since 1890) Prof. Wilhelm Roux, in essays on functional adaptation, has set forth some views akin to the foregoing in respect to the general belief they imply, though differing in respect of the physiological processes he indicates. The following relevant passage has been translated for me from an article of his in the Real-Encyclnpädie der ge. sammten Heilkunde:- "A more complete theory of functional adaptation by the autbor is founded on the assumption that the 'functional' stimulua, or 'the act of exercising the function' (in muscles and glands), and especially, in the case of bones, the concussion and tension caused by stress and strain, exert a 'trophic' stimulus on the cells, in consequence of which, and along with an increased absorption of nutriment, they grow and eventually increase (or the osteoblasts at the point of greater stimulus form more bone); while, conversely, with continued inactivity, by absence of these stimuli the 
Of course it is not alleged that osseous structures arise in this way alone. The bones of the skull and various dermal bones cannot be thus interpreted. Here the natural selection of favourable variations appears the only assignable cause-the equilibration is indirect. We know that ossific deposits now and then occur in tissues where they are not usually found; and such deposits, originally abnormal, if they occurred in places where advantages arose from them, might readily be established and increased by survival of the fittest. Especially might we expect this to happen when a constitutional tendency to form bone had been established by actions of the kind described; for it is a familiar fact that differentiated types of tissue, having once become elements of an organism, are apt occasionally to arise in unusual places, and there to repeat all their peculiar histological characters. And this may possibly be the reason why the bones of the skull, though not exposed to forces such as those which produce, in other bones, dense outer layers including less dense interiors, nevertheless repeat this general trait of bony structure. While, however, it is beyond doubt that some bones are not due to the direct influence of mechanical stress, we may, I think, conclude that mechanical stress initiates bone-formation.

$\S 302$. What is the origin of nerve? In what way do its properties stand related to the properties of that protoplasm whence the tissues in general arise? and in what way is it differentiated from protoplasm simultaneously with the other tissues? These are profoundly interesting questions; but questions to which positive answers cannot be expected. All that can be done is to indicate answers which seem feasible.

That the property specially displayed by nerve, is a prononrishment of the cell feclinea so that the maste is insufficiently replaced (or otherwise that the bone-anbstance gradually loses its power of resistance to the osteoblasts formed as a result of inactivity "). 
perty which protoplasm possesses in a lower degree, is manifest. The sarcode of a Rhizopod and the substance of an unimpregnated ovum, exhibit movements that imply a propagation of stimulus from one part of the mass to another. We have not far to seek for a probable origin of this phenomenon. There is good reason for ascribing it to the extreme instability of the organic colloids of which protoplasm consists. These, in common with colloids in general, assume different isomeric forms with great facility; and they display not simply isomerism but polymerism. Further, this readiness to undergo molecular re-arrangement, habitually shows itself in colloids by the rapid propagation of the re-arrangement from part to part. As Prof. Graham has shown, matter in this state often "pectizes" almost instantaneously-a touch will transform an entire mass. That is to say, the change of molecular state once set up at one end, spreads to the other end-there is a progress of a stimulus to change; and this is what we see in a nerve. So much being understood, let us re-state the case more completely.

Molecular change, implying as it does motion of molecules, communicates motion to adjacent molecules; be they of the same kind or of a different kind. If the adjacent molecules, either of the same kind or of a different kind, be stable in composition, a temporary increase of oscillation in them as wholes, or in their parts, may be the only result; but if they are unstable there are apt to arise changes of arrangement among them, or among their parts, of more or less permanent kinds. Especially is this so with the complex molecules which form colloidal matter, and with the organic colloids above all. Hence it is to be inferred that a molecular disturbance in any part of a living animal, set up by either an external or internal agency, will almost certainly disturb and change some of the surrounding colloids not originally implicated-will diffuse a wave of change towards other parts of the organism: a wave which will, in the absence of perfect homogeneity, travel further in some directions than in 
others.

Let us ask next what will determine the differences of distance travelled in different directions. Obviously any molecular agitation spreading from a centre, will go furthest along routes that offer least resistance. What routes will these be? Those along which there lie most moleeules that are easily changed by the diffused molecular motion, and which yet do not take up much molecular motion in assuming their new states. Molecules which are tolerably stable will not readily propagate the agitation; for they will absorb it in the increase of their own oscillations, instead of passing it on. Molecules which are unstable but which, in assuming isomeric forms, absorb motion, will not readily propagate it; since it will disappear in working the changes in them. But unstable molecules which, in being isomerically transformed, do not absorb motion, and still more those which, in being so transformed, give out motion, will readily propagate any molecular agitation; since they will pass on the impulse either undiminished, or increased, to adjacent molecules. then we assume, as we are not only warranted in doing but are obliged to do, that protoplasm contains two or more colloids, either mingled or feebly combined (since it cannot consist of simple albumen or fibrin or casein, or any allied proximate principle); it may be concluded that any molecular agitation set up by what we call a stimulus, will diffuse itself further along some lines than along others, if the components of the protoplasm are not quite homogeneously dispersed, and if some of them are isomerically transformed more easily, or with less expenditure of motion, than others; and it will especially travel along spaces occupied chiefly by those molecules which give out molecular motion during their metamorphoses, if there should be any such.

But now let us ask what structural effects will be wrought along a tract traversed by this wave of molecular disturbance. As is shown by those transformations which so rapidly propagate themselves through colloids, molecules that have undergone a certain change of form, 
are apt to communicate a like change of form to adjacent molecules of the same kind-the impact of each overthrow is passed on and produces another overthrow. Probably the proneness towards isochronism of molecular movements necessitates this. If any molecule has had its components re-arranged, and their oscillations consequently altered, there result movements not concordant with the movements in adjacent untransformed molecules, but which, impressing themselves on the parts of such untransformed molecules, tend to generate in them concordant movements-tend, that is, to produce the re-arrangements involved by these concordant movements. Is this action limited to strictly isomeric substances? or may it extend to substances that are closely allied? If along with the molecules of a compound colloid there are mingled those of some kindred colloid; or if with the molecules of this compound colloid there are mingled the components out of which other such molecules may be formed; then there arises the questiondoes the same influence which tends to propagate the isomeric transformations, tend also to form new molecules of the same kind out of the adjacent components? There is reason to suspect that it does. Already when treating of the nutrition of parts $(\S 64)$, it was pointed out that we are obliged to recognize a power possessed by each tissue to build up, out of the materials brought to it, molecules of the same type as those of which it is formed. This building up of like molecules seems explicable as caused by the tendency of the new components which the blood supplies, to acquire movements isochronous with those of the like components in the tissue; which they can do only by uniting into like compound molecules. Necessarily they must gravitate towards a state of equilibrium; such state of equilibrium-moving equilibrium of course-must be one in which they oscillate in the same times with neighbouring molecules; and so to oscillate they must fall into groups identical with the groups around them. If this be a general principle of 
tissue-growth and repair, we may conclude that it will apply in the case before us. A wave of molecular disturbance passing along a tract of mingled colloids closely allied in composition, and isomerically transforming the molecules of one of them, will be apt at the same time to form some new molecules of the same type, at any place where there exist the proximate components, either uncombined or feebly combined in some not very different way. And this will be most likely to occur where the molecules of the colloid that are undergoing the isomeric change, predominate, but have scattered through them the other molecules out of which they may be formed, either by composition or modification. That is to say, a wave of molecular disturbance diffused from a centre, and travelling furthest along a line where lie most molecules that can be isomerically transformed with facility, will be likely at the same time to further differentiate this line, and make it more characterized than before by the easy-transformability of its molecules.

One additional step, and the interpretation is reached. Analogy shows it to be not improbable that these organic colloids, isomerically transformed by slight molecular impact or increase of molecular motion, will some of them resume their previous molecular structures after the disturbance has passed. We know that what are stable molecular arrangements under one degree of molecular agitation, are not stable under another degree; and there is evidence that re-arrangements of an inconspicuous kind are occasionally brought about by very slight changes of molecular agitation. Water supplies a clear case. Prof. Graham infers that water undergoes a molecular re-arrangement at about $32^{\circ}$-that ice has a colloid form as well as a crystalloid form, dependent on temperature. Send through it an extra wave of the molecular agitation we call heat, and its molecules aggregate in one way. Let the wave die away, and its molecules resume their previous mode of aggregation. And obviously such transformations may be repeated backwards and forwards within narrow limits of temperature. 
Now among the extremely unstable organic colloids, such a phenomenon is far more likely to happen. Suppose, then, that the nerve-colloid is one of which the molecules are changed in form by a passing wave of extra agitation, but resume their previous form when the wave has passed: the previous form being the most stable under the conditions which then recur. What follows? It follows that these molecules will be ready again to undergo isomeric transformation when there again occurs the stimulus; will, as before, propagate the transformation most along the tract where such molecules are most abundant; will, as before, tend to form new molecules of their own type; will, as before, make the line along which they lie one of easier transfer for the molecular agitation. Every repetition will help to increase, to integrate, to define more completely, the course of the escaping molecular motionextending its remoter part while it makes its nearer part more permeable-will help, that is, to form a line of discharge, a line for conducting impressions, a nerve.

Such seems to me a not unfair series of deductions from the known habitudes of colloids in general and the organic colloids in particular. And I think that the implied nature and properties of nerve correspond better with the observed phenomena than do the nature and properties implied by other hypotheses. Of course the speculation as it here stands is but tentative, and leaves much unexplained. It gives no obvious reply to the questions-what causes the formation of nerves in directions adapted to the needs? what determines their appropriate connexions?-questions, however, to which, when we come to deal with physiological integration, we may find not unsatisfactory answers. Moreover it says nothing about the genesis of ganglia. A ganglion, it is clear, must consist of a colloidal matter equally unstable, or still more unstable, which, when disturbed, falls into some different molecular arrangement, perhaps chemically simpler, and gives out in so doing a large amount of molecular motion-serves as a reservoir of molecular motion which may be suddenly 
discharged along an efferent nerve or nerves, when excitement of an afferent nerve has disengaged it. How such a structure as this results, the hypothesis does not show. But admitting these shortcomings it may still be held that we are, in the way pointed out, enabled to form some idea of the actions by which nervous tissue is differentiated.

$\S 303$. A speculation akin to, and continuous with, the last, is suggested by an inquiry into the origin of muscular tissue. Contractility as well as irritability is a property of protoplasm or sarcode; and, as before suggested ( $\$ 22)$, is not improbably due to isomeric change in one or more of its component colloids. It is a feasible supposition that of the several isomeric changes simultaneously set up among these component colloids, some may be accompanied by change of bulk and some not. Clearly the isomeric change undergone by the colloid which we suppose to form nerve, must be one not accompanied by appreciable change of bulk; since change of bulk implies "internal work," as physicists term it, and therefore expenditure of force. Conversely, the colloid out of which muscle originates, may be one that readily passes into an isomeric state in which it occupies less space: the molecular disturbance causing this contraction being communicated to it from adjacent portions of nerve-substance that are molecularly disturbed; or being otherwise communicated to it by direct mechanical or chemical stimuli: as happens where nerves do not exist, or where their influence has been cut off. This interpretation seems, indeed, to be directly at variance with the fact that muscle does not diminish in bulk during contraction but merely changes its shape. That which we see take place with the muscle as a whole, is said also to take place with each fibre-while it shortens it also broadens. There is, however, a possible solution of this difficulty. A contracting colloid yields up its water; and the contracted colloid plus the free water, may have the same bulk as before though the colloid has less. If it be replied that in this 
case the water should become visible between the substance of the fibre and its sarcolemma or sheath, it may be rejoined that this is not necessary-it may be deposited interstitially. Possibly the striated structure is one that facilitates its exudation and subsequent re-absorption; and to this may be due the superiority of striated muscle in rapidity of contraction.

Granting the speculative character of this interpretation, let us see how far it agrees with the facts. If the actions are as here supposed, the contracted or more integrated state of the muscular colloid will be that which it tends continually to assume-that into which it has an increasing aptitude to pass when artificial paralysis has been produced, as shown by Dr. Norris-that into which it lapses completely in rigor mortis. The sensible motion generated by the contraction can arise only from the transformation of insensible motion. This insensible motion suddenly yielded up by a contracting mass, implies the fall of its component molecules into more stable arrangements. And there can be no such fall unless the previous arrangement is unstable. From this point of view, too, it is possible to see how the hydro-carbons and carbo-hydrates consumed in muscular action, may produce their effects. For these non-nitrogenous elements of food, when consumed in the tissues, give out large amounts of molecular motion. They do this in presence of the muscular colloids which have lost molecular motion during their fall in the stable or contracted state. From the molecular motion they give out, may be restored the molecular motion lost by the contracted colloids ; and these contracted colloids may thus have their molecules raised to that unstable state from which, again falling, they can again generate mechanical motion.

This conception of the nature and mode of action of muscle, while it is suggested by known properties of colloidal matter and conforms to the recent conclusions of organic chemistry and molecular physics, establishes a comprehensible relation between the vital actions of the lower and the higher 
animals. If we contemplate the movements of cilia, of a Rhizopod's pseudopodia, of a Polype's body, or of the long pendant tentacles of a Medusa, we shall see great congruity between them and this hypothesis. Bearing in mind that the contractile substance of developed muscle is affected not by nervous influence only, but, where nervous influence is destroyed, is made to contract by mechanical disturbance and chemical action, we may infer that it does not differ intrinsically from the primordial contractile substance which, in the lowest animals, changes its bulk under other stimuli than the nervous. We shall see significance in the fact ascertained by Dr. Ransom, that various agents which excite and arrest nervo-muscular movements in developed animals, excite and arrest the protoplasmic movements in ova. We shall understand how tissues not yet differentiated into muscle and nerve, have this joint irritability and contractility; how muscle and nerve may arise by the segregation of their mingled colloids, the one of which, not appreciably altering its bulk during isomeric change, readily propagates molecular disturbance, while the other, contracting when isomerically changed, less readily passes on the molecular disturbance; and how, by this differentiation and integration of the conducting and the contracting colloids, the one ramifying through the other, it becomes possible for a whole mass to contract suddenly, instead of contracting gradually, as it does when undifferentiated.

The question remaining to be asked is-What causes the specialization of contractile substance?-What causes the growth of colloid masses which monopolize this contractility, and leave kindred colloids to monopolize other properties? Has natural selection gradually localized and increased the primordial muscular substance? or has the frequent recurrence of irritations and consequent contractions at particular parts done it? We have, I think, reason to conclude that direct equilibration rather than indirect equilibration has been chiefly operative. The reasoning that was used in the case 
of nerve applies equally in the case of muscle. A portion of undifferentiated tissue containing a predominance of the colloid that contracts in changing, will, during each change, tend to form new molecules of its own type from the other colloids diffused through it: the tendency of these entangled colloids to fall into unity with those around them, will be aided by every shock of isomeric transformation. Hence, repeated contractions will further the growth of the contracting mass, and advance its differentiation and integration.

If, too, we remember that the muscular colloid is made to contract by mechanical disturbance, and that among mechanical disturbances one which will most readily affect it simultaneously throughout its mass is caused by stretching, we shall be considerably helped towards understanding how the contractile tissues are developed. If extension of a muscular colloid previously at rest, produces in it that molecular disturbance which leads to isomeric change and decrease of bulk, then there is no difficulty in explaining the movements of cilia; the formation of a contractile layer in the vascular system becomes comprehensible; each dilatation of a bloodvessel caused by a gush of blood, will be followed by a constriction; the heart will pulsate violently in proportion as it is violently distended; arteries will develop in power as the stress upon them becomes greater; and we shall similarly have an explanation of the increased muscularity of the alimentary canal which is brought about by increased distension of it.

That the production of contractile tissue in certain localities, is due to the more frequent excitement in those localities of the contractility possessed by undifferentiated tissue in general, is a view harmonizing with traits which the differentiated contractile tissue exhibits. These are the relations between muscular excrcise, muscular power, and muscular structure; and it is the more needful for us here to notice them because of certain anomalies they present, which, at first sight, seem inconsistent with the belicf that 
the functionally-determined modifications of muscle are inheritable.

Muscles disagree greatly in their tints: all gradations between white and deep red being observable. Contrasts are visible between the muscles of different animals, between the muscles of the same animal at different ages, and between different muscles of the same animal at the same age. We will glance at the facts under these heads: noting under each of them the connexion which here chiefly concerns us-that between the activity of muscle and its depth of colour. The cold-blooded Vertebrata are, taken as a group, distinguished from the warm-blooded by the whiteness of their flesh; and they are also distinguished by their comparative inertness. Though a fish or a reptile can exert considerable force for a short time, it is not capable of prolonged exertion. Birds and mammals show greater endurance along with the darker-coloured muscles. If among birds themselves or mammals themselves we make comparisons, we meet with kindred contrasts-especially between wild and domestic creatures of allied kinds. Barn-door fowls are lighter-fleshed than most untamed gallinaceous birds; and among these last the pheasant, moving about but little, is lighter-fleshed than the partridge and the grouse which are more nomadic. The muscles of the sheep are not on the average so dark as those of the deer; and it is said that the flesh of the wild-boar is darker than that of the pig. Perhaps, however, the contrast between the hare and the rabbit affords, among familiar animals, the best example of the alleged relation: the dark-fleshed hare having no retreat and making wide excursions, while the white-fleshed rabbit, passing a great part of its time in its burrow, rarely wanders far from home.

The parallel contrast between young and old animals has a parallel meaning. Veal is much whiter than beef, and lamb is of lighter colour than mutton. Though at first sight these facts may not seem to furnish confirmatory evidence, since lambs in their play appear to 
expend more muscular force than their sedate dams; yet the meaning of the contrast is really as alleged. For in consequence of the law. that the strains which animals have to overcome, increase as the cubes of the dimensions, while their powers of overcoming them increase only as the squares ( $\$ 46)$, the movements of an adult animal cost much more in muscular effort than do those of a young animal: the result being that the sheep and the cow exercise their muscles more vigorously in their quiet movements, than the lamb and the calf in their lively movements. It may be added as significant, that the domestic animal in which no very marked darkening of the flesh takes place along with increasing age, namely the pig, is one which, ordinarily kept in a sty, leads so quiescent a life that the assigned cause of darkening does not come into action.

But perhaps the most conclusive evidences are the contrasts which exist between the active and inactive muscles of the same animal. Between the leg-muscles of fowls and their pectoral muscles, the difference of colour is familiar; and we know that fowls exercise their leg-muscles much more than the muscles which move their wings. Similarly in the turkey, in the guinea fowl, in the pheasant. And then, adding much to the force of this evidence, we see that in partridges and grouse, which belong to the same order as our domestic fowls but use their wings as constantly as their legs, little or no difference is visible between the colour of these two groups of muscles. Special contrasts like these do not, however, exhaust the proofs; for there is a still more significant general contrast. The muscle of the heart, which is the most active of all muscles, is the darkest of all muscles.

The connexion of phenomena thus shown in so many ways, implies that the bulk of a muscle is by no means the sole measure of the quantity of force it can evolve. It would seem that, other things equal, the depth of colour varies with the constancy of action; while, other things equal, the bulk varies with the amount of force that has to be put forth upon occa- 
sion. These of course are approximate relations. More correctly we may say that the actions of pale muscles are either relatively feeble though frequent (as in the massive flanks of a fish), or relatively infrequent though strong (as in the pectoral muscles of a common fowl); while the actions of dark muscles are both frequent and strong. Some such differentiation may be anticipated by inference from the respective physiological requirements. A muscle which has upon occasion to evolve considerable force, but which has thereafter a long period of rest during which repair may restore it to efficiency, requires neither a large reserve of the contractile substance that is in some way deteriorated by action, nor highly-developed appliances for bringing it nutritive materials and removing effete products. Where, contrariwise, an exerted muscle which has undergone much molecular change in evolving much mechanical force, has soon again to evolve much mechanical force, and so on continually; it is clear that either the quantity of contractile substance present must be great, or the apparatus for nutrition and depuration must be very efficient, or both. Hence we may look for marked unlikenesses of minute structure between muscles which are markedly contrasted in activity. And we may suspect that these conspicuous contrasts of colour between active and inactive muscles, are due to these implied differences of minute structure: partly differences between the numbers of blood-vessels and partly differences between the quantities or qualities of sarcous matter.

Here, then, we have a key to the apparent anomaly above hinted at-the maintenance of bulk by certain muscles which have been rendered comparatively inactive by changed habits of life. That the pectoral muscles of those domestic birds which fly but little, have not dwindled to any great extent, has been thought a fact at variance with the conclusion that functionally-produced adaptations are inheritable. It has been argued that if parts which are exercised increase, not only in the individual but in the race, while parts which 
become less active decrease; then a notable difference of size should exist between the muscles used for flight in birds that fly much, and those in birds of an allied kind that fly little. But, as we here see, this is not the true implication. The change in such cases must be chiefly in vascularity and abundance of contractile substance; and cannot be, to any great extent, in bulk. For a bird to fly at all, its pectoral muscles, bones of attachment, and all accompanying appliances, must be kept up to a certain level of power. If the parts dwindle much, the creature will be unable to lift itself from the ground. Bearing in mind that the force which a bird expends to sustain itself in the air during each successive instant of a short flight is, other things equal, the same as it expends in each successive instant of a long flight, we shall see that the muscles employed in the two cases must have something like equal intensities of contractile power; and that the structural differences between them must have relation mainly to the lengths of time during which they can continue to repeat contractions of like intensity. That is to say, while the power of flight is retained at all, the muscles and bones cannot greatly dwindle; but the dwindling, in birds whose flights are short or infrequent or both, will be in the reserve stock of the substance that is incapacitated by action, or in the appliances that keep the apparatus in repair, or in both. Only where, as in the struthious birds, the habit of flight is lost, can we expect atrophy of all the parts concerned in flight; and here we find it.

Are such differentiations among the muscles functionally produced? or are they produced by the natural selection of variations distinguished as spontaneous? We have, I think, good grounds for concluding that they are functionally produced. We know that in individual men and animals, the power of sustained action in muscles is rapidly adaptable to the amount of sustained action required. We know that being "out of condition," is usually less shown by the inability to put out a violent effort than by the inability to continue 
making violent efforts; and we know that the result of training for prize-fights and races, is more shown in the prolongation of energy than in the intensification of energy. At the same time, experience has taught us that the structural change which accompanies this functional change, is not so much a change in the bulk of the muscles as a change in their internal state: instead of being soft and flabby they become hard. We have inductive proof, then, that exercise of a muscle causes some interstitial growth along with the power of more sustained action; and there can be no doubt that the one is a condition to the other. What is this interstitial growth? There is reason to suspect that it is in part an increased deposit of the sarcous substance and in part a development of blood-vessels. Microscopic observation tends to confirm the conclusions before drawn, that repetition of contractions furthers the formation of the matter which contracts, and that greater draughts of blood determine greater vascularity. And if the contrasts of molecular structure and the contrasts of vascularity, directly caused in muscles by contrasts in their activities, are to any degree inheritable; there results an explanation of those constitutional differences in the colours and textures of muscles, which accompany constitutional differences in their degrees of activity.

It may be added that if we are warranted in so ascribing the differentiations of muscles from one another to direct equilibration, then we have the more reason for thinking that the differentiation of muscles in general from other structures is also due to direct equilibration. That unlikenesses between parts of the contractile tissues having unlike functions, are caused by the unlikenesses of their functions, renders it the more probable that the unlikenesses between contractile tissue and other tissues, have been caused by analogous unlikenesses.

$\S 304$. These interpretations, which have already occupied too large a space, must here be closed. Of course out of 
phenomena so multitudinous and varied, it has been impracticable to deal with any but the most important; and it has been practicable to deal with these only in a general way. Much, however, as remains to be explained, I think the possibility of tracing, in so many cases, the actions to which these internal differentiations may rationally be ascribed, makes it likely that the remaining internal differentiations are due to kindred actions. We find evidence that, in more cases than seemed probable, these actions produce their effects directly on the individual; and that the unlikenesses are produced by accumulation of such effects from generation to generation. While for all the other unlikenesses, we have, as an adequate cause, the indirect effects wrought by the survival, generation after generation, of the individuals in which favourable variations have occurred-variations such as those of which human anatomy furnishes endless instances. Thus accounting for so much, we may not unreasonably presume that these co-operative processes of direct and indirect equilibration will account for what remains.

[NотE.-After having dismissed this revised chapter as done with, and sent it to the printer, further thought concerning those differentiations which produce bone, has reminded me of a fact of extreme and varied significance named in the first volume. I refer to the formation of adaptive structures round the ends of dislocated bones, and to the formation of "false joints."

These are ontogenetic changes of which phylogeny yields no explanation. They do not repeat the traits of ancestral organisms, and they cannot be ascribed to either of the recognized evolutionary factors. If a humerus be broken across and, failing to set, presently comes to have its two loose ends so modified as in a measure to simulate the parts of a normal joint-the ends becoming smooth, covered with periosteum and supplied with fibrous tissue, and attached by ligaments in such ways as to allow of restrained move- 
ments-it is impossible to think that natural selection has had anything to do with the power of adjustment thus shown. No survival of individuals in which adaptations of this kind, now in one place and now in another, were better and better effected, could account for acquirement of the ability. Nor can it be supposed that the ability might result from a functionally-produced habit; since it is scarcely conceivable that the number of cases in which individuals profited by it (at first a little and gradually more) could be such (even did they survive) as to affect the constitution of the species. Both of the alleged causes of structural modifications are out of court. It is manifest, too, that the foregoing hypothesis respecting bone-formation yields us not the slightest help.

But on carefully considering the facts, certain phenomena of profound meaning may strike us. Here, in a part of the body where no such tissues ordinarily exist and to which no such structures are ordinarily appropriate, there arise tissues and structures adapted to the physical circumstances imposed on that part. Out of what do these abnormal but appropriate tissues arise? The substances around-osseous, cartilaginous, membranous-consist of differentiated elements too far specialized to allow of transformation. These new tissues, then, must originate from the undifferentiated protoplasm pervading the part. The units of this protoplasm, subject to the actions proper to an articulation, begin to assume the appropriate histological traits-are determined by local stimuli to form tissues ordinarily associated with such stimuli. What is the inevitable implication? These units-physiological or constitutional, as we may call them-must have possessed latent potentialities of falling into these special arrangements under stress of such conditions. At one point there arises periosteum and at another ligamentous tissue, while for the shaping of the ends of the bones-here into a rude hinged form and there into a rude ball-and-socket form, according to the habitual movements-there goes on some appropriate de- 
posit of bone. Hence we must conclude that in the units of protoplasm which have not yet been organized into special tissues, there resides the ability to take on one or other type of histological structure according to circumstances; and, further, that there resides in each of them the still more marvellous ability to cooperate with kindred units dispersed around in developing that arrangement of the parts required to constitute a "false joint." So that while these units have a general proclivity towards the structure of the organism as a whole, they have also proclivities towards structures proper to the local conditions into which they fall. There is latent in each unit the constitution of the entire organism and by implication the constitution of every organ; and each unit while cooperating with the aggregate is ready to take part in that particular arrangement proper to the position it has fallen into. If the reader will refer back to $\S \S 97 d, 97 \mathrm{e}$, in which it is shown that each member of a human society possesses a combination of potentialities like these, he will be the better enabled to believe that this thing may be so while he is unable to conceive how it is so.

And here, indeed, let it be pointed out how completely irrelevant is the test of conceivableness as applied to these ultimate physiological actions. For as here, from the ununited ends of the broken bone, there presently arises a rude joint with fit membranes, ligaments, and even synovial fluid, though we are absolutely unable to imagine the process by which the adjacent tissues produce this structure; so there may be from an organ enlarged by function, such reactive effect upon the system at large as eventually to influence the reproductive cells, though we may be absolutely unable to imagine how this can be done.] 


\section{CHAPTER IX.}

PHYSIOLOGICAL INTEGRATION IN ANIMALS.

$\S 305$. Phystological differentiation and physiological integration, are correlatives that vary together. We have but to recollect the familiar parallel between the division of labour in a society and the physiological division of labour, to see that as fast as the kinds of work performed by the component parts of an organism become more numerous, and as fast as each part becomes more restricted to its own work, so fast must the parts have their actions combined in such ways that no one can go on without the rest and the rest cannot go on without each one.

Here our inquiry must be, how the relationship of these two processes is established-what causes the integration to advance pari passu with the differentiation. Though it is manifest, $\grave{a}$ priori, that the mutual dependence of functions must be proportionate to the specialization of functions; yet it remains to find the mode in which the increasing co-ordination is determined.

Already, among the Inductions of Biology, this relation between differentiation and integration has been specified and illustrated $(\$ 59)$. Before dealing with it deductively, a few further examples, grouped so as to exhibit its several aspects, will be advantageous.

$\S 306$. If the lowly-organized Planaria has its body broken up and its gullet detached, this will, for a while, continue 
to perform its function when called upon, just as though it were in its place: a fragment of the creature's own body placed in the gullet, will be propelled through it, or swallowed by it. But, as the seeming strangeness of this fact implies, we find no such independent actions of analogous parts in the higher animals. Again, a piece cut out of the disc of a Medusa continues with great persistence repeating those rhythmical contractions which we see in the disc as a whole; and thus proves to us that the contractile function in each portion of the disc, is in great measure independent. But it is not so with the locomotive organs of more differentiated types. When separated from the rest these lose their powers of movement. The only member of a vertebrate animal which continues to act after detachment, is the heart; and the heart has motor powers complete within itself.

Where there is this small dependence of each part upon the whole, there is but small dependence of the whole upon each part. The longer time whieh it takes for the arrest of a function to produce death in a less-differentiated animal than in a more-differentiated animal, may be illustrated by the case of respiration. Suffocation in a man speedily causes resistance to the passage of the blood through the capillaries, followed by congestion and stoppage of the heart: great disturbance throughout the system results in a few seconds, and in a minute or two all the functions cease. But in a frog, with its undeveloped respiratory organ, and a skin through which a considerable aëration of the blood is carried on, breathing may be suspended for a long time without injury. Doubtless this difference is proximately due to the greater functional activity in the one case than in the other, and the more pressing need for discharging the produced carbon dioxide; but the greater functional activity being itself made possible by the higher specialization of functions, this remains the primary cause of the greater dependence of the other functions on respiration, where the respiratory apparatus has become highly specialized.

Here 
indeed, we see the relation under another aspect. This more rapid rhythm of the functions which increased heterogeneity of structure makes possible, is itself a means of integrating the functions. Watch, when it is running down, a complicated machine of which the parts are not accurately adjusted, or are so worn as to be somewhat loose. There will be observed certain irregularities of movement just before it comes to rest-certain of the parts which stop first, are again made to move a little by the continued movement of the rest, and then become themselves, in turn, the causes of renewed motion in other parts which have ceased to move. That is to say, while the connected rhythmical changes of the machine are quick, their actions and reactions on one another are regular-all the motions are well integrated; but as the velocity diminishes irregularities arise-the motions become somewhat disintegrated. Similarly with organic functions: increase of their rapidity involves increase of a joint momentum which controls each and co-ordinates all. Thus if we compare a snake with a mammal, we see that its functions are not tied together so closely. The.mammal, and especially the superior mammal, requires food with considerable regularity; keeps up a respiration which varies within but moderate limits; and has periods of activity and rest that alternate evenly and frequently. But the snake, taking food at long intervals, may have these intervals greatly extended without fatal results; its dormant and its active states recur less uniformly; and its rate of respiration varies within much wider limits-now being scarcely perceptible and now, as you may prove by exciting it, becoming conspicuous. So that here, where the rhythms are very slow, they are individually less regular, and are united into a less regular compound rhythm - are less integrated.

Perhaps the clearest general idea of the co-ordination of functions that accompanies their specialization, is obtained by observing the slowness with which a little-differentiated animal responds to a stimulus applied to one of its parts, 
and the rapidity with which such a local stimulus is responded to by a more-differentiated animal. A sea-anemone and a fly will serve for the comparison. A tentacle of a seaanemone, when touched, slowly contracts; and if the touch has been rude, the contraction presently extends to the other tentacles and eventually to the entire body: the stimulus to movement is gradually diffused throughout the organism. But if you touch a fly, or rather if you come near enough to threaten a touch, the entire apparatus of flight is instantly brought into combined action. Whence arises this contrast? The one creature has but faintly specialized contractile organs, and fibres for conveying impressions. The other has definite muscles and nerves and a co-ordinating centre. The parts of the little-differentiated sea-anemone have their functions so feebly co-ordinated, that one may be strongly affected for some time before any effect is felt by another at a distance from it; but in the much-differentiated fly, various remote parts instantly have changes propagated to them from the affected part, and by their united actions thus set up, the whole organism adjusts itself so as to avoid the danger.

These few added illustrations will make the nature of this general rclation sufficiently clear. Let us now pass to the interpretation of it.

$\S 30 \%$. If a Hydra is cut in two, the nutritive liquids diffused through its substance cannot escape rapidly, since there are no open channels for them; and hence the conditions of the parts at a distance from the cut is but little affected. But where, as in the more-differentiated animals, the nutritive liquid is contained in vessels which have continuous communications, cutting the body in two, or cutting off any considerable portion of it, is followed by escape of the liquid from these vessels to a large extent; and this affects the nutrition and efficiency of organs remote from the place of injury. Then where, as in further-developed creatures, there exists an apparatus for propelling the blood 
through these ramifying channels, injury of a single one will cause a loss of blood that quickly prostrates the entire organism. Hence the rise of a completely-differentiated vascular system, is the rise of a system which integrates all members of the body, by making each dependent on the integrity of the vascular system, and therefore on the integrity of each member through which it ramifies.

In another mode, too, the establishment of a distributing apparatus produces a physiological union that is great in proportion as this distributing apparatus is efficient. As fast as it assumes a function unlike the rest, each part of an animal modifies the blood in a way more or less unlike the rest, both by the materials it abstracts and by the products it adds; and hence the more differentiated the vascular system becomes, the more does it integrate all parts by making each of them feel the qualitative modification of the blood which every other has produced. This is simply and conspicuously exemplified by the lungs. In the absence of a vascular system, or in the absence of one that is well marked off from the imbedding tissues, the nutritive plasma or the crude blood, gets what small aëration it can, only by coming near the creature's outer surface, or those inner surfaces which are bathed by water. But where there have been formed definite channels branching throughout the body, and particularly where there exist specialized organs for pumping the blood through these channels, it manifestly becomes possible for the aëration to be carried on in one part peculiarly modified to further it, while all other parts have the aërated blood brought to them. And how greatly the differentiation of the vascular system thus becomes a means of integrating the various organs, is shown by the fatal result that follows when the current of aërated blood is interrupted.

Here, indeed, it becomes obvious both that certain physiological differentiations make possible certain physiological integrations; and that, conversely, these integrations make possible other differentiations. Besides the waste products 
which escape through the lungs, there are waste products which escape through the skin, the kidneys, the liver. The blood has separated from it in each of these structures, the particular product which this structure has become adapted to separate; leaving the other products to be separated by the other adapted structures. How have these special adaptations been made possible? By union of the organs as recipients of one circulating mass of blood. While there is no efficient apparatus for transfer of materials through the body, the waste products of each part have to make their escape locally; and the local channels of escape must be competent to take off indifferently all the waste products. But it becomes practicable and advantageous for the differentlylocalized excreting structures to become fitted to separate different waste products, as soon as the common circulation through them grows so efficient that the product left unexcreted by one is quickly carried to another better fitted to excrete it. So that the integration of them through a common vascular system, is the condition under which only they can become differentiated. Perhaps the clearest idea of the way in which differentiation leads to integration, and how, again, increased integration makes possible still further differentiation, will be obtained by contemplating the analogous dependence in the social organism. While it has no roads, a country cannot have its industries much specialized: each locality must produce, as best it can, the various commodities it consumes, so long as it has no facilities for barter with other localities. But the localities being unlike in their natural fitnesses for the various industries, there tends ever to arise some exchange of the commodities they can respectively produce with least labour. This exchange leads to the formation of channels of communication. The currents of commodities once set up, make their foot-paths and horse-tracks more permeable; and as fast as the resistance to exchange becomes less, the currents of commodities become greater. Each locality takes more of the products 
of adjacent ones, and each locality devotes itself more to the particular industry for which it is naturally best fitted: the functional integration makes possible a further functional differentiation. This further functional differentiation reacts. The greater demand for the special product of each locality, excites improvements in production-leads to the use of methods which both cheapen and perfect the commodity. Hence results a still more active exchange; a still clearer opening of the channels of communication; a still closer mutual dependence. Yet another influence comes into play. As fast as the intercourse, at first only between neighbouring localities, makes for itself better roads-as fast as rivers are bridged and marshes made easily passable, the resistance to distribution becomes so far diminished, that the things grown or made in each district can be profitably carried to a greater distance; and as the economical integration is thus extended over a wider area, the economical differentiation is again increased; since each district, having a larger market for its commodity, is led to devote itself more exclusively to producing this commodity. These actions and reactions continue until the various localities, becoming greatly developed and highly specialized in their industries, are at the same time functionally integrated by a network of roads, and finally railways, along which rapidly circulate the currents severally sent out and received by the localities. And it will be manifest that in individual organisms a like correlative progress must have been caused in an analogous way.

$\S 308$. Another and higher form of physiological integration in animals, is that which the nervous system effects. Each part as it becomes specialized, begins to act upon the rest not only indirectly through the matters it takes from and adds to the blood, but also directly through the molecular disturbances it sets up and diffuses. Whether nerves themselves are differentiated by the molecular disturbances thus propagated in certain directions, or whether they are other- 
wise differentiated, it must equally happen that as fast as they become channels along which molecular disturbances travel, the parts they connect become physiologically integrated, in so far that a change in one initiates a change in the other. We may dimly perceive that if portions of what was originally a uniform mass having a common function, undertake subdivisions of the function, the molecular changes going on in them will be in some way complementary to one another: that peculiar form of molecular motion which the one has lost in becoming specialized, the other has gained in becoming specialized. And if the molecular motion that was common to the two portions while they were undifferentiated, becomes divided into two complementary kinds of molecular motion; then between these portions there will be a contrast of molecular motions such that whatever is plus in the one will be minus in the other; and hence there will be a special tendency towards a restoration of the molecular equilibrium between the two: the molecular motion continually propagated away from either will have its line of least resistance in the direction of the other.

If, as argued in the last chapter, repeated restorations of molecular equilibrium, always following the line of least resistance, tend ever to make it a line of diminished resistance; then, in proportion as any parts become more physiologically integrated by the establishment of this channel for the easy transmission of molecular motion between them, they may become more physiologically differentiated. The contrast between their molecular motions leads to the line of discharge; the line of discharge, once formed, permits a greater contrast of their molecular motions to arise; thereupon the quantities of molecular motion transferred to restore equilibrium, being increased, the channel of transfer is made more permeable; and its further permeability, so caused, renders possible a still more marked unlikeness of action between the parts. Thus the differentiation and the integration progress hand in hand as before. How the same principle holds through- 
out the higher stages of nervous development, can be seen only still more vaguely. Nevertheless, it is comprehensible that as functions become further divided, there will arise the need for sub-connexions along which there may take place secondary equilibrations subordinate to the main ones. It is manifest, too, that whereas the differentiation of functions proceeds, not necessarily by division into two, but often by division into several, and usually in such ways as not to leave any two functions that are just complementary to one another, the restorations of equilibrium cannot be so simple as above supposed. And especially when we bear in mind that many differentiated functions, as those of the senses, cannot be held complementary to any other functions in particular; it becomes manifest that the equilibrations that have to be made in an organism of much heterogeneity, are extremely complex, and do not take place between each organ and some other, but between each organ and all the others. The peculiarity of the molecular motion propagated from each organ, has to be neutralized by some counter-peculiarity in the average of the molecular motions with which it is brought into relation. All the variously-modified molecular motions from the various parts, must have their pluses and minuses mutually cancelled: if not locally, then at some centre to which each unbalanced motion travels until it meets with some opposite unbalanced motion to destroy it. Still, involved as these actions must become, it is possible to see how the general principle illustrated by the simple case above supposed, will continue to hold. For always the molecular motion proceeding from any one differentiated part, will travel most readily towards that place where a molecular motion most complementary to it in kind exists-no matter whether this complementary molecular motion be that procceding from any one other organ, or the resultant of the molecular motions proceeding from many other organs. So that the tendency will be for each channel of communication or nerve, to unite itself with some centre or ganglion, where it 
comes into relation with other nerves. And if there be any parts of its peculiar molecular motion uncancelled by the molecular motions it meets at this centre; or if, as will probably happen, the average molecular motion which it there unites to produce, differs from the average molecular motion elsewhere; then, as before, there will arise a discharge along another channel or nerve to another centre or ganglion, where the residuary difference may be cancelled by the differences it meets; or whence it may be still further propagated till it is so cancelled. Thus there will be a tendency to a general nervous integration keeping pace with the differentiation.

Of course this must be taken as nothing more than the indication of initial tendencies-not as an hypothesis sufficient to account for all the facts. It leaves out of sight the origin and functions of ganglia, considered as something more than nerve-junctions. Were there only these lines of easy

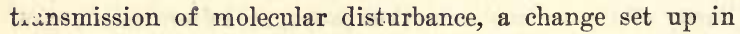
one organ could never do more than produce its equivalent of change in some other or others; and there could be none of that large amount of motion initiated by a small sensation, which we habitually see. The facts show, unmistakably, that the sligght disturbance communicated to a ganglion, causes an overthrow of that highly-unstable nervous matter contained in it, and a discharge from it of the greatly-increased quantity of molecular motion so generated. This, however, is beyond our immediate topic. All we have here to note is the interdependence and unification of functions that naturally follow the differentiation of them.

$\S 309$. Something might be added concerning the further class of integrations by which organisms are constituted mechanically-coherent wholes. Carrying further certain of the arguments contained in the last chapter, it might be not unreasonably inferred that the binding together of parts by bones, muscles, and ligaments, is a secondary result of 
those same actions by which bones, muscles, and ligaments are specialized. But adequate treatment of this division of the subject is at present scarcely possible.

What little of fact and inference has been above set down, will, however, serve to make comprehensible the general truths respecting which, in their main outlines, there can be no question. Beginning with the feebly-differentiated sponge, of which the integration is also so feeble that cutting off a piece interferes in no appreciable degree with the activity and growth of the rest, it is undeniable that the advance is through stages in which the multiplication of unlike parts having unlike actions, is accompanied by an increasing interdependence of the parts and their actions; until we come to structures like our own, in which a slight change initiated in one part will instantly and powerfully affect all other partswill convulse an immense number of muscles, send a wave of contraction through all the blood-vessels, awaken a crowd of ideas with an accompanying gush of emotions, affect the action of the lungs, of the stomach, and of all the secreting organs. And while it is a manifest necessity that along with this subdivision of functions which the higher organisms show us, there must be this close co-ordination of them, the foregoing paragraphs suggest how this necessary correlation is brought about. For a great part of the physiological union that accompanies the physiological specialization, there appears to be a sufficient cause in the process of direct equilibration; and indirect equilibration may be fairly presumed a sufficient cause for that which remains. 


\section{CHAPTER X.}

\section{SUMMARY OF PHYSIOLOGICAL DEVELOPMENT.}

$\S 310$. INTERCOURSE between each part and the particular conditions to which it is exposed, either habitually in the individual or occasionally in the race, thus appears to be the origin of physiological development; as we found it to be the origin of morphological development. The unlikenesses of form that arise among members of an aggregate that were originally alike, we traced to unlikenesses in the incident forces. And in the foregoing chapters we have traced to unlikenesses in the incident forces, these unlikenesses of minute structure and chemical composition that simultaneously arise among the parts.

In summing up the special truths illustrative of this general truth, it will be proper here to contemplate more especially their dependence on first principles. Dealing with biological phenomena as phenomena of evolution, we have to interpret not only the increasing morphological heterogeneity of organisms, but also their increasing physiologieal heterogeneity, in terms of the re-distribution of matter and motion. While we make our rapid re-survey of the facts, let us then more particularly observe how they are subordinate to the universal course of this re-distribution.

$\S 311$. The instability of the homogeneous, or, strictly speaking, the ineritable lapse of the more homogeneous into the less homogeneous, which we before saw endlessly exem- 
plified by the morphological differentiations of the parts of organisms, we have here seen afresh exemplified in ways also countless, by the physiological differentiations of their parts. And in the one case as in the other, this change from uniformity to multiformity in organic aggregates, is caused, as it is in all inorganic aggregates, by the necessary exposure of their component parts to actions unlike in kind or quantity or both. General proof of this is furnished by the order in which the differences appear. If parts are rendered physiologically heterogeneous by the heterogeneity of the incident forces, then the earliest contrasts should be between parts that are the most strongly contrasted in their relations to incident forces; the next earliest contrasts should occur where there are the next strongest contrasts in these relations; and so on. It turns out that they do so.

Everywhere the differentiation of outside from inside comes first. In the simplest plants the unlikeness of the cell-wall to the cell-contents is the conspicuous trait of structure. The contrasts seen in the simplest animals are of the same kind: the film that covers a Rhizopod and the more indurated coat of an Infusorian, are more unlike the contained sarcode than the other parts of this are from one another; and the tendency during the life of the animal is for the unlikeness to become greater.

What is true of Protophyta and Protozoa, is true of the germs of all organisms up to the highest: the differentiation of outer from inner is the first step. When the protoplasm of an Alga-cell has broken up into the clusters of granules which are eventually to become spores, each of these quickly acquires a membranous coating; constituting an unlikeness between surface and centre. Similarly with the ovule of every higher plant: the mass of cells forming it, early exhibits an outside layer of cells distinguished from the cells within. With animal-germs it is the same. Be it in a ciliated gemmule, be it in the unfertilized ova of Aphides and of the Cecidomyia, or be it in true ova, the primary differentiation conforms to the rela- 
tions of exterior and interior.

If we turn to adult organisms, vegetal or animal, we see that whether they do or do not display other contrasts of parts, they always display this contrast. Though otherwise almost homogeneous, such Fungi as the puff-ball, or, among Algo, all which have a thallus of any thickness, present marked differences between those of their cells which are in immediate contact with the environment and those which are not. Such differences they present in common with every higher plant; which, here in the shape of bark and there in the shape of cuticle, has an envelope inclosing it even up to its petals and stamens. In like manner among animals, there is always either a true skin or an outer coat analogous to one. Wherever aggregates of the first order have united into aggregates of the second and third orders-wherever they have become the morphological units of such higher aggregates-the outermost of them have grown unlike those lying within. Even the Sponge is not without a layer that may by analogy be called dermal.

This lapse of the relatively homogeneous into the relatively heterogeneous, first showing itself, as on the hypothesis of evolution it must do, by the rise of an unlikeness between outside and inside, goes on next to show itself, as we infer that it must do, by the establishment of secondary contrasts among the outer parts answering to secondary contrasts among the forces falling on them. So long as the whole surface of a plant remains similarly related to the environment, as in a Protococcus, it remains uniform; but when there come to be an attached surface and a free surface, these, being subject to unlike actions, are rendered unlike. This is visible even in a unicellular Alga when it becomes fixed; it is shown in the distinction between the under and upper parts of ordinary Fungi; and we see it in the universal difference between the imbedded ends and the exposed ends of the higher plants. And then among the less marked contrasts of surface answering to the less marked contrasts in the inci- 
dent forces, come those between the upper and under sides of leaves; which, as we have seen, vary in degree as the contrasts of forces vary in degree, and disappear where these contrasts disappear.

Equally clear proof is furnished by animals, that the original uniformity of surface lapses into multiformity, in proportion as the actions of the environment upon the surface become multiform. In a Worm, burrowing through damp soil which acts equally on all its sides, or in a Tonia, uniformly bathed by the contents of the intestine it inhabits, the parts of the integument do not appreciably differ from one another; but in creatures not surrounded by the same agencies, as those that crawl and those that have their bodies partially inclosed, there are unlikenesses of integument corresponding to unlikenesses of the conditions. A snail's foot has an under surface not uniform with the exposed surface of its body, and this again is not uniform with the protected surface. Among articulate animals there is usually a distinction between the ventral and the dorsal aspects; and in those of the Arthropoda which subject their anterior and posterior ends to different environing agencies, as do the ant-lion and the hermit-crab, these become superficially differentiated.

Analogous general contrasts occur among the Vertebrata. Fishes, though their outsides are uniformly bathed by water, have their backs more exposed to light than their bellies, and the two are commonly distinct in colour. When it is not the back and belly which are thus dissimilarly conditioned, but the sides, as in the Pleuronectida, then it is the sides which become contrasted; and there may be significance in the fact that those abnormal individuals of this order which revert to the ancestral undistorted type, and swim vertically, have the two sides alike. In such higher vertebrates as reptiles, we see repeated this differentiation of the upper and under surfaces: especially in those of them which, like snakes, expose these surfaces to the most diverse actions. Even in birds and mammals which usually, by raising the under surface considerably above the ground, 
greatly diminish the contrast between its conditions and the conditions to which the upper surface is subject, there still remains some unlikeness of clothing answering to the remaining unlikeness between the conditions.

Thus, without by any means saying that all such differentiations are directly caused by differences in the actions of incident forces, which, as before shown $(\S 294)$, they cannot be, it is clear that many of them are so caused. It is clear that parts of the surface exposed to very unlike environing agencies, become very unlike; and this is all that needs to be shown.

Complex as are the transformations of the inner parts of organisms from the relatively homogeneous into the relatively heterogeneous, we still see among them a conformity to the same general order. In both plants and animals the earlier internal differentiations answer to the stronger contrasts of conditions. Plants, absorbing all their nutriment through their outer surfaces, are internally modified mainly by the transfer of materials and by mechanical stress. Such of them as do not raise their fronds above the surface, have their inner tissues subject to no marked contrasts save those caused by currents of sap; and the lines of lengthened and otherwise changed cells which are formed where these currents run, and are most conspicuous where these currents must obviously be the strongest, are the only decided differentiations of the interior. But where, as in the higher Cryptogams and in Phænogams, the leaves are upheld, and the supporting stem is transversely bent by the wind, the inner tissues, subject to different amounts of mechanical strain, differentiate accordingly: the deposit of dense substance commences in that region where the sapcontaining cells and canals suffer the greatest intermittent compressions. Animals, or at least such of them as take food into their interiors, are subject to forces of another class tending to destroy their original homogeneity. Food is a foreign substance which acts on the interior as an environing object which touches it acts on the exterior-is 
literally a portion of the environment which, when swallowed, becomes a cause of internal differentiations as the rest of the environment continues a cause of external differentiations. How essentially parallel are the two sets of actions and reactions, we have seen implied by the primordial identity of the endoderm and ectoderm in simple animals, and of the skin and mucous membrane in complex animals (\$§288, 289). Here we have further to observe that as food is the original source of internal differentiations, these may be expected to show themselves first where the influence of the food is greatest; and to appear later in proportion as the parts are more removed from the influence of the food. They do this. In animals of low type, the coats of the alimentary cavity or canal are more differentiated than the tissue which lies between the alimentary canal and the wall of the body. This tissuein the higher Coelenterata, is a feebly-organized parenchyma traversed by canals lined with simple ciliated cells; and in the lower Mollusca the structures bounding the perivisceral cavity and its ramifying sinuses, are similarly imperfect. Further, it is observable that the differentiation of this perivisceral sac and its sinuses into a vascular system, proceeds centrifugally from the region where the absorbed nutriment enters the mass of circulating liquid, and where this liquid is qualitatively more unlike the tissues than it is at the remoter parts of the body.

Physiological development, then, is initiated by that instability of the homogeneous which we have seen to be everywhere a cause of evolution (First Principles, §§ 149-155). That the passage from comparative uniformity of composition and minute structure to comparative multiformity, is set up in organic aggregates, as in all other aggregates, by the necessary unlikenesses of the actions to which the parts are subject, is shown by the universal rise of the primary differentiation into the parts that are universally most contrasted in their circumstances, and by the rise of secondary differen- 
tiations obviously related in their order to secondary contrasts of conditions.

$\S 312$. How physiological development has all along been aided by the multiplication of effects-how each differentiation has ever tended to become the parent of new differentiations, we have had, incidentally, various illustrations. Let us here review the working of this cause.

Among plants we see it in the production of progressivelymultiplying heterogeneities of tissue by progressive increase of bulk. The integration of fronds into axes and of axes into groups of axes, sets up unlikenesses of action among the integrated units, followed by unlikenesses of minute structure. Each gust transversely strains the various parts of the stem in various degrees, and longitudinally strains in various degrees the roots; and while there is inequality of stress at every place in stem and branch, so, at every place in stem and branch, the outer layers and the successively inner layers are severally extended and compressed to unequal amounts, and have unequal modifications wrought in them. Let the tree add to its periphery another generation of the units composing it, and immediately the mechanical strains on the supporting parts are all changed in different degrees, initiating new differences internally. Externally, too, new differences are initiated. Shaded by the leaf-bearing outer stratum of shoots, the inner structures cease to bear leaves, or to put out shoots which bear leaves; and instead of that green covering which they originally had, become covered with bark of increasing thickness. Manifestly, then, the larger integration of units that are originally simple and uniform, entails physiological changes of various orders, varying in their degrees at all parts of the aggregate. Each branch which, favourably circumstanced, flourishes more than its neighbours, becomes a cause of physiological differentiations, not only in its neighbours from which it abstracts sap and pres- 
ently turns from leaf-bearers into fruit-bearers, but also in the remoter parts.

That among animals physiological development is furthered by the multiplication of effects, we have lately seen proved by the many changes in other organs, which the growth or modification of each excreting and secreting organ initiates. By the abstracted as well as by the added materials, it alters the quality of the blood passing through all members of the body; or by the liquid it pours into the alimentary canal, it acts on the food, and through it on the blood, and through it on the system as a whole: an additional differentiation in one part thus setting up additional differentiations in many other parts; from each of which, again, secondary differentiating forces reverberate through the organism. Or, to take an influence of another order, we have seen how the modified mechanical action of any member not only modifies that member, but becomes, by its reactions, a cause of secondary modifications-how, for example, the burrowing habits of the common mole, leading to an almost exclusive use of the fore limbs, have entailed a dwindling of the hind limbs, and a concomitant dwindling of the pelvis, which, becoming too small for the passage of the young, has initiated still more anomalous modifications.

So that throughout physiological development, as in evolution at large, the multiplication of effects has been a factor constantly at work, and working more actively as the development, has advanced. The secondary changes wrought by each primary change, have necessarily become more numerous in proportion as organisms have become more complex. And every increased multiplication of effects, further differentiating the organism and, by consequence, further integrating it, has prepared the way for still higher differentiations and integrations similarly caused.

$\S 313$. The general truth next to be resumed, is that these processes have for their limit a state of equilibrium-proxi- 
mately a moving equilibrium and ultimately a complete equilibrium. The changes we have contemplated are but the concomitants of a progressing equilibration. In every aggregate which we call living, as well as in all other aggregates, the instability of the homogeneous is but another name for the absence of balance between the incident forces and the forces which the aggregate opposes to them; and the passage into heterogeneity is the passage towards a state of balance. And to say that in every aggregate, organic or other, there goes on a multiplication of effects, is but to say that one part which has a fresh force impressed on it, must go on changing and communicating secondary changes, until the whole of the impressed force has been used up in generating equivalent reactive forces.

The principle that whatever new action an organism is subject to, must either overthrow the moving equilibrium of its functions and cause the sudden equilibration called death, or else must progressively alter the organic rhythms until, by the establishment of a new reaction balancing the new action a new moving equilibrium is produced, applies as much to each member of an organism as to the organism in its totality. Any force falling on any part not adapted to bear it, must either cause local destruction of tissue, or must, without destroying the tissue, continue to change it until it can change it no further; that is-until the modified reaction of the part has become equal to the modified action. Whatever the nature of the force this must happen. If it is a mechanical force, then the immediate effect is some distortion of the part-a distortion having for its limit that attitude in which the resistance of the structures to further change of position, balances the force tending to produce the further change; and the ultimate effect, supposing the force to be continuous or recurrent, is such a permanent alteration of form, or alteration of structure, or both, as establishes a permanent balance. If the force is physico-chemical, or chemical, the general result is still the same: the component molecules of 
the tissue must have their molecular arrangements changed, and the change in their molecular arrangements must go on until their molecular motions are so re-adjusted as to equilibrate the molecular motions of the new physico-chemical or chemical agent. In other words, the organic matter composing the part, if it continues to be organic matter at all, must assume that molecular composition which enables it to bear, or as we say adapts it to, the incident forces.

Nor is it less certain that throughout the organism as a whole, equilibration is alike the proximate limit of the changes wrought by each action, as well as the ultimate limit of the changes wrought by any recurrent actions or continuous action. The movements every instant going on, are movements towards a new state of equilibrium. Raising a limb causes a simultaneous shifting of the centre of gravity, and such altered tensions and pressures throughout the body as re-adjust the disturbed balance. Passage of liquid into or out of a tissue, implies some excess of force in one direction there at work; and ceases only when the force so diminishes or the counter-forces so increase that the excess disappears. A nervous discharge is reflected and re-reflected from part to part, until it has all been used up in the re-arrangements produced-equilibrated by the reactions called out. And what is thus obviously true of every normal change, is equally true of every abnormal change-every disturbance of the established rhythm of the functions. If such disturbance is a single one, the perturbations set up by it, reverberating throughout the system, leave its moving equilibrium slightly altered. If the disturbance is repeated or persistent, its successive effects accumulate until they have produced a new moving equilibrium adjusted to the new force.

Each re-balancing of actions, having for its necessary concomitant a modification of tissues, it is an obvious corollary that organisms subjected to successive changes of conditions, must undergo successive differentiations and re-differentiations. Direct equilibration in organisms, with all its accom- 
panying structural alterations, is as certain as is that universal progress towards equilibrium of which it forms part. And just as certain is that indirect equilibration in organisms to which the remaining large class of differentiations is due. The development of favourable variations by the killing of individuals in which they do not occur or are least marked, is, as before, a balancing between certain local structures and the forces they are exposed to; and is no less inevitable than the other.

$\S 314$. In all which universal laws, we find ourselves again brought down to the persistence of force, as the deepest knowable cause of those modifications which constitute physiological development; as it is the deepest knowable cause of all other evolution. Here, as elsewhere, the perpetual lapse from less to greater heterogeneity, the perpetual begetting of secondary modifications by each primary modification, and the perpetual approach to a temporary balance on the way towards a final balance, are necessary implications of the ultimate fact that force cannot disappear but can only change its form.

It is an unquestionable deduction from the persistence of force, that in every individual organism each new incident force must work its equivalent of change; and that where it is a constant or recurrent force, the limit of the change it works must be an adaptation of structure such as opposes to the new outer force an equal inner force. The only thing open to question is, whether such re-adjustment is inheritable; and further consideration will, I think, show, that to say it is not inheritable is indirectly to say that force does not persist. If all parts of an organism have their functions co-ordinated into a moving equilibrium, such that every part perpetually influences all other parts, and cannot be changed without initiating changes in all other parts-if the limit of change is the establishment of a complete harmony among the movements, molecular and other, of all parts; then 


\section{SUMMARY OF PHYSIOLOGICAL DEVELOPMENT. 395}

among other parts that are modified, molecularly or otherwise, must be those which cast off the germs of new organisms. The molecules of their produced germs must tend ever to conform the motions of their components, and therefore the arrangements of their components, to the molecular forces of the organism as a whole; and if this aggregate of molecular forces be modified in its distribution by a local change of structure, the molecules of the germs must be gradually changed in the motions and arrangements of their components, until they are re-adjusted to the aggregate of molecular forces. 


\section{CHAPTER X^.}

\section{THE INTEGRATION OF THE ORGANIC WORLD.}

$\S 314 a$. That from the beginning of life there has been an ever-increasing heterogeneity in the Earth's Flora and Fauna, is a truth recognized by all biologists who accept the doctrine of evolution. In discussing the origin of species Mr. Darwin and others have been mainly occupied in explaining the genesis of now this and now that form of organism, considered as a member of one or other series, and regarded as becoming differentiated from its allies. But by implication, if not avowedly, there has been simultaneously accepted the belief that the forms continually produced by divergences and re-divergences, have constituted an assemblage increasingly multiform in its included kinds. And this, which we are shown by the process of organic evolution as followed out in its details, is a corollary from the doctrine of evolution at large, as was pointed out in $\S 159$ of First Principles.

Meanwhile there has been little if any recognition of an accompanying change, no less fundamental. In the general transformation which constitutes Evolution, differentiation and integration advance hand in hand; so that along with the production of unlike parts there progresses the union of these unlike parts into a whole. Examples of various kinds before given will recur to the reader, and an addition to them has just been set forth in the chapter on "Physiological Integration." One more example, world-wide in its reach, has still to be named. 
For here it remains to point out that along with the increasing multiplication of types of organisms covering the Earth's surface, there has been ever going on an increasing mutual dependence of them-an increasing integration of the entire aggregate of living things.

Many facts which are obvious and many which are quite familiar will be named as evidence. But I must be excused for reminding the reader of things that he knows and things that he may easily observe, since, unless the evidence, trite as it may be, is gathered together and properly marshalled, the generalization enunciated will not be thought valid.

$\S 314 b$. Respecting the physiological characters of the earliest forms there is an assumption from which no escape seems possible-the assumption that they united animal and vegetal characters. Even among existing microscopic types of the lowest classes, there is such community of planttraits and animal-traits that doubts respecting their proper places in one or the other kingdom are continually raised - doubts, too, whether, if regarded as vegetal, they are to be grouped as algoid or fungoid.

Here, however, without entering on moot questions, we may draw the $\grave{a}$ priori conclusion that these earliest living things were double-natured, in so far that they must have had the ability to assimilate from the inorganic world all the materials of which protoplasm consists-must therefore, along with the power of appropriating carbon from its gaseous compound, also have had the power of appropriating nitrogen, either from one of its combined oxides or directly from the air with which water is more or less charged. For before organic substances existed there could have been none but inorganic sources from which nitrogen could be obtained.

This conclusion concerns us only because it implies homogeneity of nature in these primordial forms of life. There could not at first have existed among these minutest of Protozoa even such vague distinctions as are now presented 
in a shadowy way by their modern representatives. And the implication is that during the period throughout which these smallest, lowest, and simplest living things alone existed, there could have been, in the absence of kinds, no mutual dependence.

Since, among various of the lowest types now known to us, the same individual exhibits a life which is now predominantly vegetal and now predominantly animal, we cannot err in assuming that there eventually took place differentiations of this original plant-animal type into types permanently unlike: some in which the traits were more markedly vegetal and others in which they were more markedly animal. As fast as this differentiation arose, there came the beginnings of cooperation between the predominantly vegetal types which by the aid of light formed organic matter from the inorganic world, and the predominantly animal types which, in chief measure, utilized the matter so formed. Evidently with the rise of such a differentiation came an incipient mutual dependence. If to the implied algoid type and the animal type there be added the fungoid type, somewhat intermediate in character, which in a large proportion of cases lives on the decaying remnants of the other two, we are furnished with a rude conception of the primary differentiations and the accompanying vague mutual dependences.

Speculation aside, it suffices to say that early in the history of life there must have arisen the distinction between Protozoa and Protophyta, and that this distinction foreshadowed that widest contrast which the higher organic world presents - the contrast between plants and animals. It is needless to do more than name the mutual dependence between these two great divisions. That, as being respectively decomposers of carbon dioxide and exhalers of carbon dioxide, they act reciprocally, as also in some measure by interchange of nitrogenous matters; and that the implied general cooperation serves in an indirect way to unite their lives, and in that 
sense to integrate the two kingdoms; needs not to be insisted upon. Further complications of the mutual dependence will be mentioned by and by. For the present it suffices to recognize this division of organic functions as the first which arose and as continuing to be that fundamental one which more than all others binds organisms at large together.

$\S 314 c$. It will be thought by many readers that in speaking of the contrasted vital activities of plants and animals as constituting a "division of organic functions," I am straining words beyond their meanings; since the conception of organic functions postulates an organized whole in which they exist, and plants and animals constitute no such organized whole. But there is at hand an unexpected defence for this conception-a defence not fortheoming a generation ago, but which now all biologists will recognize as relevant. I refer to the phenomena of symbiosis. These present various cases in which the plant-function and the animal-function are carried on in the same body, - cases in which the cooperation is not between separate vegetal organisms which accumulate nutritive matters and separate animal organisms which consume them, but is a cooperation between vegetal elements and animal elements forming parts of the same organism.

As introductory to examples of these must first, however, be named an example of such cooperation between the two great classes of vegetal organisms-the fungoid and the algoid. Incredible as the statement once seemed, it is a statement now accepted, that what we know as lichens, and used to consider as plants forming a certain low class, are now found to be not plants in the ordinary sense at all, but compound growths formed of minute algæ and minute fungi, carrying on their lives together: the algæ furnishing to the fungi certain constituents they need but cannot directly obtain, and the fungi profiting by certain materials they obtain from the algæ, either while living or while individually decaying. Whence it would seem that after the microscopic vegetal 
type had become in a large degree differentiated into two main types, in adaptation to different conditions of life, and had acquired appropriate specialities of nature, there grew up this communistic arrangement between certain of them, enabling each to benefit by the powers which the other had acquired: evidently an exchange of services, a physiological division of labour, a mutual dependence of functions analogous to that which exists between functions in an ordinary plant or animal.

Not differing in principle but only in application, is that symbiosis above referred to as existing between Protophyta and many Protozoa, as well as between such Protophyta and the lowest kinds of Metazoa. A recent statement that certain amœbæ, made green by contained chlorophyll, continue to grow and multiply after they have consumed what nutritive matter may be at hand, is in harmony with various facts alleged of other Protozoa-various other kinds of Rhizopods, various Heliozoa, numerous ciliated and flagellated Infusoria. Among Metazoa the like association occurs in one of the sponges, in the Hydra viridis, in various turbellarians, in a rotifer, and even in two molluscs. In these cases the partnership between the regetal cells and the animal cells (existing either as units or as an organized group such as a polype), is a partnership which, as before, profits each of the partners-an inference supported by the fact that Metazoa containing these algoid cells usually place themselves where the light falls upon them, and can therefore further the production of the carbo-hydrates which eventually become useful to the animal-cells, while these in some way reciprocate the benefit.

Here, then, we have exchange of services between associated plant-elements and animal-elements-a performance by them of different organic functions for the benefit of the aggregate which they unite to form. Hence, when these vegetal elements and animal elements are separately embodied in plants and animals, which profit by one another, 
we may still properly regard their respective lives as mutuallydependent organic functions, as said in the preceding section. We are enabled the better to see how the Earth's Flora and Fauna, which are respectively accumulators of motion and expenders of motion, form mutually-dependent parts of a whole, and are in that sense integrated. And we shall be prepared to see how all other relations between organisms which make them subserrvient one to another, similarly constitute elements in a general integration of the organic world.

$\S 314 d$. Another form of mutual dependence and consequently of integration is conspicuous-that which accompanied the progressive increase of size in organisms of the higher classes. We have but to contemplate the possibilities to see that life must necessarily have commenced with minute forms, and that the progress to larger ones must have been by small steps.

For had creatures of appreciable sizes been the first to exist they would inevitably have disappeared from lack of food. Having no resource but to devour one another, they would quickly have brought life to an end. There must have been smaller types serving as prey for larger ones before these could continuc to exist and to multiply: microbes affording food to infusoria, infusoria affording food to such sized creatures as the Entomostraca, these again supplying food to small fishes, such as loch-trout, and these last yielding to larger fishes masses sufficiently great for their needs: each higher grade requiring lower grades of appropriate bulk. It needs but to ask what would become of tigers if there were no mammals larger than mice, to see that the animal world is a linked assemblage, of which the connected members stand within certain ratios of mass; and that during the evolution of higher and larger types the linking of grades has become closer.

That among plants considered as an aggregate relations of like kind, though far less distinct ones, have all along 
been growing may be reasonably concluded. In a world peopled only by microscopic types there could not have existed the conditions needful for large trees. Gradual disintegration of rock-surfaces, partly effected by physical agencies and partly by low forms of plants, had to prepare the way for superior plants. The production of sufficient soil by mineralogical decay as well as by the decay of organisms, plant and animal, may be regarded as having been a preliminary to larger plant-growth; and though at present the dependence is far less close than that among animals, yet the benefits yielded to metaphytes by the decomposing actions carried on by protophytes, as well as those carried on by microbes permeating the soil, imply a continued general interdependence throughout the aggregate of plant-forms, apart from more special interdependences. And. then along with this indebtedness of the greater plants to the smaller during the process of evolution, there must be named that indebtedness of plant-life to animal-life which Mr. Darwin has shown in his book on the agency of worms as producers of mould.

$\S 314$. Services of one to another, and consequent unions, of more special kinds are infinitely varied, alike within each kingdom and between the two kingdoms. I refer to those seen in parasitism, commensalism, and other forms of association. While they do not conduce to unions of the kind thus far considered, these nevertheless constitute innumerable links whereby the lives of organisms, plant and animal, are tied together; sometimes for the advantage of both but in most cases for the benefit of one to the injury of the other.

Among plants the degrees of dependence are various. Unable to raise themselves into the air and light, some climb, like the ivy, by modified rootlets, or spirally coil themselves, or hang by tendrils. Others there are which gradually strangle the trees they embrace, or which, like lichens in damp climates, festooning the smaller trees, by and by cause 
their decay. Of higher types of epiphytes which use trees only to gain elevation, the orchids may be instanced. And then we have plants which, like the mistletoe, fix themselves on the bark of their hosts, utilizing them partly for purposes of elevation and partly by appropriation of their juices. After these may be named those extreme cases in which the parasitic plants, ceasing to have any chlorophyll-bearing leaves, live wholly on the juices of the invaded plants. At home the common dodder, and in the tropics the Rafflesiaceer, belong to this group. There must be added the numerous forms of minute fungi which in like manner thrive at the expense of the plants they infest. In all these cases the interdependence is one-sided, though, as we shall presently see, while detrimental to one of the two concerned, it is not always detrimental to the organic world as a whole.

That utilization of one by another among animals which causes immediate death, is familiar enough in the relations between carnivores and herbivores. Almost as familiar are those seen in parasitism. Less familiar are those seen in commensalism; and the least familiar are those which show us exchange of services. Among these last-the mutuallybeneficial relations-that between the crocodile and the bird which picks parasites out of its teeth is a striking one; and no less so is that of the pique-gouffe, an African bird which pierces the tumour on a buffalo's back that incloses a parasite. Then of another kind we have the connexion between aphides and ants: the one profiting by being carried to better pastures and the other by increased saccharine excretion. Next comes the class of messmates, the connexions between some of which are relatively innocent, as witness the Sea-anemone which settles itself on the shell occupied by a Hermit-crab, or as witness the Remora fixed on a shark's skin. Less innocent is the relation under which one of the two seizes a share of the food obtained by the other, like the annelid which insinuates itself between the Hermitcrab and the whelk-shell it inhabits, or like the small fishes 
inhabiting certain Medusa, or those which nestle in the branchial sac of the Lophius. After these may be named the less injurious forms of parasites proper-those which, distinguished as Epizoa, fix themselves on the skins of their hosts, permanently or temporarily, such as, of the one kind, the Lernaca on fishes, and of the other kind the Tick on mammals and birds. Then there come the other class of parasites, most of them highly injurious, distinguished as Entozoa, living within the bodies of their hosts, now in parts of their alimentary canals, now on other of their mucous surfaces, and now in various of their organs: these last two groups being so numerous in their kinds that there are commonly more species than one proper to each larger animal. One stage further in the complication meets us in the parasites upon parasites.

But now the general fact, to which these brief indications are introductory, is that the use made of one organism by another has been ever widening and becoming more involved. Among plants utilization of the larger by the smaller-of trees by epiphytes and parasites-must have arisen since the times when the larger came into existence-times relatively late in the course of organic evolution. Moreover most of the plants which utilize others, either by climbing up them or settling themselves high up on their stems or sucking their juices, are phænogams, and the plants they utilize are also phænogams; so that these innumerable interdependences must have been established since the phænogamic type has become so predominant in respect of both size and kind. Similarly among animals. Though there are many parasites belonging, like the Trematodes, to very low classes, there are many which belong to the Arthropoda, and, bcing degraded forms of that class, must have come into existence after Arthropods of considerable structure had been evolved. Again, a large part of the animals infested by Epizoa and Entozoa are vertebrates-many of the highest types; and as these are relatively modern all this parasitism must be of 
late date. So, too, of much commensalism and many mutually-beneficial associations. The reciprocal services of ants and aphides must have originated since the Hymenoptera and Hemiptera became established types, and since the days when certain insects of the ant-type had become social, and since the days when aphides had become degraded members of their order: both dates being relatively recent. And still more recent must have been the commensalism between the ants and the many species of other insects which inhabit their nests.

Leaving out relations of the kinds just named, it seems that down from those between carnivores and their prey to those between lice and their hosts, such relations profit one of the two species concerned and injure the other, and that there the matter ends. But it does not end there; for that multiplication of effects to which people are usually blind, brings about changes which, as hinted above, though injurious to the individual are beneficial to the species, and which, when not beneficial to the species, are often beneficial to the aggregate of species.

Even where animals of one class live by devouring animals of another class, we see, on looking beyond the immediate results, certain remote results that are advantageous. In the first place the process is one by which inferior individuals - the least agile, swift, strong, or sagacious-are picked out and prevented from leaving posterity and lowering the average quality of their kind. At the same time individuals made feeble by injury or old age, are among those to be killed and saved from suffering prolonged pains: the evils of death by disease and starvation being thus limited to the predatory animals, relatively small in their numbers. Meanwhile a check is put on undue multiplication. Where a tract of country has been overrun by rabbits, weasels, thriving on the abundant supply of food, presently become numerous enough to bring the population of rabbits within moderate limits; and by doing this benefit not only all those kinds of 
plants which are being eaten down, and all those other animals which live on such plants, but also the rabbits themselves; since, increasing beyond the means of subsistence, a large part of them would, if not killed, die of hunger. Between aphides and lady-birds we see a connexion of like nature: great increase of the first yielding abundant food to larvæ of the second, ending after a season or so in swarms of lady-birds, and consequently of their larvæ, whereby the aphides, immensely diminished, cease so greatly to injure various plants and the animals dependent on them. Even minute parasites, by the evils they inflict on one species, profit others: instance the enormous destruction of flies which a microscopic fungus caused a few years ago-a destruction which relieved not only man but all the animals which flies irritate: often so much as to hinder them from feeding. Such instances remind us how numerous are the bonds by which the lives of organisms are tied together.

$\S 314 f$. I have reserved to the last the clearest and most striking illustration of this progressing integration throughout the organic world. I refer to the mutually-beneficial relations established between plants and animals through the agency of flowers and insects.

Everyone nowadays has been made familiar with the process of plant-fertilization, and knows that (leaving out of consideration plants fertilized by wind-borne pollen) the ability to bear seed depends largely on the aid given by bees, butterflies, and moths. The exchange of services has been growing ever more various and complicated during long past periods. We have the acquirement by flowers of bright colours serving to guide these insects to places where honey is to be found; and we have their perfumes, also serving for guidance. Then we have the many different arrangements, often complicated, by which the visiting insects are obliged to carry away pollen and dust with it the stigmas of flowers on which they subsequently settle: thus effecting cross- 
fertilization. Pari passu have gone on insect-developments made possible by these arrangements and furthering them. Especially must be named the modification of certain Hymenoptera into honey-storing bees: the implication being that the entire economy established by these social insects has been sequent on the growth of this system of reciprocal benefits. And then, just instancing the dependence between a particular flower having a long tubular corolla, and a particular moth having an appropriately long proboscis, it suffices to say that innumerable specialities of this general relation everywhere multiply the links by which the vegetal world and the animal world are here connected. That the effects of the connections tell largely on the prosperity of both, is suggested by some instances Mr. Darwin gives, and by a statement recently made in the United States, by Dr. L. 0 . Howard, that the greater fostering of bees would much increase certain of the crops.

But now observe the broad fact to which these few details concerning plant-fertilization are introductory. All these general and special relations between plants and animals have arisen since the phænogamic type came into existencehave, indeed, arisen since the higher members of that type, the Angiosperms, have appeared; for the Gymnosperms do not play any part in this intercommunion. But so far as we can judge of present results of geologic explorations, there were no Angiosperms during the Eozoic and Paleozoic periods. So that this class of connexions between animals and vegetals must have been established since carboniferous times-a period long, indeed, but far shorter than that which organic evolution at large has occupied.

$\S 314 \mathrm{~g}$. I have but just touched on some salient parts of a subject, immense in extent and extremely involved, which it would take a volume to set forth adequately. Enough has been said, however, to indicate the truth which it is the purpose of the chapter to bring into view and emphasize- 
the truth that both of the two great laws of evolution are exemplified in the organic world as a whole, as they are exemplified in every organism, and in all other things.

The reader has long since become familiar with the generalization that while Evolution is a change from the homogeneous to the heterogeneous, it is also a change from the ineoherent to the coherent; and this change from the incoherent to the coherent has been above exhibited as going on even throughout that vast assemblage of organisms, plant and animal, which cover the Earth's surface. In what we are obliged to conceive as the earliest stage, when the most minute types of life alone existed, the aggregate of living things was at once homogeneous and incoherent. In the course of epochs immeasurable in duration, this uniform aggregate of beings has been becoming more multiform. And now we see that instead of forms of life everywhere without the slightest union caused by mutual dependence, there have slowly arisen forms of life among which mutual dependences have entailed vital connexions correspondingly marked. Along with progressing differentiation there has ever been progressing integration. So that we may recognize something like a growing life of the entire aggregate of organisms in addition to the lives of individual organismsan exchange of services among parts enhancing the life of the whole.

In this final generalization the law of Evolution is manifested under its most transcendental form. 


\section{PART VI.}

\section{LAWS 0F MULTIPLICATION.}





\title{
CHAPTER I.
}

\author{
THE FACTORS.*
}

$\S 315$. IF organisms have been evolved, their respective powers of multiplication must have been determined by natural causes. Grant that the countless specialities of structure and function in plants and animals, have arisen from the actions and reactions between them and their environments, continued from generation to generation; and it follows that from these actions and reactions have also arisen those countless degrees of fertility which we see among them. As in all other respects an adaptation of each species to its conditions of existence is directly or indirectly brought about; so must there be directly or indirectly brought about an adaptation of its reproductive activity to its conditions of existence.

We may expect to find, too, that permanent and temporary

* An outline of the doctrine set forth in the following chapters, was originally published in the Westminster Revien for April, 1852, under the title-A Theory of Population deduced from the General Law of Animal Fertility; and was shortly afterwards republished with a prefatory note stating that it must be accepted as a sketch which I hoped at some future time to elaborate. In now revising and completing it, $I$ have omitted a non-essential part of the argument, while I have expanded the remainder by adding to the number of facts put in evidence, by meeting objections which want of space before obliged me to pass over, and by drawing varions secondary conclusions. The original paper, with omissions, will be found in Appendix A to Volume I of this work. 
differences of fertility have the same general interpretation. If the small variations of structure and function that arise within the limits of each species, are due to actions like those which, by their long-accumulating effects, have produced the immense contrasts between the various types; we may conclude that, similarly, the actions to which changes in the rate of multiplication of each species are due, also produce, in great periods of time, the enormous differences between the rates of multiplication of different species.

Before inquiring in what ways the rapidities of increase are adjusted to the requirements, both temporary and permanent, it will be needful to look at the factors. Let us set down first those which belong to the environment, and then those which belong to the organism.

§316. Every living aggregate being one of which the inner actions are adjusted to balance outer actions, it follows that the maintenance of its moving equilibrium depends on its exposure to the right amounts of these actions. Its moving equilibrium may be overturned if one of these actions is either too great or too small in amount; and it may be so overturned either by excess or defect of some inorganic agency in its environment, or by excess or defect of some organic agency.

Thus a plant, constitutionally fitted to a certain warmth and humidity, is killed by extremes of temperature, as well as by extremes of drought and moisture. It may dwindle away from want of soil, or die from the presence of too great or too small a quantity of some mineral substance which the soil supplies to it. In like manner, every animal can maintain the balance of its functions so long only as the environment adds to or deducts from its heat at rates not exceeding definite limits. Water, too, must be accessible in amount sufficient to compensate loss. If the parched air is rapidly abstracting its liquid which there is no pool or river to restore, its functions cease; and if it is an aquatic creature, 
drought may kill it either by drying up its medium or by giving it a medium inadequately aërated. Thus each organism, adjusted to a certain average in the actions of its inorganic environment, or rather, we should say, adjusted to certain moderate deviations from this average, is destroyed by extreme deviations. So, too, is it with the environing organic agencies. Among plants, only the parasitic kinds and those united by symbiosis (as well as a few innocent "lodgers") depend for their individual preservation on the presence of certain other organisms (though the presence of certain other organisms is needful to most plants for the preservation of the race by aiding fertilization). Here, for the continuance of individual life, particular organisms must be absent or not very numerous-beasts that browse, caterpillars that devour leaves, aphides that suck juices. Among animals, however, the maintenance of the functional balance is both positively and negatively dependent on the amounts of surrounding organic agents. There must be an accessible sufficiency of the plants or animals serving for food; and of organisms that are predatory or parasitic or otherwise detrimental, the number must not pass a certain limit.

This dependence of the moving equilibrium in every individual organism on an adjustment of its forces to the forces of the environment, and the overthrow of this equilibrium by failure of the adjustment, is comprehensive of all cases. At first sight it does not seem to include what we call natural death; but only death by violence, or starvation, or cold, or drought. But in reality natural death, no less than every other kind of death, is caused by the failure to meet some outer action by a proportionate inner action. The apparent difference is due to the fact that in old age, when the quantity of force evolved in the organism gradually diminishes, the momentum of the functions becomes step by step less, and the variations of the external forces relatively greater; until there finally comes an occasion when some quite moderate deviation from that average to which the 
feeble moving equilibrium is adjusted, produces in it a fatal perturbation.

$\S 31 \%$. The individuals of every species being thus dependent on certain environing actions; and severally having their moving equilibria sooner or later overthrown by one or other of these environing actions; we have next to consider in what ways the environing actions are so met as to prevent extinction of the species. There are two essentially different ways. There may be in each individual a small or great ability to adjust itself to variations of the agencies around it and to a small or great number of such varying agencies - there may be little or much power of preserving the balance of the functions. And there may be much or little power of producing new individuals to replace those whose moving equilibria have been overthrown. A few facts must be set down to enforce these abstract statements.

There are both active and passive adaptations by which organisms are enabled to survive adverse influences. Plants show us but few active adaptations: that of the Pitcher-plant and those of the reproductive parts of some flowers (which do not, however, conduce to self-preservation) are exceptional instances. But plants have various passive adaptations; as thorns, stinging hairs, poisonous and acrid juices, repugnant odours, and the woolliness or toughness that makes their leaves uneatable. Animals exhibit far more numerous adjustments, both passive and active. In some cases they survive desiccation, they hybernate, they acquire thicker clothing, and so are fitted to bear unfavourable inorganic actions; and they are in many cases fitted passively to meet the adverse actions of other organisms, by bearing spines or armour or shells, by simulating neighbouring objects in colour or form or both, by emitting disagreeable odours, or by having disgusting tastes. In still more numerous ways they actively contend with unfavourable conditions. Against the seasons they guard by storing up food, by secreting themselves in 
crevices, or by forming burrows and nests. They save themselves from enemies by developed powers of locomotion, taking the shape of swiftness or agility or aptitude for changing their media; by their strength either alone or aided by weapons; lastly by their intelligence, without which, indeed, their other superiorities would avail them little. And then these various active powers serving for defence, become, in other cases, the powers that enable animals to aggress, and to preserve their lives by the success of their aggressions.

The second process by which extinction is prevented-the formation of new individuals to replace the individuals destroyed-is carried on, as described in the chapter on "Genesis," by two methods, the sexual and the asexual. Plants multiply by spontaneous fission, by gemmation, by proliferation, and by the evolution of young ones from detached cells and scales and leaves; and they also multiply by the casting off of spores and sporangia and seeds. In like manner among animals, there are varied kinds of agamogenesis, from spontaneous fission up to parthenogenesis, all of them conducing to rapid increase of numbers; and we have the more familiar process of gamogenesis, also carried on in a great variety of ways. This formation of new individuals to replace the old, is, however, inadequately conceived if we contemplate only the number born or detached on each occasion. There are four factors, all variable, on which the rate of multiplication depends. The first is the age at which reproduction commences; the second is the frequency with which broods are produced; the third is the number contained in each brood; and the fourth is the length of time during which the bringing forth of broods continues. There must be taken into account a further element-the amount of aid given by the parent to each germ in the shape of stored-up nutriment, continuous feeding, warmth, protection, \&c. : on which amount of aid, varying between immensely wide limits, depends the number of 
the new individuals that survive long enough to replace the old, and perform the same reproductive process.

Thus, regarding every living organism as having a moving equilibrium dependent on environing forces, but ever liable to be overthrown by irregularities in those forces, and always so overthrown sooner or later; we see that each species of organism can be maintained only by the generation of new individuals with a certain rapidity, and by helping them more or less fully to establish their moving equilibria.

$\S 318$. Such are the factors with which we are here concerned. I have presented them in abstract shapes for the purpose of showing how they are expressible in general terms of force-how they stand related to the ultimate laws of redistribution of matter and motion.

For the purposes of the argument now to follow, we may, however, conveniently deal with these factors under a more familiar guise. Ignoring their other aspects, we may class the factors which affect each race of organisms as forming two conflicting sets. On the one hand, by what we call natural death, by enemies, by lack of food, by atmospheric changes, \&c., the race is constantly being destroyed. On the other hand, partly by the endurance, the strength, the swiftness, and the sagacity of its members, and partly by their fertility, it is constantly being maintained. These conflicting sets of factors may be generalized as-the forces destructive of race and the forces preservative of race. So generalizing them, let us ask what are the necessary implications. 


\section{CHAPTER II.}

\section{A PRIORI PRINCIPLE.}

$\S 319$. THE number of a species must at any time be either decreasing or stationary or increasing. If, generation after generation, its members die faster than others are born, the species must dwindle and finally disappear. If its rate of multiplication is equal to its rate of mortality, there can be no numerical change in it. And if the deductions by death are fewer than the additions by birth, the species must become more abundant. These we may safely set down as necessities. The forces destructive of race must be either greater than the forces preservative of race, or equal to them, or less than them; and there eannot but result these effects on number.

We are here concerned only with races that continue to exist; and may therefore leave out of consideration those in which the destructive forces, remaining permanently in excess of the preservative forces, cause extinction. Practically, too, we may exclude the stationary condition; for the chances are infinity to one against the maintenance of a permanent equality between the births and the deaths. Hence, our inquiry resolves itself into this:-In races that continue to exist, what laws of numerical variation result from these variable conflicting forces, which are respectively destructive of race and preservative of race?

$\S 320$. Clearly if the forces destructive of race, when once 
in excess, had nothing to prevent them from remaining in excess, the race would disappear; and clearly if the forces preservative of race, when once in excess, had nothing to prevent them from remaining in excess, the race would go on increasing to infinity. In the absence of any compensating actions, the only possible avoidance of these opposite extremes would be an unstable equilibrium between the conflicting forces, resulting in a perfectly constant number of the species: a state which we know does not exist, and against the existence of which the probabilities are, as already said, infinite. It follows, then, that as in every continuouslyexisting species, neither of the two conflicting sets of forces remains permanently in excess; there must be some way of stopping that excess of the one or the other which is ever occurring.

How is this done? Should any one allege, in conformity with the old method of interpretation, that there is in each case a providential interposition to rectify the disturbed balance, he commits himself to the supposition that of the millions of species inhabiting the Earth, each one is yearly regulated in its degree of fertility by a miracle; since in no two years do the forces which foster, or the forces which check, each species, remain the same; and therefore, in no two years is there required the same fertility to balance the mortality. Few if any will say that God continually alters the reproductive activity of every parasitic fungus and every Tape-worm or Trichina, so as to prevent its extinction or undue multiplication; which they must say if they adopt the hypothesis of supernatural adjustment. And in the absence of this hypothesis there remains only one other. The alternative possibility is, that the balance of the preservative and destructive forces is self-sustaining-is of the kind distinguished as a stable equilibrium: an equilibrium such that any excess of one of the forces at work, itself generates, by the deviation it produces, certain counter-forces which eventually out-balance it, and initiate an opposite devi- 
ation.' Let us consider how, in the case before us, such a stable equilibrium must be constituted.

$\S 321$. When a season favourable to it, or a diminution of creatures detrimental to it, causes any species to become more numerous than usual, an immediate increase of certain destructive influences takes place. If it be a plant, the supposed greater abundance itself implies fuller occupation of the places available for growth-an occupation which, leaving fewer such places as the multiplication goes on, becomes a check on further multiplication-itself causes a greater mortality of seeds that fail to root themselves. And afterwards, in addition to this passive resistance to continued increase, there comes an active resistance: the creatures which thrive at the expense of the species-the larvæ, the birds, the herbivores-increase too. If it be an animal that has grown more numerous, then, unless by some exceptional coincidence a simultaneous and proportionate addition to the animals or plants serving for food has occurred, there must result a relative scarcity of food. Enemies, too, be they beasts of prey or be they parasites, must quickly begin to multiply. Hence, each kind of organism, previously existing in something like its normal number, cannot have its number raised without a rise of the destructive forces, negative and positive, quickly commencing. Both negative and positive destructive forces must augment until this increase of the species is arrested. The competition for places on which to grow, if the species be vegetal, or for food if it be animal, must become more intense as the over-peopling of the habitat progresses; until there is reached the limit at which the mortality equals the reproduction. And as, at the same time, enemies will multiply with a rapidity which soon brings them abreast of the augmented supply of prey, the positive restraint they exert will help to bring about an earlier arrest of the expansion than pressure of population alone would cause.

One more inference may be 
drawn. Had the species to meet no repressing influence save that negative one of relatively-diminished space or relatively-diminished food-supply, the cause leading to its increase might carry it up to the limit set by this, and there leave it: its enlarged number might be permanent. But the positive repressing influence that has been called into existence, will prevent this. For the increase of enemies, commencing, as it must, after the increase of the species, and advancing in geometrical progression until it is itself checked in like manner, will end in an excess of enemies. Whereupon must result a mortality of the species greater than its multiplication-a decrease which will continue until its habitat is under-peopled, its unduly-numerous enemies decimated by starvation, and the destroying agencies reduced to a minimum. Whence will follow another increase.

Thus, as before indicated (First Prin. $\S \S 85,173$ ), there is here, as wherever antagonistic forces are in action, an alternate predominance of each, causing a rhythmical movement - a rhythmical movement which constitutes a moving equilibrium in those cases where the forces are not dissipated with appreciable rapidity, or are re-supplied as fast as they are dissipated. While, therefore, on the one hand, we see that the continued existence of a species necessarily implies some action by which the destructive and preservative forces are self-adjusted; we see, on the other hand, that such an action is an inevitable consequence of the universal process of equilibration.

$\S 322$. Is this the sole equilibration which must exist? Clearly not. The temporary compensating adjustments of multiplication to mortality in each species, are but introductory to the permanent compensating adjustments of multiplication to mortality among species in general. The above reasoning would hold just as it now does, were all species equally prolific and all equally short-lived. It yields no 
answer to the inquiries-why do their fertilities differ so enormously, or why do their mortalities differ so enormously? and how is the general fertility adapted to the general mortality in each? The balancing process we have contemplated can go on only within moderate limits-must fail entirely in the absence of a due proportion between the ordinary birthrate and the ordinary death-rate. If the reproduction of mice proceeded as slowly as the reproduction of men, mice would be extinct before a new generation could arise: even did their natural lives extend to fifteen or sixteen years, it would still be extremely improbable that any would for so long survive all the dangers they are exposed to. Conversely, did oxen propagate as fast as infusoria, the race would die of starvation in a week. Hence, the minor adjustment of varying multiplication to varying mortality in each species, implies some major adjustment of average multiplication to average mortality. What must this adjustment be?

We have already seen that the forces preservative of race are two-ability in each member of the race to preserve itself, and ability to produce other members-power to maintain individual life, and power to generate the species. These must vary inversely. When, from lowness of organization, the ability to contend with external dangers is small, there must be great fertility to compensate for the consequent mortality; otherwise the race must die out. When, on the contrary, high endowments give much capacity of self-preservation, a correspondingly-low degree of fertility is requisite. Given the dangers to be met as a constant quantity; then as the ability to meet them must be a constant quantity too; and as this is made up of the two factors, power to maintain individual life and power to multiply, these cannot do other than vary inversely: one must decrease as the other increases.

It needs but to conceive the results of nonconformity to this law, to see that every species must either conform to it or cease to exist. Suppose, first, a species whose individuals, 
having but small self-preservative powers, are rapidly destroyed, to be at the same time without reproductive powers proportionately great. The defect of fertility, if extreme, will result in the death of one generation before another has grown up. If less extreme, it will entail a scarcity such that in the next generation sexual congress will be too infrequent to maintain even the small number which remains; and the race will dwindle with increasing rapidity. If still less extreme, the consequent degree of sparseness, while not so great as to prevent an adequate number of procreative unions, will be so great as to render special food abundant and special enemies few-will thus diminish the destructive forces so much that the self-preservative forces will become relatively great: so great, relatively, that when combined with the small ability to propagate the species, they will suffice to balance the small destructive forces. Suppose, next, a species whose individuals have high powers of selfpreservation, while they have powers of multiplication much beyond what is needful. The excess of fertility, if extreme, will cause sudden extinction of the species by starvation. If less extreme, it must produce a permanent increase in the number of the species; and this, followed by intenser competition for food and augmented number of enemies, will involve such an increase of the dangers to individual life, that the great self-preserving powers of the individuals will not be more than sufficient to cope with them. That is to say, if the fertility is relatively too great, then the ability to maintain individual life inevitably becomes smaller, relatively to the requirements; and the inverse proportion is thus established.

So that when, from comparing the different states of the same species, we go on to compare the states of different species, we see that there is an analogous adjustment-analogous in the sense that great mortality is associated with great multiplication, and small mortality with small multiplication. And we see that the unlikeness of the cases con- 
sists merely in this, that what is a temporary relation in the one is a permanent relation in the other.

$\S 323$. For the moment it does not concern us to inquire what is the origin of this permanent relation. That which we have now to note, is simply that in some way or other there must be established an inverse proportion between the power to sustain individual life and the power to produce new individuals. Whether or not this permanent relation is self-adjusting in long periods of time, as the temporary relation is self-adjusting in short periods of time, is a separate question. The purpose of this chapter is fulfilled by showing that such a permanent relation must exist.

But having recognized the $\grave{a}$ priori principle that in races which continuously survive, the forces destructive of race must be equilibrated by the forces preservative of race; and that, supposing these are constant, there must be an inverse proportion between self-preservation and race-preservation; we may go on to inquire how this relation, necessary in theory, arises in fact. Leaving out the untenable hypothesis of a supernatural pre-adjustment, we have to ask in what way an adjustment comes about as a result of Evolution. Is it due to the survival of varieties in which the proportion of fertility to mortality happens to be the best? Or is the fertility adapted to the mortality in a more direct way? To these questions let us now address ourselves. 


\section{CHAPTER III.}

\section{OBVERSE A PRIORI PRINCIPLE.}

§324. WHEN dealing with its phenomena inductively, we saw that however it may be carried on, Genesis " is a process of negative or positive disintegration; and is thus essentially opposed to that process of integration which is the primary process in individual evolution." ( $(76$.$) Each new indivi-$ dual, whether separated as a germ or in some more-developed form, is a deduction from the mass of a pre-existing individual or of two pre-existing individuals. Whatever nutritive matter is stored up along with the germ, if it be deposited in the shape of an egg, is so much nutritive matter lost to the parent. No drop of blood can be absorbed by the fotus, nor any draught of milk sucked by the young when born, without taking from the mother tissue-forming and force-evolving materials to an equivalent amount. And all subsequent supplies given to progeny, if they are nurtured, involve, to a parent or parents, so much waste in exertion which does not bring its return in assimilated food.

Conversely, the continued aggregation of materials into one organism, renders impossible the formation of other organisms out of those materials. As much assimilated food as is united into a single whole, is so much assimilated food withheld from a plurality of wholes which might else have been produced. Given the absorbed nutriment as a constant quantity, and the longer the building of it up into a concrete shape goes on, the longer must be postponed any build- 
ing of it up into discrete shapes. And, similarly, the larger the proportion of matter consumed in the functional actions of parents, the smaller must be the proportion of matter which can remain to establish and support the functional actions of offspring.

Though the necessity of these universal relations is tolerably obvious as thus stated generally, it will be useful to dwell for a brief space on their leading aspects.

$\S 325$. That disintegration which constitutes genesis, may be such as to disperse entirely the aggregate which integration has previously produced-the parent may dissolve wholly into progeny. This dissolution of each aggregate into two or many aggregates, may occur at very short intervals, in which case the bulk attained can be but extremely small; or it may occur at longer intervals, in which case a larger bulk may be attained.

Instead of quickly losing its own individuality in the individualities of its offspring, each member of the race may, after growing for a time, have portions of its substance begin to develop into the parental shape and presently detach themselves; and the parent, maintaining its own identity, may continue indefinitely so to produce young ones. But clearly, the earlier it commences doing this, and the more rapidly it does it, the sooner must the increase of its own bulk be stopped.

Or again, growth and development continuing for a long period without any deduction of materials, an individual of considerable size and organization may result; and then the abstraction of substance for the formation of new individuals, or rather the eggs of them, may be so great that as soon as the eggs are laid the parent dies of exhaustion-dies, that is, from an excessive loss of the nutritive matters needed for its own activities.*

* I was here thinking only of the cases which arc general among insects, but it seems that vertebrate animals, too, furnish cases. Mr. Cunningham writes:- "There is a curious instance of this in the Conger: the female 
Once more, the deduction of materials for the propagation of the species may be postponed long enough to allow of great bulk and complex structure being attained. The procreative subtraction then setting in, while it checks and presently stops growth, may be so moderate as to leave vital capital sufficient to carry on the activities of the parent; may go on as long as parental vigour suffices to furnish, without fatal result, the materials needed to produce young ones; and may cease when such a surplus cannot be supplied, leaving the parental life to continue.

§326. The opposite side of this antagonism has also several aspects. Progress of organic evolution may be shown in increased bulk, in increased structure, in increased amount or variety of action, or in combinations of these; and under any of its forms this carrying higher of each individuality, implies a correlative retardation in the establishment of new individualities.

Other things equal, every normal addition to the bulk of an organism is an augmentation of its life.* Besides being an advance in integration, it implies a greater total of activities gone through in the assimilation of materials ; and it implies, thereafter, a greater total of the vital changes taking place from moment to moment in all parts of the enlarged mass. Moreover, while increased size is thus, in so far, the expression of increased life, it is also, where the organism is active, the expression of increased ability to maintain life-increased strength. Aggregation of substance is almost the only mode in which self-preserving power is shown among the lowest types; and even among the highest, sustaining the body in its integrity is that in which self-preservation fundamentally consists-is the end which the widest intelligence is indi-

grows to 6 or 7 feet long and a weight of $60 \mathrm{lbs}$. and upwards and then ceases to feed for 6 months while the eggs derelop, and when the eggs are shed dies."

*I say "normal" for the purpose of excluding not only morbid growths but excess of fat. 
rectly made to subserve. While, on the one hand, the increase of tissue constituting growth is conservative both in essence and in result; on the other hand, decrease of tissue, either from injury, disease, or old age, is in both essence and result the reverse. And if so, every addition to individual life thus implied, necessarily delays or diminishes the casting off of matter to form new individuals.

Other things equal, too, a greater degree of organization involves a smaller degree of that disorganization shown by the separation of reproductive gemmæ and germs. Detachment of a living portion or portions from what was previously a living whole, is a ceasing of co-ordination; and is therefore essentially at variance with that establishment of greater coordination which is achieved by structural development. In the extreme cases where a living mass is continually dividing and subdividing, it is manifest that there cannot arise much physiological division of labour; since progress towards mutual dependence of parts is prevented by the parts becoming independent. Contrariwise, it is equally clear that in proportion as the physiological division of labour is carried far, the separative process must be localized in some comparatively small portion of the organism, where it may go on without affecting the general structure-must become relatively subordinate. The advance that is shown by greater heterogeneity, must be a hindrance to multiplication in another way. For organization entails cost. That transfer and transformation of materials implied by differentiation, can be effected only by expenditure of force; and this supposes consumption of digested and absorbed food, which might otherwise have gone to make new organisms, or the germs of them. Hence, that individual evolution which consists in progressive differentiation, as well as that which consists in progressive integration, necessarily diminishes that species of dissolution, general or local, which propagation of the race exhibits.

In active organisns we have yet a further opposition 
between self-maintenance and maintenance of the race. All motion, sensible and insensible, generated by an animal for the preservation of its life, is motion liberated from decomposed nutriment-nutriment which, if not thus decomposed, would have been available for reproduction; or rathermight have been replaced by nutriment fitted for reproductive purposes, absorbed from other kinds of food. Hence, in proportion as the activities increase-in proportion as, by its more varied, complex, rapid, and vigorous actions, an animal gains power to support itself and to cope with surrounding dangers, it must lose power to propagate.

$\S 32 \%$. How may this antagonism be best expressed in a brief way? If self-preservation displayed itself in the highest organisms, as it does in the lowest, in little else but continuous growth ; and if race-preservation consisted always, as it does often, of nothing beyond detachment of portions from the parental mass; then the antagonism would be, throughout, the obviously-necessary one of integration and disintegration. Maintenance of the individual and propagation of the species, being respectively aggregative and separative, it would be as self-evident that they vary inversely, as it is self-evident that addition and subtraction undo one another. But though the simplest types show us the opposition of self-maintenance and race-maintenance almost wholly under this form; and though higher types, up to the most complex, exhibit it to a great extent under this form; yet, as we have just seen, this is not its only form. The total material monopolized by the individual and withheld from the race, must be stated as the quantity united to form its fabric, plus the quantity expended in differentiating its fabric, plus the quantity expended in its self-conserving actions. Similarly, the total material devoted to the race at the expense of the individual, includes that which is directly subtracted from the parent in the shape of egg or fœtus, plus that which is directly subtracted in the shape of milk, plus 
that which is indirectly subtracted in the shape of matter consumed in exertions for fostering the young. Hence this inverse variation is not expressible in simple terms of aggregation and separation. As we advance to more highlyevolved organisms, the total cost of an individual becomes very much greater than is implied by the amount of tissue composing it. So, too, the total cost of producing each new individual becomes very much greater than that of its mere substance. And it is between these two total costs that the antagonism exists.

We may, indeed, reduce the antagonism to a form comprehensive of all cases, if we consider it as existing between the sums of the forces, latent and active, used for the two purposes. The molecules which make up a plant or animal, have been formed by the absorption of forces directly or indirectly derived from the Sun; and hence the quantity of matter raised to the form called organic, which a plant or animal presents, is equivalent to a certain amount of force. Another amount of force is expressed by the totality of its differentiations. A further amount of force is that dissipated in its actions. And in these three amounts added together, we have the whole expense of the individual life. So, too, the whole expense of establishing each new individual includes-first the forces latent in the substance composing it when born or hatched; second the forces latent in the prepared nutriment afterwards supplied; and third the forces expended in feeding and protecting it. These two sets of forces being taken from a common fund, it is manifest that either set can increase only by decrease of the other. If, of the force which the parent obtains from the environment, much is consumed in its own life, little remains to be consumed in producing other lives; and, conversely, if there is a great consumption in producing other lives, it can only be where comparatively little is reserved for parental life.

Hence, then, Individuation and Genesis are necessarily antagonistic. Grouping under the word Individuation all 
processes by which individual life is completed and maintained; and enlarging the meaning of the word Genesis so as to include all processes aiding the formation and perfecting of new individuals; we see that the two are fundamentally opposed. Assuming other things to remain the sameassuming that environing conditions as to climate, food, enemies, \&c., continue constant; then, inevitably, every higher degree of individual evolution is followed by a lower degree of race-multiplication, and vice versâ. Progress in bulk, complexity, or activity, involves retrogress in fertility; and progress in fertility involves retrogress in bulk, complexity, or activity.

This statement needs a slight qualification. For reasons to be hereafter assigned, the relation described is never completely maintained; and in the small departure from it, we shall find a remarkable self-acting tendency to further the supremacy of the most-developed types. Here, however, this hint must suffice: explanation would carry us too far out of our line of argument. For the present it will not lead us astray if we regard this inverse variation of Individuation and Genesis as exact.

$\S 328$. Thus, then, the condition which each race must fulfil if it is to survive, is a condition which, in the nature of things, it ever tends to fulfil. In the last chapter we saw that a species cannot be maintained unless the power to preserve individual life and the power to propagate other individuals vary inversely. And here we have seen that, irrespective of an end to be subserved, these powers cannot do other than vary inversely. On the one hand, given a certain totality of destroying forces with which the species has to contend; and in proportion as its members have severally but small ability to resist these forces, it is requisite that they should have great ability to form new individuals, and vice versâ. On the other hand, given the quantity of force, absorbed as food or otherwise, which the species can 
use to counterbalance these destroying forces ; and in proportion as much of it is expended in preserving the individual, little of it ean be reserved for producing new individuals, and vice versâ. There is thus complete accordance between the requirements considered under each aspect. The two necessities correspond.

We might rest on these deductions and their several corollaries. Without going further we might with safety assert the general truths that, other things equal, advancing evolution must be accompanied by declining fertility; and that, in the highest types, fertility must still further decrease if evolution still further increases. We might be sure that if, other things equal, the relations between an organism and its environment become so changed as permanently to diminish the difficulties of self-preservation, there will be a permanent increase in the rate of multiplication; and, conversely, that a decrease of fertility will result where altered circumstances make self-preservation more laborious.

But we need not content ourselves with these à priori inferences. If they are true, there must be an agreement between them and the observed facts. Let us see how far such an agreement is traceable. 


\section{CHAPTER IV.}

\section{DIFFICULTIES OF INDUCTIVE VERIFICATION.}

\$329. WERE all species subject to the same kinds and amounts of destructive forces, it would be easy, by comparing different species, to test the inverse variation of Individuation and Genesis. Or if either the power of self-preservation or the power of multiplication were constant, there would be little difficulty in seeing how the other changed as the destroying forces changed. But comparisons are nearly always partially vitiated by some want of parity. Each factor, besides being variable as a whole, is compounded of factors that are severally variable. Not simply is the sum of the forces destructive of race different in every case; and not simply are both sets of forces preservative of race unlike in their totalities in every case; but each is made up of actions that bear such changing proportions to one another as to prevent any positive estimation of its amount.

Before dealing with the facts as well as we can, it will be best to glance at the chief difficulties; so that we may see the kind of verification which is alone possible.

$\S 330$. Either absolutely, or relatively to any species, every environment differs more or less from every other.

There are the unlikenesses of media-air, water, earth, organic matter; severally involving special resistances to movement, and special losses of heat. There are the con- 
trasts of climate: here great expenditure for the maintenance of temperature is needed, and there very little; in one zone an organism is supplied with abundant light all the year round, and in another only for a few months; this region yields an almost unfailing supply of water, while that entails the exertion of travelling many miles every night for a draught.

Permanent differences in the natures and distributions of aliment greatly interfere with the comparisons. The Swallow goes through more exertion than the Sparrow in securing a given weight of food; but then their foods are dissimilar in nutritive qualities. There is a want of parallelism between the circumstances of those herbivores which live where the plains are annually covered for a time with rich herbage, but afterwards become parched up, and of those inhabiting more temperate regions. Insects whose larvæ feed on an abundant plant, as do several of the genus Vanessa on the Nettle, have practically an environment very unlike that of insects such as Deilephila Euphorbia, whose larvæ feed on a comparatively rare plant-the Sea-Spurge.

Again, comparisons between creatures otherwise akin in their constitutions and circumstances, are hindored by inequalities in their relations to enemies. Two animals, of which one is predatory and has no foes but parasites while the other is much pursued, cannot properly be contrasted with a view to determining the influence of size or complexity.

Without multiplying instances, it will be clear enough then that the aggregate of destructive actions, positive and negative, which each species has to contend with, is so undefinable in the amounts and kinds of its components, that nothing beyond a vague idea of its relative total can be formed.

\$331. Besides these immense variations in the outer actions to be counter-balanced, there are immense variations 
in the inner actions required to counter-balance them. Even were species similarly conditioned, self-preservation would require of them extremely unlike expenditures of force.

The cost of locomotion increases in a greater ratio than the size. In virtue of the law that the weights of animals increase as the cubes of their dimensions, while their powers of bearing strains increase only as the squares of their dimensions $(\$ 46)$, preservation of its various attitudes requires a large animal to consume more substance in proportion to its weight, than it requires a small animal to consume; and there results, other things equal, a difficulty of self-maintenance which augments in a more rapid ratio than the bulk. Nor must we overlook the further complication, that among aquatic creatures the variation of resistance of the medium tends to produce an opposite effect.

Again, the heat-consumption is a changing element in the total expense of self-preservation. Creatures which have temperatures scarcely above that of the air or water, may, other things equal, accumulate more surplus nutriment than creatures which have to keep their bodies warm spite of the continual loss by radiation and conduction. This difference of cost is modified by the presence or absence of natural clothing; and it is also modified by unlikenesses of size. Here the bulky animals have the advantage: small masses cooling more rapidly than large ones.

Dissimilarities of attack and defence are also causes of variation in the outlay for self-maintenance. A creature that has to hunt, as compared with another that gets a sufficiency of prey by lying in wait, or a creature that escapes by speed as compared with another that escapes by concealment, obviously leads a life that is physiologically more costly. Animals which protect themselves passively, as the Hedge-hog by its spines or as the Skunk and the Musk-rat by their intolerable odours, are relatively economical; and have the more vital capital for other purposes.

Amplification is needless. These instances will show that 
anything beyond very general conceptions of the individual expenditures in different cases, cannot be reached.

$\S 332$. Still more entangled are we among qualifying considerations when we contrast species in their powers of multiplication. The total cost of Genesis admits of even less definite estimation than does the total cost of Individuation. I do not refer merely to the truth that the degree of fertility depends on four factors-the age of commencing reproduction, the number in each brood, the frequency of the broods, and the time during which broods continue to be repeated. There are many further obstacles in the way of comparisons.

Were all multiplication carried on sexually, the problem would be less involved; but there are many kinds of asexual multiplication alternating with the sexual. This asexual multiplication is in some cases perpetual instead of occasional; and often has more forms than one in the same species. The result is that we have to compare what is here a periodic process with what is elsewhere a cyclical process partly continuous and partly periodic: the calculation of fertility in this last case being next to impossible.

We have to avoid being misled by the assumption that the cost of Genesis is measured by the number of young produced, instead of being measured, as it is, by the weight of nutriment abstracted to form the young, plus the weight consumed in caring for them. This total weight may be very diversely apportioned. In contrast to the Cod with its millions of small ova spawned without protection, we may put the Hippocampus, or the Pipe-fish, with its few relativelylarge ova carried about by the male in a caudal pouch, or seated in hemispherical pits in its skin; or we may put the still more remarkable genus Arius, and especially Arius Boakeii-a fish some six or seven inches long, which produces ten or a dozen eggs $5-10 \mathrm{~mm}$. in diameter, that are carried by the male in his mouth till they are hatched. Here though 
the degrees of fertility, if measured by the numbers of fertilized germs deposited, are extremely unlike, they are less unlike if measured by the numbers of young which are hatched and survive long enough to take care of themselves; nor will the tax on the parent-Cod seem so immensely different from that on the parent-Arius, if the masses of the ova, instead of their numbers, are compared.

Again, while sometimes the parental loss is little else but the matter deducted to form eggs, \&c., at other times it takes the shape of a small direct deduction joined with a large indirect outlay. The Mason-wasp furnishes a typical instance. In journeyings hither and thither to fetch bit by bit the materials for building a cell; in putting together these materials, as well as in secreting glutinous matter to act as cement; and then, afterwards, in the labour of seeking for, and carrying, the small caterpillars with which it fills up the cell to serve its larva with food when it emerges from the egg; the Mason-wasp expends more substance than is contained in the egg itself. And this supplementary expenditure is manifestly so great that but few eggs can be housed and provisioned.

Estimates of the cost of Genesis are further complicated by variations in the ratio borne by the two sexes. Among Fishes the mass of milt approaches in size the mass of spawn; but among higher Vertebrata the substance lost by the one sex in the shape of sperm-cells is small compared with that lost by the other sex in the shape of albumen stored-up in the eggs, or blood supplied to the fœtus, or milk given to the young. Then there come the differences of indirect tax on males and females. While, frequently, the fostering of the young devolves entirely on the female, occasionally the male undertakes it wholly or in part. After building a nest, the male Stickleback guards the eggs till they are hatched; as does also the great Silurus glanis for some forty days, during which he takes no food. And then, among most birds, we have the male occupied in feeding the female during 
incubation, and the young afterwards. Evidently all these differences affect the proportion between the total cost of reproduction and the total cost of individuation.

Whether the species is monogamous or polygamous, and whether there are marked differences of size or of structure between males and females, are also questions not to be overlooked. If there are many females to one male, the total quantity of assimilated matter devoted by each generation to the production of a new generation, is greater than if there is a male to each female. Similarly, where the requirements are such that small males will suffice, the larger quantity of food left for the females makes possible a greater surplus available for reproduction. Another cause has a like effect. Where the liabits of the race render it needless that both sexes should have developed powers of locomotion-where, as in the Glow-worm and sundry Lepidoptera, the female is wingless while the male has wings-the cost of Individuation not being so great for the species as a whole, there arises a greater reserve for Genesis: the matter which would otherwise have gone to the production of wings and the using of them, may go to the production of ova.

Other complications, as those which we see in Bees and Ants, might be dwelt on; but the foregoing will amply serve the intended purpose.

$\S 333$. To ascertain by comparison of cases whether Individuation and Genesis vary inversely, is thus an undertaking so beset with difficulties, that we might despair of any satisfactory results, were not the relation too marked a one to be hidden even by all these complexities. Species are so extremely contrasted in their degrees of evolution, and so extremely contrasted in their rates of multiplication, that the law of relation between these traits becomes unmistakable when the evidence is looked at in its ensemble. This we shall soon find on ranging in order a number of typical cases.

In doing this it will be convenient to neglect, temporarily, 
all unlikenesses among the circumstances in which organisms are placed. At the outset, we will turn our attention wholly to the antagonism displayed between the integrative process which results in individual evolution and the disintegrative process which results in multiplication of individuals; and this we will consider first as we see it under the several forms of agamogenesis, and then as we see it under the several forms of gamogenesis. We will next look at the antagonism between propagation and that evolution which is shown by increased complexity. And then we will consider the remaining phase of the antagonism, as it exists between the degree of fertility and the degree of evolution expressed by activity.

Afterwards, passing to the varying relations between organisms and their environments, we will note how relative increase in the supply of food, or relative decrease in the quantity of force expended by the individual, entails relative increase in the quantity of force devoted to multiplication, and vice versâ.

Certain minor qualifications, together with sundry important corollaries, may then be entered upon. 


\section{CHAPTER V.}

ANTAGONISM BETWEEN GROWTH AND ASEXUAL GENESIS.

§334. WHEN illustrating, in Part IV, the morphological composition of plants and animals, there were set down in groups, numerous facts which we have here to look at from another point of view. Then we saw how, by union of small simple aggregates, there are produced large compound aggregates. Now we have to observe the reactive effect of this process on the relative numbers of the aggregates. Our present subject is the antagonism of Individuation and Genesis as seen under its simplest form, in the self-evident truth that the same quantity of matter may be divided into many small wholes or few large wholes; but that number negatives largeness and largeness negatives number.

In setting down some examples we may conveniently adopt the same arrangement as before. We will look at the facts as they are presented by vegetal aggregates of the first order, of the second order, and of the third order; and then as they are presented by animal aggregates of the same three orders.

$\S 335$. The ordinary unicellular plants are at once microscopic and enormously prolific. The often cited Spharella nivalis, which shows its immense powers of multiplication by reddening wide tracts of snow in a single night, does this by developing in its cavity a brood of young cells, which, being 
presently set free by the bursting of the parent-cell, severally grow and quickly repeat the process. The like occurs among sundry of those kindred forms of minute Alga which, by their enormous numbers, sometimes suddenly change pools to an opaque green. So, too, the Desmidiacea often multiply so greatly as to colour the water; and among the Diatomacece the rate of genesis by self-division, "is something really extraordinary. So soon as a frustule is divided into two, each of the latter at once proceeds with the act of self-division; so that, to use Professor Smith's approximative calculation of the possible rapidity of multiplication, supposing the process to occupy, in any single instance, twenty-four hours, 'we should have, as the progeny of a single frustule, the amazing number of one thousand millions in a single month." "In these cases the multiplication is so carried on that the parent is lost in the offspring - the old individuality disappears either in the swarms of zoospores it dissolves into, or in the two or four new individualities simultaneously produced by fission. Vegetal aggregates of the first order, have, however, a form of agamogenesis in which the parent individuality is not lost: the young cells arise from the old cells by external gemmation. This process, too, repeated as it is at short intervals, results in immense fertility. The Yeastfungus, which in a few hours thus propagates itself throughout a large vat of wort, offers a familiar example.

In certain compound forms that must be classed as plants of the second order of aggregation, though very minute ones, self-division similarly increases the numbers at high rates. The Sarcina ventriculi, a parasitic plant which infests the stomach and swarms afresh as fast as previous swarms are vomited, shows us a spontaneous fission of clusters of cells. An allied mode of increase occurs in Gonium pectorale: each cell of the cluster resolving itself into a secondary cluster, and the secondary clusters then separating. "Supposing, which is very probable, that a young Gonium after twentyfour hours is capable of development by fission, it follows 
that under favourable conditions a single colony may on the second day develop 16 , on the third 256 , on the fourth 4,096 , and at the end of a week $268,435,456$ other organisms like itself." In the Volvocinea this continual dissolution of a primary compound individual into secondary compound individuals, is carried on endogenously, and on a modified system: some only of the component cells giving origin to young colonies, and the parent bursting to liberate them. The numbers arising by this method also, are sometimes so great as to tint large bodies of water.

More fully established and organized aggregates of the second order, such as the higher Thallophytes and the lower Archegoniates, do not sacrifice their individualities by fission; but nevertheless, by the kindred process of gemmation, are continually hindered in the increase of their individualities. The gemmæ called tetraspores are cast off in great numbers by the marine Alga. Among those simple Jungermanniacece which consist of single fronds, the young ones that bud out grow for a time in connexion with their parents, send rootlets from their under sides into the soil, and presently separate themselves - a habit which augments the number of individuals in proportion as it checks their growths.

Plants of the third order of composition, arising by arrest of this separation, exhibit a further corresponding decrease in the abundance of the aggregates formed. Archegoniates of inferior types, in which the axes produced by integration of fronds are but small and feeble, are characterized by the habit of throwing off bulbils-bud-shaped axes which, falling and taking root, add to the number of distinct individuals. This agamic multiplication, very. general among the Mosses and their kindred, and not uncommon under a modified form in such higher types as the Ferns, many of which produce young ones from the surfaces of their fronds, becomes very unusual among Phænogams. The detachment of bulbils, though not unknown among them, is exceptional. And while it is true that some flowering plants, as the Strawberry, 
multiply by a process allied to gemmation, yet this is not characteristic of the class. A leading trait of these highest groups, to which the largest members of the vegetal kingdom belong, is that agamogenesis has so far ceased that it does not usually originate independent plants. Though the axes which, budding one out of another, compose a tree, are the equivalents of asexually-produced individuals; yet the asexual production of them stops short of separation. These vast integrations arise where spontaneous disintegration, and the multiplication effected by it, have come to an end.

Thus, not forgetting that certain Phænogams, as Begonia phyllomaniaca, revert to quite primitive modes of increase, we may hold it as beyond question that while among the most minute plants asexual multiplication is universal, and produces enormous numbers in short periods, it becomes step by step more restricted in range and frequency as we advance to large and compound plants; and disappears so generally from the highest and largest, that its occurrence is regarded as anomalous.

§336. Parallel examples furnished by animals make clear the purely quantitative nature of this relation under its original form. Among the Protozoa, as among the Protophyta, there occurs that process by which the individuality of the parent is wholly lost in producing offspring-the breaking up of the parental mass into a number of germs. Some of the Infusoria, as for instance those of the genus Kolpoda and several allied genera, become encysted and subsequently break up into young ones. The more familiar mode of increase among these animal-aggregates of the first order, by fission, though it sacrifices the parent individuality by merging it in the individualities of the two produced, sacrifices it less completely than does the dissolution into a great number of germs. Occurring, however, as this fission does, very frequently, and being completed, in some cases that 
have been observed, in the course of half-an-hour, it results in immensely-rapid multiplication. If all its offspring survive, and continue dividing themselves, a single Paramocium is said to be capable of thus originating 268 millions in the course of a month.* Nor is this the greatest known rate of increase. Another animalcule, visible only under a high magnifying power, "is calculated to generate 170 billions in four days." $\dagger$ And these enormous powers of propagation are accompanied by a minuteness so extreme, that of some species one drop of water would contain as many individuals as there are human beings on the Earth! Even if we allow a large margin for exaggeration in these estimates, it is beyond question that among these smallest of animals the rate of asexual multiplication is immensely the greatest; and this suffices for the purposes of argument.

Of animal aggregates belonging to the second order, that multiply asexually with rapidity, the familiar Polypes furnish conspicuous examples. By gemmation in most cases, in other cases by fission, and in some eases by both, the agamogenesis is carried on among these tribes. As shown in Fig. 148, the budding of young ones from the parent Hydra is carried on so actively, that before the oldest of them is cast off half-a-dozen or more others have reached various stages of growth; and even while still attached, the firstformed of the group have commenced budding out from their sides a second generation of young ones. In the Hydra tuba

* To meet a possible criticism it should bo remarked that this calculation assumes that the power of asexual reproduction is not exbausted by the end of the month. It has been found that "the successive fissions of Paramocium cannot continue indefinitely. After some hundreds of generations the products of fission are small, have no mouth, and die unless before this they have been allowed to conjugate with individuals of another brood." It mas, however, be fairly taken for granted that "some hundreds of generations" would take longer than a month.

† Even this number is far exceeded. Dr. Edward Klein, in a lecture he gave at the Royal Institution on June 2, 1898, asserted that 246 bacteria in a cubic centimetre of nutritive liquid would multiply 'to $20,000,000$ in the course of twenty-four hours: a rate which, at the end of the third day, would give, as the offspring of one individual, $537,367,797,000,000$. 
this gemmiparous multiplication is from time to time interrupted by a transverse splitting-up of the body into segments, which successively separate and swim away: the result of the two processes being that, in the course of a season, there are produced from a single germ great numbers of young Medusa, which are the adult or sexual forms of the species. Respecting cœlenterate animals of this degree of composition, it may be added that when we ascend to the larger kinds we find asexual genesis far less active. Though comparisons are interfered with by differences of structure and mode of life, yet the contrasts are too striking to have their meanings much obscured. If, for instance, we take a solitary Actinozoon and a solitary Hydrozoon, we see that the relatively-great bulk of the first, goes along with a relativelyslow agamogenesis. The common Sea-anemones are but occasionally observed to undergo self-division: multiplication by budding being in some cases largely followed, but their numbers are not rapidly increased by either process. A higher class of secondary aggregates exemplifies the same general truth with a difference. In the smaller members the agamogenesis is incomplete, and in the larger it disappears. The gemmation of the minute Polyzoa, though it does not end in the separation of the young individuals, habitually goes to the extent of producing families of partially-independent individuals ; but their near ally, the Phoronis, which immensely exceeds them in size, is solitary and not gemmiparous. So, too, is it with the Ascidioida. And then among the true Mollusca, which are relatively large, no such thing is known as fission or gemmation.

Take next the Annulosa, including under this title the Annelida and Arthropoda. When treating of morphological composition, reasons were given for the belief that the annulose animal is an aggregate of the third order, the segments of which, produced one from another by gemmation, originally became separate; but by progressive integration, or arrested disintegration, there resulted a type in which many 
such segments were permanently united ( $\$ \$ 205-7$ and note to $\S 20 \%)$. Part of the evidence there assigned, is evidence to be here repeated in illustration of the direct antagonism of Growth and Asexual-Genesis. We saw how, among the lower Annelids, the string of segments produced by gemmation presently divides transversely into two strings; and how, in some cases, this resolution of the elongating string of segments into groups that are to form separate individuals, goes on so actively that as many as six groups are found in different stages of progress to ultimate independence-a fact implying a ligh rate of fissiparous multiplication.* Then we saw that, in the superior annulose types, distinguished in the mass by including the larger species, fission does not occur. The higher Annelids do not propagate in this way; there is no known case of new individuals being so formed among the Myriapoda; nor do the Crustaceans afford us a single instance of this primordial mode of increase.

It is, indeed, true that while articulate animals never multiply asexually after this simplest method, and while they are characterized in the mass by the cessation of agamogenesis of every kind, there nevertheless occur in a few of their small species, those higher forms of agamogenesis known as parthenogenesis and pseudo-parthenogenesis; and that by these some of them multiply very rapidly. Hereafter we shall find, in the interpretation of these anomalies, further support for the general doctrine.

To the above evidence has to be added that which the Vertebrata present. This may be very briefly summed up. On the one hand this class, whether looked at in the aggregate or in its particular species, immensely exceeds all other classes in the sizes of its individuals; and on the other hand, agamogenesis under any form is absolutely unknown in it. If it be said that budding occurs among the Tunicata which,

* It has since been shown that in Myrianida fasciata as many as 29 attached groups exist. See Cambridge Natural History, Vol. II, Worms, Rotifers and Polyzoa, p. 280. 
under the common title of Chordata, are included in the same phylum with the Vertebrata, then it may firstly be replied that those types which have no vertebræ cannot properly be called Vertebrata, and secondly that if, as being Chordata, they must be recognized, then the exception which they present further illustrates the truth that agamogenetic multiplication occurs only in creatures small in size, or low in structure, or both.

\$33\%. Such are a few leading facts serving to show how deduction is inductively verified, in so far as the antagonism between Growth and Asexual Genesis is concerned. In whatever way we explain this opposition of the integrative and disintegrative processes, the facts and their implications remain the same. Indeed we need not commit ourselves to any hypothesis respecting the physical causation. It suffices to recognize the results under their most general aspects. We cannot help admitting there are at work these two antagonist tendencies to aggregation and separation; and we cannot help admitting that the proportion between the aggregative and separative tendencies, must in each case determine the relation between increase in bulk of the individual and increase of the race in number.

The antithesis is as manifest $\grave{a}$ posteriori as it is necessary à priori. While the minutest organisms multiply asexually in their billions; while the Infusoria thus multiply in their millions; while the small compound types next above them thus multiply in their thousands; while larger and more compound types thus multiply in their hundreds and their tens; the largest types do not thus multiply at all. Conversely, those which do not multiply asexually at all, are a billion or a million times the size of those which thus multiply with greatest rapidity; and are a thousand times, or a hundred times, or ten times the size of those which thus multiply with less and less rapidity. Without saying that this inverse proportion is regular, which, as we shall here- 
after see, it cannot be, we may unhesitatingly assert its average truth. That the smallest organisms habitually reproduce asexually with immense rapidity; that the largest organisms never reproduce at all in this manner; and that between these extremes there is a general decrease of asexual reproduction along with an increase of bulk; are propositions which admit of no dispute. 


\section{CHAPTER VI.}

ANTIGONISM BETWEEN GROWTH AND SEXUAL GENESIS.

$\S 338$. In so far as it is a process of separation, sexual genesis is like asexual genesis; and is therefore, equally with asexual genesis, opposed to that aggregation which results in growth. Whether deduction is made from one parent or from two, whether it is made from any part of the body indifferently or from a specialized part, or whether it is made directly or indirectly, it remains in any case a deduction; and in proportion as it is great, or frequent, or both, it must restrain the increase of the individual.

Here we have to group together the leading illustrations of this truth. We will take them in the same order as before.

$\S 339$. The lowest vegetal forms, or rather, we may say, those forms which we cannot class as either distinctly vegetal or distinctly animal, show us a process of sexual multiplication that differs much less from the asexual process than in the higher forms. The common character which distinguishes sexual from asexual genesis, is that the mass of protoplasm whence a new generation is to arise, has been produced by the union of two portions of matter which were before more widely separated. I use this general expression because, among the simplest Algax, this is not invariably matter supplied by different individuals : certain Diatomacee exhibit within a single cell, the formation of a sporangium by a drawing 
together of the opposite halves of the endochrome into a ball. Mostly, however, sporangia are products of conjugation. The protoplasmic contents of two cells unite to form the germ-mass or zygote; and these conjugating cells may be either entirely independent, as in many Desmidiacece and in the gametes of many Confervoidea; or they may be two of the adjacent cells forming a thread, as in some Conjugatece and the gametes of Confervoidece; or they may be cells belonging to adjacent threads, as in other Conjugatea. But whether it is originated by a single parent-cell, or by two parent-cells, the zygote, after remaining quiescent until there recur the fit conditions for growth, either breaks up into a multitude of spores, each of which produces an individual that usually multiplies asexually, or germinates directly to produce one new individual; and the fact here to be noted is, that as the entire contents of the parent-cells unite to form the zygote, their individualities are lost in the germs of a new generation. In these minute simple types, sexual propagation just as completely sacrifices the life of the parent or parents, as does that form of asexual propagation in which the protoplasm resolves itself directly into zoospores. And in the one case as in the other, this sacrifice is the concomitant of a prodigious fertility. Slightly in advance of this, but still showing us an almost equal loss of parental life in the lives of offspring, is the process seen in such unicellular Alga as Botrydium, and in minute Fungi of the same degree of composition. These exhibit a relativelyenormous development of the spore-producing part, and an almost entire absorption of the parental substance into it. As evidence of the resulting powers of multiplication, we have but to remember that the spread of mould over stale food, the rapid destruction of crops by mildew, and other kindred occurrences, are made possible by the incalculably numerous spores thus generated and universally dispersed.

Plants a degree higher in composition supply a parallel series of illustrations. We have among the larger Fungi, in 
which the reproductive apparatus is relatively so enormous as to constitute the ostensible plant, a similar subordination of the individual to the race, and a similarly-immense fertility. Thus, as quoted by Dr. Carpenter, Fries says- “ in a single individual of Reticularia maxima, I have counted (calculated?) $10,000,000$ sporules." It needs but to note the clouds of particles, so minute as to look like smoke, which ripe puffballs give off when they are burst, and then to remember that each particle is a potential fungus, to be impressed with the almost inconceivable powers of propagation which these plants possess.

The Lichens, too, furnish examples. Though they are nothing like so prolific as the Fungi (the difference yielding, as we shall hereafter see, further support to the general argument), yet there is a great production of germs, and a proportionate sacrifice of the parental individuality. Considerable areas of the thallus develop into the fruit-bodies characteristic of the various fungi which, combined with algr, form the different lichens (various members of the Ascomycetes and the Basidiomycetes). From these are produced great numbers of ascospores or basidiospores, as the case may be. Very many lichens also reproduce themselves by means of Soredia, i.e., little masses of algal cells closely wrapped in a weft of fungal hyphæ.

Some contrasts presented by the higher Algae may also be named as exemplifying the inverse proportion between the size of the individual and the extent of the generative structures. While in the smaller kinds relatively large portions of the fronds are transformed into reproductive elements, in the larger kinds these portions are relatively small: instance the Macrocystis pyrifera, a gigantic sea-weed which sometimes attains a length of 1,500 feet, of which Dr. Carpenter remarks"This development of the nutritive surface takes place at the expense of the fructifying apparatus, which is here quite subordinate."

When we turn to vegetal aggregates of the third order of composition, facts having the same meaning are conspicuous. 
On the average these higher plants are far larger than plants of a lower degree of composition; and on the average their rates of sexual reproduction are far less. Similarly if, among Arehegoniates and Phænogams, we compare the smaller types with the larger, we find them proportionately more prolific. This is not manifest if we simply calculate the number of seeds ripened by an individual in a single season; but it becomes manifest if we take into account the further factor which here complicates the result-the age at which sexual genesis commences. The smaller Phænogams are mostly either annuals, or perennials that die down annually; and seeding as they do annually before their deaths, or the deaths of their reproductive parts, it results that in the course of a year each gives origin to a multitude of potential plants, of which every one may the next year, if preserved, give origin to an equal multitude. Supposing but a hundred offspring to be produced the first year, ten thousand may be produced in the second year, a million in the third, a hundred millions in the fourth. Meanwhile, what has been the possible multiplication of a large Phænogam? While its small congener has been seeding and dying, and leaving multitudinous progeny to seed and die, it has simply been growing; and may so continue to grow for ten. or a dozen years without bearing fruit. Before a Cocoa-nut tree has ripened its first cluster of nuts, the descendants of a wheat plant, supposing them all to survive and multiply, will have become numerous enough to occupy the whole surface of the Earth. So that though, when it begins to bear, a tree may annually shed as many seeds as a herb, yet in consequence of this delay in bearing, its fertility is incomparably less; and its relatively-small fertility becomes still further reduced where, as in Lodoicea callipyge, the seeds take two years from the date of fertilization to the date of germination.

$\$ 340$. Some observers state that in certain Protozoa there 
occurs a process of conjugation akin to that which the Protophyta exhibit-a coalescence of the substance of two individuals to form a germ-mass. This has been alleged more especially of Actinophrys. If this statement should be proved true, * then of the minute forms that appear to be more animal than vegetal in their characters, some have a mode of sexual multiplication by which the parents are sacrificed bodily in the production of a new generation.

Among small animal aggregates of the second order, the first to be considered are of course the Colenterata. A Hydra occasionally devotes a large part of its substance to sexual genesis. In the walls of its body groups of ova, or spermatozoa, or both, take their rise; and develop into masses greatly distorting the creature's form, and leaving it much diminished when they escape. Here, however, gamogenesis is obviously supplementary to agamogenesis-the immensely rapid multiplication by budding continues as long as food is abundant and warmth sufficient, and is replaced by gamogenesis only at the close of the season.

A better example

* To this passage Prof. MacBride appends the remark:- "This is quite proven now, and the statement as it stands is quite correct; but far better and more minutely worked out cases are to be found amongst the Infusoria. In Paramacium for example, there are normally present a large macro nucleus and a small micronucleus lying alongside of it. When two individuals adhere preparatory to conjugation, the macronucleus breaks up into fragments which are absorbed: the micronucleus-which has some time previously divided into two-begins to break up further and eventually forms eight bodies; all of these except one disappear; this last piece then divides into two; of these two one represents a male genital cell, for it passes over into the body of the other Paramcecium and fuses with one of the two corresponding nuclei there; thus each of the two individuals which adhere fertilizes the other. The two individuals then separate and the nucleus (result of fusion of male and female nuclei) in each divides into four. Of these, two move to one end of the animal and two to the other. The animal then divides into two transversely-each of the products thus having two nuclei which form the micro- and macro-nucleus of it. Thus it appears that the function of sexual union is simply to give increased vigour to all the vital processes including fission. Since as mentioned above (p. 443) if it is prevented, the products of fission are eventually unable to feed thomselves." 
of the relation between small size and active gamogenesis among low types of the Metazoa is supplied by the Rotifera. Microscopic as these are, they have a great rate of sexual increase. According to Ehrenberg, Hydatina senta "is capable of a four-fold propagation every twenty-four or thirty hours, bringing forth in this time four ova, which grow from the embryo to maturity, and exclude their fertile ova in the same period. The same individual, producing in ten days forty eggs, developed with the rapidity above cited, this rate, raised to the tenth power, gives one million of individuals from one parent, on the eleventh day four millions, and on the twelfth day sixteen millions, and so on." Ehrenberg, however, characterized by Huxley as "the greatest looker and the worst observer," is not a safe authority, and it is better to state the estimate of Ludwig Plate, who says that Hydatina lays fifty eggs in two to three weeks -a number which, multiplying in the manner described, will yield in the time named a much smaller total though still an enormous total.

The Annulosa, including among them the inferior types, have habits and conditions of life so various that only the broadest contrasts can be instanced in support of the proposition before us. The differences of organization and activity greatly complicate the inverse variation of fertility and bulk. Bearing in mind, however, that the rate of multiplication depends much less on the number of each brood than on the quickness with which maturity is reached and a new generation commenced, it will be obvious that though Annelids, relatively enormous in size, produce great numbers of ova, yet as they do this at comparatively long intervals, their rates of increase fall immensely below that just instanced in the Rotifers. And when at the other extreme we come to the large articulate animals, such as the Crab and the Lobster, the further diminution of fertility is seen in the still longer delay which occurs before each new generation begins to reproduce. 
Perhaps the best examples are supplied by vertebrate animals, and especially those that are most familiar to us. Comparisons between Fishes are unsatisfactory, because of our ignorance of their histories. In some cases Fishes equal in bulk produce widely different numbers of eggs; as the Cod which spawns millions at once, and the Salmon by which nothing like so great a number is spawned. But then the eggs are very unlike in size; and if the ovaria of the two fishes be compared, the difference between their masses is comparatively moderate. There are, indeed, contrasts which seem at variance with the alleged relation; as that between the Cod and the Stickleback which, thongh so much smaller, produces fewer ova. The Stickleback's ova, however, are relatively large; and their total bulk bears as great a ratio to the bulk of the Stickleback as does the bulk of the Cod's ova to that of the Cod. Moreover if, as is not improbable, the reproductive age is arrived at earlier by the Stickleback than by the Cod, the fertility of the species may be greater notwithstanding the smaller number produced by each individual. Evidence which admits of being tolerably well disentangled is furnished by Birds. They differ but little in their grades of organization; and the habits of life throughout extensive groups of them are so similar, that comparisons may be fairly made. It is true that, as hereafter to be shown, the differences of expenditure which differences of bulk entail, have doubtless much to do with the differences of fertility. But we may set down under the present head some of those cases in which the activity, being relatively slight, does not greatly interfere with the relation we are considering; and may note that among such birds having similarly slight activities, the small produce more eggs than the large, and eggs that bear in their total mass a greater ratio to the mass of the parent. Consider, for example, the gallinaceous birds; which are like one another and unlike birds of most other groups in flying comparatively little. Taking first the wild members of this order, which 
rarely breed more than once in a season, we find that the Pheasant has from 10 to 14 eggs, the Black-cock from 6 to 10 , the Grouse 8 to 14 , the Partridge 12 to 20 , the Quail still more, sometimes reaching two broods of 7 to 12 in each. Here the only exception to the relation between decreasing bulk and increasing number of eggs, occurs in the cases of the Pheasant and the Black-cock; and it is to be remembered, in explanation, that the Pheasant is constitutionally adapted to a warmer region, is better fed-often artificiallyand leads a less active life. If we pass to domesticated genera of the same order, we meet with parallel differences. From the numbers of eggs laid, little can be inferred; for under the favourable conditions artificially maintained, the laying is carried on indefinitely. But though in the sizes of their broods the Turkey and the Fowl do not greatly differ, the Fowl begins breeding at a much earlier age than the Turkey, and produces broods more frequently: a considerably higher rate of multiplication being the result. Now these contrasts among domestic creatures which are similarly conditioned, and closely-allied by constitution, may be held to show, more clearly than most other contrasts, the inverse variation between bulk and sexual genesis; since here the cost of activity is diminished to a comparatively small amount. There is little expenditure in flight-sometimes almost none; and the expenditure in walking about is not great: there is more of standing than of actual movement. It is true that young Turkeys commence their existence as larger masses than chickens; but it is tolerably manifest that the total weight of the eggs laid by a Turkey during each season, bears a less ratio to the Turkey's weight, than the total weight of the eggs which a Hen lays during each season, bears to the Hen's weight; and this is the fairest way of making the comparison. The comparison so made shows a greater difference than appears likely to be due to the different costs of locomotion; considering the inertness of the creatures. Remembering that 
the assimilating surface increases only as the squares of the dimensions, while the mass of the fabric to be built up by the absorbed nutriment increases as the cubes of the dimensions, it will be seen that the expense of growth becomes relatively greater with each increment of size; and that hence, of two similar creatures commencing life with different sizes, the larger one in reaching its superior adult bulk, will do this at a more than proportionate expense; and so will either be delayed in commencing its reproduction, or will have a diminished reserve for reproduction, or both. Other orders of Birds, active in their habits, show more markedly the connexion between augmenting mass and declining fertility. But in them the increasing cost of locomotion becomes an important, and probably the most important, factor. The evidence they furnish will therefore come better under another head.

Contrasts among Mammals, like those which Birds present, have their meanings obscured by inequalities of the expenditures for motion. The smaller fertility which habitually accompanies greater bulk, must in all cases be partly ascribed to this. Still, it may be well if we briefly note, for as much as they are worth, the broader contrasts. While a large Mammal bears but a single young one at a time, is several years before it commences doing this, and then repeats the reproduction at long intervals; we find, as we descend to the smaller members of the class, a very early commencement of breeding, an increasing number at a birth, reaching in small Rodents to 10 or even more, and a much more frequent recurrence of broods: the combined result being a relatively prodigious fertility. If a specific comparison be desired between Mammals that are similar in constitution, in food, in conditions of life, and all other things but size, the Deer-tribe supplies it. While the large Red-deer has but one at a birth, the small Roe-deer has frequently two at a birth.*

$\S 341$. The antagonism between growth and sexual gene* A passage translated for me from the German may be here given in 
sis, visible in these general contrasts, may also be traced in the history of each plant and animal. So familiar is the fact that sexual genesis does not occur early in life, and in all organisms which expend much begins only when the limit of size is nearly reached, that we do not sufficiently note its significance. It is a general physiological truth, however, that while the building-up of the individual is going on rapidly, the reproductive organs remain imperfectly developed and inactive; and that the commencement of reproduction at once indicates a declining rate of growth, and becomes a cause of arresting growth. As was shown in $\S 78$, the exceptions to this rule are found where the limit of growth is indefinite; either because the organism expends little or nothing in action, or expends in action so moderate an amount that the supply of nutriment is never equilibrated by its expenditure.

We will pass over the inferior plants and, limiting ourselves to Phænogams, will not dwell on the less conspicuous evidence with the smaller types present. A few cases such as gardens supply will serve. All know that a Pear-tree increases in size for years before it begins to bear; and that, producing but few pears at first, it is long before it fruits abundantly. A young Mulberry-tree, branching out luxuriantly season after season, but covered with nothing but leaves, at length blossoms sparingly and sets some small and imperfect berries, which it drops while they are green; and it makes these futile attempts time after verification. Dr. Dionys Hellin in an essay on the origin of Multiparity and Twin-births, refers to the thesis above set forth, and says that "the fact that it is generally women of small growth who bear twins is in complete agreement with it." He adds that "Puech is right in his opinion that twin pregnancies are a direct result of relatively large ovaries (i.e., in comparison with the whole body). He has observed that for the same size of body the ovarium of a pluriparous animal is always of greater volume than that of a uniparous animal ... a sow has ovaries as large as a cow's; but while the latter bears only one ealf [at a time], the sow brings forth 6-15 at each litter. Even in animals of the same species but belonging to different races these relations may be verified," e.g., Barbary sheep and ordinary sheep. 
time before it succeeds in ripening any seeds. But these multi-axial plants, or aggregates of individuals some of which continue to grow while others become arrested and transformed into seed-bearers, show us the relation less definitely than certain plants that are substantially, if not literally, uni-axial. Of these the Cocoa-nut may be instanced. For some years it goes on shooting up without making any sign of becoming fertile. About the sixth year it flowers; but the flowers wither without result. In the seventh year it flowers and produces a few nuts; but these prove abortive and drop. In the eighth year it ripens a moderate number of nuts; and afterwards increases the number until, in the tenth year, it comes into full bearing. Meanwhile, from the time of its first flowering its growth begins to diminish, and goes on diminishing till the tenth year, when it ceases. Here we see the antagonism between growth and sexual genesis under both its aspects-see a struggle between self-evolution and race-evolution, in which the first for a time overcomes the last, and the last ultimately overcomes the first. The continued aggrandizement of the parent-individual makes abortive for two seasons the tendency to produce new individuals; and the tendency to produce new individuals, becoming more decided, stops any further aggrandizement of the parent individual.

Parallel illustrations occur in the animal kingdom. The eggs laid by a pullet are relatively small and few. Similarly, it is alleged that, as a general rule, "a bitch has fewer puppies at first, than afterwards." According to Burdach, as quoted by Dr. Duncan, "the elk, the bear, \&c., have at first only a single young one, then they come to have most frequently two, and at last again only one. The young hamster produces only from three to six young ones, while that of a more advanced age produces from eight to sixteen. The same is true of the pig." It is remarked by Buffon that when a sow of less than a year old has young, the number of the litter is small, and its members are feeble and even im- 
perfect. Here we have evidence that in animals growth checks sexual genesis. And then, on the other hand, we have evidence that sexual genesis checks growth. It is well known to breeders that if a filly is allowed to bear a foal, she is thereby prevented from reaching her proper size. And a like loss of perfection as an individual, is suffered by a cow which breeds too early. It may be added, as a converse fact, that castrated animals, as capons and notably cats, often become larger than their unmutilated associates.

§342. Notwithstanding the way in which the inverse variation of growth and sexual genesis is complicated with other relations, its existence is, I think, sufficiently manifest. Individually, many of the foregoing instances are open to criticism, and have to be taken with qualifications; but when looked at in the mass their meaning is beyond doubt. Comparisons between the largest with the smallest types, whether vegetal or animal, yield results which are unmistakable. On the one hand, remembering the fact that during its centuries of life an Oak does not produce as many acorns as a Fungus does spores in a single night, we see that the Fungus has a fertility exceeding that of the Oak in a degree literally beyond our powers of calculation or imagination. On the other hand when, taking a microscopic protophyte which has billions of descendants in a few days, we ask how many such would be required to build up the forest tree which is years before it drops a seed, we are met by a parallel difficulty in conceiving the number, if not in setting it down. Similarly, if from the minute and prodigiouslyfertile Rotifer we turn to the Elephant, which approaches thirty years before it bears a solitary young one, we find the connexions between small size and great fertility and between great size and small fertility, too intensely marked to be much disguised by the perturbing relations that have been indicated. Finally, as this induction, reached by a survey of organisms in general, is verified by observations on the rela- 
tion between decreasing growth and commencing reproduction in individual organisms, we may, I think, consider the alleged antagonism as proved.*

* When, after having held for some years the general doctrine elaborated in these chapters, I agreed, early in 1852, to prepare an outline of it for the Westminster Review, I consulted, among other works, the just-issued third edition of Dr. Carpenter's Principles of Physiology, General and Comparative-seeking in it for facts illustrating the different degrees of fertility of different organisms, I met with a passage, quoted above in $\$ 339$, which seemed tacitly to assert that individual aggrandizement is at variance with the propagation of the race; but nowhere found a distinct enunciation of this truth. I did not then read the Chapter entitled "General View of the Functions," which held out no promise of such evidence as I was looking for. But on since referring to this chapter, I discovered in it the definite statement that- " there is a certain degree of antagonism between the Nutritive and Reproductive functions, the one being executed at the expense of the other. The reproductive apparatus derives the materials of its operations through the nutritive system, and is entirely dependent upon it for the continuance of its function. If, therefore, it be in a state of excessive activity, it will necessarily draw off from the individual fabric some portion of the aliment destined for its maintenance. It may be universally observed that, when the nutritive functions are particularly active in supporting the ixdividual, the reproductive system is in a corresponding degree undeveloped,and vice versh." P. 692. 


\section{CHAPTER VII.}

THE ANTAGONISM BETWEEN DEVELOPMENT AND GENESIS, ASEXUAL AND SEXUAL.

$\S 343 . \mathrm{Br}$ Development, as here to be dealt with apart from Growth, is meant increase of structure as distinguished from increase of mass. As was pointed out in $\S 50$, this is the biological definition of the word. In the following sections, then, we have to note how complexity of organization is hindered by reproductive activity, and conversely.

This relation partially coincides with that which we have just contemplated; for, as was shown in $\S 44$, degree of growth is to a considerable extent dependent on degree of organization. But while the antagonism to be illustrated in this chapter is much entangled with that illustrated in the last chapter, it may be so far separated as to be identified as an additional antagonism.

Besides the direct opposition between that continual disintegration which rapid genesis implies, and the fulfilment of that pre-requisite to extensive organization-the formation of an extensive aggregate, there is an indirect opposition which we may recognize under several aspects.

The change from homogeneity to heterogeneity takes time; and time taken in transforming a relatively-structureless mass into a developed individual, delays the period of reproduction. Usually this time is merged in that taken for growth; but certain cases of metamorphosis show us the one separate from the other. An insect, passing from its lowly-organized cater- 
pillar-stage into that of chrysalis, is afterwards a week, a fortnight, or a longer period in completing its structure: the re-commencement of genesis being by so much postponed, and the rate of multiplication therefore diminished. Further, that re-arrangement of substance which development implies, entails expenditure. The chrysalis loses weight in the course of its transformation; and that its loss is not loss of water only, may be inferred from the fact that it respires, and that respiration indicates consumption. Clearly the matter consumed is, other things equal, a deduction from the surplus which may go to reproduction.

Yet again, the more widely and completely an organic mass becomes differentiated, the smaller is the portion of it which retains the relativelyundifferentiated state that admits of being moulded into new individuals, or the germs of them. Protoplasm which has become specialized tissue cannot be generalized afresh, and afterwards transformed into something else; and hence the progress of structure in an organism, by diminishing the unstructured part, diminishes the amount available for making offspring.

It is true that higher structure, like greater growth, may insure to a species advantages which eventually further its multiplication-may give it access to larger supplies of food, or enable it to obtain food more economically; and we shall hereafter see how the inverse variation we are considering is thus qualified. But here we are concerned only with the necessary and direct effects; not with those that are contingent and remote. These necessary and direct effects we will now look at as exemplified.

$\S 344$. Speaking generally, the simpler plants propagate both sexually and asexually; and, speaking comparatively, the complex plants propagate only sexually: their asexual propagation is usually incomplete-produces a united aggregate of individuals instead of numerous distinct individuals. The Protophytes that perpetually subdivide, the merely- 
cellular Algae that shed their tetraspores, the Archegoniates that spontaneously separate their fronds or drop their gemmæ, show us an extra mode of multiplication which, among flowering plants, is exceptional. This extra mode of multiplication among these simpler plants, is made easy by their low development. Tetraspores arise only where the frond consists of untransformed cells; gemmæ bud out and drop off only where the tissue is comparatively homogeneous.

Should it be said that this is but another aspect of the antagonism already set forth, since these undeveloped forms are also the smaller forms; the reply is that though in part true this is not wholly true. Various marine Algoe which propagate asexually, are larger than some Phænogams which do not thus propagate. The objection that difference of medium vitiates this comparison, is met by the fact that it is the same among land-plants themselves. Sundry of the lowly-organized Liverworts which are habitually gemmiparous, exceed in size many flowering plants. And the Ferns show us agamic multiplication occurring in plants which, while they are inferior in complexity of structure, are superior in bulk to numbers of annual Monocotyledons and Dicotyledons.

$\S 345$. In the ability of the lowly-organized substance of a Sponge to transform itself into multitudes of gemmules, we have an instance of this same direct relation in the animal kingdom. Moreover, the instance yields very distinct proof of an antagonism between development and genesis, independent of the antagonism between growth and genesis; for the Sponge which thus multiplies itself asexually, as well as sexually, is far larger than hosts of more complex animals which do not multiply asexually.

Once again may be cited the creature so often brought in evidence, the Hydra, as showing us how rapidity of agamic propagation is associated with inferiority of structure. Its power to produce young ones from nearly all parts of its body, is due to the comparative homogeneity of its body. In 
kindred but more-organized types, the gemmiparity is greatly restricted, or disappears. Among the free-swimming Hydrozoa, multiplication by budding, when it occurs at all, occurs only at special places. That increase of structure apart from increase of size, is here a cause of declining agamogenesis, we may see in the contrast between the simple Hydra and the compound Hydroids. These last, along with moredifferentiated tissues, show us a gemmation which does not go on all over the body of each polype, and much of it does not end in separation.

It is, however, among the Annulosa that progressing organization is most conspicuously operative in diminishing agamogenesis. The segments or "somites" composing an animal belonging to this class, are primordially alike; and, as before argued ( $\$ \S 205-7)$, are probably the homologues of what were originally independent individuals. The progress from the lower to the higher types of the class, is at once a progress towards types in which the strings of segments cease to undergo subdivision, and towards types in which the segments, no longer alike in their structures and functions, have become physiologically integrated or mutually dependent. Already this group of cases has been named as illustrating the antagonism between growth and asexual genesis; but it is proper also to name it here, since, on the one hand, the greater size due to the ceasing of fission, is made possible only by the specialization of parts and the development of a co-ordinating apparatus to combine their actions, and since, on the other hand, specialization and co-ordination can advance only in proportion as fission ceases.

$\S 346$. The inverse variation of development and sexual genesis is by no means easy to follow. One or two facts indicative of it may, however, be named.

Phænogams that have but little supporting tissue may fairly be classed as structurally inferior to those having stems with a bulky and complex woody system; for these imply 
additional differentiations, and constitute wider departures from the primitive type of vegetal tissue. That the concomitant of this higher organization is a slower gamogenesis, scarcely needs pointing out. While the herbaceous annual is blossoming and ripening seed, the young tree is transforming its originally-succulent axis into dense fibrous substance; and year by year the young tree expends in doing the like, nutriment which successive generations of the annual expend in fruit. Here the inverse relation is between sexual reproduction and complexity, and not between sexual reproduction and bulk, seeing that besides seeding, the annual often grows to a size greater than that reached by the young infertile tree in several years.

Proof of the antagonism between complexity and gamogenesis in animals, is still more difficult to disentangle. Perhaps the evidence most to the point is furnished by the contrast between Man and certain other Mammals approaching him in mass. To compare him with the domestic Sheep which, though not very unlike in size, is relatively prolific, is objectionable because of the relative inactivity of Sheep; and this, too, may be alleged as a reason why the $0 x$, though far more bulky, is also far more fertile, than Man. Further, against a comparison with the Horse which, while both larger and more prolific, is tolerably active, it may be urged that in his case, and the cases of herbivorous creatures generally, the small exertion required to procure food, joined with the great ratio borne by the alimentary organs to the organs they have to build up and repair, vitiates the result. We may, however, fairly draw a parallel between Man and a large carnivore. The Lion, superior in size, and perhaps equal in activity, has a digestive system not proportionately greater; and yet has a higher rate of multiplication than Man. Here the only decided want of parity, besides that of organization, is that of food. Possibly a carnivore gains an advantage in having a surplus nutriment consisting almost wholly of those nitrogenous materials from which the bodies 
of young ones are mainly formed. But, allowing for all other differences, it appears not improbable that the smallness of human fertility compared with the fertility of large feline animals, is due to the greater complexity of the human organization-more especially the organization of the nervous system. Taking degree of nervous organization as the chief correlative of mental capacity; and remembering the physiological cost of that slow evolution whereby high mental capacity is reached; we may suspect that nervous organization is very expensive: the inference being that bringing it up to the level it reaches in Man, whose digestive system, by no means large, has at the same time to supply materials for general growth and daily waste, involves a great retardation of maturity and sexual genesis. 


\section{CHAPTER VIII.}

\section{ANTAGONISM BETWEEN EXPENDITURE AND GENESIS.}

$\S 347$. UNDER this head we have to set down no evidence derived from the regetal kingdom. Plants are not expenders of force in such degrees as to affect the general relations with which we are dealing. They have not to maintain a heat above that of their environment, nor have they to generate motion; and hence consumption for these two purposes does not diminish the stock of material which serves on the one hand for growth and on the other hand for propagation.

It will be well, too, if we pass over the lower animals: especially those aquatic ones which, being nearly of the same temperature as the water, and nearly of the same specific gravity, lose but little in evolving motion, sensible and insensible. A further reason for excluding from consideration these inferior types, is that we do not know enough of their rates of genesis to permit of our making, with any satisfaction, those involved comparisons here to be entered upon.

The facts on which we must mainly depend are those to be gathered from terrestrial animals, and chiefly from those higher classes of them which are at the same time great expenders and have rates of multiplication about which our knowledge is tolerably definite. We will restrict ourselves, then, to the evidence which Birds and Mammals supply.

$\S 348$. Satisfactory proof that loss of substance in the 
maintenance of heat diminishes the rapidity of propagation, is difficult to obtain. It is, indeed, obvious that the warmblooded Vertebrata are less prolific than the cold-blooded; but then they are at the same time more vivacious. Similarly, between Mammals and Birds (which are the warmerblooded of the two) there is, other things equal, a parallel, though much smaller, difference; but here, too, the unlikenesses of muscular action complicate the evidence. Again, the annual return of generative activity has an average correspondence with the annual return of a warmer season, which, did it stand alone, might be taken as evidence that a diminished cost of heat-maintenance leads to such a surplus as makes reproduction possible. But then, this periodic rise of temperature is habitually accompanied by an increase in the quantity of food-a factor of equal or greater importance. We must be content, therefore, with such few special facts as admit of being disentangled.

Certain of these we are introduced to by the general relation last named-the habitual recurrence of genesis with the recurrence of spring. For in some cases a domesticated creature has its supplies of food almost equalized; and hence the effect of varying nutrition may be in great part eliminated from the comparison. The common Fowl yields an illustration. It is fed through the cold months, but nevertheless, in mid-winter, it either wholly leaves off laying or lays very sparingly. And then we have the further evidence that if it lays sparingly, it does so only on condition that the heat, as well as the food, is artificially maintained. Hens lay in cold weather only when they are kept warm. To which fact may be added the kindred one that "when pigeons receive artificial heat, they not only continue to hatch longer in autumn, but will recommence in spring sooner than they would otherwise do." An analogous piece of evidence is that, in winter, inadequately sheltered Cows either cease to give milk or give it in diminished quantity. For though giving milk is not the same thing as bearing a young one, yet, as milk 
is part of the material from which a young one is built up, it is part of the outlay for reproductive purposes, and diminution of it is a loss of reproductive power. Indeed the case aptly illustrates, under another aspect, the struggle between self-preservation and race-preservation. Maintenance of the cow's life depends on maintenance of its heat; and maintenance of its heat may entail such reduction in the supply of milk as to cause the death of the calf.

Evidence derived from the habits of the same or allied genera in different climates, may naturally be looked for; but it is difficult to get, and it can scarcely be expected that the remaining conditions of existence will be so far similar as to allow of a fair comparison being made. The only illustrative facts I have met with which seem noteworthy, are some named by Mr. Gould in his work on The Birds of Australia. He says:- "I must not omit to mention, too, the extraordinary fecundity which prevails in Australia, many of its smaller birds breeding three or four times in a season; but laying fewer eggs in the early spring when insect life is less developed, and a greater number later in the season, when the supply of insect food has become more abundant. I have also some reason to believe that the young of many species breed during the first season, for among others, I frequently found one section of the Honey-eaters (the Melithrepti) sitting upon eggs while still clothed in the brown dress of immaturity; and we know that such is the case with the introduced Gallinacece (or poultry) three or four generations of which have been often produced in the course of a year." Though here Mr. Gould refers only to variation in the quantity of food as a cause of variation in the rate of multiplication, may we not suspect that warmth is a part-cause of the high rate which he describes as general?

$\S 349$. Of the inverse variation between activity and genesis, we get clear proof. Let us begin with that which Birds furnish. 
First we have the average contrast, already hinted, between the fertility of Birds and the fertility of Mammals. Comparing the large with the large and the small with the small, we see that creatures which continually go through the muscular exertion of sustaining themselves in the air and propelling themselves rapidly through it, are less prolific than creatures of equal weights which go through the smaller exertion of moving about over solid surfaces. Predatory Birds have fewer young ones than predatory Mammals of approximately the same sizes. If we compare Rooks with Rats, or Finches with Mice, we find like differences. And these differences are greater than at first appears. For whereas among Mammals a mother is able, unaided, to bear and suckle and rear halfway to maturity, a brood that probably weighs more in proportion than does the brood of a Bird; a Bird, or at least a Bird that flies much, is unable to do this. Both parents have to help; and this indicates that the margin for reproduction in each adult individual is smaller.

Among Birds themselves occur contrasts which may be next considered. In the Raptorial class, various species of which, differing in their sizes, are similarly active in their habits, we see that the small are more prolific than the large. The Golden Eagle has usually 2 eggs: sometimes 3, sometimes only 1 . As we descend to the Kites and Falcons, the number is 2 or 3 , and 3 or 4 . And when we come to the Sparrow-Hawk, 3 to 5 is the specified number. Similarly among the Owls: while the Great Eagle-Owl has 2 or 3 eggs, the comparatively small Common Owl has 4 or 5 . As before hinted, it is impossible to say what proportions of these differences are due to unlikenesses of bulk merely, and what proportions are due to unlikenesses in the costs of locomotion. But we may fairly assume that the unlikenesses in the costs of locomotion are here the more important factors. Weights varying as the cubes of the dimensions, while the surfaces of digestive systems vary as the squares, the expense of flight increases more rapidly than does the ability to take 
in nutriment; and as motion through the air requires more effort than motion on the ground, this geometrical progression tells more rapidly on Birds than on Mammals. Be this as it may, however, these contrasts support the argument; as do various others which may be set down. The Finch-family, for example, have broods averaging about 5 in number, and have commonly 2 broods in the season; while in the Crow-family the number of the brood is on the average less, and there is but one brood in the season. And then on descending to such small birds as the Wrens and the Tits, we have $8,10,12$ to 15 eggs, and sometimes two broods in the year. One of the best illustrations is furnished by the Swallow-tribe, throughout which there is little or no difference in mode of life or in food. The Sand-Martin, much the least of them, has 4 to 6 eggs and two broods; the Swallow, somewhat larger, has 4 or 5 ; and the Swift (similar in habits though unrelated), larger still, has but 2. Here we see a lower fertility associated in part with greater size, but associated still more conspicuously with greater expenditure. For the difference of fertility is more than proportionate to the difference of bulk, as shown in other cases; and for this greater difference there is the reason, that the Swift has to support not only the cost of propelling its larger mass through the air, but also the cost of propelling it at a higher velocity.

Omitting much evidence of like nature, let us note that disclosed by comparisons of certain groups of birds with other groups. "Skulkers" is the descriptive title applied to the Water-Rail, the Corn-Crake, and their allies, which evade enemies by concealment-consequently expending but little in locomotion. These birds have relatively large broods-6 to 11,8 to $12, \&$ c. Not less instructive are the contrasts between the Gallinaceous Birds and other Birds of like sizes but more active habits. The Partridge and the Wood-Pigeon are about equal in bulk and have much the same food. Yet while the one has from 12 to 20 young ones, the other has but 2 young ones twice a-year: its annual reproduction is less than 
one-third. It may be said that the ability of the Partridge to bring up so large a brood, is due to that habit of its tribe which one of its names, "Scrapers," describes; and to the accompanying habit of the young, which begin to get their own living as soon as they are hatched: so saving the parents' labour. Conversely, it may be said that the inability of Pigeons to rear more than 2 at a time, is caused by the necessity of fetching everything they eat. But the alleged relation holds nevertheless. On the one hand, a great part of the food which the Partridge chicks pick up, is food which, in their absence, the mother would have picked up. Though each chick costs her far less than a young Pigeon costs its parents, yet the whole of her chicks cost her a great deal in the shape of abstinence-an abstinence she can bear because she has to fly but little. On the other hand, the Pigeon's habit of laying and hatching but two eggs, must not be referred to any foreseen necessity of going through so much labour in supporting the young, but to a constitutional tendency established by such labour. This is proved by the curious fact that when domesticated, and saved from such labour by artificial feeding, Pigeons, says Macgillivray (quoting Aitkin), " are frequently seen sitting on eggs long before the former brood is able to leave the nest, so that the parent bird has at the same time young birds and eggs to take care of."

$\S 350$. Made to illustrate the effect of activity on fertility, most comparisons among Mammals are objectionable: other circumstances are not equal. A few, however, escape this criticism.

One is that between the Hare and the Rabbit. These are closely-allied species of the same genus, similar in their diet but unlike in their expenditures for locomotion. The relatively-inert Rabbit has 6 young ones in a litter, and four litters a-year; while the relatively-active Hare has but 2 to 5 in a litter. This is not all. The Rabbit begins to breed at six months old; but a year elapses before the Hare begins 
to breed. These two factors compounded, result in a difference of fertility far greater than can be ascribed to unlikeness of the two creatures in size.

Perhaps the most striking piece of evidence which Mammals furnish, is the extreme infertility of our common Bat. The Cheiroptera and the Rodentia are not very dissimilar in their internal structures. Diversity of constitution, therefore, cannot vitiate the comparison between Bats and Mice, which are about the same in size. Though their diets differ, the difference is in favour of the Bat: its food being exclusively animal while that of the Mouse is mainly vegetal. What now are their respective rates of genesis? The Mouse has several litters in a year of 5 to 7 in each; while the Bat produces only one at a time. Whether the Bat repeats its one more frequently than the Mouse repeats its 7 is not stated; but it is quite certain that even if it does so (an absurd supposition), the more frequent repetition cannot be such as to raise its fertility to anything like that of the Mouse. And this relatively-low rate of multiplication we may fairly ascribe to its relatively-high rate of expenditure.

Here let us note, in passing, an interesting example of the way in which a species which has no specially-great power of self-preservation, while its power of multiplication is extremely small, nevertheless avoids extinction because it has to meet an unusually-small total of race-destroying forces. Leaving out parasites, the only enemy of the Bat is the Owl; and the Owl is sparingly distributed.

$\S 351$. These general evidences may be enforced by some special evidences. We have few opportunities of observing how, within the same species, variations of expenditure are related to variations of fertility. But a fact or two showing the connexion may be named.

Doctor Duncan quotes a statement to the point respecting the breeding of dogs. Already in $\S 341 \mathrm{I}$ have extracted a part of this statement, to the effect that before her growth is com- 
plete, a bitch bears at a birth fewer puppies than when she becomes full-grown. An accompanying allegation is, that her declining vigour is shown by a decrease in the number of puppies contained in a litter, "ending in one or two." And then it is further alleged that, "as regards the amount of work a dog has to perform, so will the decline be rapid or gradual; and hence, if a bitch is worked hard year after year, she will fail rapidly, and the diminution of her puppies will be accordingly; but if worked moderately and well kept, she will fail gradually, and the diminution will be less rapid."

In this place, more fitly than elsewhere, may be added a fact of like implication, though of a different order. Of course whether excessive expenditure be in the continual repairs of nervo-muscular tissues or in replacing other tissues, the reactive effects, if not quite the same, will be similarthere will be a decrease of the surplus available for genesis. If, then, in any animals there from time to time occur unusual outlays for self-maintenance, we may expect the periods of such outlays to be periods of diminished or arrested reproduction. That they are so the moulting of birds shows us. When hens begin to moult they cease to lay. While they are expending so much in producing new clothing, they have nothing to expend for producing eggs. 


\section{CHAPTER IX.}

COINCIDENCE BETWEEN HIGH NUTRITION AND GENESIS.

$\S 352$. UNDER this head may be grouped various facts which, in another way, tell the same tale as those contained in the last chapter. The evidence there put together went to show that increased cost of self-maintenance entailed decreased power of propagation. The evidence to be set down here, will go to show that power of propagation is augmented by making self-maintenance unusually easy. For into this may be translated the effect of abundant food.

To put the proposition more specifically-we have seen that after individual growth, development, and daily consumption, have been provided for, the surplus nutriment measures the rate of multiplication. This surplus may be raised in amount by such changes in the environment as bring a larger supply of the materials or forces on which both parental life and the lives of offspring depend. Be there, or be there not, any expenditure, a higher nutrition will make possible a greater propagation. We may expect this to hold both of agamogenesis and of gamogenesis; and we shall find that it does so.

$\S 353$. On multi-axial plants, the primary effect of surplus nutriment is a production of large and numerous leaf-shoots. How this asexual multiplication results from excessive nutrition, is well shown when the leading axis, or a chief branch, is broken off towards its extremity. The axillary buds below 
the breakage quickly swell and burst into lateral shoots, which often put forth secondary shoots: two generations of agamic individuals arise where there probably would have been none but for the local abundance of sap, no longer drawn off. In like manner the abnormal agamogenesis which we have in proliferous flowers, is habitually accompanied by a general luxuriance, implying an unusual plethora.

No less conclusive is the evidence furnished by agamogenesis in animals. Sir John Dalyell, speaking of Hydra $t u b a$, and of the period before strobilization commences, says - "It is singular how much propagation is promoted by abundant sustenance." This Polype goes on budding-out young polypes from its sides, with a rapidity proportionate to the supply of materials.

So, too, is it with the agamic reproduction of the Aphis. As cited by Professor Huxley, Kyber "states that he raised viviparous broods of both this species (Aphis Dianthi) and A. Rosa for four consecutive years, without any intervention of males or oviparous females, and that the energy of the power of agamic reproduction was at the end of that period undiminished. The rapidity of the agamic proliferation throughout the whole period was directly proportional to the amount of warmth and food supplied."

In these cases the relation is not appreciably complicated by expenditure. The parent having reached its limit of growth, the absorbed food goes to asexual multiplication: scarcely any being deducted for the maintenance of parental life.

$\S 354$. The sexual multiplication of organisms under changed conditions, undergoes variations conforming to a parallel law. Cultivated plants and domesticated animals yield us proof of this.

Facts showing that in cultivated plants sexual genesis increases with nutrition, are obscured by facts showing that a less rapid asexual genesis, and an incipient sexual genesis, 
accompany the fall from a high to a moderate nutrition. The confounding of these two relations has led to mistaken inferences. When treating of Genesis inductively, we reached the generalization that "the products of a fertilized germ go on accumulating by simple growth, so long as the forces whence growth results are greatly in excess of the antagonist forces; but that when diminution of the one set of forces, or increase of the other, causes a considerable decline in this excess, and an approach towards equilibrium, fertilized germs are again produced." (§78.) It was pointed out that this holds of organisms which multiply by heterogenesis, as well as those which multiply by homogenesis. And plants were referred to as illustrating, both generally and locally, the decline of agamic multiplication and commencement of gamic multiplication, along with a lessening rate of nutrition. Now the many cases which are given of fruitfulness caused in trees by depletion, are really cases of this change from agamogenesis to gamogenesis; and simply go to prove that what would naturally arise when decreased peripheral growth had followed increased size, may be brought about artificially by diminishing the supply of materials for growth. Cramping its roots in a pot, or cutting them, or ringing its branches, will make a tree bear very early: bringing about a premature establishment of that relative innutrition which would have spontaneously arisen in course of time. Such facts by no means show that in plants sexual genesis increases as nutrition diminishes. When it has once set in, sexual genesis is scanty or imperfect unless nutrition is good. Though the starved plant may blossom, yet many of its blossoms will fail; and such seeds as it produces will be illfurnished with those enveloping structures and that store of albumen, \&c., needed to give good chances of successful germination-the number of surviving offspring will be diminished. Were it otherwise, the manuring of fields which are to bear seed-crops, would be not simply useless but injurious. Were it otherwise, dunging the roots of a fruit-tree would in 
all cases be impolitic; instead of being impolitic only where the growth of sexless axes is still luxuriant. Were it otherwise, a tree which has borne a heavy crop should, by the consequent depletion, be led to bear a still heavier crop next year; whereas it is apt to be wholly or partially barren next year-has to recover a state of tolerably-high nutrition before its sexual genesis again becomes large.

But the best illustrations are yielded by animals-those animals at least in which we have, besides an increased supply of nutriment, a diminished expenditure. Two classes of comparisons, alike in their implications, may be madecomparisons between tame and wild animals of the same species or genus, and comparisons between tame animals of the same species differently treated.

To begin with Birds, let us first contrast the farm-yard Gallinacea with their kindred of the fields and woods. Notwithstanding their greater size, which, other things equal, should be accompanied by smaller fertility, the domesticated kinds have more numerous offspring than the wild kinds. A Turkey has a dozen in a brood, while a Pheasant has from 6 to 10. Twice or thrice in a season, a Hen rears as many chickens as a Partridge rears once in a season. Anserine birds show us parallel differences. The Tame Goose sits on 13 to 18 eggs and often sits a second time; but the Wild Goose sits on 5, 6, or 7, and these are noted as considerably smaller. It is the same with Ducks. The domesticated variety lays and hatches twice as many eggs as the wild variety. And the like holds of Pigeons. After remarking of the Columba livia that "in spring when they have plenty of corn to pick from the newly-sown fields, they begin to get fat and pair; and again in harvest, when the corn is cut down," Macgillivray goes on to say that " the same pair when tamed generally breed four times" in the year.

That between different poultry-yards inequalities of fertility are caused by inequalities in the supplies of food, is a familiar truth. High feeding shows its effects not only in the con- 
tinuous laying, but also in the sizes of the eggs. Among directions given for obtaining eggs from pullets late in the year, it is especially insisted on that they shall have a generous diet. Respecting Pigeons Macgillivray writes:" that their breeding depends much on their having plenty of food to fatten them, seems, I think, evident from the circumstance that, when tamed, which they easily are, they are observed to breed in every month of the year. I do not mean that the same pair will breed every month; but some in the flock, if well fed, will breed at any season."

There may be added a fact of like meaning which partially-domesticated birds yield. The Sparrow is one of the Finch tribe that has taken to the neighbourhood of houses; and by its boldness secures food not available to its congeners. The result is that it has several broods in a season, while its field-haunting kindred have none of them more than two broods, and some have only one.

Equally clear proof that abundant nutriment raises the rate of multiplication, occurs among Mammals. Compare the litters of the Dog with the litters of the Wolf and the Fox. Whereas those of the one range in number from 6 to 14, those of the others contain respectively 5 or 6 or occasionally 7 , and 4 or 5 or rarely 6 . Again, the Wild Cat has 4 or 5 kittens; but the tame Cat has 5 or 6 kittens 2 or 3 times a-year. So, too, is it with the Weasel tribe. The Stoat has 5 young ones once a-year. The Ferret has 2 litters yearly, each containing from 6 to 9 ; and this notwithstanding that it is the larger of the two. Perhaps the most striking contrast is that between the wild and tame varieties of the Pig. While the one produces, according to its age, from 4 to 8 or 10 young ones once a year, the other produces sometimes as many as 17 in a litter; or, in other cases, will bring up 5 litters of 10 each in two years-a rate of reproduction which is unparalleled in animals of as large a size.* And let us not omit to note that this excessive fertility occurs where there is the

* The climate, the locality, and the kind of food, are of course all factors; 
greatest inactivity - where there is plenty to eat and nothing to do. There is no less distinct evidence that among domesticated Mammals themselves, the well-fed individuals are more prolific than the $\cdot$ ill-fed individuals. On the high and comparatively-infertile Cotswolds, it is unusual for ewes to have twins; but they very commonly have twins in the adjacent rich valley of the Severn. Similarly, among the barren hills of the west of Scotland, two lambs will be borne by about one ewe in twenty; whereas in England, something like one ewe in three will bear two lambs. Nay, in rich pastures, twins are more frequent than single births; and it occasionally happens that, after a genial autumn and consequent good grazing, a flock of ewes will next spring yield double their number of lambs-the triplets balancing the uniparæ. So direct is this relation, that I have heard a farmer assert his ability to foretell, from the high, medium, or low, condition of an ewe in the autumn, whether she will next spring bear two, or one, or none.

$\S 355$. An objection must here be met. Many facts may be brought to prove that fatness is not accompanied by fertility but by barrenness; and the inference drawn is that high feeding is unfavourable to genesis. The premiss may be admitted while the conclusion is denied.

There is a distinction between what may be called normal plethora, and an abnormal plethora, liable to be confounded with it. The one is a mark of constitutional wealth; but the other is a mark of constitutional poverty. Normal plethora is a superfluity of materials both for the building up of

and hence, probably, the differences between the statements of different authorities concerning these several cases. Prof. MacBride writes :-

"According to Flower (Mammals, Living and Extinct) the Ferret is a domesticated variety of the common polecat, which has 3 to 8 young. Darwin (Animals and Plants) says that the wild sow often breeds twice a year and produces a litter of 4 to 8 , and sometimes even 12. The domestic sow breeds twice and would breed oftener if permitted, and if any good at all produces 8 in litter." 
tissue and the evolution of force; and this is the plethora which we have found to be associated with unusual fecundity. Abnormal plethora which, as truly alleged, is accompanied by infecundity, is a superfluity of force-evolving materials joined with either a positive or a relative deficiency of tissueforming materials: the increased bulk indicating this state, being really the bulk of so much inert or dead matter. Note, first, a few of the facts which show us that obesity implies physiological impoverishment.

Neither in brutes nor men does it ordinarily occur either in youth or in that early maturity during which the vigour is the greatest and the digestion the best: it does not habitually accompany the highest power of taking up nutritive materials. When fatness arises in the prime of life, whether from peculiarity of food or other circumstance, it is not the sign of an increased total vitality. On the contrary, if great muscular action has to be gone through, the fat must be got rid of; either, as in a man, by training, or as in a horse that has grown bulky while out at grass, by putting him on such more nutritive diet as oats.

The frequency of senile fatness, both in domesticated creatures and in ourselves, has a similar implication. Whether we consider the smaller ability of those who display it to withstand large demands on their powers, or whether we consider the comparatively-inferior digestion common among them, we see that the increased size indicates, not an abundance of materials which the organism requires, but an abundance of materials which it does not require. Of like meaning is the fact that women who have had several children, and animals after they have gone on bearing young for some time, frequently become fat; and lose their fecundity as they do this. In such cases the fatness is not to be taken as the cause of the infecundity; but the constitutional exhaustion which the previous production of offspring has left, shows itself at once in the failing fecundity and the commencing fatness.

There is yet another kind of evi- 
dence. Obesity not uncommonly sets in after the system has been subject to debilitating influences. Often a serious illness is followed by a corpulence to which there was previously no tendency. And the prolonged administration of mercury, constitutionally injurious as it is, sometimes produces a like effect.

Closer inquiry verifies the conclusion to which these facts point. The microscope shows that along with the increase of bulk common in advanced life, there goes on what is called "fatty degeneration:" oil-globules are deposited where there should be particles of flesh-or rather, we may say, the hydrocarbonaceous molecules locally produced by decomposition of the nitrogenous molecules, have not been replaced by other nitrogenous molecules, as they should have been. This fatty degeneration is, indeed, a kind of local death. For so regarding it we have not simply the reason that an active substance has its place occupied by an inert substance; but we have the further reason that the flesh of dead bodies, under certain conditions, is transformed into a fatty matter called adipocere.

The infertility that accompanies fatness in domestic animals has, however, other causes than that declining constitutional vigour which the fatness commonly indicates. Being artificially fed, these animals cannot always obtain what their systems need. That which is given to them is given expressly because of its fattening quality. And since the capacity of the digestive apparatus remains the same, the absorption of fat-producing materials in excess, implies defect in the absorption of materials from which the tissues are formed, and out of which young ones are built up. Moreover, this special feeding with a view to rapid and early fattening, continued as it is through generations, and accompanied as it is by a selection of individuals and varieties which fatten most readily, tends to establish a modified constitution, more fitted for producing fat and correspondingly-less fitted for producing flesh-a 
constitution which, from this relatively-deficient absorption of nitrogenous matters, is likely to become infertile; as, indeed, these varieties often do become. Hence, no conclusions respecting the effects of high nutrition, properly so called, can be drawn from cases of this kind. The cases are, in truth, of a kind which could not exist but for human agency. Under natural conditions no animal would diet itself in the way required to produce such results. And if it did its race would quickly disappear.*

There is yet another mode in which accumulation of fat diminishes fertility. Even supposing it unaccompanied by a smaller absorption of nitrogenous materials, it is still a cause of lessening the surplus of nitrogenous materials. For the repair of the motor tissues becomes more costly. Fat stored-up is weight to be carried. A creature loaded with inert matter must, other things equal, consume a greater amount of tissue-forming substances for keeping its locomotive apparatus in order; and thus expending more for selfmaintenance can expend less for race-maintenance. Abnormal plethora is thus antagonistic to reproduction in a double way. It ordinarily implies a smaller absorption of tissue-forming matters, and an increased demand on the diminished supply. Hence fertility decreases in a geometrical progression.

The counter-conclusion drawn from facts of this class is, then, due to a misconception of their nature-a misconception

* It is worth while inquiring whether unfitness of the food given to them, is not the chief cause of that sterility which, as Mr. Darwin says, "is the great bar to the domestication of animals." He remarks that "when animals and plants are removed from their natural conditions, they are extremcly liable to have their reproductive systems seriously affected." Possibly the relative or absolute arrest of genesis, is less due to a direct effect on the reproductive system, than to a changed nutrition of which the reproductive system most clearly shows the results. The matters required for forming an embryo are in a greater proportion nitrogenous than are the matters required for maintaining an adult. Hence, an animal forced to live on insufficientlynitrogenized food. may have its surplus for reproduction cut off, but still have a sufficiency to keep its own tissues in repair, and appear to be in good health $\rightarrow$ meanwhile increasing in bulk from excess of the non-nitrogenous matters it eats. 
arising partly from the circumstance that the increase of bulk produced by fat is somewhat like the increase of bulk which growth of tissues causes, and partly from the circumstance that abundance of good food normally produces a certain quantity of fat, which, within narrow limits, is a valuable store of force-evolving material. When, however, we limit the phrase high nutrition to its proper meaning - an abundance of, and due proportion among, all the substances which the organism needs-we find that, other things equal, fertility always increases as nutrition increases. And we see that these apparently-exceptional cases, are cases which really show us the same thing; since they are cases of relative innutrition.

[Note.-By a strange oversight when writing this chapter in the first edition-an oversight I was on the eve of repeating in this present edition-I omitted to bring forward the familiar and all-important evidence furnished by the variations of genesis which ordinarily accompany the alternations of the seasons. These variations, in multitudinous creatures of all types, show unmistakably that reproduction begins at those times of the year when greater warmth and larger supplies of food render maintenance of individual life relatively easy, and when there is therefore a surplus available for producing new individuals. Conversely, along with the decrease of heat and the relative deficiency of food which make it comparatively difficult in winter to maintain individual life, there ceases to be the power of producing other lives: the reproductive organs become quiescent and often dwindle. With this general fact is associated a special fact. Though among wild animals-birds, mammals, and others-breeding ceases when Nature no longer supplies abundant food and warmth; in domesticated mammals and birds, artificially supplied with food and warmth, the breeding season is greatly extended and often made continuous, as, under the same conditions, it is in Man himself.

Evidence yielded by the vegetal world is less conspicuous, 
for the reason that the cold which arrests reproductive activity also arrests individual activity: growth of the individual and multiplication of the race vary simultaneously with variations in the seasons. Still there are some familiar facts showing that the external conditions which favour nutrition also bring about reproduction. Early in the year we are supplied with flowers from regions warmer than our own, and by and by there come to our markets fruits and vegetables from the south of France, the Channel Islands, and even from the Scilly Isles, which are much in advance of those furnished by the gardens of our own colder regions: reproduction commences earlier where the light and heat furthering nutrition are greater. And then there is a kindred meaning in the not unfrequent occurrence of a second flowering and even of a second fruiting in warm, bright and prolonged autumns. Here the abnormal recommencement of reproduction is determined by an abnormal increase of nutrition.] 


\section{CHAPTER X.}

SPECIALITIES OF THESE RELATIONS.

$\S 356$. TEsts of the general doctrines set forth in preceding chapters, are afforded by organisms having modes of life which diverge widely from ordinary modes. Here, as elsewhere, aberrant cases yield crucial proofs.

If certain organisms are so circumstanced that highlynutritive matter is supplied to them without stint, and they have nothing to do but absorb it, we may infer that their powers of propagation will be enormous.

If there are classes of creatures which expend very little for self-support in comparison with allied creatures, a relatively-extreme prolificness may be expected of them.

Or if, again, we find species presenting the peculiarity that while some of their individuals have much to do and little to eat, others of their individuals have much to eat and little to do, we may look for great fertility in these last and comparative infertility or barrenness in the first.

These several anticipations we shall find completely verified.

§357. Plants which, like the Rafflesiacea, carry their parasitism to the extent of living on the juices they absorb from other plants, exhibit one of these relations in the vegetal kingdom. In them the organs for self-support being needless, are rudimentary; and the parts directly or indirectly concerned in the production and distribution of germs, constitute the mass of the organism. That small ratio which 
the race-preserving structures bear to the self-preserving structures in ordinary Phænogams, is, in these Phænogams, inverted. A like relation occurs in the common Dodder.

There may be added a kindred piece of evidence which the Fungi present. Those of them which grow on living plants, repeat the above connection completely; and those of them which, though not parasitic, nevertheless subsist on organized materials previously elaborated by other plants, substantially repeat it. The spore-producing part is relatively enormous; and the fertility is far greater than that of Cryptogams of like sizes, which have to form for themselves the organic compounds of which they and their germs consist.

$\S 358$. The same lesson is taught us by animal-parasites. Along with the decreased cost of Individuation, they similarly show us an increased expenditure for Genesis; and they show us this in the most striking manner where the deviation from ordinary conditions of life is the greatest.

Take, among the Epizoa, such an instance as Chondracanthus gibbosus. Belonging to the Entomostraca, both males and females of this species are, in their early days, similar to their allies; and the males, practically parasitic, though they become greatly degraded, continue throughout life to show by their segmentation and other external traits their original nature. The female, however, having fixed herself where she can suck the juices of her host, the Lophius, grows to twelve times the length of the male and probably a thousand times its bulk, and becomes utterly transformed by loss of the organs of animal life and enormous development of the organs of reproduction. "No heart is discoverable, and the nervous system and organs of sense (if any) are equally undistinguishable. The interspace between the alimentary canal and the walls of the body is almost wholly occupied by the ovarium." * And then beyond this there are appended ovi-sacs twice the length of the body. So that the

* Huxley, Anatomy of Invcrtebrated Animals, p. 274. 
germ-producing organs and their contents, eventually acquire a total bulk many times that of all the other organs put together. Numerous species of this type and habit, repeat this relation between a life of inaction with high feeding, and an enormous rate of genesis. Parasites belonging to another great division of the animal kingdom, the Platyhelminthes, supply an example of an epizoon in which the rate of multiplication is made great not so much by immense development of the egg-producing organs as by the rapidity with which generations succeed one another-a rapidity such that each generation partially develops the next before it is itself anything like ready for independent life. This is the Gyrodactylus elegans, of which it is said that "its most remarkable feature is that it is viviparous, and its embryos before they leave the body of their mother have already developed their embryos inside them; and the latter may contain their embryos, so that four generations may be included under the cuticle of the sexually mature animal." *

Entozoa yield us many examples of this causal relation, raised to a still higher degree. The Gordius, or Hair-worm, is a creature which, finding its way when young into the body of an insect which is afterwards swallowed by a fish, there grows rapidly, and then emerging to breed, lays as many as $8,000,000$ eggs in less than a day. Similarly with those larger types infesting the higher animals. It has been calculated by Dr. Eschricht, as quoted by Professor Owen, that there are " $64,000,000$ of ova in the mature female Ascaris lumbricoides." Very many of the Entozoa belong to the Platyhelminthes, and among them occur examples of fertility caused not only by great numbers of ova, but by rapid succession of partially-developed individuals and also examples of fertility caused by production of ova almost exceeding numeration. Among the first the Liver-fluke may be named. of the half-million eggs it produces each yields a free-swim-

* Shipley, Zoology of Invertebrata, p. 112. 
ming ciliated embryo, and any one of these, which finds its way into a water-snail, becomes a sporocyst-a bag, presently occupied exclusively by masses of cells: each mass by and by becoming a Redia, which makes its way out. Like all its fellows which develop in succession, this, with the exception of a small space occupied by the stomach, devotes the whole of its interior partly to the formation of other Redice (which presently escape and become similarly transformed), and partly to the development of Cercaria, into which the internal substance of all the Redice is eventually transformed: Cercarioe which, escaping from the host, become agents for infecting other creatures. So that each ovum thus gives rise to a number of forms which severally subserve multiplication in different ways. Of the other division of Platyhelminthes referred to as carrying on its multiplication by production of ova only, the commonest of the Cestoidea furnishes the best example. Immersed as a Tape-worm is in nutritive liquid, which it absorbs through its integument, it requires no digestive apparatus. The room which one would occupy, and the materials it would use up, are therefore available for germ-producing organs, which nearly fill each segment: each segment, sexually complete in itself, is little else than an enormous reproductive system, with just enough of other structures to bind it together. Remembering that the Tape-worm, retaining its hold, continues to bud-out such segments as fast as the fully-developed ones are cast off, and goes on doing this as long as the infested individual lives; we see that here, where there is no expenditure, where the cost of individuation is reduced to the greatest extent while the nutrition is the highest possible, the degree of fertility reaches its extreme.

These Entozoa yield us further interesting evidence. Of their various species, most if not all undergo passive migration from animal to animal before they become mature. Usually, the form assumed in the body of the first host is devoid of all that part in which the reproductive structures take their rise; and this part grows and 
develops reproductive structures, only in some predatory animal to which its first host falls a sacrifice. Occasionally, however, the egg gives origin to the sexual form in the animal that originally swallowed it, but the development remains incomplete-there is no sexual genesis, no formation of eggs in the rudimentary segments. That these may become fertile it is needful, as before, for the containing animal to be devoured; so that the imperfect Tape-worm may find its way into the intestine of a higher animal. Thus the Bothriocephalus solidus, found in the abdominal cavity of the Stickleback, is barren while it remains there; but if the Stickleback be eaten by a Water-fowl, the reproductive system of the transferred Bothriocephalus (then known as B. nodosus) becomes developed and active. So, too, a kind of Tape-worm which remains infertile while in the intestine of a Mouse, becomes fertile in the intestine of a Cat that devours the mouse. May we not regard these facts as again showing the dependence of fertility on nutrition? Barrenness here accompanies conditions unfavourable to the absorption of nutriment; and it gives way to fecundity where nutriment is large in quantity and superior in quality.

$\S 359$. Extremely significant are those cases of partial reversion to primitive forms of genesis, which occur under special conditions in some of the higher Annulosa. I refer to the pseudo-parthenogenesis and metagenesis in Insects.

Under what conditions do the Aphides exhibit this strange deviation from the habits of their order? Why among them should imperfect females produce, agamically, others like themselves, generation after generation, with great rapidity? There is the obvious explanation that they get plenty of easily-assimilated food without exertion. Piercing the tender coats of young shoots, they sit and suck-appropriating the nitrogenous elements of the sap and ejecting its saccharine matter as "honey dew." Along with a sluggishness strongly contrasted with the activity of most insects-along 
with a very low rate of consumption and a correlative degradation of structure; we have here a retrogression to asexual genesis, and a greatly-increased rate of multiplication.

The recently discovered instance of internal metagenesis in the maggots of certain Flies has a like meaning. Incredible as it at first seemed to naturalists, it is now proved that the Cecydomia-larva develops in its interior a brood of larvæ of like structure with itself. In this case, as in the last, abundant food is combined with low expenditure. These larvæ are found in such habitats as the refuse of beet-rootsugar factories-masses of nitrogenous débris remaining after the extraction of the saccharine matter. Each larva has a practically-unlimited supply of sustenance imbedding it on all sides.*

It is true that some other maggots, as those of the Fleshfly, are similarly, or still better, circumstanced; and, it may be said, ought therefore to have the same habit. But this does not necessarily follow. Survival of the fittest will determine whether such specially-favourable conditions result in aggrandizement of the individual or in multiplication of the race. And in the case of the Flesh-fly there is a reason why greater individuation rather than more rapid genesis will occur. For a decomposing animal body lasts so short a time, that were Flesh-fly larræ to multiply agamically, the second generation would die from the disappearance of their food. Hence individuals in which the excessive nutrition led to internal metagenesis, would leave no posterity, and natural selection would establish the variety in

* I am told that "Wagner, who described the larva, found that it bored into the bark of trees. It attacks also the wheat plant, and is a most destructive parasite." Apparently this statement is at variance with the foregoing inference. It is clear, however, that since these heaps of nitrogenous refuse in which it has been found are artificial and recent, they cannot be its natural habitats; and it seems not improbable that these larvæ, suddenly supplied with a more nutritive food in unlimited amount, may have as a consequence acquired this hahit of agamogenctic multiplication which did not characterize the species under its natural conditions and relatively low nutrition. 
which greater growth resulted. All which the argument requires is that when such reversion to agamogenesis does take place, it shall be where the food is unusually abundant and the expenditure unusually small; and this the cases instanced go to show.

$\S 360$. The physiological lesson taught us by Bees and Ants, not quite harmonizing with the moral lesson they are supposed to teach, is that highly-fed idleness is favourable to fertility, and that excessive industry has barrenness for its concomitant.

The egg of a Bee develops into a small barren female or into a large fertile female, according to the supply of food given to the larva hatched from it. We here see that the germ-producing action is an overflow of the surplus remaining after completion of the individual; and that the lower feeding which the larva of a working Bee has, results in a dwarfing of the adult and an arrested development of the generative organs. Further, we have the fact that the condition under which the perfect female, or mother-Bee, goes on, unlike insects in general, laying eggs continuously, is that she has plenty of food brought to her, is kept warm, and goes through no considerable exertion. While, contrariwise, it is to be noted that the infertility of the workers is associated with the ceaseless labour of bringing materials for the combs and building them, as well as the labour of feeding the queen, the larvæ, and themselves.

Ants also show us these relations, and they are shown in a greatly exaggerated form by what are called white antsinsects belonging to a quite different order. The contrast in bulk between the fecund and infecund females is here immensely greater. The mother-Ant has the reproductive system so enormously developed, that the remainder of her body is relatively insignificant. Entirely incapable of locomotion, she is unable to deposit her eggs in the places where they are to be hatched; so that they have to be carried away 
by the workers as fast as they are extruded. Her life is thus reduced substantially to that of a parasite-an absorption of abundant food supplied gratis, a total absence of expenditure, and a consequent excessive rate of genesis. "The queen-ant of the African Termites lays 80,000 eggs in twentyfour hours."

$\S 361$. It may be needful to say that these exceptional relations cannot be ascribed to the assigned causes acting alone. The extreme fertility which, among parasites and social insects, accompanies extremely high feeding and an expenditure reduced nearly to zero, presupposes typical structures and tendencies of suitable kinds; and these are not directly accounted for. On creatures otherwise organized, unlimited supplies of food and total inactivity are not followed by such results. There of course requires a constitution fitted to the special conditions, and the evolution of this cannot be due simply to plethora joined with rest. These cases are given as illustrating the conditions under which extreme exaltations of fertility become possible. Their meanings, thus limited, are clear, and completely to the point. We see in them that the devotion of nutriment to race-preservation, is carried furthest where the cost of self-preservation is reduced to a minimum; and, conversely, that nothing is devoted directly to race-preservation by individuals on which falls an excessive expenditure for self-preservation and preservation of other's offspring.

[NoTE.-Among specialities of these relations may be fitly added here a very strange one, for a description of which I am indebted to M. Charles Julin, Professor of Comparative Anatomy in the University of Liège. In the Revue Générale des Sciences for 30th August, 1894, in an account of certain investigations of M. Giard, he describes what he calls "la castration parasitaire"- a castration not of a literal kind 
but one effected by the arrest of development which follows from the depletion caused by a parasite. The Sacculina is an amazingly transformed type belonging to the Cirrhipedia -a type without segments or appendages and without mouth and alimentary canal. Fixing itself, during its early locomotive stage, under the abdomen of a decapodous crustacean, and leaving behind its exo-skeleton, it makes its way into the interior, and there becoming a mere bag containing the reproductive organs, obtains the needful nutriment by developing what are practically roots and rootlets which run everywhere among the viscera and absorb nutriment from the surrounding tissues. Here we are concerned merely with the effect produced upon the host by this physiological robbery. This effect is to arrest the development not only of the primary sexual organs devoted to the production of germs, but also of those secondary sexual organs which characterize the male. M. Julin writes :-

"Il convient cependant de dire, pour être plus exact, que, dans les cas des Crabes infestés par des Sacculines, il n'y a pas, en réalité, apparition de caractères femelles chez le sexe mâle, mais plutôt absence de développement des caractères mâles. En fait, l'animal reste à un stade jeune, non différencié sexuellement, tout en prenant une taille plus considérable. Cela nous porte à attribuer les modifications dont nous avons parlé à un simple arrêt de développement, qui est plus sensible chez le mâle, parce que chez lui les caractères sexuels secondaires sont à l'état normal plus développés que chez la femelle.

D'une manière générale, nous croyons, avec M. Giard, qu'il faut assimiler les modifications dues à la castration parasitaire à celles qui sont le résultat de la progenèse ou qui engendrent le dimorphisme saisonnier.

Il y a progenèse lorsque, chez un animal, la reproduction sexuée s'opère d'une façon plus ou moins précoce, c'est-à-dire lorsque les produits sexuels (œufs ou spermatozoīdes) se forment et mûrissent avant que l'être n'ait atteint son complet développement. On peut citer comme exemples les Axolotls et les larves de Tritons qui, les uns normalement, les autres accidentellement, pondent en ayant encore leurs branchies.

Très souvent la progenèse n'affecte qu'un seul sexe. Tantôt, c'est 
le sexe femelle qui mûrit à l'état larvaire comme chez les pucerons, les Stylops, etc...Tantôt c'est le sexe mâle, comme chez la Bonellie, les mâles complémentaires de Cirripèdes, les mâles pygmées des Rotifères, le mâle de l'Anguille, etc. D'autres fois, enfin, l'animal présente successivement les deux sexes avec progenèse pour l'un d'entre eux. C'est ainsi qu'il y a progenèse protandrique chez les Crustacés cymothoadiens, et, parmi les Vertébrés, chez les Myxines, qui, mâles dans le jeune âge, deviennent femelles en vieillissant et en achevant de prendre leur développement. Le cas des vieilles femelles de Gallinacés à plumage et à instincts masculins semble être, au contraire, un exemple imparfait de progenèse protogynique, puisque ces femelles ont pondu lorsqu'elles avaient encore la livrée des jeunes et qu'elles ont continué plus tard leur développement, et présentent le caractère des mâles sans que, cependant, l'on ait constaté la production de spermatozoīdes.

Dans les cas extrêmes de progenèse femelle, la reproduction se fait même sans le concours de l'élément mâle, revenant ainsi à la forme agamique primordiale. Ces cas sont connus depuis longtemps sous le nom de pédogenèse. On les a observé chez les larves de Miastor, de Chironomus et chez certains pucerons.

Chaque fois qu'il y a progenèse dans un type déterminé, on constate soit momentanément, soit d'une façon définitive, un arrêt de croissance et de développement: l'animal progénétique a, par suite, l'aspect d'une larve sexuée, lorsqu'on le compare soit à l'autre sexe, soit aux formes voisines, qui ne présentent pas le phénomène de la progenèse.

Cela est en parfaite harmonie avec le principe, si bien mis en lumière par Herbert Spencer, de Cantagonisme entre la genèse et la croissance et entre la genèse et le développement. Cet antagonisme s'explique facilement si l'on songe que les matériaux employés pour la reproduction ne peuvent servir à l'accroissement de l'individu. S'il est avantageux pour un organisme de se reproduire sans acquérir des organes inutiles, la sélection naturelle déterminera bientôt une progenèse de plus en plus complète. Les animaux parasites, outre qu'ils tirent de leur hôte une nourriture abondante, n'ont guère besoin d'une foule d'organes qui servent à leurs congénères libres dans la vie de relation. Aussi voyons-nous qu'un très grand nombre d'animaux parasites sont progénétiques. Les mâles progénétiques de la Bonellie et des Cirripèdes vivent en parasites dans leurs femelles. Chez certains types, les pucerons, la progenèse cesse dès que, la nourriture devenant moins abondante, un déplacement pourra être nécessaire. 
En rẻsumé, l'arrêt de développement dâ à la progenèse résulte d'une dérivation des principes nourriciers au détriment de l'animal progénétique. Dans les exemples de castration parasitaire que nous avons examinés, le parasite joue, par rapport à son hôte, absolument le même rôle que la glande génitale d'un type progénétique. Il détourne, pour sa propre subsistance, une partie des principes qui auraient servi au développement de l'animal. Aussi les effets produits sont-ils tout à fait de même ordre."

A phenomenon so anomalous as this, explicable upon the hypothesis set forth but not otherwise explicable, furnishes striking verification.] 


\section{CHAPTER XI.}

\section{INTERPRETATION AND QUALIFICATION.}

§362. Considfring the difficulties of inductive verification, we have, I think, as clear a correspondence between the $a$ priori and $a$ posteriori conclusions, as can be expected. The many factors co-operating to bring about the result in every case, are so variable in their absolute and relative amounts, that we can rarely disentangle the effect of each one, and have usually to be content with qualified inferences. Though in the mass organisms show us an unmistakable relation between great size and small fertility, yet special comparisons among them are nearly always partially vitiated by differences of structure, differences of nutrition, differences of expenditure. Though it is beyond question that the more complex organisms are the less prolific, yet as complexity has a certain general connexion with bulk, and in animals with expenditure, we cannot often identify its results as independent of these. And, similarly, though the creatures which waste much matter in producing motion, sensible and insensible, have lower rates of multiplication than those which waste less, yet, as the creatures which waste much are generally larger and more complex, we are again met by an obstacle which limits our comparisons, and compels us to accept conclusions less definite than are desirable.

Such difficulties arise, however, only when we endeavour, as in foregoing chapters, to prove the inverse variation 
between Genesis and each separate element of Individuation - growth, development, activity. We are scarcely at all hampered by qualifications when, from contemplating these special relations, we return to the general relation. The antagonism between Individuation and Genesis is shown by all the facts which have been grouped under each head. We have seen that in ascending from the lowest to the highest types, there is a decrease of fertility so great as to be absolutely inconceivable, and even inexpressible by figures; and whether the superiority of type consists in relative largeness, in greater complexity, in higher activity, or in some or all of these combined, matters not to the ultimate inference. The broad fact, enough for us here, is that organisms in which the integration and differentiation of matter and motion have been carried furthest, are those in which the rate of multiplication has fallen lowest. How much of the decline of reproductive power is due to the greater integration of matter, how much to its greater differentiation, how much to the larger amounts of integrated and differentiated motions generated, it may be impossible to say; and it is not needful to say. These are all elements of a higher degree of life, an augmented ability to maintain the organic equilibrium amid environing actions, an increased power of self-preservation; and we find their invariable accompaniment to be, a diminished expenditure of matter, or motion, or both, in racepreservation.

In brief, then, examination of the evidence shows that there does exist that relation which we inferred must exist. Arguing from general data, we saw that for the maintenance of a species, the ability to produce offspring must be great, in proportion as the ability of the individuals to contend with destroying forces is small; and conversely. Arguing from other general data, we saw that, derived as the self-sustaining and race-sustaining forces are from a common stock of force, it necessarily happens that, other things equal, increase of one involves decrease of the other. And then, turning 
to special facts, we have found that this inverse variation is clearly traceable throughout both the animal and vegetal kingdoms. We may therefore set it down as a law, that every higher degree of organic evolution, has for its concomitant a lower degree of that peculiar organic dissolution which is seen in the production of new organisms.

$\S 363$. Something remains to be said in reply to the inquiry-how is the ratio between Individuation and Genesis established in each case? This inquiry has been but partially answered in the course of the foregoing argument.

Many specialities of the reproductive process are manifestly due to the natural selection of favourable variations. Whether a creature lays a few large eggs or many small ones equal in weight to the few large, is not determined by any physiological necessity: here the only assignable cause is the survival of varieties in which the matter devoted to reproduction happens to be divided into portions of such size and number as most to favour multiplication. Whether in any case there are frequent small broods or larger broods at longer intervals, depends wholly on the constitutional peculiarity that has arisen from the dying out of families in which the sizes and intervals of the broods were least suited to the conditions of life. Whether a species of animal produces many offspring of which it takes no care or a few of which it takes much care-that is, whether its reproductive surplus is laid out wholly in germs or partly in germs and partly in labour on their behalf-must have been decided by that moulding of constitution to conditions slowly effected through the more frequent preservation of descendants from those whose reproductive habits were best adapted to the circumstances of the species. Given a certain surplus available for race-preservation, and it is clear that by indirect equilibration only, can there be established the more or less peculiar distribution of this surplus which we see in each case.

Obviously, too, survival of the fittest 
has a share in determining the proportion between the amount of matter that goes to Individuation and the amount that goes to Genesis. Whether the interests of the species are most subserved by a higher evolution of the individual joined with a diminished fertility, or by a lower evolution of the individual joined with an increased fertility, are questions ever being experimentally answered. If the moredeveloped and less-prolific variety has a greater number of survivors, it becomes established and predominant. If, contrariwise, the conditions of life being simple, the larger or more-organized individuals gain nothing by their greater size or better organization; then the greater fertility of the less evolved ones, will insure to their descendants an increasing predominance.

But direct equilibration all along maintains the limits within which indirect equilibration thus works. The necessary antagonism we have traced, rigidly restricts the changes that natural selection can produce, under given conditions, in either direction. A greater demand for Individuation, be it a demand caused by some spontaneous variation or by an adaptive increase of structure and function, inevitably diminishes the supply for Genesis; and natural selection cannot, other things remaining the same, restore the rate of Genesis while the higher Individuation is maintained. Conversely, survival of the fittest, acting on a species that has, by spontaneous variation or otherwise, become more prolific, cannot again raise its lowered Individuation, so long as everything else continues constant.

$\S 364$. Here, however, a qualification must be made. It was parenthetically remarked in $\S 32 \%$, that the inverse variation between Individuation and Genesis is not exact; and it was hinted that a slight modification of statement would be requisite at a more advanced stage of the argument. We have now reached the proper place for specifying this modification. 
Each increment of evolution entails a decrement of reproduction which is not accurately proportionate, but somewhat less than proportionate. The gain in the one direction is not wholly cancelled by a loss in the other direction, but only partially cancelled: leaving a margin of profit to the species. Though augmented power of self-maintenance habitually necessitates diminished power of race-propagation, yet the product of the two factors is greater than before; so that the forces preservative of race become, thereafter, in excess of the forces destructive of race, and the race spreads. We shall soon see why this happens.

Every advance in evolution implies an economy. That any increase in bulk, or structure, or activity, may become established, the life of the organism must be to some extent facilitated by the change- the cost of self-support must be, on the average, reduced. If the greater complexity, or the larger size, or the more agile movement, entails on the individual an outlay that is not repaid in food more-easily obtained, or danger more-easily escaped; then the individual will be at a relative disadvantage, and its diminished posterity will disappear. If the extra outlay is but just made good by the extra advantage, the modified individual will not survive longer, or leave more descendants, than the unmodified individuals. Consequently, it is only when the expense of greater individuation is out-balanced by a subsequent saving, that it can tend to subserve the preservation of the individual, and, by implication, the preservation of the race. The vital capital invested in the alteration must bring a more than equivalent return.

A few instances will show that, whether the change results from direct equilibration or from indirect equilibration, this must happen. Suppose a creature takes to performing some act in an unusual way-leaps where ordinarily its kindred crawl, eludes pursuit by diving instead of, like others of its kind, by swimming along the surface, escapes by doubling instead of by speed. Clearly, perseverance in the modified habit will, other 
things equal, imply that it takes less effort. The creature's sensations will ever prompt desistance from the more laborious course; and hence a congenital habit is not likely to be diverged from unless an economy of force is achieved by the divergence. Assuming, then, that the new method has no advantage over the old in directly diminishing the chances of death, the establishment of it, and of the structural complications involved, nevertheless implies a physiological gain. Suppose, again, that an animal takes to some abundant food previously refused by its kind. It is likely to persist only if the comparative ease in obtaining this food, more than compensates for any want of adaptation to its digestive organs; so that superposed modifications of the digestive organs are likely to arise only when an average economy results. What now must be the influence on the creature's system as a whole? Diminished expenditure in any direction, or increased nutrition however effected, will leave a greater surplus of matcrials. The animal will be physiological richer. Part of its augmented wealth will go towards its own greater individuation-its size, or its strength, or both, will increase; while another part will go towards more active genesis. Just as a state of plethora directly produced enhances fertility; so will such a state indirectly produced.

In another way, the same thing must result from those additions to bulk or complexity or activity that are due to survival of the fittest. Any change which prolongs individual life will, other things remaining the same, further the production of offspring. Even when it is not, like the foregoing, a means of economizing the forces of the individual, still, if it increases the chances of escaping destruction, it increases the chances of leaving posterity. Any further degree of evolution, therefore, will be established only where the cost of it is more than repaid: part of the gain being shown in the lengthened life of the individual, and part in the greater production of other individuals. 
We have here the solution of various minor anomalies by which the inverse variation of Individuation and Genesis is obseured. Take as an instance the fertility of the Blackbird as compared with that of the Linnet. Both birds lay five eggs, and both usually have two broods. Yet the Blackbird is far the larger of the two, and ought, according to the general law, to be much less prolific. What causes this nonconformity? We shall find an answer in their respective foods and habits. Except during the time that it is rearing its young, the Linnet collects only vegetal food-lives during the winter on the seeds it finds in the fields, or, when hard pressed, picks up around farms; and to obtain this spare diet is continually flying about. The result, if it survives the frost and snow, is a considerable depletion; and it recovers its condition only after some length of spring weather. The Blackbird, on the other hand, is omnivorous. While it eats grain and fruit when they come in its way, it depends largely on animal food. It cuts to pieces and devours the dew-worms which, morning and evening, it finds on the surface of a lawn, and, even discovering where they are, unearths them; it swallows slugs, and breaking snail-shells, either with its beak or by hammering them against stones, tears out their tenants; and it eats beetles and larvæ. Thus the strength of the Blackbird opens to it a store of good food, much of which is inaccessible to so small and weak a bird as a Linnet-a store especially helpful to it during the cold months, when the hybernating snails in hedge-bottoms yield it abundant provision. The result is that the Blackbird is ready to breed very early in spring, and is able during the summer to rear a second, and sometimes even a third, brood. Here, then, a higher degree of Individuation secures advantages so great, as to much more than compensate its cost. It is not that the decline of Genesis is less than proportionate to the increase of Individuation, but there is no decline at all.

Comparison of the Rat with the Mouse yields a parallel result. Though they differ greatly in size, yet the one is as prolific 
as the other. This absence of difference cannot be ascribed to their unlike degrees of activity. We must seek its cause in some facility of living secured to the Rat by its greater intelligence, greater power and courage, greater ability to utilize what it finds. The Rat is notoriously cunning; and its cunning gives success to its foraging expeditions. It is not, like the Mouse, limited mainly to regetal food; but while it eats grain and beans like the Mouse, it also eats flesh and carrion, devours young poultry and eggs. The result is that, without a proportionate increase of expenditure, it gets a far larger supply of nourishment than the Mouse; and relative excess of nourishment makes possible a larger size without a smaller rate of multiplication. How clearly this is the cause, we see in the contrast between the common Rat and the Water-Rat. While the common Rat has ordinarily several broods a-year of from 10 to 12 each, the Water-Rat, though somewhat smaller, has but 5 or 6 in a brood, and but one brood, or sometimes two broods, a-year. But the WaterRat lives on vegetal food, and it lacks all that its bold, sagacious, omnivorous congener gains from the warmth as well as the abundance which men's habitations yield.

The inverse variation of Individuation and Genesis is, therefore, but approximate. Recognizing the truth that every increment of evolution which is appropriate to the circumstances of an organism, brings an advantage somewhat in excess of its cost; we see the general law, as more strictly stated, to be that Genesis decreases not quite so fast as Individuation increases. Whether the greater Individuation takes the form of a larger bulk and accompanying access of strength; whether it be shown in higher speed or agility; whether it consists in a modification of structure which facilitates some habitual movement, or in a visceral change that helps to utilize better the absorbed aliment; the ultimate effect is identical. There is either a more economical performance of the same actions, internal or external, or there is a securing of greater advantages by modified actions, which 
cost no more, or have an increased cost less than the increased gain. In any case the result is a greater surplus of vital capital, part of which goes to the aggrandizement of the individual, and part to the formation of new individuals. While the higher tide of nutritive matters, everywhere filling the parent-organism, adds to its power of self-maintenance, it also causes a reproductive overflow larger than before.

Hence every type which is best adapted to its conditions, (and this on the average means every higher type), has a rate of multiplication that insures a tendency to predominate. Survival of the fittest, acting alone, is ever replacing inferior species by superior species. But beyond the longer survival, and therefore greater chance of leaving offspring, which superiority gives, we see here another way in which the spread of the superior is insured. Though the moreevolved organism is the less fertile absolutely, it is the more fertile relatively. 


\section{CHAPTER XII.}

\section{MULTIPLICATION OF THE HUMAN RACE.}

$\S 365$. The relative fertility of Man considered as a species, and those changes in Man's fertility which occur under changed conditions, must conform to the laws which we have traced thus far. As a matter of course, the inverse variation between Individuation and Genesis holds of him as of all other organized beings. His extremely low rate of multiplication-far below that of all terrestrial Mammals except the Elephant, (which though otherwise less evolved is, in extent of integration, more evolved)-we shall recognize as the necessary concomitant of his much higher evolution. And the causes of increase or decrease in his fertility, special or general, temporary or permanent, we shall expect to find in those changes of bulk, of structure, or of expenditure, which we have in all other cases seen associated with such effects.

In the absence of detailed proof that these parallelisms exist, it might suffice to contemplate the several communities between the reproductive function in human beings and other beings. I do not refer simply to the fact that genesis proceeds in a similar manner; but I refer to the similarity of the relation between the generative function and the functions which have for their joint end the preservation of the individual. In Man, as in other creatures that expend much, genesis commences only when growth and development are declining in rapidity and approaching their termination. Among the higher organisms in general, the reproductive 
activity, continuing during the prime of life, ceases when the vigour declines, leaving a closing period of infertility; and in like manner aniong ourselves, barrenness supervenes when middle age brings the surplus vitality to an end. So, too, it is found that in Man, as in beings of lower orders, there is a period at which fecundity culminates. In $\S 341$, facts were cited showing that at the commencement of the reproductive period, animals bear fewer offspring than afterwards; and that towards the close of the reproductive period, there is a decrease in the number produced. In like manner it is shown by the tables of Dr. Duncan's recent work, that the fecundity of women increases up to the age of about 25 years, and continuing high with but slight diminution till after 30 , then gradually wanes. It is the same with the sizes and weights of offspring. Infants born of women from 25 to 29 years of age, are both longer and heavier than infants born of younger or older women; and this difference has the same implication as the greater total weight of the offspring produced at a birth, during the most fecund age of a pluriparous animal. Once more, there is the fact that a too-early bearing of young produces on a woman the same injurious effects as on an inferior creature-an arrest of growth and an enfeeblement of constitution.

Considering these general and special parallelisms, we might safely infer that variations of human fertility conform to the same laws as do variations of fertility in general. But it is not needful to content ourselves with an implication. Evidence is assignable that what causes increase or decrease of genesis in other creatures, causes increase or decrease of genesis in Man. It is true that, even more than hitherto, our reasonings are beset by difficulties. So numerous are the inequalities in the conditions, that but few unobjectionable comparisons can be made. The human races differ considerably in their sizes, and notably in their degrees of cerebral development. The countries they inhabit entail on them widely different consumptions of matter for maintenance of 
temperature. Both in their qualities and quantities the foods they live on are unlike; and the supply is here regular and there very irregular. Their expenditures in bodily action are extremely unequal; and even still more unequal are their expenditures in mental action. Hence the factors, varying so much in their amounts and combinations, can scarcely ever have their respective effects identified. Nevertheless there are a few comparisons the results of which may withstand criticism.

$\S 366$. The increase of fertility caused by a nutrition that is greatly in excess of the expenditure, is to be detected by contrasting populations of the same race, or allied races, one of which obtains good and abundant sustenance much more easily than the other. Three cases may here be set down.

The traveller Barrow, describing the Cape-Boers, says:" Unwilling to work and unable to think," . . . “indulging to excess in the gratification of every sensual appetite, the African peasant grows to an unwieldy size;" and respecting the other sex, he adds - " the women of the African peasantry lead a life of the most listless inactivity." Then, after illustrating these statements, he goes on to note "the prolific tendency of all the African peasantry. Six or seven children in a family are considered as very few; from a dozen to twenty are not uncommon."

The native races of this region yield evidence to the same effect. Speaking of the cruelly-used Hottentots (he is writing a century ago), who, while they are poor and ill-fed, have to do all the work for the idle Boers, Barrow says that they "seldom have more than two or three children; and many of the women are barren." This unusual infertility stands in remarkable contrast with the unusual fertility of the Kaffirs, of whom he afterwards gives an account. Rich in cattle, leading easy lives, and living almost exclusively on animal food (chiefly milk with occasional flesh), these people were then reputed 
to have a very high rate of multiplication. Barrow writes:"They are said to be exceedingly prolific; that twins are almost as frequent as single births, and that it is no uncommon thing for a woman to have three at a time." Probably both these statements are in excess of the truth; but there is room for large discounts without destroying the extreme difference.

A third instance is that of the French Canadians. "Nous sommes terribles pour les enfants!" observed one of them to Prof. Johnston, who tells us that the man who said this "was one of fourteen childrenwas himself the father of fourteen, and assured me that from eight to sixteen was the usual number of the farmers' families. He even named one or two women who had brought their husbands five-and-twenty, and threatened 'le vingt-sixième pour le prêtre." "From these large families, joined with the early marriages and low rate of mortality, it results that, by natural increase, "there are added to the French-Canadian population of Lower Canada four persons for every one that is added to the population of England." Now these French-Canadians are described by Prof. Johnston as home-loving, contented, unenterprising; and as living in a region where "land and subsistence are easily obtained." Very moderate industry brings to them liberal supplies of necessaries; and they pass a considerable portion of the year in idleness. Hence the cost of Individuation being much reduced, the rate of Genesis is much increased. That this uncommon fertility is not due to any direct influence of the locality, is implied by the fact that along with the " restless, discontented, striving, burning energy of their Saxon neighbours," no such rate of multiplication is observed; while further south, where the physical circumstances are more favourable if anything, the Anglo-Saxons, leading lives of excessive activity, have a fertility below the average. And that the peculiarity is not a direct effect of race, is proved by the fact that in Europe, the rural French are certainly not more prolific than the rural English. 
To every reader there will probably occur the seeminglyadverse evidence furnished by the Irish; who, though not well fed, multiply fast. Part of this more rapid increase is due to the earlier marriages common among them, and consequent quicker succession of generations-a factor which, as we have seen, has a larger effect than any other on the rate of multiplication. Part of it is due to the greater generality of marriage-to the comparative smallness of the number who die without having had the opportunity of producing offspring. The effects of these causes having been deducted, we may doubt whether the Irish, individually considered, would be found more prolific than the English. Perhaps, however, it will be said that, considering their diet, they ought to be less prolific. This is by no means obvious. It is not simply a question of nutriment absorbed. It is a question of how much remains after the expenditure in selfmaintenance. Now a notorious peculiarity in the life of the Irish peasant is, that he obtains a return of food which is large in proportion to his outlay in labour. The cultivation of his potatoe-ground occupies each cottager but a small part of the year; and the domestic economy of his wife is not of a kind to entail on her much daily exertion. Consequently the crop, tolerably abundant in quantity though innutritive in quality, possibly suffices to meet the comparatively-low expenditure, and to leave a good surplus for genesis-perhaps a greater surplus than remains to the males and females of the English peasantry, who, though fed on better food, are harder worked.

We conclude, then, that in the human race, as in all other races, such absolute or relative abundance of nutriment as leaves a large excess after defraying the cost of carrying on parental life, is accompanied by a high rate of genesis.*

$\S 36 \%$. Evidence of the converse truth, that relative in-

" This is exnctly the reverse of Mr. Doubleday's doctrine; which is that throughout both the animal and vegetable kingdoms, "over-feeding ehecks increase; whilst, on the other hand, a limited or deficient nutriment stimu- 
crease of expenditure, leaving a diminished surplus, reduces the degree of fertility, is not wanting. Some of it has been set down for the sake of antithesis in the foregoing section. Here may be grouped a few facts of a more special kind having the same implication.

To prove that much bodily labour renders women less prolific, requires more evidence than has at present been collected. Nevertheless it may be noted that De Boismont in France and Dr. Szukits in Austria, have shown by extensive statistical comparisons, that the reproductive age is reached a year later by women of the labouring class than by middle-class women; and while ascribing this delay in part to inferior lates and adds to it." $O r$, as he elsewhere says - "Be the range of the natural power to increase in any species what it may, the plethoric state inva. riably checks it, and the deplethoric state invariably develops it ; and this happens in the exact ratio of the intensity and completencss of each state, until each state be carried so far as to bring about the actual death of the animal or plant itself."

I have space here only to indicate the misinterpretations on which Mr. Doubleday bas based his argument.

In the first place, he has confounded normal plethora with what I have, in $\S 355$, distinguished as abnormal plethora. The cases of infertility accompanying fatness, which he cites in proof that over-feeding checks increase, are not cases of high nutrition properly so called; but eases of such defective absorption or assimilation as constitutes low nutrition. In Chap. IX, abundant proof was given that a truly plethoric state is an unusually fertile state. It may be added that much of the evidence by which Mr. Doubleday seeks to show that among men, highly-fed elasses are infertile classes, may be outbalanced by counter-evidence. Many years ago Mr. G. H. Lewes pointed this out : extracting from a book on the peerage, the names of 16 peers who had, at that time, 186 children ; giving an average of $11 \cdot 6$ in a family.

Mr. Doubleday insists much on the support given to his theory by the barrenness of very luxuriant plante, and the fruitfulness produced in plants by depletion. Had he been aware that the change from barrenness to fruitfulness in plants, is a change from agamogenesis to gamogenesis - had it been as well known at the time when he wrote as it is now, that a tree which goes on putting out sexless shoots, is thus producing new individuals; and that when it begins to bear fruit, it simply begins to produce new individuals after another manner-he would have perceived that facts of this elass do not tell in his favour.

In the law which Mr. Doubleday alleges, he sees a guarantee for the maintenance of species. He argues that the plethoric state of the indivi- 
nutrition, we may suspect that it is in part due to greater muscular expenditure. A kindred fact, admitting of a kindred interpretation, may be added. Though the comparatively-low rate of increase in France is attributed to other causes, yet, very possibly, one of its causes is the greater proportion of hard work entailed on French women, by the excessive abstraction of men for non-productive occupations, military and civil. The higher rate of multiplication in England than in continental countries generally, is not improbably furthered by the easier lives which English women lead.

That absolute or relative infertility is commonly produced in women by mental labour carried to excess, is more clearly shown. Though the regimen of upper-class girls is not what it should be, yet, considering that their feeding is better than that of girls belonging to the poorer classes, while, in most other respects, their physical treatment is not worse, the

duals constituting any race of organisms, presupposes conditions so favourable to life that the race ean be in no danger; and that rapidity of multiplication becomes needless. Conversely, he argues that a deplethoric state implics unfavourable conditions-implies, consequently, unusual mortality; that is-implies a neeessity for inereased fertility to prevent the race from dying out. It may be readily shown, however, that such an arrangement would be the reverse of self-adjusting. Suppose a species, too numerous for its food, to be in the resulting deplethoric state. It will, according to Mr. Doubleday, become unusually fertile; and the next generation will be more numerous rather than less numerous. For, by the hypothesis, the unusual fertility due to the deplethoric state, is the cause of undue inerease of population. But if the next generation is more numerous while the supply of food has not increased in proportion, then this next generation will be in a still more deplethoric state, and will be still more fertile. Thus there will go on an ever-increasing rate of multiplication, and an ever-decreasing share of food, for each person, until the species disappears. Suppose, on the other hand, the members of a speeies to be in an unusually plethoric state. Their rate of multiplication, ordinarily sufficient to maintain their numbers, will become insufficient to maintain their numbers. In the next generation, therefore, there will be fewer to eat the already abundant food, which becoming relatively still more abundant, will render the fewer members of the species still mora plethoric, and still less fertile, than their parents. And the aetions and reactions continuing, the species will presently die out from absolute barrenness. 
deficiency of reproductive power among them may be reasonably attributed to the overtaxing of their brains-an overtaxing which produces a serious reaction on the physique. This diminution of reproductive power is not shown only by the greater frequency of absolute sterility; nor is it shown only in the earlier cessation of child-bearing; but it is also shown in the very frequent inability of such women to suckle their infants. In its full sense, the reproductive power means the power to bear a well-developed infant and to supply that infant with the natural food for the natural period. Most of the flat-chested girls who survive their high-pressure education, are incompetent to do this. Were their fertility measured by the number of children they could rear without artificial aid, they would prove relatively very infertile.

The cost of reproduction to males being so much less than it is to females, the antagonism between Genesis and Individuation is not often shown in men by suppression of generative power consequent on unusual expenditure in bodily action. Nevertheless, there are indications that this results in extreme cases. We read that the ancient athletre rarely had children; and among such of their modern representatives as acrobats, an allied relation of cause and effett is alleged. Indirectly this truth, or rather its converse, appears to have been ascertained by those who train men for feats of strength-they find it needful to insist on continence.

Special proofs that in men great cerebral expenditure diminishes or destroys generative power, are difficult to obtain. It is, indeed, asserted that intense application to mathematics, requiring as it does extreme concentration of thought, is apt to have this result; and it is asserted, too, that this result is produced by the excessive emotional excitement of gambling. Then, again, it is a matter of common remark how frequently men of unusual mental activity leave no offspring. But facts of this kind admit of another interpretation. The reaction of the brain on the body is so violent 
-the overtaxing of the nervous system is so apt to prostrate the heart and derange the digestion; that the incapacities caused in these cases, are probably often due more to constitutional disturbance than to the direct deduction which excessive action entails. Such instances harmonize with the hypothesis; but how far they yield it positive support we cannot say.

$\S 368$. An objection must here be guarded against. It is likely to be urged that since the civilized races are, on the average, larger than many of the uncivilized races; and since they are also somewhat more complex as well as more active; they ought, in conformity with the alleged general law, to be less prolific. There is, however, no evidence to prove that they are so: on the whole, they seem rather the reverse.

The reply is that were all other things equal, these superior varieties of men should have inferior rates of increase. But other things are not equal; and it is to the inequality of other things that this apparent anomaly is attributable. Already we have seen how much more fertile domesticated animals are than their wild kindred; and the causes of this greater fertility are also the causes of the greater fertility, relative or absolute, which civilized men exhibit when compared with savages.

There is the difference in amount of food. Australians, Fuegians, and sundry races that might be named as having low rates of multiplication, are obviously underfed. The sketches of natives contained in the volumes of Livingstone, Baker, and others, yield clear proofs of the extreme depletion common among the uncivilized.

In quality as well as in quantity, their feeding is bad. Wild fruits, insects, larvæ, vermin, \&c., which we refuse with disgust, often enter largely into their dietary. Much of this inferior food they eat uncooked; and they have not our elaborate appliances for mechanically-preparing it, and rejecting its useless parts. So that they live on matters of less nutritive value, which 
cost more both to masticate and to digest.

Further, to uncivilized men supplies of food come very irregularly. Long periods of scarcity are divided by short periods of abundance. And though by gorging when opportunity occurs, something is done towards compensating for previous fasting, yet the effects of prolonged starvation cannot be neutralized by occasional enormous meals. Bearing in mind, too, that improvident as they are, savages often bestir themselves only under pressure of hunger, we may fairly consider them as habitually ill-nourished-may see that even the poorer classes of civilized men, making regular meals on food separated from innutritive matters, easy to masticate and digest, tolerably good in quality and adequate if not abundant in quantity, are much better nourished.

Then, again, though a greater consumption in muscular action appears to be undergone by civilized men than by savages; and though it is probably true that among our labouring people the daily repairs cost more; yet in many cases there does not exist so much difference as we are apt to suppose. The chase is very laborious; and great amounts of exertion are gone through by the lowest races in seeking and securing the odds and ends of wild food on which they largely depend. We naturally assume that because barbarians are averse to regular labour, their-muscular action is less than our own. But this is not necessarily true. The monotonous toil is what they cannot tolerate; and they may be ready to go through as much or more exertion when it is joined with excitement. If we remember that the sportsman who gladly scrambles up and down rough hillsides all day after grouse or deer, would think himself hardly used had he to spend as much effort and time in digging; we shall see that a savage who is the reverse of industrious, may nevertheless be subject to a muscular waste not very different in amount from that undergone by the industrious.

When it is added that a larger physiological expenditure is entailed on the uncivilized than on the 
civilized by the absence of good appliances for shelter and protection-that in some cases they have to make good a greater loss of heat, and in other cases suffer much wear from irritating swarms of insects; we shall see that the total cost of self-maintenance among them is probably in many cases little less, and in some cases more, than it is among ourselves.

So that though, on the average, the civilized are probably larger than the savage; and though they are, in their nervous systems at least, somewhat more complex; and though, other things equal, they ought to be the less prolific; yet other things are so unequal as to make it quite conformable to the general law that they should be more prolific. In $\S 365$ we observed how, among inferior animals, higher evolution sometimes makes self-preservation far easier, by opening the way to resources previously unavailable: so involving an undiminished, or even an increased, rate of genesis. And similarly we may expect that among races of men, those whose slight further developments have been followed by habits and arts which immensely facilitate life, will not exhibit a lower degree of fertility, and may even exhibit a higher.

$\S 369$. One more objection has to be met-a kindred objection to which there is a kindred reply. Cases may be named of men conspicuous for activity, bodily and mental, who were also noted, not for less generative power than usual, but for more. As their superiorities indicate higher degrees of evolution, it may be urged that such men should, according to the theory, have lower degrees of reproductive activity. The fact that here, along with increased powers of self-preservation, there go increased powers of race-propagation, seems irreconcilable with the general doctrine. Reconciliation is not difficult however.

The cases are analogous to some before named, in which more abundant food simultaneously aggrandizes the indi- 
vidual and adds to the production of new individuals: the difference between the cases being, that instead of a better external supply of materials there is a better internal utilization of materials. Creatures of the same species notoriously differ in goodness of constitution. Here there is some visceral defect, showing itself in feebleness of all the functions; while here some peculiarity of organic balance, some high quality of tissue, some abundance or potency of the digestive juices, gives to the system a perpetual high tide of rich blood, which serves at once to enhance the vital activities and to raise the power of propagation. Such variations, however, are independent of changes in the proportion between Individuation and Genesis. This remains the same, while both are increased or decreased by the increase or decrease of the common stock of materials.

An illustration will best clear up any perplexity. Let us say that the fuel burnt in the furnace of a locomotive steamengine, answers to the food which a man consumes. Let us say that the produced steam expended in working the engine, corresponds to that portion of absorbed nutriment which carries on the man's functions and activities. And let us say that the steam blowing off at the safety-valve, answers to that portion of the absorbed nutriment which goes to the propagation of the race. Such being the conditions of the case, several kinds of variations are possible. All other circumstances remaining the same, there may be changes of proportion between the steam used for working the engine and the steam that escapes by the safety-valve. There may be a structural or organic change of proportion. By enlarging the safety-valve or weakening its spring, while the cylinders are reduced in size, there may be established a constitutionally-small power of locomotion and a constitutionally-large amount of escape-steam; and inverse variations so produced, will answer to the inverse variations between Individuation and Genesis which different types of organisms 
show us. Again, there may be a functional change of proportion. If the engine has to draw a considerable load, the abstraction of steam by the cylinders greatly reduces the discharge by the safety-valve; and if a high velocity is kept up, the discharge from the safety-valve entirely ceases. Conversely, if the velocity is low, the escape-steam bears a large ratio to the steam consumed by the motor apparatus; and if the engine becomes stationary the whole of the steam escapes by the safety-valve. This inverse variation answers to that which we have traced between Expenditure and Genesis, as displayed in the contrasts between species of the same type but unlike activities, and in the contrasts between active and inactive individuals of the same species. But now beyond these inverse variations between the quantities of consumed steam and escape-steam, which are structurally and functionally caused, there are coincident variations, producible in both by changes in the quantity of steam supplied-changes which may be caused in several ways. In the first place, the fuel thrown into the furnace may be increased or made better. Other things equal, there will result a more active locomotion as well as a greater escape; and this will answer to that simultaneous addition to its individual vigour and its reproductive activity, caused in an animal by a larger quantity, or a superior quality, of food. In the second place, the steam generated may be economized. Loss by radiation from the boiler may be lessened by a covering of non-conducting substances; and part of the steam thus prevented from condensing, will go to increase the working power of the engine, while part will be added to the quantity blowing off. This variation corresponds to that simultaneous addition to bodily vigour and propagative power, which results in animals that have to expend less in keeping up their temperatures. In the third place, by improvement of the steam-generating apparatus, more steam may be obtained from a given weight of fuel. A better-formed evaporating surface, or boiler tubes which conduct more rapidly, or an increased number of them 
may cause a larger absorption of heat from the burning mass or the hot gases it gives off ; and the extra steam generated by this extra heat will, as before, augment both the motive force and the emission through the safety-valve. And this last case of coincident variation, is parallel to the case with which we are here concerned-the augmentation of individual expenditure and of reproductive energy, that may be caused by a superiority of some organ on which the utilizing or economizing of materials depends.

Manifestly, therefore, an increased expenditure for Genesis, or an increased expenditure for Individuation, may arise in one of two quite different ways-either by diminution of the antagonistic expenditure, or by addition to the store which supplies both expenditures; and confusion results from not distinguishing between these. Given the ratio 4 to 20, as expressive of the relative costs of Genesis and Individuation; then the expenditure for Genesis may be raised to 5 while the expenditure for Individuation is raised to 25, without any alteration of type, merely by favourable circumstances or superiority of constitution. On the other hand, circumstances remaining the same, the expenditure for Genesis may be raised from 4 to 5 , by lowering the expenditure for Individuation from 20 to 19 : which change of ratio may be either functional and temporary, or structural and permanent. And only when it is the last does it illustrate that inverse variation between degree of evolution and degree of procreative dissolution, which we have everywhere seen.

$\S 370$. There is no reason to suppose, then, that the laws of multiplication which hold of other beings, do not hold of the human being. On the contrary, there are special facts which unite with general implications to show that these laws do hold of the human being. The absence of direct evidence in some cases where it might be looked for, we find fully explained when all the factors are taken into account. And certain seemingly-adverse facts prove, on examination, 
to be facts belonging to a different category from that in which they are placed, and harmonize with the rest when rightly interpreted.

The conformity of human fertility to the laws of multiplication in general, being granted, it remains to inquire what effects must be caused by permanent changes in men's natures and circumstances. Thus far we have observed how, by their exceptionally-high evolution and exceptionally-low fertility, mankind display the inverse variation between Individuation and Genesis, in one of its extremes. And we have also observed how mankind, like other kinds, are functionally changed in their rates of multiplication by changes of conditions. But we have not observed how alteration of structure in Man entails alteration of fertility. The influence of this factor is so entangled with the influences of other factors which are for the present more potent, that we cannot recognize it. Here, if we proceed at all, we must proceed deductively.

[Note.-From among the publications of the American Academy of Political and Social Science, there was sent to me some years ago an essay entitled "The Significance of a Decreasing Birth Rate" by (Miss) J. L. Brownell, Fellow in Political Science, Bryn Mawr College. This essay contains a number of elaborate comparisons drawn from the vital statistics of the tenth United States Census. The results of these comparisons are thus summed up:-

"1. Whether or not it be true that the means spoken of by Dr. Billings, M. Dumont, M. Levasseur, and Dr. Edson has become nn important factor in the diminishing birth-rate of civilized countries, it is evident that it is not the only factor, and that, quite apart from voluntary prevention, there is a distinct problem to be investigated. This is shown by the fact that the white and the colored birth-rate vary together.

“2. Mr. Spencer's generalization that the birth-rate diminishes ns the rate of individual evolution increases is confirmed by a comparison of the birth-rates with the death-rates from nerrous diseases, and also 
with the density of population, the values of agricultural and manufactured products, and the mortgage indebtedness."

Of course multitudinous differences of race, class, mode of living, occupation, locality, make it difficult to draw positive inferences from the data; but the inferences above drawn are held to remain outstanding after allowing for all the qualifying conditions.] 


\section{CHAPTER XIII.}

\section{HUMAN POPULATION IN THE FUTURE.}

§371. ANY further evolution in the most-highly evolved of terrestrial beings, Man, must be of the same nature as evolution in general. Structurally considered, it may consist in greater integration, or greater differentiation, or bothaugmented bulk, or increased heterogeneity and definiteness, or a combination of the two. Functionally considered, it may consist in a larger sum of actions, or more multiplied varieties of actions, or both-a larger amount of sensible and insensible motion generated, or motions more numerous in their kinds and more intricate and exact in their co-ordinations, or motions that are greater alike in quantity, complexity, and precision.

Expressing the change in terms of that more special evolution displayed by organisms; we may say that it must be one which further adapts the moving equilibrium of organic actions. As was pointed out in First Principles, $\S 173$, "the maintenance of such a moving equilibrium, requires the habitual genesis of internal forces corresponding in number, directions, and amounts to the external incident forces-as many inner functions, single or combined, as there are single or combined outer actions to be met." And it was also pointed out that "the structural complexity accompanying functional equilibration, is definable as one in which there are as many specialized parts as are capable, separately and jointly, of counteracting the separate and joint forces 
amid which the organism exists." Clearly, then, since all incompletenesses in Man as now constituted, are failures to meet certain of the outer actions (mostly involved, remote, irregular), to which he is exposed; every advance implies additional co-ordinations of actions and accompanying complexities of organization.

Or, to specialize still further this conception of future progress, we may consider it as an advance towards completion of that continuous adjustment of internal to external relations, which Life shows us. In Part I. of this work, where it was shown that the correspondence between inner and outer actions which under its phenomenal aspect, we call Life, is a particular kind of what, in terms of Evolution, we called a moving equilibrium; it was shown that the degree of life varies as the degree of correspondence. Greater evolution or higher life implies, then, such modifications of human nature as shall make more exact the existing correspondences, or shall establish additional correspondences, or both. Connexions of phenomena of a rare, distant, unobtrusive, or intricate kind, which we either suffer from or do not take advantage of, have to be responded to by new connexions of ideas, and acts properly combined and proportioned: there must be increase of knowledge, or skill, or power, or of all these. And to effect this more extensive, more varied, and more accurate, co-ordination of actions, there must be organization of still greater heterogeneity and definiteness.

$\S 372$. Let us, before proceeding, consider in what particular ways this further evolution, this higher life, this greater co-ordination of actions, may be expected to show itself.

Will it be in strength? Probably not to any considerable degree. Mechanical appliances are fast supplanting brute force, and doubtless will continue doing this. Though at present civilized nations largely depend for self-preservation on vigour of limb, and are likely to do so while wars con- 
tinue; yet that progressive adaptation to the social state which must at last bring wars to an end, will leave the amount of muscular power to adjust itself to the requirements of a peaceful regime. Though, taking all things into account, the muscular power then required may not be less than now, there seems no reason why more should be required.

Will it be swiftness or agility? Probably not. In savages these are important elements of the ability to maintain life; but in civilized men they aid self-preservation in quite minor degrees, and there seems no circumstance likely to necessitate an increase of them. By games and gymnastic competitions, such attributes may indeed be artificially increased; but no artificial increase which does not bring a proportionate advantage can be permanent; since, other things equal, individuals and societies that devote the same amounts of energy in ways which subserve life more effectually, must by and by predominate.

Will it be in mechanical skill, that is, in the betterco-ordination of complex movements? Most likely in some degree. Awkwardness is continually entailing injuries and deaths. Moreover the complicated tools which civilization brings into use, are constantly requiring greater delicacy of manipulation. All the arts, industrial and æsthetic, as they develop, imply a corresponding development of perceptive and executive faculties in men: the two act and react.

Will it be in inteliigence? Largely, no doubt. There is ample room for advance in this direction, and ample demand for it. Our lives are universally shortened by our ignorance. In attaining complete knowledge of our own natures and of the natures of surrounding things-in ascertaining the conditions of existence to which we must conform, and in discovering means of conforming to them under all variations of seasons and circumstances; we have abundant scope for intellectual progress.

Will it be in morality, that is, in greater power of self- 
regulation? Largely also : perhaps most largely. Right conduct is usually come short of more from defect of will than defect of knowledge. For the right co-ordination of those complex actions which constitute human life in its civilized form, there goes not only the pre-requisite-recognition of the proper course; but the further pre-requisite-a due impulse to pursue that course. On calling to mind our daily failures to fulfil often-repeated resolutions, we shall perceive that lack of the needful desire, rather than lack of the needful insight, is the chief cause of faulty action. A further endowment of those feelings which civilization is developing in us-sentiments responding to the requirements of the social state- emotive faculties that find their gratifications in the duties devolving on us-must be acquired before the crimes, excesses, diseases, improvidences, dishonesties, and cruelties, that now so greatly diminish the duration of life, can cease.

Thus, looking at the several possibilities, and asking what direction this further evolution, this more complete moving equilibrium, this better adjustment of inner to outer relations, this more perfect co-ordination of actions, is likely to take; we conclude that it must take mainly the direction of a higher intellectual and emotional development.

$\S 373$. This conclusion we shall find equally forced on us if we inquire for the causes which are to bring about such results. No more in the case of Man than in the case of any other being, can we presume that evolution has taken place, or will hereafter take place, spontaneously. In the past, at present, and in the future, all modifications, functional and organic, have been, are, and must be, immediately or remotely consequent on surrounding conditions. What, then, are those changes in the environment to which, by direct or indirect equilibration, the human organism has been adjusting itself, is adjusting itself now, and will continue to 
adjust itself? And how do they necessitate a higher evolution of the organism?

Civilization, everywhere having for its antecedent the increase of population, and everywhere having for one of its consequences a decrease of certain race-destroying forces, has for a further consequence an increase of certain other racedestroying forces. Danger of death from predatory animals lessens as men grow more numerous. Though, as they spread over the Earth and divide into tribes, men become wild beasts to one another, yet the danger of death from this cause also diminishes as tribes coalesce into nations. But the danger of death which does not diminish, is that produced by augmentation of numbers itself-the danger from deficiency of food. Supposing human nature to remain unchanged, the mortality hence resulting would, on the average, rise as human beings multiplied. If mortality, under such conditions, does not rise, it must be because the supply of food also augments; and this implies some change in human habits wrought by stress of human needs. Here, then, is the permanent cause of modification to which civilized men are exposed. Though the intensity of its action is ever being mitigated in one direction by greater production of food, it is, in the other direction, ever being added to by the greater production of individuals. Manifestly, the wants of their redundant numbers constitute the only stimulus mankind have to obtain more necessaries of life. Were not the demand beyond the supply, there would be no motive to increase the supply. And manifestly, this excess of demand over supply is perennial: this pressure of population, of which it is the index, cannot be eluded. Though by the emigration that takes place when the pressure arrives at a certain intensity, temporary relief is from time to time obtained; yet as, by this process, all habitable countries must become peopled, it follows that in the end the pressure, whatever it may then be, must be borne in full.

This constant increase of people beyond the means of sub- 
sistence causes, then, a never-ceasing requirement for skill, intelligence, and self-control-involves, therefore, a constant exercise of these and gradual growth of them. Every industrial improvement is at once the product of a higher form of humanity, and demands that higher form of humanity to carry it into practice. The application of science to the arts, is the bringing to bear greater intelligence for satisfying our wants, and implies continued progress of that intelligence. To get more produce from the acre, the farmer must study chemistry, must adopt new mechanical appliances, and must, by the multiplication of processes, cultivate both his own powers and the powers of his labourers. To meet the requirements of the market, the manufacturer is perpetually improving his old machines and inventing new ones; and by the premium of high wages incites artizans to acquire greater skill. The daily-widening ramifications of commerce entail on the merchant a need for more knowledge and more complex calculations; while the lessening profits of the ship-owner force him to build more scientifically, to get captains of higher intelligence and better crews. In all cases pressure of population is the original cause. Were it not for the competition this entails, more thought and energy would not daily be spent on the business of life; and growth of mental power would not take place. Difficulty in getting a living is alike the incentive to a higher education of children, and to a more intense and long-continued application in adults. In the mother it prompts foresight, economy, and skilful house-keeping; in the father, laborious days and constant self-denial. Nothing but necessity could make men submit to this discipline; and nothing but this discipline could produce a continued progression.

In this case, as in many others, Nature secures each step in advance by a succession of trials; which are perpetually repeated, and cannot fail to be repeated, until success is achieved. All mankind in turn subject themselves more or 
less to the discipline described; they either may or may not advance under it; but, in the nature of things, only those who do advance under it eventually survive. For, necessarily, families and races whom this increasing difficulty of getting a living which excess of fertility entails, does not stimulate to improvements in production-that is, to greater mental activity -are on the high road to extinction; and must ultimately be supplanted by those whom the pressure does so stimulate. This truth we have recently seen exemplified in Ireland. And here, indeed, without further illustration, it will be seen that premature death, under all its forms and from all its causes, cannot fail to work in the same direction. For as those prematurely carried off must, in the average of cases, be those in whom the power of selfpreservation is the least, it unavoidably follows that those left behind to continue the race, must be those in whom the power of self-preservation is the greatest-must be the select of their generation. So that, whether the dangers to existence be of the kind produced by excess of fertility, or of any other kind, it is clear that by the ceaseless exercise of the faculties needed to contend with them, and by the death of all men who fail to eontend with them successfully, there is cnsured a constant progress towards a higher degree of skill, intelligence, and self-regulation-a better co-ordination of actions-a more complete life.*

$\S 374$. The proposition at which we have thus arrived is, then, that excess of fertility, through the changes it is ever

* A good deal of this chapter retains its original form; and the above paragraph is reprinted verhatim from the Westminstcr Reviero for April, 1852 , in which the views developed in the foregoing hundred pages were first sketched out. This paragraph shows how near one may be to a great generalization without secing it. Though the struggle for life is the alleged motive force; though the process of natural selection is recognized; and though to it is ascribed $n$ share in the evolution of a higher type; yet the conception is not that which Mr. Darwin has worked out with such wonderful skill and knowledge. In the first place, natural selection is here described only as furthering direct adaptation-only as aiding progress by the preservation of individuals in whom functionally-produced modifications hare 
working in Man's environment, is itself the cause of Man's further evolution; and the obvious corollary here to be drawn is, that Man's further evolution so brought about, itself necessitates a decline in his fertility.

All future progress in civilization which the neverceasing pressure of population must produce, will be accompanied by an enhanced cost of Individuation, both in structure and function; and more especially in nervous structure and function. The peaceful struggle for existence in societies ever growing more crowded and more complicated, must have for its concomitant an increase of the great nervous centres in mass, in complexity, in activity. That larger body of emotion needed as a fountain of energy for men who have to hold their places and rear their families under the intensifying competition of social life, is, other things equal, the correlative of larger brain. Those higher feelings presupposed by the better self-regulation which, in a better society, can alone enable the individual to leave a persistent posterity, are, other things equal, the correlatives of a more complex brain; as are also those more numerous, more varied, more general, and more abstract ideas, which must also become increasingly requisite for successful life as society advances. And the genesis- of this larger quantity of

gone on most favourably. In the second place, there is no trace of the idea that natural selection may by co-operation with the cause assigned, or with other causes, produce divergences of structure; and of course, in the absence of this idea, there is no implication that natural selection has anything to do with the origin of specics. And in the third place, the all-important factor of variation-"spontaneous," or incidental as we may otherwise call it-is wholly ignored. Though use and disuse are, I think, much more potent causes of organic modification than Mr. Darwin supposes-though, while pursuing the inquiry in detail, I have been led to believe that direct equilibration has plared a more active part even than I had myself at one time thought; yet $\mathrm{I}$ hold $\mathrm{Mr}$. Darwin to hare shown beyond question, that a great part of the facts-perhaps the greater part-are explicable only as resulting from the survival of individuals which have deviated in some indirectly-caused way from the ancestral type. Thus, the above paragraph contains merely a passing recognition of the selective process; and indicates no suspicion of the enormous range of its effects, or of the conditions under which a large part of its effects rre produred. 
feeling and thought, in a brain thus augmented in size and developed in structure, is, other things equal, the correlative of a greater wear of nervous tissue and greater consumption of materials to repair it. So that both in original cost of construction and in subsequent cost of working, the nervous system must become a heavier tax on the organism. Already the brain of the civilized man is larger by nearly thirty per cent. than the brain of the savage. Already, too, it presents an increased heterogeneity-especially in the distribution of its convolutions. And further changes like these which have taken place under the discipline of civilized life, we infer will continue to take place.

But everywhere and always, evolution is antagonistic to procreative dissolution. Whether it be in greater growth of the organs which subserve self-maintenance, whether it be in their added complexity of structure, or whether it be in their higher activity, the abstraction of the required materials implies a diminished reserve of materials for race-maintenance. And we have seen reason to believe that this antagonism between Individuation and Genesis, becomes unusually marked where the nervous system is concerned, because of the costliness of nervous structure and function. In $\S 346$ was pointed out the apparent connexion between high cerebral development and prolonged delay of sexual maturity; and in $\S \S 366,36 \%$, the evidence went to show that where exceptional fertility exists there is sluggishness of mind, and that where there has been during education excessive expenditure in mental action, there frequently follows a complete or partial infertility. Hence the particular kind of further evolution which Man is hereafter to undergo, is one which, more than any other, may be expected to cause a decline in his power of reproduction.

The higher nervous development and greater expenditure in nervous action, here described as indirectly brought about by increase of numbers, and as thereafter becoming a check on the increase of numbers, must not be taken to imply 
an intenser strain-a mentally-laborious life. The greater emotional and intellectual power and activity above contemplated, must be understood as becoming, by small increments, organic, spontaneous, and pleasurable. As, even when relieved from the pressure of necessity, large-brained Europeans voluntarily enter on enterprises and activities which the savage could not keep up even to satisfy urgent wants; so, their still larger-brained descendants will, in a still higher degree, find their gratifications in careers entailing still greater mental expenditures. This enhanced demand for materials to establish and carry on the psychical functions, will be a constitutional demand. We must conceive the type gradually so modified, that the more-developed nervous system irresistibly draws off, for its normal and unforced activities, a larger proportion of the common stock of nutriment; and while so increasing the intensity, completeness, and length of the individual life, necessarily diminishing the reserve applicable to the setting up of new lives-no longer required to be so numerous.

Though the working of this process will doubtless be interfered with and modified in the future, as it has been in the past, by the facilitations of living which civilization brings; yet nothing beyond temporary interruptions can so be caused. However much the industrial arts may be improved, there must be a limit to the improvement; while, with a rate of multiplication in excess of the rate of mortality, population must continually tread on the heels of production. So that though, during the earlier stages of civilization, an increased amount of food may accrue from a given amount of labour, there must come a time when this relation will be reversed, and when every additional increment of food will be obtained by a more than proportionate labour: the disproportion growing ever higher, and the diminution of the reproductive power becoming greater.

$\S 375$. There now remains but to inquire towards what 
limit this progress tends. So long as the fertility of the race is more than sufficient to balance the diminution by deaths, population must continue to increase. So long as population continues to increase, there must be pressure on the means of subsistence. And so long as there is pressure on the means of subsistence, further mental development must go on, and further diminution of fertility must result; provided that the actions and reactions which have been described are not artificially interfered with. I append this qualifying clause advisedly, and especially emphasize it, because these actions and reactions have been hitherto, and are now, greatly interfered with by governments, and the continuance of the interferences may retard, if not stop, that further evolution which would else go on.

I refer to those hindrances to the survival of the fittest which in earlier times resulted from the undiscriminating charities of monasteries and in later times from the operation of Poor Laws. Of course if the competition which increasing pressure of population entails, is prevented from acting on a considerable part of the community, such part, saved from the needed intellectual and moral stress, will not undergo any further mental development; and must ever tend to leave a posterity, and an increasing posterity, in which none of that higher individuation which checks genesis takes place. Such State-meddlings with the natural play of actions and reactions produce a further evil equally great or greater. For those who are not self-maintained, or but partially self-maintained, are supplied with the means they lack by the better members of the community; and these better members have thus not only to support themselves and their offspring, but also to support or aid the inferior members and their offspring. The under-working of one part is accompanied by the over-working of the other part-by a working which at each stage of progress exceeds that which the normal conditions necessitate, and results sometimes in illness, premature age, or death, or in lessened 
number of children, or in imperfect rearing of children: the bad are fostered and the good are repressed.

It does not follow that the struggle for life and the survival of the fittest must be left to work out their effects without mitigation. It is contended only that there shall not be a forcible burdening of the superior for the support of the inferior. Such aid to the inferior as the superior voluntarily yield, kept as it will be within moderate limits, may be given with benefit to both-relief to the one, moral culture to the other. And aid willingly given (little to the least worthy and more to the most worthy) will usually be so given as not to further the increase of the unworthy. For in proportion as the emotional nature becomes more evolved, and there grows up a higher sense of parental responsibility, the begetting of children that cannot be properly reared will be universally held intolerable. If, as we see, public opinion in many places and times becomes coercive enough to force men to fight duels, we can scarcely doubt that at a higher stage of evolution it may become so coercive as to prevent men from marrying improvidently. If the frowns of their fellows can make men commit immoral acts, surely they may make men refrain from immoral acts-especially when the actors themselves feel that the threatened frowns would be justified. Hence with a higher moral nature will come a restriction on the multiplication of the inferior.

In brief, the sole requirement is that there shall be no extensive suspension of that natural relation between merit and benefit which constitutes justice. Holding, then, that this all-essential condition will itself come to be recognized and enforced by a more evolved humanity, let us consider what is the goal towards which the restraint on genesis by individuation progresses.

$\S 375 a$. Supposing the Sun's light and heat, on which all terrestrial life depends, to continue abundant for a period long enough to allow the entire evolution we are contem- 
plating; there are still certain changes which must prevent such complete adjustment of human nature to surrounding conditions, as would permit the rate of multiplication to become equal to the rate of mortality. As before pointed out ( $\$ 148$ ), during an epoch of 21,000 years each hemisphere goes through a cycle of temperate seasons and seasons extreme in their heat and cold-variations which are themselves alternately exaggerated and mitigated in the course of far longer cycles; and we saw that these cause perpetual ebbings and flowings of species over different parts of the Earth's surface. Further, by slow but inevitable geologic changes, especially those of elevation and subsidence, the climate and physical characters of every habitat are modified; while old habitats are destroyed and new are formed. This, too, we noted as a constant cause of migrations and of resulting alterations of environment. Now though the human race differs from other races in having a power of artificially counteracting external changes, yet there are limits to this power; and, even were there no limits, the changes could not fail to work their effects indirectly, if not directly. 'If, as is thought probable, these astronomic cycles entail recurrent glacial periods in each hemisphere, then parts of the Earth which are at one time thickly peopled, will at another time be almost deserted, and vice versâ. The geologically-caused alterations of climate and surface, must produce further slow re-distributions of population; and other currents of people, to and from different regions, will be necessitated by the rise of successive centres of higher civilization. Consequently, mankind cannot but continue to undergo changes of environment, physical and moral, analogous to those which they have thus far been undergoing. Such changes may eventually become slower and less marked; but they can never cease. And if they can never cease there can never arise a perfect adaptation of human nature to its conditions of existence. To establish that complete correspondence between inner and outer actions which constitutes the highest life and 
greatest power of self-preservation, there must be a prolonged converse between the organism and circumstances which remain the same. If the external relations are being altered while the internal relations are being adjusted to them, the adjustment can never become exact. And in the absence of exact adjustment, there cannot exist that theoretically-highest power of self-preservation with which there would co-exist the theoretically-lowest power of race-production.

Hence though the number of premature deaths may ultimately become very small, it can never become so small as to allow the average number of offspring from each pair to fall so low as two. Some average number between two and three may be inferred as the limit-a number, however, which is not likely to be quite constant, but may be expected at one time to increase somewhat and afterwards to decrease somewhat, according as variations in physical and social conditions lower or raise the cost of self-preservation.

To this qualification must be added a further qualification. The foregoing argument tacitly assumes that the causes described will continuously operate on all mankind; whereas a survey of the facts makes it clear that some parts only of the Earth's surface are capable of bearing high types of civilization, and consequently high types of Man. There must remain hereafter, as there are now, considerable parts of its surface which can support only groups of nomads, or other groups obliged by their habitats to lead simple and inferior kinds of life. Only by subjection to the discipline we have been contemplating can there be produced the fully-developed Man; and evidently in many parts of the world this discipline will continue to be eluded. Not only must we conclude that the varieties of our race now living in desert regions and arctic climates will continue hereafter to do so, but we may conclude that always, as now, a certain proportion of men who are born in civilized societies, impatient of the stress which pressure of population puts on them, will escape into unoccupied or sparsely-peopled 
regions, where they can lead unrestrained lives though lives of hardship. Recognizing as we must the probability that in common with all other things, humanity will continue to differentiate and produce a more heterogeneous assemblage of types, we must infer that only in some of the highest of these will the antagonism of individuation and genesis have the anticipated effects.

Restricting 3 ourselves to these, then, we may conclude that in the end, [pressure of population and its accompanying evils will almost disappear; and will leave a state of things requiring from each individual, little more than a normal and pleasurable activity. Cessation in the decrease of fertility implies cessation in the development of the nervous system; and this implies a nervous system which has become equal to all that is demanded of it-has not to do more than is natural to it. But that exercise of faculties which does not exceed what is natural, constitutes gratification.

The necessary antagonism of Individuation and Genesis, not only, then, fulfils the a priori law of maintenance of race, from the monad up to Man, but ensures final attainment of the highest form of this maintenance-a form in which the amount of life shall be the greatest possible and the births and deaths the fewest possigle From the beginning pressure of population has becn the proximate cause of progress. It produced the original diffusion of the race. It compelled men to abandon predatory habits and take to agriculture. It led to the clearing of the Earth's surface. It forced men into the social state; made social organization inevitable; and has developed the social sentiments. It has stimulated to progressive improvements in production, and to increased skill and intelligence. It is daily thrusting us into closer contact and more mutually-dependent relationships. And after having caused, as it ultimately must, the due peopling of the globe, and the raising of its habitable parts into the highest state of culture-after having perfected all processes for the satisfaction of human wants-after 
having, at the same time, developed the intellect into competence for its work, and the feelings into fitness for social life-after having done all this, the pressure of population must gradually approach to an end-an end, however, which for the reasons given it cannot absolutely reach.]

$\S 37 \%$. In closing the argument let us not overlook the self-sufficingness of those universal processes by which the results reached thus far have been wrought out, and which may be expected to work out these future results.

Evolution under all its aspects, general and special, is an advance towards equilibrium. We have seen that the theoretical limit towards which the integration and differentiation of every aggregate advances, is a state of balance between all the forces to which its parts are subject, and the forces which its parts oppose to them (First Prin. $\S 170$ ). And we have seen that organic evolution is a progress towards a moving equilibrium completely adjusted to environing actions.

It has been also pointed out that, in civilized Man, there is going on a new class of equilibrations-those between his actions and the actions of the societies he forms (First Prin. $\S 175)$. Social restraints and requirements àre ever altering his activities and by consequence his nature; and as fast as his nature is altered, social restraints and requirements undergo more or less re-adjustment. Here the organism and the conditions are both modifiable; and by successive conciliations of the two, there is effected a progress towards equilibrium.

More recently we have seen that in every species, there establishes itself an equilibrium of an involved kind between the total race-destroying forces and the total race-preserving forces-an equilibrium which implies that where the ability to maintain individual life is small, the ability to propagate must be great, and vice versâ. Whence it follows that the evolution of a race more in equilibrium with the environment, is also the evolution of a race in which there is a cor- 
relative approach towards equilibrium between the number of new individuals produced and the number which survive and propagate.

The final result to be observed is that in Man, all these equilibrations between constitution and conditions, between the structure of society and the nature of its members, between fertility and mortality, advance simultaneously towards a common climax. In approaching an equilibrium between his nature and the ever-varying circumstances of his inorganic environment, and in approaching an equilibrium between his nature and all the requirements of the social state, Man is at the same time approaching that lowest limit of fertility at which the equilibrium of population is maintained by the addition of as many infants as there are subtractions by death in old age. But in a universe of which all parts are in motion and every part is consequently subject to change of conditions, neither this equilibrium nor any other equilibrium can become complete. 
A P P EN DICES. 


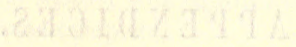




\section{APPENDIX A.}

SUBSTITUTION OF AXIAL FOR FOLIAR ORGANS IN PLANTS.

I APPEND here the evidences referred to in $\$ 190$. The most numerous and striking I have met with among the Umbelliferce. Monstrosities having the alleged implication, are frequent in the common Cow-Parsnep-so frequent that they must be familiar to botanists ; and wild Angelica supplies many over-developments of like meaning. Omitting numerous cases of more or less significance, I will limit myself to two.

One of them is that of a terminal umbel, in which nine of the outer umbellules are variously transformed-here a single flower being made monstrous by the development of some of its members into buds; there several such malformed flowers being associated with rays that bear imperfect umbellules; and elsewhere, flowers

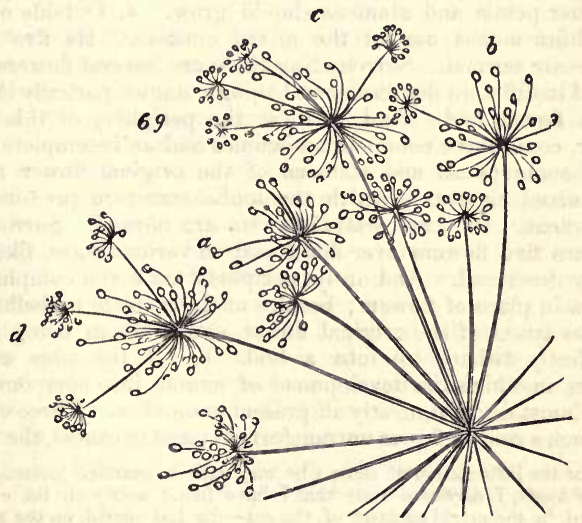

being replaced by umbellules : some of which are perfect, and others imperfect only in the shortness of the flower-stalks. The annexed Fig. 69, representing in a somewhat conventionalized way, a part of 
the dried specimen, will give an idea of this Angelica. At $a$ is shown a single flower partially changed; in the umbellule marked $b$, one of the rays bears a secondary umbellule; and there may be seen at $c$ and $d$, several such over-developments.

But the most conclusive instance is that of a Cow-Parsnep, in which a single terminal umbel, besides the transformations already mentioned, exhibits higher degrees of such transformations.* The components of this complex growth are ; - three central umbellules, abnormal only in minor points; one umbellule, external to these, which is partially changed into an umbel; one rather more out of the centre, which is so far metamorphosed as to be more an umbel than an umbellule : nine peripheral clusters formed by the development of umbellules into umbels, some of which are partially compounded still further. Examined in detail, these structures present the following facts: -1 . The innermost umbellule is normal, save in having a peripheral Hower of which one member (apparently a petal) is transformed into a flower-bud. 2. The next umbellule, not quite so central, has one of its peripheral flowers made monstrous by the growth of a bud from the base of the calyx. 3. The third of the central umbellules has two abnormal outer flowers. One of them carries a flower-bud on its edge, in place of a foliar member. The other is half tlower and half umbellule: being composed of three petals, three stamens, and five flower-buds growing where the other petals and stamens should grow. 4. Outside of these umbellules comes one of the mixed clusters. Its five central Howers are normal. Surrounding these are several flowers transformed in different degrees : one having a stamen partially changed into a flower bud. And then, at the periphery of this mixed cluster, come three complete umbellules and an incomplete one in which some petals and stamens of the original flower remain. 5. A mixed cluster, in which the umbel-structure predominates, stands next. Its three central flowers are normal. Surrounding them are five flowers over-developed in various ways, like those already described. And on its periphery are seven complete umbellules in place of flowers; besides an incomplete umbellule that contains traces of the original flower, one of them being a petal imperfectly twisted up into a bud. 6. Of the nine external clusters, in which the development of simple into compound umbels is most decided, nearly all present anomalies. Three of them have each a central flower untransformed; and in others, the central

* For the information of those who may wish to examine metamorphoses of these kinds, I may here state that I have found nearly all the examples described, in the neighbourhood of the sea-the last-named, on the shore of Locheil, near Fort William. Whether it is that I have sought more diligently for cases when in such localities, or whether it is that the sea-air favours that excessive nutrition whence these transformations result, I am unable to say. 
nmbellule is composed of two, three, or four flowers. 7. But the most remarkable fact is, that in sundry of these peripheral clusters, resulting from the metamorphosis of simple umbels into compound umbels, the like metamorphosis is carried a stage higher. Some of the component rays, are themselves the bearers of compound umbels

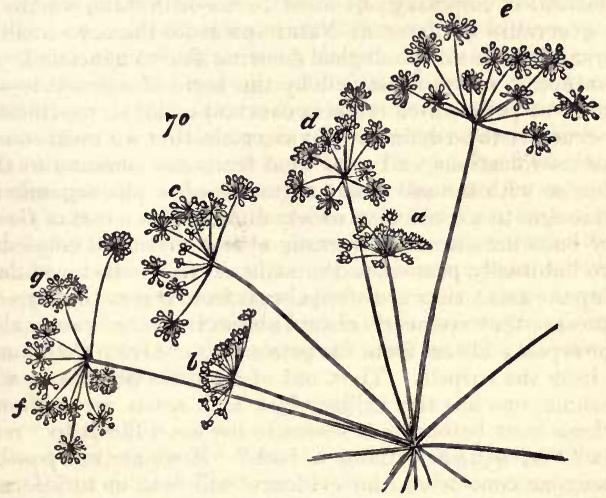

instead of simple nmbels. In Fig. 70, a portion of the dried specimen is represented. Two of the central umbellules are marked $a$ and $b$; those marked $c$ and $d$ are mixed clusters; at $e$ and $f$ are compound umbels replacing simple ones; and $g$ shows one of the rays on which the over-development goes still further.

Does not this evidence, enforced as it is by much more of like kind, go far to prove that foliar organs may be developed into axial organs? Even were not the transitional forms traceable, there would still, I think, be no other legitimate interpretation of the facts last detailed. The only way of eluding the conclusion here drawn, is by assuming that where a cluster of flowers replaces a single flower, it is because the axillary buds which hypothetically belong to the several foliar organs of the flower, become developed irto axes ; and assuming this, is basing an hypothesis on another hypothesis that is directly at variance with facts. The foliar organs of flowers do not bear buds in their axils; and it would never have been supposed that such buds are typically present, had it not been for that mistaken conception of "type "which has led to many other errors in Biology. Goethe writes: "Now as we cannot realize the idea of a leaf apart from the node out of which it springs, or of a node without a bud, we may venture to infer," \&c. See here an example of a method of philosophizing not uncommon among the Germans. 
The method is this-Survey a portion of the facts, and draw from them a general conception; project this general conception back into the objective world, as a mould in which Nature casts her products ; expect to find it everywhere fulfilled; and allege potential fulfilment where no actual fulfilment is visible.

If instead of imposing our ideal forms on Nature, we are content to generalize the facts as Nature presents them, we shall find no warrant for the morphological doctrine above enunciated. The only conception of type justified by the logic of science, is-that correlation of parts which remains constant under all modifications of the structure to be defined. To ascertain this, we must compare all these modifications, and note what traits are eommon to them. On doing so with the successive segments of a phrnogamic axis, we are brought to a conclusion widely different from that of Goethe. Axillary buds are almost universally absent from the cotyledons; they are habitually present in the axils of fully-developed leaves higher up the axis; they are often absent from leaves that are close to the flower; they are nearly always abscnt from the bracts; absent from the sepals ; absent from the petals ; absent from the stamens ; absent from the carpels. Thus, out of eight leading forms which folia assume, one has the axillary bud and seven are without it. With these facts before us, it seems to me not difficult to "realize the idea" "of a node without a bud." If we are not possessed by a foregone conclusion, the evidence will lead us to infer, that each node bears a foliar appendage and may bear an axillary bud.

Even, however, were it granted that the typical segment of a Phænogam includes an axillary bud, which must be regarded as always potentially present, no legitimate counter-interpretation of the montrosities above described could thence be drawn. If when an umbellule is developed in place of a flower, the explanation is, that its component rays are axillary to the foliar organs of the flower superseded; we may fairly require that these foliar organs to which they are axillary, shall be shown. But there are none. In the last specimen figured, the inner rays of each such umbellule are without them; most of the outer rays are also without them; and in one cluster, only a single ray has a bract at its point of origin. There is a rejoinder ready, however: the foliar organs are said to be suppressed. Though Goethe could not "realize the idea" "of a node without a bud," those who accept his typical form appear to find no difficulty in realizing the idea of an axillary bud without anything to which it is axillary. But letting this pass, suppose we ask what is the warrant for this assumed suppression. Axillary buds normally occur where the nutrition is high enough to produce fully-developed leaves; and when axillary buds are demonstrably present in flowers, they accompany foliar organs that are more leaflike than usual-always greener if not always larger. That is to 
say, the normal and the abnormal axillary buds, are alike the coneomitants of foliar organs coloured by that chlorophyll which habitually favours foliar development. How, then, can it be supposed that when, out of a flower there is developed a cluster of flower-bearing rays, the implied excess of nutrition causes the foliar organs to abort? It is true that very generally in a branched inflorescence, the bracts of the several flower-branches are very small (their smallness being probably due to that defective supply of certain chlorophyll-forming matters, which is the proximate cause of flowering); and it is true that, under these conditions, a flowering axis of considerable size, for the development of which chlorophyll is less needful, grows from the axil of a dwarfed leaf. But the inference that the foliar organ may therefore be entirely suppressed, seems to me irreconcilable with the fact, that the foliar organ is always developed to some extent before the axillary bud appears. Until it has been shown that in some cases a lateral bud first appears, and a foliar organ afterwards grows out beneath it, to form its axil, the conception of an axillary bud of which the foliar organ is suppressed, will remain at variance with the established truths of development.

The above originally formed a portion of $\$ 190$. I have transferred it to the Appendix, partly because it eontains too much detail to render it fit for the general argument, and partly because the interpretations being open to some question, it seemed undesirable to risk compromising that argument by including them. The criticisms passed upon these interpretations have not, however, sufficed to convince me of their incorrectness. Unfortunately, I have since had no opportunity of verifying the above statements by microscopic examinations, as I had intended.

Though unable to enforce the inference drawn by further facts more minutely looked into, I may add some arguments based on facts that are well known. One of these is the fact that the soealled axillary bud is not universally axillary-is not universally seated in the angle made by the axis and an appended foliar organ. In certain plants the axillary bud is placed far above the node, half-way between it and the suceeeding node. So that not only may a segment of a phænogamic axis be without the axillary bud, but the axillary bud, when present, may be removed from that place in which, according to Goethe, it necessarily exists. Another fact not congruous with the current doctrine, is the common occurrence of "adventitious" buds-the buds that are put out from roots and from old stems or branches bare of leaves. The name under which they are thus classed, is meant to imply that they may be left out of consideration. Those, however, who have not got a theory to save by 
putting anomalies out of sight, may be inclined to think that the occurrence of buds where they are avowedly unconnected with nodes, and are axillary to nothing, tells very much against the assumption that every bud implies a node and a corresponding foliar organ. And they may also see that the development of these adventitious buds at places where there is excess of nutritive materials, favours the view above set forth. For if a bud thus arises at a place where it is not morphologically accounted for, simply because there happens to be at that place an abundance of unorganized protoplasm; then, clearly, it is likely that if the mass of protoplasm from which a leaf would usually arise, is greatly increased in mass by excess of nutrition, it may develop into an axis instead of a leaf.

Many years after this work was published, I discovered among my papers a memorandum which unfortunately I had overlooked, containing further evidence in support of the foregoing conclusion. With the omission of an error concerning the species of plant, I reproduce this memorandum just as it stood:-

"I found at Dieppe, July 1, 1860, in a garden near the sea a sample of cultivated wild flower (I thought it was grown as an ornamental flower) in which some of the single flowers of the umbel were developed into groups of flowers thus:-

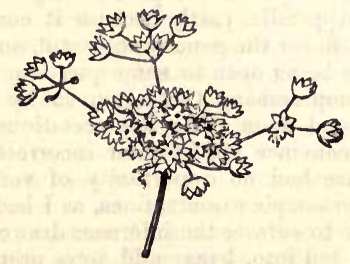

"In the case where the transformation was fully effected the umbellule had six flowers, answering to the six petals of the original flowers. In other cases the transformation was incomplete. There were instances where but two of the petals were developed into flowers; and the other petals remained unchanged. Others in which three were developed; and others where four were developed. In some cases, too, the development of a petal into a flower was imperfect, in the absence of the flower stalkthe flowers were sessile in the place where the petals would have been. In one case there was an imperfect flower sessile; another imperfect flower on a short stalk; and three perfect flowers on long stalks. 
"I was in some doubt whether the petals or the stamens were developed. In cases of imperfect transformation the petals at the base of the umbellule seemed to stand in the position of calyx or involucrum, giving the idea that the stamens were developed into flowers. But in the case where there were six flowers developed there were no petals at the base.

"That it was a matter of extra nutrition was shown by this:-

"I. That they were cultivated as garden flowers.

" 2 . That where there was one perfectly developed umbellule, it was the only one in the umbel.

" 3 . That where there were three umbellules they were all imperfect.

"4. That in this imperfect umbellule the perfect flowers were on long stalks and the imperfect ones sessile.

" 5 . That the umbellules were on stalks both longer and thicker than those of single flowers."

[Concerning the foregoing argument at large an expert writes:- "The abnormalities you describe certainly show that an axis may arise abnormally in the place of a normal leafstructure, and every modern botanist would be in agreement with you in your criticism of the older form of the doctrine of axillary buds. I think we are largely emancipated from the dextrous juggling with the arrangements and relations of organs which used to pass current as morphology.

"You have quoted sufficient evidence in the text $(\$ 190)$ to establish the conclusion that no sharp line can be drawn between axes and leaf-structure; and a very great deal more could be added in the same sense. Petioles for instance, exist which the most highly trained histological observer could not distinguish from stems.

"But I must demur to the suggestion that the replacement of one by the other is primarily a question of nutrition. We are as ignorant as ever of the proximate cause of the production of a leaf or a shoot at a certain spot in meristematic tissue."

To this last remark I had at first made only the reply that the plants exhibiting the abnormalities were in all cases excessively luxuriant in their growths; but to this $I$ am now able to add a more definite reply. The expert from whom I have just quoted, had read this appendix before there had been made to it the above addition describing the flower from Dieppe; and I was not myself aware, until I came to read over this addition, what clear evidence it contains that extra nutrition was the cause of these transformations of foliar structures into axial structures; but the above paragraphs $1,2,3,4,5$, contain different evidences conspiring to prove this.] 


\section{APPENDIX B.}

A CRITICISM ON PROF. OWEN'S THEORY OF THE VERTEBRATE SKELETON.

[From the British \& Foreign Medico-Chirdrgical Review for Oct., 1858.]

I. On the Archetype and Homologies of the Vertebrate Skeleton. By Richard Owen, F.R.S.-London, 1848. pp. 172.

II. Principes d'Ostéologie Comparée, ou Recherches sur l'Archétype et les Homologies du Squelette Vertébré. Par Richard OwnN.-Paris.

Principles of Comparative Osteology; or, Researches on the Archetype and the Homologies of the Vertebrate Skeleton. By Richard Owen.

III. On the Nature of Limbs. A Discourse delivered on Friday, February 9, at an Evening Meeting of the Royal Institution of Great Britain. By Richard OWen, F.R.S.-London, 1849. pp. 119.

JUDGING whether another proves his position is a widely different thing from proving your own. To establish a general law requires an extensive knowledge of the phenomena to be generalized; but to decide whether an alleged general law is established by the evidence assigned, requires merely an adequate reasoning faculty. Especially is such a decision easy where the premises do not warrant the conclusion. It may be dangerous for one who has but little previous acquaintance with the facts, to say that a generalization is demonstrated; seeing that the argument may be one-sided : there may be many facts unknown to him which disprove it. But it is not dangerous to give a negative verdict when the alleged demonstra- 
tion is manifestly insufficient. If the data put before him do not bear out the inference, it is competent for every logical reader to say so.

From this stand-point, then, we venture to criticize some of Professor Owen's osteological theories. For his knowledge of comparative osteology we have the highest respect. We believe that no living man has so wide and detailed an acquaintance with the bony structure of the Vertebrata. Indeed, there probably has never been any one whose information on the subject was so nearly exhaustive. Moreover, we confess that nearly all we know of this department of biology has been learnt from his lectures and writings. We pretend to no independent investigations, but merely to such knowledge of the phenomena as he has furnished us with. Our position, then, is such that, had Professor Owen simply enunciated his generalizations, we should have accepted them on his authority. But he has brought forward evidence to prove them. By so doing he has tacitly appealed to the judgments of his readers and hearers-has practically said, "Here are the facts; do they not warrant these conclusions?" And all we propose to do, is to consider whether the conclusions are warranted by the facts brought forward.

Let us first limit the scope of our criticisms. On that division of comparative osteology which deals with what Professor Owen distinguishes as "special homologies," we do not propose to enter. That the wing of a bird is framed upon bones essentially parallel to those of a mammal's fore-limb; that the cannon-bone of a horse's leg answers to the middle metacarpal of the human hand; that various bones in the skull of a fish are homologous with bones in the skull of a man-these and countless similar facts, we take to be well established. It may be, indeed, that the doctrine of special homologies is at present carried too far. It may be that, just as the sweeping generalization at one time favoured, that the embryonic phases of the higher animals represent the adult forms of lower ones, has been found untrue in a literal sense, and is acceptable only in a qualified sense; so the sweeping generalization that the skeletons of all vertebrate animals consist of homologous parts, will have to undergo some modification. But that this generalization is substantially true, all eomparative anatomists agree.

The doctrine which we are here to consider, is quite a separate one-that of "general homologies." The truth or falsity of this may be decided on quite apart from that of the other. Whether certain bones in one vertebrate animal's skeleton correspond with certain bones in another's, or in every other's, is one question; and whether the skeleton of every vertebrate animal is divisible into a series of segments, each of which is modelled after the same type, is another question. While the first is answered in the affirmative, 
the last may be answered in the negative; and we propose to give reasons why it should be answered in the negative.

In so far as his theory of the skeleton is concerned, Professor Owen is an avowed disciple of Plato. At the conclusion of his Archetype and Homologies of the Vertebrate Skeleton, he quotes ap-

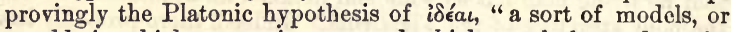
moulds in which matter is cast, and which regularly produce the same number and diversity of species." The vertebrate form in general (see diagram of the Archetypus), or else the form of each kind of vertebrate animal (see p. 172, where this scems implied), Professor Owen conceives to exist as an "idea"-an "archetypal exemplar on which it has pleased the Creator to frame certain of his living creatures." Whether Professor Owen holds that the typical vertebra also exists as an "idea," is not so certain. From the title given to his figure of the "ideal typical vertebra," it would seem that he does; and at p. 40 of his Nature of Limbs, and indeed throughout his general argument, this supposition is implied. But on the last two pages of the Archetype and Homologies, it is distinctly alleged that "the repetition of similar segments in a vertebral column, and of similar elements in a vertebral segment, is analogous to the repetition of similar crystals as the result of polarizing force in the growth of an inorganic body ;" it is pointed out that, "as we descend the scalc of animal life, the forms of the repeated parts of the skeleton approach more and more to geometrical figures;" and it is inferred that "the Platonic i $i \delta ́ a$ or specific organizing principle or force, would seem to be in antagonism with the general polarizing force, and to subdue and mould it in subserviency to the exigencies of the resulting specific form." If Professor Owen's doctrine is to be understood as expressed in these closing paragraphs of his Archetype and Homologies - if he considers that "the i $\delta \in \delta^{\prime}$ " "which produces the diversity of form belonging to living bodies of the same materials," is met by the "counter-operation" of "the polarizing force pervading all space," which produces "the similarity of forms, the repetition of parts, the signs of unity of organization," and which is "subdued" as we ascend "in the scale of being;" then we may pass on with the remark that the hypothesis is too cumbrous and involved to have much vraisemblance. If, on the other hand, Professor Owen holds, as every reader would suppose from the general tenor of his reasonings, that not only does there exist an archetypal or ideal vertebrate skeleton, but that there also exists an archetypal or ideal vertebra; then he carries the Platonic hypothesis much further than Plato does. Plato's argument, that before any species of object was created it must have existed as an idea of the Creative Intelligence, and that hence all objects of such species must bo 
copies of this original idea, is tenable enough from the anthropomorphic point of view. But while those who, with Plato, think fit to base their theory of creation upon the analogy of a carpenter designing and making a table, must yield assent to Plato's inference, they are by no means committed to Professor Owen's expansion of it. To say that before creating a vertebrate animal, God must have had the conception of one, does not involve saying that God gratuitously bound himself to make a vertebrate animal out of segments all moulded after one pattern. As there is no conceivable advantage in this alleged adhesion to a fundamental pattern-as, for the fulfilment of the intended ends, it is not only needless, but often, as Professor Owen argues, less appropriate than some other construction would be (see Nature of Limbs, pp. 39, 40), to suppose the creative processes thus regulated, is not a little startling. Even those whose conceptions are so anthropomorphic as to think they honour the Creator by calling him " the Great Artificer," will scarcely ascribe to him a proceeding which, in a human artificer, they would consider a not very worthy exercise of ingenuity.

But whichever of these alternatives Professor Owen contends for-whether the typical vertebra is that more or less crystalline figure which osseous matter ever tends to assume in spite of "the ¿ó́a or organizing principle," or whether the typical vertebra is

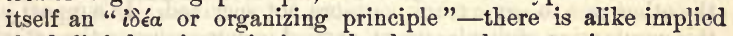
the belief that the typical vertebra has an abstract existence apart from actual vertebrix. It is a form which, in every endoskeleton, strives to embody itself in matter-a form which is potentially present in each vertebra; which is manifested in each vertebra with more or less clearness; but which, in consequence of antagonizing forces, is nowhere completely realized. Apart from the philosophy of this hypothesis, let us here examine the evidence which is thought to justify it.

And first as to the essential constituents of the "ideal typical vertebra." Exclusive of "diverging appendages" which it "may also support," "it consists in its typical completeness of the following elements and parts":-A centrum round which the rest are arranged in a somewhat radiate manner; above it two neurapophyses - converging as they ascend, and forming with the centrum a trianguloid space containing the neural axis; a neural spine, surmounting the two neurapophyses, and with them completing the neural arch; below the centrum two homapophyses and a homal spine, forming a hæmal arch similar to the neural arch above, and enclosing the hæmal axis; two pleurapophyses radiating horizontally from the sides of the centrum; and two parapophyses diverging from the centrum below the pleurapophyses. "These," says Professor Owen, " being usually developed from distinct and independent 
centres, I have termed 'autogenous elements.'" The remaining elements, which he classes as "exogenous," because they "shoot out as continuations from some of the preceding elements," are the diapophyses diverging from the upper part of the centrum as the parapophyses do below, and the zygapophyses which grow out of the distal ends of the neurapophyses and hæmapophyses.

If, now, these are the constituents of the vertebrate segment "in its typical completeness;" and if the vertebrate skeleton consists of a succession of such segments; we ought to have in these constituents, representatives of all the elements of the vertebrate skeleton-at any rate, all its essential elements. Are we then to conclude that the "diverging appendages," which Professor Owen regards as rudimental limbs, and from certain of which he considers actual limbs to be developed, are typically less important than some of the above-specified exogenous parts-say the zygapophyses?

That the meaning of this question may be understood, it will be needful briefly to state Professor Owen's theory of The Nature of Limbs ; and such criticisms as we have to make on it must be included in the parenthesis. In the first place, he aims to show that the scapular and pelvic arches, giving insertion to the fore and hind limbs respectively, are displaced and modified hæmal arches, originally belonging in the one case to the occipital vertebra, and in the other case to some trunk-vertebra not specified. In support of this assumption of displacement, carried in some cases to the extent of twenty-seven vertebræ, Professor Owen cites certain acknowledged displacements which occur in the human skeleton to the extent of half a vertebra-a somewhat slender justification. But for proof that such a displacement has taken place in the scapular arch, he chiefly relies on the fact that in fishes, the pectoral tins, which are the homologues of the fore-limbs, are directly articulated to certain bones at the back of the head, which he alleges are parts of the occipital vertebra. This appeal to the class of fishes is avowedly made on the principle tbat these lowest of the Vertebrata approach closest to archetypal regularity, and may therefore be expected to show the original relations of the bones more nearly. Simply noting the facts that Professor Owen does not give us any transitional forms between the alleged normal position of the scapular arch in fishes, and its extraordinary displacement in the higher Vertebrata; and that he makes no reference to the embryonic phases of the higher Vertebrata, which might be expected to exhibit the progressive displacement; we go on to remark that, in the case of the pelvic arch, he abandons his principle of appealing to the lowest vertebrate forms for proof of the typical structure. In fishes, the rudimentary pelvis, widely removed from the spinal column, shows no signs of having belonged to any vertebra; and here Professor Owen instances the perennibranchiate Batrachia as 
exhibiting the typical structure : remarking that " mammals, birds, and reptiles show the rule of connexion, and fishes the exception." Thus in the case of the scapular arch, the evidence afforded by fishes is held of great weight, because of their archetypal regularity ; while in the case of the pelvic arch, their evidence is rejected as exceptional. But now, having, as he considers, shown that these bonv frames to which the limbs are articulated are modified hæmal arches, Professor Owen points out that the hæmal arches habitually bear certain "diverging appendages;" and he aims to show that the "diverging appendages" of the scapular and pelvic arches respectively, are developed into the fore and hind limbs. There are several indirect ways in which we may test the probability of this conclusion. If these diverging appendages are "rudimental limbs" - "future possible or potential arms, legs, wings, or feet," we may fairly expect them always to bear to the hæmal arches a relation such as the limbs do. But they by no means do this. "As the vertebræ approach the tail, these appendages are often transferred gradually from the pleurapophysis to the parapophysis, or even to the centrum and neural arch." (Arch. and Hom., p. 93.) Again, it might naturally be assumed that in the lowest vertebrate forms, where the limbs are but little developed, they would most clearly display their alliance with the appendages, or " rudimental limbs," by the similarity of their attachments. Instead of this, however, Professor Owen's drawings show that whereas the appendages are habitually attached to the pleurapophyses, the limbs, in their earliest and lowest phase, alike in fishes and in the Lepidosiren, are articulated to the hæmapophyses. Most anomalous of all, however. is the process of development. When we speak of one thing as being developed out of another, we imply that the parts next to the germ are the first to appear, and the most constant. In the evolution of a tree out of a seed, there come at the outset the stem and the radicle; afterwards the branches and divergent roots; and still later the branchlets and rootlets; the remotest parts being the latest and most inconstant. If, then, a limb is developed out of a " diverging appendage" of the hæmal arch, the earliest and most constant bones should be the humerus and femur; next in order of time and constancy should come the coupled bones based on these; while the terminal groups of bones should be the last to make their appearance, and the most liable to be absent. Yet, as Professor Owen himself shows, the actual mode of development is the very reverse of this. At p. 16 of the Archetype and Homologies, he says :

"The earlier stages in the development of all locomotive extremities are permanently retained or represented in the paired fins of fishes. First the essential part of the member, the hand or foot, appears : then the fore-arm or leg, both much shortened, flattened, and expanded, as in all fins and all embryonic rudiments of limbs: finally eome the humeral and femoral segments; but this stage I have not found attained in any fish." 
That is to say, alike in ascending through the Vertebrata generally, and in tracing up the successive phases of a mammalian embryo, the last-developed and least constant division of the limb, is that basic one by which it articulates with the hæmal arch. It seems to us that, so far from proving his hypothesis, Profess $2 r$ Owen's own facts tend to show that limbs do not belong to the vertebræ at all; that they make their first appearance peripherally; that their development is centripetal; and that they become fixed to such parts of the vertebrate axis as the requirements of the case determine.

But now, ending here this digressive exposition and criticism, and granting the position that limbs " are developments of costal appendages," let us return to the question above put-Why are not these appendages included as elements of the "ideal typical vertebra ?" It cannot be because of their comparative inconstancy ; for judging from the illustrative figures, they seem to be as constant as the hæmal spine, which is one of the so-called autogenous elements: in the diagram of the Archetypus, the appendage is represented as attached to every vertebrate segment of the head and trunk, which the hæmal spine is not. It eannot be from their comparative unimportance: sceing that as potential limbs they are essential parts of nearly all the Vertebrata-much more obviously so than the diapophyses are. If, as Professor Owen argues, "the divine mind which planned the archetype also foreknew all its modifications;" and if, among these modifieations, the development of limbs out of diverging appendages was one intended to characterize all the higher Vertebrata; then, surely, these diverging appendages must have been parts of the "ideal typical vertebra." Or, if the "ideal typical vertebra" is to be understood as a crystalline form in antagonism with the organizing prineiple; then why should not the appendages be included among its various offshoots? We do not ask this question because of its intrinsic importance. We ask it for the purpose of ascertaining Professor Owen's method of determining what are true vertebral constituents. He presents us with a diagram of the typical vertebra, in which are included certain bones, and from which are excluded certain others. If relative constancy is the criterion, then there arises the questionWhat degree of constaney entitles a bone to be included? If relative importance is the criterion, there comes not only the question -What degree of importance suffices? but the further question - How is importance to be measured? If neither of these is the criterion, then what is it? And if there is no criterion, does it not follow that the selection is arbitrary?

This question serves to introduce a much wider one:- Has the "ideal typical vertebra" any essential constituents at all ? It might 
naturally be supposed that though some bones are so rarely developed as not to seem worth including, and though some that are included are very apt to be absent, vet that certain others are invariable: forming, as it were, the basis of the ideal type. Let us see whether the facts bear out this supposition. In his " summary of modifications of corporal vertebræ" (p. 96), Professor Owen says-"The homal spine is much less constant as to its existence, and is subject to a much greater range of variety, when present, than its vertical homotype above, which completes the neural arch." Again he says_-"The homapophyses, as osseous elements of a vertebra, are less constant than the pleurapophyses." And again"The pleurapophyses are less constant elements than the neurapophyses." And again-"Amongst air-breathing vertebrates the pleurapophyses of the trunk segments are present only in those species in which the septum of the heart's ventricle is complete and imperforate, and here they are exogenous and confined to the cervical and anterior thoracic vertebræ." And once more, both the neurapophyses and the neural spine " are absent under both histological conditions, at the end of the tail in most air-breathing vertebrates, where the segments are reduced to their central elements." That is to say, of all the peripheral elements of the "ideal typical vertebra," there is not one which is always present. It will be expected, however, that at any rate the centrum is constant: the bone which "forms the axis of the vertebral column, and commonly the central bond of union of the peripheral elements of the vertebrate (p. 97), is of course an invariable element. No: not even this is essential.

"The eentrums do not pass beyond the primitive stage of the notochord (undivided column) in the existing lepidosiren, and they retained the like rudimental state in every fish whose remains have been found in strata earlier than the permian æra in Geology, though the number of vertebræ is frequently indicated in Devonian and Silurian ichthyolites by the fossilized neur- and hæmapophyses and their spines" (p. 96).

Indeed, Professor Owen himself remarks that "the neurapophyses are more constant as osseous or cartilaginous elements of the vertebræ than the centrums" (p. 97). Thus, then, it appears that the several elements included in the "ideal typical vertebra" have various degrees of constancy, and that no one of them is essential. There is no one part of a vertebra which invariably answers to its exemplar in the pattern-group. How does this fact consist with the hypothesis? If the Creator saw fit to make the vertebrate skeleton out of a series of segments, all formed on essentially the same model -if, for the maintenance of the type, one of these bony segments is in many cases formed out of a coalesced group of picces, where, as Professor Owen argues, a single piece would have served as well or better; then we ought to find this typical repetition of parts 
uniformly manifested. Without any change of shape, it would obviously have been quite possible for every actual vertebra to have contained all the parts of the ideal one-rudimentally where they were not wanted. Even one of the terminal bones of a mammal's tail might have been formed out of the nine autogenous pieces, united by suture but admitting of identification. As, however, there is no such uniform typical repetition of parts, it seems to us that to account for the typical repetition which does occur, by supposing the Creator to have fixed on a pattern-vertebra, is to ascribe to him the inconsistency of forming a plan and then abandoning it.

If, on the other hand, Professor Owen means that the "ideal typical vertebra" is a crystalline form in antagonism with "the idea or organizing principle;" then we might fairly expect to find it most clearly displaying its crystalline character, and its full complement of parts, in those places where the organizing principle may be presumed to have "subdued" it to the smallest extent. Yet in the Vertebrata generally, and even in Professor Owen's Archetypus, the vertebræ of the tail, which must be considered as, if anything, less under the influence of the organizing principle than those of the trunk, do not manifest the ideal form more com. pletely. On the contrary, as we approach the end of the tail, the successive segments not only lose their remaining typical elements, but become as uncrystalline-looking as can be conceived.

Supposing, however, that the assumption of suppressed or undeveloped elements be granted-supposing it to be consistent with the hypothesis of an "ideal typical vertebra," that the constituent parts may severally be absent in greater or less number, sometimes leaving only a single bone to represent them all; may it not be that such parts as are present, show their respective typical natures by some constant character: say their mode of ossification?

To this question some parts of the Archetype and Homologies seem to reply, "Yes;" while others clearly answer, "No." Criticising the opinions of Geoffroy St. Hilaire and Cuvier, who agreed in thinking that ossification from a separate centre was the test of a separate bone, and that thus there were as many elementary bones in the skeleton as there were centres of ossification, Professor Owen points out that, according to this test, the human femur, which is ossified from four centres, must be regarded as four bones; whilc the femur in birds and reptiles, which is ossified from a single centre, must be regarded as a single bone. Yct, on the other hand, he attaches weight to the fact that the skull of the human fœetus presents "the same ossific centres" as do those of the embryo kangaroo and the young bird. (Nature of Limbs, p. 40.) And at p. 104 of the Homologies, after giving a number of instances, he says-

"These and the like correspondences between the points of ossification of 
the human fotal skeleton, and the separate bones of the adult skeletons of inferior animals, are pregnant with interest, and rank among the most striking illustrations of unity of plan in the vertebrate organization."

It is true that on the following page he seeks to explain this seeming contradiction by distinguishing

" between those centres of ossification that have homological relations, and those that have teleological ones-i.e., between the separate points of ossification of a human bone which typify vertebral elements, often permanently distinct bones in the lower animals; and the separate points which, without such signification, facilitate the progress of osteogeny, and have for their obvious final cause the well-being of the growing animal."

But if there are thus centres of ossification which have homological meanings, and others which have not, there arises the question-How are they always to be distinguished? Evidently independent ossification ceases to be a homological test, if there are independent ossifications that have nothing to do with the homologies. And this becomes the more evident when we learn that there are cases where neither a homological nor a teleological meaning can be given. Among various modes of ossification of the centrum, Professor Owen points out that " the body of the human atlas is sometimes ossified from two, rarely from three, distinct centres placed side by side" (p. 89); while at p. 87 he says :- "In osseous fishes I find that the centrum is usually ossified from six points." It is clear that this mode of ossification has here no homological signification; and it would be difficult to give any teleological reason why the small centrum of a fish should have more centres of ossification than the large centrum of a mammal. The truth is, that as a criterion of the identity or individuality of a bone, mode of ossification is quite untrustworthy. Though, in his "ideal typical vertebra," Professor Owen delineates and classifies as separate "autogenous" elements, those parts which are "usually developed from distinct and independent centres;" and though by doing so he erects this characteristic into some sort of criterion; yet his own facts show it to be no criterion. The parapophyses are classed among the autogenous elements; yet they are autogenous in fishes alone, and in these only in the trunk vertebræ, while in all air-breathing vertebrates they are, when present at all, exogenous. The neurapophyses, again, "lose their primitive individuality by various kinds and degrees of confluence :" in the tails of the higher Vertebrata they, in common with the neural spine, become exogenous. Nay, even the centrum may lose its antogenous character. Describing how, in some batrachians, "the ossification of the centrum is completed by an extension of bone from the bases of the neurapophyses, which effects also the coalescence of these with the centrum," Professor Ower adds:"In Pelobates fuscus and Pelobates cultripes, Müller found the en- 
tire centrum ossified from this source, without any independent points of ossification" (p. 88). That is to say, the centrum is in these cases an exogenous process of the neurapophyses. We see, then, that these so-called typical elements of vertebræ have no constant developmental character by which they can be identified. Not only are they undistinguishable by any specific test from other bones not included as vertebral elements; not only do they fail to show their typical characters by their constant presence; but, when present, they exhibit no persistent marks of individuality. The central element may be ossified from six, four, three, or two points; or it may have no separate point of ossification at all: and similarly with various of the peripheral elements. The whole group of bones forming the "ideal typical vertebra" may severally have their one or more ossific centres; or they may, as in a mammal's tail, lose their individualities in a single bone ossified from one or two points.

Another fact which seems very difficult to reconcile with the hypothesis of an "ideal typical vertebra," is the not infrequent presence of some of the typical elements in duplicate. Not only, as we have seen, may they severally be absent, but they may severally be present in greater number than they should be. When we see, in the ideal diagram, one centrum, two neurapophyses, two pleurapophyses, two hæmapophyses, one neural spine, and one hremal spine, we naturally expect to find them always bearing to each other these numerical relations. Though we may not be greatly surprised by the absence of some of them, we are hardly prepared to find others multiplied. Yet such cases are common. Thus the neural spine " is double in the anterior vertebræ of some fishes" (p. 98). Again, in the abdominal region of extinct saurians, and in crocodiles, "the freely-suspended hæmapophyses are compounded of two or more overlapping bony pieces" (p. 100). Yet again, at p. 99, we read- "I have observed some of the expanded pleurapophyses in the great Testudo elephantopus ossified from two centres, and the resulting divisions continuing distinct, but united by suture." Once more "the neurapophyses, which do not advance beyond the cartilaginous stage in the sturgeon, consist in that fish of two distinct pieces of cartilage; and the anterior pleurapophyses also consist of two or more cartilages, set end on end" (p. 91). And elsewhere referring to this structure, he says:-

"Vegetative repetition of perivertebral parts not only manifests itself in the composite neurapophyses and pleurapophyses, but in a small accessory (interneural) cartilage, at the fore and back part of the base of the neurapophysis; and by a similar (interhæmal) one at the fore and back part of most of the parapophyses" (p. 87).

Thus the neural and hremal spines, the neurapophyses, the pleu- 
rapophyses, the hamapophyses, may severally consist of two or more pieces. This is not all: the like is true even of the centrums.

"In Heptanchus (Squalus cinerens) the vertebral centres are feebly and vegetatively marked out by numerous slender rings of hard cartilage in the notochordal capsule, the number of vertebræ being more definitely indicated by the neurapophyses and parapophyses. . . . In the piked dog-fish (Acanthias) and the spotted dog-fish (Scyllium) the vertebral centres coincide in number with the neural arehes" (p. 87).

Is it not strange that the pattern vertebra should be so little adhered to, that each of its single typical pieces may be transformed into two or three?

But there are still more startling departures from the alleged type. The numerical relations of the elements vary not only in this way, but in the opposite way. A given part may be present not only in greater number than it should be, but also in less. In the tails of homocercal fishes, the centrums " are rendered by centripetal shortening and bony confluence fewer in number than the persistent, neural, and hæmal arches of that part" - that is, there is only a fraction of a centrum to each vertebra. Nay, even this is not the most heteroclite structure. Paradoxical as it may seem, there are cases in which the same vertebral element is, considered under different aspects, at once in excess and defect. Speaking of the hæmal spine, Professor Owen says:-

"The horizontal extension of this vertebral element is sometimes aceompanied by a median division, or in other words, it is ossified from two lateral centres; this is seen in the development of parts of the human sternum; the same vegetative character is constant in the broader thoracic hæmal spines of birds; though, sometimes, as e.g., in the struthionidæ, ossification extends from the same lateral centre lengthwise-i.e., forcards and backwards, calcifying the connate cartilaginous homologues of halves of four or five homal spines, before these finally coalesce with their fellows at the median line" (p. 101).

So that the sternam of the ostrich, which according to the hypothesis, should, in its cartilaginous stage, have consisted of four or five transverse pieces, answering to the vertebral segments, and should have been ossified from four or five centres, one to each cartilaginous piece, shows not a trace of this structure; but instead, consists of two longitudinal pieces of cartilage, each ossified from one centre, and finally coalescing on the median line. These four or five hæmal spines have at the same time doubled their individualities transversely, and entirely lost them longitudinally!

There still remains to be considered the test of relative position. It might be held that, spite of all the foregoing anomalies, if the typical parts of the vertebræ always stood towards each other in the same relations-always preserved the same connexions, something like a case would be made out. Doubtless, relative position 
is an important point; and it is one on which Professor Owen manifestly places great dependence. In his discussion of "moot cases of special homology," it is the general test to which he appeals. The typical natures of the alisphenoid, the mastoid, the orbitosphenoid, the prefrontal, the malar, the squamosal, \&c., he determines almost wholly by reference to the adjacent nerve-perforations and the articulations with neighbouring bones (see pp. 19 to 72): the general form of the argument being-This bone is to be classed as such or such, because it is connected thus and thus with these others, which are so and so. Moreover, by putting forth an "ideal typical vertebra," consisting of a number of elements standing towards each other in certain definite arrangement, this persistency of relative position is manifestly alleged. The essential attribute of this group of bones, considered as a typical group, is the constancy in the connexions of its parts : change the connexions, and the type is changed. But the constancy of relative position thus tacitly asserted, and appealed to as a conclusive test in "moot cases of special homology," is clearly negatived by Professor Owen's own facts. For instance, in the "ideal typical vertebra," the hæmal arch is represented as formed by the two hæmapophyses and the hæmal spine; but at p. 91 we are told that

"The contracted hæmal arch in the caudal region of the body may be formed by different elements of the typical vertebra: e.g., by the parapopbyses (fishes generally); by the pleurapophyses (lepidosiren); by both parapophyses and pleurapophyses (Sudis, Lepidosteus), and by hæmapophyses, shortened and directly articulated with the centrums (reptiles and mammals)."

And further, in the thorax of reptiles, birds, and mammals, "the hæmapophyses are removed from the centrum, and are articulated to the distal ends of the pleurapophyses; the bony hoop being completed by the intercalation of the hæmal spine" (p. 82). So that there are five different ways in which the hæmal arch may be formed -four modes of attachment of the parts different from that shown in the typical diagram! Nor is this all. The pleurapophyses " may be quite detached from their proper segment, and suspended to the hæmal arch of another vertebra:" as we have already seen, the entire hæmal arch may be detached and removed to a distance, sometimes reaching the length of twenty-seven vertebræ; and, even more remarkable, the ventral fins of some fishes, which theoretically belong to the pelvic arch, are so much advanced forward as to be articulated to the scapular arch-" the ischium elongating to join the coracoid." With these admissions it seems to us that relative position and connexions cannot be appealed to as tests of homology, nor as evidence of any original type of vertebra.

In no class of facts, then, do we find a good foundation for the hypothesis of an "ideal typical vertebra." There is no one con- 
ceivable attribute of this archetypal form which is habitually realised by actual vertebræ. The alleged group of true vertebral elements is not distinguished in any specified way from bones not included in it. Its members have various degrees of inconstancy; are rarely all present together; and no one of them is essential. They are severally developed in no uniform way: each of them may arise either out of a separate piece of cartilage, or out of a piece continuous with that of some other element; and each may be ossified from many independent points, from one, or from none. Not only may their respective individualities be lost by absence, or by confluence with others; but they may be doubled, or tripled, or halved, or may be multiplied in one direction and lost in another. The entire group of typical elements may coalesce into one simple bone representing the whole vertebra; and even, as in the terminal piece of a bird's tail, half-a-dozen vertebræ, with all their many elements, may become entirely lost in a single mass. Lastly, the respective elements, when present, have no fixity of relative position: sundry of them are found articulated to various others than those with which they are typically connected; they are frequently displaced and attached to neighbouring vertebræ; and they are even removed to quite remote parts of the skeleton. It seems to us that if this want of congruity with the facts does not disprove the hypothesis, no such hypothesis admits of disproof.

Unsatisfactory as is the evidence in the case of the trunk and tail vertebræ, to which we have hitherto confined ourselves, it is far worse in the case of the alleged cranial vertebræ. The mere fact that those who have contended for the vertebrate structure of the skull, have differed so astonishingly in their special interpretations of it, is enough to warrant great doubt as to the general truth of their theory. From Professor Owen's history of the doctrine of general homology, we gather that Duméril wrote upon "la tête considérée comme une vertèbre;" that Kielmeyer, "instead of calling the skull a vertebra, said each vertebra might be called a skull;" that Oken recognized in the skull three vertebræ and a rudiment; that Professor Owen himself makes out four vertebræ; that Goethe's idea, adopted and developed by Carus, was, that the skull is composed of six vertebræ; and that Geoffroy St. Hilaire divided it into seven. Does not the fact that different comparative anatomists have arranged the same group of bones into one, three, four, six, and seven vertebral segments, show that the mode of determination is arbitrary, and the conclusions arrived at fanciful? May we not properly entertain great doubts as to any one scheme being more valid than the others? And if out of these conflicting schemes we are asked to accept one, ought we not to accept it only on the production of some thoroughly conclusive proof-some 
rigorous test showing irrefragably that the others must be wrong and this alone right? Evidently where such contradictory opinions have been formed by so many competent judges, we ought, before deciding in favour of one of them, to have a clearness of demonstration much exceeding that required in any ordinary case. Let us see whether Professor Owen supplies us with any such clearness of demonstration.

To bring the first or occipital segment of the skull into correspondence with the "ideal typical vertebra," Professor Owen argues, in the case of the fish, that the parapophyses are displaced, and wedged between the neurapophyses and the neural spine-removed from the hæmal arch and built into the upper part of the neural arch. Further, he considers that the pleurapophyses are teleologically compound. And then, in all the higher vertebrata, he alleges that the hæmal arch is separated from its centrum, taken to a distance, and transformed into the scapular arch. Add to which, he says that in mammals the displaced parapophyses are mere processes of the neurapophyses (p.. 133): these vertebral elements, typically belonging to the lower part of the centrum, and in nearly all cases confluent with it, are not only removed to the far ends of elements placed above the centrum, but have become exogenous parts of them!

Conformity of the second or parietal segment of the cranium with the pattern-vertebra, is produced thus:-The petrosals are excluded as being partially-ossified sense-capsules, not forming parts of the true vertebral system, but belonging to the "splanchno-skeleton." A centrum is artificially obtained by sawing in two the bone which serves in common as centrum to this and the preceding segment; and this though it is admitted that in fishes, where their individualities ought to be best seen, these two hypothetical centrums are not simply coalescent, but connate. Next, a similar arbitrary bisection is made of certain elements of the hæmal arches. And then, "the principle of vegetative repetition is still more manifest in this arch than in the occipital one:" each pleurapophysis is double; each hæmapophysis is double ; and the hæmal spine consists of six pieces!

The interpretation of the third and fourth segments being of the same general character, need not be detailed. The only point calling for remark being, that in addition to the above various modes of getting over anomalies, we find certain bones referred to the dermo-skeleton.

Now it secms to us, that even supposing no antagonist interpretations had been given, an hypothesis reconcilable with the facts only by the aid of so many questionable devices, could not be considered satisfactory ; and that when, as in this case, various comparative anatomists have contended for other interpretations, the character of this one is certainly not of a kind to warrant the rejection of the others in its favour; but rather of a kind to make 
us doubt the possibility of all such interpretations. The question which naturally arises is, whether by proceeding after this fashion, groups of bones might not be arranged into endless typical forms. If, when a given element was not in its place, we were at liberty to consider it as suppressed, or connate with some neighbouring element, or removed to some more or less distant position;-if, on finding a bone in excess, we might consider it, now as part of the dermoskeleton, now as part of the splanchno-skeleton, now as transplanted from its typical position, now as resulting from vegetative repetition, and now as a bone teleologically compound (for these last two are intrinsically different, though often used by Professor Owen as equivalents); -if, in other cases, a bone might be regarded as spurious (p. 91), or again as having usurped the place of another; -if, we say, these various liberties were allowed us, we should not despair of reconciling the facts with various diagrammatic types besides that adopted by Professor Owen.

When, in 1851, we attended a course of Professor Owen's lectures on Comparative Osteology, beginning though we did in the attitude of discipleship, our scepticism grew as we listened, and reached its climax when we came to the skull; the reduction of which to the vertebrate structure, reminded us very much of the interpretation of prophecy. The delivery, at the Royal Society, of the Croonian Lecture for 1858, in which Professor Huxley, confirming the statements of several German anatomists, has shown that the facts of embryology do not countenance Professor Owen's views respecting the formation of the cranium, has induced us to reconsider the vertebral theory as a whole. Closer examination of Professor Owen's doctrines, as set forth in his works, has certainly not removed the scepticism generated years ago by his lectures. On the contrary, that scepticism has deepened into disbelief. Andweventure to think that the evidence above cited shows this disbelief to be warranted.

There remains the question-What general views are we to take respecting the vertebrate structure? If the hypothesis of an "ideal typical vertebra" is not justified by the facts, how are we to understand that degree of similarity which vertebræ display?

We believe the explanation is not far to seek. All that our space will here allow, is a brief indication of what seems to us the natural view of the matter.

Professor Owen, in common with other comparative anatomists, regards the divergences of individual vertebræ from the average form, as due to adaptive modifications. If here one vertebral element is largely developed, while elsewhere it is small-if now the form, now the position, now the degree of coalescence, of a given part varies; it is that the local requirements have involved this change. The entire teaching of comparative osteology implies that 
differences in the conditions of the respective vertebræ necessitate differences in their structures.

Now, it seems to us that the first step towards a right conception of the phenomena, is to recognize this general law in its converse application. If vertebræ are unlike in proportion to the unlikeness of their circumstances, then, by implication, they will be like in proportion to the likeness of their eircumstances. Wbile successive segments of the same skeleton, and of different skeletons, are all in some respects more or less differently acted on by incident forces, and are therefore required to be more or less different; they are all, in other respects, similarly acted on by incident forces, and are therefore required to be more or less similar. It is impossible to deny that if differences in the mechanical functions of the vertebrw involve differences in their forms; then, community in their mechanical functions, nust involve community in their forms. And as we know that throughout the Vertebrata generally, and in each vertebrate animal, the vertebræ, amid all their varying circumstances, have a certain community of function, it follows necessarily that they will have a certain general resemblance-there will recur that average shape which has suggested the notion of a pattern vertebra.

A glance at the facts at once shows their harnony with this conclusion. In an eel or a snake, where the bodily actions are such as to involve great homogeneity in the mechanical conditions of the vertebræ, the series of them is comparatively homogeneous. On the contrary, in a mammal or a bird, where there is considerable heterogeneity in their circumstances, their similarity is no longer so great. And if, instead of comparing the vertebral columns of different animals, we compare the successive vertebræ of any one animal, we recognize the same law. In the segments of an individual spine, where is there the greatest divergence from the common mechanical conditions? and where may we therefore expect to find the widest departure from the average form? Obviously at the two extremities. And accordingly it is at the two extremities that the ordinary structure is lost.

Still clearer becomes the truth of this view, when we consider the genesis of the vertebral column as displayed throughout the ascending grades of the Vertebrata. In its first embryonic stage, the spine is an undivided column of flexible substance. In the early fishes, while some of the peripheral elements of the vertetıræ were marked out, the central axis was still a continuous unossified cord. And thus we have good reason for thinking that in the primitive vertebrate animal, as in the existing Amphioxus, the notochord was persistent. The production of a higher, more powerful, more active creature of the same type, by whatever method it is conceived to have taken place, involved a change in the notochordal structure. Greater muscular endowments presupposed a firmer internal fulcrum 
-a less yielding central axis. On the other hand, for the central axis to have become firmer while remaining continuous, would have entailed a stiffness incompatible with the creature's movements. Hence, increasing density of the central axis necessarily went hand in hand with its segmentation: for strength, ossification was required ; for flexibility, division into parts. The production of vertebræ resulting thus, there obviously would arise among them a general likeness, due to the similarity in their mechanical conditions, and more especially the muscular forces bearing on them. And then observe, lastly, that where, as in the head, the terminal position and the less space for development of muscles, entailed smaller lateral bendings, the segmentation wonld naturally be less decided, less regular, and would be lost as we approached the front of the head.

But, it may be replied, this hypothesis does not explain all the facts. It does not tell us why a bone whose function in a given animal requires it to be solid, is formed not of a single piece, but by the coalescence of several pieces, which in other creatures are separate; it does not account for the frequent manifestations of unity of plan in defiance of teleological requirements. This is quite true. But it is not true, as Professor Owen argues respecting such cases, that " if the principle of special adaptation fails to explain them, and we reject the idea that these correspondences are manifestations of some archetypal exemplar, on which it has pleased the Creator to frame certain of his living creatures, there remains only the alternative that the organic atoms have concurred fortuitously to produce such harmony." This is not the only alternative: there is another, which Professor Owen has overlooked. It is a perfectly tenable supposition that all higher vertebrate forms have arisen by the superposing of adaptations upon adaptations. Either of the two antagonist cosmogonies consists with this supposition. If, on the one hand, we conceive species to have resulted from acts of special creation; then it is quite a fair assumption that to produce a higher vertebrate animal, the Creator did not begin afresh, but took a lower vertebrate animal, and so far modified its pre-existing parts as to fit them for the new requirements; in which case the original structure would show itself through the superposed modifications. If, on the other hand, we conceive species to have resulted by gradual differentiations under the influence of changed conditions; then, it would manifestly follow that the higher, heterogeneous forms, would bear traces of the lower and more homogeneous forms from which they were evolved.

Thus, besides finding that the hypothesis of an "ideal typical vertebra" is irreconcilable with the facts, we find that the facts are interpretable without gratuitous assumptions. The average community of form which vertebræ display, is explicable as resulting 
from natural causes. And those typical similarities which are traceable under adaptive modifications, must obviously exist if, throughout creation in general, there has gone on that continuous superposing of modifications upon modifications which goes on in every unfolding organism.

[I might with propriety have added to the foregoing criticisms, the remark that Professor Owen has indirectly conferred a great benefit by the elaborate investigations he has made with the view of establishing his hypothesis. He has himself very conclusively proved that the teleological interpretation is quite irreconcilable with the facts. In gathering together evidence in support of his own conception of archetypal forms, he has disclosed adverse evidence which I think shows his conception to be untenable. The result is that the field is left clear for the hypothesis of Evolution as the only tenable one.] 


\section{APPENDIX C.}

[From the Transactions of the Linnean Society, vol. xxv.]

XV. On Circulation and the Formation of Wood in Plants. By Herbert Spencer, Esq. Communicated by George Busk, Esq., F.R.S., Sec. L.S.

\section{Read March 1st, 1866.}

Opinions respecting the functions of the vascular tissues in plants appear to make but little progress towards agreement. The supposition that these vessels and strings of partially-united cells, lined with spiral, annular, reticulated, or other frameworks, are carriers of the plant-juices, is objected to on the ground that they often contain air : as the presence of air arrests the movement of blood through arteries and veins, its presence in the ducts of stems and petioles is assumed to unfit them as channels for sap. On the other hand, that these structures have a respiratory office, as some have thought, is certainly not more tenable, since, if the presence of air in them negatives the belief that their function is to distribute liquid, the presence of liquid in them equally negatives the belief that their function is to distribute air. Nor can any better defence be made for the hypothesis which I find propounded, that these parts serve "to give strength to the parenchyma." Tubes with fenestrated and reticulated internal skeletons have, indeed, some power of supporting the tissue through which they pass; but tubes lined with spiral threads can yield extremely little support, while tubes lined with annuli, or spirals alternating with annuli, can yield no support whatever. Though all these types of internal framework are more or less efficient for preventing closure by lateral pressure, they are some of them quite useless for holding up the mass through which the vessels pass; and the best of them are for this purpose mechanically inferior to the simple cylinder. The same quantity of matter made into a continuous tube would be more effective in giving stiffness to the cellular tissue around it.

In the absence of any feasible alternative, the hypothesis that these vessels are distributors of sap claims reconsideration. The objections are not, I think, so serious as they seem. The habitual 
presence of air in the ducts that traverse wood, can scarcely be held anomalous if when the wood is formed their function ceases. The canals which ramify through a Stag's horn, contain air after the Stag's horn is fully developed; but it is not thereby rendered doubtful whether it is the function of arteries to convey blood. Again, that air should frequently be found even in the vessels of petioles and leaves, will not appear remarkable when we call to mind the conditions to which a leaf is subject. Evaporation is going on from it. The thinner liquids pass by osmose out of the vessels into the tissues containing the liquids thickened by evaporation. And as the vessels are thus continually drained, a draught is made upon the liquid contained in the stem and roots. Suppose that this draught is unusually great, or suppose that around the roots there exists no adequate supply of moisture. A state of capillary tension must result-a tendency of the liquid to pass into the leaves resisted below by liquid cohesion. Now, had the vessels impermeable coats, only their upper extremities would under these conditions be slowly emptied. But their coats, in common with all the surrounding tissues, are permeable by air. Hence, under this state of capillary tension, air will enter; and as the upper ends of the tubes, being both smaller in diameter and less porous than the lower, will retain the liquids with greater tenacity, the air will enter the wider and more porous tubes below-the ducts of the stem and branches. Thus the entrance of air no more proves that these ducts are not sap-carriers, than does the emptiness of tropical river-beds in the dry season prove that they are not channels for water. There is, however, a difficulty which seems more serious. It is said that air, when present in these minute canals, must be a great obstacle to the movement of sap through them. The investigations of Jamin have shown that bubbles in a capillary tube resist the passage of liquid, and that their resistance becomes very great when the bubbles are numerous-reaching, in some experiments, as much as three atmospheres. Nevertheless the inference that any such resistance is offered by the air-bubbles in the vessels of a plant, is, I think, an erroneous one. What happens in a capillary tube having impervious sides, with which these experiments were made, will by no means happen in a capillary tube having pervious sides. Any pressure brought to bear on the column of liquid contained in the porous duct of a plant, must quickly cause the expulsion of a contained air-bubble through the minute openings in the coats of the duct. The greater molecular mobility of gases than liquids, implies that air will pass out far more readily than sap. Whilst, therefore, a slight tension on the column of sap will cause it to part and the air to enter, a slight pressure upon it will force out the air and reunite the divided parts of the column.

To obtain data for an opinion on this vexed question, I have 
lately been experimenting on the absorption of dyes by plants. So far as I can learn, experiments of this kind have most, if not all of them, been made on stems, and, as it would seem from the results, on stems so far developed as to contain all their characteristic structures. The first experiments I made myself were on such parts, and yielded evidence that served but little to elucidate matters. It was only after trying like experiments with leaves of different ages and different characters, and with undeveloped axes, as well as with axes of special kinds, that comprehensible results were reached; and it then became manifest that the appearances presented by ordinary stems when thus tested, are in a great degree misleading. Let me briefly indicate the differences.

If an adult shoot of a tree or shrub be cut off, and have its lower end placed in an alumed decoction of logwood or a dilute solution of magenta, * the dye will, in the course of a few hours, ascend to a distance varying according to the rate of evaporation from the leaves. On making longitudinal sections of the part traversed by it, the dye is found to have penetrated extensive tracts of the woody tissue ; and on making transverse sections, the openings of the ducts appear as empty spaces in the midst of a deeply-coloured prosenchyma. It would thus seem that the liquid is carried up the denser parts of the vascular bundles; neglecting the cambium layer, neglecting the central pith, and neglecting the spiral vessels of the medullary sheath. Apparently the substance of the wood has afforded the readiest channel. When, however, we examine these appearances critically, we find reasons for doubting this conclusion. If a transverse section of the lower part, into which the dye passed first and has remained longest, be compared with a transverse section of the part which the dye has but just reached, a marked difference is visible. In the one case the whole of the dense tissue is stained; in the other case it is not. This uneven distribution of stain in the part which the dye has incompletely permeated is not at random; it admits of definite description. A tolerably regular continuous ring of colour distinguishes the outer part of the wood from the inner mass, implying a passage of liquid up the elongated cells next the cambium layer. And the inner mass is coloured more round the mouths of the pitted ducts than elsewhere: the dense tissue is darkest close to the edges of these ducts; the colour fades away gradually on receding from their edges; there is most colour where there are several ducts together; and the dense tissue which

* These two dyes have affinities for different components of the tissues, and may be advantageously used in different cases. Magenta is rapidly taken up by woody matter and other secondary deposits; while logwood colours the cell-membranes, and takes but reluctantly to the substances seized by magenta. By trying both of them on the same structure, we may guard ourselves against any error arising from selective combination. 
is fully dyed for some space, is that which lies between two or more ducts. These are indications that while the layer of pitted cells next the cambium has served as a channel for part of the liquid, the rest has ascended the pitted ducts, and oozed out of these into the prosenchyma around. And this conclusion is confirmed by the contrast between the appearances of the lowest part of a shoot under different conditions. For if, instead of allowing the dye time for oozing through the prosenchyma, the end of the shoot be just dipped into the dye and taken out again, we find, on making transverse sections of the part into which the dye has been rapidly taken up, that, though it has diffused to some distance round the ducts, it has left tracts of wood between the ducts uncoloured-a difference which would not exist had the ascent been through the substance of the wood. Even still stronger is the confirmation obtained by using one dye after another. If a shoot that has absorbed magenta for an hour be placed for five minutes in the logwood decoction, transverse sections of it taken at a short distance from its end show the mouths of the ducts surrounded by dark stains in the midst of the much wider red stains.

Based on these comparisons only, the inference pointed out has little weight; but its weight is increased by the results of experiments on quite young shoots, and shoots that develope very little wood. The behaviour of these corresponds perfectly with the expectation that a liquid will ascend capillary tubes in preference to simple cellular tissue or tissue not differentiated into continuous canals. The vascular bundles of the medullary sheath are here the only channels which the coloured liquid takes. In sections of the parts up to which the dye has but just reached, the spiral, fenestrated, scalariform, or other vessels contained in these bundles are alone coloured, and lower down it is only after some hours that such an exudation of dye takes place as suffices partially to colour the other substances of the bundle. Further, it is to be noted that at the terminations of shoots, where the vessels are but incompletely formed out of irregularly-joined fibrous cells which still retain their original shapes, the dye runs up the incipient vessels and does not colour in the smallest degree the surrounding tissue.

Experiments with leaves bring out parallel facts. On placing in a dye a petiole of an adult leaf of a tree, and putting it before the fire to accelerate evaporation, the dye will be found to ascend the midrib and veins at various rates, up even to a foot per hour. At first it is confined to the vessels; but by the time it has reached the point of the leaf, it will commonly be seen that at the lower part it has diffused itself into the sheaths of the vessels. In a quite young leaf from the same shoot, we find a much more rigorous restriction of the dye to the vessels. On making oblique sections of its petiole, midrib, and veins, the vessels have the appcarance of groups of 
sharply defined coloured rods imbedded in the green prosenchyma; and this marked contrast continues with scarcely an appreciable change after plenty of time has been allowed for exudation.

The facts thus grouped and thus contrasted seem, at first sight, to imply that while they are young the coats of these ramifying canals lined with spiral or allied structures are not readily permeable, but that, becoming porous as they grow old, they allow the liquids they carry to escape with increasing facility; and hence a possible interpretation of the fact that, in the older parts, the staining of the tissue around the vessels is so rapid as to suggest that the dye has ascended directly through this tissue, whereas in the younger parts the reverse appearance necessitates the reverse conclusion. But now, is this difference determined by difference of age, or is it otherwise determined? The cvidence as presented in ordinary stems and leaves shows us that the parts of the vascular system at which there is a rapid escape of dye are not simply older parts, but are parts where a deposit of woody matter is taking place. Is it, then, that the increasing permeability of the ducts, instead of being directly associated with their increasing age, is directly associated with the increasing deposit of dense substance around them?

To get proof that this last connexion is the true one, we have but to take a class of cases in which wood is formed only to a small extent. In such cases experiments show us a far more general and continued limitation of the dye to the vessels. Ordinary herbs and vegetables, when contrasted with shrubs and trees, illustrate this; as instance the petioles of Celery, or of the common Dock, and the leaves of Cabbages or Turnips. And then in very succulent plants, such as Bryophyllum calycinum, Kalanchoë rotundifolia, the various species of Crassula, Cotyledon, Kleinia, and others of like habit, the ducts of old and young leaves alike retain the dye very persistently: the concomitant in these cases being the small amount of prosenchyma around the ducts, or the small amount of deposit in it, or both. More conclusive yet is the evidence which meets us when we turn from very succulent leaves to very succulent axes. The tender young shoots of Kleinia ante-euphorbium, or Euphorbia Mauritanica, which for many inches of their lengths have scarcely any ligneous fibres, show us scarcely any escape of the coloured liquid from the vessels of the medullary sheath. So, too, is it with Stapelia Buffonia, a plant of another order, having soft swollen axes. And then we have a repetition of the like connexion of facts throughout the Cactacea : the most succulent showing us the smallest permeability of the vessels. In two species of Rhipsalis, in two species of Cereus, and in two species of Mammillaria, which I have tried, I have found this so. Mammillaria gracilis may be named as exemplifying the relation under its extreme form. Into one of these small spheroidal masses, the dye ascends through the large bundles 
of spiral or annular ducts, or cells partially united into such ducts. colouring them deeply, and leaving the feebly-marked sheath of prosenchyma, together with the surrounding watery cellular tissue, perfectly uncoloured.

The most conclusive evidence, however, is furnished by those Cactacece in which the transition from succulent to dense tissue takes place variably, according as local circumstances determine. Opuntia yields good examples. If a piece of it including one of the joints at which wood is beginning to form, be allowed to absorb a coloured liquid, the liquid, running up the irregular bundles of vessels and into many of their minute ramifications, is restricted to these where they pass through the parenchyma forming the mass of the stem; but near the joints the hardened tissue around the vessels is coloured. In one of these fleshy growths we get clear evidence that the escape of the dye has no immediate dependence on the age of the vessels, since, in parts of the stem that are alike in age, some of the vessels retain their contents while others do not. Nay, we even find that the younger vessels are more pervious than the older ones, if round the younger ones there is a formation of wood.

Thus, then, is confirmed the inference before drawn, that in ordinary stems the staining of the wood by an ascending coloured liquid is due, not to the passage of the coloured liquid up the substance of the wood, but to the permeability of its ducts and such of its pitted cells as are united into irregular canals. And the facts showing this, at the same time indicate with tolerable clearness the process by which wood is formed. What in these cases is seen to take place with a dye, may be fairly presumed to take place with sap. Where the dye exudes but slowly, we may infer that the sap exudes but slowly; and it is a fair inference that where the dye leaks rapidly out of the vessels, the sap does the same. Inferring, thus, that whereever there is a considerable formation of wood there is a considerable escape of the sap, we see in the one the result of the other. The thickening of the prosenchyma is proportionate to the quantity of nutritive liquid passing into it; and this nutritive liquid passes into it from the vessels, ducts, and irregular canals it surrounds.

But an objection is made to such experiments as the foregoing, and to all the inferences drawn from them. It is said that portions of plants cut off and thus treated, have their physiological actions arrested, or so changed as may render the results misleading; and it is said that when detached shoots and leaves have their cut ends placed in solutions, the open mouths of their vessels and ducts are directly presented with the liquids to be absorbed, which does not happen in their natural states. Further, making these objections look serious, it is alleged that when solutions are alsorbed through the roots, quite different results are obtained: the absorbed matters are found in the tissues and not in the vessels. Clearly, were the ex- 
periments yielding these adverse results conducted in unobjectionable ways, the conclusion implied by them would negative the conclusions above drawn. But these experiments are no less objectionable than those to which they are opposed. Such mineral matters as salts of iron, solutions of which have in some cases been supplied to the roots for their absorption, are obviously so unlike the matters ordinarily absorbed, that they are likely to interfere fatally with the physiological actions. If experiments of this kind are made by immersing the roots in a dye, there is, besides the difficulty that the mineral mordant contained by the dye is injurious to the plant, the further difficulty that the colouring matter, being seized by the substances for which it has an affinity, is left behind in the first layers of root tissues passed through, and that the decolorized water passing up into the plant is not traceable. To be conclusive, then, an experiment on absorption through roots must be made with some solution which will not seriously interfere with the plant's vital processes, and which will not have its distinctive element left behind. To fulfil these requirements I adopted the following method. Having imbedded a well-soaked broad-bean in moist sand, contained in an inverted cone of cardboard with its apex cut off for the radicle to come through-having placed this in a wide-mouthed dwarf bottle, partly filled with water, so that the protruding radicle dipped into the water-and having waited until the young bean had a shoot some three or more inches high, and a cluster of secondary rootlets from an inch to an inch and a-half long-I supplied for its absorption a simple decoction of logwood, which, being a vegetal matter, was not likely to do it much harm, and which, being without a mordant, would not leave its suspended colour in the first tissues passed through. To avoid any possible injury, I did not remove the plant from the bottle, but slightly raising the cone out of its neck, I poured away the water through the crevice and then poured in the logwood decoction; so that there could have been no broken end or abraded surface of a rootlet through which the decoction might enter. Being prepared with some chloride of tin as a mordant, I cut off, after some three hours, one of the lowest leaves, expecting that the application of the mordant to the cut surface would bring ont the characteristic colour if the logwood decoction had risen to that height. I got no reaction, however. But after eight hours I found, on cutting off another leaf, that the vessels of its petiole were made visible as dark streaks by the colour with which they were charged-a colour differing, as was to be expected, from that of the logwood decoction, which spontaneously changes even by simple exposure. It was then too late in the day to pursue the observations; but next morning the vessels of the whole plant, as far as the petioles of its highest unfolded leaves, were full of the colouring-matter; and on applying chloride of tin to the cut surfaces, the vessels assumed that purplish 
red which this mordant produces when directly mixed with the logwood decoction. Subsequently, when onc of the cotyledons was cut open by Prof. Oliver, to whom, in company with Dr. Hooker, I showed the specimen, we found that the whole of its vascular system was filled with the decoction, which everywhere gavethe characteristic reaction. And it became manifest that the liquid absorbed through the rootlets, in the central vessels of which it was similarly traceable, had part of it passed directly up the vessels of the axis, while part of it had passed through other vessels into the cotyledon, out of which, no doubt, the liquid ordinarily so carried returns charged with a supply of the stored nutriment. I have since obtained a verification by varying the method. Digging up some young plants (Marigolds happened to afford the best choice) with large masses of soil round them, placing them in water, so as gradually to detach the soil without injuring the rootlets, planting them afresh in a flower-pot full of washed sand, and then, after a few days, watering them with a logwood decoction, I found, as before, that in less than twentyfour hours the colouring-matter had run up into the vessels of the leaves. Though the reaction produced by the mordant was not so strong as before, it was marked enough to be quite unquestionable.

As these experiments were so conducted that there was no access to the vessels except through the natural channels, and as the vital actions of the plants were so little interfered with that at the end of twenty-four hours they showed no traces of disturbance, I think the results must be held conclusive.

Taking it, then, as a fact that in plants possessing them the vessels and ducts are the channels through which sap is distributed, we come now to the further question-What determines the varying permeability of the walls of the vessels and ducts, and the consequent varying formation of wood? To this question I believe the true reply is -Theexposure of the parts tointermittent mechanical strains, actual or potential, or both. By actual strains I of course mean those which the plant experiences in the course of its individual life. $\mathrm{Bv}$ potential strains I mean those which the form, attitude, and circumstances common to its kind involve, and which its inherited structure is adapted to meet. In plants with stems, petioles, and leaves, having tolerably constant attitudes, the increasing porosity of the tubes and consequent deposit of dense tissue takes place in anticipation of the strains to which the parts of the individual are liable, but takes place at parts which have been habitually subject to such strains in ancestral individuals. But though in such plants the tendency to repeat that distribution of dense tissue caused by mechanical actions on past generations, goes on irrespective of the mechanical actions to which the developing individual is subject, these direct actions, while they greatly aid the assumption of the typical structure, are the sole causes of those deviations in the rela- 
tive thickenings of parts which distinguish theindividual from others of its kind. And then, in certain irregularly growing plants, such as Cactuses and Euphorbias, where the strains fall on parts that do not correspond in successive individuals, we distinctly trace a direct relation between the degrees of strain and the rates of these changes which result in dense tissue. I will not occupy space in detailing the evidence of this relation, which is conspicuous in the orders named, butwill pass to thequestion-What are the physicalprocesses by which intermittent mechanical strains produce this deposit of resistant substance at places where it is needed to meet the strains? We have not to seek far for an answer. If a trunk, a bough, a shoot, or a petiole, is bent by a gust of wind, the substance of its convex side is subject to longitudinal tension: the substance of its concave side being at the same time compressed. This is the primary mechanical effect. There is, however, a secondary mechanical effect, which here chiefly concerns us. That bend by which the tissues of the convex side are stretched, also produces lateral compression of them. Buttoning on a tight glove and then closing the hand, will make this necessity clear : the leather, while it is strained along the backs of the fingers, presses with considerable force on the knuckles. It is demonstrable that the tensions of the outer layer of a mass made convex by bending, must, by composition of forces, produce at every point a resultant at right angles to the layer beneath it ; that, similarly, the joint tensions of these two layers must throw a pressure on the next deeper layer; and so on. Hence, if at some little distance beneath the surface of a stem, twig, or leafstalk, there exist longitudinal tubes, these tubes must be squeezed each time the side of the branch they are placed on becomes convex. Modifying the illustration just drawn from the clenched hand will make this clear. When, on forcibly grasping something, the skin is drawn tightly over the back of the hand, the whitening of the knuckles shows how the blood is expelled from the vessels below the surface by the pressure of the tightened skin. If, then, the sapvessels must be thus compressed, what will happen to the liquid they contain? It will move away along the lines of least resistance. Part, and probably the greater part, will escape length ways from the place of greatest pressure: some of it being expelled downwards, and some of it upwards. But, at the same time, part of it will be likely to ooze through the walls of the tubes. If these walls are so perfect as to permit the passage of liquid only by osmose, it may still be inferred that the osmose will increase under pressure; and probably, under recurrent pressure, the places at which the osmotic current passes most readily will become more and more permeable, until they eventually form pores. At any rate it is manifest that where pores and slits exist, whether thus formed or formed in any other way, the escape of sap into the adjacent tissue at each bend 
will become easy and rapid. What further must happen? When the branch or shoot recoils, the vessels on the side that was convex, being relieved from pressure, will tend to resume their previous diameters; and will be helped to do this by the elasticity of the surrounding tissue, as well as by those spiral, annular, and allied structures which they contain. But this resumption of their previous diameters must cause an immediate rush of sap back into them. Whence will it come? Not to any considerable extent from the surrounding tissues into which part of it has been squeezed, seeing that the resistance to the return of liquid through small pores will be greater than the resistance to its return along the vessels themselves. Manifestly the sap which was thrust up and down the vessels from the place of compression will return - the quantities returning from above and from below varying, as we shall hereafter see, according to circumstances. But this is not all. From some side a greater quantity must come back than was sent away; for the amount that has escaped out of the tube into the prosenchyma has to be replaced. Thus during the time when the side of the branch or twig becomes concave, more sap returns from above or below than was expelled upwards or downwards during the previous compression. The refilled vessels, when the next bend renders their side convex, again have part of their contents forced through their parietes, and are again refilled in the same way. There is thus set up a draught of sap to the place where these intermittent strains are going on, an exudation proportionate to the frequency and intensity of the strains, and a proportionate nutrition or thickening of the wood-cells, fitting them to resist the strains. A rude idea of this action may be obtained by grasping in one hand a damp sponge, having its lower end in water, while holding a piece of blotting-paper in contact with its upper end, and then giving the sponge repeated squeezes. At each squeeze some of the water will be sent into the blotting-paper; at each relaxation the sponge will refill from below, to give another portion of its contents to the blottingpaper when again squeezed.

But how does this explanation apply to roots? If the formation of wood is due to intermittent transverse strains, such as are produced in the aërial parts of upright plants by the wind, how does it bappen that woody matter is deposited in roots, where there are no lateral oscillations, no transverse strains? The answer is, that longitudinal strains also are capable of causing the effects described. It is true that perfectly straight fibres united into a bundle and pulled lengthways would not exert on one another any lateral pressure, and would not laterally compress any similarly-straight canals running along with them. But if the fibres united into a bundle are variously bent or twisted, they cannot be longitudinally strained without compressing one another and structures imbedded in them. It needs 
but to watch a wet rope drawn tight by a capstan, to see that an action like that which squeezes the water out of its strands, will squeeze the sap out of the vessels of a root into the surrounding tissue, as often as the root is pulled by the swaying of the plant it belongs to. Here, too, as before, the vessels will refill when the pull intermits; and so, in the roots as in the branches, this rude pumping process will produce a growth of hard tissue proportionate to the stress to be borne.

These conclusions are supported by the evidence which exceptional cases supply. If intermittent mechanical strains thus cause the formation of wood where wood is found, then where it is not found, there should be an absence of intermittent mechanical strains. There is such an absence. Vascular plants characterized by little or no deposit of dense substance, are those having vessels so conditioned that no considerable pressures are borne by them. The more succulent a petiole or leaf becomes, the more do the effects of transverse strains fall on its outer layers of cells. Its mechanical support is chiefly derived from the ability of these minute vesicles, full of liquid, to resist bursting and tearing under the compressions and tensions they are exposed to. And just as fast as this change from a thin leaf or foot-stalk to a thick one entails increasing stress on the superficial tissue, so fast does it diminish the stress on the internallyseated vascular tissue. The succulent leaf cannot be swayed about by the wind as much as an ordinary leaf; and such small bends as can be given to it and its foot-stalk are prevented from affecting in any considerable degree the tubes running through its interior. Hence the retentiveness of the vessels in these fleshy leaves, as shown by the small exudation of dye; and hence the small thickening of their surrounding prosenchyma by woody deposit. Still more conspicuously is this connexion of facts shown when, from the soft thick leaves before named and such others as those of Echeveria, Rochea, Pereskia, we turn to the thick leaves that have strong exo-skeletons. Gasteria serves as an illustration. The leathery or horny skin here evidently bears the entire weight of the leaf, and is so stiff as to prevent any oscillation. Here, then, the vessels running inside are protected from all mechanical stress; and accordingly we find that the cells surrounding them are not appreciably thickened.

Equally clear, and more striking because more obviously exceptional, is the evidence given by succulent stems which are leafless. Stapelia Buffonia, having soft procumbent axes not liable to be bent backwards and forwards in any considerable degree by the wind, has, ramifying through its tissue, vessels that allow but an extremely slow escape of dye and have unthickened sheaths. Such of the Euphorbias as have acquired the fleshy character while retaining the arborescentgrowth, like Euphorbia Canariensis, teach us the same truth in another way. In them the forntation of wood around the 
vessels is inconspicuous where the intermittent strains are but slight; but it is conspicuous at those joints on which lateral oscillations of the attached branches throw great extensions and compressions of tissue. Throughout the Cactacea we find varied examples of the alleged relation. Mammillaria furnishes a very marked one. The substance of one of these globular masses, resting on the ground, admits of no bending from side to side; and accordingly its large bundles of spiral and annular vessels, or partially-united cells, have very feebly-marked sheaths not at all thickened. In such types as Cereus and Opuntia we see, as in the Euphorbias, that where little stress falls on the vessels, little deposit takes place around them; while there is much deposit where there is much stress. Here let me add a confirmation obtained since writing the above. After observing among the Cactuses the very manifest relation between strain and the formation of wood, I inquired of Mr. Croucher, the intelligent foreman of the Cactus-house at Kew, whether he found this relation a constant one. He replied that he did, and that he had frequently tested it by artificially subjecting parts of them to strains. Neglecting at the time to inquire how he had done this, it afterwards occurred to me that if he had so done it as to cause constant strains, the observed result would not tell in favour of the foregoing interpretation. Subsequently, however, I learned that he had produced the strains by placing the plants in inclined attitudes - a method which, by permitting oscillations of the strained joints, allowed the strains to intermit. And then, making the proof conclusive, Mr. Croucher volunteered the statement that where he had produced constant strains by tying, no formation of wood took place.

Aberrant growths of another class display the same relations of phenomena. Take first the underground stems, such as the Potato and the Artichoke. The vessels which run through these, slowly take up the dye without letting it pass to any considerable extent into the surrounding tissues. * Only after an interval of many hours does the prosenchyma become stained in some places. Here, as before, an absence of rapid exudation accompanies an absence of woody deposit; and both these go along with the absence of intermittent strains. Take again the fleshy roots. The Turnip, the Carrot, and the Beetroot, have vessels that retain very persistently the coloured liquids they take up. And differing in this, as these roots do, from ordinary roots, we see that they also differ from them in not being woody, and in not being appreciably sub-

* Those who repeat these experiments must be prepared for great irregularities in the rates of absorption. Succulent structures in general absorb mueh more slowly than others, and sometimes will scarcely take up the dye at all. The differences between different structures, and the same structure at different times, probably depend on the degrees in which the tissues are charged with liquid and the rates at which they are losing it by evaporation. 
ject to the usual mechanical actions. In these cases, as in the others, parts that ordinarily become dense, deviate from this typical character when they are not exposed to those forces which produce dense tissue by increasing the extravasation of sap.

To complete the proof that such a relation exists, let me add the results of some experiments on equal and similarly-developed parts, kept respectively at rest and in motion. I have tested the effects on large petioles, on herbaceous shoots, and on woody shoots. If two such petioles as those of Rhubarb, with their leaves attached, have their cut ends inserted in bottles of dye, and the one be bent backwards and forwards while the other remains motionless, there arises, after the lapse of an hour, scarcely any difference in the states of their vessels: a certain proportion of these are in both cases charged with the dye, and little exudation has been produced by the motion. Here, however, it is to be observed that the causes of exudation are scarcely operative; the vascular bundles are distributed all through the mass of the petiole, which is formed of soft watery tissue; and they are, therefore, not so circumstanced as to be effectually compressed by the bends. In herbaceous stems, such as those of the Jerusalem Artichoke and of the Foxglove, an effect scarcely more decided is produced ; and here, too, when we seck a reason, we find it in the non-fulfilment of the mechanical conditions; for thevascular bundles are not so seated between a tough layer of bark and a solid core as to be compressed at each bend. When, however, we come to experiment upon woody shoots, we meet with conspicuous effects, though by no means uniformly. In some cases oscillations produce inmense amounts of exudation-parallel transverse sections of the compared shoots showing that where, in the one that has been at rest, there are spots of colour round but a few pitted ducts, in the one that has been kept in motion the substance of the wood is soaked almost uniformly through with dye. In other cases, especially where there is much undifferentiated tissue remaining, the exudation is not very marked. The difference appears to depend on the quantity of liquid contained in the shoot. If its substance is relatively dry, the exudation is great; but it is comparatively small if all the tissues are fully charged with sap. This contrast of results is one which contemplation of the mechanical actions will lead us to expect.

And now, with these facts to aid our interpretation, let us return to ordinary stems. If the upper end of a growing shoot, the prosenchyma of which is but little thickened, be allowed to imbibe the dye, the vessels of its medullary sheath alone become charged; and from them there takes place but a slow oozing. If a like experiment be tried with a lower part of the shoot, where the wood in course of formation has its inner boundary marked but not its outer boundary, we find that the pitted ducts, and more especially the inner ones, come into play. And then lower still, where the wood 
has its periphery defined and its histological characters decided, the appearances show that the tissue forming its outer surface begins to take a leading part in the transmission of liquid. What now is the explanation of these changes, mechanically considered ? In the young soft part of the shoot, as in all normal and abnormal growths that have not formed wood, the channels for the passage of sap are the spiral, annular, fenestrated, or reticulated vessels. These vessels, here included in the bundles of the medullary sheath, are, in common with the tissues around them, subject, by the bendings of the shoot, to slight intermittent compressions, and, especially the outermost of them, are thus forced to give the prosenchyma an extra supply of nutritive liquid. The thickening of the prosenchyma, spreading laterally as well as outwards from each bundle of the medullary sheath, goes on until it meets the thickenings that spread from the other bundles; and there is so formed an irregular cylinder of hardened tissue, surrounding the medulla and the vascular bundles of its sheath. As soon as this happens, these vascular bundles become, to a considerable extent, shielded from the effects of transverse strains, since the tensions and compressions chietly fall on the developing wood outside of them. Clearly, too, the greatest stress must be felt by the outer layer of the developing wood: being further removed from the neutral axis, it must be subject to severer strains at each bend; and lying between the bark and the layer of wood first formed, it must be most exposed to lateral compressions. Among the elongated cells of this outer layer, some unite to form the pitted ducts. Being, as we see, better circumstanced mechanically, they become greater carriers of sap than the original vessels, and, in consequence of this, as well as in consequence of their relative proximity, become the sourees of nutrition to the still more external layers of wood-cells. The same causes and the same effects hold with each new indurated coat deposited round the previously indurated coats.

This description may be thought to go far towards justifying the current views respecting the course taken by the sap. But the justification is more apparent than real. In the first place, the implication here is that the sap-carrying function is at first discharged entirely by the vessels of the medullary sheath, and that they cease to discharge this function only as fast as they are relatively incapacitated by their mechanical circumstances. And the second implication is, that it is not the wood itself, but the more or less continuous canals formed in it, which are the subsequent sap-distributors. This, though readily made clear by microscopic examination of the large pitted ducts in a partially lignified shoot that bas absorbed the dye, is less manifestly true of the peripheral layer of sap-carrying tissue finally formed. But it is really true here. For this layer, though nominally a layer of wood, is practically a layer of inosculating 
vessels. It is formed out of irregular lines and networks of elongated pitted cells, obliquely united by their ends. Examination of them after absorption of a dye, shows that it is only along the continuous channels they unite to form that the current has passed. But the essentially vascular character of this outer and latest-formed layer of the alburnum is best seen in the fact that the vascular systems of new axes take their rise from it, and form with it continuous canals. If a shoot of last year in which growth is recommencing, be cut lengthways after it has imbibed a dye, clear proof is obtained that the passage of the dye into a lateral bud takes place from this outermost layer of pitted cells, and that the channels taken by the dye through the new tissue are composed of cells that pass through modified forms into the spiral vessels of the new medullary sheath. 'This transition may be still more clearly traced in a terminal bud that continues the line of last year's shoot. A longitudinal section of this shows that the vessels of the new medullary sheath do not obtain their sap from the vessels of last year's sheath (which, as shown by the non-absorption of dye, have become inactive), but that their supplies are obtained from those inosculating canals formed out of last year's outermost layer of prosenchyma, and that letween the component cells of this and those of the new vascular system there are all gradations of structure.*

* It may be added here that, on considering the mechanical actions that must go on, we are enabled in some measure to understand both how such inosculating channels are initiated, and bow the structures of their component cells are explicable. What must happen to ope of these elongated prosenchyma-cells if, in the course of its development, it is subject to intermittent compressions? Its squeezed-out liquid while partially escaping laterally, will more largely escape uj,wards and downwards; and while repeated lateral escape will tend to form lateral channels communicating with laterally-adjacent cells, repeatcd longitudinal escape will tend to form channels communicating with longitudinally-adjacent cells-so producing continuous though irregular longitudinal canals. Meanwhile each ccll into and out of which the nutritive liquid is from time to time squeezed through small openings in its walls, cannot thicken internally in an even manner: deposition will be interfered with by the passage of the currents through the pores. The rush to or from each pore will tena to maintain a funnel-shaped depression in the deposit around; and the opening from cell to cell will so acquire just that shape which the microscope shows up-two hollow cones with their apices meeting at the point where the cell-membranes are in contact. Moreover, as confirming this interpretation, it may be remarked that we are thus supplied with a reason for the differences of shape between these passages from one pitted cell to another, and the analogous passages that exist between cells otherwise formed and otherwise conditioned. In the cells of the medulla, and others which are but little exposed to compression, the passages are severally formed more like a tube with two trumpet-mouths, one in each ecll. This is just the form which might be expected where the nutritive fluid passes from cell to cell in moderate currents, and not by the violent rushes caused by intermittent pressures. Of course it is not meant that in each 
It is not the aim of the foregoing reasoning to show that mechanical actions are the sole causes of the formation of dense tissue in plants. Dense tissue is in many cases formed where no such causes have come into play - as, for example, in thorns and in the shells of nuts. Here the natural selection of variations can alone have operated. It is manifest, too, that even those supporting structures the building up of which is above ascribed to intermittent strains, may, in the individual plant of a species that ordinarily has them, be developed to a great extent when intermittent strains are prevented. We see this in trees that are artificially supported by nailing to walls; and we also see a kindred fact in natural climbers. Though in these cases the formation of wood is obviously less than it would be were the stem and branches habitually moved about by the wind, it nevertheless goes on. Clearly the tendency of the plant to repeat the structure of its type (in the one case the structure of its species; and in the other case that of the order from which it has diverged in becoming a climber) is here almost the sole cause of wood-formation. But though in plants so circumstanced intermittent mechanical strains have little or no direct share, it may still be true, and I believe is true, that intermittent mechanical strains are the original cause; for, as before hinted, the typical structure which the individual thus repeats irrespective of its own conditions, is interpretable as a typical structure that is itself the product of these actions and reactions between the plant and its environment. Grant the inheritance of functionally-produced modifications; grant that natural selection will always co-operate in such way as to favour those individuals and families in which functionally-produced modifications have progressed most advantageously ; and it will follow that this mechanically-caused formation of dense substance, accumulating from generation to generation by the survival of the fittest, will result in an organic habit of forming dense tissue at the required places. The deposit arising from exudation at the places of greatest strain, recurring from generation to generation at the same places, will come to be reproduced in anticipation of strain, and will continue to be reproduced for a long time after a changed habit of the species prevents the strain-eventually, however, decreasing, both through functional inactivity and natural selection, to the point at which it is in equilibrium with the requirement.

individual cell these structures are determined by these mechanical actions. The facts clearly ncgative any such conclusion, showing us, as they in many cases do, that these structures are assumed in advance of these mechanical actions. The implication is, that such mechanical actions initiated modifications that have, with the aid of natural selection, been accumulated from generation to generation; until, in conformity with ordinary embryological laws, the cells of the parts exposed to such actions assume these special structures irrespective of the actions-the actions, however, still serving to aid and complete the assumption of the inherited type. 
Anotherside of the general question may now beconsidered. We have seen how, by intermittent pressures on capillary vesseis and ducts and inosculating canals, there must be produced a draught of sap towards the point of compression to replace the sap squeezed out. But we have still to inquire what will be the effect on the distribution of sap throughout the plant as a whole. It was concluded that out of the compressed vessels the greater part of the liquid would escape longitudinally - the longitudinal resistance to movement being least. In every case the probabilities are infinity to one against the resistances being equal upwards and downwards. Always, then, more sap will be expelled in one direction than in the other. But in whichever direction least sap is expelled, from that same direction most sap will return when the vessels are relieved from pressure- the force which is powerful in arresting the back current in that direction being the same force which is powerful in producing a forward current. Ordinarily, the more abundant supply of liquid being from below, there will result an upward current. At each bend a portion of the contents will be squeezed out through the sides of the vessels-a portion will be squeezed downwards, reversing the current ascending from the roots, but soon stopped by its resistance; while a larger portion will be squeezed upwards towards the extremities of the vessels, where consumption and loss are most rapid. At each recoil the vessels will be replenished, chiefly by the repressed upward current; and at the next bend more of it will be thrust onwards than backwards. Hence we have everywhere in action a kind of rude force-pump, worked by the wind; and we see how sap may thus be raised to a height far beyond that to which it could be raised by capillary action, aided by osmose and evaporation.

Thus far, however, the argument proceeds on the assumption that there is liquid enough to replenish every time the vessels subject to this process. But suppose the supply fails-suppose the roots have exhausted the surrounding stock of moisture. Evidently the vessels thus repeatedly having their contents squeezed out into the surrounding tissue, cannot go on refilling themselves from other vessels without tending to empty the vascular system. On the one hand, evaporation from the leaves causing a draught on the capillary tubes that end in them, continually generates a capillary tension upwards; while, on the other hand, the vessels below, expanding after their sap has been squeezed out, produce a tension both upwards and downwards towards the point of loss. Were the limiting membranes of the vessels impermeable, the movement of sap would, under these conditions, soon be arrested. But these membranes are permeable; and the surrounding tissues readily permit the passage of air. This state of tension, then, will cause an entrance of air into the tubes; the columns of liquid they contain will be interrupted by bubbles. It seems, indeed, not improbable that this entrance of air may take 
place even when there is a good supply of liquid, if the mechanical strains are so violent and the exudation so rapid that the currents cannot refill the half-emptied vessels with sufficient rapidity. And in this case the intruding air may possibly play the same part as that contained in the air-chamber of a force-pump-tending, by moderating the violence of the jets, and by equalizing the strains, to prevent rupture of the apparatus. Of course when the supply of liquid becomes adequate, and the strains not too violent, these bubbles will be expelled as readily as they entered.

Here, as before, let me add the conclusive proof furnished by a direct experiment. To ascertain the amount of this propulsive action, I took from the same tree, a Laurel, two equal shoots, and placing them in the same dye, subjected them to conditions that were alike in all respects save that of motion: while one remained at rest, the other was bent backwards and forwards, now by switching and now by straining with the fingers. After the lapse of an hour, I found that the dye had ascended the oscillating shoot three times as far as it had ascended the stationary shoot-this result being an average from several trials. Similar trials brought out similar effects in other structures. The various petioles and herbaceous shoots experimented upon for the purpose of ascertaining the amount of exudation produced by transverse strains, showed also the amount of longitudinal movement. It was observable that the height ascended by the dye was in all cases greater where there had been oscillation than where there had been rest-the difference, however, being much less marked in succulent structures than in woody ones.

It need scarcely be said that this mechanical action is not here assigned as the sole cause of circulation, but as a cause co-operating with others, and helping others to produce effects that could not otherwise be produced. Trees growing in conservatories afford us abundant proof that sap is raised to considerable heights by other forces. Though it is notorious that trees so circumstanced do not thrive unless, through open sashes, they are frequently subject to breezes sufficient to make their parts oscillate, yet there is evidently a circulation that goes on without mechanical aid. The causes of circulation are those actions only which disturbtheliquid equilibriun in a plant, by permanently abstracting water or sap from some part of it; and of these the first is the absorption of materials for the formation of new tissue in growing parts; the second is the loss by evaporation, mainly through adult leaves; and the third is the loss by extravasation, through compressed vessels. Only so far as it produces this last, can mechanical strain be regarded as truly a cause of circulation. All the other actions concerned must be classed as aids to circulation-as facilitating that redistribution of liquid that continually restores the equilibrium continually disturbed; and of these 
capillary action may be named as the first, osmose as the second, and the propulsive effect of mechanical strains as the third. The first two of these aids are doubtless capable by themselves of producing a large part of the observed result-more of the observed result than is at first sight manifest; for there is an important indirect effect of osmotic action which appears to be overlooked. Osmose does not aid circulation only by setting up, within the plant, exchange currents between the more dense and the less dense solutions in different parts of it; but it aids circulation much more by producing distention of the plant as a whole. In consequence of the average contrast in density between the water outside of the plant and the sap inside of it, the constant tendency is for the plant to absorb a quantity in excess of its capacity, and so to produce distention and erection of its tissues. It is because of this that the drooping plant raises itself when watered; for capillary action alone could only refill its tissues without changing their attitudes. And it is because of this that juicy plants with collapsible structures bleed so rapidly when cut, not only from the cut surface of the rooted part, but from the cut surface of the detached part-the elastic tissues tending to press out the liquid which distends them. And manifestly if osmose serves thus to maintain a state of distention throughout a plant, it indirectly furthers circulation ; since immediately evaporation or growth at any part, by abstracting liquid from the neighbouring tissues, begins to diminish the liquid pressure within such tissues, the distended structures throughout the rest of the plant thrust their liquid contents towards the place of diminished pressure. This, indeed, may very possibly be the most efficient of the agencies at work. Remembering how great is the distention producible by osmotic absorption-great enough to burst a bladder-it is clear that the force with which the distended tissues of a plant urge forward the sap to places of consumption, is probably very great. We must therefore regard the aid which mechanical strains give as being one of several. Oscillations help directly to restore any disturbed liquid equilibrium ; and they also help indirectly, by facilitating the redistrubution caused by capillary action and the process just described; but in the absence of oscillations the equilibrium may still be restored, though less rapidly and within narrower limits of distance.

One half of the problem of the circulation, however, has been left out of sight. Thus far our inquiry has been, how the ascending current of sap is produced. There remains the rationale of the descending current. What forces cause it, and through what tissues it takes place, are questions to which no satisfactory answers have been given. That the descent is due to gravitation, as some allege, is difficult to conceive, since, as gravitation acts equally on all liquid columns contained in the stem, it is not easy to see why it should produce downward movements in some while permitting 
upward movements in others-unless, indeed, there existed descending tubes too wide to admit of much capillary action, which there do not. Moreover, gravitation is clearly inadequate to cause currents towards the roots out of branches that droop to the ground. Here the gravitation of the contained liquid columns must nearly balance that of the connected columns in the stem, leaving no appreciable force to cause motion. Nor does there seem much probability in the assumption that the route of the descending sap is through the cambium layer, since experiments on the absorption of dyes prove that simple cellular tissue is a very bad conductor of liquids: their movement through it does not take place with onefiftieth of the rapidity with which it takes place through vessels.*

Of course the defence for these hypotheses is, that there must be a downward current, which must have a course and a cause; and the very natural assumption has been that the course and the cause must be other than those which produce the ascending current. Nevertheless there is an alternative supposition to which the foregoing considerations introduce us. It is quite possible for the same vascular system to serve as a chanuel for movement in opposite directions at different times. We have among animals well-known cases in which the blood-vessels carry a current first in one direction and then, after a brief pause, in the reverse direction. And there scems an $\grave{a}$ priori probability that, lowly organized as they are, plants are more likely to have distributing appliances of this imperfect kind than to have two sets of channels for two simultaneous currents. If, led by this suspicion, we inquire whether among the forces which unite to produce movements of sap, there are any variations or intermissions capable of determining the currents in different directions, we quickly discover that there are such, and that the hypothesis of an alternating motion of the sap, now centrifugal and now centripetal, through the same vessels, has good warrant. What are the several forces at work? First may be set down that tendency existing in every part of a plant to expand into its typical form, and to absorb nutritive liquids in doing this. The resulting competition

* Some exceptions to this occur in plants that have retrograded in the character of their tissues towards the simpler vegetal types. Certain very succulent leaves, suel as those of Scmpervivum, in which the cellular tissue is immenscly developed in comparison with the vascular tissue, seem to have resumed to a considerable extent what we inust regard as the primitive form of vegetal circulation-simple absorption from cell to cell. Thesc, when they have lost much of their water, will take up the dye to some distance through their general substance, or rather through its interstices, even neglecting the vessels. At other times, in the same leaves, the vessels will become charged while comparatively little absorption takes place throngh the cellular tissue. Even in these exceptional cases, however, the movement throngh cellular tissue is nothing like as fast as the movement through vessels. 
for sap will, other things being equal, cause currents towards the most rapidly-growing parts-towards unfolding shoots and leaves. but not towards adult leaves. Next we have evaporation, acting more on the adult leaves than on those which are in the bud, or but partially developed. This evaporation is both regularly and irregularly intermittent. Depending chiefly on the action of the sun, it is, in fine weather, greatly checked or wholly arrested every evening; and in cloudy weather must be much retarded during the day. Further, every hygrometric variation, as well as every variation in the movement of the air, must vary the evaporation. This chief action, therefore, which, by continually emptying the ends of the capillary tubes, makes upward currents possible, is one which intermits every night, and every day is strong or feeble as circumstances determine. Then, in the third place, we have this rude pumping process above described, going on with greater vigour when the wind is violent, and with less vigour when it is gentle - drawing liquid towards different parts according to their degrees of oscillation, and from different parts according as they can most readily furnish it. And now let us ask what must result under changing conditions from these variously-conflicting and conspiring forces. When a warm sunshine, causing rapid evaporation, is emptying the vessels of the leaves, the osmotic and capillary actions that refill them will be continually aided by the pumping action of the swaying petioles, twigs, and branches, provided their oscillations are moderate. Under these conditions the current of sap, moving in the direction of least resistance, will set towards the leaves. But what will happen when the sun sets? There is now nothing to determine currents either upwards or downwards, except the relative rates of growth in the parts and the relative demands set up by the oscillations; and the oscillations acting alone, will draw sap to the oscillating parts as much from above as from below. If the resistance to be overcome by a current setting back from the leaves is less than the resistance to be overcome by a current setting up from the roots, then a current will set back from the leaves. Now it is, I think, tolerabiy manifest that in the swaying twigs and minor branches, less force will be required to overcome the inertia of the short columns of liquid between them and the leaves than to overcome the inertia of the long columns between them and the roots. Hence during the night, as also at other times when evaporation is not going on, the sap will be drawn out of the leaves into the adjacent supporting parts : and their nutrition will be increased. If the wind is strong enongh to produce a swaying of the thicker branches, the back current will extend to them also; and a further strengthening will result from their absorption of the elaborated sap. And when the great branches and the stem are bent backwards and forwards by a 
gale, they too will share in the nutrition. It may at first sight seem that these parts, being nearer to the roots than to the leaves, will draw their supplies from the roots only. But the quantity which the roots can furnish is insufficient to meet so great a demand. Under the conditions described, the exudation of sap from the vessels will be very great, and the draught of liquid required to refill them, not satisfied by that which the root-fibres can take in, will extend to the leaves. Thus sap will flow to the several parts according to their respective degrees of activity - to the leaves while light and heat enable them to discharge their functions, and back to the twigs, branches, stem, and roots when these become active and the leaves inactive, or when their activity dominates over that of the leaves. And this distribution of nutriment, varying with the varying activities of the parts, is just such a distribution as we know must be required to keep up the organic balance.

To this explanation it may be objected that it does not account for the downward current of sap in plants that are sheltered. The stem and roots of a drawing-room Geranium display a thickening which implies that nutritive matters have descended from the leaves, although there are none of those oscillations by which the sap is said to be drawn downwards as well as upwards. The reply is, that the stem and roots tend to repeat their typical structures, and that the absorption of sap for the formation of their respective dense tissues, is here the force which determines the descent. Indeed it must be borne in mind that the mechanical strains and the pumping process which they keep up, as well as the distention caused by osmose, do not in themselves produce a current either upwards or downwards : they simply help to move the sap towards that place where there is the most rapid abstraction of it-the place towards which its motion is least resisted. Whether there is oscillation or whether there is not, the physiological demands of the different parts of the plant determine the direction of the current; and all which the oscillations and the distention do is to facilitate the supply of these demands. Just as much, therefore, in a plant at rest as in a plant in motion, the current will set downwards when the function of the leaves is arrested, and when there is nothing to resist that abstraction of sap caused by the tendency of the stem-and root-tissues to assume their typical structures. To which admission, however, it must be added that since this typical structure assumed, though imperfectly assumed, by the hot-house plant, is itself interpretable as the inherited effect of external mechanical actions on its ancestors, we may still consider the current set up by the assumption of the typical structure to be indirectly due to such actions.

Intereșting evidence of another order here demands notice. In the course of experiments on the absorption of dyes by leaves, it happened that in making sections parallel to the plane of a leaf, with 
the view of separating its middle layer containing the vessels, I came upon some structures that were new to me. These structures, where they are present, form the terminations of the vascular system. They are masses of irregular and imperfectly united fibrous cells, such as those out of which vessels are developed; and they are sometimes slender, sometimes bulky - usually, however, being more or less clubshaped. In transverse sections of leaves their distinctive characters are not shown: they are taken for the smaller veins. It is only by carefully slicing away the surface of a leaf until we come down to that part which contains them, that we get any idea of their nature. Fig. 1 represents a specimen taken from a leaf of $E u$ phorbia neriifolia. Occupying one of the interspaces of the ultimate venous network, it consists of a spirally-lined duct or set of ducts, which connects with the neighbouring vein a cluster of halfreticulated, half-scalariform cells. These cells have projections, many of them tapering, that insert themselves into the adjacent intercellnlar spaces, thus producing an extensive surface of contact between the organ and the imbedding tissues. A further trait is, that the ensheathing prosenchyma is either but little developed or wholly absent ; and consequently this expanded vascular structure, especially at its end, comes immediately in contact with the tissues concerned in assimilation. The leaf of Euphorbia neriifolia is a very fleshy one; and in it these organs are distributed through a compact, though watery, cellular mass. But in any leaf of the ordinary type which possesses them, they lie in the network parenchyma composing its lower layer; and wherever they occur in this layer its cells unite to enclose them. This arrangement is shown in fig. 2, representing a sample from the Caoutchouc-leaf, as seen with the upper part of its envelope removed; and it is shown still more clearly in a sample from the leaf of Panax Lessonii, fig. 3. Figures 4 and 5 represent, without their sheaths, other such organs from the leaves of Panax Lessonii and Clusia flava. Some relation seems to exist between their forms and the thicknesses of the layers in which they lie. Certain very thick leaves, such as those of Clusia flava, have them less abundantly distributed than is usual, but more massive. Where the parenchyma is developed not to so great an extreme, though still largely, as in the leaves of Holly, Aucuba, Camellia, they are not so bulky; and in thinner leaves, like those of Privet, Élder, \&c., they become longer and less conspicuously club-shaped. Some adaptations to their respective positions seem implied by these modifications; and we may naturally expect that in many thin leaves these free ends, becoming still narrower, lose the distinctive and suggestive characters possessed by those shown in the diagrams. Relations of this kind are not regular, however. In various other genera, membets of which I have examined, as Rhus, Viburnum, Griselinia, Brexia, Botryodendron, Pereskia, the variations in the 
bulk and form of these structures are not directly determined by the spaces which the leaves allow: obviously there are other modifying causes. It should be added that while these expanded free extremities graduate into tapering free extremities, not differing from ordinary vessels, they also pass insensibly into the ordinary inosculations. Occasionally, along with numerous free endings, there occur loops; and from such loops there are transitions to the ultimate meshes of the veins.

These organs are by no means common to all leaves. In many that afford ample spaces for them they are not to be found. So far as I have observed, they are absent from the thick leaves of plants which form very little wood. In Sempervivum, in Echeveria, in Bryophyllum, they do not appear to exist; and I have been unable to discover them in Kalanchoë rotundifolia, in Kleinia ante-euphorbium and ficoides, in the several species of Crassula, and in other succulent plants. It may be added that they are not absolutely confined to leaves, but occur in stems that have assumed the functions of leaves. At least I have found, in the green parenchyma of Opuntia, organs that are analogous though much more rudely and irregularly formed. In other parts, too, that have usurped the leaf-function, they occur, as in the phyllodes of the Australian Acacias. These have them abundantly developed; and it is interesting to observe that here, where the two vertically-placed surfaces of the flattened-out petiole are equally adapted to the assimilative function, there exist two layers of these expanded vascular terminations, one applied to the inner surface of each layer of parenchyma.

Considering the structures and positions of these organs, as well as the natures of the plants possessing them, may we not form a shrewd suspicion respecting their function? Is it not probable that they facilitate absorption of the juices carried back from the leaf for the nutrition of the stem and roots ? They are admirably adapted for performing this office. Their component fibrous cells, having angles insinuated between the cells of the parenchyma, are shaped just as they should be for taking up its contents; and the absence of sheathing tissue between them and the parenchyma facilitates the passage of the elaborated liquids. Moreover there is the fact that they are allied to organs which obviously have absorbent functions. I am indebted to Dr. Hooker for pointing out the figures of two such organs in the "Icones Anatomic " of Link. One of them is from the end of a dicotyledonous root-fibre, and the other is from the prothallus of a young Fern. In each case a cluster of fibrous cells, seated at a place from which liquid has to be drawn, is connected by vessels with the parts to which liquid has to be carried. There can scarcely be a doubt, then, that in both cases absorption is effected through them. I have met with another such organ, more elaborately constructed, but evidently adapted to the same 
office, in the common Turnip-root. As shown by the end view and longitudinal section in figs. 6 and 7, this organ consists of rings of fenestrated cells, arranged with varying degrees of regularity into a funnel, ordinarily having its apex directed towards the central mass of the Turnip, with which it has, in some cases at least, a traceable connexion by a canal. Presenting as it does an external porous surface terminating one of the branches of the vascular system, each of these organs is well fitted for taking up with rapidity the nutriment laid by in the Turnip-root, and used by the plant when it sends up its flower-stalk. Nor does even this exhaust the analogies. The cotyledons of the young bean, experimented upon as before described, furnished other examples of such structures, exactly in the places where, if they are absorbents, we might expect to find them. Amid the branchings and inosculations of the vascular layer running through the mass of nutriment deposited in each cotyledon, there are conspicuous free terminations that are clubshaped, and prove to be composed, like those in leaves, of irregularly formed and clustered fibrous cells; and some of them, diverging from the plane of the vascular layer, dip down into the mass of starch and albumen which the young plant has to utilize, and which these structures can have no other function but to take up.

Besides being so well fitted for absorption, and besides being similar to organs which we cannot doubt are absorbents, these vascular terminations in leaves afford us yet another evidence of their functions. They are seated in a tissue so arranged as specially to facilitate the abstraction of liquid. The centripetal movement of the sap must be set up by a force that is comparatively feeble, since, the parietes of the ducts being porous, air will enter if the tension on the contained columns becomes considerable. Hence it is needful that the exit of sap from the leaves should meet with very little resistance. Now were it not for an adjustment presently to be described, it would meet with great resistance, notwithstanding the peculiar fitness of these organs to take it in. Liquid cannot be drawn out of any closed cavity without producing a collapse of the cavity's sides; and if its sides are not readily collapsible, there must be a corresponding resistance to the abstraction of liquid from it. Clearly the like must happen if the liquid is to be drawn out of a tissue which cannot either diminish in bulk bodily or allow its components individually to diminish in bulk. In an ordinary leaf, the upper layer of parenchyma, formed as it is of closely-packed cells that are without interspaces, and are everywhere held fast within their framework of veins, can neither contract easily as a mass, nor allow its separate cells to do so. Quite otherwise is it with the network-parenchyma below. The long cells of this, united merely by their ends and having their flexible sides surrounded by air, may severally have their contents considerably increased and decreased without offering 
appreciable resistances; and the network-tissue which they form will, at the same time, be capable of undergoing slightexpansions and contractions of its thickness. In this layer occur these organs that are so obviously fitted for absorption. Here we find them in direct communication with its system of collapsible cells. The probability appears to be, that when the current sets into the leaf, it passes through the vessels and their sheaths chiefly into the upper layer of cells (this upper laver having a larger surface of contact with the veins than the lower layer, and being the seat of more active processes); and that the juices of the upper layer, enriched by the assimilated matters, pass into the network-parenchyma, which serves as a reservoir from which they are from time to time drawn for the nutrition of the rest of the plant, when the actions determine the downward current. Should it be asked what happens where the absorbents, instead of being inserted in a network-parenchyma, are, as in the leaves of Euphorbia neriifolia, inserted in a solid parenchyma, the reply is, that such a parenchyma, though not furnished with systematically arranged air-chambers, nevertheless contains air in its intercellular spaces; and that when there occurs a draught upon its contents, the expansion of this air and the entrance of more from without, quickly supply the place of the abstracted liquid.

If then, returning to the general argument, we conclude that these expanded terminations of the vascular system in leaves are absorbent organs, we find a further confirmation of the views set forth respecting the alternating movement of the sap along the same channels. These spongioles of the leaves, like the spongioles of the roots, being appliances by which liquid is taken up to be carried into the mass of the plant, we are obliged to regard the vessels that end in these spongioles of the leaves as being the channels of the down current whenever it is produced. If the elaborated sap is abstracted from the leaves by these absorbents, then we have no alternative but to suppose that, having entered the vascular system, the elaborated sap descends through it. And seeing how, by the help of these special terminations, it becomes possible for the same vessels to carry back a quality of sap unlike that whicb they bring up, we are enabled to understand tolerably well how this rhythmical movement produces a downward transfer of materials for growth.

The several lines of argument may now be brought together; and along with them may be woven up such evidences as remain. Let me first point out the variety of questions to which the hypothesis supplies answers.

It is required to account for the ascent of sap to a height beyond that to which capillary action can raise it. This ascent is accounted for by the propulsive action of transverse strains, joined with that of osmotic distention. A cause has to be assigned for that rise of sap 
which, in the spring, while yet there is no considerable evaporation to aid it, goes on with a power which capillarity does not explain. Theco-operation of the same twoagencies is assignable for this result also.* The circumstance that vessels and ducts here contain sap and there contain air, and at the same place contain at different seasons now air and now sap is a fact calling for explanation. An explanation is furnished by these mechanical actions which involve the entrance or expulsion of air according to the supply of liquid. That vessels and ducts which were originally active sap-carriers go completely out of use, and have their function discharged by other vessels or ducts, is an anomaly that has to be solved. Again, we are supplied with a solution: these deserted vessels and ducts are those which, by the formation of dense tissue outside of them, become so circumstanced that they cannot be compressed as they originally werc. A channel has to be found for the downward current of sap, which, on any other hypothesis than the foregoing, must be a channel separate from that taken by the upward current; and yet no good evidence of a separate channel has been pointed out. Here, however, the difficulty disappears, since one channel suffices for the current alternating upwards and downwards according to the conditions. Moreover there has to be found a force producing or facilitating the downward current, capable even of drawing sap out of drooping branches; and no such force is forthcoming. The hypothesis set forth dispenses with this necessity; under the recurring change of conditions, the same distention and oscillation which before raised the sap to the places of consumption, now bring it down to the places of consumption. A physical process has to be pointed out by which the material that forms dense tissue is deposited at the places where it is wanted, rather than at other places. This physical process the hypothesis indicates. It is requisite to find an explanation of the fact that, when plants ordinarily swayed about by the wind are grown indoors, the formation of wood is so much diminished that they become abnormally slender. Of this an explanation is supplied. Yet a further

* It seems probable, however, that osmotic distention is here, especially, the more important of the two factors. The rising of the sap in spring may indirectly result, like the sprouting of the seed, from the transformation of starch into sugar. During germination, this change of an oxy-hydro-carbon from an insoluble into $\mathrm{a}$ soluble form, leads to rapid endosmose; consequently to great distention of the sced; and therefore to a force which thrusts the contained liquids into the plumule and radicle, and gives them power to displace the soil in their way: it sets up an active internal movement when neither evaporation nor the change which light produces can be operative. And similariy, if, in the spring, the starch stored up in the roots of a tree passes into the form of sugar, the unusual osmotic absorption that arises will cause an unusual distention-a distention which, being resisted by the tough bark of the roots and stcm, will result in a powerful upward thrust of the contained liquid. 
fact to be interpreted is, that in the same individual plant homologous parts, which, according to the type of the plant, should be equally woody, become much thicker one than another if subject to greater mechanical stress. And of this too an interpretation is similarly afforded.

Now the sufficiency of the assigned actions to account for so many phenomena not otherwise explained, would be strong evidence that the rationale is the true one, even were it of a purely hypothetical kind. How strong, then, becomes the reason for believing it the true one when we remember that the actions alleged demonstrably go on in the way asserted. They are ever operating before our eyes; and that they produce the effects in question is a conclusion deducible from mechanical principles, a conclusion established by induction, and a conclusion verified by experiment. These three orders of proof mav be briefly summed up as follows.

That plants which have to raise themselves above the earth's surface, and to withstand the actions of the wind, must have a power of developing supporting structure, is an $\grave{a}$ priori conclusion which may be safely drawn. It is an equally safe $\grave{a}$ prior $i$ conclusion, that if the supporting structure, either as a whole or in any of its parts, has to adapt itself to the particular strains which the individual plant is subject to by its particular circumstances, there must be at work some process by which the strength of the supporting structure is everywhere brought into equilibrium with the forces it has to bear. Though the typical distribution of supporting structure in each kind of plant may be explained teleologically by those whom teleological explanations satisfy; and though otherwise this typical distribution may be ascribed to natural selection acting apart from any directly adaptive process; yet it is manifest that those departures from the typical distribution which fit the parts of each plant to their special conditions are explicable neither teleologically nor by natural selection: We are, therefore, compelled to admit that, if in each plant there goes on a balancing of the particular strains by the particular strengths, there must be a physical or physico-chemical process by which the adjustments of the two are effected. Meanwhile we are equally compelled to admit, $\grave{a}$ priori, that the mechanical actions to be resisted, themselves affect the internal tissues in such ways as to further the increase of that dense substance by which they are resisted. It is demonstrable that bending the petioles, shoots, and stems must compress the vessels beneath their surfaces, and increase the exudation of nutritive matters from them, and must do this actively in proportion as the bends are great and frequent; so that while, on the one hand, it is a necessary deduction that, if the parts of each plant are to be severally strengthened according to the several strains, there must be some direct connexion between strains and strengths, it is, on the other hand, a necessary deduction from 
mechanical principles that the strains do act in such ways as to aid the increase of the strengths. How a like correspondence between two $\dot{a}$ priori arguments holds in the case of the circulation, needs not to be shown in detail. It will suffice to remind the reader that while the raising of sap to heights beyond the limit of capillarity implies some force to effect it, we have in the osmotic distention and the intermittent compressions caused by transverse strains, forces which, under the conditions, cannot but tend to effect it; and similarly with the requirement for a downward current, and the production of a downward current.

Among the inductive proofs we find a kindred agreement. Different individuals of the same species, and different parts of the same individual, do strengthen in different degrees ; and there is a clearly traceable connexion between their strengthenings and the intermittentstrains they are exposed to. This evidence, derived from contrasts between growths on the same plant or on plants of the same type, is enforced by evidence derived from contrasts between plants of different types. The deficiency of woody tissue which we see in plants called succulent, is accompanied by a bulkiness of the parts which prevents any considerable oscillations; and this character is also habitually accompanied by a dwarfed growth. When, leaving these relations as displayed externally, we examine them internally, we find the facts uniting to show, by their agreements and differences, that between the compression of the sap-canals and the production of wood there is a direct relation. We have the facts, that in each plant, and in every new part of each plant, the formation of sapcanals precedes the formation of wood; that the deposit of woody matter, when it begins, takes place around these sap-canals, and afterwards around the new sap-canals successively developed; that this formation of wood around the sap-canals takes place where the coats of the canals are demonstrably permeable, and that the amount of wood-formation is proportionate to the permeability. And then that the permeability and extravasation of sap occur wherever, in the individual or in the type, there are intermittent compressions, is proved alike by ordinary cases and by exceptional cases. In the one class of cases we see that the deposit of wood round the ressels begins to take place when they come into positions that subject them to intermittent compressions, while it ceases when they become shielded from compressions. And in the other class of cases, where, from the beginning, the vessels are shielded from compression by surrounding fleshy tissue, there is a permanent absence of wood-formation.

To which complete agreement between the deductive and inductive inferences has to be added the direct proof supplied by experiments. It is put beyond doubt by experiment that the liquids absorbed by plants are distributed to their different parts through their 
vessels-at first by the spiral or allied vessels originally developed, and then by the better-placed ducts formed later. By experiment it is demonstrated that the intermittent compressions caused by oscillations urge the sap along the vessels and ducts. And it is also experimentally proved that the same intermittentcompressionsproduce exudation of sap from vessels and ducts into the surrounding tissue.

That the processes here described, acting through all past time, have sufficed of themselves to develope the supporting and distributing structures of plants, is not alleged. What share the natural selection of variationsdistinguishedas spontaneous, has had in establishing them, is a question which remains to be discussed. Whether acting alone natural selection would have sufficed to evolve these vascular and resisting tissues, I do not profess to say. That it has been a co-operating cause, I take to be self-evident: it must all along have furthered the action of any other cause, by preserving the individuals on which such other cause had acted most favourably. Seeing, however, the conclusive proof which we have that another cause has been in action-certainly on individuals, and, in all probability, by inheritance on races-we may most philosophically ascribe the genesis of these internal structures to this cause, and regard natural selection as having here played the part of an accelerator.

\section{EXPLANATION OF PLATE.}

Fig. 1. Absorbent organ from the leaf of Euphorbia neriifolia. The cluster of fibrous cells forming one of the terminations of the vascular system is here imbedded in a solid parenchyma.

Fig. 2. A structure of analogous kind from the leaf of Ficus elastica. Here the expanded terminations of the vessels are imbedded in the network parenchyma, the cells of which unite to form envelopes for them.

Fig. 3. Shows on a larger scale one of these absorbents from the leaf of Panax Lessonii. In this figure is clearly seen the way in which the cells of the network parenchyma unite into a closelyfitting case for the spiral cells.

Fig. 4. Represents a much more massive absorbent from the same leaf, the surrounding tissues being omitted.

Fig. 5. Similarly represents, without its sheath, an absorbent from the leaf of Clusia flava.

Fig. 6. End view of an absorbent organ from the root of a Turnip. It is taken from the outermost layer of vessels. Its funnel-shaped interior is drawn as it presents itself when looked at from the outside of this layer, its narrow end being directed towards the centre of the Turnip.

Fig. 7. A longitudinal section through the axis of another such organ, showing its annuli of reticulated cells when cut through. The cellular tissue which fills the interior is supposed to be removed. 
Fig. 8. A less-developed absorbent, showing its approximate connexion with a duct. In their simplest forms, these structures consist of only two fenestrated cells, with their ends bent round so as to meet. Such types occur in the central mass of the Turnip,
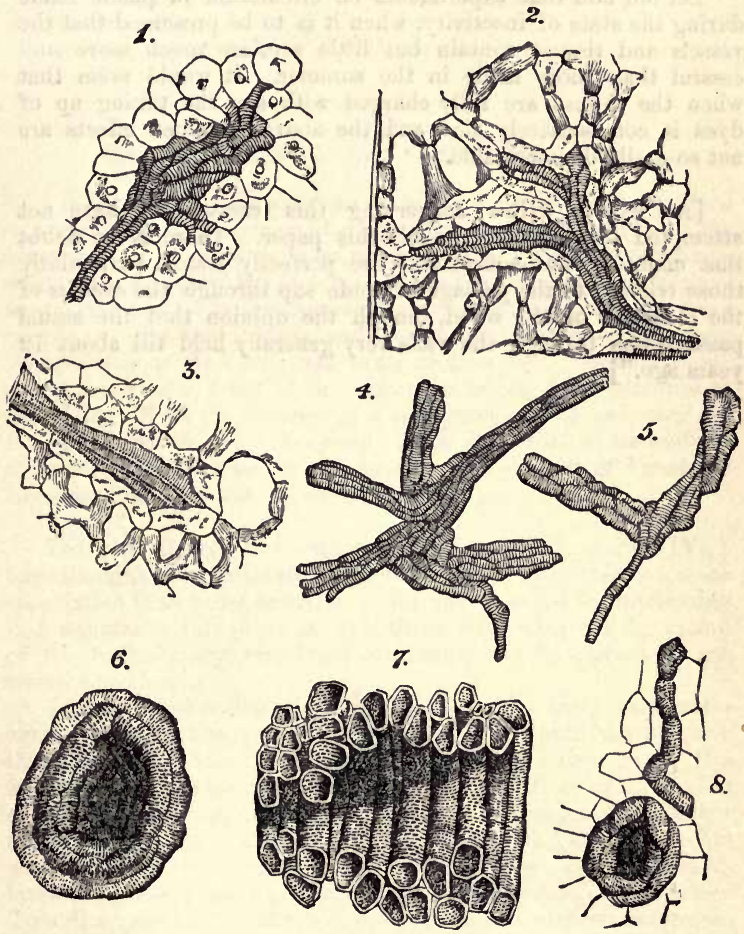

where the vascnlar system is relatively imperfect. Besides the comparatively regular forms of these absorbents, there are forms composed of amorphous masses of fenestrated cells. It should be added that both the regular and irregular kinds are very variable in their numbers: in some turnips they are abundant, and in others scarcely to be found. Possibly their presence depends on 
the age of the Turnip. Judging from the period during which my investigations were made, namely winter and early spring, I suspect that they are developed only in preparation for sending up the flower-stalk.

Let me add that experiments on circulation in plants made during the state of inactivity, when it is to be presumed that the vessels and tissues contain but little sap, are much more successful than those made in the summer. It would seem that when the tissues are fully charged with sap the taking up of dyes is comparatively slow and the above-described effects are not so easily demonstrable.

[An expert writes concerning this essay:- "I have not attempted to annotate critically this paper. There is no doubt that many of your conclusions are perfectly sound, particularly those relating to the passage of crude sap through the cavities of the elements of the wood, though the opinion that the actual passage was through the walls very generally held till about 12 years ago."] 


\section{APPENDIX D.}

\section{ON THE ORIGIN OF THE VERTEBRATE TYPE.}

[When studying the development of the vertebrate skeleton, there occurred to me the following idea respecting the possible origin of the notochord. I was eventually led to omit the few pages of Appendix in which I had expressed this idea, because it was unsupported by developmental evidence. The developmental evidence recently discovered, however, has led Professor Haeckel and others to analogous views respecting the affiliation of the Vertebrata on the Molluscoida. Having fortunately preserved a proof of the suppressed pages, I am able now to add them. With the omission of a superfluous paragraph, they are reprinted verbatim from this proof, which dates back to the autumn of 1865 , at which time the chapter on "The Shapes of Vertebrate Skeletons" was written.-December, 1869.]

The general argument contained in Chap. XVI. of Part IV., I have thought it undesirable to implicate with any conception more speculative than those essential to it; and to avoid so implicating it, I transfer to this place an hypothesis respecting the derivation of the rudimentary vertebrate structure, which appears to me worth considering.

Among those molluscoid animals with which the lowest vertebrate animal has sundry traits in common, it very generally happens that while the adult is stationary the larva is locomotive. The locomotion of the larva is effected by the undulations of a tail. In shape and movement one of these young Ascidians is not altogether unlike a Tadpole. And as the tail of the Tadpole disappears when its function comes to be fulfilled by limbs; so the Ascidian larva's tail disappears when fixation of the larva renders it nseless. This disappearance of the tail, however, is not without exception. The Appendicularia is an Ascidian which retains its tail throughont life; and by its aid continues throughout life to swim about. Now this tail of the Appendicularia has a very suggestive structure. It is long, tapering to a point, and flattened. From end to end there runs a mid-rib, which appears to be an imbedded gelatinous rod, not unlike a notochord. Extending along the two sides of 
this mid-rib, are bundles of muscular fibres; and its top bears a gangliated nervous thread, giving off, at intervals, branches to the muscular fibres. In the Appendicularia this tail, which is inserted at the lower part of the back, is bent forwards, so as not to be adapted for propelling the body of the animal head foremost; but the homologous tails of the larval Ascidians are directed backwards, so as to produce forward movement. If we suppose a type like the Appendicularia in the structure and insertion of its permanent tail, but resembling the larval forms in the direction of its tail, it is, I think, not difficult to see that functional adaptation joined with natural selection, might readily produce a type approximating to that whose origin we are considering. It is a fair assumption that an habitually - locomotive creature would profit by increased power of locomotion. This granted, it follows that such further development of the tail-structures as might arise from enhanced function, and such better distribution of them as spontaneous variation might from time to time initiate, would be perpetuated. What must be the accompanying changes ? The more vigorous action of such an appendage implies a firmer insertion into the body; and this would be effected by the prolongation forwards of the central axis of the tail into the creature's back. As fast as there progressed this fusion of the increasinglypowerful tail with the body, the body would begin to partake of its oscillations; and at the same time that the resistant axis of the tail advanced along the dorsal region, its accompanying muscular fibres would spread over the sides of the body: gradually taking such modified directions and insertions as their new conditions rendered most advantageous. Without further explanation, those who examine drawings of the structures described, will, I think, sce that in such a way a tail homologous with that of the Appendicularia, would be likely, in the course of that development required for its greater efficiency, gradually to encroach on the body, until its mid-rib became the dorsal axis, its gangliated nerve-thread the spinal chord, and its muscular fibres the myocommata. Such a development of an appendage into a dominant part of the organism, though at first sight a startling supposition, is not without plenty of parallels : instance the way in which the cerebral ganglia, originally mere adjuncts of the spinal chord, eventually become the great centres of the nervous system to which the spinal chord is quite subordinate; or instance the way in which the limbs, small and inconspicuous in fishes, become, in Man, masses which, taken together, outweigh the trunk. It may be added that these familiar cases have a further appropriateness; for they exhibit higher degrees of that same increasing dominance of the organs of external relation, which the hypothesis itself implies. 
Of course, if the rudimentary vertebrate apparatus thus grew into, and spread over, a molluscoid visceral system, the formation of the notochord under the action of alternating transverse strains, did not take place as suggested in $\S 255$; but it does not therefore follow that its differentiation from surrounding tissues was not mechanically initiated in the way described. For what was said in that section respecting the effects of lateral bendings of the body, equally applies to lateral bendings of the tail; and as fast as the developing tail encroached on the body, the body wou'd become implicated in the transverse strains, and the differentiation would advance forwards under the influences originally alleged. Obviously, too, though the lateral muscular masses would in this case have a different history; yet the segmentation of them would be eventually determined by the assigned causes. For as fast as the strata of contractile fibres, developing somewhat in advance of the dorsal axis, spread along the sides, they would come under the influence of the alternate flexions; and while, by survival of the fittest, their parts became adjusted in direction, their segmentation would, as before, accompany their increasing massiveness. The actions and reactions due to lateral undulations would still, therefore, be the causes of differentiation, with which natural selection would cooperate. 


\section{A P PENDIX D 2.}

\section{THE ANNULOSE TYPE.}

THE production of a segmental structure by undulatory movements, suggested in Appendix D, as also in B (first published in 1858) as explaining the vertebral column, has been recently suggested by Prof. Korschelt as the cause of that segmentation of the annulose type which gives the name to it. He espouses a"view which is based upon the assumption that at first an unsegmented, elongated ancestral form was produced by terminal growth, whereupon the entire body became separated at once into a large number of scgments by a rearrangement of the individual organs. This assumption is supported by the consideration that with the lateral sinuous movement of the body, and with the rigidity of the tissues caused by increasing differentiation, the formation of alternating regions of greater and less motility was of con. siderable advantage to the individual, and rendered possible a further elongation of the body. The first cause for the appearance of metameric gegmentation would then be sought in the manner of locomotion and in mechanical conditions. However, this latter view is not supported in any way by embryology." (Embryology of Invertebrates, Part I, pp. 349-50.)

I venture to think the confession that this view "is not supported in any way by embryology" should be joined with the confession that it is at variance with that abstract embryology which comprehends the process of development in general. The assumption that there took place " a rearrangement of the individual organs" of "an unsegmented, elongated ancestral form," in such wise that the organs, previously single, presently became multiple, so that instead of one organ of each kind there were substituted many organs of each kind, is inconsistent with the general law of evolution, organic and other-implies not integration but disintegration. Everywhere the advance is from many like parts performing like functions to relatively few unlike parts performing unlike functions. The higher forms of the annulose type itself show this. Compare a myriapod and a crab. In the one we have not only a great number of similar segments bearing similar limbs, but we have in each segment a dilatation of the main blood-vessel $-a$ rudimentary heart-a swollen portion of the nervo cord-a small ganglion-and so on; whereas in the other, 
besides relatively few segments and few limbs (sundry of them extremely unlike the rest) we have a vascular system concentrated into a central heart with arteries and a concentrated nervous system, such that the great ganglia in the integrated carapace immensely subordinate the ganglia of the remaining segments; and similarly with the other organs. Now unless it be denied that these highest decapods have been evolved from low types akin to myriapods in composition, it must be admitted that the progress has been from a string of many like segments with similar sets of organs to a group of relatively-few unlike segments with dissimilar sets of organs. If so we cannot rationally deny that the progress has been of this nature up from the lowest annelid, instead of having been, as Prof. Korschelt's hypothesis implies, of opposite nature at the beginning.

In a preceding passage a clear recognition of the normal course of development occurs. In opposing the view set forth in §§ 205-7 of this work, Prof. Korschelt says :-

"It seems scarcely favourable to this theory that the degree of independence which the individual segments present is comparatively slight. The most important organs (nervous system, body musculature, blood-vascular system) show themselves to be single fundaments of the entire body, and are also developed as such even though they also exhibit evidences of metamerism. Even the excretory canals may give up their segmental isolation and become united to one another by means of longitudinal canals." (16. p. 348.)

On turning back to $\S 206$, the reader will, I think, demur to the assertion that the independence is " comparatively slight"; seeing that, as in Ctenodrilus, a single segment sometimes becomes separate and reproduces other segments to form a new series. Instead of admitting that "the most important organs" "show themselves to be single fundaments of the entire body," it may be held, contrariwise, that their original independence in each segment is masked only to the degree involved by their cooperation as parts of a compound organism. But chiefly I remark that when it is said that "the excretory canals may give up their segmental isolation and become united" by "longitudinal canals," there is a clear confession that the isolation of these organs was original and their union superinduced-an implication that the course of evolution is as I have described it, and at variance with the course of evolution assumed by Prof. Korschelt.

Yet another incongruity is involved in his interpretation. He writes :-

"Just as in the consideration of the tape-worm chain we were indueed by the comparison with unsegmented forms to refer the entire chain to an unsegmented individual, and, on the other hand, to see in the proglottis, not a complete individual, but only the abstricted hinder portion of the body of the Cestode, in the same manner, and with much more reason, we aubere to the individuality of the Annelid body." (P. 349.) 
And then on the preceding page, referring to the composition of the Annelid body, he says:- "The most natural comparisons are those with the tapeworm chain and with the strobila of the Scyphomedusæ." Now since it is here assumed that the tapeworm and the strobila are analogous in composition, it is implied that the detached proglottis and the detached medusa are analogous ; and hence if we are to regard the proglottis as "not a complete individual but only the abstricted hinder portion of the body of the Cestode," then we must similarly regard the medusa as not a complete individual, but only the abstricted hinder portion of the strobila. This commits us to the strange conclusion that whereas individuality is ascribed to the original simple polyp, and by-and-by to the partially-segmented strobila, though these are without special senses and with only rudiments of muscular and nervous systems, individuality is denied to the detached medusa, which has organs of sense, a distinct nervo-muscular system and a considerable power of locomotion, as well as a generative system: traits which in other cases characterize developed individnals. Here also, then, there seems to be an inversion of the ordinary conception.

This conception of the proglottis and the medusa is, I see, accepted by some as tenable. But if we accept it we must accept also an analogous conception, which will I think be regarded as untenable. It is that supplied by the Aphides. From an egg proceeds a series of sexless and wingless females, and at the end of the series there come winged males and females with resulting gamic reproduction. If instead of forming a discrete series the imperfect females formed a concrete series, the members of which could individually feed without being detached from one another, as the segments of a tapeworm can, the parallelism would be complete; and then, according to the view in question, we should have to regard the perfect males and females eventually arising, not as individuals but as terminal portions of the series, containing generative products and having wings for the dispersion of them-locomotive egg-bearing segments of the chain. Whoever espouses this view must hold either that the first imperfect female of the series was the individual or that the entire string of them constituted the individual (in conformity with a view once propounded by Prof. Huxley). But he must do more than this. Since the Aphides have descended from some winged species of the order Hemiptera, he must hold that among those remote ancestors each particular fly, male or female, was an individual ; but that when abundant food and inert life led to the parthenogenetic habit, and to chains of sexless forms, the males and females eventually produced at the end of each chain, though, like their remote ancestors, possessed of procreative organs and wings, are not individuals. 
[Some memoranda bearing on the question here discussed, mislaid at the time when the chapter dealing with it was revised, have been discovered in time for utilization in this appendix.]

One of my critics says :-

"You have overstated the case in your favour: the alimentary canal does not, as you suggest, show a segmentation corresponding to that of the other organs in Annelids. Either it is a simple uniform tube, or else its differentiations (pharynx, œsophagus, crop, intestine) are quite independent of the repetition of the somites."

In presence of statements made in works of authority, this objection greatly surprises me. I meet with the descriptive word "moniliform" applied to the intestine in some Annelids, and then in the Text-book of Claus, translated and edited by Sedgwick, it is said, concerning the alimentary canal in the Annelida :

"This is followed by the gastric region of the gut, which occupies the greatest portion of the length of the body, and is either regularly constricted in correspondence with the segments, or possesses lateral diverticula." (P. 365.)

And again on p. 369 it is said:-

"The intestine usually preserves the same structure in its entire length and is divided by regular constrictions into a number of divisions or chambers, which correspond to the segments and dilate again into lateral diverticula and cæca."

The alimentary canal thus presents the segmental character as clearly as consists with fulfilment of its function. If the successive segments are cooperating units of a compound animal having but one mouth, then, necessarily, the gut cannot be completely cut into parts, each answering to a segment, for there could be, in that case, no passage for the food. If the portion of the intestine belonging to each segment has a conspicuous dilatation, or has a cæcum on each side, it exhibits the segmental character as much as the physical requirements permit. So far from being at variance with the hypothesis, its structure exhibits a verification of it.

The next objection runs as follows:-

"Then, again, the ovaries and testes do not exhibit a corresponding segmentation. When it is allowable to speak of ovary or testis at all as in Lumbricus, we find that in the case of both organs we have at most two pairs."

It seems to me that the distribution of the generative organs in a comparatively-developed member of the Annelid type, is not the question. We have to ask what it is in undeveloped members of that type. Among them the repetition of generative parts is in some cases just what the theory implies. Thus in Claus I read :"In the marine Chatopoda, the ova or spermatozoa originate on the body-wall from cells of the peritoneal membrane, either in 
the anterior segments alone or along the whole length of the body." So that in these last cases there are, in all the segments, parts from which arise generative products. The fact that these parts are not definite ovaries and testes is irrelevant. Ovaries and testes are developed generative structures, and in the order of evolution are preceded by undeveloped ones; and the fact that these undeveloped ones are found in little-developed members of the type conforms perfectly to the hypothesis. [I may remark in passing that here is a good illustration of that process of evolution which, in the above speculation of Prof. Korschelt, is supposed to be inverted: many dispersed, similar, and indefinite parts, are integrated into a few localized and definite parts.]

In continuation the critic above quoted says:- "My position is that the repetition of segments in an Annelid is a phenomenon of the same nature as the repetition of hairs in a Mammal or of scutes in a Reptile", and he proceeds to give instances of repetitions of organs in other types, as of the reproductive structures and excretory system in the young Dog-fish or of the ovaries in Amphioxus. These examples do not seem to me relevant. No parallelism exists between the repetition of a particular organ in an animal, and the repetition of an entire cluster of organs constituting a physiological whole. The repetitions of the ovaries in Amphioxus and of the excretory system in a young Dog-fish, occur without threatening to divide into similar parts the entire organism. But the segmental repetitions in an annulose creature implicate the structures at large, and would, if pushed a little further, result in separate creatures. The segment of a low Annelid contains alimentary, vascular, nervous, excretory, reproductive, sensory and locomotive organs-all the organs required for carrying on life, save certain organs of external relation which its position excludes. When there is shown some vertebrate animal, or proto-vertebrate animal, that is divisible into parts each of which is in great measure physiologically independent, I shall feel obliged to abandon my position.

While this appendix is in hand I have received from another expert, whose view is in general agreement with my own, a letter containing the following passage:-

"You will see that Dohrn's theory was the antithesis of your own view of vertebrate structure, namely that the vertebræ were formed by the segmentation, from mechanical causes of a body originally simple. This view of yours bas been confirmed by later researches, which have shown that the most primitive forms allied to the Vertebrates, possessing the essential organs, viz., gill-slits, notochord, and dorsal nerve eord, are not segmented animals, like Annelids and Crustacea, but simple animals, having at most three regions, not exactly corresponding to segments. These primitive unsegmented forms are Ascidian tadpoles, Balanoglossus, and certain other primitive forms. The embryology ': Vertebrates also proves that they are 
originally simple and not segmented animals, especially the faet that there is originally one pronephric duct or primitive kudney."

Nevertheless there survives a leaning towards the notion of a segmental origin of the Vertebratu. But the repetitions of organs named in support of this notion have, 1 think, no more relation to the genesis of the vertebrate type than the multiplication of vertebrø in a snake has relation to the genesis of the vertebral column. 


\section{APPENDIX E.}

\section{THE SHAPES AND ARRANGEMENTS OF FLOWERS.}

IN Part IV., Chapter X., under the title of "The Shapes of Flowers," I have, after describing their several kinds of symmetry, as habitually related to their positions, made some remarks by way of interpretation. The truth that flowers exhibit a radial symmetry when they are so placed as to be equally affected all round by incident forces, having been exemplified, and also the truth that they assume a bilateral symmetry when they are so placed that their two sides are conditioned in ways different from the ways in which their upper and lower parts are conditioned; I have gone on to inquire (in $\S 234$ ) by what causes such modifications of form are produced. I have stated that, originally, I inclined to ascribe them entirely to differences in the relations of the parts to physical forces-light, heat, gravitation, etc.; but that I found sundry facts stood in the way of this interpretation. And I have said that "Mr. Darwin's investigations into the fertilization of Orchids led me to take into account an unnoticed agency." Continuing to recognize the physical forces as factors having some influence, I have concluded that the most important factor is the action of insects; which, aiding most the fertilization of those flowers which most facilitate their entrance, produce, in course of generations, a form of flower specially adapted to the special position.

Though still adhering to this interpretation, I have since found reason to think that the original interpretation contains a larger portion of truth than I supposed at the time when I was led thus to revise it. While staying at Mürren, in Switzerland, in 1872, I observed some modifications in a species of Gentian, which proved to me that the action of incident physical forces on flowers is, in some cases, very rapid and decided. The species furnishing this evidence was the Gentiana Asclepiadea; which Ifound in a copse formed of bushes that were here wide apart and there close together. In some places not near to the bushes, the individuals of the species grew vertically ; in other places, partially shaded, their inclined shoots curved in such 
directions as to get the most light; and in other cases their shoots were led to take directions almost or quite horizontal. That, along with these modifications in the directions of their shoots, there went adjustments in the attitudes of their leaves, was a fact not specially worthy of remark; for plants placed inside the windows of houses habitually show us that leaves quickly bend themselves into attitudes giving them the greatest amounts of light. But the fact which attracted my attention was, that the flowers changed their attitudes in an equally-marked manner. The radial distribution passed into a bilateral distribution with the greatest readiness. Comparison of the annexed figures will show the character of this change.

Figure I. represents part of a vertically growing shoot. This belonged to an individual growing unimpeded by bushes, and getting light on all sides. Here it is observable that the pairs of leaves, placed alternately in directions transverse to one another-one pair pointing, say, north and south, and the next pair pointing east and west-maintain, taking them in the aggregate, a radial distribution; and it is also observable that the alternate pairs of flowers are similarly arranged.

Figure II. is a sketch from a shoot which leaned towards one side, and of which the higher part, as it bent more and more, got its upper side more and more differently conditioned from its lower side. Here we find that not only the leaves, but also the flowers, have adjusted themselves to the changed conditions. The leaves of the lowest pair hang out in the normal way, on the opposite sides of the axis, so that a plane passing through their surfaces will cut the axis transversely; and their two axillary flowerbuds, $c$ and $d$, are similarly placed on opposite sides of the axis. But at the other part of the shoot, we see both that the leaves have adjusted themselves so that their planes, no longer cutting the axis transversely, keep a fit adjustment with respect to the light; and also that the flowers, no longer on opposite sides of the axis, have bent round to the upper side, as at $a$ and $b$.

Figure III. shows us this re-arrangement carried still further. The shoot it represents was growing in a direction nearly horizontal, and therefore receiving the light only on one side. And here, besides seeing that the leaves have so adjusted themselves that they all lie in approximately the same plane, which is parallel to the axis instead of transverse to it, we see that the two pairs of flower-buds have both come round to the upper side of the axis. So that in this shoot, the original radial symmetry in the arrangement of leaves and flowers, is completely changed into a bilateral symmetry.

These facts do not, it is true, prove any modification in the forms 


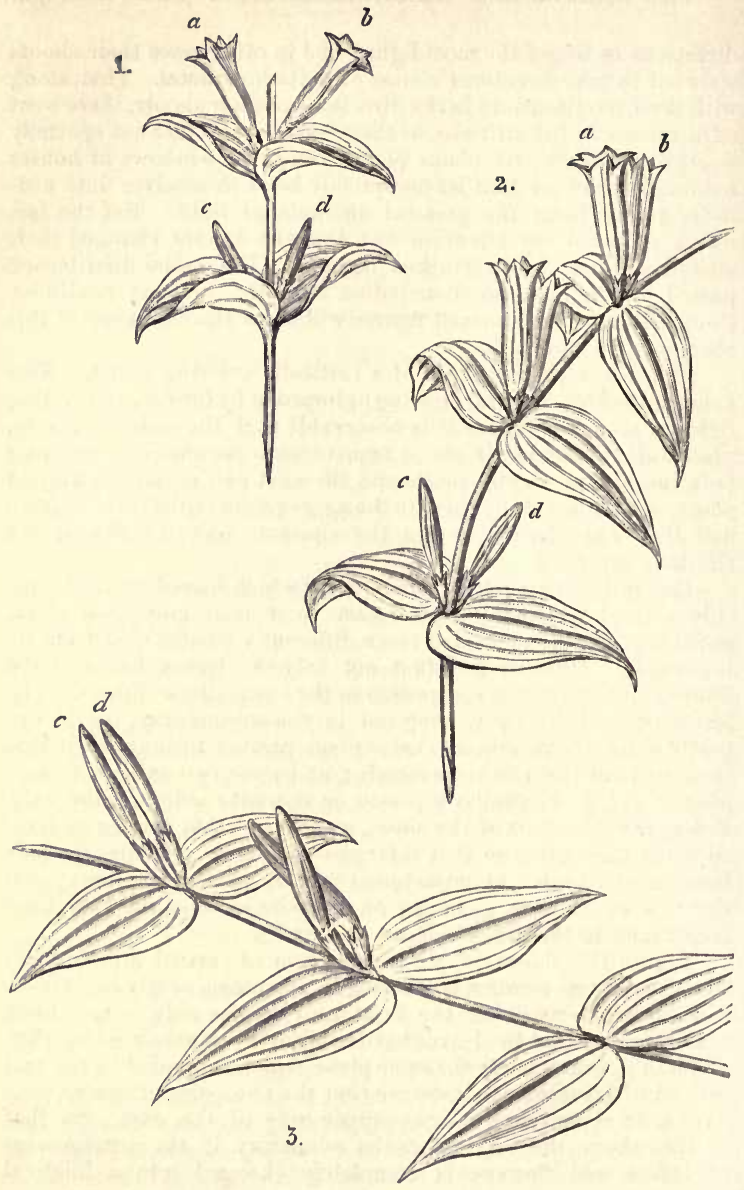


of the flowers themselves: they only prove modification in the grouping of the flowers. But beyond showing, as they do conclusively, how readily a bilateral arrangement of flowers is producible out of an arrangement that was not bilateral, by the action of light, etc.; they give increased probability to the belief that changes in the shapes of flowers are producible by the same agencies. Doubtless this change in the attitudes of the flower-buds is due to the action of light on their calyces and peduncles more than to its action on their unfolding corollas. But along with an action so decided on the growth of these sheathing and supporting organs containing chlorophyl, it is scarcely probable that there is no action on the growth of the petals, containing other colouring matter; considering that in both cascs the development of the colouring matter depends on the action of light, and considering also the effect of light on petals, familiarly shown by their opening and closing. And if even but a small effect is producible on the growth of the corolla, then it is to be expected that light will be an agent in changing the form of the corolla, when the attitude of the flower causes its parts to be-differently exposed. For a small effect on the individual flower will become a great effect in the flowers of remote descendants; provided the changed attitudes of the flowers preserve considerable constancy throughout the succession of individuals.

Be this as it may, however, the facts I have here described, which I doubt not other observers have seen paralleled in other plants, are instructive, as showing how quickly certain metamorphoses are produced, and as implying the easy establishment of such metamorphoses as permanent characters in a species, if the modifying conditions become permanent. The changes of arrangement I have pointed out, do not become permanent in this species because its individuals are variously affected by the modifying forces: on some they do not act at all, on some a little, on some much; and even on the same individual the different shoots are quite differently affected. But if the habit of this plant were greatly changed-if, for instance, by spreading into habitats yielding abundant nutriment, the plant became very luxuriant, and, multiplying its branches, grew shrub-like; it is clear that, being shaded by one another, these branches would be habitually circumstanced in a way like that which we here see produces bilateralness in the distribution of the flowers, if not in the flowers themselves; and being thus permanently affected, would become permanently bilateral. Accumulating by inheritance, what is here only an individual peculiarity, would become a peculiarity of the species-a specific character. 


\section{APPENDIX F.}

\section{PHYSIOLOGICAL (OR CONSTITUTIONAL) UNITS.}

There has recently come before me a fact which has a significant bearing on the hypothesis of Constitutional units: serving, indeed, to give an apparently conclusive proof of its truth. Before stating it, however, I may with advantage re-state the several evidences already assigned in support of it.

1. First comes the $\dot{a}$ priori reason. These units in the germ of an organism which cause development into a special structure, cannot be chemical units - cannot be simply molecules of proteid substance in one or other of its forms; since these are not special to any type of creature but common to all creatures. Nor can they be what we may call morphological units-the cells or protoplasts; because in the early stages of development the cells of one organism are indistinguishable from those of others, and because were cells the units of composition there could be no interpretation of what are called unicellular organisms-nothing to account for the innumerable varieties of them. Hence, of necessity, the structural elements of which each organism is built, being neither proteid molecules nor cells, must be something between them: probably some complex combination of different isomeric forms of proteids.

2. That units of such natures are the essential components of each species of organism, is shown by the fact that in low types of creatures, little differentiated into special tissues, any considerable portion of the body will, when separated, begin to assume the structure proper to the species-a truth recently shown afresh by Prof. T. H. Morgan's experiments on the regeneration of Planaria maculata (already referred to in $\$ 206$ ) showing that various fragments cut out develop into new individuals, and that when, being too small they die before doing this, there is always an abortive attempt to assume the specific structure.

3. This truth that a portion of undifferentiated tissue, if adequate in quantity, assumes the structure of the type, illustrating 
as it does the proclivity of the constitutional units towards the structure of the species, allies itself with the phenomena of both agamogenesis and gamogenesis. The first of these shows us how a fissiparously-detached portion of the parental tissue takes on the same form as the parent; and the second shows how those small detached portions distinguished as sperm-cell and germ-cell also, when united and supplied with the needful materials, do the same thing.

4. But the set of phenomena following the union of sperm-cell and germ-cell differ in a certain way from those which follow when a gemma or other unfertilized portion of parental tissue is detached. The incomprehensibleness of this difference as otherwise contemplated, and the partial comprehensibleness of it when joined with the hypothesis of physiological units, furnish a further support for the hypothesis.

The familiar truth learnt by the tyro in algebra that an apparent solution which contains the unknown quantity is no solution, is a truth apt to be overlooked in other spheres than the algebraic. An illustration is supplied by the answer once given in Parliament to the question "What is an Archdeacon?"

"One who discharges archidiaconal functions." But science as well as daily life furnishes examples. When it is said by Engelmann, Hensen, Hertwig, and Maupas that "the essential end of sexuality is rejuvenescence, that is, the restoration of growthenergy," we have another instance of an explanation which explains nothing. What is the phenomenon to be explained? That unfolding of an organism from a germ which displays growth-energy. And what is the explanation? The giving of fresh growth-energy. The unknown quantity "growth-energy" is contained in the explanation proposed. There exists no conception of "juvenescence" save that derived from observing developing plants and animals; and if "re" be prefixed, no interpretation is thereby given to the unexplained thing " juvenescence."

Coleridge somewhere comments on a source of fallacy which he calls the "hypostasis of a relation"-the changing of a relation into a thing. The plumber who tells you that water rises in a pump "by suction" supplies an instance. Having assumed suction to be an agent, he thinks that he understands how the piston does its work. Some of the explanations given of fertilization supply further instances. When it is said that sexual union has for its end "to give increased vigour to all the vital processes," it is tacitly implied that vigour is a something-a something which can be given. But now, in the first place, it is only by the hypostasis of a relation that we are led to think of vigour as a thing. Vigour is a state-that state of a living body which enables it to 
give out much motion. What enables it to do this? The presence in it of abundant molecules containing much molecular motion which can be transformed into molar motion: the transformation being effected by the falling of these molecules into their simpler and relatively-inert components, which are thereupon excreted. Energy-containing matter is used up, and more energy or vigour can be given only by supplying more such matter. How then can the union of two nuclei-those of the sperm-cell and germcell-give vigour? Only an infinitesimal portion of vigour in the sense above explained exists in either, and the union of them leaves it still infinitesimal. And then, even supposing the vigour to be an entity and to be appreciable in quantity, how could it go on producing that immense combination of physiological actions seen in the unfolding of the germ into an organism? and how could it go on producing the physiological actions of an adult organism during a whole century ?

May we not then say that these proposed explanations leave the question where it was-are nominal solutions, not real solutions?

5. But the hypothesis of constitutional units furnishes, if not a satisfactory answer yet, something in the nature of an answer-a true cause; that is to say, a cause actually known to us as operating in other cases. In $\$ 92$ it was pointed out that in proportion as units are similar, there may be built up from them an aggregate which is relatively stable, and that along with increasing dissimilarity the stability of the aggregate decreases. It was inferred that if a group of constitutional units belonging to one individual which have become moulded into relatively exact congruity with the organism and with one another by long cooperation, are mingled with some belonging to another individual which, differently circumstanced, has become somewhat different in itself and in its nnits, then the mass formed by the union of the two groups will be relatively unstable-relatively modifiable by incident forces. Whereas in either organism, no longer perpetually changed in the relations of its parts by growth, there is an approach towards equilibrium between the whole and its components, the components contributed by the two to form a germ, being slightly unlike one another, will not form a group in a state of equilibrium. The group they form will be capable of easy change by incident forces; and they will so be rendered free to follow their proclivities towards the typical form of the species. Inferring this we must also infer that so long as these two sets of slightly different units are not exposed to any constant forces tending to coerce them into the same form, there will continue to exist in the nuclei of all descendant cells this same relative instability and consequent plasticity. 
Such evidence as we have verifies this interpretation. There is first the universal fact that development of the germ begins when it is exposed to an incident force-heat-the undulations of which, increasing the oscillations of the mixed units, give them greater freedom to arrange themselves in conformity with their type. We see this alike when spring warmth makes a seed germinate and when the warmth of a sitting hen sets up organization in her eggs. Heat frees the molecules of inorganic matter from local restraints and, as we see in molten metal, lets them yield to other forces; and similarly in this organic matter, the units are made free to follow their proclivities. Then, secondly, there comes the evidence from comparisons between the effects of mixing constitutional units differing in various degrees. Let the cluster of mixed units be derived from animals that are ordinally distinct. Nothing happens. The units each contributes tend to arrange themselves after the parental type. Hence a conflict between the tendencies towards two markedly unlike structures, and no structure arises. Suppose the mixed units come from two kindred species-say horse and ass. The structures which they respectively tend to form, being in their main characters alike, there is such cooperation as produces a working organism but an organism in certain respects imperfect-a mule. Suppose, again, the units come from two varieties of the same species. A perfect organism results, and, as shown by Mr. Darwin when detailing the effects of crossing, an unusually vigorous organism. The units being more unlike than those belonging to the same variety, the instability of the germ-plasm is unusually great, and the transformations which constitute development and action become unusually active. When, as in ordinary cases, the units are supplied by members of the same variety who have not been made very much alike by their antecedents, there follows the usual amount of organic vigour. Coming now to the results of breeding in-and-in-breeding between individuals whose constitutions (i.e. constitutional units) have for generations been growing more alike in the absence of crossing with other stirps-we see that diminution of organic vigour is displayed: there is a decrease in the rate of physiological change. Finally, on coming to a closer relationship, as in marriages between cousins, in whom the constitutional units are more than commonly alike, we see there frequently follows either barrenness or the production of feeble offspring.

All these facts, then, are congruous with the hypothesis that the use of fertilization is the mixing of unlike units, and consequent production of plasticity. Leaving out cases in which the unlikenesses are so great as wholly to prevent cooperation among the units, the degree of vigour, that is, the activity of physiologi- 
cal change, is great where the unlikeness is great and diminishes with the approach towards likeness.

6. The existence of constitutional units seems otherwise necessarily implied. I refer to the, fact that no organism is a homogeneous mean between its parents but consists of a mixture of parts, some following one parent and some the other. Among illustrations of this the most conspicuous are those yielded by the variously-mixed colours of hair or feathers. Horses, cattle, dogs, cats, hens, pigeons display these mixtures: colours in one place like the mother and in another place like the father. As the internal organs are invisible, and as visible organs have indefinite shapes and graduate indefinitely into adjacent ones, the mixture of traits is elsewhere less conspicuous; but occasional marked cases (especially in malformations) leave no doubt that it pervades the entire organism.

This peculiarity of transmission seems necessarily to imply that there are distinct units derived from the two parents, and that in the course of development there is more or less segregation of them-those of the one origin predominating so far in some places as to give special likeness to one parent, and those derived from the other doing the like in other places. All which interpretation is impossible unless the hypothesis of constitutional units be admitted.

7. I come at length to the special evidence referred to at the outset. It is evidence of the same nature as that just assigned, but carried to a higher stage. It is furnished not by the segregation of traits derived from two parents of the same variety, but is furnished by the segregation of traits derived from parents of different varieties. In articles on "Bud Variations or Sports" (Gardener's Chronicle, 1891) Dr. Masters gives various examples of the separation or unmixing of ancestral constitutions. Mr. Noble formed a hybrid between Clematis Jackmani and C. patens. One of these varieties flowers in the autumn on new wood, while the other flowers in the spring on old wood; and the result is that flowers of two kinds, quite unlike, are produced at different parts of the year, and that by pruning so as to cut away one or other set of shoots, the plant may be made to produce exclusively for the time being one or other sort of flower.

"Another very interesting case of unmixing, or, if it be preferred, of partial mixture, is afforded by Neubert's Berberis. This is a hybrid between the evergreen pinnate-leaved Mahonia and the deciduous simple-leaved Berberis vulgaris, and it bears leaves some of which are intermediate in appearance, while others are much like those of one or other of its parents.

"A not uncommon illustration of a similar kind, is the production of a Peach and a Nectarine on the same branch, and we have just learnt from 
Canon Ellacombe that some of the Berlin Hellebores show evidence of their hybrid nature by occasionally producing foliage [and flowers?] of the two parents separately from the same root-stock.

"In addition to the cases given above, we may here cite a few more which have come under our notice, such as a Chrysanthemum, half the florets of which are of one colour, half of another. A hybrid Calanthe, showing a similar piebald variation, is shown in Fig. 14. A very curious case was that of the Narcissus received from Mr. Walker, and in which flowers of two distinct varieties sprang from the same bulb. Grapes not uncommonly show their crossed origin by presenting a striped appearance, one stripe being of one colour, one of another, as may also be seen in the Orange, Apple, Lemon, and Currant."

Thus, however the germ-plasm is constituted its essential components cannot be all alike. Before there can be this dissociation of ancestral characters, there must be in the germ-plasm different elements capable of being dissociated. This single fact seems to compel us to assume constitutional units. 


\section{A P PENDIX G.}

\section{THE INHERITANCE OF FUNCTIONALLY-CALSED MODIFICATIONS.}

IN Part II, Chapter $X^{\wedge}$, I have confessed that the process by which a structure changed by use or disuse affects the spermcells or germ-cells whence arise descendants, is unimaginable: without, however, inferring that therefore such a process does not exist. With others it seems different. Some three years ago the following expression of opinion came to me from a zoological expert :-

"Many zoologists-most of us here at Cambridge-are intensely opposed to the doctrine of the inheritability of acquired variations. Even assuming that the developmental power of a germ is determined by its molecular structure (and I for one would question this-Driesch and his school when they find that they can squeeze a developing egg into all sorts of shapes without altering the final result, that one blastomere in an egg which has divided into 8 is still able to reproduce a whole embryo-question it also), we still fail to conceive any means by which, for instance, a change in the development of a muscle or nerve can effect a corresponding change in that part of the germ which is destined to produce a corresponding part in the descendant."

Here it will be observed that belief in the inheritance of structural effects wrought by use and disuse, is rejected because of inability "to conceive any means" by which the modifications produced in an organ can effect a correlated modification in the germ of a descendant: failure to conceive is the test. The implication is that some alternative hypothesis is accepted because the correlating of a variation in an organ with a corresponding germ-variation is effected by a means which is conceivable. This is the hypothesis of Weismann. Concerning its conceivability 1 have, in the chapter just named, already written as follows :-

"If we follow Prof. Weismann we are led into an astounding supposition. He admits that every variable part must have a special determinant, and that this results in the assumption of over two hundred thousand for the four wings of a butterfly. Let us ask what must happen in the case of a peacock's feather. On looking at the eye near its end, we see that the minute processes on the edge of each lateral thread must have been in some way exactly adjusted, in colour and position, so as to fall into line with the processes on adjacent threads: otherwise the symmetrical arrangement of coloured rings would be impossible. Each of these processes, then, being an 
independent variable, must have had its particular determinant. Now there are about 300 threads on the shaft of a large feather, and each of them bears on the average 1,600 processes, making for the whole feather 480,000 of these processes. For one feather alone there must have been 480,000 determinants, and for the whole tail many millions. And these, along with the determinants for the detailed parts of all the other feathers, and for the variable components of all organs forming the body at large, must have been contained in the microscopic bead of a spermatozoon!" [And each of them must, throughout all the complex developmental processes, have preserved the ability to find its way to the exact place where it was wanted !]

If my Cambridge correspondent is able to conceive this process implied by the hypothesis of Weismann, I can only say that he has an enviable power of imagination.

But now comes the strange fact that an impossibility of thought implied by Weismann's hypothesis does not cause rejection of it, but yet is urged as a reason for rejecting an alternative hypothesis which does not imply it. One objector cannot conceive that " a change in the development of a muscle or nerve can effect a corresponding change in that part of the germ which is destined to produce a corresponding part in the descendant"; and another objector says it is "very hard to believe" that a functionally-changed organ will so affect spermatozoa and ova that "one particular part of them will be so altered that the organisms which grow up from them will be able to present the same modification on the application of a different stimulus." It is tacitly assumed by both that, as in the hypothesis of Weismann so in the counter-hypothesis, a particular part of the germ-plasm gives origin to a particular part of the developed organism. But nothing of the kind is implied. The nature of the counter-hypothesis (at any rate as held by me) is entirely misapprehended. Anyone who turns back to the chapters in the first volume where the conception of physiological units (or constitutional units) was set forth, or who re-reads the foregoing appendix, will see that there is altogether excluded any idea of correlation between certain parts of the germ and certain parts of the resulting organism. The units are supposed to be all alike, and during the progressive embryological changes local groups of them are supposed to take on different forms and structures nnder the combined forces, general and local, brought to bear on them. This conception is necessitated by all the evidence. The fact disclosed by the experiments of Driesch, Wilson, and Chabry, that from fractions of an ovum structures may be obtained like that obtained from the whole ovum, only smaller, necessitates it. The fact that any sufficiently large fragment of a polyp or planarian, no matter from what part of the body taken, will develop into a complete polyp or planarian necessitates it. The fact that from an undifferentiated portion 
of a plant, even so small as a scale, a complete plant may arise necessitates it. And it is necessitated by the fact that among plants, roots are produced by imbedded shoots and shoots by roots, as well as by the fact that low animals, such as hydroids, if deprived of both head and root, will develop a head from the root part and a root from the head part, if their respective conditions are inverted. All this evidence shows conclusively that the component units of each species, whether existing in the germ or in the developed organism, are, when not yet differentiated by local conditions, all alike, and that the notion of special parts of the germ-plasm correlated with special parts of the resulting organism, is entirely alien to the hypothesis.

"But how do the units of a modified organ affect the units of the germ in such wise that these produce an inherited modification of the organ ?" will be asked. This difficulty has been dealt with in $\$ \$ 97 d, 97 e$, where the analogy between the social organism and the individual organism has been brought in aid: serving, if not to furnish a conception, yet to furnish an adumbration. Regarding citizens as the units of an unfolding society, say a colony, it was pointed out that the nature they inherit from a mothersociety gives them a proclivity towards a society of like structure, the traits of which are progressively assumed as the colony grows sufficiently large to make them possible. At the same time it was pointed out that while the influence of the entire aggregate on the individuals is seen in this forming of them into a society of the inherited type, the influences of local circumstances, and of individuals on onc another, in each group, make them differentiate into appropriate social structures, taking on fit occupations and industries: the implication being that in virtue of their inherited natures they all have partial capacities for the various activities they undertake; so that an immigrant clerk sets up a tavern, a compositor takes to carpentering, and a university man rides after cattle or is employed on a shecp farm. Evidence was given in that place, as in the above paragraph, that the constitutional units of an organism similarly have all of them potentialities for taking on this or that structure and mode of action which local conditions determine. It was further argued that as citizens are continually being remoulded by their society into congruity with it, and, if circumstances change them, tend to remould their society; so in the individual organism, there is this reciprocal action of the whole on the units and of the units on the whole. Hence it was inferred that the modified units in any modified part tend to diffuse modifications like their own through the units at large: being aided by the circulation of protoplasm, as suggested in $\$ \$ 54 d$ and $97 f$. And it was urged that, however inconceivably complex such a process may be, yet it seems not 
incredible when we recognise the probability that an organism is more or less permeable to undulations propagated by its molecules: Rontgen rays giving warrant. If such units throughout the tissues may take in and send out ethereal waves which bring it into rhythmical relations with others of its kind and tend to produce congruity, it becomes, if not conceivable still supposable, that throughout the circulating protoplasm there goes on a continual harmonization of its components - a moulding of each by all and of all by each. Should it be said that such a process is too marvellous to be reasonably assumed, the reply is that it is not more marvellous than heredity itself, which, were it not familiar to us, would be thought incredible.

But as I have said in the place referred to- "At last then we are obliged to admit that the actual organizing process transcends conception. It is not enough to say that we cannot know it; we must say that we cannot even conceive it:" can only conceive the possibility of a suggested interpretation.

Hence we have to rely upon evidences of other kinds. Among these, some which I think dispose absolutely of the fashionable hypothesis while they harmonize with the opposed hypothesis, have now to be named. That their implication should not have been generally recognized would have seemed to me incomprehensible were it not that I have myself only now observed this implication. The facts are these:-

"Verlot mentions a gardener who could distinguish 150 kinds of camellia, when not in flower; and it has been positively asserted that the famous old Dutch florist Voorhelm, who kept above 1,200 varieties of the hyacinth, was hardly ever deceived in knowing each variety by the bulb alone. Hence we must conclude that the bulbs of the hyacinth and the branches and leaves of the camellia, though appearing to an unpractised eye absolutely undistinguishable, yet really differ." (Darwin, Variation of Animals and Plants, \&c., vol. ii, p. 251.)

More recently testimony to like effect has been given by Dr. Maxwell Masters, and has already been quoted by me in a note to $\S 286$ in illustration of another truth. He says concerning such variations :-

"To the untrained eye, the primordial differences noted are often very slight; even the botanist, unless his attention be specially directed to the matter, fails to see minute differences which are perceptible enough to the raiser or his workmen. . . . These apparently trifling morphological differences are often associated with physiological variations which render some varieties, say of wheat, much better enabled to resist mildew and disease generally than others. Some, again, prove to be better adapted for certain soils or for some climates than others; some are less liable to injury from predatory birds than others, and so on."

In his Vegetable Teratology, p. 493, Dr. Masters names another fact having a like implication-the fact that among seedling 
stocks which have not yet flowered, those which will produce double flowers are distinguishable. He says:-

"This separation of the single from the double-flowered plants, M. Chatie tells us is not so difficult as might be supposed. The single stocks, he ex. plains, have deep green leaves (glabrous in certain species), rounded at the top, the heart being in the form of a shuttlecock, and the plant stout and thick-set in its general aspect, while the plants yielding double flowers have very long leaves of a light green colour, bairy and curled at the edges, the heart consisting of whitish leaves, curved so that they enclose it completely."

What is the general truth implied ? Clearly that there exists no such thing as an independent local variation. Some marked change in the form or colour of a flower or a fruit draws attention; and, being a change which interests the florist or gardener, pecuniarily or otherwise, not only draws attention but usually monopolizes attention: the natural impression produced being that this variation stands there by itself-is without relation to variations elsewhere. But now it turns out that there are concomitant variations all over the plant. Even in underground bulbs certain appreciable differences go along with certain conspicuous differences in the flowers. And if along with a striking change in a flower which the florist contemplates, there go changes all over the plant not obvious to careless observers but visible to him, we must infer that there are everywhere minute differences which even the florist cannot perceive: the whole constitution of the plant has diverged in some measure from the constitutions of kindred plants. Every local variation implies a change pervading the entire organism, manifested in concomitant variations everywhere else.

If so, what becomes of the hypothesis of determinants-the hypothesis that there is a special element in the germ-plasm which results in a special local modification in the adult organism? That there are no facts supporting it has been all along manifest; but now it is manifest that the facts directly contradict it.

At the same time it may be remarked that while the facts are wholly incongruous with the hypothesis of determinants and its accompanying elaborate speculation, they are not incongruous with the alternative hypothesis. Impossible though it may be to imagine the natures of those ultimate units peculiar to each species, which have proclivities towards the particular form of organization characterizing it, yet that a change of structure arising in one part of the organism is accompanied by multitudinous changes of structure in other parts of the organism, is not only congruous with the belief that there exist such constitutional units, but yields it distinct support. For if, as above argued, a conspicuous local variation is not the result of any modification of units special to the locality, but is the result of a modification of 
the units at large, then it must happen that such modification must have its effects on all other parts of the organism; so that there cannot fail to result all those small concomitant variations above indicated.

May we not also say that it becomes less incomprehensible that structural changes caused by use and disuse are inherited? If, as we see, a local variation spontaneously arising is accompanied by multitudinous other local variations, implying a necessary correlation between each local variation and the general constitution of the organism; then it may be argued that if a marked change of function in an organ causes increase or decrease of it, this general correlation implies that there must be a reciprocal reaction between the part and the whole, tending to re-establish their congruity. The constitution at large will in so far be changed, and along with its change will go corresponding changes in the sperm-cells and germ-cells.

Finally let me add, not another argument, but another fact of observation, of the kind which opponents demand, but which, when they are from time to time furnished, are severally poohpoohed as not enough. Each of them is spoken of as a solitary fact and slighted as inadequate; and when by-and-by another is named, this is treated in the same way; so that the facts which if brought together would be recognized as sufficient are never brought together. That to which I refer is set forth in a pamphlet by M. Leo Errera, Professor at the University of Brussels, entitled "Hérédité d'un Caractère acquis chez un Champignon pluricellulaire;" being an account of experiments of Dr. Hunger, at the Botanical Institute in Brussels. First enumerating various instances of adaptations to climate, as those of plants which, fitted to northern regions, preserve their constitutional rapidity of growth and seeding when brought south, and do this for several generations, he goes on to detail the culture-experiments of M. Hunger, and sums up the results of these in the following words :-

"On déduit de là que:

“ $1^{\circ}$ Les conidies d'Aspergillus niger sont adaptées à la concentration du milieu où a vécu l'individu qui les porte; cet effet est encore plus marqué après deux générations passées dans un milieu donné (Expér. I et II);

“ $2^{\circ}$ Il s'agit d'une véritable adaptation et non pas simplement d'un accroissement de vigueur chez les conidies provenant des liquides concentrés, car ces mêmes conidies germent moins rapidement et donncnt des plantes moins vigoureuses que les conidies normales lorsqu'on les sème de nouveau sur le milieu-type: en s'adaptant aux liquides concentrés, elles se sont désadaptées du liquide normal (Expér. III);

“ $3^{\circ}$ Une génération passée sur le liquide normal n'efface pas l'influence d'une ou de deux générations antérieures passées sur une liquide plus concentré (Expér. IV).

"Tous ces résultats concordent: ils montrent une légère, mais incontestable transmission héréditaire de l'adaptation au milieu." 



\section{S UBJECT - I N DEX.}

(For this Index as it appeared in previous editions the Author is indebted to $F$. Howard Collins, Esq., of Edgbaston, Birmingham. It has now been adjusted to suit the present revised and enlarged edition.)

AcACra, follar organs, II, 41, 264. Acalepha: environment, I, 105; water in, I, 173.

Acari: speciai creation and effects of, I, 428; direct transformations, I, 706; segmentation, II, 111.

Acorus calamus, agamic propagation, I, 642.

Acquired characters, Inheritance of: functionally-produced modifleations in piants and animals, I, $307-13,318,526,541,562,692$ 5, II, 618-22; concelvability of, on the hypothesis of physiological units, I, 368-71, 695, II, 61822 ; diminution of faw, I, 541-2, 693; current views on, I, 559-60; cessation of selection, I, 560-3; Eimer's theory of orthogenesis, I, 560; species differentiation, I, 573; iocation of mammalian testes, I, 573; tactual perceptiveness, I, 602-8, 633, 665, 666, 672-3, 692; blindness of cave-animals, I, $612-3,647-9$; coadaptation of cooperative parts, I, $621,663-5$; transmission of disease, I, 622-3; hypothesis supported by telegony, I, 624-8, 644-6, 649-50; vlews of Darwin and neo-Darwinists, $I$, $630,685,690$; why facts in support are meagre, I, 632; degradation of little toe, I, 652-3, 673; neuter forms of soclal insects, I, 658-9, 663-4, 670, 675; degenerated Instinct in ants, I, 660-2; rudimeutary limbs of whale, I, 669 , 692; importance of question, I, 672 , 690; monstrous development of honey-ants; I, 683-4; osteology of Punjabis, I, 689; summary of eridences in support, I, 692-5; genesis of vertebrate skuil, II, 227 ; faise foints, II, 371,372 ; concelvablitty of rival hypotheses, II, 618-22; adaptation to environment In Aspergillus, II, 623.

Acrogens, the term, II, 55-6. (See Archegoniatca.)

Actinophrys: a primary aggregate, II, 76, geuesis, II, 452.

Actinozoa: multiaxial development, I, 166; waste and repair, I, 213, 219 ; differentlation, I, 391; parasitism, I, 397; integration, II, 92 ; symmetry, II, 189, 192; growth and genesis, II, 444.

Activity: the principle of, the essential element in Life, I, 113, 114, 122; not Inherent in living matter, I, 120; nutrition and genesis, résume, II, 497-9; and evolution, II, 501-4.

Adaptation: general truths, I, 22733, 233-5; botanleal, I, 227 ; physiologicai, I, 228-33; isychological, I, 229, 230-3; structural, functional, and interdependence, I, $235-9,240-1,318$; soclal and organic stability, I, 240-2; résumé, I, 242-3; to varied media, I, 470-81, 489, 556: multiplication of effects, I, 512-3, 550; direct equilibration, I, 522-3; natural selection and equllibration, I, 530-5; non-adaptive speciflc characters, I, 565; time required for effecting, I, 565-6; an obstacle to re-adaptation, II, 11; of skin and skeleton, II, 215, 217; outer tissue, II, $312-4,387$; skin and mucous membrane differentiation, II, 321-2; 389 ; vascular system, II, 343-4; osseous, II, 352; muscuiar, II, 
368-9, 391; persistence of force and physiologleal, II, 394; of reproductive activity to conditions, II, 411-6; vertebræ development, II, 563-6. (See also Co-adaptation.)

Africa, effect of climate on inhabitants, I, 30.

Agumogenesis : alternation with gamogenesis, I, 266-7, 272-3, 284$94,336,592$, II, 415 ; parallellsm in karyokinesis, I, 267-8; a process of dislutegration, I, 276-7; conditlons determining its continuance, I, 284-94, 295-7, 330; physiologleal nnits, I, 351, II, 613; spontaneous fission, I, 582, 584-7, 589-92, $595-6$, 599; remarkable extent of, under favourable conditions, I, 501-2, 640-1; in Actinozoa, II, 92; in Hydrozoa, II, 102; in Annelida, II, 103; innutrition, II, 179-80.

Agaricince, II, $139,257$.

Agassiz, L. J. R., zoological classlfication, I, 380.

Aggregates, Animal and Plant (see Morphology).

Agility, a vital attribute, I, 578 .

Agrimony, floral symmetry, II, 42, $167,170$.

Air, in vegetal tlssues, II, 567-8, 583 , 591, 593.

“ Alr plants," I, 208.

Albumen: propertles, I, 12; Lleberkühn's formula, I, 13; diffusibility, I, 19; in organic tissues, I, 41. Alcohols, propertles, I, 10-12.

Alga: reproduction, and the $d y$ namic element in llfe, I, 118-9; multicentral development, I, 163, 164; axial development, I, 165; locomotive powers of minute forms, I, 196; unlform tissue and function, I, 200, 586; gamogenesis, I, 271, 279, 280, 283, II, 448, 449, 450; fertility, I, 582, II, 440, 441; fission, I, 584, 585; unicelluiar forms, II, 22; Integration In Confervoidca and Conjugatece, II, 25; pseudo-follar and axlal development, II, 28-33, 57; follar development, II, 76, 91; branch symmetry, II, 145: cell metamorphoses, II, 176; tissue differentla- tion, II, 244, 246, 251, 252, 256, 272 , 385-6; adaptation of reproductive activity to couditions, II, 289 ; integration, II, 292; indefiniteness, II, 295; genesis and development, II, 463 .

Alimentary canai: metabollc processes and agents, I, 68-9, 74; structural traits, I, 192; progresslve development, I, 195 ; relation to environment, I, 196; function, I, 205; segmentation in annellds, II, 125; differentiatlon, II, 301, 302, 321-2, 323-5, 389; specializatlons in birds, II, 325 ; in rumlnants, II, 327-9; differentlation of II rer, II, 329-33; muscularity, II, 364.

Allotropism: of organic constituents, I, 4, 9; muscular action, I, 59. Alloys, melting point of, I, 339 .

Alternation of generations, misleadIng application of term, II, 84 . (See Agamogenesis and Gamogenesis.)

Amitosls, occurrence of, in morbld tissues, I, 264.

Ammonla: propertles, I, 7, 9; nerve stimulation, I, 55.

A mæba: central development, I, 163; a primary aggregate, II, 86 ; symmetry of encysted, II, 186; symblosIs, II, 400.

Amphibia: classiffcation of, I, 392; embryonic resplratory system, I, 457; structure and medla, I, 483; Ilmb locomotion, II, 15; segmentation, II, 122, 225; outer tissues, II, 311; respiration, II, 334, 338; Owen on skeleton, II, 552, 557, 558.

A mphtoxus: separation of segmentation spheres of egg, I, 691; embryogeny, II, 121; local seginentation, II, 125-7, 605; genesis of vertebrate axis, II, 213-6, 218, 222 ; development, II, 564.

Amphipnous cuchia, vascular airsacs, II, 337.

Anabas scandens, the climbing fish, I, $480,483$.

Anacharis (see Floldra).

Annesthetics, diverse effects of, I, 55. 
Angrøcum, assimilative function of root, II, 255 .

"Animal Spirits," vitalism and, I, 115.

Animais: nutrition and molecular rearrangement, I, 36-7; nitrogenous character, I, 39-41; sensible motion, I, 57; metabolism, I, 6277 ; multiplication of energies, I, 75; contrasted traits of piants and, I, 196; what is an individual? I, 246-7; solar influence, I, 500, 556; geologic changes affecting, I, 5014, 549, 550, 556; interdependence with plants, I, 504-6, 514, II, 398401 ; complexity of influences affecting, I, 506; geographical isolation and origin of specles, I, 568-9; vital attributes, I, 577-9; distribution and antiquity of plant and animal types, II, 297; mutual dependence of organisms at large, II, 397-408; hypotheticai plant-animal type, II, 397; progressive increase of size, II, 401; laws of multiplication, II, 411-6; rhythm in numbers, II, 419; law of weights and dimensions, II, 434.

Animais, domesticated: variation, I, $324,326,560,563,693$; interbreeding, I, 345-7, 354, II, 615; pure and mixed breeds, I, 354, 625.

Annelida: phosphorescence, I, 50; axlal development, I, 165, 166; integration, I, 363; larval forms and phylogeny, I, 447, II, 115; segmental fission, I, 588-9; segmentation, II, 98-101, 103-4, 6025, II, 107-9, 125-7; lateral gemmation, II, 105; embryogeny, II, 119 ; bilateral symmetry, II, 197200; genesis, II, 444, 453.

Annulosa: regeneration, I, 361-2; distinctire traits, I, 392; origin of type, II, 98-110, 602-6; unit of composition, II, 105; application of term, II, 111; vertebrate symmetry compared, II, 203-6; segmental differentiation, II, 207-9; unintegrated function in Planaria, II, 373; development and genesis, II, 464; nutrition and genesis, II,
490. (See also Annelida and Arthropoda.)

Anthropomorphism, former prevalence of, I, 419.

Ants: utilization of aphids, I, 660 1, II, 403, 405; nest-mates, II, 405; castes in social species, I, 658-9, 670,675 ; loss of self-feeding instinct in Amazons, I, 660-1, 6634 ; monstrous development of Honey-ants, I, 683; bulk and fecundity, II, 492. (See aiso Termites.) Aphis: individuallty, I, 249, 250; II, 603; parthenogenesis, I, 274-5, 289 ; fertillty, I, 582, 640-1; II, 476, 490; utllized by ants, I, 660 1; II, 403, 405; over-multiplication checked by lady-bird, II, 406. Aquatic animals, large size attained by, I, 156.

Arachnida: avoidance of danger, I, 92; oviparous homogenesis, I, 271; segmentation, I, 469; II, 113, 114; integration and homology, II, 111, 121; bilateral symmetry, II, 198.

Arcella: symmetry, II, 186; outer tissue differentiation, II, 309.

Archegoniatec: morphological composition, II, 32-5; growth and development, II, 50-6; tubular structure, II, 58, 62; alternating generation not distinctive, II, 84; asymmetry and environment, II, 140 ; Integration, II, 293, 296; individuation and genesis, II, 441, 451, 463.

Archenteron: primitive externaisty, II, 301; formation of cœlom, II, 302.

Archiannelida: segmentation, II, 125.

Arenicola marina: polytrochai larvæ, II, 109.

Arm: embryogeny of buman, I, 169; vicarious use of, I, 209.

Army, morphologlcal analogy, II, 6. Arterles (see Vascular System).

Arthropoda: unlaxial development, I, 165; protoplasmic continuity, I, 190, 629; excursiveness, I, 481; limb locomotion, II, 15; integration and homology, II, 111-4, 121; bllateral symmetry, II, 197-200; genesis, II, 445, 453 . 
Ascidians: multiaxial development, I, 165, 166; functional differentiation, I, 202; composite IndiviulualIty of Doliolum, I, 247; seif-fertillzation, I, 342; integration, II, 94, 96, 97; symmetry, II, 194; origin of vertebrate type, II, 194, 598,605 .

Ascomycetes, reproduction, II, 450.

Assimilation: compared with reasoning, I, 81-7; a trait of vitality, I, 577.

Asteroidea, radial symmetry, II, 196.

Astronomy: growth of celestial bodles, I, 135; Schlelden on individuality, I, 245; evolution, I, 432, 435; classification of stars, I, 444; rhythm of, and organic change, I, 499-501, 557; law of equilibratiou, I, 519-20; cooperation of structure and function, II, 3.

Atavism: occurrence of, I, 305-6. 314; digital variation, I, 321-3.

Atoms: use of term, I, 6, 31; ethereal undulations and oscillations, I, 31-5.

Australla: settler's usages, I, 364; ratio of jaw to skull in natives, I, 541.

Axlliary buds, origin and development, II, 65-8.

Axls: " neutral" of mechanles, II, 210; genesis of vertebrate, II, 212-6, 224-7.

Bacteria: fisslon, I, 270; non-nucleated, II, 20; rate of increase, II, 443.

Baer, K. E. von: embryological formula, I, $171,172,451,453,461$, 466; zoological classifleation, I, 383 ; on animal transitions, I, 480.

Balanophork, Inner tissue, II, 274.

Bark: varled development, II, 24i9; physiological differentiation, II, $249-50,258,386$.

Basidiomycetcs, reproduction, II, 450.

Bat, Infertility of, II, 473.

Bates, H. W., protective mimicry of butterfles, I, 398.
Batrachia (see Amphibia).

Bean, vascular system, II, 573, 591.

Beaver, tall and co-adapted structures, I, 616.

Bees (see Insects).

Begoniacea: muitiplleatlon I, 224, 317,442 ; Individuality, I, 251; development from scales, I, 282; symmetry, II, 159, 166; derelopment, II, 271.

Berkeley, M. J., indefiniteness of mosses and ferns, II, 296.

Blle, arrest of excretion, I, 209. Billrubin and blliverdine, function of, II, $330,333$.

Blology: definition and divisions, I, 124-5; organic structural phenomena, I, 125-7; also functional, I, 127-9; actions and reactions of function and structure, I, 129-30; genesis, I, 130-1; ilmited knowledge of, I, 131; evolution, I, 432, 434; soclologleal anaiogles (see Soclology).

Blophors, Welsmann's germ-plasm units (sce Welsmanu).

Birds: flesh-eating and grain-eatIng contrasted, I, 68; growth and expenditure of force, I, 142; size of egg and aduit, I, 144; IImitations on flight, I, 155; self-mobility, I, 175; temperature, I, 176; functional and strueturai differentiation, I, 201; food of starving pigeon, I, 215; viviparousness, I, 271; heredity and pigeon breeding, I, 305; atavism in plgeon, I, 314; osseous varlatlon in plgeon, I, 321; classlficatlon, I, 392; migratlons and change of hablts, I, 399, 402, 500; distribution in time, I, 410; Darwin on petrels, I, 455; rudimentary teeth, I, 457; vertebræ, I, 471 ; II, 564; feather development, I, 473; habits of water ouzel, I, 485; egg shells and direct equilibration, I, 526; bones of waders and direct equllibration, I, 527; fertillty and nervous development, I, 598; cellular continulty, I, 629; adaptation of structure to environment, II, 12; 
sexual selectlon, II, 269; wing spurs, II, 313; outer tissue differentiation, II, 314-5, 387; allmentary canal development, II, 325 , 327; muscular colour and activity, II, 365-9; nutrition, II, 433; cost of genesis, II, 436; growth and genesis, II, 454, 458; heat expenditure and genesis, II, $468-9,474$; activity and genesis, II, 470-2, 474; contrasted mammalian fertility, II, 470; eggs of wild and tame, II, 478; fertlilty of blackbird and innet compared, II, 503; Owen on skeleton of, II, $559,560,561$.

Bischoff, embryogeny of human arm, I, 169.

Bison, modiflcations entalled by increased weight of head, I, 512.

Blackbird, contrasted with ilnnet in development, II, 503.

Biainville, de, definition of life, I, $79,93$.

Blastosphere, independence of cells in Echinoderm larræ, I, 185.

Blastula, deflnition of life and formation of, I, 112.

Blood: similarity of iron peroxide, I, 17; metabolic processes, I, 69; segregation of abnormal constituents, I, 180; protozoon life of corpuscles, I, 186-7; morbid changes, I, 221, 701; assimllative power and organle repalr, I, 221-2; respiratory tissue differentiation, II, 310-1; pressure in mammais, II, 340. (See also Vascular System.)

Blow-fiy, Welsmann on nutrition and genesis in, I, 678-9.

Boers, Cape, hablts and fertility, II, 508.

Boismont, A. B. de, on human fertillty, II, 511.

Bone: growth and function, I, 151; adaptabillty, I, 230; II, 217-8; function and weight, I, 308, 693; mammalian cervical vertebræ, I, 394; evolution and vertebral column, I, 470-1; partlal development, I, 473; size of head as influencing, I, 512, 536-9; direct equilibration and strength, $I$, 527; naturai selection and co- adaptations, I, 614-21, 674, 677; rudimentary limbs of whale, I, $668,685,692$; inheritance of acquired modifications in Punjabis, I, 689; skull development, II, 222; theory of supernumerary, II, 223; Cope on origin of vertebrate osseous system, II, 225-7; differentiation, II, 344-56; false jolnts, II, 370-2; Owen's theory of vertebrate skeleton, II, 548-66.

Book-worm, food of, I, 77.

Born, G., experiments on frog-larvæ, I, 365 .

Botany, blological classlfication, I, 124, 125. (See Plants.)

Bothriocephalus, deveiopment, II, 490.

Botryllida: development, I, 166; independence of components, I, 247; agamogenesis, I, 641.

Bower, Prof., on alternation of generations, II, 84.

Brachiopoda, rude vascular system, II, 340 .

Bradbury, J. B., on vaso-dilators, I, 55.

Brain: natural selection and mental evolution, I, 553; analysis of substance, I, 596; welght in higher animais, I, 598-9; size in clvilized and uncivilized, II, 530.

Branches (see Morphology).

Branchia (see Respiratory System). Brass, effect of antimony on, I, 121. Bread, dlamagnetism, I, 370.

Breeding: heredity, I, 304-5; inand-in, I, 344-7, 353; II, 615; pure and mlxed, I, 354, 625 .

Bricks, changed equllibrium shown by, I, 38, 42.

Brodie, T. G., cell chemlstry, I, 260.

Brownell, Miss J. L., on birth-rate in United States, II, 520.

Brown-Séquard, on inherited epilepsy, I, 312, 624 .

Bryophyllum, peculiar proliferation, II, 295.

Bryophyta, large size attained by some, I, 138.

Bryozoa, gemmation, I, 588.

Budding (see Gemmation).

Buds: development, I, 167-8; the- 
ories of heredity and canline, I, 358-9, 360; axlllary, II, 65-9; effects of nutrition, II, 73-4.

Butterfly: protectlve mimiery, I, 398 ; Instance of tame, I, 684 .

Cabbagh, varietles of, I, 302.

Cactacea: follar and axial derelopment, II, 4i-9; differeutlation in, II, 258, 276, 282; vascular system, II, 282; dye permeability and circulation, II, 571, 572; wood formation, II, 575, 577, 578, 580.

" Callus," budding from, I, 358, 359.

Camel, natural selection and hump of, I, 534 .

Canadians, French, fertility of, II, 509.

Cancer, the definition of llfe, I, 111; œsophageal, II, 324 ; and vascular system, II, 343.

Caoutchouc, leaf structure, II, 589.

Capllaries (see Vascular System).

Caplliarity, and vegetal vascular system, II, 279-80, 286, 568, 570, 585, 587, 592-6.

Carbohydrates: instability, I, 10; the term "bydro-carbon," $i b$. ; molecular changes in, I, 42-3; organic transformatlon, I, 43, 48; metabolic processes, I, 63-7ī, 262-3, II, 362.

Carbon: propertles, I, 3-5, 20; compounds, I, $6,7,9,10-12,13,24-5$.

Carbonic acid (carbon dioxide): propertles, I, 6, 7, 9; in animal and plant functions, I, 62, 214, II, 398; diffusibllity, II, 331.

Carbonic oxide, propertles, I, 6.

Carnivores: nitrogenous food, I, 47, 68 ; katabolic process, I, 71 ; restricted environment, I, 396 ; their beneficial effects on animal life, II, 405-6.

Carpenter, W. B.: on functional specialization, I, 208; reproduction of sea-weed, I, 582; vegetal cell multiplleation, I, 585; structure and multipilcation of compound organisns, I, 586-9; on fundamental traits of sex, I, 595; nutritlve system of invertebrates, I, 595; Macrocystis, II, 450; nutri- tion and reproductive function, II, 460.

Cartllage (see Bone).

Castration, effect of, on growth, II, 459.

“ Castration parasitalre," Julln on, II, $493-6$.

Catalysis, and vital metamorphosis, I, 39, 43.

Cattell, McKeen, on tactual perceptiveness, I, 666.

Caulerpa, simulation of higher plant-1orms, II, 22.

Cave-animals, degeneration of ejes, I, 309, 612-3, 614, 64i-9, 693.

Cell, the: incomprehensiblity of forces at work in, I, 118; protoplasts and their traits, I, 181; the cell-theory, I, 1S4, 252, II, 1721,85 ; differentiation, $I, \quad 188-9$, 194 ; the continuity of protoplasm, I, 190-2, 194, 628-30, II, 21; Its structure, I, 253-5; function of centrosome, I, 254-5, 257; structure and function of nucleus, $I$, 255-6, 258-9; karyokinesls, I, 2578 ; function of chromatln, I, 25965; fertillzation and function of polar bodies, I, 266-8; theorles of heredity based on theory, I, 356; Weismann's differentiation into reproductive and somatlc, I, 622 , $628-30,633-44$; nucleus alsent or dispersed, II, 20, 85; uorphological differentiation, II, $175-7$; anlmal morphology, II, 228-30; morphological summary, II, 233; vegetal tissue differentlation, II, 249-50, 386; vascular development, II, 279-84, 389.

Centlpede, bllateral symmetry, II, 198-200.

Ccphalopoda: bllateral synimetrs, II, 203; vascuiar system, II, 341 .

Cercaria (see Distoma).

Ccreus, tissue differentlation, II, 276, 283.

Cesalpino, I, 377.

Cestoda (see Entozoa).

Chrtopoda, segmentation, II, 98, $103,605$.

Chaja, wing spurs, II, 313.

Change, and definition of life, I, 81-00, 113. 
Charies, R. H., on inheritance of acquired modlfications in legbones of Punjabis, I, 689 .

Chatle, on single and double stocks, II, 622 .

Chemistry: properties of organlc elements, I, 3-5, 20, 22; of dlatomic compounds, I, 7-10; trlatomle, I, 10-12; polyatomic, I, 12-13, 25; traits of evolution, I, 23-4; ethereal undulations and atomic oscillation, I, 31-6; chemical affinity and organlc change, I, $36-7,38-43$; oxidation and generation of heat, I, 46-9, 60; generatlon of nerve force, I, 52, 60; metabollsm, I, 62-77; physiology and organle, I, 127; flesh constituents, I, 154; composition of organlsms and environment, I, 173; organic development and differential assimilation, I, 179-80; chemical units, I, 225, II, 612; primltive ideas of elements, I, 41،; evolution of organic compounds, I, 696-701, 703.

Chestnut, leaf s5mmetry, II, 149, 153.

Chiton: slmulation of segmentation, II, 116, 118; symmetry, II, 202.

Chlorophyll: function, I, 65, II, 263; nutrition and absence of, II, 74 ; constitution, II, 262; symblotic presence in animals, II, 400 .

Chandracanthus gibbosus, enormous development of reproductive system, II, 487.

Chordata, affinitles, I, 466.

Chromatin (see Cell).

Circle, the, and evolution hypothesis, I, 433.

Circulation (see Vascular System).

Cirripedia: Darwln on retrograde development, I, 458; remarkable transformation in Sacculina, II, 494-5.

Civillzation, human evolution and genesls, II, 529-31.

Cladophora: integration, II, 25; axial development, II, 28.

Classlficatlon: subjectlve conception, I, 78; two purposes of, I, 374 ; a gradual process, I, 375; botanical, I, 377-80, 389-90; zo- ological, I, 380-9; incomplete equivalence of groups, I, 389 , $445-6,448,555,572$; group attributes, I, 390-3; the truths interpreted, I, 393-4; ethnologic and llnguistle evolution, I, 441-6; organic evolution, I, 443, 44i, 555; differences in kind and degree, I, 444-6; antecedent structural slmllarity, I, 447, 448-9; Von Baer's formula, I, 451-4, 555; organic, not uniserlal, II, 115.

Classification of the Sciences, The, and evolution and dissolution, II, 5.

Claus, C., on segmentation in Annelids and Chrtopods, II, 605 .

Clover: flower and axial development, II, 45; symmetry, II, 152.

Co-adaptation of cooperative parts: principles underiying, I, 234-5, 511-3, 514-5; slow operation of the process, I, 236; soclological analogy, I, 237-40; reverslon under origlnal condltions, I, 240; the analogy continued, $i b$. ; the case of bison's head, I, 512; natural selection an inadequate explanatlon, I, 535, 614-21, 692; Romanes on "cessation of selection" as effecting, I, 560, 561-2; Welsmann's theories, I, 560-3, 663-5, $670,674-5$; natural selectlon and economy of growth, I, 562; physiological processes involved, I, 566-7; Wallace's argument from artlflalal selection, I, 615; what are cooperative parts? I, 616-7; "Intra-selection" examined, I, 676-8.

Coal, social effects of supply, I, 238-9, 241.

Cocoa-nut, growth and fertillty, II, 457.

Coccospheres: vital problem presented by protectlre structures, I, 119; imbrlcated plates, I, 182.

Cockroach, ousting of European species, I, 399.

Cod: ova of, II, 435; growth and fertlity, II, 454.

Codium: symmetry, II, 136; tissue differentiation, II, 246. 
Colenterata: rudimentary contractlle organs, I, 58; vitál changes in polyp, I, 95; axial development, I, 165, 166; environment and strncture, I, 173; self-mobllity, I, 175; II, 14, 15; funetional differentiation, I, 201, 391; inactlvity and waste, I, 213; reparative power, I, 219, 224; indivlduality, I, 246, 247, 250; heterogenesis, I, $273,277,296$; negatlve disintegratlon in Hydrozoa, I, 276, 587; reproductive tissue, I, 281; differentlation In Hydrozoa, I, 391; classificatory value, I, 446; regeneratịon of fragments, II, 90; Integration, II, $90,102,105$, 124; gemmation, II, 91; tertlary aggregatlon, II, $92,95,124$; molluscan affinItiês, II, 115; radial symmetry, II, 188; symmetry of compound, II, 192-3; segmental differentlation, II, 207; physiological differentlation in Hydra and analogy, II, 300; clllation of blastula, II, 301; tissue reduplication, II, 301-2, 389 ; outer tissue differentiation, II, 309; osmosis in Hydra, II, 339; vascular system In Hydra, II, 340, 376; functional co-ordination, II, 376; symblosis, II, 400; asexual genesis, II, 443-4; growth and sexual genesis, II, 452; development and genesis, II, 462; nutrition and genesls, II, 476.

Coelom, origin and function, II, 302-3.

Colllns, F. Howard, Jaws and teeth of savages and cirllized, I, 541.

Collolds: T. Graham on, I, 15-8; diffusibility, I, 18-21; organic, I, $21,25,26$; pllabllity and elasticlty, I, 27; caplliary affinity, I, 28; Isomerism, I, 59; instabllity, I, 350: molecular moblilty and diffusibility, II, 331; instablilty of, and nerve differentiation, II, 35661; and muscuiar tissue, II, 361-4. Colonles, autogenous development and parallel in heredity, I, 3668; II, 620.

Colour: sensation of, I, 54; phœnogamic, II, 75, 265-6; light and vegetal, II, 261-2; floral fertlliza- tlon, II, 267-9; sexual selection, II, 269; actlvity and muscular, II, 365-9; physiologleal unlts and mixture of, in offspring, II, 616, 617.

Commensalism, organic integration

as displayed in, II, 402-4.

Composita: floral symmetry, II, 173. Condor, welght of, I, 155.

Confcrvoidca, I, 279, 280; II, 25, 28, 419. (See Algar.)

Conjugatea, II, 449. (See Alga.)

Conjugation, in Algc, I, 279; in Protozoa, I, 280; II, 452; can fission persist wlthout? I, 637; relation to growth, II, 449.

Connective tissue, Hertwig's classification, I, 189.

Constitutional unlts, I, 369.

Physlological Units.)

Consumption, heredltary transmlsslon, I, 307.

Co-ordination of actions (see Life). Cope, E. D., on orlgln of vertebrate structure, II, 225-7.

Cormophyta: sllght internal differentlation, II, 273; rascular system, II, 280.

Corpuscula tactus, their function, I, 75.

Correspondence, use of word, I, 97. (Sec Life.)

Cousin-marrlages, I, 345, II, 615 .

Cow: what prompts her to numble a bone? I, 120.

Cow-parsnip (see Heracleum).

Crab (see Crustacea).

Creation (sec Speclal creation).

Crinoidea, symmetry, II, 195-6.

Crocodile, continuous growth, I, $154,292$.

Crookes, Sir W., hypothetical chemical unit " protyle," I, 22, 23. Crucifera, foral symmetry, II, 164, 171.

Crustacea: locomotion of lobster, I, 175 ; regeneration of $11 \mathrm{mbs}, \mathrm{I}, 224$, 360 , 589, II, 76; homogenesis, I, 2i1; genesls and nutrition In Daphnida, I, 200-1; growth and genesis, I, 292; degeneration of eye In cave-lnhablting, I, 309,614 , 648; hermit crab parasite, I, 397; changes of med!a, I, 401, 481-2; 
retrograde development in cirrlpedes, I, 458; segmentation, I, 468-9, II, 114; Darwin on jaws and legs, I, 471; survival of eirripedes, I, 517; integration and homology, II, 111-4, 121, 603; bllateral symmetry, II, 198-201; eyes, II, 318; dermal structure of hermit crab, II, 322 , 387; fertility, II, 453; nutrition and genesis in parasitic specles, II, 487; "castration parasitaire," II, 493-6.

Crystallolds: Prof. Graham on, I, 15-8; diffusibllity, I, 18-21; organic, I, 21-2, 26.

Crystals: slmulation of life in " storm glass," I, 96; growth, I, 135-7, 577; segregation, I, 179, 221, 223; equllibration, I, 337; physiological units and polarity, I, 701-6; time and formation, II, 77. Ctenodrilus, segmenta] IndividualIty, II, 103, 603, 604.

Cube; bllateral symmetry, II, 132.

Cunningham, J. T., I, vi; Ir, vi; on non-adaptive speclfic characters, I, 565; food of blow-fly larræ, I, 678; arthropod segmentation, II, 114; egg-production of Conger, II, 425.

Cuttle-fish, individuality of Hectocotylus, I; 250.

Cuvier, zoological classification, I, 381.

Cyanogen, propertles, I, 7, 9.

Cyclichthys, dermal structure, II, 306.

DALYelL, Slr J., regeneration in Dasychone, I, 361; propagation of Hydra, II, 476.

Daphnida, heterogenesis and nutrition, I, 290-1.

Darwin, C.: Origin of Species, I, 129, II, 528; natural selection and function, I, 308-9, 693: atarism, I, 314 ; osseous rariations in pigeons, I, 321; plant rariation and domestlcation, I, 325; "spontaneous variation," I, 328,697 ; floral fertilization, I, 340 , II, 168,267 , 407,608 ; intercrossing and selffertllizatlon, I, 344, 345; iuter- crossing I, 347, 611, 669; his theory of pangenesis examined, I, $356-62,370,372$; plant fertillzation and distribution, I, 397; habits of blrds, I, 400; distribution and natural barriers, I, 102, 476; dlsappearance and non-re:ıppearance of species, I, 406; distributlon in time and space, I, 410; linguistic classification, I, 442; classification of organisus, I, 443; classificatiou and descent, I, 448; on petrels, I, 455; suppression of organs, I, 457; development of Cirrhipedia, I, 458; jaws and legs of Crustacea, I, 471; aborted organs, I, 474, 56?; relations of species in Galapagos archipelago, I, 478; oplnions of E. Darwin and Lamarck, I, 491; the term "survival of the fittest," I, 530; indirect equilibration by natural selection, I, 530-5; inheritance of acquired characters, I, 535-42, 560, 630, 685, 690; WaIlace on natural selection In man, I, 553; misleading connotations of term " natural selection," I, 609 , 695 ; caste gradations and jaws of driver ants, I, 658; attachment of climbing plants, II, 276-7; vegetal fructification, II, 294; earthworm, II, 402; animal sterllity and domestication, II, 480, 483; variation in hyacinth and camel11a, II, 621.

Darwin, Dr. E., modilabllity of organisms, I, 490, 492-7.

Death: an arrest of vital correspondence, I, 102; only limit to vegetal growth, I, 153; cessation of coordination of actions, $\mathbf{I}, 578$, 579; Welsmann's hypothesis, I, 636-8; physiological integration, II, 374,392 ; cause of natural, II, 413; relation to births, II, 417.

Definiteness: of vital change, I, 87$90,106,109$; developmental, I, 178; functional, I, 212; segregation of evolution, I, 514-6.

Definition, difficulties of, I, 78; II, 17.

Degeneracy, morphological obscuratlons due to, II, 12, 13. 
Dendrobium (see Orchlds).

Desmidiacew: unicelluiar, II, 21; linear and central aggregation, II, 23 ; natural selection and symmetry, II, 134, 135; morphologieai differentiation, II, 177; tissue, II, 244; genesis, II, 440, 449.

Determinants, Weismann's germplasm units (8ee Germ-piasm).

Development: an increase of structure, I, 162, II, 461; primarily central, I, 162, 166; uni-and multi-central, I, 163-4, 166-7; axial, I, 164, 167; unl- and multi-axial, I, 165-6; a change to coherent definite heterogenelty, I, 167-70, 179; Von Baer's formula, I, 171-2; individuai differentiation from enviroument, I, 172-8; cell formation, I, 225; discontinuous, and agamogenesis, I, 275; Prof. Hnxley's classification, I, 276; soclological parallei to autogenous, I, 364-8, II, 620 ; retrograde, I, 4578: inequalitles among co-operative parts, I, 617; " heterochrons," I, 655; continuous and discontinuous vegetal, II, 52; summary of physiological, II, 384-90; nutrition and genesis, résumé, II, 4979; evolution, II, 501-5; commencement of genesis, II, 506; of vertebrate limbs, II, 553. (See also Multiplication.)

Development Hypothcsis, The, I, 417. Dialects (sec Language).

Diaiysis, and diffusibility, I, 19, 20.

Diastase, decomposition of, I, 38 , 40.

Diatomacea: tissue, II, 244; genesis, II, 440, 448.

Diatomic compounds (sce Chemistry).

Dicotyledons: growth, I, 139, 143, II, $63-4,62-72,78,82-3$; uniaxial development, I, 165; stem and leaf functions, II, 257; mechanical stress and wood formation, II, 277; growth and genesis, II, 451.

Differentiation (see Morphology and Physiology).

Diffugia: primary aggregate, II, 867; symmetry, II, 186; outer tissue differentlation, II, 209.
Diffusion, of colloids and crystalloids, I, 18-20; II, 331.

Digestion: action of nitrogenous compounds, I, 69 ; obesity, II, 480-4; fertility, II, 514.

Ilmorphism: florai, I, 534; sexual, in parasites, I, 315; social insects (see Insects).

Dinosaurs, size of, I, 139.

Diphyes: Individuality, I, 246; symmetry, II, 192.

Ilsease: segregation of blood constituents, I, 179; changes in blood from, I, 221, 701; heredity, I, 306-7, 312-3, 622-3; belief in supernatural origin, I, 419; parasitism and speclal ereation, I, 427; morbid products as specific characters, I, 507; telegony, I, 646; dermal structure, II, 806 ; intestinal muscuiar hypertrophy, II, 325; indigestion and allmentary canal development, II, 328; Jaundice and bllirubin, II, 330; locallzation of excretion, II, 331; membranes in inflammatory, II, 343; osseons differentiation in rickets, II, 352; fatty degeneration, II, 482.

Disintegration, physiological (see Physiology).

Distoma: metagenesis, I, 273-4; disintegration of genesis, I, 276; eycle of generations, II, 489.

Distribution: physical ilmits, I, 396; organic environment, I, 396-8; parasitic conditions, I, 397-8; simuitaneity of agencies affecting, I, 398; mutual encroachments of species, I, 398-401, 477, 489; facts disproving pre-adaptation to habitats, I, 401-3, 411-2; of animais and plants in time, I, 404-11, 412; ousting of natire species in New Zealand, I, 477; local influences, I, 477-9, 489; through varied media, I, 479-85, 489, 556; past and present organic forms, I, 485-9, 556; complex organization and, II, 296-7.

Division of labour, physlological (see Labonr).

Dog: contrasted lives of tortolse and, I, 103, 104; Inherited habits, 
I, 309, 573; abnormal digits, I, 324 ; interbreeding of divergent varietles, I, 565; decrease of Jaw, I, 615 , 693; telegony, I, 645; conditions affecting fertility, II, 474, 479.

Dohrn, theory of vertebrate structure, II, 606.

Doliolum, combination of individualities, I, 247.

Domestication (see Animals).

Doubleday, E., on nutrition of genesis, II, 510-2.

Driesch, separation of segmentation spheres of Echinus ovum, I, 691; II, 618.

Dropsy (see Disease).

Drosera: Individuality, I, 251; proliferous growth, II, 75 .

Du Bois-Reymond, E. H., electricity from muscles and nerves, I, 50.

Dumas, antithesis of animals and plants, I, 62.

Dwarfs, Hindu family of, I, 316.

EAR, development of vertebrate, II, $318,320$.

Earth, elimatic rhythm and organic change, I, 499-501, 557.

Farth-worm: bilateral symmetry, II, 199, 200; mould production, if, 402.

Echinococcus (see Entozoa).

Echinodermata: independence of blastosphere cells, I, 185; protoplasmic continuity in embryos, I, 190 ; separation of segmentation spheres of orum, I, 691; II, 618; symmetry, II, 191, $195-6$.

Economy: of growth in naturai selection, I, 536, 562; a trait of organic evolution, II, 501, 504.

Ectoderm: Iunctional differentiation, I, 202, 203; functional vicariousness, I, 209; reproductive function, I, 281.

Effects, Multiplication of: variation, I, 329-30, 333; organic evolution, I, 511-4, 515, 517, 549, 557, II, 405-6; morphological derelopment, II, 7-9, 234; physlological differentiation, II, 390-1, 392.
Eggs (see Embryology).

Eimer, T., theory of orthogenesis, I, 563-4.

Elasmobranchii: protoplasmic continuity, I, 629; segmentation, II, 126.

Eiectricity: genesis in organie matter, I, 50-2, 60; muscular action, I, 59; incomprehensibility, I, 121.

Elephant: fertillty, I, 583, 599, II, 459, 506; cerebro-spinal system, I, $598,599$.

Elk, Irlsh, horns and correlated parts, I, 537, 674.

Eloidea canadensis: individuality, I, 248 ; enormous agamic multipileation, I, 642.

Elongation, and locomotion in anlmals, II, 15.

Embryology: as aiding biology, I, 125-6; simulated growth, I, 136; initial and final organic bulks, I, $143,158,161$; fotal flesh constituents, I, 154; human arm derelopment, I, 169; Von Baer's formula, I, 170-2, 451-4, 466: embryonic heat, I, 177; spherical organic form, I, 177; unit-life in muiticeliular organisms, I, 18:-6; functional differentiation, I, 203; individuality, I, 246-7: unspecialized reproductive tissue, I, 27983, 317; changes followiug impregnation, I, 283-4: nutrition and vegetal growth, I, 285-8, 295-7; and animal growth, I, 289-94, 295-7; physiological units and heredity, I, 317-9; variation and parental functional condition, I, 324 ; uterine environment, I, 327-8; physiological units and variation, I, 330-4, 458; fertilized and unfertllized ova, I, 340-1; hermaphrodism, I, 341-2, 344; sociological parallel, I, 366-8: erolution hypothesis, I, 434, 436, 453, 454, 555; petrel development, I, 455; substitution and suppression of organs, I, 456-8, 466, 472-3; structural proclivities of physlological units, I, 458; abridgment of stages, I, 458-9, 464: disappearance of intermedlate forms, I, 
459-60, 463; pre-adaptation, I, 461-3; discrimination of specles in early stages, I, 461; anomalous persistence of ancestral traits, I, 463-5; phylogeny, I, 466; egg-shell function, I, 527; genesis of grades in social insects, I, 654-6, 658-9, 670-80; determination of sex, I, 657; order of development quallfied by needs, I, 679; osteology of Punjabis, I, 689; direct transformatlons and physlologleal units, I, 706: transformation of blastema, II, 20; arrest of growth and innutrition, II, 73: development of segmented animals, II, 100-2, 602; adaptive vertebrate segmentation, II, 118-23, 124, 223-4, 605-6; anlmal cell morphology, II, 228; primary differentiations of germinal layers, II, 300-2; lung development, II, 333-4; mammalian ova maturation, II, 342-3: movements of ova, II, 356,363 ; modifications In mole, II, 391; genesis and nutrition, II, 424, 425; fish ova, II, 435,454 ; cost of genesis, II, 435 6; number of birds' eggs, II, 454 6,478 ; heat and genesis, II, 468, 474: activity and genesis in birds, II, $470-2,474$; vertebrate $11 \mathrm{mb}$ development, II, 553; ossification in vertebrates, II, 556; Owen's vertebrate theory, II, 563; development of vertebra, II, 564. (Sce also Multiplication.)

Embryology of conceptlons, I, 451.

Emigrants, type of organization among, I, 364, II, 620.

Fndoderm: functional differentiation, I, 202, 203; functional vicariousness, I, 209.

Endogen, application of term, II, 62, 78, 82. (Bee Monocotyledons.)

Energy: evolution of, In animals, I, 71-7; organic growth and expenditure, I, 141; functional transfer, I, 201-6; chromatin as the source of, in karyokinesis, II, 261-5. (See also Force.)

Entozoa: metagenesis, I, 273, 641; self-fertllization, I, 342; distribution, I, 398; and special creation, I, 428; fission in simple types, I,
584; nutrition and genesis, I, 641 ; II, 488; direct transformation, I, 706; integration, II, 102; segmentation, II, 107, 108; interdependence and organlc integration, II, 404.

Environment: degree of life and complexity of, I, 104-7; relation to organle structure and function, I, 172-8; II, 12-5; adaptation to rarled media an evidence of evolution, I, 479-81, 556; influence of solar system, I, 500, 556; inherited adaptation to, II, 623.

Kiolis, branchlæ, II, 118.

Epldermls (see Skln).

Epllepsy: definition of life and movements in, I, 112; heredity, I, 312.

Fpithellum: cillated, I, 187; Hertwig's ciassification, I, 189; reproductive function, I, 280; "pave. ment " and " cyllnder," II, 229.

Epizoa: distribution, I, 398 ; special creation and effects of, I, 428: interdependence and organic integration, II, 404; nutrition and genesls, II, 487.

Equilibration: variation and law of, I, 326, 334; molecular arrangement, I, 337-45; of organic change, I, 348, 547, 557; direct and indlrect, I, 519-22, 573: adaptation by direct, I, 522-3, 551, 557: nutrition, defence, and fer1lilzation of plants, I, 523-5; dlrect of anlmais, I, 525-8, 551, 557; natural selection and Indlrect, I, 530-4, 552, 557; of natural selection, I, 543-7, 552-3, 557; increasing importance of direct, I, 553 ; of forces acting on species, I, 571-2, II, 417-20; phenomena not accounted for by, I, 573; tissue differentiation, II, 245; genesis of nervous system, II, 307-8; functional, II, 391-4; laws of multiplication, II, 411-6; in human and social evolution, II, 537. (See also Acquired characters and Natural selection.)

Errera, I., on Inherited adaptation to environment in Aspergillus, II, cos. 
Ethnology: heredity, I, 303-4, 310; plasticity of mixed races, I, 354; primitive ideas, I, 417; evolution and classification, $I, 441-3,446$; natural selection, I, 555 .

Euphorbiacec: follar and axlal development, II, 47-8; physiological differentiation, II, 258; dye permeabllity and circulation, II, 571; wood formation, II, 575, 577, 578; follar vascular system, II, 589-92, 596.

Evaporation: organic change, I, 28; vegetal clrculatlon, II, 587.

Evolution: chemlcal elements and compounds, I, 22-4, 67; primordial form of llving matter, I, 63-4, 181; II, 21-2; definltions of life, I, 107-10; growth the primary trait of, I, 135; comprehends growth and development, I, 162; fllustratlons in development, I, 167-70, 178-9; progressive structural differentiation, I, 181-4, 192-6, 2112 ; llfe before organization, I, 210; heterogeneity of function, I, 211; stabillty of species, I, 242, 515, 518 ; individuality, I, 247; cell-organization, I, 262; genesis, heredity, and variation resulting from, I, 354-5; period required for organle, I, 407, 565-6; contrasted wlth special-creation bypothesis, I, $415,431-40$; derivation of hypothesis, I, 431, 439, 554 ; IncreasIng bellef in, I, 431-3, 439; experlences supporting conceivability, I, 433-5, 439; direct evidence, I, 435-7, 439; malevolence not implied by, I, 437-9; evidence from classification, I, 443, 444, 449, 466, 555; embryologỳ, I, 451-3, 466; substitution and suppression of organs, I, 456-8, 466, 472-3; insect segmentation, I, 468-9; vertebral column development, I, 470-2; rudimentary orgaus, I, 472-5; adaptation to varied media, I, 479-85, 556; growth of the theory of organic, I, 490-8; instabllity of the homogeneous, a cause, I, 509-11, 516, 550; multiplication of effects, I, 511-14, 517-8, 550, II, 405; segregation, and heteroge- neity and definiteness of, I, 514-8, 550 ; natural selection and general doctrine of, I, 543-8, 557; factors tabulated, I, 551; Inductlve evidences summarized, I, 555-6; surviving disbellef in Frauce, I, 559; current theories of organic, I, 559-74; Elmer's theory of orthogenesis, I, 563-4; Gulick on monotyple and polytypic, I, 569; phenomena unexplained by theorles, I, 573-4; Inorganic and the System of Philosophy, I, 693; “ spontaneous generation," I, 69 j701, 702; dissolution and probiems of morphology, II, 4-6; morphology and formula, II, 7-9, 231-5; difficulties of definition, II, 17; cell-doctrine, II, 17-21, 85; unicellular origin of plants, II, 21-2; résumé of plant morphology, II, $78-80$; origin and differentiation of phænogamic type, II, 83; physlological problems, II, 239-43; tissue dlfferentiation, II, 244-6, 385 ; integration of organic world, II, 396, 406; race and individual multiplication, II, 428-30; declining fertility and human, II, 431, 529-30; individuation, genesis, and, II, 501-5; human life, prospective, II, 522-5; forces influencing human, II, 525-8; future of population, II, 532-7; self-sufficingness of, II, 537; vertebrai, II, 563-6.

Excretion: genesis of organs of, II, 303 ; locallzation of, II, 331-3.

Exogen, application of term, II, 82. (See Dicotyledons.)

Expenditure (see Muitiplication).

Eye, the: molecular transformations in visual process, I, 75-6; progressive development, I, 195, II, 317-9; waste and repair, I, 218; transmitted defects, I, 308 , 311, 694; degeneration in caveanimals, I, 309, 612-3, 614, 647-9, 693; late development in lnsects, I, 658; migration in flat fishes, II, 205.

FABRE, J. H., nutrition and sex in Osmia tricornis, I, 657. 
False joints, I, 230; theorfes of heredity and, I, 362, 364, II, 371-2.

Fats, the: physical and chemleal propertles, I, 10-12; non-nitrogenous, I, 41; action of bile, II, 330 .

Fatty degeneration, and falling vitality, I, 41.

Feathers, development, I, 474, II, 314-6.

Feet, heredity and size, I, 311.

Ferments, changes and nitrogenous character of, I, 38.

Ferns: follar development and nutrition, II, 76; inner tissue differentiation, II, 273; Indefiniteness, II, 296; genesis, II, 441, 463.

Fertility, the General Law of Animal, I, 577-601. (See Multiplication.)

Fertllization: unit-life of generative elements, I, $185-6$; the function of chromatin, I, 260, 263-5; extrusion of polar bodfes, I, 266-8; nature and functions of generative elements, I, 279-83, 317, 334, 342, 593-7; differentlation and variation effected by, I, 330-2; the essential object of, I, 340-1, II, 6146; hermaphrodism and self-, I, 341-2; crossing and its effects, I, 343-7; isolation of specles in respect of, I, 570; floral (see Flowers).

Ficus, follar strueture, II, 589, 596. Fingers: embryogeny of human, I, 169; heredity and abnormal, I, $305,314,321-3$; autogenous development of supernumerary, I, 363; rudimentary, I, 473.

Fishes: sizes of ova and adult, I, 143-4; growth of plke, I, 154, 292; size and environment, I, 156; temperature, I, 174; self-mobility, I, 175; continuity of blastomeres, I, 214, II, 327; genesis, I, 271, II, 435, 436; conditions affecting genests, I, 292-3, 583, 598, 599, II, 454; classification, I, 392; change of media, I, 401, 480 ; distribution in time, I, 408-9; climbing specles, I, 480, 482; migrations, I, 500; dermal structure, I, 526, II. 305-6, 315, 387; Cunningham on non-adaptive specific characters,
I, 565; elongation and locomotion, II, 15; segmentation, II, 122, 225; bllateral symmetry, II, 203-5; eyes of Pleuronectida, II, 205; genesis of vertebrate axis, II, 212-6, 218-21, 225; ossification of paleozolc, II, 218; respiratory organs, II, 334-8; activity and museular colour, II, 365-9; Owen on skeleton, II, 552, 557, 558-60, 562, 564.

Fission (8ee Agamogenesis).

Flint, Austin, on telegony, I, 644.

Flounder, symmetry and eyes, II, 205.

Flower, Sir W., on ferret, II, 480.

Flowers: pollen propulsion in orchids, I, 57; nature of reproductive elements, I, 283; Insect fertilization, I, 340,525 , II, 168, 174, 267, 407; self- and mutual fertllization, I, 342-5, 570; Darwin on homologies, I, 472; direct equillbration and fertilization, I, 5245; dimorphlsm, I, 534; follar homology of petals, II, 43-6; symmetry, II, 132, 161, 162-4, 170, 174, 608; fertllization and symmetry, II, 164-70; elusters and components, II, 170-4; nutrition and inflorescence, II, $179-80,541-$ $2,546-7$; tissue differentiation, II, 265-9; separation of ancestral traits in hybrids, II, 616-7.

Fly, beneflclal parasitism, II, 406 .

Food (see Nutrition).

Food-cavity, genesis and development of, I, 188, 195.

Foraminifera: form, I, 173; primary aggregate, II, 87,124 ; progressIng integration, II, 89-80, 124.

Force: action on like and unllke units, I, 5; expenditure and organle growth, I, $149-54,161$; functional accumulation, transfer, and expenditure, I, 198-9, 201-3, 391; waste and expenditure, I, 214-5; distributlon during straln, II, 20912. (See also Energy, and Persistence of Force.)

Jossils (see Palæontology).

Foster, Sir M., on storage of glycogen, I, 70, 74; Increase of welght in hybernating dormouse, I, 214. 
Fowls (see Gallinacea).

Foxglove: abnormal development, I, 287, II, 46; floral distribution, II, 141; nutrition and growth, II, 179.

France: surviving disbelief in organic evolution, I, 559; rate of muitlplicatlon, II, $509,512$.

Frankland, SIr E., on isomerism of protein, I, 700.

Fraser, Col. A. T., on famlly of Hindu dwarfs, I, 316.

Frles, E., multiplication of Reticularia, I, 582, II, 450.

F'rog: vitallty of detached heart, I, 111; of larval fragments, I, 365 .

Fry, Sir E., on alternation of generatlons, II, 84.

Fuci: cell multiplication, II, 27; undifferentiated outer tissue, II, 256.

Function: as a basis of classification, I, 124-9, 129-31; slmultaneous progress of structure and, I, 197, 211; divisions of, I, 198-200, 391; correlative complexity of structure, I, 200, 210-1; progressive differentiatlons, I, 201-4; concomitant Integration, I, 205-8; specialization and vicariousness, I, 208-10; formula of evolution, I, 211; dlminlshed ability and overwork, I, 215-6; growth and increased, I, 228-33, 234-5; interdependence of soclal and organic, I, 237-9, 240-2; structure and heredity, I, 306-13, 318-9 (see Acquired Characters); alds natural selection, I, 308; organic interdependence, I, 318-9; parental conditlon and varlation, I, 324, 326; variatlon and altered, I, 325-6, 333-4; as causing variation, I, 334-5; effect on physlological vnlts, I, 353-4, II, 620; zoological classiflcation, I, 391-3; multipllcation of effects, I, 512; law of equilibration, I, 519-22, 557; correlation of changes in, I, 529; structural effects of changlng, I, 541-2; structural cooperatlon, II, 3, 217; vicarlous vegetal, II, 270; vicariousness and specializatlon, II, 293; epidermic structure, II, 312-4, 387; structure and muscu- lar, II, 369, 391; adaptive bonestructures, II, 370-1; equllibratlon and adaptation, II, 392; perslstence of force and adaptation, II, 394. (See also Physiology.)

Fungi: nitrogenous character, I, 40; development, I, 163, 164, 165; conjugation, I, 279 , II, 449; flsslon, I, 584, 585; Integration, II, 24-5, 293; symmetry, II, 137-40, 146: puff-ball tissue, II, 246, 252, 386; tissue differentiation, II, 256; inner tissue, II, 279; indefiniteness, II, 295; growth and genesIs, II, 459; nutrition and genesis, II, 487.

Gallinacea: conditions affecting ferthlity, II, 454-5, 469, 471; mascullne traits of old hens, II, 495.

Gall: definltion of life and, I, III; Hertwig on, I, 690.

Galton, F., on varlation outslde the mean, I, 669.

Gamogenesis: homogenesis, I, 270, 271, 336; heterogenesis, I, 270, 336; Independence of offspring, I, 278 ; reproductive tissue, I, 27984; vegetai nutrition, I, 285-8, 293; II, 39; animal nutritlon, I, 289-94, 297; when und why does It recur? I, 294-7, 336-40; effect on specles, I, 347-9; leaf formatlon, II, 39; alternating generatlon In llverworts, II, 80-4; molluscan homogenesis, II, 116, 1178 ; vertebrate, II, 118; growth, II, 266. (See also Fertilization, and Multipllcation.)

Gasteropoda (see Mollusca).

Geddes and Thompson, on the determlnation of sex, I, 657.

Gelatine, nutritive value of, I, 77. Gemmation: and genesis, I, 272-6; theories of heredity and, I, 361; annulose, II, 100-5, 106.

Generalization, impossibility of perfect, I, 450.

Generation, and genesls: the words, I, 269.

Genesis (8ee Multiplication).

Gentiana: floral arrangement, II, 608-11.

Genns: Indeflnite vaiue, I, 389, 446; 
Instabllity of homogeneous and heterogeneity of, I, 509-11, 515, $517-8,550,557$.

Geology: growth displayed in, I, 135, 136; distribution in time, I, 404-11, 412; special creation, I, 419,426 ; evolution, I, 432, 437; record congruous with evolution, I, 485-9, 556; organic influence of changes, I, 501-3, 549, 550, 557; climatic influence of changes, I, 503; time required for organic evolution, I, 565-6; rise of insect and plant relations, II, 407; human evolution and changes, II, 534.

Geometry, evolution lllustrated by, I, 433-4.

Germ-cell: unspeclallzed nature, I, $279-83,317$; dissimilarity, I, 330 , $332,334,342$; equilibrium, I, 340 . (See also Fertillzation.)

Germ-plasm, Weismann's theory of, I, 357-8; inconsistent with plant embryogeny, I, 359; regeneration of lost $11 \mathrm{mbs}, I, 362$; variatious in peacock's tall feather, I, 372, 695; II, 618-9; alleged differentiation of reproductive and somatic cells, I, $622,628-30,633-44,646$; origln of variations in neuter insects, $I$, $659,663-5,671,675$; correlated variations in stag, I, 677; insuperable difficulties, I, 682; concelvability of hypothesis, I, 695 ; II, 619; correlated variations in cultivated plants, II, 621-2.

Ghost-theory, Vitalism and, I, 114. Girafle, co-adaptation of structures, I, 615 .

Gizzard, development of birds, II, 320.

Glass, molecular rearrangement, I, 337, 352, 704.

Glove, strain analogy, II, 575.

Glycogen, in animal metabolism, I, $70,72$.

Goethe, J. W. von: foliar homology, II, 43-4, 543, 544, archetypal hypothesis, II, 122; vegetal fructifleation and nutrition, II, 180; theory of supernumerary bones, II, 223 ; on the skull, II, 561.

Gold, effect of blsmuth on, I, 121.
Gorilla, callosities, II, 312.

Gould, J., Birds of Australia, II, 469.

Gout (see Disease).

Grafting, Born's experiments with frog larvæe, I, 365.

Graham, T., propertles of water, I, 9, II, 359; collolds and crystalloids, I, 15-8, II, 356; their diffusibility, I, 18-20; sapid and insipid substances, I, 53.

Gramine: follar surfaces, II, 61, 263; floral symmetry, II, 165; physiological differentiation, II, 257.

Graminivores, food contrasted with that of carnivores, I, 68.

Grassi, on food-hablts of Termites, I, 686.

Gravity: Its ultimate incomprehensibllity, I, 121; vegetal circulation, II, 586. (See also Speclfic Grav'ty.)

Gregarina: central development, I, 163; primary aggregate, II, 87 ; symmetry, II, 186.

Grimaux, on artificial protelds, I, 39.

Growth: organic and inorganic, I, 135-7; simulation of, I, 136; limits to, I, 137, 155-7; structural complexity, I, 138-40, 145-7, 161; nutrition, I, 140, 147-9, 161; expenditure of energy, I, 141-3, 161; initlal and final bulks, I, 143-4, $157-60,161$; flnal arrest of, I, 149-55, 639; where unceasing, I, 154; résumé with generallzations, I, 161; deflned, I, 162; II, 461; increased function, I, 228-33, 234 5 ; functional interdependence, I, 235-9, 240; nutrition and regetal, I, 293, 294-7, 336, II, 39; heterogenesis and animal nutrition, I, 289-93, 296, 336; homo- and heterogenesis and natural selection, I, 294-8; of acrogens, II, 56; cylindrlcal form of vegetal, II, 56-64; endogenous, II, 60-2, 78; exogenous, II, $63-4,78$; plant differentlation, II, 129-131; tissue differentlation, II, 370 ; formation of adaptive bone-structures, II, 370 2 ; progressive increase of size 
with evolution, II, 401-2; vegetal, and asexual genesis, II, 439-42; animal, and asexual genesis, II, 442-5; antagonlstlc to asexual genesis, II, 446; vegetal and sexual genesIs, II, 448-51; anlmal and sexual genesis, II, 452-6, 495; antagonistic to sexual genesis, II, 457-8; nutrition and genesis, résume, II, 497-9; evolutlon and, II, 501-5; commencement of genesis, II, 506; fertllization and restoration of growth-energy, II, 613.

Gulick, T.: on monotyplc and polytyple evolution, I, 569; physiological selection, I, 569-71.

Gunpowder, nitrogenous instabllity, I, 8, 43.

Gymnotus, electricity of, I, 51.

Gyrodactylus elcgans, rapid successlon of generations, I, 641; II, 488.

HАвіт, change of, in plants, I, 308.

Hæmal, term applled to female element, I, 594-5.

Halrs: non-conductors of heat, I, 526; regetal, ănd natural selection, I, 532; development, II, 3146 ; tactual organs, II, 317.

Hand: embryogeny, I, 169; heredity and slze of, I, 311; distribution of veins, I, 364 .

Hardy, W. B., I, vIl; II, VI.

Hare: activity and muscular colour, II, 365; expenditure and genesls, II, 472.

Hart, J. A., on "Parasol " ants, I, 687-8.

Harlland, G. D., collection of Termites, I, 687.

Haystack, chemical action in, I, 74. Head, structural influence of size, I, 512, 537.

Hearing: the sense of, I, 54; multiplying agencles, I, 75 .

Heart (see Vascular System).

Heat: action on di- and trl-atomic compounds, I, $7-8,10-12,23,24$; on colloids and crystallolds, I, 26; organlc changes from evaporation, I, 29; chemlcal decomposition by, I, 33; organic oxldation, I, 46-9,
60; growth and organic, I, 152-3; animal, vegetal, and environment, I, 174-5, 177; alloy melting polnts, I, 339; organlc effects of rhythm in terrestrlal, I, 498, 557; effect on physlological units, I, 705; respiration in fishes, II, 337; anlmal preservation, II, 434; vertebrate expenditure and genesis, II, 468-9, 474; insect genesis, II, 476; seasonal varlations and genesis, II, 484-5; in germination, II, 615 . Hebrew Idea of creation, I, 421.

Hectocotylus, indlviduality, I, 250.

Hellin, D., on multiparity and twin-births, II, 457.

Hen, what prompts her to pick up egg-shell fragments? I, 120.

Henslow, Rev. G., inheritance of functionally-produced changes, I, 560.

Hepatica: Schlelden on, II, 51, 52; continuous and discontinuous development, II, 52x phyletlc homologles, II, $80-4$; meaning of socalled alternating generation, II, 84 ; vascular system, II, 280 ; genesls and development, II, 463.

Heredity: structural modification, I, 232; function of cell-nucleus in, 258-59; general truths, I, 301-4; transmission of congenltal pecullarities, I, 304-7; structure and altered function, I, 307-13, 318-9 (see also Acqulred Characters); atavism, or recurrence of ancestral tralts, I, 314; sex limitation, I, 314-6; physiologieal units, résumé, I, 350-5; II, 612-6; Darwin's and Weismann's theorles examined, I, 356 et seq., 559-61; II, 622; true theory must Include plants, I, 358; inadequacy of theory of physlological units, I, 360-1; soclological parallel, I, 366-8; natural selection (q. v.), I, 545-7, 553, 557; ethnology and natural selectlon, I, 553; unsolved problems, I, 573-4; mutilatlons, I, 631; ult1mate process incomprehensible, I, 695; cell doctrine, II, 19; physiologleal development, II, 242; wood formation, II, 287; tissue differentiation, II, 304, 312-4; resplra- 
tory system, II, 311; osseons differentiation, II, 351 ; muscular adaptation, II, 367 ; persistence of force and physiological adaptatlon, II, 394; vegetal vascular system, II, 574, 582, 589, 596.

Hermaphrodism, I, 340-3.

Hertwig, O.: on Weismann's germplasm theory, I, 690; cell characters, I, 691; meaning of fertilizatlon, II, 613.

Hertwig, R., classification of tissues, I, 189.

Heterochrony of derelopment, I, 655.

Heterogeneity: in chemical evolutíon, I, 23-4; of vital changes, I, 84-90; of development, I, 170, 178; functional, I, 204-8, 211-2; of organic matter, I, 350-5; organic and Instability of homogeneous, I, 509-11, 517, 549, 55i; segregation accompanying, I, 514-6, 517-8, 550.

Heterogenesis: occurrence, I, 270, 272-5, 336; anlmal nutrition, I, 289-91, 295-7; natural selectlon, I, 295-8; heredity, I, 301.

Hindus: food, I, 68; dwarf famlly, I, 316.

Histology (8ee Physlology).

Hofmeister, sporophytic generation of Archegonlates, II, 80.

Hollyhock, floral symmetry, II, 167, $169,170$.

Homogeneous, Instabllity of the: varlation, I, $330,334,342$; evolutlon, I, 509-11, 517, 549, 557; morphologlcal development, II, 7-9, 234; direction of vegetal growth, II, 181; radial symmetry, II, 190; physiological differentiation, II, $354,392$.

Homogenesis (8ce Gamogenesis).

Homology, simulation of, by analogJ, II, 14.

Hooker, Sir J. D., I, Ix; European plants in New Zealand, I, 477; plant distrlbutlon, I, 479; adaptation of plants to varied media, I, 484; plant growth, II, 56; Balanophore and Raflesiacex, II, 274; structural complexity, II, 295, 297 ; relatire antiquity and dis- tribution of plants and anlmals, II, 297; bean vascular system, II, 574.

Hooker, Sir W., on eructification in Jungermanniaece, II, 52.

Horns, natural selection and correlated varlation, I, 537, 567, 674, 677.

Horse: ancestral types, I, 409; fertillty, I, 598; weight of brain, I, 599; quagga markings, I, 624, 627.

Husbandry, co-ordination of actions in, I, 96, 579.

Hutchinson, Sir J., hereditary syphilis, I, 623.

Huxley, T. H., I, ix; “ contlnuous" and "discontinuous" development, I, 164; ciassification of development, I, 276; hermaphrodism, I, 344; zoological classification, I, 383; on "Persistent Types," I, 408- 0 ; ancestral equine types, $b$.; segmentation of artlculates, I, 468-9, II, 113; agamic multiplication of Aphis and Entozoa, I, 6401; II, 476; cell-doctrine, II, 21; vertebrate embryo, II, 119, 120; molluscan symmetry, II, 202; tegumentary organs, II, 314, 315; vertebrate sensory organs, II, 318 , 319; Chondracanthus, II, 487; Owen's vertebrate thcory, II, 563. Hyacinth: lateral splke, II, 42; symmetry, II, 141, 162.

Hybcrnation, waste and repair in, I, 214-5.

Hybrids, separation of ancestral tralts in, II, 616-7.

Hydro-carbons: properties, I, 6-9; the term carbo-hydrates $(q . v$.$) , I,$ 10.

Hydrochloric acid, in gastric juice, I, 69.

Hydrogen: chemical and physical propertles, I, 3-5; compounds, I, $6,8,9,10-12 ; 12-13$.

Hydrozoa (see Colenterata).

Hymenoptera (see Insects).

Hypertrophy (see Disease).

Hypospadias, telegonlc transmission, I, 646.

Hypostasls of a relatlon, exemplified in explanations of fertilizatlon, II, 613. 
IDeas (see Psychology).

Individuality: the botanical, I, 244 6 ; the zoological, I, 246-7; the fertllized germ product, I, 248-9; definition of llfe, I, 250.

Indivlduation: and genesis, I, 5834; II, 428-30, 499; total cost, II, 435-7; genesis and evolution, II, 501-5, 529, 530 .

Infusoria: functlonal speclallzation, I, 391 ; primary aggregate, II, 87 ; asymmetry, II, 187, 188; differentlatlon, II, 299, 385; genesis, II, $442,446,452$.

Injurles, repalr of anlmal, I, 219, 222-4, 316, II, 102, 611.

Insanlty, Inherited, I, 314.

Insects: temperature, I, 47, 174; phosphorescence, I, 49; self-mobility, I, 175; parthenogenesis, I, 274-5, 277, 294, 592, 640; growth and reproduction, I, 292; specles distrlbutlon determined by presence of, I, 396-7; eyes of cave-Inhablting, I, 309, 612-3, 614, 647-9, 693 ; persistent types, I, 408; retrograde development, I, 458; segmentation, I, 468-9; II, 114; aborted organs, I, 474; East Indlau distributlon, I, 478; fioral fertllization, I, 525; II, 168-9, 406 7, 608; appllances for cleanlng antennæ, I, 651; eyes, I, 658, II, 318; integratlon and homology, II, 111-3, 121; bllateral symmetry, II, 198; sexual selection, II, 269; eyes, II, 318; enrironment, II, 433 ; cost of genesls, II, 436, 437; development and genesis, II, 461; nutrition and genesls, II, 476, 490-2.

Insects, Social, orlgin of castegradatlons $\ln , I, 654-65,670,674$, $675,678-84,686-8$.

Instabllity of the homogeneous (see Homogeneous).

Instlnct: organlc evolution and coordination of, in mason-wasp, I, 574; a vital attrlbute, I, 578; loss of self-feeding, In Amazon ants, I, 660-1, 663-4.

Integration: In chemlcal evolutlon, I, 23; morphological composition, II, 4-6; arthropod, II, 111-4, 121; physlological, in plants, II, 292-5, $295-8,390$; of organlc world, II, 396-408; genesis, II, 424, 426-9.

Intelligence, a vital attrlbute, I, 579.

Internodes: varled development, II, 45; nutrltion and length, II, 178-9. Intestlne (see Alimentary Canal).

Intra-selection, Roux's theory of, I, $562,676-8$.

Irish, nutrition and genesis, II, 510. Iron: colloldal form of peroxide, I, 17, 20; molecular rearrangement, I, 337, 704; vegetal absorption, II, 573.

Iron Industry, Interdependence of social function, I, 237-41.

Isolatlon, and specles differentiation, I, 568-9.

Isomerism: of organle constltuents, I, 4, 9, 25; tri- and poly-atomic compounds, I, 11, 13, 25; muscular action, I, 59; organlc evolutlon, I, 700,703 ; dlfferentiation of nervetlssue, II, 356-60, 361 ; of muscular tissue, II, 361-4.

JACKsoN, J. Hughlings, on Inheritance of nervous pecullaritles, I, 313,694 .

Jaundlee (see Disease).

Jaws, of unclvillzed and civilized, I, 541-2, 612, 693.

Johnson, G. Lindsey, on Inherited myopia, I, 694.

Jones, T. Rymer, on fisslon, I, 585, 590.

Julin, C., on " castration parasltalre " In Crustaceans, II, 493-6.

Jungermanniacca: morphology, II, 33-4; relations of hlgh and low types, II, 35, 55; contlnuous and discontlnuous development, II, 52-5, 92: tubular structure, II, 5S, 62; prollferous growth, II, 67, 91; colour, II, 75, 265: symmetry, II, 140; fertllity and growth, II, 441. Jussleu, A. de, plant classification, I, 378 .

KARYOKINESIS, I, 257, 259, 263-5.

Kerner, A., on caullne buds, I, 358; plant-classlficatlon in Natural History of Plants, I, 378-9. 
KIdd, Benj., his acceptance of Welsmannism, I, 690.

Kltto, Dr., his visuai memory and deafness, I, 230.

Klebs, on Hydrodictyon, I, 288; Vauchcria, II, 84.

Kleln, E., multlplication of Bacteria, II, 443.

Korschelt, E., annulose segmentation, II, 103, 601-3, 605; Arenicola larvæ, II, 109.

LABOUR, physlological division of, I, 204, 207, 591, II, 373; its meanIng and Welsmann's fallaclous interpretation, I, 634-5.

Lacaze-Duthlers, on orlgln of annulose type, II, 110.

Lamarck: zoological classification, I, 382: oplnlons of E. Darwln and, I, 491, 493-7; neo-Darwinlsts and, I, 630-1.

Laminariacca: pseudo-follar and axlal development, II, 30; tissue, II, 247, 256, 272.

Language: and evolution, I, 442, 444,446 ; perceptlveness of tonguetip, I, 607 .

I a ankester, Sir E. Ray, absence of nucleus in Archerina, I, 183; diversity of Protozoa, 1b.; zoological classification, I, 387; blindness of cave-animals, I, 647-8, 649 .

Laugh, definition of life and, I, 112.

Laurel, leaves of, II, 149, 249.

Leaves: growth of shoot, I, 168; development and aggregation, II, $37-42,76$; stem-llke stalks, II, 41; homologles, II, 42, 75-7, 83; nutrition and compound, II, 42; follar and axial development, II, 46-50, 541-7; " adnate," II, 58; prollferous growth, II, 67,91 ; nutrition and development, II, 76-8; symmetry, and of branches, II, 148-50, 151; size and distribution of leaflets, II, 152-5; transition from compound to simple, II, 1558; unsymmetrical form, II, 158 9; natural selection and distributlon, II, 179; morphological summary, II, 234-5; tissue differentlation, II, 247; distribution, II, 249; outer tissues of stem and, II,
$256-9,270,386$; distribution of stomata, II, 260-1; wax deposit on, II, 260, 261; light and colour, II, 261-2; superficial differentlatlon, II, 263-5, 270, 387; abortive in parasitlc plants, II, 274; submerged, In aquatle plants, II, 274-5; iuner tissue differentiation, II, 278, 388; vascular tissue dilferentlation, II, 286, 288, 388; dye absorption and circulation, II, $570-4,577$; vascular system, II, 588-92, 596; arrangement, II, 608 11.

Lepidoptera (see Insects).

Lcpidosiren: ossification, II, 218; resplration, II, 338; skeleton, II, 553, 555, 560.

Lcpidostcus: armour, I, 526; alr bladder, II, 334.

Leroy-Beaulleu, Plerre, on Australian miners' usages, I, 364.

Lessonia: Hooker on growth, II, 56; branch symmetry, II, 146.

Lewes, G. H., definition of lffe, I, 80.

Llchens: tissue, I, 586; cell mult1plleation, II, 27; Hooker on growth, II, 56; tubular structure, II, 57; integration, II, 293; dual nature, II, 399 ; reproduction, II, 450.

Lleblg, Baron, nitrogenous food stuffs, I, 47-8.

Life: co-ordination of actlons, I, $79,89,577-80$; defined by SchellIng, I, 78, 178; Rlcheraud, I, 79; De Blalnvllle, I, 79, 93; Lewes, I, 80; definltion ylelded by contrastIng most unlike klnds, I, 81-8; changes showling, I, 91; vital actlons and environment, I, 92-3; resulting addition to conception, I, 93, 326; Comte's definition, I, 93; correspondence of external and Internal relations, $I, 93-6$, 100; II, 523; continuous adjustment of such relatlons, I, 99; completeness proportionate to correspondence, I, 101-4, 109, 349; length and complexity, I, 103; complexity of environment and degree of, I, 104-6; definitlons of evolution and, I, 107-10; deficien- 
cies of formula, I, 112-3; activity the essential element, I, 113; hypothesis of independent vital principle examined, I, 114-7; difficulties of physico-chemical theory, I, 117-20; ultimate incomprehensibility, I, 120-3, 373: valldity of conclusions reached, I, 123; is organization produced by? I, 197; precedes organization, I, 210; definitions of individuality and, I, 250 ; effect of incident forces on, I, 348-9, 355: leugth in individuals and species, I, 422; equilibration of, I, 547, 557; flnal formulation of definition, I, 580; co-ordination of actions and sexual differentiation, I, 593; "absolute" commencement of, I, 699 , 702; integration and augmentation, II, 426; prospective human, II, 522-5.

Light: Influence on organisms, I, $30-6$, II, 433; nitrogenous plants, I, 40; organic phosphorescence, I, 49; heliotropism, I, 92, II, 160 ; effects on organic matter, I, 149; plant adaptation, I, 227; rhythmical variation of, and organic life, I, 499, 557; regetai influences, II, 130, 131, 147, 149, 158; influence on flowers, II, 167-8, 608-11; vegetal tissue-differentiation, II, 253-5, 258, 259; action on leaves, II, $260-4$; on plant vascular system, II, 288, 297, 586; development of sensory organs, II, 320 .

Liliacea, floral symmetry, II, 170.

Lime, leaf forms, II, 158, 159.

Lindley, J., plant classiflcation, I, 377.

Linnæus, C., classificatory system, I, $377,380$.

I.innet, contrasted with biackbird in development, II, 503.

Liver: metabolic processes, I, 69, 70 ; vitality of excised, I, 111; derelopment, II, 329-33.

Liver-fluke (see Distoma).

Liverworts (see Hepatica).

Lizard, regeneration of lost tail, I, 360.

Locomotion (see Motion).

Logic, reasoning and definition of life, I, 81-6.
Logwood, vegetal staining, II, 56974, 577-81, 584.

Longevity, and complexity of life, I, 102-3.

Lubbock, Sir J.: on growth and genesis in insects and crustaceans, I, 292; aquatic flies, I, 400.

Lungs (see Respiratory System).

Lymphatic system: amœboid cells, I, 187; structural traits, I, 192, 193.

MacBride, E. W., I, vi, II, vi; zoological phyla, I, 386-7; arthropod segmentation, II, 114; ctenIdia of siug, II, 117; conjugation of Paramacium, II, 452.

Macrocystis pyrifera, gigantic seaweed, I, 121.

Magenta, vegetal staining, II, 56974, 577-81, 584 .

Magnetism: muscuiar action, I, 59; incomprehensibility, I, 121.

Maillet, B. de, modiflability of organisms, I, 490, 496.

Mammalia: temperature and molecular change, I, 30 ; nutrition and growth, I, 141; expenditure of force, I, 142, 156; flesh constituents, I, 154; temperature, I, 174, 177; self-mobility, I, 175; functionai and structural differentlation, I, 201; heart-function, I, 206; viviparous homogenesis, I, 271; variation and uterine environment, I, 327; classification, I, 392; cervical vertebræ, I, 394, II, כ64; aquatic types, I, 400 ; fossil remains and rate of evolution, I, 407; ancient and modern forms contrasted, I, 408-10; embryonic respiratory system, I, 456; suppression of teeth, I, 457; arrested development, I, 473-4; simulated homologies, I, 485; natural selection and inactive parts, I, 534; re-development of rudimentary organs, I, 563; location of testes and current theories, I, 573; fertility and development, I, 583, II, 465; fertility and nervous development, I, 598-9; locomotion and elongated form, II, 15; symmetry, II, 204; tegumentary structure, II, 
314; circulation, II, 340; vascularity and ova-maturation, II, 342-3; actlvity and muscular colour, II, 365-9; functional integration, II, 375; outer tissue differentiation, II, 387; growth and genesls, II, 456, 459; comparative fertillty, II, 465, 470; heat expenditure and genesis, II, 467-9; activity and fertility, II, 472; nutrition and genesis, II, 479-80.

Man: effect of climate on vigour, I, 30 ; flesh and grain eaters compared, I, 68; longevity and life, I, 103; complex environment, I, 105; embryogeny of arm, I, 169; fertility and conditions affecting it, I, $300,570,583$, II, 484, 506-21; inheritance of functionally produced changes, I, 310-3, 541, 605, $608,612,652,673,689,693-4$; heredity and sex, I, 315-6; function of bllirubin, I, 330; cousinmarriages, I, 346, II, 615; primltive notions, I, 417-9; lnutility of Appendix vermiformis, I, 474; d1minution of jaw, I, 541, 612, 693; co-ordination of actlons greatest in, I, 579; fundamental tralts of sex, I, 594-7; obesity, I, 594; substance and weight of brain, I, 596, 599; distribution of tactual perceptireness, I, 602-8, 665-6, 672-3, 692; telegony, I, 625, 644-5; degradation of Iittle toe, I, 652, 673; transmitted osteologlcal pecullarities of Punjabis, I, 689; traits of twin-bearing women, II, 457; comparative maminalian fertility, II, 465; future evolution, II, 522-37. (Sce also Language and Soclology.)

Manatee, nailless paddles, I, 473.

Manx cats, I, 303.

Marchantiacea: symmetry, II, 140; outer tissue differentiation, II, 252.

Marmot, hybernation and waste, I, $214-5$.

Marriage (sce Multiplication).

Marsh, O. C., on telegony, I, 644.

Masters, M. T., on follar homology, II, 46-7; selection of inconspicuous variations in plants, II, 298,
621; separation of ancestral constltutions in plant hybrids, II, 616; single and double stocks, II, 622.

Matter, incomprehensibllity of interactlons, I, 121-2.

Mechanles: tranverse strains, II, 209-12; genesis of vertebrate axis, II, 212-6, 216-8, 224, 225-7; osseous differentiation, II, $345-51$; disintegrated motion, II, 375; anaiogy from locomotive, II, 517-9; future human evolution, II, 524; strain and vegetal structure, II, 574-88, 592-6.

Mcdusa: contractlle functions, I, 58; II, 374; indivlduallty, I, 248; heterogenesis, I, 273; fertllity, I, 582 ; strobllization, I, 592 ; symmetry, II, 188-91.

Mehnert, E., on feet of pentadactyle vertebrates, I, 461.

Mensel's salt, temperature and isomerism, I, 77.

Metabollsm: antithesls between plants and animals, I, 62-3; cvolution-hypothesis and primordial, I, 63-4; in plants, I, 64-7; an1mals, I, 67-77; nerro-muscular activities, I, 71-7; summary, I, 77; cell processes, I, 261.

Metals: remarkable interactions of some, I, 121; melting of alloys, I, 339; atomlc re-arrangement, I, 352.

Metamerism (8ce Segmentation).

Metazoa: cellular structure, I, 181, 194, II, 21; subordluation of units, I, 185-7; general characters of tissues, I, 188-9; protoplasmic contlnulty, I, 190-2, 194, 628; genesis of food carity and visual organ, I, 195; Welsmann's differcntlation theory, I, 637-43.

Meteorology: non-vital changes shown in, I, 82, 84; crystalllzation of "storm glass," I, 96; speclal creation, I, 419; rhythm in, and organic change, I, 499-501, 557; varlations due to geologle change, I, 503.

Microstomida, segmental reproductlon, II, 102.

Migration: of anlmal specles, I, 
396-401, 411; solar influences, I, 500 ; part played by, in organic evolution, I, 568; causes of, II, 533-4.

Milk, heat and supply of, II, 468.

Milne-Edwards, H., " physiological division of labour," I, 204; Weismann's erroneous application of it, I, 634; on ocular structure, II, 318.

Mind (see Psychology).

Mitosis (8ce Karyokinesis).

Mobility, molar and molecûlar, I, 14; environment and self mobllity, I, 177.

Mohl, on phænogamic growth, II, 82.

Mole, modifications due to habits, II, 391.

Molecules: mechanicaily considered, I, 14; stabllity, I, 337-40; nervedifferentiation, II, 355-61, 379-82.

Mollusca: axial development, I, 165; genesis, I, 271, II, 444; hermaphrodism, I, 341; classificatory tralts, I, 392; distribution in time, I, 405, 408, 410, 446-7: trochophore and its relationships, I, 447, II, 108, 109, 115; development, I, 460; amphiblous and terrestrial, I, 481; indirect equilibration, I, 534; secondary aggregation, II, 115-7; symmetry, II, 201-3; outer tissue, II, 310, 387; alimentary system, II, 325; vascular system, II, 340-1.

Molluscoida, II, 598. (See Polyzoa and Tinicata.)

Monocotyledons: growth, I, 138, 139, 143; uniaxial development, I, 165; cotyledonous germination and endogenous growth, II, 59-62, 69$72,82-3,181-2$; absence of helical phyllotaxy in Ravenala, II, 182; surface contrasts, II, 257; outer leaf tissue, II, 263; wood formation, II, 278; growth and genesis, II, 451.

Monstrosities, in plants, II, 78, 541, 546; vertebrate, II, 118.

Morgan, T. H., on regeneration of Planaria, II, 102, 611.

Morphology: facts comprised in, I, 125-6; morphological units, I, 190-
2, 225; rudimentary organs, I, $472-5$, 556; structural and functional co-operation, II, 3, 239; integration, II, 4-6, 181-96; change of shape, II, 6; formula of evolution, II, 7-9; as interpreted by phylogeny, II, 10-6; evolution and cell doctrine, II, 17-21.

Morphology, Animal: evolution ani segmentation of Articulata, I, 4689 ; vertebral column development, I, 470; simulated homologies, II, 14-5; primary aggregates, II, 858, 123-4; secondary, II, 88-91, 124; certiary, II, 91-3; integration and Independence of individuality, II, 93-9, 124; annulose segmentation, II, 98-101, 106-10, 125-7, 602-7; progressive annulose integration, II, $100-5,111-5,121,124,223$; unintegrated molluscan form, II, 115-7; vertebrate segmentation and integration, II, 117-23, 124-7, $223-4,602,606-7$; motion and symmetry, II, 183-5; symmetry of primary and secondary aggregates, II, 186, 187-91; of compound Colentcrata, II, 192-4; simulation of plant shapes, II, 192; symmetry of Polyzoa and Tunicata, II, 194; of Platyhelminthes and Echinoderms, II, 1957; of Annulosa, II, 197-201; of molluses, II, 201-3; of vertebrates, II, 203-6, 208; similarity of animal and plant, II, 203; cellshapes, II, 228-30; evolution and generalizations summarized, II, 231-5. (See also Structure.)

Morphology, Vegetal: simuiated homologies, II, 13-4; unicellular plants, II, 21; aggregation and integration, II, 22-6, 78-9; pseudofollar development, II, 2f-8; pseud-axial, II, 28-9; pseudofollar and axial, II, 30-2; composition of Archegonlates, II, 335 ; leaf derelopment and aggregation, II, 37-42, 75-8; follar homologies, II, 42-6, 75-8; follar and axial development, II, 46-50, 5417; growth and development of Archegonlates, II, 50-6; of Phænogams, II, 56-64, 78-80; axil- 
lary bud development, II, 65-9; phænogamic modes of growth, II, 69-72; homologles, II, 73-5, 80-4; development of foliar into axial organs, II, 75-8; résumé, II, 7880 ; criticisms and replies, II, 80 4; can plant-shapes be formulated? II, 128; growth and differentiation, II, 129-31; kinds of symmetry, II, 131-3; symmetry of primary aggregates, II, 134-7; of secondary, II, 137-40; tertiary, II, 140-3; symmetry and environing influences, II, 143-4; symmetry of branches, II, 145-8; leaf and branch symmetry, II, 148-50; phænogamic unit homology, II, 151; size and distribution of leaflets, II, 152-5; transition from compound to simple leaves, II, 155-8; unsynmetrical lear development, II, 158-9; differentiation of homologous units, II, $159-60$; florai symmetry, II, 161-74; celldifferentiation and metamorphosis, II, 175-7; nutrition and differentiation, Ir, 178; and inflorescence, II, 179; helleal growth of phænogams, II, 180-1; summary of symmetry, II, 234; stress and structure, II, 275-9, 388. (See also Structure.)

Morton, Lord, quagga-marked foal, I, 624 .

Moser, impressions produced by light on metals, I, 352.

Mosses: varied development, II, 501, 52; homologies, II, 80,81 ; indefiniteness, II, 296; multiplication, II, 441.

Moth, clothes, food of larva, I, 77.

Motion: organic, and enrironment, I, 75-7, 175-8, 196; of animals and waste, I, 214, 220; simulation of locomotive structures, II, 15.

Motor organs, differentlation of, I, 262.

Mountains: climatle effects, I, 504; growth of trees on, II, 142.

Mouse: fertility of, II, 421, 473; tapeworm parasitism, II, 490; compared with rat, II, 503-4.

Mucor, II, 22, 123.
Mucous membrane, differentiation, II, 321-2, 389.

Multiplication: decline of fertility with evolution, I, 103, II, 431; vitalism, I, 116; phenomena classified, I, 130; the term " genesis," I, 269: processes classified, I, 270$6,336,583$; a process of disintegration, I, 276; reproductive tissue in gamogenesis, I, 278-84; nutrition and growth, I, 285-94, 295-7, 299; natural selection, I, 295-8; hermaphrodism, I, 340-4: in-and-in breeding, I, 344-7; physiological units, I, 350-5; law of race-maintenance, I, 581; II, 420 3,430 ; effect of mental application, I, 597, II, 511-4, 516-9, 530; Individuation antagonistic to, I, $598-600$, II, 428-30, 435- 7,499 , 501-5; checks put by carnivores on, II, 405; four factors in rate of, II, 416, 435; destructive and preservative forces, II, $417-20$; rhythm of species, II, 419; nutrition and disintegration of, II, 424, 425, 430; Integration and genesis, II, 426-8; Influence of environment, II, 432-3; and variatlons of expenditure, II, 433-5; growth and asexual genesis, II, 439-46; asexual and sexual distinguished, II, 448; sexual genesis and growth, II, 448-58, 495; and development, II, 461-5; plant expenditure, II, 467; animal expenditure, II, 468-T2; nutrition in plants, II, 475, 511; in animals, II, 476-84, 511; seasonal rarlations, II, 484-5; nutrition, résumé, II, 486, 497-9; nutrition and parasitic, II, 456-00; reversion to agamogenesis, II, 490-2; human fertility, II, 506-10; Doubleday on, II, 510-2; civilized and uncivillzed, II, 514-6; human evolution and decline in. II, 529-31; the future of population, II, 532-7: equilibration and evolution, II, 537.

Muscle: electrical contrasts, I, 50: action of, I, 59; metabolism, I, 70, 71-4: definition of llfe and actions of, I, 112-3: growth and function, 
I, 151, 155; development, I, 170; Hertwig's classification of tissues, I, 189; functional differentiation, I, 203-4; waste and repair, 215-7; modifiabillty and adaptability, I, $228-9,230,232$; correlated variatlons, I, 536-9, 614-21, 676, 693; resistance to strains, I, 639; action on bones in Punjabis, I, 689: differentiation, II, 361-9; activity and colour, II, 365-9: Integration, II, 376, 382: equilibration in action, II, 393; actlvity and fertlilty in birds, II, 470-2; future human evolution, II, 523; origin of vertebrate type, II, 598-600.

Music: limited adaptability of volce and ear, I, 231; Inheritance of faculty, I, 311-2, 694.

Mutilations, the question of their inheritance, I, 631.

Mycetozoa, growth and reproduction, I, 298-9.

Myocominata (myotomes), and vertebrate skeleton, II, 216, 217-8, 222.

Myopla, inheritance of, I, 306, 694 . Myrianida fasciata, I, 361; II, 445.

Myriapoda: gemmation, I, 589; segmentation, I, 590, II, 113, 114, 601; degenerated eyes of cave-inhabiting, I, 649; Integration and homology, II, 111-4; genesis, II, 445.

Myxothallophyta, I, 378.

NaILs, mammalian, I, 473.

Nais: regeneration of detached parts, I, 219, 361.

Narcissus, separation of ancestral traits in hybrids, II, 61 .

Natural selection: structural modiftcation, I, 211; in cell processes, I, 263-4; multiplieation, I, 295-8; alded by function, I, 308-10; special creation, I, 426-7; the term " survival of the fittest," I, 530; Indirect equillbration, I, 530-5, 552-3, 557, 571; changes unexplained by, I, 535-42, 571, II, 371; tendency to economy, I, 536, 562 ; decrease of jaw, I, 541, 693; general doctrine of evolution, I, 5438, 557; unceasing operation, I,
552; human races, I, 553; current views, I, 559-60; panmisia and cessation of selection, I, 560-3: Intra-selection, I, 562, 676-8; Eimer's theory of orthogenesis, I, 564; Mr. Cunningham's criticism, I, 565-6; location of mammalian testes, I, 573; co-ordinated instincts of mason-wasp, I, 574; tactual perceptiveness, I, 603-8, $633,646,665,671,672,692$; erroneousiy identifled with artificial selection, I, 609, 695; reversed selection, I, 611; blindness of caveanimals, I, 613, 614, 647-8, 693; coadaptation of co-operative parts, I, $614,621,663-5,670,674,675$, 689,692 ; where operative, I, 632; Weismann on conceivability of process, I, 651; degeneration of little toe, I, 652-3, 673; genesis of caste gradations in social insects, I, 654-60, 663, $670,675,684$; selffeeding instinct in ants, I, 660-2, 670 ; rudimentary organs, I, 667-9, 671,692 ; horns of stag, I, $676-8$, 692; musical faculty, I, 694; the neo-Darwinian position revlewed, I, 694-5; vegetal nutrition, II, 512 ; upright vegetal growth, II, 567; endogenous growth, II, 57-8; exogenous, II, 64; Navicula symmetry, II, 135; foliar, II, 158; follar distribution, II, 167, 179; floral fertilization and symmetry, II, 168-70, 608-11; helical phrnogamic growth, II, 181; Echinodermata and bilateral symmetry, II, 197; vertebrate structure, II, 214 20,227 ; phænogamic tissue differentiation, II, 248: physlological differentiation, II, 252, 256; rootlets of Ivy, II, 254; stomata and follar surfaces, II, 261, 262; floral fertllization, II, 268-9; sexual selection, II, 269; vegetal tissue differentiation, II, 279; wood formation, II, 287-8, 290; anlmal tissue differentiation, .II, 304-8; evolution of nervous system, II, 307-8; respiratory system, II, 311; dermal callositles, II, 312-4; sensory organ complexitles, 2I, 321; skin and mucous membrane differen- 
tlation, II, 322; locallzation of exeretion, II, 333; respiratory organs of flshes, II, 335-8; heart and vascular system, II, 341, 344; osseous differentiation, II, 355; IIso muscular, II, $363,368-9$; " faise jolnts," II, 371; insect nutrition and genesis, II, 499; economics of evolution, II, 501-5; author's enunciation of survival of the fittest in 1852, II, 528-9; evlls of interference with, in man, II, 532-3; vegetal tissue formation, II, 582, 594-6; origln of vertebrate type, II, 599 .

Nature, more complex than supposed, I, 252, 450.

Navicula, symmetry, II, 134-5.

“ Nebuiar Hypothesis," I, 23.

Negatlon, Inconcelvability of, the uitimate test of truth, I, 675 .

Negroes, telegony in Unlted States, I, 644-5.

Nemertida: continulng vitality of plildium, I, 250; bllateral symmetry, II, 195.

Neo-Darwinists, and Lamarck, I, 630 ; their position revlewed, I, 694-5.

Nerves: electrical phenomena, I, 51; generation of nerve-force, I, 52-6, 60 ; corpuscula tactus, I, 75; Hertwig's classiflcation of tissues, I, 189: structural traits, I, 192, 193; environment and structure, I, 196; differentlation, I, 203; II, 355-61; vasomotor system, I, 206; vicarlous function, I, 209; activity and waste, I, 216; adaptabllity, I, $229,232,236$; parallelism in cellprocesses, I, 260-2; heredity, I, 313; effects of severance, I, 349; relative development in men and women, I, 594; analysis of brain substance, I, 596; individuation and development of, I, 595, 599, 600 ; distribution of tactual perceptlveness, I, 603-8, 633, 646, $665-6,671,672,692$; alleged costliness of tissue, I, 662; Instinct degeneration in ants, $i b$. ; " sensation areas," I, 666; segmentation In Annellis, II, 125; ectodermal derivation, II, 303-4; cooperating factors in evolution of, II, 307-8; differentiation from muscle, II, 363. (See also Psychology.)

Nervousness, hereditary transmisslon, I, 307.

Neurine, I, 594, 597.

Neuter-Insects (see Insects).

New Zealand: Invasion of allen specles, I, 477; kinship of past and present forms, I, 489.

Nitrogen: propertles, I, 3-5, 20, 24; compounds and thelr propertles, I, $6,8,9,12-14,25-6,39,41,42-3$, II, 250; organic Importance, I, 42-3; evolution of heat and oxidation, I, 47; violent organic effects of compounds, I, 54-5; function in metabolism, I, 63-4, 66, 68-76; presence in protopiasm, I, 66; action in dlgestlon, I, 69; fat accumulation and fertlity, II, 483.

Nitro-glycerlne, vlolent effects of, I, 55, 122.

Notochord: segmentation, II, 125, 218-22; formation, II, 217-8, 600 ; In Permlan vertebrates, II, 225.

Noumenon, life not manifested as, I, 5 SO.

Nuclein, II, 21.

Nucleus: central development, I, 163; in simple organisms, I, 183; phenomena exhibited by, I, 2558; current hypotheses of function, I, 258-9; properties and function of chromatin, I, 259-65; fusion in fertilization, I, 283-4; function in unicellular reproduction, I, 595-6; absence of, II, 20-1; diffused form, II, 85; macro- and micronucleus in conjugation, II, 452.

Nutrition: organic molecuiar re-arrangement, I, 36 ; nitrogenous and non-nitrogenous, I, 47-8, 68, 71-4, 77, II, 362; food assinilation and reasoning, I, 81; needful for vital change, I, 94; relation to growth, I, 140,143,144, 147-9, 150, 157, 161; expenditure of energy, I, 157, 391; fiuld, I, 208; vegetal fructlfication, I, 267; II, 266; vegetal growth and genesis, I, 293, 294-7, 336; animal growth and genesis, I, 289-93, 295-7, 336; conditions quallfying antagonism 
of growth and genesis, I, 299; competition among parts of an organism for, I, 562, 566, 676; sex differentiation, I, 594-5; cell-multipilcation, I, 638; differentiation of neuter insects, I, 655-60, 670, $674,686-8$; monstrous ant forms, I, 683 4: leaf-detelopment, II, 39 , 42, 73-8; regetal development, II, $51-2,178,276$; axtllary buds, II, $65-9,73-4$; effect on animal aggregation, II, 93; internodes and inflorescence, II, 178-80; hellcal phænogamic growth, II, 181; action of bile, II, 330; osseous development, II, 349,353 ; genesis, II, $419,422,427,435-7,452$; parentai loss in feeding young, II, 424, 429; diverse sources, II, 433; Carpenter on reproduction and, II, 4G0; animal development and genesis, II, 465; expenditure and genesis, II, 468; variations of genésis, II, 475-80, 511; obesity and genesis, II, 480-4, 511; generai doctrine of genests, II, 486; genesis and vegetal parasitism, II, 486; aiso animai, II, 487-90, 495; insect genesis, II, 490-2: genesis, résumé, II, 497-9; and evolution, II, 501-4; of blackbird and linnet, II, 503; genesis in human race, II, 508-10, 514-6; Doubieday on, II, 510-2; future human evolution, II, 526, 531; floral monstrosities, II, 542, 546, 547.

OBesity, nutrition and genesis, II, $480-4,511$.

Odoriferous glands, natural selection and, I, 534.

Odours: florai fertilization, II, 2689 ; animal protection, II, 434 .

Offspring: parental loss entalied by nurture, II, 424, 429; influence of age on, II, 507.

Oken, L., archetypai hypothesis, II, 122; theory of supernumerary bones, II, 223; on the skuli, II, 561.

Ollver, F. W., ciassifleation of plants, I, 378-9.

ophryotrocha purritis, ciliation of segments, II, 109.
Orchids: pollen propuision, I, 57; leaf formation in Dendrobium, II, 60-1; aërlai roots and physiologicai differentiation, II, 255, 257; follar surface, II, 264.

Organc matter: properties of elements, I, 3-5, 22; of compounds, I, 5-13, 25; molar and molecuiar mobility, I, 12-14; colloid and crystalloid form, $\mathrm{I}, \mathrm{15}-8,25$; their diffusibiiity, I, 18-21, 26; extreme complexity, I, 21; laws of evolution and genesis of, I, 22-4; modifiability, I, 27, 44; capillarity and osmosis, I, 28; effects of heat, I, 29; of light, I, 30-4; nitrogenous, I, 39-43; oxidation and erolution of heat, I, 46, 60; genesis of electricity, I, 50-2, 60; sensible motions in, I, 59; transformations and persistence of force, I, 61; metabolism, I, 62-77; artificial production of compounds, I, 64; contrasted with inorganic matter, I, 107-8; incomprehensibility of vital changes in, I, 122; instability, I, 149, 508; phosphorus in celi-organization, I, 260-1; heterogeneity, I, 350-5; “ spontaneous generation" and evolution of, I, 696701; cell-doctrine and evolution of, II, 17-21.

Organization (see Structure).

Ormerod, Dr., on sex and nutrition in wasps, I, 656.

Orthogenesis, Eimer's theory of, I, 563-4.

Osmosis: organie effects, I, 28, 29; in animais, I, 58; in vascular system, II, 339; in vegetal tissue, II, 568, 575, 577, 585, 592-6.

Osteology (sce Bone).

Ovum (sce Egg and Fertilization).

Owen, Sir R.: metagenesis and parthenogenesis, I, 273-4; fossil mammals, I, 410; human parasites, I, 427; continuous operation of creative power, I, 492; fission in Infusoria, I, 584, 5\$5, 595-6; parthenogenesis, I, 592; theory of vertebrate skeleton, II, 123, 54866 ; theory of supernumerary bones, II, 223; Eschricht on Ascaris, II, 488. 
Oxalis: radial symmetry, II, 152; follar surface, II, 264.

Oxen: comparlson with sheep, I, 158, 160; cerebro-spinal system, I, 508.

Oxldation (see Oxygen).

Oxygen: properties, I, 3-5, 20, 22; compounds, I, 6-7, 10-13, 22, 24-5; a crystallold, I, 21; comblning power and atomle welght, I, 33; organlc change from, I, 37; heat generatlon, I, 46-9; phosphorescence, I, 49; nerve force dependent on, I, 53; anlmal metabolism, I, 72, 73; necessary to anlmal life, I, 94-5, 577; activity and amount inhaled, I, 214.

Packard, A. S., on eyes of caveanlmals, I, 648-9, 693.

Paget, Sir J., bloot changes in small-pox and scarlatlna, I, 221, 701.

Palæontology: distribution in time, I, 404-11, 412; speclal creation, I, 425; congruity with evolution hypothesis, I, 485-9, 556; relations of present to extlnct species, II, 10-11; scarcity of remains, II, 34-5; secondary thlckening in plants, II, 56; Cope on osteology of Permian Vertebrates, II, 225-6.

Pangenesis, Darwin's theory of, I, 356, 357, 359, 360, 362, 372.

Panmixia, Welsmann's hypothesis of: Its relation to Romanes" " cessation of selectlon," I, 560; alleged selective process denled, I, 561-3, 667, 685; distribution of tactual perceptlveness, I, 608; rudimentary eyes of cava-fauna, I, 612-3, 647; Romanes on process, I, 649, 667; degeneration of self-feeding lnstinct in Amazonants, I, 660-2, 670; rudimentary limbs of whale, I, 668-9, 685; a pure speculatlon, I, 671; markings on leg-bones of Punjabis, I, 659.

Paramoecium: parasite infestlng, I, 427; reproduction, II, 443, 452.

Farasites: sexual dimorphism, I, 315; limits to distribution, I, 397; special-creation and, I, 427-9, 439; retrograde development, I, 457,
II, 12; aphls and ant, I, 660-1, II, 403,405 ; as an integratlng agency, II, 402-4; its comparative recency, II, 404; nutrition and genesis in vegetal, II, 486; in animal, II, 487-90, 493; " castratlon parasltaire" In crustaceans, II, 493-6.

Parasol Ants, origin of classes, I, 687-8.

Parthenogenesis: occurrence, I, 274-5; alternating with gamogenesis, I, 289-91; Owen on, I, 592 ; laws of multiplication, II, 415; in articulate animals, II, 445.

Pasteur, L., sllk-worm diseases, I, 622-3.

Peacock: theories of heredity and structure of tail feather, I, 372-3, 695, II, 618-9.

Pear, foreright shoots, I, 287.

Pelorla: In gloxinia, II, 166; phænogams, II, 180.

Penguin, dermal structure, II, 314. Pepsin, I, 69.

Perleyclic fibres of monocotyledons, II, 278 .

Peripatus capensis, protoplasmic continuity, I, 629.

Peri-visceral sac, functlon and differentlation, I, 391.

Perkin, W. H., I, ri.

Persistence of force, corollaries from: properties of compounds, I, 3; organic transformation, I, 60 ; growth, I, 150; organle energy, I, 220; "variation, I, 335; genesis, heredity, and varlation, I, 354-5; morphological summary, II, 235; vegetal tissue differentlation, II, 245; physlological development, II, 394.

Petals: follar homology, II, 43-6; " adnate," II, 58.

Petrels, Darwin on, I, 45 J̄.

Phænogams: production of spermatozolds, I, 186; morphological compositlon, II, 37-79; leaf transitions, II, 37-42; follar homologies, II, 42-9; orlgin of type, II, 49-84; vertleal growth, II, 56-64; axillary buds, II, 66 ; cotyledonous germination and endogenous growth, II, 69-72; axlal homolo- 
gles, II, 73-5; Irregular development, II, 75-8; degree of composition, II, 78; reproductive homology, II, 80-4; uul- and multiaxlal symmetry, II, 141-3; unlt of composition, II, 151; hellcal growth, II, 181; secondary thickening, II, 247; tissue and leaf differentiation, II, 247-9, 387; also bark and cambium, II, 249-50, 386; also outer tissue, II, 252, $256-9,270,386-7$; wax deposit on leaves, II, 260-2; differentlation of Inner tissues, II, 273-5, 388; vascular system development, II, 280-4, 388; Integration, II, 293-5, 296, 390; insect-fertilization, II, 407; multiplleation, II, 441, 442; genesis and growth, II, 451, 457; and development, II, 464; and nutrition, II, 476, 477, 511; subst1tution of axlal for follar organs, II, 541-7.

Pheuomenon, life manifested as, I, 580.

Phllology (see Language).

Phoronis, indivlduality, II, 444.

Phosphorescence, organlc, I, 49.

Phosphorus: allotroplc, I, 4; in cell physlology, I, 259-62; cerebral actlvity, I, 596-7; organle evolution, I, 703 .

Photogenes, visibility of, I, 218.

Phylogeny: as interpreting morphology, II, 10-12; difficultles of affiliation, II, 34-5. (See Embryology and Evolution.)

Phystological Units: definition, I, 226; genesis, I, 280-1, 316; heredIty, I, 315-9; variatlon, I, 330, $331-2,333$, II, 619: stability, I, 340: II, 614; self-fertllization, I, 342-4, 353; interbreeding, I, 345, 353 , II, 615 ; recapitulation of hypothesis, I, 350-5; II, 612-7; structural procllvitles I, 362,364 , 369-71, II, 613, 622, soclological analogy, I, 364, II, 620; complexity in organized types, I, 368-70; re-named "constitutional units," I, 369; telegony, I, 650; " mechanical theory," I, T01-6; morphological development, II, 7-9; cell doetrine, II, 17-21; derelop- ment, II, 76; " false-jolnts," II, 371-2; dissociation of ancestral traits in hybrids, II, 616-7; inheritance of acquired characters, II, 618-23.

Physlological division of labour (see Labour).

Physiological Selection, I, 569-71.

Physlology: and psychology, I, 127; subdivislons, I, 128: viearious function, I, 208; primitive interpretations, I, 417; multiplication of effects exemplified, I, 512, II, 390 ; relations to morpliology, II, 3 , 239-41; evolutlonary interpretation of phenomena, II, 241-5, 384-95; ultimate inconcelvablity of processes, II, 372; correlated integration and differentlatlon, Ir, 373.

Physlology, Anlmai: metabolism, I, 67-77; vertebrate Internal symmetry, II, 108; tissue differentiation in Protozoa, II, 299, 385; primary tissue differentlation, II, 300$2,382,389$; natural selection and tissue differentlation, II, 304-8; outer tissue in Colenterata, II, 309-10; resplratory organs, II, $310-1$, 333-8; differentiation of animal epidermic tlssue, II, 312-4, 387; development of tegumentary organs, II, 314-6; of sensory, Ir, 317-20: Inner and outer tissue transltion, II, 321-2, 389; allmentary canal differentiatlon, II, 3235; glzzard development in birds, II, 325; allmentary canal of ruminants, II, 327-9; differentiation of llver, II, $329-33$; of animal vascular system, II, 339-44; of osseous system, II, 344-55; of nerre tissue, II, 355-61; of muscle, II, 361-9: differentiation and integratiou, II, 373-6; in vascular system, II, 3769 , 383; In nerves, II, $379-82$; origln of development, II. 384 ; differentiation and instabillty of homogeneous, II, 384-9, 392: summary of development, II, 384-94; multiplication of effects, II, 390-1, 392; equilibration, II, 391-4. (See also Function.)

Physiology, Plant: metabolism, I, 
62-7; tissue differentiation in secondary aggregates, II, 246, 385; in phænogams, II, 247-9, 386; in bark and cambium, II, 249-50, 386 ; in free and flxed surfaces, II, 251-6, 270, 386; outer stem and leaf tissue, II, $256-9,270,386$; superficial differentiation In leaves, II, 260-4, 270, 387; floral tissue differentiation, II, 265-9; outer tissue, résumé, II, 270: inner tissue differentiation, II, 273-5, 388; supporting tissue, II, 275-9, 285-8, 388; vascular system development, II, 273-5, 279-84, 285-8, 388: inner tissue, summary, II, 288-91, 388; Integration, II, 292-8; differentiation and instability of homogeneous, II, 384-9, 392; multiplication of effects, II, 390-1, 392; equilibration, II, 391-4; circulation and wood formation, II, 564-97; dye permeability, II, 56974, 577-81, 584, 586. (See also Function.)

Pickering, J. W., on artificial proteids, I, 39.

Pig: colour of muscles, I, 365-6; telegony, I, 627; fertillty of domestle and wild sow, II, 479-80.

Plgeons: food of starving, I, 215; heredity and variation, I, 305, 321,615 ; atavism, I, 314 ; fertility, II, 471-2, 478.

Plke, unceasing growth, I, 154, 292.

Pique-gouffe, commensal relations with buffaio, II, 403.

Plagiochila, evolution of stem, II, 62.

Planaria: integration, II, 101-2; Morgan on regeneration, II, 102, 611 ; segmentation, II, 107; symnetry, II, 195: nnintegrated functíon, II, 373.

Piants: influence of heat, I, 29; effect of solar rays, I, 31-6, 500, 557; chemical composition, I, 401; heat generation, I, 47; phosphorescence, I, 49; eiectricity, I, 51 ; sensible motion, I, 56-7, 58 ; metabolism, I, 62-7, 70; vital changes, I, 86, 87, 01, 94; simulation by crystals, I, 96; vital adjustments, I, 102; length and com- plexity of life, I, 103-4; blological classitication, I, 125; growth, I, $136,138,140,143,145-9,153,160-$ 1, II, 401-2; development, I, 1635, 167-70, 272; weight, temperature, and self-mobility, I, 174; function, I, 174-8; structure, I, 194-6, II, 21; animal structure contrasted, I, 196; function and structure, I, 200; vicarious functlon, I, 208-9; waste and repair, I, 213, 220; physiological units, I, 225-6, 317, 360; adaptation, I, 227; what is an individual? I, 244-6, 250-1; genesis, I, 270, 271, 272-3, 274, 276-8, 279-85; reiation of nutrition to growth and genesis, I, 284-9, 294, $295-300,642$, II, 39 ; orule homologues, I, 288; natural selection, I, 294-8, 532, 533, II, 51; heredity, I, 301-4, 308, 358-60; variation, I, 320, 323-4, 325-6; fertilization, I, $340-5$; classiflcation, I, $37 \vec{\imath}-80$, 389-90; distribution, I, 396-400, 401-3, 404-12, 478-9, 556; special creation and parasitism, I, 428; evolution hypothesis, I, 434, 443, 449-50; rudlmentary organs, I, $474,475,556$; varled nedia, I, 484, II, 32 ; alien and native specles in New Zealand, I, 477; E. Darwin and Lamarck on evolution of, I, 490-8; geologic changes affecting, I, 501-3, 557; interdependence of animals and, I, 504-6, 514, II, 398 ; complexity of influences affecting, I, 506; direct equillbration, I, 523-5; indirect, I, 532, 533; seed distribution, I, 546; wood development, II, 285-7, 289, 567-97; interdependence, II, 4023, 404; Insect relations, II, 406-7; adaptation and multiplication, II, 411-6; rhythm in numbers, II, 419; growth and asexual genesis, II, 439-42; growth and sexual genesls, II, 448-51; expenditure, II, 467; horticulture, nutrition, and genesis, II, 477; tree development, II, 553; circulation and wood formation, II, 567-92; dye permeability and circulation, II, 569-74, 577-81, 584, 586; résumé ou circulation 
and wood formation, II, 592-7. (Bee also Multiplleation, Morphology, and Physiology.)

Plasmodium, dissolution of, I, 185. Plato, ‘séa of, II, 550.

Platyhelminthes: transverse fission, II, 101; segmented and non-segmented types, II, 102, 107; symmetry, II, 195, 197; multiplication and growth, II, 488-9.

Plethora, fertility and, II, 480-4, 511.

Fleurococcacce, unicellular form, II, 21, 134.

Pleuronectida: symmetry and location of eyes, II, 205; outer tissue, II, 387.

Plumatella: metagenesis, I, 277; symmetry, II, 195.

Podostemace $\boldsymbol{x}$, undeveloped circuiatory system, II, 274.

Polar bodles, hypothesis concerning extrusion of, I, 266-8.

Polarlty, organic, of physiological units, I, 226, 315, 317, 332, 350-1, 701-6.

Polyatomic compounds (see Chemistry).

Polychato, anomalous development in Myrianida, I, 361.

Polycytharia, integratlon, II, 90, 124.

Polygastrica, aggregation, I, 586.

Polymerism: of compounds, I, 9, 11,

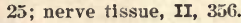

Polypori, symmetry and environment, II, 139.

Polyps (see Calenterata).

Polyzoa: size, I, 140; multiaxial development, I, 165; structural indefinlteness, I, 173: functional differentiation, I, 202; trochophoral klnship, I, 447; integration, II, 93-4, 96, 124; symmetry, II, 194, 207: vascular system, II, 340 ; gemmatlon, II, 444.

Poor Laws, and natural selection, II, 532.

Population, A Theory of, I, 265, 577601, II, 411.

Potato: sImulated growth, I, 136; vicarious function of tuber, I, 209, II, 255: sub-specles, I, 302; dye absorption, II, 279.
Preservation: fertility and self-, I, 581; II, 423, 430; nutrition, II, 493.

"Progress; its Law and Cause," theory of species differentiatlon, I, 568.

Projectiles, factors in flight of, I, 450-1.

Protelds: metabolic function, I, 67, $68,69,72,76$; complexlty of molecule, I, 122.

Protein: evolution, I, 23, 24; isomerism, I, 700, 703, 704.

Protcus, degeneration of eye, I, 613.

Protodrilus, intestine segmentation, II, 125.

Protophyta: internal movements, I, 56 ; limit of growth, I, 138; development, I, 164; structure, I, 173, 181-3; self-mobility, I, 175; individuallty, I, 245; multiplication, I, $270,276,279,581,581-5$, II, 439, 462; genesis and nutrition, I, 295; unicellular, II, 21; central aggregation, II, 24; symmetry, II, 134; tlssues, II, 244, 249; prlmary differentiation, II, 385; primordiai type, II, 398; symbiosis, II, 400.

Protoplasm: self-increasing function of primordial, I, 63-4; plant metabolism, I, 65- 7 ; complexity, I, 122, 253-5; differentiation in slmple organlsms, I, 182-3; contInuity and inter-circulation, I, 190-2, 371,629 , II, 21, 620; “' streaming," I, 253; structure, I, 253-5. (See also Cell.)

Protozoa: inorganic components, I, 17; locomotion, I, 58, 175, II, 14; vital changes shown by, I, 94; llmitation of growth, I, 138; development, I, 164; structure, I, 173, 181-3; inciplent differentlation, I, 198, 391, II, 299, 309; multiplication, I, 270, 276, 279, 280, 582,584 ; II, 442,451-2; genesls and nutrition, I, 295; distributlon, I, 396; parasites infesting, I, 427; Weismann's hypothesis of immortality, I, 637; "spontaneous generation," I, 697-701; non-nucleated, II, 20; primary aggregate, II, 86-7, 124; progressing integration, II, 89-91, 124; synunetry, II, 
186; primordial plant-animal type, II, 397-8: symblosis, II, 400.

Protyle, hypothetical chemical unit, I, 22, 23.

Pseud-axial development, vegetal, II, 28-9, 30.

Pseudo-foliar development, regetal, II, 26-8, 30 .

Psychida: parthenogenesis, I, 275; sexual dimorphism, I, 683.

Psychology: reasoning and definition of life, I, 81-8; correspondence shown by recognition, I, 95; contrasted with physlology, I, 127; departments of, I, 127-8; vicarlous function, I, 209; waste and repair in sensory organs, I, 217; sensory adaptabillty, I, 229, 231,232 ; inherltance of sensory defects, I, 306; musical talent, I, 311-2; Intellectual progress and special-creation hypothesis, I, 417; special-creation a pseud-idea, I, $420,429,433,554$; legitimacy of evolution-hypothesis, I, 433-5, 439, 554; embryology of Ideas, I, 450, 457; persistent formative power unrepresentable, I, 492; E. Darwin's and Lamarck's theory of desires, I, 494; natural selection and brain evolution, I, 553; genesis and cerebral activity, I, 594, II, 512-4, 516-9, 530; heredity and distribution of tactual perceptiveness, I, 602-8, 646, 665-6, 672, 692 ; inconcelvability of the negation, I, 675; vitiation of eridence, II, 88; repetition and perception, II, 143; differentlation of sensory organs, II, 317-20; differentiation of nerve tissue, II, 355-61: functional integration, II, 376; also integration, II, 350-2; equillbration of nerve discharge, II, 393; human fertllity and nerve development, II, 466, 532; future human erolutíon, II, 523-5, 527; human evolution and genesis, II, 529-31; future mental development, II, 535; origin of rertebrate type, II, 598-600.

Pteridophyta: size attained by, I, 138, 139; homologles, II, 80-1, 82; frond surface dicferentlation, II, 260.
Pteropoda: bllateral symmetry, II, 201 ; dermal resplration, II, 310.

Ptyaline, metabollc function, I, 69. Punjabis, Inheritance of acquired osteological pecullarities, I, 689 .

Pyrosomida: phosphorescence, I, 47; integration, I, 588, II, 97.

QUAGGa, telegonic transmission of markings to offspring of mare, I, $624,627,646$.

Qulls, development, II, 314-6.

RABBIT: activity and muscle colour, II, 365; over-ruuning checked by weasels, II, 405; expendlture and genesis, II, 472.

Radial, definition, II, 148.

Radiolaria: unicentral development, I, 163; secondary aggregation, II, 88; symmetry, II, 187.

Radula, development of roots from leaflets, II, 34 .

Raflesiacec: homogenesis, I, 272; tissue dlfferentlation, II, 274; nutrition and genesis, II, 486.

Rat (see Rodentia).

Rathke, H., on vertebrate embryo, II, 119.

Ray, J., plant classifleation, I, 378.

Reasoning, compared wlth assimilation, I, 81-7.

Recapltulation, embryological, I, 453.

Regeneration (see Repair).

Rejuvenescence, and sexual fertillzation, I, 637; II, 613 .

Remak, R., vertebrate embryo, II, 120.

Repair: continulty of, I, 216-9; anlmal injuries, I, 219, 222-4, II, 102 , 611; deductive interpretation, I, 221-2; theories of heredity and regenerative phenomena, I, 300-1.

Repetition of like parts, II, 126.

Reproduction (8ee Muitiplication).

Rcptilla: growth and expendlture of force, I, 142; sizes of ova and adult, I, 144; longerity of crocodile, I, 154; temperature, I, 174; waste, I, 214; distlnctive characters, I, 392; distribution in time, I, 409, 412; rerteliral seginentation, I, 4\%0; rudinentary limbs of 
snakes, I, 473; fertility and development, I, 583, 598, 599; regeneration, I, 589; elongated form, II, 15; supernumerary vertebræ, II, 123, 564; bilaterai symmetry, II, 203, 204; Cope on segmentation in extinct, II, 225, 226; activity and muscular colour, II, 365; functional integration, II, 375; outer tissue differentiation, II, 387; Owen on skeleton, II, 560.

Resistance of media to locomotion, II, 15.

Respiratory System: effect of light, I, 31; organic re-arrangement, I, 37; cutaneous, I, 209; air-cells of lungs, I, 254; embryonic branchiæ of salamander, I, 457; dffferentiation, II, 310-1, 333-8; physiological integration, II, 374-5, 382; vascular differentiation aud integration, II, 377.

Retrograde metamorphoses, in animais, II, 12.

Retzlus, G., superfleial nerve-endings, I, 666.

Reversed Selection, I, 611, 612.

Khabdospheres, calcareous armour and dynamic element in life, I, 119.

Rhizolds, follar expansions, II, 50.

Rhizopoda: structure, I, 173; undifferentlated function, I, 200; a primary aggregate, II, 86; symmetry, II, 186; tissue differentiated, II, 299, 385; motion of sarcode, II, 356; symblosis, II, 400 .

Rhythm: astronomic and organic, I, 499 , 557; law of equitibration, I, 520-1; in multiplication, II, 419.

Rleheraud, Baron A., definition of life, I, 79.

Riley, C. V., on telegony, I, 645; Termites, I, 680, 681; pouch of Honey-ants, I, 684.

Rodentia: Incursions, I, 399; Ameriean types, I, 403; fertlity and development, I, 583, 599.

Rivinus, plant ciassification, I, 277. Rokitansky, on faise jolnts, I, 230.

Romanes, G. J.: on "cessation of selection," I, 560-2; isolation and species differentlation, I, 569; "physiological selection," I, 569
71; panmixia, I, 649, 667; influence of a previous sire on progeny, I, 649.

Röntgen rays, I, 121, II, 621.

Roots: developed from leaflets, II, 34; physiological differentiation, II, 253-5, 270; nutrition from leaves, II, 274; size and function, II, 276.

Rotifera: latent vitality of desiccated, I, 117; trochopore, II, 108, 109; molluscan relationshlp, II, 115; fertility and size, II, 453, 459. Roux, W.: "Intra-selection," I, 676; functional adaptation, II, 354 .

Rudimentary organs: the definition of life and, I, 112, natural selection and eyes of cave fauna, I, $309,612-4,647-9,693$; evolution hypothesis, I, 472-5, 556; limbs of whale, I, 668-9, 685, 693 .

Ruminants, alimentary canai development, II, 327-9.

Salamander, embryonic branchiæ, I, 457.

Salmonida, reproduction and growth, I, 291-3, II, 454.

Salpida: heterogenesis, I, 272, 277; integration, I, 588, II, 97.

Sap (see Vascular system).

Sarcina: central aggregation, II, 24; fertility, II, 440.

Savage, Dr., on "Heredity and Neurosis," I, 313.

Scenedesmus, individuation, II, 24.

Scent: natural selection and keenness of, I, 610; floral fertllization, II, 268-9; animal protection, II, 434.

Scheiling, E. W. J. von, definition of life, I, 78, 178.

Schieiden, J. M., on individuality, I, 245; on liferworts, II, 50, 52; atgal indefiniteness, II, 296.

Science, complex revelations of, I, 252, 369, 450.

Scyphomedusæ, strobllization, II, 108.

Sea: changes and movements in, I, 83; life in, lower than terrestrial, I, 104; distribution, I, 396, 517; change of media caused by, I, 481; geologic influence, I, 502 . 
Seals: nall-bearing toes, I, 473; oi brissa, II, 317.

Seasons: reproductive periodicity, I, 299; variations of genesis with, II, 484-5.

Sedgwick, Adam: on continulty of protoplasm in anlmals, I, 190, 629, II, 21; zoological classification, I, 387; discrimination of specles in embryonic stages, I, 461; persistence of ancestral traits, I, 463-4; Archiannelidan segmentation, II, 109.

Sedgwick, Wm.: heredity and sex, I, 305, 314; telegonic transmission of hypospadias, I, 646 .

Seeds: nitrogenous, I, 40 ; temperature of germinating, I, 47, II, 615; vitalism and latent vitality of, I, 116-7; variation in environment, I, 327; natural selection among, I, 532.

Segmentation (metameric): special creation hypothesis, I, 468-9; Huxley on number of somites in higher articulates, $i b . ;$ in annulose animals, II, 98-110, 111-5, 601-5; simulated molluscan, II, 116 ; in vertebrates, II, 125-7, 225-7, 606-7; in elasmobranchs, II, 126.

Segregation: of growth, I, 136; of like units, I, 179; organic repalr, I, 221; variation, I, 331, 334 ; heterogeneity, and definiteness of evolution, I, 514-6, 517-8; morphological development, II, 7-9; physlological units, II, 616.

Self-fertilization, animal and vegetal, I, 341-4, 353.

Senses, the (see Psychology).

Sex: In Ascidian colonles, I, 247; limitation of heredity by, I, 314-6; correlated traits, I, 371-2, 513; nutrition and determination of, in social insects, I, $655-60,678-84$, 686-9; neural and hremal traits, I, 683; differentiation of organs, II, 303; castration and growth, II, 459; Julin on " castration parasltaire" in crustaceans, II, 493-6; the object of fertilization, II, 613 . (See also Fertilization.)

Sexuai Selection (see Natural Selection).
Sharp, D.: on insect somites, I, 469; food habits of Termites, I, 686-7.

Sheep: contrasted with oxen, I, 158, 160; crossing of English and French breeds, I, 625; nutrition and genesis, II, 480 .

Sherrington, Prof., on effects of nerve severance, I, 349.

Ship-buliding, interdependence of social functions, I, 237-9, 241.

Shipley, A. E.: segmentation of Microstomida, II, 102; Protodrilus, II, 125.

Sillea, colloid and crystalloid, I, 16.

Silicic acid: propertles, I, 16; isomerism, I, 59.

Silicon, allotropic, I, 4.

Silkworm disease, I, 622-3.

Simulation: of homology by analogy, II, 14, 485; of segmented structure by moliuses, II, 116.

Siphonophora, specialization of component poisps, II, 95.

Sirenia, simulated fish form, I, 495. Size (see Growth).

Skeleton, vertebrate (see Vertebrata).

Skin: respiratory function, I, 209; adaptablity, I, 228, II, 312-4, 387; transmitted peculiarities, I, 306; Waliace on distribution of sensitiveness, I, 646-7; differentiation, II, 215, 217, 304-7; tegumentary deveiopment, II, 314-6, 387; differentlation of sensory organs, II, 317-20; and mucous membrane, II, 303-4, 321-2, 389.

" Skin friction," and locomotion of aquatic animais, I, 156.

Skull (see Vertebrata).

Sleep, repair favoured by, I, 216.

Small-pox, blood changes from, I, 221.

Smith, Prof. W., on fertility of diatomaece, II, 440.

Smith, W. P., on telegony in calves and foals, I, 645 .

Smith, W. W., on habits of Tetramorium, I, 660.

Snakes (see Rcptilia).

"Social organism," author's essay on, I, 363, 676.

Soclology: environment and degree of life, I, 105-6; functional dif- 
ferentiation, I, 204; divlsion of labour, I, 207, 363-4, 367; functlonal Interdependence, I, 237-9, 240-2; autogenous development of units in colonles, I, 364, 367-8, II, 620 ; bellef in soclal evolution, I, 432; natural selectlon, I, 553, II, 532 ; Integratlon and differentiatlon, II, 378-9; effects of populatlon, II, 535-6; equllibratlon, II, 537.

Soil, dependence of plant evolution on, II, 402.

Solanum jasminoides, organs of attachment, II, 276.

Solar system, autogenous development lllustrated by distribution of forces in, I, 366.

Sole, symmetry and locatlon of eyes, II, 205.

Soma-plasm, Welsmann's theory of differentiation from germ-plasm, I, 357, 622, 628-30, 633-44.

Somites (see Segmentation).

Speclal ereation: and evolution, I, $412,415,431$; Improbabilities, I, $418-9,430,439,554$; Inconcelvabllity, I, 420, 429, 431, 554; of Indivlduals and specles, I, 421-4; the Implleation of beneficence, I, 425-9; summary, I, 429, 554; Von Baer's formula, I, 451-6; vertebrate skeleton, II, 551, 556, 565 .

Specles: adaptation and stability, I, 242; hereditary transmission, I, $301-4$; variation in wlld and cult1vated, I, 323-5, 326, 693; gamogenesis and llfe of, I, 347-9; physiologleal units, I, 362, 364, 36971,458 , II, 613 ; Indefinlteness, I, $389,445,572$; special creation, I, 422-4; Instabllity of homogeneous, and differentlation of, I, 509-11, $515,517-8,550,557$; persistence of, I, 516, 518, II, 10-11; natural selection and equillbration, I, 543-8, 553, 557; non-adaptive characters, I, 565; morbld products as marks of, I, 567; migration and isolation as causes of differentiation, I, 568-9; Increasing mult1formity of aggregate, II, 396.

Specific gravity, of organlsms and environment, I, 174, 177. $\left.\begin{array}{l}\text { Spermatozoa } \\ \text { Sperm-cell }\end{array}\right\}$ (see Fertlllzation).

Sphere: tendency of units to form, I, 15; the embryonlc form, I, 177; symmetry, II, 131.

Spherold, symmetry, II, 132.

Splders (see Arachnida).

Splne (see Vertebrata).

Sponge: structure and dynamlc element In llfe, I, 119; multicentral development, I, 164; units and aggregate, I, 185; reproductive tissue, I, 283; Integratlon, I, 586; II, 90 , 383; physlologlcal differentlation, II, 300, 386; development and genesls, II, 463; analogy from, II, 5 76.

Spontaneous generation: and heterogenesls, I, 270; and evolutlon, I, 696-701, 703.

Stag, horns and correlated structures, I, 567, 670, 676-7, 692.

Stamens, and follar homology, II, 44.

Starches: propertles, I, 11; transformatlons, I, $66,68,69,70$, II, 593.

Star-fishes (see Asteroidea).

Statoblasts, of Plumatella, I, 277.

Steenstrup, on "Alternate Generatlon," I, 592.

Sterlity (see Multipllcatlon).

Stlckleback: ova, II, 454; bothriocephalus in, II, 490.

Stomach (see Allmentary canal).

Stomata, distribution, II, 260-1.

Straight line, and evolution hypothesis, I, 433.

Strain: compression and tenslon of, I, 151, II, 209-12; relation to mass, I, 155-7; vegetal structure, II, $574-88$, 592-6; orlgln of vertebrate type, II, 600 .

Strawberry: multlaxlal development, I, 166; multiplication, II, 441.

Strength, a vital attribute, I, 578.

Structure: appllances for generatIng motlon, I, 75-7; blologleai classification, I, 125-7, 129; slze and organle, I, 137; growth and complexity, I, 138,145 , 161 ; relatlon to environment, I, 172-8, 195-6; of uniceliuiar organlsms, I, 181-3; 
multicellular, I, 183-96; Hertwlg's classification of tissues, I, 189; continulty of units, I, 190-2; systems of organs, I, 192; divlsion Into unlversal and particular, I, 193-4; general truths, I, 194-5; plant and anlmal, contrasted, I, 195-6; precedence of function or, I, 197, 211; correlative complexity of function and, I, 200, 211; progressive concomitant differentlatlon, I, 201-4; physiologicai units, I, 225-6, 362, 364, 369-71, II, 613; social and organle interdependence, I, 235-42; varied by functlon, I, 334, 535; II, 217 (see Acquired Characters); zoological classification, I, 390-2; equllibration, I, 521, 557; progress of, and genesis, I, 590-1; II, 462; cooperatlon with function, II, 3 ; evolution and increased, II, 4; retrograde metamorphosis, II, 12; slmulated homologles, II, 13-14; earllest organic forms, II, 19; cylindrical vegetal, II, 57-62; permanence and complexity, II, 295 , 296; functlon and epldermic, II, 312-4, 387; and muscular, II, 369, 391 ; adaptation and equllibration, II, 392 ; persistence of force and physiological adaptation, II, 394; evolution, II, 501-4. (Sce also Morphology.)

Struggle, for nutriment among components of an organism, I, 562, 676; for existence (sce Natural Selection).

Struthers, Sir J.: on heredity, I, 305 , 314; digital variation, I, 321; rudimentary limbs of whale, I, 668.

Strychnine, effects of, I, 54, 55.

Sturgeon, size of ova and aduit, I, 144.

Sugars: properties, I, 10-11; transformations, I, $38,40,66,69,70$, II, 593.

Sulclde, hereditary tendency to, I, 307.

Suiphur: allotroplc, I, 4, 59; organic evolution, I, 703.

Sun (see Light).

Survival of the Fittest, the expres- slon, I, 530, 610. (See Natural Selection.)

Swan, vertebræ of neck, II, 123.

Swlftness, a vital attribute, I, 578.

Syllis ramosa, lateral branchlng, I, 166, 361, II, $105,108$.

Symblosis, II, 399, 400.

Symmetry (see Morphology).

Syphlils, hereditary transmission, I, 623.

TACTUAL Perceptiveness, heredity and the distribution of, I, 602-8, $633,665,666,672,692$.

Tania (see Entozoa).

Tansley, A. G., I, vI, II, vl; adaptatlon of reproductive actlvity to conditions in Algo, I, 288-9; shapes of Caulerpa, II, 22; stemthickening in extinct Thaliophytes, II, 56; natural selection and leaf-distribution, II, 179.

Tape-worm (see Entozoa).

Taste, dependent on chemical actlon, I, 54.

Teeth: hereditary transmission, I, 306; suppression of mammallan, I, 457; of unclvillzed and clvllized, I, 541, 693.

Tegumentary organs, origln of, I, $314-6$.

Telegony, or the influence of a previous slre on offspring, I, 624-7, 644-6, 649-50.

Temperature (8ee Heat).

Tension (sce Strain).

Termites: fertlllty, I, 583, II, 493; late development of sexual organs, I, 680; nutrition and differentlation of forms, I, 681 .

T'etramorium, utillzatlon of aphides by, I, 660-1.

Thallophyta: size, I, 138, 139; low co-ordination of parts, I, 164; pseudo-follar, II, 28; "transition place," II, 30; simulation of higher types, II, 32; secondary thickening in extinct species, II, 56 ; sexual and asexual genesis, II, 84. (See also Alga.)

Tickling, physlology of, I, 76.

Tlde (see Sea).

Time, as a factor in growth, II, 77. 
Tissue, Hertwig's classification, I, 189. (See Physiology.)

Tongue, perceptiveness of tip, I, 606-8, 665, 672-3.

Tortoise: contrasted life of dog and, I, 103-4; natural selection and carapace, I, 534 .

“Transcendental Physiology," I, 176.

Tree, as symbollzlng phylogeny, I, 428, 452-3. (See Plants.)

Trematoda: agamogenesis, I, 277; parasltism, I, 428; alternate generation, I, 592.

Trembley, A., on the polyp, I, 223.

Trichinosis, In Germany, I, 428.

Trochophore, phyletlc relationships shown by, I, 447, II, 108-9.

Tubicola: development, II, 100; bilateral symmetry, II, 197.

Tunieata: gemmatlon, I, 588, II, 445; alternate generation, I, 592; integration, II, 93-4; tertiary aggregation, II, 124; symmetry, II, 194-5.

Tunny, size of ova and adult, I, 144.

Turbellaria: segmentation, II, 102; symblosis, II, 400.

Turnip: chlorophyll in roots, I, 209, II, 254; vascular system, II, 281, 284, 578, 591, 596.

Twins: similarity of, I, 324; traits of women bearing, II, 457 .

“ Types, perslstent," Huxley on, I, 408.

ULCER, dermal structure, II, 306.

Uitlmate Reality, incomprehensibilIty of, I, 120.

Ulva: cell multiplication, II, 26; outer tissue, II, 256.

Umbelliferce: floral symmetry, II, 171; axial and follar organs, II, 541-6.

Unlted States: cases of telegony, I, 644-5; birth rate, II, 520 .

Units: differentlation and dissimilarity, I, 20; “protyle," I, 22-3; shapes in blgher types, I, 164; differentlal asslmilation, I, 180; primordlal organle, I, 181; morphological composition, I, 184-7, 194, 252, II, 5, 7-9, 21, 79, 85-6; segregation and organic repair, I, 221-2, 222-6; chemleal, morphologleal, and physlologleal, I, 225-6; II, 612; stabllity, I, 339; instability and heterogenelty of organic, I, 350; Darwln's gemmules, I, $356-60, \quad 362,372$; Weissmann's germ-plasm (q. v.) ib.; soclologlcal comparison, I, 363-8; speclfic proclivities In embryogeny, I, 458; phænogamlc, II, 73, 151; annulose, II, 105; Incident force and homologous, II, 159; morphologlcal summary, II, 233. (See also Physlologlcai units.)

“ Unlversal Postulate," I, 675.

Unsymmetrlcal, definition, II, 131.

Urea, muscular energy and excretion, I, 72.

VAN Beneden, P. J., on Tania, II, 103.

Varlation: dlgital, I, 331; effects of parental condltlons, I, 324; of altered function, I, $325,334,693$; dlssimilarity of initial conditions, I, 327-32, 333; “'spontaneous," I, $328,513,697$, II, 529; persistence of force, I, 335; physlologicai units, I, 348-54, 360, 369, 371-3, II, 614-7, 622-3; Weismann's germ-plasm theory, I, 357-8, $372-3,671,677$; II, 622 ; equllibration and vegetal, I, 523-5; Welsmann's panmixia theory, I, 561-3, $649,667-9,671,685$; reproductive organs, I, 570; natural selection and concomitant, I, 614-21, 653, $664,674,692$; and dlsused organs, I, 648,668 ; plus and minus, I, 667, 685; Masters on correlated, in plants, II, 298, 621-2; equilibration of favourable, II, 394 .

Vascuiar System: effects of vegetoalkalies, I, 55; nutritlon, I, 146, 148; embryonic development, I, 169 ; structural tralts, I, 192, 193; function, I, 199; of Ascidians, I, 202; functional differentiation and integratlon, I, 205-6; organic repair, I, 217, 221-2; effect of functlon, I, 229, 234-5, 236; equilibration, I, 535; communlty in compound organisms, I, 588; develop- 
ment of vegetal, II, 273-5, 279-84, 285-8, 388; differentiation of, summary, II, 288-90, 388; differentiation of animal, II, 339-44; osseous development, II, 347-51; muscularity, 1I, 364; muscular colour, II, 365-9; heart-motor apparatus, II, 374; differentiation and integration in animal, II, 376-9, 383; wood formation, II, 567-92; résumé of wood formation, II, 592-7.

Vaucheria, reproduction, I, 279, 289.

Vegetative System, co-ordination of actions in, I, 578.

Vegeto-alkalles, physlological effects of, I, 54-5.

Velocity, of moving bodies, II, 219 20.

Vertebrata: size, I, 139; size at birth and maturity, I, 144; axlai structure, I, 165; embryonlc development and sele-mobility, I, 175; functional differentiation, I, 206 , 591 ; reparative power, I, 219 , 223, 589; homogenesis universal, I, 271; distinctive traits, I, 392, II, 35; distribution in time, I, 408; classifleatory value, I, 446; embryonic mammalian respiratory system, I, 456; embryological preadaptation, I, 461; evolution and vertebral column, I, 470; rudimentary organs, I, 473; evolution and varied media, I, 479-85; size of head and vertebræ, I, 512, 537; segregation and evolution of vertebræ, I, 515; fertillty and development, I, 583, 598-9; Welsmann on reproductive cells, I, 635 ; $11 \mathrm{mb}$ locomotion, II, 15; adaptive segmentation, II, 117-23, $125-7,223,602,605-7$; supernumerary vertebræ, II, 123; bllateral symmetry, II, 203-6; internal organic symmetry, II, 208; genesis of rudimentary axis, II, 212-6; natural selection and genesis of structure, II, 216, 227; origin of notochord, II, 216-8; spinai segmentation, II, 218-22, 224; skull development, II, 222, 227; résumé of axis development, II, 224; Cope on author's theory, II, 225-7; nerve differentiation, II, 304; sen- sory organs, II, 318; air chambers, II, 334; osseous differentiation, II, 344-55; activity and muscular colour, II, 365-9; heart-motor apparatus, II, 374 ; cost of genesis, II, 436; agamogenesis unknown, II, 445; growth and genesis, II, 454; heat expenditure and genesis, II, 468-9, 474; Owen, theory of skeleton, II, 548-66; evolution of vertebræ, II, 563-6; origin of type, II, $598-600$.

Vestiges of Creation, I, 491.

Vibrissæ, function of, I, 75 .

Vitalism, hypothesis examined, I, 114-7.

Vittadini, C., on silkworm disease, I, 622-3.

VIviparous genesis, I, 271, 274-5, 278.

Volce, correlated sexual traits, I, 371-2.

Volcano, definition of life and, I, $85,89$.

Volvocinec: unicentrai development, I, 163; individuality, I, 245; disintegration of genesis, I, 276, 587; spherical aggregation, II, 24; symmetry, II, 137, 187; fertility, II, 441.

Vomiting, alimentary canal development, II, 328.

Vorticella: secondary aggregate, II, 90; symmetry, II, 188.

Wallace, A. R.: "The Origin of the Human Races," I, 553; the expression "Survival of the Fittest," I, 530; his association of natural with artifleial selection, I, 609; co-adaptation in giraffe, I, 615; skin sensitiveness, I, 646.

Wasp: co-ordination of instincts in Mason-, I, 574, 679-80; genesis of worker, I, 654-7.

Waste, animal, I, 69, 213-5, 228; relation to activity, I, 196, 220-1; in plants, I, 213, 220.

Water: properties, I, 7, 9; colloldal affinity for, I, 28; organic change from, I, 29; organle need for, I, 147; proportion in mammalian adult and fotus, I, 154; motion through, I, 156; organic develop- 
ment and environment, I, 173, 177,479 ; terrestrial organisms inhablting, I, 400; adaptation of organisms to change of media, I, 479-85; vegetal tissue differentiation, II, 253; molecular rearrangement, II, 359; colloidal contraction, II, 361-2.

Water-weed, American, Inrasion of, I, 399.

Watts, Dr., on The Principles of Biology, I, ix.

Wax, follar deposit, II, 260-1.

Weber, on tactuai discriminativeness, I, 602.

Weight: relation to environment of organic, I, 174, 177; varying as cube of dimensions, I, 151, II, $434,470$.

Weismann, Aug.: reproductive tissue in Medusa, I, 281; in Daphnida, I, 290; his theory of the differentiated germ-piasm and its fundamental units, I, 357, 622-3, $628-30,633-44,646$, II, 618-9, 622; the alleged differentiation and plant-phenomena, I, 359-60; and regenerative processes, I, 360; false joints, I, 362; implied compiexity of determinants, I, 370; theory inadequate to explain correlation of sexual traits, I, 372; and variations in peacock's tail feather, I, 372-3, 695, II, 618; his view of natural selection as sole factor in organic evolution, I, 559; the doctrine of panmixia, I, 561-3, $612,632,649,667-9,671,685$, 689 ; arguments against inheritance of acquired characters, $I$, 612-3, 651-65, 669-71; blindness of cave-animals, I, 613; current acceptance of his views, I, 631, 690 ; cannot explain the process of natural selection, I, 651; the degradation of the little toe in man, I, 652, 669, 673; caste gra- dations of social insects, I, 654, $658-65,670,675,678-84,685$; foodseeking instinct in Amazon ants, I, 660,670 ; the co-adaptation of co-operative parts, I, 663-4, 670, $674,675,676$; tactual discriminatlveness, I, 665, 672; Intra-selection, I, 676-8; effect of nutrition on fertillty of blow-fly, I, 678-9.

Whale: weight of brain, I, 599; rudimentary limbs, I, $668-9,685$, 693.

Wheat, adaptive variations, II, 298. Whistling, definition of life and, I, 112.

White-Cooper, Mr., on inheritance of abnormal vision, I, 306.

Willow, nutrition and growth, I, 294.

Wilson, E. B.: composition of chromatin, I, 260; separation of segmentation spheres of Amphyoxus ovum, I, 691.

Wind: and vegetal bilateral symmetry, II, 142; and Inner vegetal tissue differentiation, II, 275-9, $285,288,388$; and proliferation of Bryophyllum, II, 295; and vegetal sap movement, II, 583, 584, 587; résumé, 592-6.

Wolff, C. : vegetal fructification and nutrition, I, 283, II, 179-80; vegetal vascular system, II, 283.

Women (see Man).

Wood (see Plants).

YEAST: fermentation, I, 38; fertility, I, 581, II, 440; linear aggregation, I, 587, II, 23.

ZeBRA marks in horses, I, 314.

Zoology, classification, I, 124-5, 380-9.

Zoophytes, structural indefiniteness, I, 173.

Zoospores, unit-life of, I, 185.

Zygote, of conjugating Alge, I, 283. 


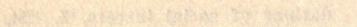

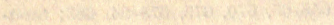

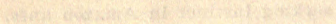

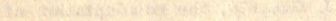

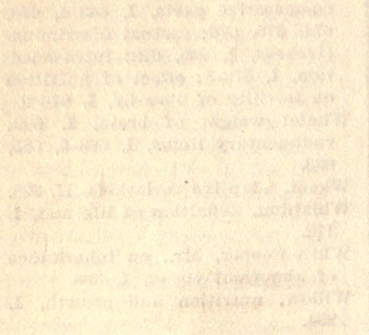

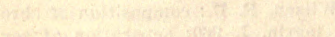

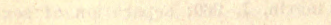

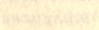

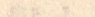

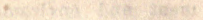
4.

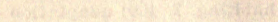

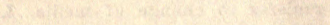

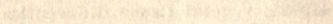

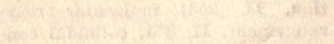
+ $7^{2}$

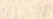

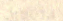







\section{SOUTHERN BRANCH, UNIVERSITY OF CALIFORIHA, \\ LIBRARY, \\ 208 ANGIIES, CALIF.}


Sh\%

2.

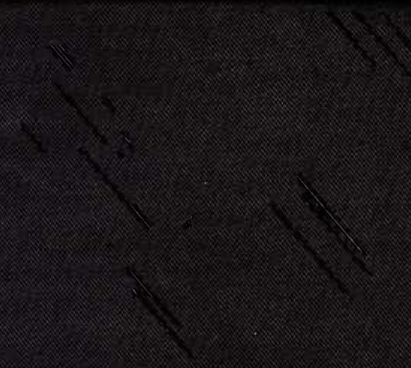

Sing 